\title{
Chinese Poetry in Times of Mind, \\ Mayhem and Money
}

by

Maghiel van Crevel

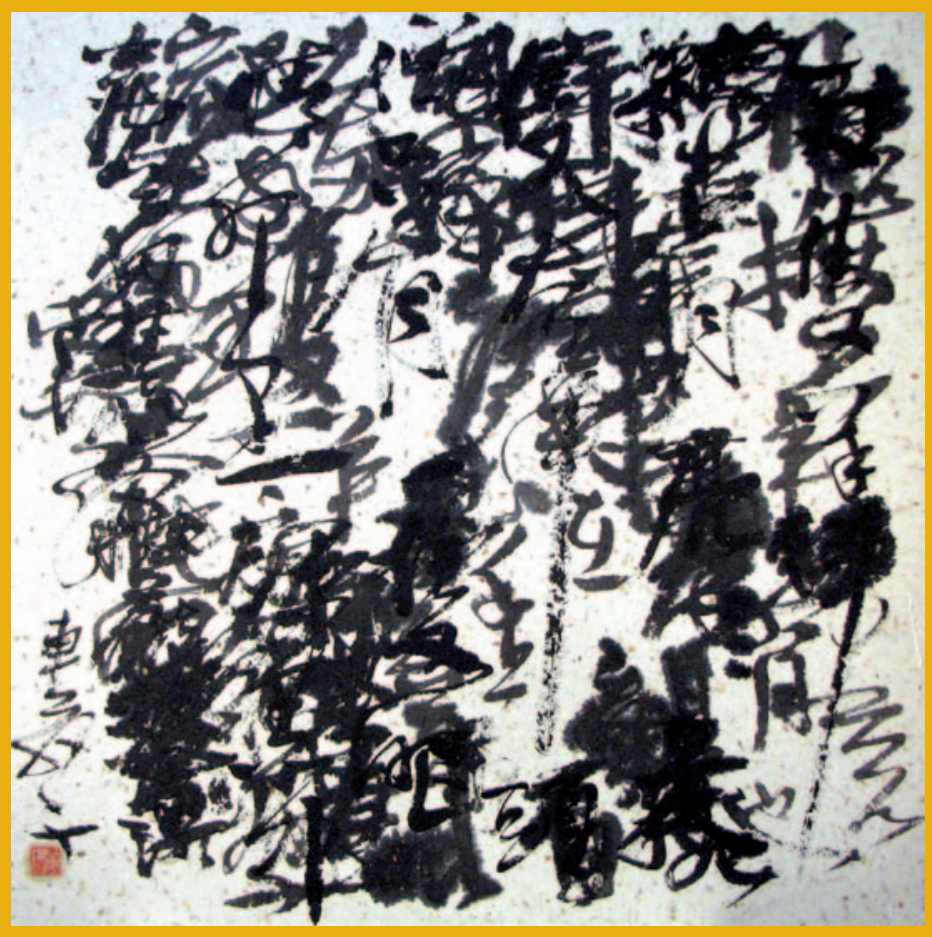


Maghiel van Crevel - 978-90-47-44273-8 Downloaded from Brill.com $04 / 25 / 2023$ 11:38:45PM via free access 


\section{Chinese Poetry in Times of Mind, Mayhem and Money}




\title{
Sinica Leidensia
}

\author{
Edited by \\ Barend J. ter Haar
}

In co-operation with

P.K. Bol, W.L. Idema, D.R. Knechtges, E.S. Rawski,

E. Zürcher†, H.T. Zurndorfer

VOLUME 86 


\title{
Chinese Poetry in Times of Mind, Mayhem and Money
}

\author{
By \\ Maghiel van Crevel
}

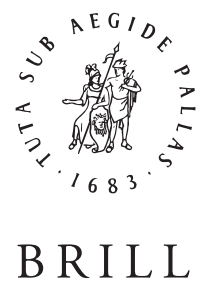

LEIDEN • BOSTON

2008 

the original author(s) and source are credited.

The support of the Leiden University Institute for Area Studies (LIAS) for the open access publication of this book is gratefully acknowledged.

Cover illustration: calligraphy by Che Qianzi (photograph by Jeroen Wiedenhof)

This book is printed on acid-free paper.

\section{Library of Congress Cataloging-in-Publication Data}

Crevel, Maghiel van.

Chinese poetry in times of mind, mayhem and money / By Maghiel van Crevel.

p. cm. - (Sinica leidensia ; 86)

Includes bibliographical references and index.

ISBN 978-90-04-16382-9 (alk. paper)

1. Chinese poetry - 20th century - History and criticism. 2. Experimental poetry,

Chinese - History and criticism. 3. Avant-garde (Aesthetics) - China. I. Title. II. Series.

PL2333.C87 2008

$895.1 ' 15209-\mathrm{dc} 22$

2008031294

ISSN: 0169-9563

ISBN: 9789004163829 (hardback)

ISBN: 9789047442738 (e-book)

Copyright 2008 by Maghiel van Crevel.

This work is published by Koninklijke Brill NV. Koninklijke Brill NV incorporates the imprints Brill, Brill Nijhoff and Hotei Publishing.

Koninklijke Brill NV reserves the right to protect the publication against unauthorized use and to authorize dissemination by means of offprints, legitimate photocopies, microform editions, reprints, translations, and secondary information sources, such as abstracting and indexing services including databases. Requests for commercial re-use, use of parts of the publication, and/or translations must be addressed to Koninklijke Brill NV.

PRINTED IN THE NETHERLANDS 


\section{CONTENTS}

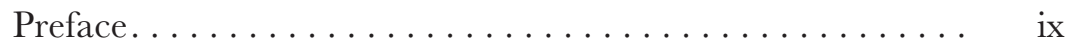

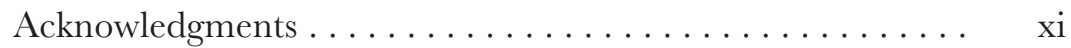

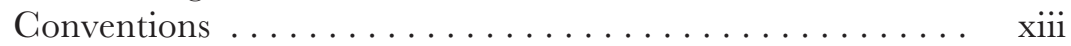

List of Illustrations $\ldots \ldots \ldots \ldots \ldots \ldots \ldots \ldots$ xvii

\section{Chapter One}

Avant-Garde Poetry from China: Text, Context and Metatext 1

1. What Went Before .................. 1

2. The Unofficial Poetry Scene and the Avant-Garde.... 5

3. Context: Times of Mind, Mayhem and Money. ..... . 13

4. Text: From Elevated to Earthly and from What to How 23

5. Metatext: Images of Poetry and Poethood. . . . . . . . 30

6. The Case Studies, and What This Book Wants to Do 50

\section{Chapter Two}

True Disbelief: Han Dong . . . . . . . . . . . . . . . . 63

1. The Rejection of Obscure Poetry ............ 65

2. An Original Poetics .................. 76

\section{Chapter Three}

Thanatography and the Poetic Voice: Haizi ........... 91

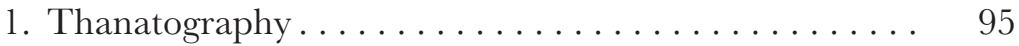

2. The Poetic Voice ................... 123

\section{Chapter Four}

Exile: Yang Lian, Wang Jiaxin and Bei Dao . . . . . . . . . . 137

1. Poets in Exile .................... 146

2. Exile in Poetry ................... 159

\section{Chapter Five}

Mind over Matter, Matter over Mind: Xi Chuan . . . . . . 187

1. Spirituality versus Materialism and the Barbarians... 189

2. A Different Voice: Poetry Rising, Poets Falling . . . . . 194

3. Words Capturing Images, Images Capturing Words. . . 215 
Chapter Six

Fringe Poetry, But Not Prose: Xi Chuan and Yu Jian . . . . 223

1. A Wonderful Inadequacy of Definitions . . . . . . . . . 225

2. «Salute» and «File 0»: Poetry or Prose? . . . . . . . . . 229

3. Fringe Poetry ... . . . . . . . . . . . . . . . . 244

\section{Chapter Seven}

Objectification and the Long-Short Line: Yu Jian . . . . . . 247

1. Objectification and Subjectification ............ 252

2. Long Lines and Blanks . . . . . . . . . . . . . . . . 274

Chapter Eight

Narrative Rhythm, Sound and Sense: Sun Wenbo ....... 281

1. Content Bias . . . . . . . . . . . . . . . . . . . . . . . 284

2. «The Program»: Content and Plot . . . . . . . . . . . 288

3. «The Program»: Form . . . . . . . . . . . . . . . . . . . 294

4. Narrativity and Its Context . . . . . . . . . . . . 301

Chapter Nine

The Lower Body: Yin Lichuan and Shen Haobo . . . . . . . 305

1. Lower Body Poetry . . . . . . . . . . . . . . . . 307

2. A Poetic Lineage ... . . . . . . . . . . . . . . 338

Chapter Ten

Not at Face Value: Xi Chuan's Explicit Poetics . . . . . . . . 345

1. Explanations, Issues and Alchemy . . . . . . . . . . . . . . . . . . . . . . . 347

2. A Bigger Picture ................... 360

Chapter Eleven

Desecrations? Han Dong's and Yu Jian's Explicit Poetics . . . 365

1. Poethood According to Han Dong and Yu Jian . . . . . 366

2. Metatextual Styles. . . . . . . . . . . . . . . 392

Chapter Twelve

What Was All the Fuss About? The Popular-Intellectual Polemic 399

1. What Were the Issues? . . . . . . . . . . . . . . . . . 400

2. What Was at Stake? ... . . . . . . . . . . . . . 441

Appendix: A Chronological Bibliography. ........... 451 
Chapter Thirteen

More Than Writing, As We Speak: Yan Jun . . . . . . . . . 459

1. Three-Dimensional Performance ............ 461

2. Writing, Event Culture and Poetry Opening Up . . . . 471

Works Cited ........................ 475

Index and Glossary . . . . . . . . . . . . . . . . 505 
Maghiel van Crevel - 978-90-47-44273-8 Downloaded from Brill.com $04 / 25 / 2023$ 11:38:45PM via free access 


\section{PREFACE}

One of my hang-ups is what it means to call something marginal, or more precisely, what it means to call avant-garde poetry from China so. I'll save this issue for a subsection of chapter One and the occasional relapse later on. Here I will only say that it is to do with a questionable mechanism that makes numbers the measure of all things, that this mechanism has sometimes been applied to not just poetry but also scholarship on poetry, and that on both levels it is often unwarranted and potentially deceptive. While I am aware that the poetry crowd in Chinese Studies and Literary Studies is smaller than the politics crowd or the fiction crowd, I'm not sure that this makes it marginal in any sense other than the quantitative, or that quantitative marginality is a bad thing. What's more, just like poetry's notorious undefinability and diatribes against its uselessness have never endangered its acknowledged right to exist - or rather the fact of its existence as an essential expression of humanity - so the scholarly study of poetry somehow always manages to hang on, regardless of the number of people involved. It appears, quite simply, to be worth it. On that note, and specifically in light of the dynamic modern manifestations of a civilization with a massive cultural tradition, it is good to see that the Chinese poetry crowd continues to attract new faces in China and elsewhere, and that the object of their fascination continues to generate new research. And it makes perfect sense, for there are many more things about the Chinese avant-garde to get hung up on than its marginality, as I hope this book will show.

The documented history of the avant-garde is roughly a hundred times shorter than that of Chinese poetry as a whole. Still, the amount of material that has become available since the late 1970s can feel overwhelming to the individual researcher-and yet it isn't always easy to find, especially if one is based elsewhere in the world. To facilitate research, teaching and translation, I present this study in conjunction with three online research bibliographies published by the Modern Chinese Literature and Culture Resource Center: "Unofficial Poetry Journals from the People's Republic of China: A Research Note and an Annotated Bibliography" (2007, see Works 
Cited), "Avant-Garde Poetry from the People's Republic of China: A Bibliography of Single-Author and Multiple-Author Collections" (2008a) and "Avant-Garde Poetry from the People's Republic of China: A Bibliography of Scholarly and Critical Books in Chinese" (2008b).

I hope my work will be useful to others, with other hang-ups than mine.

MvC, February 2008 


\section{ACKNOWLEDGMENTS}

Research for this book, including the collection of source materials, was facilitated by grants from the Netherlands Organization for Scientific Research (NWO), the Faculty of Arts at the University of Sydney, the Faculty of Arts at Leiden University, the Leiden University Research School for Asian, African and Amerindian Studies (CNWS), the Leiden University International Office, the Leiden University Fund (LUF), the International Institute for Asian Studies (IIAS), the Peking University Office for International Cooperation and the Research Center for the Theoretical Study of Literature and Art of the Faculty of Arts at Beijing Normal University.

In addition to anonymous reviewers who commented on journal submissions over the years, I thank Ernst van Alphen, Piet Gerbrandy and Petra Couvée, for what they have to say about poetry, and Michel Hockx and Michael Day, for what they had to say about this book once it was written. More generally, I am indebted to critical audiences at the academic institutions where I have presented this research, in classroom and conference settings. Steve Bradbury, David Godwin, Lloyd Haft, Oliver Moore and Simon Patton were among those kind enough to comment on my translations. Remy Cristini and Hanno Lecher of the Leiden University Sinological Library provided superb librarial and IT support.

As is true for my earlier work, I am deeply grateful to the many Chinese poets, scholars, critics and other readers who helped me find the poetry that this study is about and all that comes with it, including its performance and its many histories. They are too numerous to list here, but I wish to reiterate publicly the gratitude that I have conveyed to each of them in private settings. There is one name that cannot be left unsaid: Che Qianzi, whose art graces the cover of this book.

I thank the editors of the following journals, books and websites for permission to use previously published material. In order of appearance in the present volume:

Chapter One: The China Quarterly 183, reprinted as Julia Strauss \& Michel Hockx (eds), Culture in the Contemporary PRC, Cambridge: 
Cambridge UP, 2005; Modern Chinese Literature and Culture Resource Center $\rightarrow$ Publications, 2003 and 2007; Sidse Laugesen \& Anne Wedell-Wedellsborg (eds), Kineserne kommer! Dansk-Kinesisk poesifestival (The Chinese Are Coming! Danish-Chinese Poetry Festival), Aarhus: Aarhus University, 2004; 《新诗评论》3, The Drunken Boat 6-I/II. Chapter Two: Tamkang Review xxxvi-4, Full Tilt 1, Poetry International 2006. Chapter Three: minima sinica 2006-1. Chapter Five: Modern Chinese Literature and Culture 11-2, HEAT 8, Renditions 51, Seneca Revierw xxxiii-2. Chapter Six: Journal of Modern Literature in Chinese 3-2, Renditions 56. Chapter Eight: Journal of Modern Literature in Chinese 6-1, HEAT 5. Chapter Nine: Lu Jie (ed), China's Cultural Scene at the Turn of the 21 st Century, London etc: Routledge, 2008; Full Tilt 1, Index on Censorship 35-4. Chapter Ten: Olga Lomova (ed), Recarving the Dragon: Understanding Chinese Poetics, Prague: Karolinum Press, 2003. Chapter Eleven: Studies on Asia 2-1 and 2-2. Chapter Thirteen: Modern Chinese Literature and Culture Resource Center $\rightarrow$ Publications, 2007.

I thank the photographers whose work enlivens this book and their portrayees, as well as the authors and editors of the publications in which I encountered them, for permission to include the images in question. Their names are listed in the captions. Unfortunately, many of the photographers remain unidentified. 


\section{CONVENTIONS}

Poem titles are marked by double angular brackets (e.g. «What the Eagle Says»), to distinguish them from journal articles, book chapters and so on (double quotation marks) and book titles (italics). Footnote numbers appear at the end of the paragraph that precedes the poem, out of respect for the integrity of the text. For the sake of consistency, this also holds for other indented quotations. Reference to untitled poems, the originals of which are actually called «Untitled» (无题) in Chinese, is marked by lower case after the first letter of the poem's first word, and named after the poem's opening line, followed by four successive dots (e.g. «He opens his third eye....»). In poetry and other citations, three separate dots . . . indicate the omission of words from the passage in question.

As for my use of upper case in poetry translations (titles aside), this has depended on the feel of the original. Some of my renditions are in lower case throughout (e.g. Yan Jun); in others only names and the first-person singular $I$ are capitalized (e.g. Han Dong); in a third category the first word of each stanza also starts with upper case (e.g. Haizi); and in clearly punctuated texts the first word of each sentence is capitalized (e.g. Sun Wenbo).

The points of the compass are written with lower case only if their usage is strictly spatial or geographical: Haizi lived north of Beïing, but a highly ideologized polemic produced a North-South dichotomy. Literary-critical terms are written with lower case only if they are of wide, multi-interpretable scope, as distinct from specific, localized literaryhistorical categories: hence, romantic poethood but Western Romantics like Byron and Shelley, and modernism but Socialist Realism.

Following current usage, for alphabetizing Chinese I have used Hanyu pinyin (汉语拼音) but only added tone marks when sound is truly important, and retained other transcriptions as they occur in bibliographical detail. The same principle has informed my use of simplified characters throughout, but of full-form characters for full-form publications as they appear in the list of works cited.

The narrative is entirely in English, with original forms given in parentheses for relevant terms and titles translated from other languages. 
In most cases the original form appears at first mention, and the reader who wants to check at a later stage will have to consult the index. Some of the original titles are provided only when the discussion arrives at the text in question, and original terminology is repeated if the term in question features centrally more than once, at far-between points in the narrative. The titles of poems that are part of the discourse studied in this book and feed directly into the analysis are accompanied by the poem's year of composition or, if I have been unable to ascertain this, by its year of publication, followed by a question mark if the date is an estimation.

The characters for Chinese personal names are found in the index, which lists life years for all well-known avant-garde poets mentioned in this study, with their recognition as such measured roughly by visibility in multiple-author anthologies, unofficial journals, individual collections, literary histories and so on. This extends to precursors of the avant-garde such as Huang Xiang and Guo Lusheng, but not to authors such as Tang Xiaodu and Chen Chao, whose association with the avant-garde is primarily in their capacity as critics, even if they are published poets in their own right. Life years appear in the main text for poets whose work is studied in depth. With a few exceptions that are motivated by the narrative, I have not referred to "real" or “original” names (原名、本名, e.g. Zhao Zhenkai for Bei Dao) that the authors in question haven't used in their capacity as published poets, since there is nothing real or original about them in the present context. In transcribing names, I have adhered to previous transcription in Western-language publications where it exists, even if this flouts the rules for Chinese (family) names (e.g. Xi Chuan rather than Xichuan), and otherwise gone by those rules (e.g. Zhongdao rather than Zhong Dao). For Beiling, Duoduo and Haizi, whose names have also been transcribed as Bei Ling, Duo Duo and Hai Zi, I have opted for the aggregated versions, basing myself on "real names" after all, for want of better reasons: Beiling's "real name" is Huang Beiling, Duoduo named himself after his daughter Li Duoduo, and Haizi's "real name" was Zha Haisheng, which makes it unlikely that Hai in Haizi should be read as a family name.

From the material that was available to me I have picked author portraits that I feel convey the presence of the individuals as I have experienced this over the years during public readings, interviews and so on-rather than looking for pictures from particular times or occa- 
sions that would establish some sort of historical linkage to the poems discussed or build an orderly line-up in which, for instance, Bei Dao should always be older than Yang Lian. Hence, in chapter Four the reader will encounter a Bei Dao who is younger than Yang Lian; and in chapter Two, a Han Dong who wrote the poetry under scrutiny some fifteen or twenty years ago; and so on.

Information that is not common knowledge and for which no source is given comes from fieldwork notes covering the years since 1991, when I started building what has since become an archive of avantgarde poetry from China.

Reliable access to the online resources consulted for this study is ensured through a dedicated citation repository of the relevant website and web page downloads in the Leiden University division of the Digital Archive for Chinese Studies (DACHS Leiden, see p475).

On the whole, as regards these conventions and the design of the table of contents, the introductory chapter One, the index and so on, I have tried to write not just for those who will read this book from cover to cover, but also for those especially interested in this or that chapter or piece of information, and to be sensible rather than rigidly systematic. 
Maghiel van Crevel - 978-90-47-44273-8 Downloaded from Brill.com $04 / 25 / 2023$ 11:38:45PM via free access 


\section{LIST OF ILLUSTRATIONS}

$1.1 \quad$ Li Hongqi.......................... 40

$1.2 \quad$ "Li Hongqi killing himself" . . . . . . . . . . . . . 40

1.3 Yi Sha at age eight..................... 41

1.4 Mang Ke and Bei Dao, founders of Today.......... 42

1.5 The Coquetry School. ....................... 42

1.6 Luo Yihe's letter describing Haizi's suicide . . . . . . . . 43

1.7 Manuscript of Yi Sha's «Starve the Poets» . . . . . . . . . 44

$1.8 \quad$ Han Dong, eating. . . . . . . . . . . . . . . . . 45

$2.1 \quad$ Han Dong . . . . . . . . . . . . . . . . . . 64

2.2 Them 5 , front cover.................... 74

$3.1 \quad$ Haizi. . . . . . . . . . . . . . . . . . . . . . . . . 92

$3.2 \quad$ Small Station............................ 99

3.3 The Poetry of Haizi . . . . . . . . . . . . . . . . . . . 99

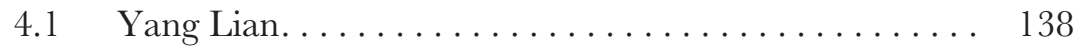

4.2 Wang Jiaxin ......................... 140

4.3 Bei Dao .............................. 142

$5.1 \quad$ Xi Chuan . . . . . . . . . . . . . . . . . . . . . . . . . . . . 188

$7.1 \quad \mathrm{Yu}$ Jian . . . . . . . . . . . . . . . . . . . . . 248

7.2 Small type: a page from «Event: Wedding»........ 276

$8.1 \quad$ Sun Wenbo . . . . . . . . . . . . . . . . . . . . . . . 282

8.2 «The Program»: Content and Plot ............. 292

$9.1 \quad$ Yin Lichuan . . . . . . . . . . . . . . . . . . . . . 306

9.2 Shen Haobo . . . . . . . . . . . . . . . . . . . . . . . . . . . 308

9.3 The Lower Body 1, front cover . . . . . . . . . . . . . . . . 316

9.4 "Cool Sister" Yin Lichuan. . . . . . . . . . . . . . . . . . 336

9.5 Shen Haobo's "Record of a Head Shave". . . . . . . . . . 337 
12.1 "Turn-of-the-Century Poetry Polemic," Taiyuan Daily. . . 422

13.1 Yan Jun . . . . . . . . . . . . . . . . . . 460

13.2 Yan Jun with fm3 and Wu Quan.............. 463

13.3 Yan Jun as support act for Hei Dachun and Vision .... 464

13.4 Sub Fam 012: Donald Rumsfeld with "subtitles" ...... 467 


\section{CHAPTER ONE}

\section{AVANT-GARDE POETRY FROM CHINA: TEXT, GONTEXT AND METATEXT}

What is Chinese poetry today? Following a quick look at former times, this chapter examines two phenomena that have been central to the situation in mainland China since the late 1970s: the unofficial poetry scene and the avant-garde. It then recalls salient moments in the avantgarde's history, with sketchy reference to context. After sampling four individual texts and identifying two overall textual trends, it considers metatextual images of poetry and poethood. Finally, it introduces the next chapters and explains what this book wants to do.

By text, I mean poetry, on the page and in recitation; by context, poetry's social, political and cultural surroundings; by metatext, discourse on poetry.

\section{What Went Before}

Chinese poetry boasts an uninterrupted, enduring tradition of a good two and a half thousand years. Early specimens are found in the Book of Songs (诗经) and the Songs of the South (楚辞), the latter with China's arch-poet Qu Yuan as its (co-)author. They remain popular to this day, with Chinese and foreign readers alike. So do the works of celebrated Tang and Song dynasty poets such as Li Bai, Du Fu, Li Shangyin, Su Shi and Li Qingzhao. Their lives span a centuries-long period that predates modernity by roughly a millennium and their works are widely seen as the pinnacle of Chinese literature, indeed of Chinese culture at large. And if poems from the Tang and Song have been canonized to the point of being imperishable to the mortal eye, there is a wealth of accomplished poetry before the Tang and after the Song, too.

Classical Chinese poetry comes in a variety of sophisticated, musical forms and styles. It employs archetypal themes that include the majesty of the natural world, the fate of kingdoms and empires, and

(C) MAGHIEL VAN CREVEL, 2008 | DOI 10.1163/9789047442738_002

This is an open access chapter distributed under the terms of the Creative Commons AttributionNoncommercial 3.0 Unported (CC-BY-NC 3.0) License. 
the tragedy of the official whose advice goes unheeded by the ruler. The ruler's failure to appreciate his servant's loyalty also serves as a habitual interpretation of poetry that speaks of unrequited love. This illustrates the age-old entanglement of Chinese poetry and politics, brought on by poets as well as politicians, and by poetry's readers as well as its writers. Writers are usually readers, too, and Chinese poets and politicians have coincided in the same bodies. Li Yu, the last emperor of the Southern Tang dynasty, is an example of a thousand years ago. Mao Zedong is one from our time.

In China, such coincidence is perhaps less coincidental than elsewhere, in light of an ontological association of government and literature. In a traditional Chinese worldview both reflect the Way (道 Dao, alternatively transcribed as Tao), a cosmic principle that determines the order of all things, from the changing of the seasons to human relations within the state and the family. According to a central component of traditional Chinese poetics, the value of literature lies in its capacity to "convey the Way": to praise, for instance, a virtuous ruler, or remonstrate with one unworthy of the throne. The notion of literature to convey the Way (文以载道) doesn't contradict the ancient Chinese adage that poetry "articulates what is on the mind intently" or "verbalizes emotion" (诗言志), in Stephen Owen's and Zhang Longxi's renditions. Here, emotion and what is on the mind intently refer not to individual feelings and even less to idiosyncratic obsession, but to the entire mental state that is appropriate in a given set of circumstances and will prompt equally appropriate expression and action prescribed by the socio-moral code of Confucianism - the sort of mindset, in other words, that one would want in a government official. This explains why in premodern times, imperial civil service examinations tested aspiring officials for their command of poetry. It also explains how it is that in a traditional Chinese view of literature one's command of poetry can be objectively assessed, and reading the poem is, in Owen's words, reading the poet. ${ }^{1}$

The specialists know better, but still: it is also our mortal perspective that is wont to divide Chinese poetry into classical and modern corpora whose size appears unbalanced. There is close to three millennia of the former and one century of the latter. Whether we will still call ourselves modern a hundred or a thousand years from today is not an

\footnotetext{
${ }^{1}$ Owen 1992: 26-28, Zhang Longxi 1992: 133; Owen 1979: 232-234.
} 
acute concern, but such speculation and the limits of living memory aside, it is a fact that in the last one hundred years or so Chinese poetry has crossed several watersheds. It has moved from one language to another, from relative self-containment to vigorous interaction with foreign traditions and from entanglement with politics and society to the mixed blessings of autonomy — or, depending on one's perspective, of marginality.

After the last imperial dynasty had collapsed and the Republic of China emerged (1911), champions of change such as $\mathrm{Hu}$ Shi and Chen Duxiu advocated literature in a colloquial, modern language, in what has gone down in history as the Literary Revolution (文学革 命) of 1917, triggered in the pages of New Youth (新青年). Vernacular usage (白话文) was to supersede the classical Chinese (文言文) that had been the exclusive medium of high literature. The classical and the vernacular were not different linguistic registers but distinct languages, as far apart as Latin and present-day French. Incidentally, for all their modernity, many vernacular texts from the first years and decades after the Literary Revolution were still anything but colloquial. They retained heavy traces of classical Chinese and incorporated many neologisms of foreign origin. A New Poetry (新诗), in free verse as well as foreign and indigenous modern forms, set out to replace a time-honored tradition whose rigidity and elitism were now felt to thwart the development of a modern literature, and by implication of a modern society. The drive for literary reform was motivated in large part by social concerns and was by no means a purely aesthetic affair, so the Way was never far away. Crucially, however, now that poetry was no longer an integral part of officialdom, China's poets lost their self-evident social status. As scholars such as Lloyd Haft and Michelle Yeh have shown, they began to grapple with an identity crisis and problems of legitimation that continue to this day, forcing them to reconsider why, how, what and for whom they wrote. ${ }^{2}$

If in early modern times the marriage of Chinese literature and politics became uneasy, in the public sphere its fundamental validity was rarely questioned with any profound impact. The period up to the 1940s saw foreign-influenced experimentation and heated debate on the New Poetry and its social obligations, by authors whose work is regularly reprinted in China and has been translated into many lan-

\footnotetext{
${ }^{2}$ Haft 1989: "Introduction,”Yeh 1991a: ch 1.
} 
guages: Guo Moruo, Wen Yiduo, Xu Zhimo, Bing Xin, Li Jinfa, Bian Zhilin, He Qifang, Feng Zhi, Dai Wangshu, Ai Qing, Zang Kejia, Tian Jian, Zheng Min, Chen Jingrong and others. At the end of the day the New Poetry's practitioners were forced to engage with the crisis in which their country found itself, meaning imperialist aggression, crippling social problems, a world war and a civil war. Art for art's sake, or art that could be construed as arrogating the right to remain aloof from its national and social environs, fought a losing battle. Tendentious though the metaphors of aloofness and battle may be, it is difficult to deny them access to this particular bit of literary history.

As Chinese leaders have done through the ages, Mao Zedong thought highly of the political potential of literature. In his 1942 “Talks at the Yan'an Forum on Literature and Art" (在延安文艺座 谈会上的讲话), he laid down the law for writers in Communist-controlled areas, subordinating their work to politics in so many words. ${ }^{3}$ This meant a ban on many types of literature, including those of the so-called Individualist (个人主义) and Humanist (人道主义) kinds. It also led to the active commission of literary works designed to advance the war effort against the Japanese and the Chinese Nationalists. In the People's Republic of China, established in 1949, these wartime rules for literature and art remained in force for decades after the war was over. Taiwan, now home to the Nationalist government of the Republic of China, and Hong Kong, still a British colony at the time, were worlds apart from the mainland, as is borne out by their subsequent literary histories.

In China, literature and art-production, publication, distribution, criticism, scholarship - came under near-complete control of the Communist Party and were institutionalized as ideological tools in state-sponsored bodies like the Chinese Writers' Association (中国作 家协会) on national and local levels. Successful and popular works in all genres treated of politically correct subject matter in politically correct forms. Their aggressively prescriptive poetics was that of Socialist Realism (社会主义现实主义) and later the Combination of Revolutionary Realism and Revolutionary Romanticism (革命现实主义和 革命浪漫主义的结合). For poetry this gave rise to a dominant trend known as Political Lyricism (政治抒情诗). Control and activism extended to issues of style that reached down to the sentence level and

\footnotetext{
3 McDougall 1980, Denton 2003.
} 
indeed that of the individual word. The mark this left on the Chinese language as it was spoken and written in the PRC over the next three decades and beyond, especially but not exclusively in public discourse, is known as the Mao Style or Maospeak (毛文体), with a predilection for political lingo, ideologically heavy abstractions and the grand gesture. Censorship, including systematically stimulated self-censorship, became the order of the day, and many writers abandoned their art for safer occupations. Those who continued to write but failed to toe the line risked punishment, ranging from harassment in their private and professional lives to domestic exile, house arrest, incarceration and mental and physical violence, especially during the Cultural Revolution (1966-1976). This led, for instance, to the alleged suicide of famed fiction writer and dramatist Lao She - or effectively his murder by Red Guards. They were youngsters who had been instructed by Mao to "bomb the headquarters" and take the law into their own hands, but soon became the pawns of infighting within the Party that led the country to the brink of mass psychosis, economic collapse and civil war.

In the 1950s and the early 1960s there had still been a regular production of literary texts, albeit monotonous and predictable, with much banner-waving, heroic battling of sinister landlords, glorious steel production and so on. Also, while the People's Republic was incomparably less cosmopolitan and outward-looking than the Republic had been and went on to be in Taiwan, and the selection of works for translation was increasingly determined by the political loyalties of their authors and their countries of origin, foreign literature did continue to be published in 1950s and early 1960s China. But by the late 1960s, after the outbreak of the Cultural Revolution, literary activity in China came to a virtual standstill. ${ }^{4}$

\section{The Unofficial Poetry Scene and the Avant-Garde}

Ideological repression was now at a fever pitch. In a Maoist anti-intellectual outburst, schools and universities were closed, and urban high school and university students designated as Intellectual Youths (知

\footnotetext{
${ }^{4}$ Yang Lan has shown that the production of new fiction did not stop altogether, but his research confirms the general picture of a literary wasteland (1998). Cf Hsu 1975.
} 
识青年) were rusticated to learn from peasants and factory workers instead. This drive at reeducating the urban youths was frequently counterproductive and led to their disillusionment with official representations of reality, including state-sanctioned PRC literature and art to date. At the same time, in a quirk of history, Red Guard razzia's of public and private "bourgeois" libraries exposed many of them to foreign literature in translation. This acquainted them with texts that were normally not widely available because they were older publications or because they were for "internal" (内部) use, restricted by the authorities for access by a high-level cadre readership: works by Baudelaire, Kafka, Akhmatova, Tsvetayeva, Kerouac, Salinger, Solzhenitsyn and many more. Inside the particular synergy of the tumult of the "Ten Years of Chaos," estrangement from official culture, foreign inspirations and the exploration of their individual talent, the Intellectual Youths began to meet in informal, clandestine circuits for reading and writing that became the breeding ground of the poetry that this book is about. ${ }^{5}$

China's unofficial (非官方) poetry scene (诗坛) has its origins in this literary underground (地下) during the Cultural Revolution. Strikingly, literary historiography and literary events show that it is in the un-official scene - as opposed to the official (官方) scene, also called orthodox and establishment in English - that everybody that is anybody in contemporary poetry from the PRC first published and developed their voice. Equally remarkable, most if not all successful contemporary poets subscribe to a designation of their work as avant-garde (先锋), a category which is of narrower scope in many other literary histories. Hence, we should take a closer look at the notions of the unofficial poetry scene and the avant-garde as they occur in Chinese-domestic critical discourse. I have extensively analysed these notions elsewhere: they overlap, and each can be used in aesthetic as well as institutional senses, which are not always easy to separate ${ }^{6}$ Here, we first focus on their primary associations. For the unofficial poetry scene, these are institutional. For the avant-garde, they are aesthetic.

By scene I mean poets, poetry and their circumstances, including critics and other readers. The contemporary poetry scene as a whole is anything but homogeneous. Authors identify with the unofficial and

\footnotetext{
${ }^{5}$ Van Crevel 1996: ch 2 and 2007, Song Yongyi 1997 and 2007.

${ }^{6}$ Van Crevel 2007.
} 
official scenes and their subsets - regional, gendered, stylistic, medial - to varying degrees, ranging from high-profile organizational activism to dismissal of any identity that transcends the individual.

\section{The Unofficial Poetry Scene}

From an institutional angle, the unofficial poetry scene is that part of contemporary poetry that operates of its own initiative, outside the publishing business as formally administered by the state. After the underground preliminaries during the Cultural Revolution, the unofficial scene moved to the overground in December 1978, with the publication of the Beijing-based journal Today (今天). ${ }^{7}$ This was a landmark in PRC literary history, as the journal defied the state's monopoly on literature. Today featured authors such as Bei Dao, Mang Ke, Shu Ting, Gu Cheng, Yang Lian and Duoduo, ${ }^{8}$ to name some of the best-known poets of the first generation that ventured beyond the Maoist pale. Since the early 1980s, as the state's grip on literature and art has progressively weakened, the unofficial scene has expanded in urban centers throughout the country - Nanjing, Shanghai, Hangzhou, Chengdu, Kunming, Harbin, Guangzhou - and made its texts available to whoever is interested. In a self-protective measure, these texts often claim to be aimed at "internal" exchange, in an ironic appropriation of orthodox terminology for a designation that is demonstrably untrue. Unofficial publications make no attempt to control their readership and would indeed love to see it grow uncontrollably. Tapping into highly effective, informal networks of poets and critics, the unofficial scene produces serial journals and one-time single-author and multiple-author anthologies, from the scruffy to the glossy, in print and online. It also organizes literary events such as poetry recitals and cooperative projects with other arts like theater and music.

In many places elsewhere in the world the institutional notion of publication hinges on formal involvement by members of officially recognized, professional communities such as publishing houses and book reviewers. In discourse on mainland-Chinese unofficial poetry, however, and in other literary scenes where writers and politicians en-

\footnotetext{
${ }^{7}$ Usage of underground has continued after the Cultural Revolution but no longer denotes active concealment from the authorities.

${ }^{8}$ Yang and Duoduo called themselves Fei Sha and Bai Ye at the time.
} 
tertain seriously conflicting visions of literature and politicians have the power and claim the right to interfere, the notion of publication should be taken in the broadest possible sense. Publication then simply means the making public of a text beyond inner-circle audiences hand-picked by the author. The point is illustrated by the difference between the Chinese terms 发表 'announce, make public' and 出版 'come off the press, publish' (cf German veröffentlichen 'make public' and herausgeben 'publish,' meaning 'act as publisher of'; the English publish is ambiguous in this respect). Not everything that is made public is brought out by an official publisher. Even if it rarely appeared between the covers of officially published books or journals until the late 1980s, unofficial poetry was definitely published in the said, broad sense.

One important feature of the unofficial poetry scene is its rejection of the strictures of official cultural policy. In the Reform era, since 1978, such policy has seen considerable if fitful relaxation. This raises the question why the unofficial scene should need to exist any longer, for contemporary poetry has explored an infinitely larger space outside orthodoxy than that which continues to be off limits, with explicit political dissent as an example of the latter. Still, the unofficial scene retains its significance to this day. For one thing, political repression does in fact continue at fluctuating levels. Many of the poets involved are highly educated, well-connected people who generally have a good time, and tired Cold War visions of the poetry scene as a theater of artistically inclined guerilla warfare are grossly inaccurate, but it is certainly not the case that anything goes. Censorship and other types of political interference with literature remain very much operational: witness, for instance, the cultural purge that followed June Fourth (六·四), the violent suppression of the 1989 Protest Movement. When it happened, the unofficial scene rallied together on a national level to keep poetry alive.

More generally, there is ample reason to question Geremie Barmé's claim, made in an admirable study of contemporary Chinese culture that is slightly marred by cynicism, that unofficial poetry stands out only "against the gloomy backdrop manufactured by the state," or what we may call the art of the state - whose quality hinges on being embedded in its own, orthodox discourse, except when it is viewed as camp. In its own right, the unofficial scene lies at the core of a lively poetry climate that is instrumental for the development of individual poets and the poetry landscape as a whole. This is in evidence in lit- 
erary historiography as well as in poetry's general impact, domestic and international. In this light, Lü Zhouju's and Luo Zhenya's classification of the unofficial scene as a subculture (亚文化) is open to debate. $^{9}$

Of course, historiography can be disproportionally dominated by particular interest groups. In the present context, an obvious example would be the repression of popular literature from late in the Qing dynasty and early in the Republican era (1911-1949) by the May Fourth (五四) and New Literature (新文学) paradigms, whose near-monopoly over "the modern" has only come to be seriously questioned since the 1980s. Early in the twentieth century, however, the fact that literary reform was part of a nation-building project gave its proponents singular purchase on the making of literary history. No such thing is true for the contemporary avant-garde.

\section{Avant-Garde Poetry}

What goes by the name of avant-garde poetry in post-Cultural-Revolution China is a mixed bag of texts. Their designation as such in this particular socio-cultural framework has little to do with the various meanings of avant-garde in discourse on, say, modern Western literatures, Chinese literature from the Republican era and the Mao years and in Taiwan, and modernism at large. And while one could explore interfaces of contemporary avant-garde poetry in China with what is known as the avant-garde fiction (先锋小说) of the late 1980s and early 1990s - for instance in each genre's negotiation of social change - in this case poetry and fiction are distinct if not separate operations that hardly interact. A more meaningful comparison might involve trends called avant-garde across literature and other art forms in contemporary China, but this lies outside the scope of the present study. ${ }^{10}$

Especially in the early years the poetics of the avant-garde was negatively defined, by dissociation from and exclusion of the thematics, imagery, poetic form and linguistic register that appear in the products of orthodoxy. Since the mid-1980s, however, avant-garde poetry - at

9 For the cultural purge and the "gloomy backdrop" argument, see Barmé 1999: ch 2 and 206. Kong Shuyu demonstrates the importance of the "second channel" (第二渠道、二渠道) in the publishing business (2005: ch 3 et passim); cf Yeh 2007a: 30. Lü 2001: ch 4, Luo Zhenya 2005: 25-35.

${ }^{10}$ Cf Huot 2000: ch 5. 
first also called experimental (实验) and explorative (探索)—has outshone orthodoxy in the eyes of audiences in China and elsewhere, ${ }^{11}$ and it has tremendously diversified. This has rendered orthodox poetics irrelevant as a point of reference. It enables the study of various trends in contemporary poetry not as Others of orthodoxy but in their own right, or with the simple qualification that orthodoxy is not among them. ${ }^{12}$ Carrying this argument further, one might contemplate a negative definition of orthodox poetry instead, as unreceptive to the individual, original and idiosyncratic language usage, imagery and worldviews that have been associated with literary modernity.

In a clichéd comparison, positive observations are attractive because defining blue as the color of the sky on a bright day tells us more than defining blue as not the color of blood. If by now, four decades into the avant-garde's history, we can in fact make observations of this nature, one might be that in present-day China, more so than in other times and places, an opposition of two broadly defined aesthetics that I call the Elevated and the Earthly is of particular relevance; a detailed discussion of these notions follows below. This holds for poetry but also for images of poethood and explicit poetics, which avantgarde poets generate in large amounts. Second, on the Elevated side of things, avant-garde poetry stands out by its rich and idiosyncratic use of metaphor. Third, the avant-garde has produced many poems that stand out by their sheer size, albeit in very different styles.

\section{Aesthetic $\leftrightarrow$ Institutional, Unofficial $\leftrightarrow$ Official}

As practitioners and students of avant-garde movements the world over have observed, relations between the aesthetic and the institutional are complex if not problematic. China is no exception. On the face of it, in the titles, blurbs and introductions of multiple-author poetry anthologies and historical and critical survey works, the notion of the avantgarde often appears to operate in the aesthetic dimension rather than the institutional. ${ }^{13}$ Since on closer inspection it works as catchall for different and indeed divergent poetics, it must at the same time be fundamentally institutional. Similarly, unofficial is an ambiguous term in

${ }^{11}$ Cf He Yuhuai 1992: ch 7, Zhang Xudong 1997: 123 and Lovell 2006: 162.

${ }^{12}$ Cf Hu Xudong 2005.

${ }^{13}$ E.g. Li Lizhong et al 1990 and Lü 2001. 
that beyond its institutional connotations it can also refer to aesthetic matters. This ambiguity has been put to clever use in poetical debates within the avant-garde, most of all during an extended polemic in the years 1998-2000. More generally, it is operational in various stakeholders' claims to symbolic capital, in Pierre Bourdieu's terms. ${ }^{14}$ No self-respecting avant-garde poet will accept being called official in the aesthetic sense, meaning that their work reflects orthodox preferences in thematics and so on. In addition to publishing through unofficial channels, however, just about every such poet sets great store by appearing in publications that are official in the institutional sense. That is: they are formally registered, and their colophon contains library catalogue data, a fixed price and so on. One can, in other words, publish in institutionally official books and journals or hold membership of official institutions such as the Writers' Association, and yet enjoy recognition as an aesthetically unofficial poet.

Yu Jian and Xi Chuan, two authors whose work features prominently in this book, are cases in point. Since the 1990s both have counted as leading poets in China and built up international renown. While they are aesthetically of unofficial provenance and formative stages of their careers unfolded through institutionally unofficial channels, both have published collections with major official presses. In addition, Yu Jian has been employed by the Yunnan Province Federation of Literary and Art Circles (云南文艺界联合会) as editor of the Yunnan Literature and Art Review (云南文艺评论) for the full length of his parallel career as an unofficial poet. Xi Chuan, who teaches at the Central Institute for Fine Arts in Beijing, was one of five poets who received the eminently official, four-yearly Lu Xun Award for Literature (鲁迅文学奖) in 2002, and Yu Jian was among the laureates in 2007. Rather than letting these things influence any assessment of the integrity of these or other poets vis-à-vis caricatures of an orthodoxy that continues to ideologize literature, Yu Jian's and Xi Chuan's literary output raises the question whether this is perhaps a sign of the unofficial scene changing the official scene.

As part of overall rapid social change, cultural life in the People's Republic displays increasing pluriformity. This pluriformity and the said ambiguities clarify how, in spite of a chasm of aesthetic difference that continues to separate official and unofficial poetry scenes, their

\footnotetext{
${ }^{14}$ Bourdieu 1993: ch 1.
} 
institutional distinctions have become blurred. Little remains of the antagonism that made them incompatible and indeed mutually exclusive in the early years, up to the mid-1980s. Nowadays they coexist in parallel worlds with their middle ground awaiting further exploration, as John Crespi and Heather Inwood have noted. ${ }^{15}$ Official and unofficial scenes do occasionally brush past one another and indeed interact, even if such interaction is rarely explicitly recognized. It occurs, for instance, in institutionally official book and journal publications whose aesthetics are clearly of the unofficial kind. These are often contracted and produced by aesthetically unofficial poets that have "gone to sea" (下海) - that is, into business - as book brokers (书商). While these books and journals usually have ISBN or book license numbers (书号), this has long ceased to indicate any compatibility with orthodox aesthetics. ${ }^{16}$ There is a lively trade in such numbers that involves public institutions, private individuals and everything in between, and niceties such as the procurement of single numbers for multiple-author series of individual collections, for cost effectiveness. Crudely put, one can now buy the status of being an officially published poet, at prices to the tune of RMB 5000 and up. It is common knowledge that this happens all the time, even though it is illegal.

Distinctions of orthodoxy and avant-garde, and of official, unofficial, underground and so on, also operate in other media and genres of literature and art in China: theater and performance, music, film, painting, sculpture. They do so in similar or comparable fashion, from utter incompatibility to fluid interaction. As part of a society that has been transformed in the past three decades and continues to be in flux, these distinctions are anything but static. They reflect an ongoing, multidimensional dynamic of forces ranging from government ideology and cultural policy to personal initiative, the market and the politics of place, from the local to the global.

${ }^{15}$ Crespi 2005, Inwood 2008: passim.

${ }^{16}$ On the interaction of official and unofficial circuits in poetry and other arts forms, see Edmond 2006 and Liu (Melinda) 2004. On book brokers, also called "book agents" and "book traders" in English, see Kong 2005: ch 3. 


\section{Context: Times of Mind, Mayhem and Money}

Let's return for a moment to the notions of text, context and metatext. First of all, text $\rightarrow$ context $\rightarrow$ metatext is the order in which, by and large, my interest in poetry has developed over the years, but not one to which I necessarily adhere for the presentation of my material. In this chapter, for instance, it seems practical to have the present section, on context, precede the sections on text and metatext; and in this study at large, to have the present chapter with its extensive treatment of context and metatext precede the first of several textually oriented case studies. Second, text + context + metatext is a pragmatic, flexible trinity, not a trichotomy. I have no desire to cut these things off from one another, for in a project such as this they inter-act more often than not, with boundaries that are positively fuzzy and occasionally deceptive, for instance in the case of Xi Chuan's explicit poetics. There is much text that is also context and metatext, context and metatext often overlap, and so on. Text, context and metatext are real categories and anything but arbitrary or interchangeable, but their mobilization depends on one's perspective.

Subtitling this section times of mind, mayhem and money is an attempt to sum up vast changes in the social, political and cultural context of contemporary poetry from the late 1970s until the present, often simplified as a contrast between “the Eighties" (八十年代、80年代) and “the Nineties” (九十年代、90年代) and beyond that applies in the intellectual-cultural realm at large. It is in this particular usage that I occasionally write Eighties or Nineties - mostly in the phrase Poetry of the Nineties (九十年代诗歌、90年代诗歌), which we will encounter several times - as distinct from 1980s and 1990s, the latter being neutral indications of calendar time.

Mind refers to the upbeat atmosphere during the Reform era until the summer of 1989. In these years the subordination of literature and art to politics gradually came to an end. There was a great deal of exhilaration in the life of the mind, that expressed itself in a high culture craze or high culture fever (文化热), in Wang Jing's words. ${ }^{17}$ Poetry was positively hot. This was apparent in frenzied, extraverted activity, much of it practiced in joint initiatives linked to journals, multipleauthor anthologies, societies, slogans, Isms and events.

\footnotetext{
17 Wang Jing 1996.
} 
Mayhem refers to the violence of June Fourth and its aftermath. For the atmosphere on the poetry scene, June Fourth was a catalyst in the transition from the roaring, collectivist 1980s to private and sober, questioning if not skeptical and cynical moods in later years. The bloodshed of June 1989 and reintensified repression over the next three years or so - until after Deng Xiaoping told the nation to keep its eye on the money during his 1992 Southern Tour-meant a shocking end to the Eighties, and traumatizing disillusionment for large parts of the intelligentsia. Its direct reflection in poetry is complicated by the fact that inside China, the portrayal of government action as violent and repressive remains taboo in any kind of writing. To be sure, there are poems that can be seen to be about June Fourth even if they don't explicitly address it, but the political sensitivity of this topic is such that most if not all poets tread extremely carefully. ${ }^{18}$ Palpable responses aside, there is only so much one can read into particular types of silence, including the silence of the many poets who stopped writing altogether after 1989, something that was caused by not just mayhem but also money.

Money, then, refers to the China of the 1990s and the early twentyfirst century, where, as economic whistle-blower He Qinglian writes, "the championing of money as a value" has reached unprecedented heights. ${ }^{19}$ This period has seen poetry keeping itself afloat in a maelstrom of consumerism, entertainment, (new) media and popular culture, as marketization, commodification, commercialization and indeed moneyfication - not a common word, but one that captures the day-to-day experience - sweep through all spheres of life, including elite practices in literature and art.

\section{Some Avant-Garde History}

A few contextual observations hold across the contemporary period in its entirety. While mechanisms of literary censorship have remained operational, political interest in poetry has declined, in a shift from totalitarian pre-scription of compulsory form and content to authoritarian pro-scription of dissent. After high visibility in the 1980s poetry has been subject to overwhelming competition by other distractions

\footnotetext{
18 Day 2005a: ch 11 and 2007a.

19 Cited in Liu Binyan \& Link 1998: 22.
} 
in high and popular culture and consumables of every kind, and has had to reposition itself in a radically commercializing environment. Poetry's relation to foreign literatures, most of all an ineradicable generalization known as "the West" (西方), has moved from the uncritical celebration of cultural imports in the early 1980s to the problematization of source and target cultures and to reassessment of Chinese cultural identity in an age of globalization, in criticism as much as in poetry itself.

It is against this backdrop that the development of avant-garde poetry takes place. This book doesn't offer anything like a comprehensive history of the avant-garde, if only because we are up against a difficult side of studying something from our own time, namely its closeness and its ongoing transformations. Still, it may be useful at this point to recall some salient moments in what is by now forty years of avantgarde history, if we start from its earliest inspirations in the Cultural Revolution underground. ${ }^{20}$

The avant-garde had two precursors in the late 1960s, Huang Xiang and Guo Lusheng, who has also been known as Shizhi since the mid-1970s. The work of neither can be called avant-garde in the aesthetic sense, but they returned to poetry the ability - and, in a traditional Chinese poetics, the right - to defy political authority rather than function as an artistically shaped extension of its ideology, and to speak with the voice of something like an individual self. Huang's work centrally featured in the unofficial journal Enlightenment (启蒙). The inaugural issue appeared two months before that of Today, but Enlightenment was much more political and short-lived, and has had nothing like Today's literary impact. Especially Guo's poetry, circulated among rusticated Intellectual Youths throughout the country at the time, has been cited as an inspiration by early avant-garde poets. ${ }^{21}$

One example is that of Bei Dao, China's best-known contemporary poet, who has recalled how Guo's poetry made him start writing in

${ }^{20}$ These are some examples of the many books and journal articles that offer historical and critical surveys of the avant-garde and its underground history: $\mathrm{Xu}$ Jingya 1989, Wu Kaijin 1991, Yeh 1992b and 2007a, Wang Guangming 1993, Yang Jian 1993, Van Crevel 1996: ch 2-3, Liao 1999, Chen Zhongyi 2000, Li Xinyu 2000, Hong 2001: 142-205, Lü 2001, Chang \& Lu 2002, Lovell 2002, Xiang 2002, Cheng Guangwei 2003, Wang Jiaping 2004, Hong \& Liu 2005, Tao 2006, Li Runxia 2008.

${ }^{21}$ On Huang Xiang, see Emerson 2001 and 2004 and Li Runxia 2004; on Guo Lusheng / Shizhi, Van Crevel 1996: ch 2 and Liao 1999: ch 2. 
the early 1970s. At the end of the decade, together with Mang Ke and painter Huang Rui, Bei Dao was the driving force behind Today, fountainhead of the avant-garde and the home of early Obscure Poetry (朦胧诗) before this made its way into official publications. This poetry sustains tragic-heroic images of poethood that have traveled with modern Chinese poetry since its inception, drawing on the $\mathrm{Qu}$ Yuan lore and its modern transformations as well as European high Romanticism. ${ }^{22}$ Early Obscure Poetry is characterized by a defiant, humanist indictment of the horrors of the Cultural Revolution, a highflown tone and fanciful, often private metaphors. The metaphors were certainly obscure to orthodox critics in the PRG, and they are by no means transparent to all other readers. Obscure Poetry provoked a protracted controversy which showed that neither poetry nor literary criticism and scholarship were mere mouthpieces of government cultural policy any longer. In 1983-1984 Obscure Poetry and sympathetic criticism ended up among the targets of the campaign to Eradicate Spiritual Pollution (清除精神污染), an orthodox backlash against what was perceived as a rising tide of Western "modernism." 23

When the campaign had fizzled out and it appeared safe to assume that poetic innovation wouldn't simply be stamped out by the authorities, it became clear that the avant-garde no longer presented a united front and that regional actors no longer accepted the hegemony of the single geographical center in Beijing that had existed around the Today poets. New poetics were put forward in unofficial journals that mushroomed throughout the country from the mid-1980s on, sometimes explicitly dissociating themselves from their Obscure predecessorswho had once been hailed for being courageously artistic but were now coming under fire for naive utopianism and for being ideologically and stylistically dated if not complicit with orthodoxy, in a literary landscape that was changing by the day. One of the new trends was that of the Colloquial Poetry (口语诗) associated with the Nanjingbased journal Them (他们), known for its low-key language usage and

22 Yeh 1991: ch 2, Schneider 1980.

23 On Today and Obscure Poetry, from a plethora of commentary, see Soong \& Minford 1984, Tian 1987, Yao 1989, He Yuhuai 1992: ch 7, Zhuang 1993, Patton 1994: ch 1, Chen Zhongyi 1996, Van Crevel 1996: ch 2 and 2007, Liao 1999: ch 5-6 and Liu He 2001. On the campaign and on poetry as one of its targets, see Pollard 1985, Larson 1989 and He Yuhuai 1992: ch 6; for some primary material, see Poetry Monthly 1983-12: $31 \mathrm{ff}$. 
down-to-earth semantics, with Han Dong as its driving force and contributors from all over the country. Another was that of the Macho Men (莽汉) in Chengdu, with authors such as Wan Xia and Li Yawei enthusiastically offending against social and educational taboos. A third, that of Women's Poetry (女性诗歌) and an accompanying critical discourse, with Zhai Yongming, also from Chengdu, as its foremost representative. A fourth, yet again based in Chengdu, Root-Seeking (寻根) trends toward reviving cultural origins, such as those found in the Wholism (整体主义) championed in the pages of Han Poetry (汉 诗) by poets including the brothers Song Qu and Song Wei and Shi Guanghua. A fifth, also out of Sichuan province, that of the rambunctious Not-Not (非非) project, deadly serious and flippant at the same time, involving Zhou Lunyou and Yang Li among others. A sixth, the self-mocking Coquetry School (撒娇派) in Shanghai, with Momo and Jingbute as central contributors. A seventh, poetry of Intellectual (知 识分子) inclination by poets including Xi Chuan and Haizi in Beijing and Chen Dongdong in Shanghai, with Tendency (倾向) as their journal. These examples are from 1984-1988, and there are many more in those and later years. And while Beijing, the greater Shanghai area - including Nanjing and Hangzhou - and especially Sichuan were centers of activity and activism, they certainly weren't the only places where the avant-garde was developing and diversifying. ${ }^{24}$

Perhaps because of the immense, initial impact of Obscure Poetry and the convenience of thinking in neatly successive generations, literary historiography has tended to lump together divergent and indeed incompatible trends of the mid- and late 1980s and the early 1990s such as those listed above, under denominators like the Third Generation (第三代, pre-Cultural-Revolution poets being a First, and Obscure Poetry a Second Generation), the Newborn Generation (新生代) and Post-Obscure Poetry (后朦胧诗). These labels have occasionally been made to encompass so much that they border on the meaningless, apart from representing slices in time of the avantgarde's history. Something similar is true for later examples such as the Fourth Generation (第四代), the Middle Generation (中间代), the Post-70 Generation (70后一代) and the Post-80 Generation (80后一

${ }^{24}$ On Colloquial Poetry, see Chen Zhongyi 2000: ch 10 and Hong \& Liu 2005: 216-221; on Macho Men Poetry, Day 2005a: ch 4; on Women's Poetry, Zhang (Jeanne Hong) 2004; on Wholism, Day 2005a: ch 9; on Not-Not, Day 2005a: ch 10; on the Coquetry School, Jingbute 1998; on Tendency, Chen Dongdong 1995. 
代), often actively propagated or "stir-fried" (炒作) by their proponents to ensure coverage in criticism and literary histories..$^{25}$ Be that as it may, two important, generalizable points about the 1980s are that the avant-garde exploded into pluriformity and abundance, and that the first signs of the opposition of the Elevated and the Earthly as one of its distinguishing features became apparent.

The first point is illustrated by Xu Jingya's spectacular "Grand Exhibition of Modern Poetry Groups on China's Poetry Scene, 1986" (中国诗坛 1986'现代诗群体大展), followed up in 1988 by a fat survey anthology entitled Overview of Chinese Modernist Poetry Groups 1986-1988 (中国现代主义诗群大观1986-1988), from among a wealth of other evidence. For the second point, witness the late 1980s self-proclamation of (Elevated) Intellectual Writing and, in Yeh's words, the emergence of a "cult of poetry" on the one hand - tragic-heroic like Obscure Poetry but semi-religious rather than semi-political - in mutual antagonism with an (Earthly) anti-cult of colloquializing and vulgarizing trends on the other. To both sides, poet-hood was as important as, if not more important than, poetry. Beyond Obscure Poetry, the opposition of the Elevated and the Earthly was also visible in a broad association of the notion of a Third Generation with the Earthly side of things, and of the notion of Post-Obscure Poetry with the Elevated. ${ }^{26}$

Then came June Fourth. Its most immediate consequence was an added sense of identity and urgency for an exile poetry scene that had gradually formed in the late 1980s. This abruptly gained in visibility as authors who found themselves outside China, such as Yang Lian, Bei Dao and Duoduo, were given huge international media exposure, occasioned by widely felt outrage over the PRC government's violence against its citizens. The significance of poetry by authors exiled from the PRC is the reason why this chapter's title speaks of avant-garde poetry from China, encompassing poetry written within the nation's

${ }^{25}$ See Gong \& Nie 2000, An et al 2004, Huang Lihai 2001 and the unofficial journal Selected Post-80 Poetry (80后诗选, since 2002).

${ }_{26}$ On the Third Generation and kindred categories, often contrasted with Obscure Poetry, see Tang Xiaodu 1992: volume editor's preface, Chen Zhongyi 1993 and 1994: 45-58, Chen Xuguang 1996, Zhang Qinghua 1997: 147-158, Wang Yichuan 1998: ch 3, Yang Xiaobin 1999: ch 3, Li Zhen 2001a, Luo Zhenya 2002: ch 5-6 and 2005, Wang Guangming 2003: ch 11, Day 2005a: ch 1 and ch 4 and Zhu Dake 2006: ch 6; on the "Grand Exhibition" and related material, Xu Jingya 1986 and Xu Jingya et al 1988 (and on the relation of the latter two documents, Day 2005b); on the cult of poetry, Yeh 1996a. 
borders and elsewhere. Meanwhile, inside China the cultural purge that had started in the summer of 1989 limited the avant-garde's access to official publication channels. Poet and avant-garde advocate Wang Jiaxin, for instance, soon lost his job as editor at the influential Poetry Monthly (诗刊). The unofficial scene, however, showed its resilience in several new journals out of Chengdu, Shanghai, Beijing and other places between 1989 and 1992. One called Modern Han Poetry (现代汉诗) — with the Han in its title referring to the Chinese language rather than ethnicity - was managed from Beijing but rotated editorship between contributors in different cities, in an explicit effort to unite poets and readers from all over the country.

Inside China, later in the 1990s new unofficial journals continued to appear. Especially from 1993 on, after the purge had abated, possibilities for official single-author and multiple-author book publication increased. Still, the extraverted, collectivist atmosphere of the 1980s was definitely a thing of the past, with objectifiable reasons for this change lying in mayhem and money. If June Fourth didn't fundamentally alter individual poets' voices, the massacre certainly caused them to reflect on the future of an art that had been at the forefront of cultural development not long before but now seemed futile in light of the recent social trauma. Such misgivings were reinforced by lightningspeed socio-economic change that appeared to have relegated poetry and other elite practices in literature and art to irrelevance almost overnight, at least in the wider public domain. As noted, not a few poets who had published in the 1980s stopped writing altogether in the 1990s.

Yet, many others continued or began in earnest. In retrospect, publication histories show that while on the surface- for example as regards collective, high-profile projects - the poetry scene was less bustling than in the 1980s, the number of published poets was in fact rising. ${ }^{27}$ Poetic production was becoming more diversified and, arguably, more sophisticated. If, aside from the sociology of the scene, we had to summarize textual developments in the 1990s in one word, this would have to be individualization, or, in two words taken from domestic terminology, Individual Writing (个人写作) or, less frequently, Individualized Writing (个人化写作). Up until the end of the 1990s it would be hard to identify collective initiatives in poetry or criticism

\footnotetext{
27 Van Crevel 2008a.
} 
with a public impact that could compare to that of journals like Today or Not-Not, or of Xu Jingya's "Grand Exhibition," but there are any number of successful individual poetic trajectories that run through these years and are equally if not more interesting from a literarycritical point of view. Diversification of styles didn't mean one poet per style, of course - or, for that matter, one style per poet. Still, some labels applied to particular authors or groups of authors in more or less fixed terms, such as the famously unclassifiable Alternative Poetry (另 类诗歌) of Che Qianzi and the Narrative Poetry (叙事诗) of Zhang Shuguang, Sun Wenbo and Xiao Kaiyu.

As the decade progressed, however, especially in its final few years, the opposition of Elevated and Earthly resurfaced with a vengeance, leading to the formation of two veritable camps in poetry. In the years 1998-2000, scores of poets and critics were involved in a high-profile Polemic (论争) between so-called Intellectual Writing (知识分子写作) and Popular Writing (民间写作), the origins of which can be traced back to the rift between Elevated and Earthly that had first opened in the early and mid-1980s. If we go by rhetoric, loudness and aggression, and publication strategies such as the production of partisan poetry Yearbooks (年鉴), the Popular camp was more effective in publicizing its case, although this resulted in collateral damage to the reputations of renowned poets and critics in its own ranks, in addition to casualties among the Intellectuals. Even though the Polemic didn't end in anything like an undisputed Popular $\approx$ Earthly victory, it did provide a launch pad for extreme manifestations of the Earthly aesthetic in the first years of the twenty-first century, often invoking taboo artist and polemicist Yi Sha, celebrated and denounced ever since his proposal to "starve the poets," as something of a patron saint. The clearest examples are the 2000-2001 Lower Body (下半身) troupe, with Shen Haobo and Yin Lichuan among its core members, and the Trash School (垃圾派) and the Low Poetry Movement (低诗歌运动) of subsequent years. Interestingly, while these trends scandalized the poetry scene and many see the behavior of their proponents as a violation of the rules of literary and social decency, their poetry displays above-average social concern for disadvantaged groups in the urban jungle, such as migrant workers and prostitutes. ${ }^{28}$

${ }^{28}$ On the Polemic, see Li Dian 2007 and chapter Twelve of this study; on the Lower Body, chapter Nine; on Low poetry and Trash Poetry, Day 2007a and Inwood 2008: ch 2. In English, Trash Poetry has also been called Garbage Poetry and 
At around the same time, roughly in 1999-2000, the poetry scene acquired a new dimension as it began to explore the possibilities of the Internet. What happens on the web lies outside the scope of this study, but some brief observations are in order here, drawing on scholarship by Michael Day, Heather Inwood and Michel Hockx. First of all, the web is a natural habitat for the unofficial scene and the avant-garde in that it provides endless possibilities for publication in the broadest sense, as defined above. The amount of text uploaded in the past decade or so is frankly astonishing. The open-the-floodgates feeling of it all confronts the online reader with what Day calls an anarchic state of poetry. This includes digital versions of recent and older print publications as well as texts whose first publication happens online. There are currently about a hundred dedicated websites for avantgarde poetry alone, and, after a recent upsurge, several hundreds of blogs maintained by individual authors, with women poets as notably successful bloggers. The other side to the coin is that, just like elsewhere in the world, web text quality is uneven and cannot keep up with its quantity.

Second, as regards medium-specific features of poetry on the web, Chinese poets near-exclusively employ the Internet to facilitate publication of linear text that could technically appear in print just as well, as opposed to poetry that enables multimedial and interactive reading and writing. But there are other medium-specific features to online poetry than the strictly technological. Poets avidly use the web to communicate directly with other poets, critics and general readers. As Inwood notes, if not so much on text, the medium does have striking effects on metatext - and on the relationship between text and metatext, illustrating what I have called positively fuzzy boundaries - and on the overall sociology of the poetry scene. This appears to remain true when the Chinese scene is considered in international comparison. In China the web has sped up intracommunal and intercommunal traffic to a breathless pace, with remarkably frequent and fiery polemical components.

Aside from China's rich tradition in discourse on poetry, an explanation of this metatextual hyperactivity should take into account the web's annihilation of vast domestic distances and its cautious appro-

Rubbish Poetry. For Yi Sha's proposal, made in a poem of the same name, see Yi 1994: 3-4. 
priation of greater freedom of expression than exists in print culture. The PRC government has at its disposal cutting-edge technology and vast human resources for controlling web traffic, and predictions that the web would mean an end to effective censorship have not at all come true. Clearly, however, online poetry goes farther than print culture in testing the limits, quite aside from the literary merits of the texts in question.

Another factor at play here is the sheer intensity of web traffic at large among those parts of the Chinese population that are online, especially the urban young. On that note, it is safe to say that to younger generations of poets and readers who have come of age in the Internet era, the poetry experience quite simply starts on the web. For many it stays there as well, for there appear to be increasing numbers of poets and readers who hardly encounter poetry in print. Still, print editions of online poetic production continue to function as tokens of cultural consecration in the Bourdieuian sense. This has been observed for poetry on the web in other regions and languages as well, and it may be because books still involve higher measures of editorial selection than most websites and certainly than blogs, or because print culture per se hasn't lost its charms. Yet, according to Inwood, print culture no longer has automatic relevance for China's online poetry scene, which is fast developing its own, internal dynamic. In all, research to date suggests that the advent of the Internet has meant vastly more than technical change and that its effects on the poetry scene at large may be sufficiently far-reaching to make it a major topic of scholarship and criticism, and a landmark for literary-historical periodization. ${ }^{29}$

Online developments have an interface with multimedial poetry performance that is crying out to be further explored. Performances such as Hei Dachun's recitals to the accompaniment of the rock band Vision (目光) and especially Yan Jun's multifaceted shows are well suited to (online) documentation. Yan combines poetry with electronically managed soundscapes and VJ-ing, often working together with

${ }^{29}$ On the avant-garde and the Internet, see the DACHS poetry chapter, Day 2007a, Inwood 2008: ch 2 and Yeh 2007a: 31; for online poetry scenes in China at large, Hockx 2004 and 2005. Loss Pequeño Glazier makes a convincing case for "digital poetics" as being a fundamentally different type of writing from print poetics, in both textual-critical and sociological respects, but also notes the continuing weight of print culture in matters of cultural consecration (2002: ch 8, esp 156). Day has signaled the latter point for the Chinese avant-garde (2007b). 
the experimental duo fm3 and video artist Wu Quan. Growing Internet use and multimedial poetry performance illustrate how the avantgarde's development is part of larger cultural trends, regardless of its relative (in)ability to ride the technology tide. ${ }^{30}$

\section{Text: From Elevated to Earthly and from What to How}

Before we take a first glance at some of the avant-garde poetry reviewed in more detail later in this book, let's recall the range of claims currently laid in China to modern poetry at large, through a contrastive comparison similar to those made in essays by Gregory Lee and Ronald Janssen. Consider these two red flags: ${ }^{31}$

We

The youngest citizens of the Republic

Know how in the long river of history

The venerable older generations

Weathered battle after battle of blood and fire

The slowly rising Red Flag with its five stars

Once again makes us shed hot tears

Ah, salute!

The Red Flag with its five stars

As before the eyes of each of us

Images from the long night

Flash up in multitudes

and:

"Red Flag Limo in Wind and Rain»

behind the provincial government building

behind the trees and the lawn

in a small open space

sits a red flag limo long discarded as useless

that's weathered untold years of wind and rain

rusty to the point of being unrecognizable

you get all cynical again

but it's really not worth it

30 On Yan Jun, see chapter Thirteen.

31 Lee (Gregory) 1996: 50-51, Janssen 2002: 259ff. 


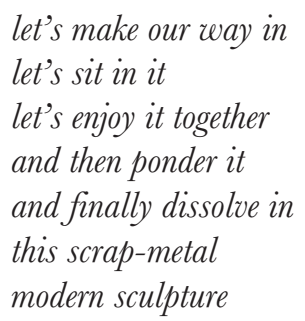

The first text is excerpted from the book-length poem «Manifesto of Youth» (青春宣言, 2002) by Gui Xinghua, composed at the request of the Chinese Communist Youth League Shanghai branch. «Manifesto» is straightforward Political Lyricism, commissioned by the political establishment. It is a socio-moral policy document in verse, set against background photographs signifying dynamic modernization (computers, mobile phones, spaghetti junctions), nationally symbolic sites (Tiananmen Square, the Jinggangshan Museum) and China's status as a major player on the international stage (the 2001 APEG summit, the 2008 Olympics). The second text is a short poem by Yi Sha, typical of a style that doesn't invariably rise above the provocative and the witty. «Red Flag Limo in Wind and Rain» (风雨中的红旗车, 2000) is roughly six hundred times shorter than Gui's poem and as different as can be from Political Lyricism in all other respects, too. Although included in an officially registered publication, it qualifies as unofficial by virtue of its aesthetics, which display irreverence with some condescending nostalgia for a socialist past symbolized by the decrepit Red Flag limo: this is an unabashed send-up of orthodox discourse. Between these two poems lies the full distance from vintage orthodoxy to roguish avant-garde. Somewhere toward the orthodox end lies an oeuvre, less aggressively political than Gui's, that is perhaps the closest that contemporary poetry has come to popular culture: the mawkish lessons-in-life of Wang Guozhen, whose fame reached remarkable heights in the late 1980 s and the early 1990 s. $^{32}$ After this broader positioning, once we focus on the avant-garde side of things, two textual trends are apparent amid a jumble of styles since the late 1970s. They are a trend from Elevated to Earthly and one from what to how.

Avant-garde poetry can be viewed as a spectrum between the outer limits of two divergent, broadly defined aesthetics. This is manifest in

${ }^{32}$ Gui 2002: 19, Yi 2003: 155; on Wang Guozhen, see Wang Guozhen 1991 and Yuan 1992. 
poets' and critics' frequent use of dichotomies such as these, in individual case studies as well as sweeping descriptions of the entire field:

$\begin{array}{lll}\text { heroic } & \text { V } & \begin{array}{l}\text { quotidian } \\ \text { literary }\end{array} \\ \text { cultural } & \text { V } & \begin{array}{l}\text { anti-, pre- or non-cultural } \\ \text { lyrical }\end{array} \\ \text { mythical } & \text { V } & \text { anti-lyrical } \\ \text { sacred } & \text { V } & \text { anti-mythical } \\ \text { utopian } & \text { V } & \text { mundane } \\ \text { absolute } & \text { V } & \text { realist } \\ \text { elitist } & \text { V } & \text { relative } \\ \text { academic } & \text { V } & \text { ordinary } \\ \text { Westernized } & \text { V } & \text { authentic } \\ \text { central } & \text { V } & \text { indigenous } \\ \text { Northern } & \text { V } & \text { local } \\ \text { mind } & \text { V } & \text { Southern } \\ \text { intellectual } & \text { V } & \text { body } \\ & \text { V } & \text { popular }\end{array}$

These dichotomies apply to subject matter and style, and they often run parallel to one another. Together, the items on the left and those on the right represent the said two aesthetics, which I have identified as the Elevated and the Earthly. There is a connection here with previous research on poetry and other genres by scholars including Leo Ou-fan Lee, Michelle Yeh, Wang Ban and Tang Xiaobing. ${ }^{33}$

In principle, notions like the Elevated and the Earthly can be applied to literature and art from any time or place, and there is nothing inherently Chinese or poetic about them. Nor is the current trend unique to China, with an eye to a deconstruction of "serious" literature and art in various genres and media that has been going on for decades in global and local settings. Poetry in contemporary China, however, brings the Elevated and the Earthly to mind with particular force. This doesn't make these notions into tools for reifying an image of the poetry scene as something that can be captured

${ }^{33}$ E.g. Li Zhen 1995: 91. Lee (Leo Ou-fan) 1973, Yeh 1991c, 1992b and 1996a, Wang Ban 1997, Tang Xiaobing 2000. My use of Elevated rather than sublime is in order to steer clear of philosophical and aesthetic connotations of the latter term in European Enlightenment and Romantic traditions. 
in binary oppositions, as polemically inclined critics have done. In fact, even individual oeuvres easily seen as quintessentially Elevated or quintessentially Earthly resist such simple classification. Xi Chuan's work tends toward the Elevated but contains important "antimythical" and "relativizing" elements; Yu Jian's work is representative of the Earthly but contains important "absolute" and "mind" elements; Zhou Lunyou is a central figure in the "anti-cultural" or "pre-cultural" Not-Not group, but his work contains important "cultural" elements. ${ }^{34}$ The Elevated and the Earthly, then, are not pigeonholes but coordinates in a multidimensional body of texts. If we bear this caveat in mind, it is safe to say that across the contemporary period, the overall trend has been away from the Elevated and toward the Earthly.

By a trend from what to how I mean a development away from easily paraphraseable, often historically-referential subject matter and toward the elaboration of individual style, made up of things like (experimental) idiolect, thematics, figures of speech, and acoustic and visual poetic form. Crudely put, in the 1970s and the early 1980s, after the gruesome upheaval of the Cultural Revolution and in the midst of exhilarating developments toward regaining a modicum of individual freedom, so much needed to be said that how it was said was of secondary importance. Hence, the message dominated the medium at the time- but the balance shifted from the mid-1980s onward, and especially in the 1990s. For reading the earliest avant-garde poems, basic knowledge of recent Chinese history is indispensable: well-known specimens of Obscure Poetry such as Bei Dao's «Answer» (回答, 1972) and Gu Cheng's «A Generation» (一代人, 1979), for example, hinge upon the reader's interpretation of the dark night and the ice age as metaphors for the Cultural Revolution. ${ }^{35}$ In later years one can usually do without such background knowledge. Often, China is simply not there. When it is

\footnotetext{
${ }^{34}$ See, for instance, Xi Chuan 1999a, Yu Jian 2000 and Zhou Lunyou 1999.

${ }^{35}$ Yan Yuejun et al 1985: 1, 122. «Answer» was written in 1972, not in 1976, as has been widely and understandably assumed. When Bei Dao published it in Today in 1978, he dated it April 1976 to give it an ideological alibi by linking it to the Tiananmen Incident, which the Beijing Party Committee had recently reassessed as not "counter-revolutionary" but "completely revolutionary" in nature. See Van Crevel 1996: 51 (note 87) and 59-68.
} 
there, for instance in Lower Body writings, it tends to be identified explicitly.

Neither the trend from Elevated to Earthly nor the trend from what to how is constant, absolute or irreversible, but this is what a bird's-eye view of the past several decades shows. We will presently take a look at four texts from recent years, to get a sense of where the avant-garde was at around the turn of the century and hopefully whet the reader's appetite for the case studies that follow this chapter. The selection of these samples, all from the late 1990s and after, is informed by the considerations noted above. Xi Chuan and Yu Jian have been the two most influential poets writing in China since the 1990s, and they are associated with the Elevated and the Earthly trends, respectively; Yin Lichuan is a prominent voice in the Lower Body group that emerged toward the end of the Popular-Intellectual Polemic; and Yan Jun has made a name for himself by innovative, audio-visually supported poetry performance. In addition to their domestic impact, all four have undertaken many invited readings abroad.

Below are two of the ninety-nine stanzas of a prose poem called «What the Eagle Says» (鹰的话语, 1998) that is typical of Xi Chuan's writing since the 1990s. One of his enigmatic texts that invite and yet resist interpretation, this poem contains a wealth of subject matter and yet remains elusive. Addressing issues such as identity and relations of self and other in a tone that is solemn and humorous at the same time, it strikes something of an expository pose, but ultimately turns out to flout the rules of expository logic and celebrate ambiguity, paradox and contradiction instead. Playful and down to earth, and generated by its own musicality and sentence-patterning as much as anything else, it exemplifies what Marjorie Perloff calls the tension between reference and the compositional game. ${ }^{36}$

56/ Thereupon I shun my flesh and turn into a drop of perfume, actually drowning an ant. Thereupon I turn into an ant drilling my way into an elephant's brain, upsetting it so that it stamps all four of its legs. Thereupon I turn into an elephant, my entire body exuding a great stench. Thereupon I turn into a great stench, and those who cover their noses when they smell me are men. Thereupon I turn into a man, and a plaything of fate.

${ }^{36}$ Perloff 1999: 72. Bibliographical detail for the following poetry samples is provided in chapters Five, Seven, Nine and Thirteen. 
$\cdots$

58/ Thereupon I turn into my posterity and let the rain test if I am waterproof. Thereupon I turn into rain, and splash upon the bald head of an intellectual. Thereupon I turn into the intellectual, detesting the world and its ways, and I pick up a stone from the ground and hurl it at the oppressor. Thereupon I turn into stone and oppressor at the same time: when I am hit by me, that sets both of my brains roaring.

$\mathrm{Yu}$ Jian's poetry could hardly be more different from Xi Chuan's. Thus begins Yu's 71-line «Outside the Poet's Scope: Observation of the Life of a Raindrop» (在诗人的范围以外对一个雨点一生的观察, 1998):

right it's going to rain

the poet on a bar stool in the coffee shop

shoots a glance at the sky quietly mumbles

and his tongue withdraws into the dark

but back in those dark clouds its life its

drop-by-drop tiny story is only just beginning

how to say this this sort of small thing happens every moment

i'm concerned with bigger things says the poet to his female reader

obedient to that invisible straight line coming down

maintaining consistency with surroundings equally perpendicular to the earth just like the poet's daughter always maintains consistency with kindergarten and then in skies twisted by pedagogy

becoming twisted it cannot but become twisted

In his patiently insistent tone of voice, characterized by the absence of punctuation characters and the use of blank spaces instead, Yu Jian makes room for the conventionally trivial and the quotidian. The parallel stories of poet and raindrop come together when at the end of its short but eventful life, the raindrop leaves a wet mark on the poet's trouser leg. The text exemplifies the phenomenon of objectification in Yu's poetry, meaning the presentation of everyday human realities as dislodged from habitual perception and interpretation, and imaginative attention to (inanimate) objects.

Yu Jian's dismantling of clichéd, heroic visions echoes domestic debate on notions of poethood, and goes together well with Xi Chuan's caricaturing portrayal of the intellectual and the oppressor. One feature of poetry in China today as compared with earlier times is that it 
contains plenty of irony. In this respect, Yu Jian, Xi Chuan and others have opened new perspectives, starting in the 1980s and coming into full swing in the 1990s.

In the work of several younger authors who build on that of their predecessors and grew up at a time when solemn social and political ideologies were fast losing ground, irony goes without saying and cynicism is never far away. This is evident in Yin Lichuan's use of literary phraseology in «Why Not Make It Feel Even Better» (为什么不再舒 服一些, 2000). Toward the end of the poem, which contains cynical instructions to a clumsy man by a woman maximizing her sexual pleasure, Yin ridicules the Popular-Intellectual Polemic. There is more to Lower Body poetry than irony, cynicism and sex, but this definitely counts as one of its "representative works" (代表作):

\section{"Why Not Make It Feel Even Better»}

ah a little higher a little lower a little to the left a little to the right

this isn't making love this is hammering nails

oh a little faster a little slower a little looser a little tighter

this isn't making love this is anti-porn campaigning or tying your shoes

ooh a little more a little less a little lighter a little heavier

this isn't making love this is massage writing poetry washing your hair your feet

why not make it feel even better huh make it feel even better

a little gentler a little ruder a little more Intellectual a little more Popular

why not make it feel even better

$\mathrm{Xi}$ Chuan, Yu Jian and Yin Lichuan are accomplished reciters of their own work, Xi Chuan the most musical and Yu Jian the most theatrical. If Yin Lichuan likes to preface her readings by saying she's not much good at them, this comes across as part of her act. When reading her poetry she studiously keeps her eyes on the page and away from the audience. The detached, monotonous use of her voice combines with bleak subject matter to produce an effect that is at once hilarious and painful.

Yan Jun's readings are sensational, because of the spectacular use of his voice and the audio-visual media that support his recitation. His poetry breathes a jumpy, unruly type of social engagement, not unlike that found in the above-mentioned extreme manifestations of Earthliness, after the Popular-Intellectual Polemic. Yet, stylistically, «Against All 
Organized Deception» (反对一切有组织的欺骗, 2000) also brings to mind the work of Xi Chuan, by its prosaic form and its use of imagery. Here's one stanza:

against advertisements, against forgetfulness. against tearing up anyone's ID and ugly face. against coming through meteoric showers clad in a golden cape but forgetting your daughter's name. against carnivores dancing. against computers dying. against living like a sickle. against night fragrance dying at night. against faddish magazines and dotcoms. against day-dreaming, see-through garments, the heart exploding like goose feathers.... drink killing a man from ten steps away.... dumb shits ruling the world.... porn magazines for exam papers.... against fear.

Yan Jun's multi-media performance tallies well with contemporary cultural trends. As such, it is slightly closer to popular culture than the work of most if not all of his fellow poets. Xi Chuan's, Yu Jian's, Yin Lichuan's and most other avant-garde poetry is definitely high art. This is reflected on the metatextual level.

\section{Metatext: Images of Poetry and Poethood}

Metatext, or discourse on poetry, includes everything from one person's inability to name even a single author- "Are there still people who write poetry today?" - and the identification in 2006 by the People's Daily online edition (人民网) of poet (诗人) as one of “forty-nine old words that have disappeared from people's lips in the last ten years" to someone else's scholarly genealogy of the avant-garde ever since its underground beginnings, and from theories of writing to ad hominem polemics on poethood. ${ }^{37}$

\section{What Others Think}

The textual trends from Elevated to Earthly and from what to how decrease readership in light of a traditional Chinese poetics, which continues to enjoy considerable influence: poetry as the epitome of serious, high art and inherently incapable of aspiring to any other status, literature to convey the Way, and the poem as offering insight into the

\footnotetext{
37 Renminwang 2006, Xiang 2002.
} 
poet's exemplary morality and worldview as well as his (sic) personal position within a stable conception of social order.

This helps explain why the general public's overall perception of the avant-garde is characterized by prejudice and disregard, if not plain ignorance. To most Chinese, poetry means classical poetry. Few people know that there is such a thing as modern poetry beyond the products of 1920s-1930s New Culture Movement (新文化运动) and Communist cultural policy since the 1940s, and perhaps the work of Bei Dao, Shu Ting, Gu Cheng and Haizi in the 1970s and 1980s. With the exception of Shu Ting, whose work bridges the gap between orthodoxy and archetypal Obscure Poetry, the latter four poets are remembered primarily for their extra-textual impact: Bei Dao's "dissidence" and legendary success abroad, and Haizi's and Gu Cheng's dramatic suicides, the latter coupled with Gu's murder of Xie Ye, his wife. If people do know about contemporary poetry, even if they haven't read it, they usually assume that whatever is being written now cannot possibly compare to the New Culture poets, much less to scores of premodern greats. The poets' own relation to premodern predecessors is ambiguous. No contemporary poet will question the beauty of classical poetry other than in theatrical settings - say, the manifesto with which the Lower Body burst upon the scene. Simultaneously, poets experience the classical tradition as near-insurmountable and a potential source of frustration. This is reinforced by the public's aforesaid prejudice, disregard and ignorance.

So why was there a full house when in June 2003, with minimal preparation and publicity, a new Beijing mega-bookstore specialized in anything but high literature organized a reading called "Open Your Eyes: Chinese Poetry after SARS," in which most if not all participants were avant-garde poets ${ }^{38}$ Cynically put, any standing that the Poet retains beyond the poetry scene may be a misunder-standing based on traditional expectations. Doubtless, part of the crowd were disappointed to find that the reading included idiosyncratic texts that failed to touch on topics of general concern like the SARS breakout and the infrastructural face-lift of the capital.

Less cynical and more to the point, even if the avant-garde cannot dream of the number of readers that classical poetry continues to satisfy, it is in fact a small but tenacious industry in its own right, a

${ }^{38}$ Haidian Book-Buying Center (海淀购书中心), 6 June 2003. 
high-cultural niche area populated and held together by highly educated and well-connected practitioners and supporters. The latter include editors and specialist and amateur readers, meaning professional critics and scholars as well as dedicated fans: university students and generations of graduates, and generally those whose lifestyle means keeping abreast of high-cultural development. Also, one effect of the commercialization of culture in China has been the emergence of financial sponsorship - by companies and individuals, named and unnamed - for poets, publications and events, and indeed for academic institutions for the study of poetry. Beijing-based real estate tycoon Huang Nubo of the Zhongkun Investment Group, also known as poet Luo Ying, is one of several patrons of poetry who come from corporate life. ${ }^{39}$

Thus, while the poetry crowd might barely constitute even a singledigit percentage of the population of a few big cities, not to mention parts of the country that cannot afford to be poetically inclined, this still means a sizable reference group in absolute numbers. What's more, they are influential in terms of symbolic capital. Yet, since the mid- and late 1990s, even specialist readers have despaired at what they perceive as a crisis (危机) in poetry, often presented as the result of its marginalization (边缘化). A famous instance is Peking University professor Xie Mian's concern, voiced in 1997 at a large-scale international conference on modern Chinese poetry held in Wuyishan, that “certain types of poetry are moving away from us" (有些诗歌正在离 我们远去). This was all the more telling because in 1980 Xie had courageously intervened in the controversy surrounding Obscure Poetry, coming to the defense of a budding avant-garde that had just emerged from its underground origins into overground culture. ${ }^{40}$ During the discussion at the Wuyishan conference, Xie's colleague Hong Zicheng opined that "we" might just be "moving away from certain types of poetry" instead. The exchange between these two renowned scholars reflects the shifting relationship between primary texts and commentary. This has become thoroughly unpredictable in comparison to the Maoist years, when scholarship and criticism were allowed little ambiguity, and even in comparison to the 1980 s, although this decade saw the beginning of real debate rather than foregone conclusions.

\footnotetext{
39 Cf Crespi 2007b, Inwood 2008: 62-65, 133, 228-255.

40 Xie Mian 1980.
} 
The crisis discourse shows how growing contestation of the nature of poetry requires that legitimizing and morally evaluative powers of scholarship and criticism, once self-evident, be rethought. It is no longer obvious with what kind of authority critics such as the Poetry Monthly editorial board, Cai Yi, Wu Xinhua, Zhang Hong, Chen Chao, Wu Sijing and many others announce that there is a crisis and there are "problems" or “issues" (问题) in contemporary poetry, often speaking in an unspecified first-person plural, like that used by Xie Mian in the above citation. Moralizing and nationalist overtones of the crisis discourse are out of sync with the texts on which it professes to comment. The same is true for the mobilization of prescriptive notions such as poetry's “alignment” (走向), meaning the speaker's preferred direction of poetry's development, often coupled with multiple oughts and shoulds, and of "optimism" and "pessimism" as critical positions, implying dated judgmental perspectives that block out much of what is going on.

But there is a larger issue here, that is common to modern poetries in various cultural traditions, not just in China. If poetry is no longer a stable concept but fiercely contested, this need not automatically constitute a crisis. Or the other way around: perhaps embodying crisis is something modern poetry inherently does. As scholars such as Derek Attridge and Jonathan Culler point out, modern poetries tend to challenge assumptions of order and cohesion in the world and in ourselves, and to be disruptions of culture rather than the repositories of time-honored, canonized values often found in classical texts. In China, the massive weight of the classical tradition and its prominent place in (national) cultural identity produce an especially acute discrepancy with what Yeh sums up as modern poetry's international, hybrid, iconoclastic and experimental nature. If this discrepancy is disturbing to many readers, this is because they set off contemporary poetry and its position in society at large against expectations that continue to be shaped by the classical paradigm. A similar mismatch is in evidence when contemporary poetry's unmarketability is framed as a cause for lament and ridicule by unwarranted comparison to flood waves of commercialization in other spheres of life. We will return to this below. ${ }^{41}$

${ }^{41}$ 现代汉诗国际研讨会 (福建师范大学中文系、中国社会科学院文学研究所 举办), 26-30 July 1997; 《诗刊》编辑部, 〈中国诗歌现状调查〉 [nvestigation into 
Writing in 2003 on a Nanjing-based group of novelists, Henry Zhao dismisses poetry in China today as self-indulgent and inconsequential: ${ }^{42}$

they were all formerly poets who made their name in the late $1980 \mathrm{~s} .$. In the 1990s they turned to fiction, knowing that writing poetry is now very much a narcissistic 'karaoke' art.

Although Bourdieu may not have had karaoke in mind, it certainly comes under "production for producers," exemplified by the avantgarde. ${ }^{43}$ As such, Zhao's metaphor makes sense. Inasmuch as karaoke means performing other people's words and music, it does not. Production for producers is a useful notion but also a hyperbole, ${ }^{44}$ and only valid if we take into account that proportionally, in poetry there are many more readers $=$ consumers who are also writers $=$ producers than in other genres and media of literature and art, virtually all of them amateurs, unknown outside a small number of more or less private readers. But this qualification is not enough. Measured by individual and multiple-author collections, unofficial and official journals and websites, the avant-garde scene has quite simply displayed vitality and resilience all along, albeit with notable changes from the 1980s to the 1990s and beyond.

As for poetry's high visibility in the $1980 \mathrm{~s}$ - beyond a cultural elite, or the incrowd audience for karaoke, so to speak-aside from hardcore readers who came mostly from artistic and academic circles, it is doubtful that others forayed beyond the best-known specimens of Obscure Poetry: Bei Dao's «Answer», Shu Ting's «Motherland, My Beloved Motherland» (祖国啊, 我亲爱的祖国, 1979), Gu Cheng's 《A Generation», Liang Xiaobin's «China, I've Lost My Key» (中国, 我的 钥匙丢了, 1980), Mang Ke's «The Vineyard»(葡萄园, 1978), Jiang He’s «Monument» (纪念碑, 1979), Yang Lian's «We, from Our Own Footsteps....» (我们从自己的脚印上...., 1980) and a few other quickly canonized texts, most inviting socio-historical, allegorical readings to do with the Cultural Revolution. ${ }^{45}$

the Current State of Chinese Poetry], 《诗刊》1998-9: 4-8; Cai 1999: 178-202, Xiao Ying 1999: 231, Wu Xinhua 2004, Zhang Hong 2003: 149-151, Chen Chao 2005, Wu Sijing 2005, Attridge 1981: 243, Guller 1997: ch 5, Yeh 2007b.

${ }^{42}$ Zhao (Henry) 2003: 203.

${ }^{43}$ Bourdieu 1993: 39 et passim in parts I-II.

${ }^{44}$ E.g. Lovell 2006: 149.

${ }^{45}$ Yan Yuejun et al 1985: 1, 42-43, 122, 148, 190-192, 247-248. 
More fundamentally, while the rock star status that the best-known poets enjoyed from the late 1970s well into the 1980s was real, it was also an anomaly, captured by the aforesaid metaphor of high culture craze or fever. It resulted from a happy meeting of the public's hunger for cultural liberalization and poets' activism, before other distractions had begun to compete. There is a popular saying that in the 1980s a stone thrown over one's shoulder was sure to hit a poet, but this reflects the conspicuous presence of a relatively small number of avant-garde authors, not so much the emergence of truly great numbers of people writing in a truly great variety of individual styles. The latter image is in fact a defensible description of the 1990s and beyond. If falling stones have stopped hitting only poets, that is because the streets have become crowded with other potential victims, following rapid intensification and variegation of people's socio-cultural activity and mobility at large.

From the rise of Obscure Poetry through the campaign to Eliminate Spiritual Pollution, poets' activism was in part a reaction to extreme repression and monomaniacal prescriptions for literature and art in the preceding years, the memory of which made the experiment extra thrilling. The second half of the 1980s was a time of unprecedented freedoms, with an exuberant life of the mind unfolding in borrowed time, before mayhem and money made themselves felt. By contrast, in China as elsewhere, production for producers - as qualified above - is the normal situation for innovative poetries that claim no social or economic significance and are not primarily instruments of propaganda for government policy. Bob Perelman sums up the matter in an essay that is also a poem: ${ }^{46}$

"The Marginalization of Poetry"-it almost
goes without saying. Fack Spicer wrote,
"No one listens to poetry," but
the question then becomes, who is
Jack Spicer? Poets for whom he
matters would know...

Zhao's metaphor is defensible in that poetry will normally not draw large crowds, and neither will karaoke. The term incrowd audience,

46 Perelman 1996: 3. 
above, covers settings from a handful of people in a private room to the entire clientele inside a bar with public karaoke facilities, whose joint spectatorship is to some extent coincidental. But whereas successful karaoke operations make money, avant-garde poetry is unmarketable in terms of economic capital, making it the foremost example of what Bourdieu calls the reversion of the economic world. ${ }^{47}$ As such, inside China, poetry is different from fiction and film and to a lesser extent from most drama, art and popular music. Paradoxically, as Crespi argues, it is precisely because its unmarketability can be construed as the quality of being untainted by the market's immorality that both avant-garde and official poetry have recently been able to enter into intriguing advertising partnerships with real estate development, with poetry's symbolic value balancing the image of the business as utterly corrupted by money and power. One surmises that the unmarketability is structural and the partnerships are incidental, even if they are well-paid. ${ }^{48}$ At any rate, while Zhao's contention is inspirational in that it offers avenues into complex metatextual issues, poetry is not karaoke. We will recall the metaphor once more in a discussion of the visual presentation of poets and their publications, below.

With regard to internationalization, poetry's economic unmarketability stands out when compared to the successes of Chinese film and visual arts, whether in public places such as movie theaters, galleries and museums or in private ones like the homes of wealthy individuals. Yet, through translations, international festivals and writerships in residence, Chinese poetry has made itself heard and seen inside a long list of foreign poetry scenes - which, in their turn, tend to be equally unmarketable in economic terms. Crudely speaking, what foreign audiences know of Chinese literature is mostly classical poetry and modern fiction.

In sum, the general public is ignorant of avant-garde poetry, and some of its (specialist) readers are angry, disappointed or at a loss. These things reflect only part of what others think - here, I won't dwell on poetry's many optimistic readers - but they are acutely relevant to what poets think.

\footnotetext{
47 Bourdieu 1993: ch 1. Cf Kong 2005: 189-190 (note 10).

${ }^{48}$ Crespi 2007b.
} 


\section{What Poets Think}

As do many other Chinese poets, Xi Chuan and Yu Jian have extensive explicit poetics to their name. ${ }^{49} \mathrm{Xi}$ Chuan's poetics contains solemn, sometimes grandiloquent claims. In 1986 he writes: "The poet is both god and devil," and in 1999: "When the strong poet touches iron, it turns to gold." By contrast, Yu Jian, writing in 1997, holds that the poet is no more than a processor of language, a craftsman anchored in everyday reality who uses language to "retreat from metaphor," indeed as "a method to eliminate the imagination" - nothing like a tragic genius who writes by moonlight or an alchemist, as in $\mathrm{Xi}$ Chuan's book.

Still, neither author's poetics are unequivocal in this respect. In 1995 Xi Chuan writes: "There are indeed those who announce that although they do not write poetry, they are poets." In their turn, Yu Jian's exercises in demystification and indeed desecration are invalidated by pompous statements that bespeak the romanticism they claim to oppose. In 1999, Yu calls poetry

a movement of language that cuts through forgetting and returns to the home of being . . . an original truth of the world, the light emitted by wisdom and the soul.

These remarks show the usefulness of the Elevated and the Earthly as coordinates in not just text but also metatext. Poetics of the Elevated are powerfully present in the cult of poetry, with its origins in the late 1970s and the 1980s, elevating the poet to superhuman if not divine status and as such very much a cult of poet-hood. Its impact in the 1990s and beyond is manifest in the continuing worship and mythification of Haizi, whose apotheosis was occasioned by his suicide, and of Hei Dachun on account of his bohemian lifestyle. Recent years have shown aggressive explicit-poetical efforts at the Earthly end of the spectrum, with Yu Jian as the most prolific contributor, especially during the Popular-Intellectual Polemic of 1998-2000.

One thing the Polemic showed was that for all their self-proclaimed ordinariness, members of the Earthly camp still view poethood as a superior quality of extraordinary importance and social relevance. As for authors of Elevated persuasion, the special status of the poet has

${ }^{49}$ Bibliographical detail for the following citations is provided in chapters Ten and Eleven. 
always been among the tenets of their poetics. Perhaps the need to reclaim something of the dwindling visibility of the poet was extra pressing for the Earthly polemicists in light of their professed ability to stay in touch with the realities of everyday life (in China) and "ordinary people" - whose ignorance of their art would hence have been all the more painful. At any rate, the primacy of bread and circuses in today's society has made it hard for poets of varying persuasion to maintain a prideful self-image. Up to a point, the removal of their art from mainstream social consumption can be turned into incrowd dignity, but they cannot indefinitely do without an audience beyond the "inner circle" (圈子). In modern times, in China and elsewhere, for a poet to be publicly misunderstood and suppressed by Uncool Powers, be they political dictators, the bourgeoisie or the stock market, can be an honorable fate. Conversely, in the interaction of artists and whatever type of audience has the power to suppress and to the extent that artistic achievement is measured in terms of rebellion and controversy, a variation on Oscar Wilde suggests itself. There is only one thing worse than being misunderstood and suppressed, and that is being ignored.

The textual trend from what to how, then, has a metatextual pendant in one from what to who, meaning the promotion of poet-hood. Since roughly 2000 this has found expression in the visual presentation of poets and their publications. Young authors such as those in the Lower Body group and generally the Post-70 Generation and beyond - meaning those born after 1970 — were the first to include all manner of photographs and spectacular formatting in unofficial journals like Poetry Text (诗文本). ${ }^{50}$ Older poets and editors soon caught on, as visible in poetry collections by Yi Sha and Yu Jian, Momo's booklike revival issues of the Coquetry Poetry Fournal (撒娇诗刊) and so on. ${ }^{51}$ Then there is the popular genre of illustrated memoirs and informal histories regaling stories of the avant-garde from its underground origins to the present day, by authors such as Zhong Ming, Liao Yiwu, Mang Ke and Yang Li. In Song Zuifa's The Face of Chinese Poetry (中 国诗歌的脸), portrait photographs of a hundred and fifty poets and twenty critics constitute the primary material, "illustrated" in turn by poems and poetical statements; Song's portraits received high-profile exposure during a "poetry exhibition" in Guangzhou in 2006, curated

\footnotetext{
50 E.g. Poetry Text 4 (2001).
}

51 Yi 2003, Yu Jian 2003. 
by Song with poets Yang Ke and Qi Guo. Likewise, a good dozen poets are included in Xiao Quan's This Our Generation (我们这一代), a portrait collection of writers and artists published in various editions since the 1990s. ${ }^{52}$ Especially for younger authors, to whom it would come naturally, this visualization of the poetry scene is explained in part by overall cultural trends of other media encroaching upon the hegemony of the written word, embodied in the changing physical presentation of books among other things. It is, however, also a strategic exercise in poet image-building, in order to sustain readership or indeed spectatorship.

Photographs and other illustrations come in three types. The first is hip, stylized, sometimes theatrical and provocative portraits, individual or collective, typical of Poetry Text and kindred publications: a loud, visual extension of poetry as performance, vaguely showcasing rock-n-roll lifestyles. The second is a mix of pictures taken at public events such as poetry readings and conferences on the one hand, and banal snapshots on the other, mostly recent but sometimes including family-album-type childhood pictures, facsimiles of the poet's handwriting and so on, as in Yi Sha's and Momo's recent books. The third type, frequently encountered in the upsurge of poetry memoirs, is that of (group) portraits to mark public occasions that belong to literary history as opposed to the here and now. It will be hard to distinguish from the second once both may reasonably be called old.

The transition between what is experienced as past and present is gradual, and Yi Sha has been around since the early 1990s. Still, a picture of Yi Sha is not the same thing as one of Bei Dao and Mang Ke just out of the underground and about to trigger a sea change in overground literature, pointing to a moment that is definitely in the past, has left its mark and can claim stable historical significance. Something similar holds for the facsimile of a letter by Luo Yihe to Wan Xia in April 1989, describing Haizi's suicide shortly after the event - as opposed to that of a manuscript of a 1990 poem by Yi Sha, advertising the authenticity of his handwriting, that may have been copied out anew in 2003 for all we know. On that note, many pictures in Mang Ke's memoirs aren't old at all but have been reproduced in sepia colors and less than perfect focus, conjuring up the image of a past that is barely retrievable and therefore all the more special.

52 Zhong 1998, Liao 1999, Mang Ke 2003, Yang Li 2004, Song Zuifa 2008, Xiao Quan 2006. For the poetry exhibition, see Van Crevel 2007. 

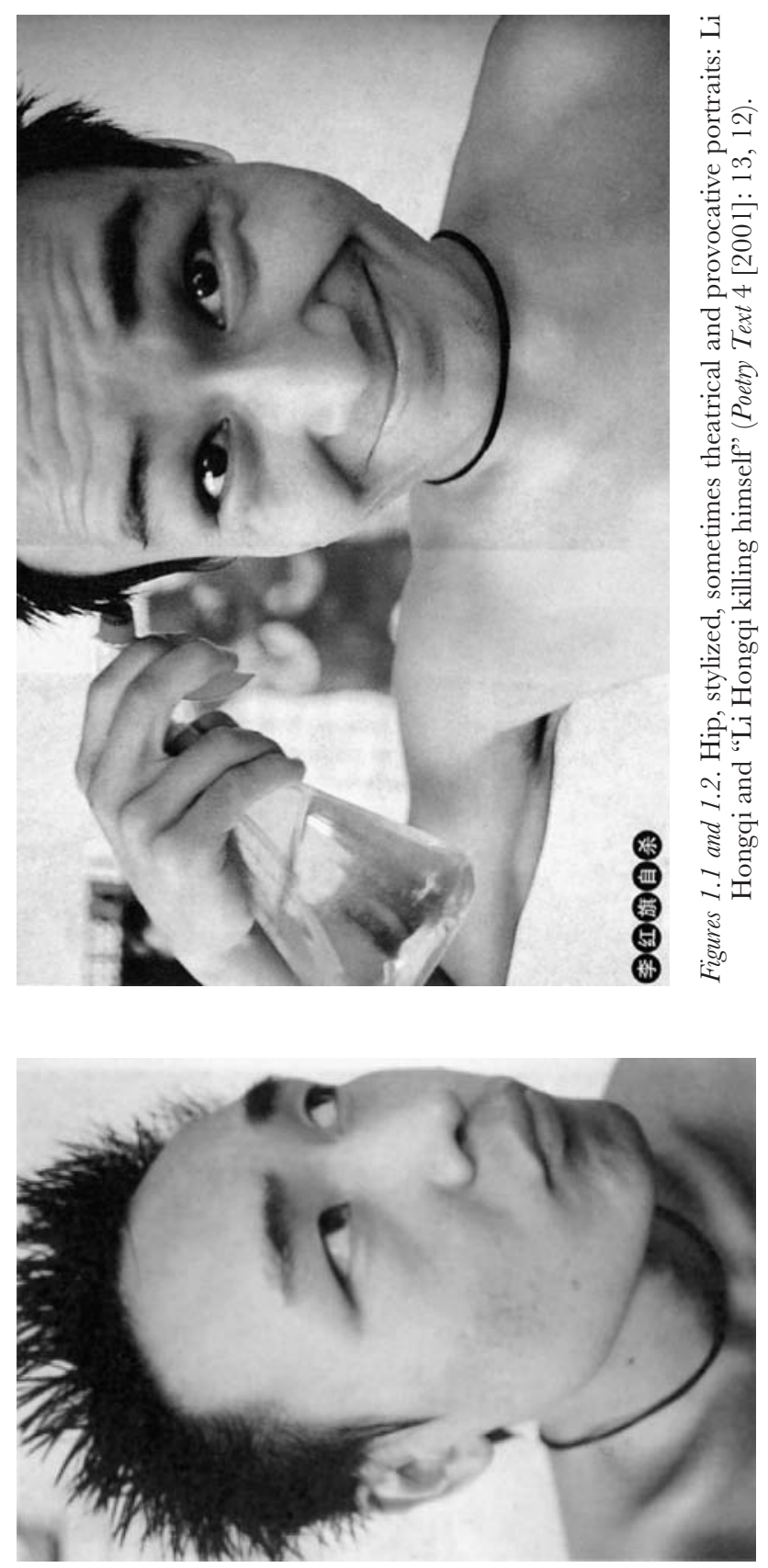


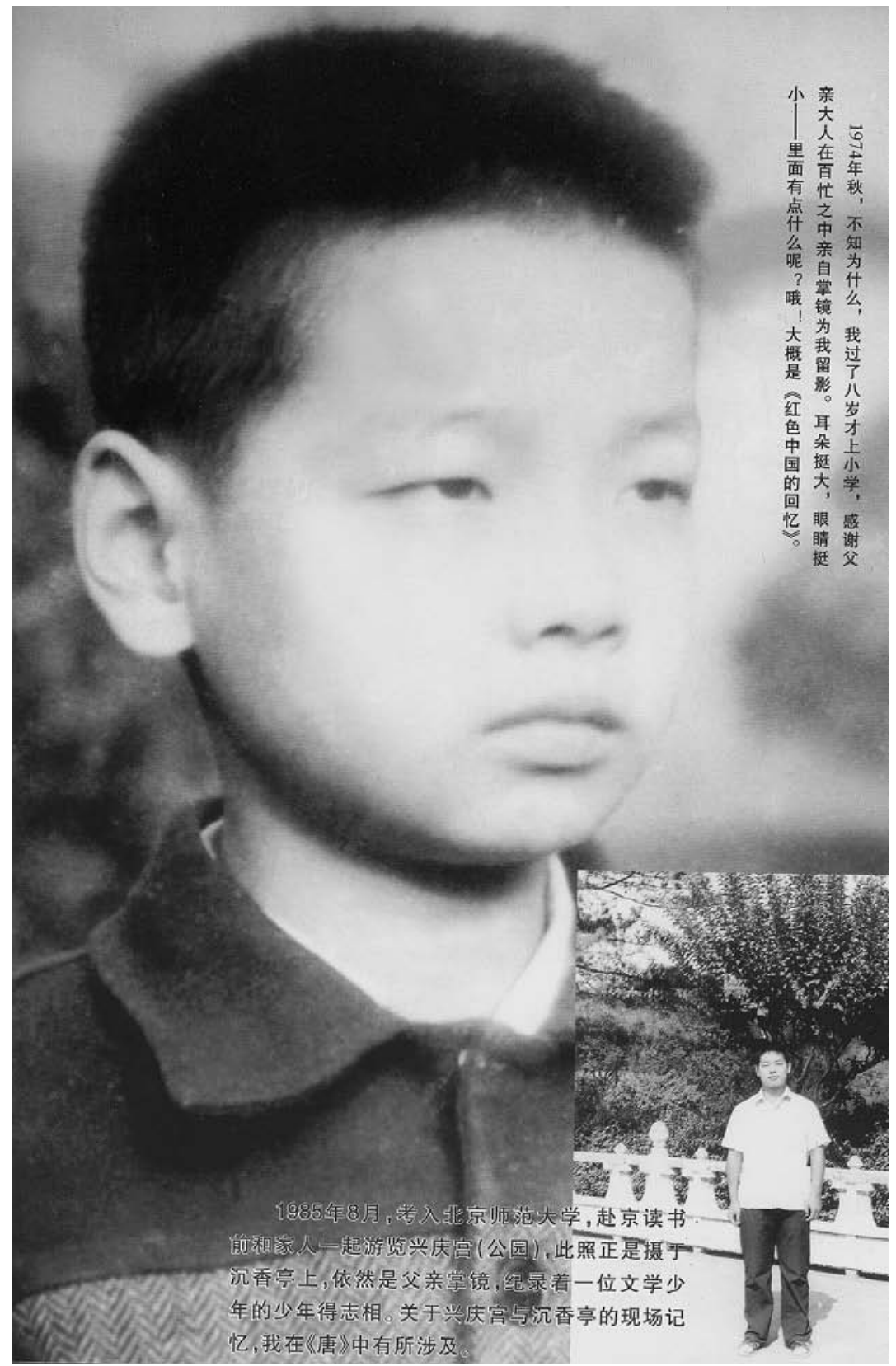

Figure 1.3. Family-album-type childhood pictures: Yi Sha at age eight, when he first went to school, and age nineteen (inset), when he entered university (Yi 2003: 30+1). 

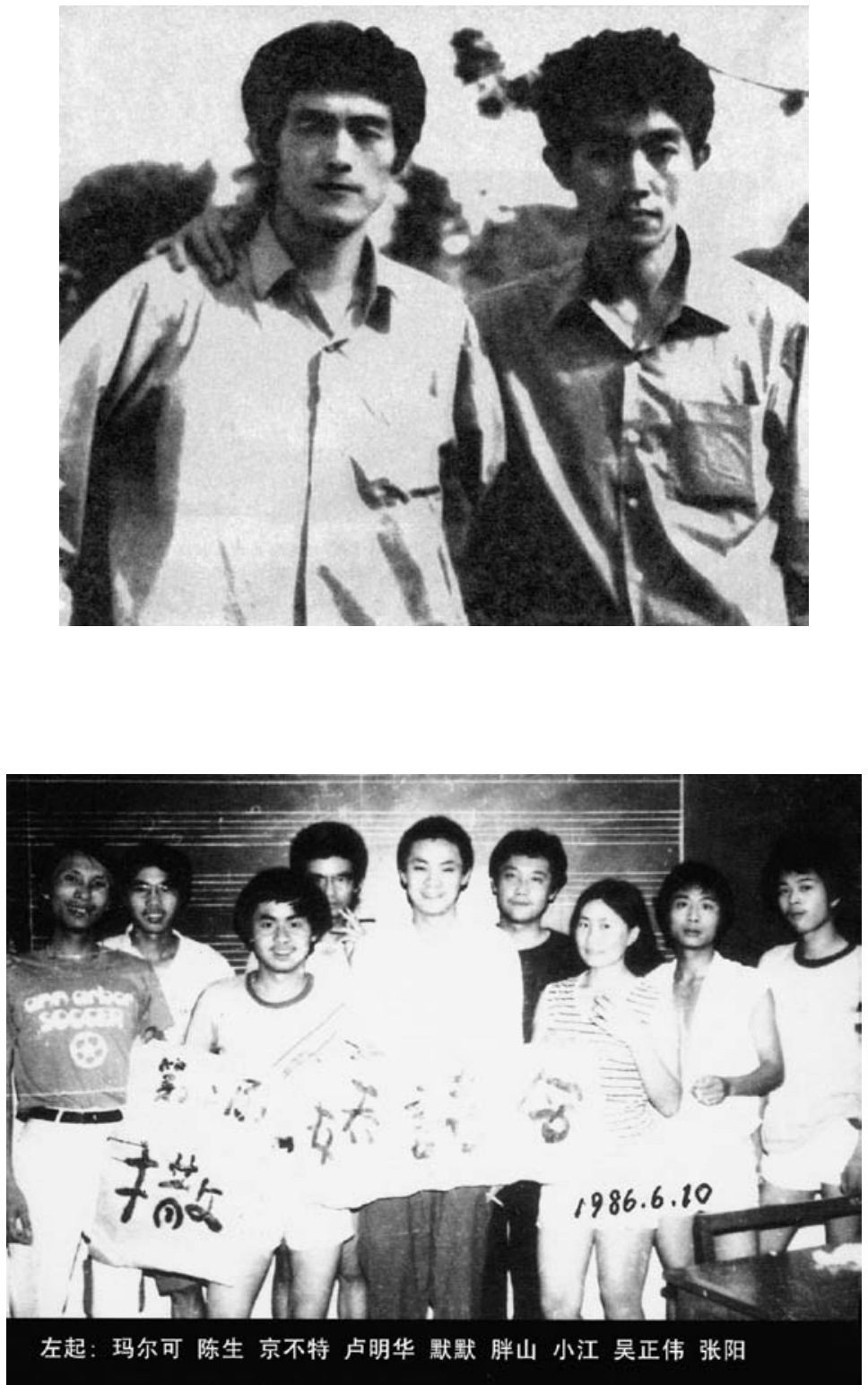

Figures 1.4 and 1.5. Public occasions that definitely belong to literary history: Mang Ke and Bei Dao, founders of Today, 1978 or 1979 (Mang Ke 2003: 21); and the Coquetry School, 1986 (The Coquetry Poetry fournal revival issue [January 2004]: inside cover). 


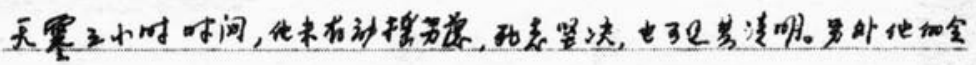

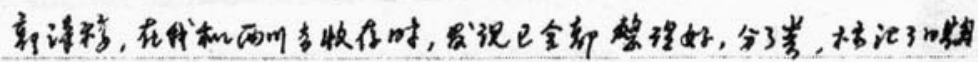

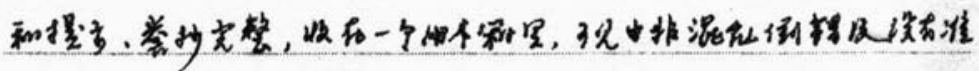
各的。

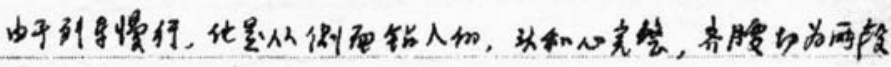

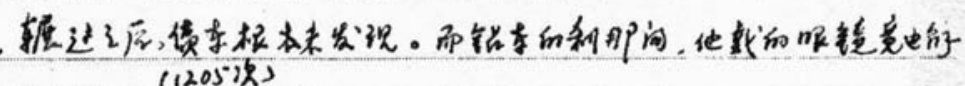
象石磷损。

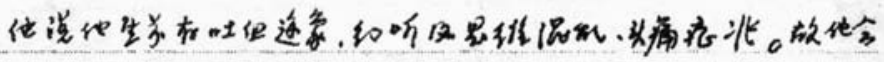

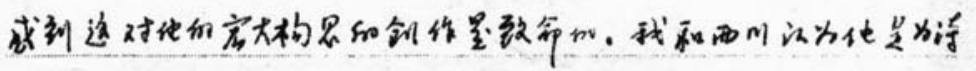

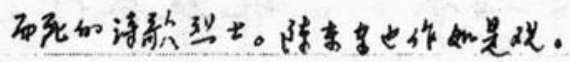

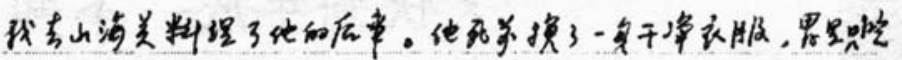

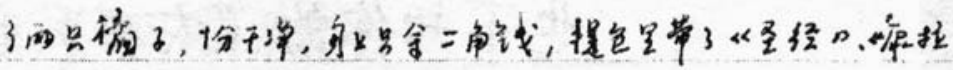

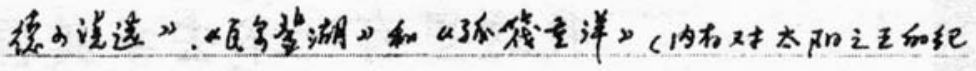

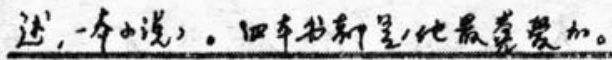
图交满能易

Figure 1.6. Page from Luo Yihe's letter to Wan Xia, describing Haizi's suicide. The second paragraph reads: "The train was going slow, and [Haizi] had thrown himself [under the wheels] from the side. His head and heart were intact, but he had been cut in two at the abdomen. The freight train crew (it was the 1205 service) never realized he had been run over. In the instant that he had thrown himself under the wheels the glasses he was wearing hadn't even been cracked or damaged"

(Yang Li 2004: 16). 


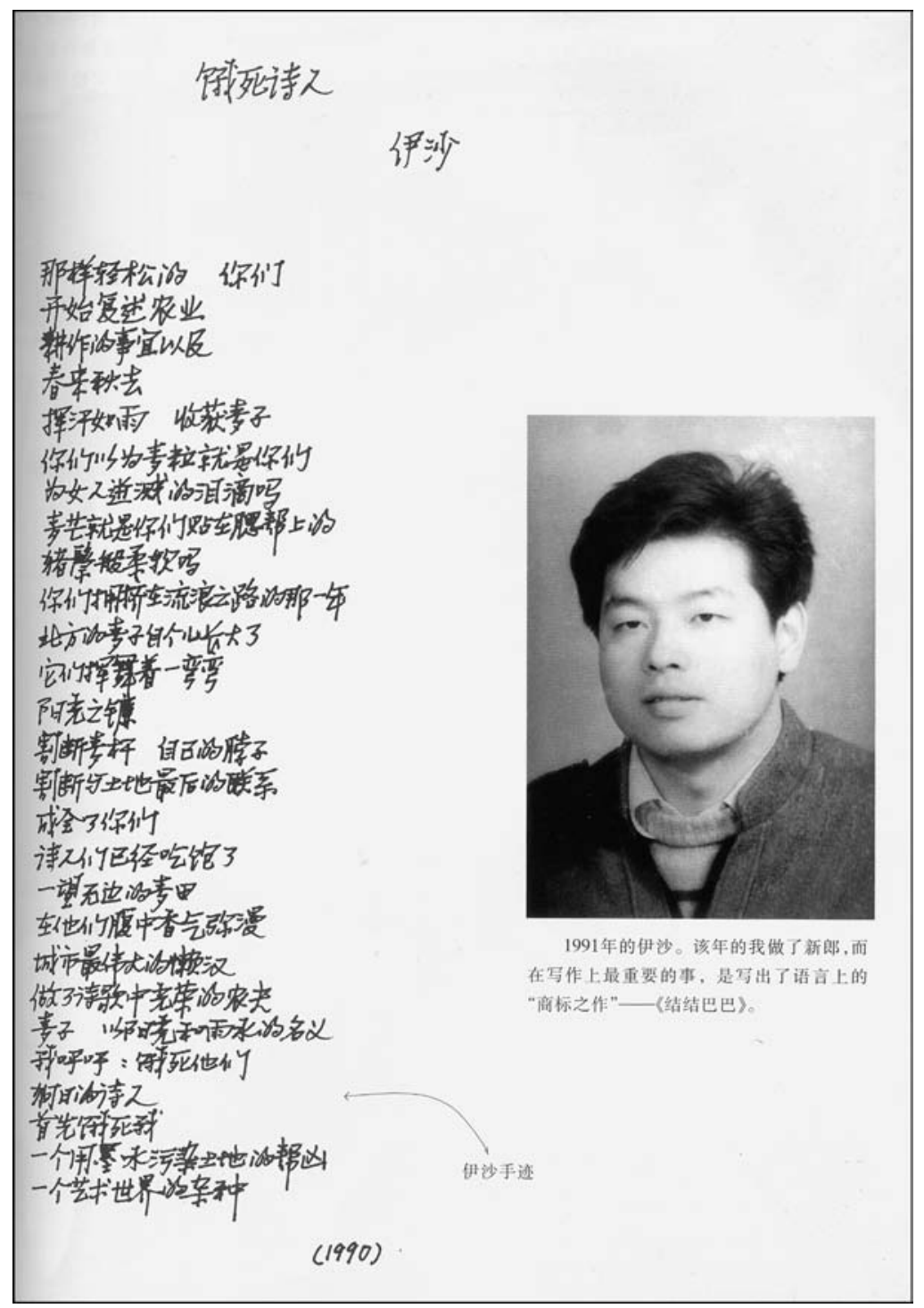

Figure 1.7. Manuscript of Yi Sha's «Starve the Poets» (Yi 2003: 30+3) 


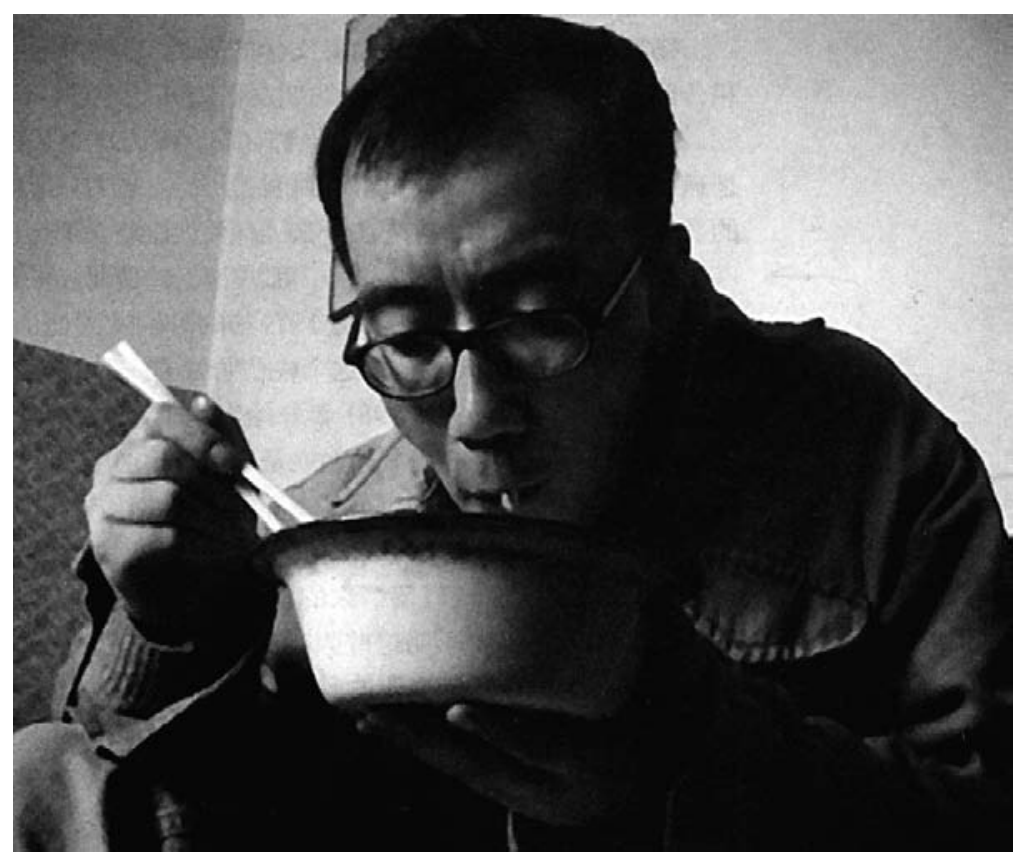

Figure 1.8. If the picture is of a poet, that should automatically make it interesting, even if all the poet does is eat a bowl of noodles: Han Dong (Yang Li 2004: 295).

One reading of the snapshot-type pictures takes its cue from Zhao's karaoke metaphor inasmuch as it portrays poets as addressing an audience of friends and colleagues, even if their performance is photographically and historically insignificant. Another reading, that fits squarely with strategic image-building vis-à-vis an audience beyond the incrowd, draws on the continuing currency of poethood as a thing of extraordinary importance, especially in Earthly circles: if the picture is of a poet, that should automatically make it interesting, even if all the poet does is eat a bowl of noodles. Notably, while the professional quality of author portraits on book covers has improved across the board, proponents of Elevated poetics appear much less frequently in this process of visualization.

(Self-)images of contemporary poethood, then, have seen multiple reinventions. In early Obscure Poetry there is the humanist spokesman for the emancipation of art, akin to political activists of the 1978-1979 Democracy Movement and to some extent still operating on the terms 
of the Maoist discourse he seeks to question. From the mid-1980s on, when overt political messages have all but disappeared, opposing constructions of the poet emerge: elitist high priest of a cult of poetry, and "ordinary" demystifier-cum-desecrator advertising the realities of everyday life as the building blocks of art. While the Elevated and Earthly aesthetics develop and diverge, the 1990s bring the disintegration of groups and Isms, and a shift toward individual efforts incapable of claiming social significance and not necessarily aspiring to do so anyway. The turn of the century shows efforts at image-building, partly in reaction to the poet's removal from center stage in society at large, and partly reflecting overall cultural trends: visualization, but also things like the increasing popularity of personal columns in lifestyle magazines.

My generalization of masculine nouns and pronouns for the poet reflects the near-exclusive male dominance of the metatextual arena. This is all the more remarkable in light of women poets' important textual contributions to the avant-garde, made from what Julia Lovell calls a marginal position within a marginal genre ${ }^{53}$ - even if marginality is a complicated notion, an issue to which we will shortly turn. In metatext, in spite of attempts by male activists to enlist their female colleagues for the cause, female poets appear less inclined to leave their mark on the debate, or less driven by compulsive ambition and aspirations to priesthood or desecratorship. Zhai Yongming's refusal to take sides in the Popular-Intellectual Polemic is but one example. ${ }^{54}$

The said reinventions and image-building facilitate a modest, politically disinterested celebrity discourse and commodification of poethood in the contemporary avant-garde, a category that has now traveled the full breadth from the proud and righteous to the hip and shameless. Any understanding of its versatility, not to say its frantic leaps and bounds amid diverse and conflicting stimuli, must take into account modern Chinese poets' identity crisis and their problems of legitimation, beginning early in the twentieth century and evolving up to the present day, triggered and perpetuated by unceasing social, political and cultural upheaval and exacerbated by the recent impact of capitalist market ideology. Poets sustain the importance of

\footnotetext{
53 Lovell 2006: ch 1.

54 Cf Yeh 1996a: 75 and Day 2007a.
} 
poethood - whether as representing (traditional) cultural essence, or (modern) national salvation, or (contemporary) individual identityby cherishing it as an abstraction that permits different manifestations and interpretations to succeed one another and coexist.

\section{Whose Margins?}

In metatextual matters, avant-garde poetry in China remains part of a society whose values and styles are changing fast. While any attempt at marketization would be doomed - in the sense of generating real money, not just fame and free drinks - the genre has had some success in the celebrity discourse noted above and in new media.

These things work differently for different generations and personalities, as evidenced by the poets whose work we have sampled above. Yu Jian can be seen to adapt, actively working toward a hip presentation in his general pursuit of publicity, through sheer noise and notoriety if need be. Yin Lichuan and Yan Jun, whose age more naturally puts them in touch with rapidly expanding youth culture, help constitute socio-cultural change, and their careers are tied to the Internet. $\mathrm{Xi}$ Chuan is typical of reticence at the Elevated end of the spectrum in matters like the visual presentation of publications and events.

For $\mathrm{Yu}$, Yin and other poets - and to a lesser degree for Yan - there is a discrepancy between text and metatext: high art and few readers on the one hand, and celebrity discourse and the commodification of poethood on the other. Even if we count not just those who read poetry on paper and include the many visitors of poetry websites, the fact remains that beyond the field of restricted production, texts by the avant-garde are incompatible with overall socio-cultural trends whose dominance is defined by numbers. While this holds for poets from all quarters, it is exemplified by the self-proclaimed Popular poets. Yu Jian's claim that classical poetry was part of the everyday life of ordinary people in the Tang and Song dynasties and that the right kind of contemporary poetry operates "among the [ordinary] people" is unconvincing. When Yin Lichuan says that for all its professed antielitism, Lower Body poetry hardly reaches beyond an elite audience, that is easier to believe. That Lower Body poetry's relative accessibility allows it to count more of Bourdieu's "non-producers" among its 
readers than Xi Chuan or a typical poet's poet like Che Qianzi doesn't change this. ${ }^{55}$

Questions of the type Whither Poetry? occur frequently in mainland-Chinese critical discourse, and trigger discussions in which the value of poetry's development to date and the desirability of this or that one among its possible futures are linked to the said socio-cultural trends. This happens through lament - or jubilation - over poetry's in-compatibility with these trends, but also through the confident assertion of its ability to avoid falling behind the times. But what's the point of appraising the suitability of various poetics to their physical surroundings, and deploring or celebrating the fact that there are more people who watch TV than poetry readers, or that poetry's contribution to the Gross National Product is hard to quantify? Instead, we may wish to observe that starting in the 1980s and especially in the $1990 \mathrm{~s}$ and beyond, a large number of authors have written a wide variety of avant-garde poetry that continues to appear through channels that range from reputable publishing houses to privately run websites and sustains a dedicated, well-positioned audience. Equations of the 1980s with the rise of contemporary poetry and of the 1990s and beyond with its decline say something about context, not text or metatext, and are not substantiated by evidence.

Let's return to the two red flags for a moment. The publication of Gui Xinghua's poetry is the product of government policy; that of $\mathrm{Yi}$ Sha's, the product of a publisher's decision. The latter is informed by considerations of prestige at a time when automatic government subsidies have long been a thing of the past and any expectation to make money from poetry is as unrealistic as ever under normal circumstances, as opposed to the anomaly of the 1980s or people's fascination for self-killing poets. Many rank-and-file avant-garde publications wouldn't appear without external sponsors, but publishers will in fact make an effort to publish the work of prominent poets as so-called “original editions” (本版书), meaning books for which the author gets paid. At any rate, to make numbers - money, print runs, readershipthe measure of all things, in this case of the "relevance" of a poetry whose objectives do not include traditional and orthodox ideals of broad recognition and dissemination as an instrument of social moral-

${ }^{55}$ Yu Jian 1999b: 12; Yin \& That's Beijing 2004 and Q \& A session, Gent: De Centrale, May 2004. 
ity, is socio-economic reductionism. Bourdieu recognizes this when he defines the literary field as

a separate social universe having its own laws of functioning independent of those of politics and the economy.

Yet, subsequently he writes that to understand literature is to understand $^{56}$

how it is defined in relation to the field of power and, in particular, in relation to the fundamental law of this universe, which is that of economy and power.

Throughout the twentieth century and beyond, with the Maoist interlude as a complicated exception to the rule, Chinese-poetic modernity has proven difficult to combine with traditional poetics summed up as literature to convey the Way. Seen in this light and according to Bourdieu's "fundamental law," modern poetry's oft-noted marginalization is a valid, indeed an ineluctable notion, as Yeh argues - not without suggesting that the margin is where modern poetry can be at its most creative and powerful. ${ }^{57}$ But with an eye to its inclinations since the 1980s and to radical changes in the relations between social, political, economic and cultural forces at work in contemporary China, we might ask: Whose margins? What makes the classical poetry paradigm, socio-economic development or power relations the center? Whose center? Artistic creativity gives a unique twist to our efforts to make sense of an ever-changing world, and perhaps its uniqueness lies precisely in the fact that it isn't easily made to fit consensual truths, or financially quantified, or translated into palpable power over others. Lest we reduce it to a flaw in the fabric of rigidly canonized cultural identities or all-encompassing economic "rationalism," we should be wary of an argument that may appear plausible enough but is deeply problematic. For anything like a comprehensive understanding of Chinese poetry today, it makes no sense to apply criteria informed by forces that are largely alien to the avant-garde's development: orthodoxy - be it premodern or modern, Confucian or Communist - and marketization. Is this poetry suitable for conveying the Way? and Does this poetry sell? are the wrong questions.

\footnotetext{
56 Bourdieu 1993: 162-164.

57 Yeh 1992: xxiii-l and 2007a.
} 


\section{Who Cares?}

Answering the wrong questions would be turning a blind eye to a demonstrably thriving if somewhat self-contained cultural scene, and do little more than reaffirm disparaging comments on the "relevance" of (modern) poetry that are something of a genre in themselves, across diverse cultural traditions - as are, conversely, apologies for poetry. If there is a need for either, there is nothing Chinese about that.

Alternatively, while recognizing changes in the cultural landscape that surrounds and obviously affects poetry in contemporary China, we may wish to leave sufficient room for approaching it on its own terms, gleaned from the niche where it finds itself. This is not a gratuitous assertion of the absolute autonomy of art, but an attempt to grasp what this poetry means, and how it works, and for whom.

\section{The Gase Studies, and What This Book Wants to Do}

The twelve chapters after this one are in rough chronological order of literary impact. I like to think of the ground they cover as a coherent poetic discourse, in Anthony Easthope's definition. ${ }^{58}$ That is, what happens above the level of the individual line, in individual poems and then individual oeuvres, but also between these oeuvres and occasionally across several or all of them. As noted, if I have found the categories of text, context and metatext useful to organize my thinking, I haven't drawn strict boundaries between them in the organization of this book. By and large, however, chapters Two through Nine focus on text - with large metatextual and contextual components in Three and Four - and chapters Ten through Twelve on metatext. Context runs through all. Chapter Thirteen functions as a coda, with a little bit of everything.

Within the overarching, interwoven notions of the Easthopian discourse and text + context + metatext, the majority of the case studies are delineated by another organizing principle, that of the poetic voice. By this I mean a distinct, individual presence in both form and content, that is discernible throughout a poet's oeuvre and enables one to recognize previously unfamiliar texts by the author in question. Por-

\footnotetext{
58 Easthope 1983: ch 1.
} 
trait photographs aside, the historical person of the author appears in biographical notes, and in the argument proper if their story advances the discussion. I consider authorial intent to be unknowable and irrelevant, the only relevant intent being that of the text and that of the reader, once they meet. After Hugo Brems I hold that for poetry of the sort that is considered in these pages - different from premodern and Maoist traditions - what matters is not the emotion that creates the poem but the emotion that the poem creates. ${ }^{59}$ Accordingly, I take declarations of authorial intent as statements made by authors in their capacity as readers. Case studies of individual oeuvres are not surveys or summaries but each have a particular focus, identified in the chapter titles. They are complemented by chapters that take their cue from moments in literary history that transcend the individual. Some additional remarks on theory and methodology follow below.

The selection of a dozen voices in text and metatext from among scores of widely published poets and poet-critics entails the act of canonization and at the same time remains a personal affair. Canonization, of course, is rarely objective or systematic, whether by design or with hindsight. It is at best intersubjective, and usually subjective on individual and collective levels, and it can indeed be coincidental and arbitrary. I hold, however, that each of the authors studied in these pages has had demonstrable impact in the public domain and made distinct contributions to the avant-garde's multidimensional discourse as a whole. While this study doesn't attempt anything like a full overview of avant-garde poetry from China, it does hope to give the reader a rough idea of what such poetry is all about, with reference to critical discourse to date and facilitating access to the material through the research bibliographies mentioned in the preface. ${ }^{60}$

\section{Twelve Case Studies}

The case studies start in the early 1980s, after Obscure Poetry, which has been well covered in previous research. ${ }^{61}$ Han Dong's poetry (chapter Two) has often been discussed in terms of its resistance to Obscure poetics. This is a notable part of the story, but negative defi-

\footnotetext{
59 Brems 1991: 137.

60 Van Crevel 2007, 2008a and 2008b.

61 See note 23.
} 
nition is as problematic for individual oeuvres a it is for larger trends and the significance of Han's work in its own right extends far beyond its classification as anti-Obscure. Similarly, while the late 1980s high point of the cult of poetry in the work of Haizi was in part a rejection of colloquializing and vulgarizing trends in the work of authors including Han Dong, Yu Jian and the Macho Men, the poetic voice in Haizi's work presents something new, rather than a simple return to pre-colloquial and pre-vulgar days. Subtle, intensely personal aspects of his poetry have been drowned out by his mythification as a martyr of poetry after his suicide in March 1989 (Three). Later that year, June Fourth spurred the development of an exile poetry scene involving authors such as Yang Lian, Wang Jiaxin and Bei Dao (Four), whose art it catalysed rather than fundamentally changing it. June Fourth also catalysed poetic practice by poets inside China, including Xi Chuan, for whom the year 1989 was a turning point in a personal sense as well. From the early 1990s onward Xi Chuan's poetry becomes truly innovative through the quality of creative indeterminacy, visible in interaction of the text's surface and its "deep meaning," among other things (Five). The sheer length of two early 1990s milestone texts of the Elevated and Earthly aesthetics, by Xi Chuan and Yu Jian, invites a comparison of the work of these two most prominent voices of the avant-garde and some reflection on generic definitions of poetry and prose (Six). Another rewarding angle on Yu Jian's poetry lies in its central feature of objectification, briefly introduced above. This is, paradoxically, a highly sub-jective process, to do with form as well as content (Seven). Likewise, the mutual reinforcement of form and content is essential to Sun Wenbo's poetry of the mid- and late 1990s, with poetic rhythm as a co-constituent of its narrative character (Eight). Written in 2000-2001, right after the Popular-Intellectual Polemic, the work of Yin Lichuan and Shen Haobo shows that Lower Body poetry is intimately linked to rapid, radical social change and concomitant generation gaps, but that there is more to it than meets the sociodocumentary eye (Nine).

Chinese poets are remarkably active as contributors to metatext. In this respect, too, Xi Chuan has fascinating writings to his name, for one thing because his work exemplifies the fuzziness of the boundaries between text and metatext (Ten). Han Dong's and Yu Jian's abundant explicit poetics (Eleven), on the other hand, contain much more commentary on the actualities of the poetry scene, even though their 
concerns can be subsumed under topics similar to those explored by $\mathrm{Xi}$ Chuan. The work of all three poets brings out the relative nature of the Elevated and Earthly as textual and metatextual labels, without detracting from their usefulness as discursive coordinates. This is further illustrated by the Popular-Intellectual Polemic (Twelve). Around the turn of the century, poetry treads new ground through Yan Jun's multimedial performances (Thirteen). While their textual component exceeds the realm of the written, as writing they belong inside the poetic discourse of the avant-garde. Yet, in other ways, as part of larger cultural trends summed up as technologization and remediation, Yan Jun's work is sufficiently different from most avant-garde poetry to prompt reflection on the nature and the scope of this discourse to date and in future.

At this point a few disclaimers are in order. First of all, poetry from Taiwan and Hong Kong, two sinophone communities with extremely rich literatures, lies outside the scope of this study. When I say China or Chinese, unless otherwise indicated, I refer to the People's Republic as defined by its borders prior to the 1997 handover of Hong Kong, and within the PRG my research does not extend to poetries written in other languages than Chinese. This reflects two things: the limitations of my work and the observation that the historical circumstances which hold for Chinese-language poetry in the People's Republic add to the coherence of the avant-garde as an Easthopian discourse. In recognition of the work of scholars such David Der-wei Wang and Michelle Yeh, the latter point isn't intended to reify geopolitical dividing lines as having literary significance per se. Second, of the ten poets whose work I examine closely, only one is a woman. I have guesstimated elsewhere that the proportion of male-authored poems in the avant-garde lies around ninety percent, but I seek no justification in these numbers. My original outline for this project included a chapter on Women's Poetry and I had published a preliminary essay on Zhai Yongming; but subsequently I had the privilege of acting as advisor to Jeanne Hong Zhang, whose work on Women's Poetry made anything I could have done in this respect pale in comparison. Third, I had planned a chapter on the 1980s Sichuan scene with its singular activism and aesthetics, but then I had the privilege of acting as advisor to Michael Day, whose work on the Sichuan avant-garde.... etc. Of course, that others have written on a given topic is anything but a reason not to do so oneself. In these two cases, however, I found my energies redirected into talking back to Jeanne and Michael, and hap- 
pily so. Fourth, as noted, this study doesn't extend to poetry on the Internet, for the simple reason that I have found it hard to keep up with poetry in print to begin with. Fifth, while the emergence of modern Chinese poetry has involved close encounters with foreign literatures, I haven't attempted anything in the way of influence studies beyond noting the occasional intertextuality. ${ }^{62}$

\section{Chineseness, the West and Sinologists}

What is Chinese about the poetry studied in this book? To borrow Rey Chow's pertinent question, isn't it just poetry, rather than Chinese poetry? ${ }^{63}$ First and foremost, this poetry is written in Chinese, as part of the larger linguistic environment (语境) of cultural China (文化中 国) and specifically contemporary mainland China - which, in exile poetry, doesn't stop at the nation's borders. This raises a question that is as thrilling as it is difficult. Could this poetry have been written in another language? I won't go into this here, but I'm disinclined to assume that the answer is a simple yes. Second, this poetry operates as a coherent discourse within local socio-historical and literary-historical contexts. Here, one can think of Communist Party policy or the particularities of the unofficial poetry scene, but also of the lingering influence of traditional Chinese views of literature. Many poets will declare that poetry should be autonomous from mainstream social development, but metatextual traffic shows that they have not internalized this view.

Speaking of Chineseness along these lines is another way of saying that my data is regionally and linguistically defined, and that certain aspects of this definition are particular to this data and don't necessarily hold for poetries in other regions and languages. I hope my study will show that calling this poetry Chinese doesn't mean its readers must be Chinese in whatever sense, or make it the object of a misguided quest for essentialized, exoticized types of authenticity. Moreover, the resonance of Chinese contexts doesn't make the poetry discussed in these pages exclusively Chinese. On that note, let's switch perspectives and recall that since day one, modern poetry in China has regularly been

${ }^{62}$ Yeh 199la and 1992a, Wang (David Der-wei) 2000; Van Crevel 2007 and 2003a; Zhang (Jeanne Hong) 2004, Day 2005a.

63 Chow 2000: 11. 
taken to task for being insufficiently Chinese, and for being "foreign" (外国的、外来的) and “Westernized" (西化). Such assessments are still being made today, by specialist and non-specialist readers, and occasionally lead to representations of this or that poem, oeuvre or trend as being derivative material or second-hand news imported from abroad.

A major part of the bigger picture is China's precarious, troubled relationship to the West and Japan ever since the Opium Wars, even if in the contemporary period, things are not what they were in 1839. In the cultural and academic realms, this geopolitical situation is reflected in what is widely perceived as uneven exchange between national literatures and academies in the modern era, within contested notions of "world literature" and "international" scholarship, usually meaning scholarship in English. In plain words, modern literatures from elsewhere - not just from the West and Japan, but also from Central and Eastern Europe and from South America- have exerted greater influence on modern Chinese literature than the other way around. Similarly, Western theory is overwhelmingly present in not just international but also Chinese-domestic scholarship on modern Chinese literature.

On interindividual and intercommunal levels, cultural and scholarly development rarely start from "purity" and usually involve some measure of hybridity, and the long-term view tends to problematize representations of influence as a one-way affair. A stock example is how classical Chinese poetry influenced the modern Western poetry that went on to influence modern Chinese poetry. In spite of such qualifications, the issue of uneven exchange remains topical and sensitive. Understandably so, for with regard to literature it activates explosive notions such as authenticity, originality, primacy, imitation, inequality and subordination, and with regard to discourse on literature, it highlights the dangers of centrism and chauvinism in various quarters. This has generated much debate involving Stephen Owen, William Jenner, Michelle Yeh, Rey Chow, Perry Link, Zhang Longxi, Zhang Yingjin, Andrew Jones, Gregory Lee, Huang Yunte, Bonnie McDougall, Julia Lovell and many others, for poetry often focusing on the work of Bei Dao. The discussion isn't limited to Chinese literature and its relationship to other literatures but extends to the study 
of Chinese literature as conducted in China and elsewhere, and to its translation. ${ }^{64}$

Can Western studies of Chinese literature steer clear of Occidentocentrism (西方中心主义), if we were to accept the static homogenization of the West that this question presupposes? A few basics, none of them terribly original, may serve to outline my position. Most if not all literary theory and methodology that claim any universal validity originate in a particular (literary, linguistic, social, ideological) framework $\mathrm{F} x$. There are many such frameworks, and they are rarely "pure" at any point in time. Their interaction contributes to cultural development and entails the encounter of perspectives that are experienced as relatively "native" and "foreign" - even if neither the native nor the foreign view themselves as such prior to the encounter, neither are pure or fixed and both will change as a consequence of the encounter. In the contemporary world this interaction is inevitable. Theory and methodology from $\mathrm{F} x$ shouldn't be mechanically applied to literature from $\mathrm{Fy}$, nor should their applicability to literature from $\mathrm{Fy}$ be mechanically rejected. What scholars who come from $\mathrm{F} x$ bring to the study of literature from $\mathrm{F} y$ includes a perspective $\mathrm{P} x$, without excluding others. $\mathrm{P} x$, in its turn, sometimes includes explicit theory and methodology and always includes a general intellectual-cultural makeup, which is usually less explicit. It reflects communal orientations but also has room for individual aesthetics. Scholars from $\mathrm{F} x$ who study literature from $\mathrm{F} y$ cannot block out $\mathrm{P} x$, which has a bearing on the questions they ask of this literature, and hence on their representations of it. This need not be a problem, as long as they are aware of this situation and know that $\mathrm{P} x$ is but one possible perspective and not a truth claim.

In the present context, a controversial perspective is that of foreign, usually Western sinologists (汉学家) who study and translate Chinese literature and function as its brokers vis-à-vis foreign publishers, media and university curricula. Their role is often considered in the context of a general discontent with modern Chinese literature's low international impact. Assessment of their achievements ranges from the wel-

64 Owen 1990 and 2003; Jenner 1990; Yeh 1991b, 1998, 2000a and 2007b; Chow 1993: ch 1-2 and 2000; Link 1993; Zhang Longxi 1993; Zhang Yingjin 1993; Jones 1994; Lee (Gregory) 1996: ch 4; Huang Yunte 2002: ch 2; McDougall 2003: 12 et passim in ch 1-2. With the exception of Yeh $1991 \mathrm{~b}$, an early rejoinder to Owen 1990, these references are limited to English-language scholarship. 
coming and complimentary to the deprecatory and hostile, by "native" and "foreign" commentators alike; ${ }^{65}$ the latter distinction is of course increasingly problematic. Optimists emphasize that the sinologists advance cultural exchange, sometimes classifying their work as supporting a cause called Chinese literature's "march toward the world" (走 向世界). Pessimists believe that the sinologists' command of Chinese is insufficient and they work from a Western perspective, and that this disqualifies them for judging literary works in Chinese and producing responsible and effective translations. Occasionally, the pessimists will cast doubt on the integrity of the sinologists and that of the authors they translate, suggesting that Chinese writers' success in "connecting" (接轨) with a globalizing literary market and more generally their ties of allegiance (关系) with the scholar-translators ultimately determine who ends up in world literature and who doesn't. Chapter Eleven of this study contains examples of avant-garde poets engaging in such sinologist-bashing and Chinese-author-bashing.

For poetry, some academics have hyperbolized the sinologists' role and that of the foreign audiences they create, in a way that leads to association with an overly literal reading of Bourdieu's production for producers and doesn't reflect the realities of the poetry scene. Writing in 1996, Gregory Lee claims that in the early 1990s, "internal clampdowns and enforced exile ma[d]e the West the [Chinese poet's] main audience," although he later notes that in China, "there [was] still a significant readership of poetry ... not a negligible readership either in terms of size or influence." ${ }^{" 66}$ Zhang Xudong holds that ${ }^{67}$

the aesthetic institution of "pure poetry" or "global poetry" has proven to be the last refuge of this ephemeral high modernism [i.e. Obscure Poetry], now surviving as an endangered species outside China, thanks to the "academic" interest of Western universities and foundations.

This is a stark exaggeration clad in questionable rhetoric, as Haun Saussy has pointed out. ${ }^{68}$

Western literary and academic institutions have paid much less attention to modern Chinese literature than to literatures in European languages. Chinese studies are on the rise throughout the world, but

\footnotetext{
65 Cf Yeh 2007a: 33.

66 Lee (Gregory) 1996: 13, 38.

67 Zhang Xudong 1997: 136.

68 Saussy 1999.
} 
foreign scholar-translators of Chinese literature are still relatively few in number and thus exert considerable, perhaps unbalanced or disproportionate individual influence on representations of this literature to audiences elsewhere. Their pivotal role is reinforced because foreign consecration of Chinese literary works carries much weight in domestic discourse, as a consequence of the uneven exchange noted earlier. Before anything else, however, we should note that sinologist means different things to different people. Especially in North-American discourse, if it is used at all it often has connotations of Orientalist representations of traditional Chinese culture, insufficient disciplinary theorization and delusions of all-encompassing visions of an essentialized "China." Remarkably, China scholar, which should really mean the same thing, carries much less of a negative connotation. In Europe these issues are recognized but sinologist is a less controversial term, perhaps because the study of China is generally concentrated in departments of Chinese Studies and less developed in disciplinarily defined departments such as Comparative Literature or History.

For now, with regard to modern Chinese literature's low international impact and the role of the scholar-translators, suffice it to observe the following points. One: while the presence of European languages in Western high school curricula doesn't automatically generate top-quality translations from these languages, there is doubtless room for improvement in the field of translation from a language that most of the current professionals started studying only when they went to university. Two: there are many examples of successful cooperation between native speakers of Chinese and of the various target languages. Three: when assessing scholarship and translation we should bear in mind that modern Chinese literature "itself" - the primary text in the exercise, so to speak - has had a hard time finding its footing during the extreme upheavals of modern Chinese history. Four: concerns about sinological and Western perspectives, which are often grossly generalized, should perhaps not move scholar-translators to stop studying and translating Chinese literature. As others have done, Bonnie McDougall rightly cautions against the naive adoption of Western perspectives, but whether one should "adapt criticism to native expectations" - and whether one can, to begin with - is open to debate. This position implies that foreign scholar-translators can do little more than report on domestic discourse, and presupposes a view of literature as primarily social documentation that limits the potential of 
the text to be realized in various ways in its encounter with a variety of readers. McDougall recognizes the complexity of the issue when she urges the scholar-translators not to accept domestic canons uncritically. ${ }^{69}$

\section{Theory and Methodology}

In light of the variety of the poetry studied in this book, I haven't adopted one single literary-theoretical angle throughout. Instead, I draw on the work of various theorists as it speaks to questions I believe are raised by the material: John Glad on exile, Marjorie Perloff on indeterminacy, Amittai Aviram on rhythm and so on. One issue that informs several of the case studies is that of the synergy of form and content, which I view as neither a dichotomy nor two simply equatable concepts, and rather as relative to and dependent upon one another. I take the position that poetry is art before anything else, that any socio-documentary or generally representative function it may have is secondary, that its form is essential to its realization, and that we should be alert to the pitfalls of content bias and what Chow calls the informationalization of literature. ${ }^{70}$

My methodology is best summed up as close reading. I read not for completeness but for coherence, which is not the same thing as all-encompassing, rigid consistency, and often emerges in unresolved tension rather than closure. In this respect, too, the material doesn't always ask the same questions. Close reading makes more sense for Sun Wenbo's poetry, for instance, than for Shen Haobo's. Several years ago Kirk Denton said of a journal article containing an earlier version of chapter Five, on Xi Chuan, that it showed that close reading was "still a valuable activity." 71 That this needed to be said illustrates the extent to which close reading has been discredited since the mid-twentieth century. To some extent this has happened through association with caricatures of blinkered New Critics in exclusive worship of the literary text in the narrowest sense, grudgingly admitting that the words on the page might have a generally accepted referential value. This is not what I do. The development of literary and cultural

\footnotetext{
69 McDougall 2003: 9 et passim in ch 1-2.

70 Chow 1993: 132.

${ }^{71}$ Denton 1999.
} 
studies over the past several decades is a wonderful thing, most of all because of their current diversity and inclusiveness. There is room for projects that keep the text on board, with attention to "minute detail" like syllable stress and punctuation if need be. This particular type of respect for the text informs my preference for citing individual poems in their entirety. For poetry, this is often pragmatically possible and theoretically desirable.

If only because I have wondered whether this poetry could have been written in another language than Chinese, a few words on translation are in order. All translations in this book are mine. This is for practical reasons - in a book written in one language on poetry in another, analysis and interpretation are hand in glove with translation - and out of love for the art. For a few of the poems in question, other translators have gone before; while I have organized my personal encounters with the texts in question, I haven't changed my phrasings if they coincided with those of my predecessors. As for the issue of academic versus literary translation, I am inclined to the latter but aware of the limitations that come with the claim of commenting on the Chinese originals. There are no hard and fast rules for these things, as I hope the reader will remember in chapter Seven, where I argue that a particular occurrence of 灯 'lamp' should really be rendered as window in English. Another perennial issue is that of the translatability of poetry per se. While this is obviously not unique to the Chinese case, I would like to cite fellow specialists of Chinese poetry to clarify where I stand. I second Brian Holton's dismissal of the myth of untranslatability, and I express my admiration for Holton's own, Andrea Lingenfelter's, Simon Patton's, Michael Day's and Steve Bradbury's translations as some of the strongest English-language evidence against this myth. ${ }^{72}$

$*$

Translatability in a broader sense takes us to a final, contiguous point, which concerns the very nature of scholarship on literature and especially on poetry, within linguistic borders or across them. Why speak about texts, perhaps even claim to speak for texts that should speak for themselves? The question brings to mind classifications of criticism as

72 Holton 1994: 122-123 and 1999: 188 et passim. 
the most influential high literary form of our day at one end, ${ }^{73}$ and the clichéd, hostile image of medical dissection for the scholarly discussion of poetry, at the other. The dissection metaphor is an extreme case of the rejection of paraphraseability: a poem is a poem precisely because it is unalterably made of the exact words of which it is made, and as the other verbalizations that they are, words about the poem are useless at best and a fatal violation of the poem's integrity at worst. But there are other possible answers. Tonnus Oosterhoff presents an image as powerful as that of dissection, but infinitely more engaging and productive: $:^{74}$

Does secondary, interpretive literature have to be hard science? Isn't the genre more comparable to singing the second voice? Around the main melody, that of the work of art, a second melody plays its way, lending perspective and depth. The writing reader must be precise, but what $\mathrm{s} /$ he is after is meaningful polyphony, rather than the impersonal, context-immanent meticulousness of science.

To the second voice.

73 Cited in Yu (Pauline) et al 2000: 6.

74 Oosterhoff 2006. 
Maghiel van Crevel - 978-90-47-44273-8 Downloaded from Brill.com $04 / 25 / 2023$ 11:38:45PM via free access 


\section{TRUE DISBELIEF: HAN DONG}

We have seen that up to the mid-1980s the avant-garde was often negatively defined, by dissociation from orthodoxy. One recalls the 1917 Literary Revolution as an earlier watershed in the history of Chinese poetry that was negatively defined, then with reference to the classical tradition. Notably, Hu Shi's "Some Modest Proposals for the Reform of Literature” (文学改良刍议, 1917) is also known as the Eight Don'ts (八不). ${ }^{1}$

Negative definitions make sense inasmuch as literature and art are a cumulative undertaking, and our expectations of them are shaped by what has gone before- which is precisely what the new thing may deny us. They operate not just on the level of trends, movements, schools and so on, but also on that of individual oeuvres and indeed single works, when they focus on what a poem or a painting is not, on features that it doesn't have: rhyme, for instance, or figurative resemblance to the natural world. A negative definition such as this poetry doesn't rhyme does not exclude a simultaneous, positive definition such as this poetry highlights performative aspects of literature. If, however, a poem's distinguishing features are limited to the rejection of another, it operates as a commentary rather than a primary text, even though this is a relative distinction.

As a poet, an editor and a producer of metatext, Han Dong (1961) has been a distinct, influential voice within the avant-garde since the early 1980s. In addition to two individual collections, his poetry appears in numerous major multiple-author anthologies; he was founding editor of Them (他们), discussed below, and of the ambitious Epoch Poetry Series (年代诗丛) and has contributed to poetical debates throughout the years; and his work features prominently in scores of journal articles and book-length scholarly surveys of contemporary poetry. As for English-language scholarship, Michelle Yeh, Su Wei and Wendy

\footnotetext{
${ }^{1} \mathrm{Hu}$ Shi 1996.
} 


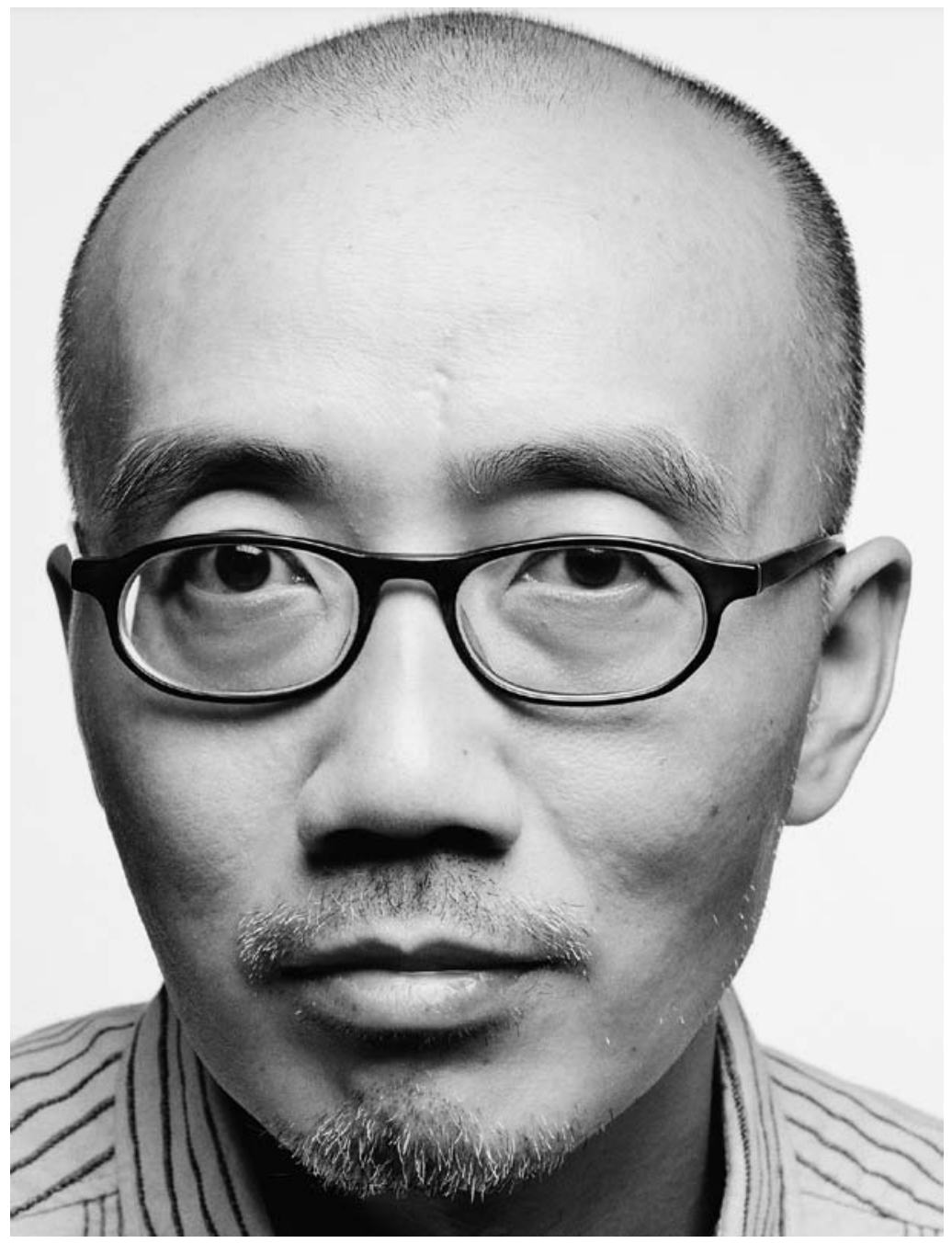

Figure 2.1. Han Dong, 2006 (photograph by Pieter Vandermeer) 
Larson, and Julia Lovell touch on Han's poetry in comparisons of Obscure Poetry and categories such as Post-Obscure, New Period (新时 代) and Third Generation Poetry, Jeffrey Twitchell-Waas and Huang Fan give it pride of place in an essay on the Nanjing scene, and Simon Patton offers a sensitive introduction to his translations of Han's work for the Poetry International Web. ${ }^{2}$

All avant-garde poetry since the groundbreaking unofficial journal Today continues to stand more or less in opposition to orthodoxy, including Han's, but to say so has become flogging a dead horse since the avant-garde began to outshine the establishment in the mid-1980s. What matters is that within the avant-garde, Han Dong's poetry has often been negatively defined by its rejection of Obscure Poetry. This is because some of his early, best-known work writes back to famous Obscure poets and poems, as do some of his poetical statements.

Section 1 of this chapter recognizes the significance of Han Dong's initial, anti-Obscure stand and of his work's function as a commentary on what was a major poetic trend at the time. This is, however, not the whole story. Section 2 shows that negative definition captures only a fraction of Han's art as a primary text and that it does no justice to his oeuvre in the full breadth of its development. Han's rejection of Obscure Poetry is but one manifestation of a multi-faceted, original poetics that transcends its local literary-historical context.

\section{The Rejection of Obscure Poetry}

Today was closed down by the police in 1980, less than two years after the publication of its first issue in December 1978. Short-lived as the journal was, it had a huge impact among young urban intellectuals, especially those studying at university. Many of them contributed to the upsurge of Campus Poetry (校园诗歌), a collective name for poetry by university students that circulated throughout China through unof-

${ }^{2}$ Han 1992b and 2002. On the Epoch series, see Van Crevel 2003b. It was prematurely terminated after a policy change at the Hebei Education Press. Yeh 1992, Su \& Larson 1995, Lovell 2002, Twitchell-Waas \& Huang 1997, Patton 2006. English translations of Han's poetry are found in Tang Chao \& Robinson 1992, Zhao (Henry) \& Cayley 1996, Twitchell-Waas \& Huang 1997, Zhao (Henry) et al 2000, Renditions 57 (2002), the DACHS poetry chapter ( $\rightarrow$ China's Second World of Poetry $\rightarrow$ related material $\rightarrow$ translations), The Drunken Boat 6-I/II (2006, online), Full Tilt 1 (2006, online), Patton 2006, Tao \& Prince 2006 and Zhang Er \& Chen 2007. 
ficial channels. Han Dong, who was studying philosophy at Shandong University, was a Campus poet of some renown. Wu Kaijin notes that in 1981 Han received an award from the official journal Youth (青春) for a poem series that still reflected the tragic-heroic Obscure tradition established by Today, particularly by the early Bei Dao. Soon thereafter Han radically changed his style. «Mountain People» (山民, 1982) is widely seen as a harbinger of trends that would supersede Obscure Poetry from the mid-1980s onward. ${ }^{3}$

"Mountain People»

as a child, he asked his father

"what's beyond the mountains"

his father said "mountains"

"and beyond beyond"

"mountains, more mountains"

he made no sound, looking in the distance

for the first time, the mountains made him tired

he thought he couldn't get out of the mountains in this life

the sea was there, but far away

so before he'd get there

he'd die halfway

die in the mountains

he felt he should set out together with his old lady

his old lady would give him a son

and by the time he died

his son would have grown up

and his son would have an old lady too

and his son would have a son too

and his son's son would have a son too

he stopped thinking

his son made him tired too

he only regretted

his ancestors hadn't thought that way

or the one to see the sea would have been him

${ }^{3}$ Wu Kaijin 1991: 214, Lao Mu 1985a: 572-573. 
If «Mountain People» alludes to the fable of the Foolish Old Man Moving the Mountain (患公移山) and its Maoist reception, it takes an ironic turn when its protagonist grows tired of the mountains and of thinking about his sons, in contradistinction to the Old Man's unflinching determination and perseverance. ${ }^{4}$ Of interest to us here is the poem's sharp deviation from Obscure Poetry, famous for its grandiloquent tone and its daring metaphors.

Immature as it is when compared to Han Dong's later work, «Mountain People» does presage his two best-known poems, «Of the Wild Goose Pagoda» (有关大䧹塔, 1982) and «So You've Seen the Sea», which appear in many anthologies and literary-historical surveys of contemporary Chinese poetry. Written in the same deceptively simple style, they are characterized by skepticism and irony. Notably, these literary mechanisms had been in exceptionally short supply in Maoist China - and in the first phase of the avant-garde, that is: in Obscure Poetry. ${ }^{5}$

"Of the Wild Goose Pagoda»

of the Wild Goose Pagoda

what do we really know

many people come rushing from afar

to climb up

and be a hero

some come a second time

or even more than that

people not pleased with themselves

people grown stout

they all climb up

to be that hero

and then they come down

walk into the road below

and disappear in the blink of an eye

some real gutsy ones jump down

red flowers blooming on the steps

${ }^{4}$ E.g. Jin 2002: 290 (with Luo Hanchao as poetry editor) and Liu Shuyuan 2005: 213-215. For the fable of the Foolish Old Man Moving the Mountains and its Maoist reception, see Mao Tse-tung 1967, vol iii: 271-274. 205. 
now there's a real hero-
a hero of our time
of the Wild Goose Pagoda
what do we really know
we climb up
look at the view around us
and then come down again

This is the poem's canonized version. Side by side with a little-known, earlier version published in the Lanzhou-based unofficial journal Same Generation (同代), it illustrates the transformation of Han Dong's individual style, away from moralizing explication and toward effective reticence.

In the second half of this chapter we will focus on positively defined features of Han Dong's work. Here, following earlier scholarship, let's first register that «Of the Wild Goose Pagoda» writes back to Obscure Poetry, specifically to Yang Lian's «The Wild Goose Pagoda» (大雁 塔, 1980). ${ }^{6}$ Han Dong deconstructs Yang Lian's conventional view and its bombastic literary presentation of the Pagoda as a proud landmark of Chinese civilization, as well as the average Chinese tourist's supposed consciousness of these things. Rather than of Lermontov's novel, a hero of our time reminds one of the many larger-than-life heroes in literature from the People's Republic, in both orthodox works and early Obscure Poetry.

Almost twenty years after Han Dong's rewriting, the lasting impact of his poem shows in Cai Kelin's subsequent appropriation of the Pagoda. The title of Cai's poem, «The Wild Goose Pagoda» (大雁塔, 2004) is the same as that of Yang Lian's. Cai's text, excerpted below, responds to Han's opening words (of the Wild Goose Pagoda / what do we really know) and to the suicide scene: ${ }^{7}$

${ }^{6}$ Twitchell-Waas \& Huang 1997: 30-31 and Wang Yichuan 1998: 236ff provide detailed discussions of this intertextuality; see also Chen Sihe 1997: 52-53. «The Wild Goose Pagoda» was first published in Yang's unofficial collection There Is a New Sun Every Day (太阳每天都是新的, 1980). The poem's early appearances include one in Flower City (花城) (第5增刊, 1982: 9-14). An English translation is found in Soong \& Minford 1984: 256.

${ }^{7}$ Liu Shuyuan 2005: 245-247. Liu doesn't discuss the allusion to Bei Dao, noted below. 
not a shred of doubt left

the Wild Goose Pagoda is right ahead

$\cdots$

I've climbed up the Pagoda

and if I spread my wings

I'd take off straight into the blue sky

now that'd be true happiness

and there's no way that

in an age without heroes

I'd want to play the hero

all I want is to brush off the dust

put my mind at ease

and listen to the Buddha

Thus, the intertextuality continues and expands, not least because after using Yang Lian's title and rewriting important scenes in Han Dong's poem, Cai alludes to an early, much-anthologized text by Bei Dao that gives Han's gutsy ones yet another twist. Bei Dao wrote «Declaration» (宣告, 1980?) to commemorate Yu Luoke, a victim of Red Guard violence during the Cultural Revolution. This is the operative passage: ${ }^{8}$

In an age without heroes

I just want to be a human being

A peaceful horizon

cuts through the ranks of the living and the dead

I can only choose the sky

and will not kneel on the ground

to make the executioners look tall

and block the winds of freedom

Finally, leaving behind national pride (Yang), its deconstruction (Han) or the injustice of the Cultural Revolution (Bei Dao), Cai redirects the reader to other, older spheres, foregrounding the Pagoda's original function as a storehouse of Buddhist scriptures brought to China from India: listen to the Buddha.

Back in the early 1980s, just as in «Of the Wild Goose Pagoda» Han Dong writes back to Yang Lian, so in «So You’ve Seen the Sea» (你见

\footnotetext{
${ }^{8}$ Bei Dao 1987: 73-74.
} 
过大海, 1983) he writes back to Obscure poet Shu Ting, specifically to her exalted «To the Sea» (致大海, 1973) and her «Morning Songs at the Seaside» (海滨晨曲, 1975). Interestingly, «So You've Seen the Sea» is also something of a sequel to Han's own «Mountain People», in which seeing the sea is a wish of the protagonist that goes unfulfilled. Together, these intertextualities help dismantle what Wang Yichuan calls a literary myth of the sea, and Liu Shuyuan its imagined cultural meaning. ${ }^{9}$

«So You've Seen the Sea»

so you've seen the sea

you've imagined

the sea

you've imagined the sea

and then seen it

just like this

so now you've really seen the sea

and imagined it as well

but you're not

a sailor

just like this

so you've imagined the sea

you've seen the sea

perhaps you even like the sea

just like this, and nothing more

so you've seen the sea

and you've imagined the sea

you're not willing

to be drowned by the sea

just like this

just like everybody else

There can be little doubt that a critical response to and dissociation from Obscure Poetry were part of the early Han Dong's motivation. In interviews in recent years, he has acknowledged the overwhelming

${ }^{9}$ Shu Ting 1982: 1-6. Wang Yichuan 1998: 239ff, Liu Shuyuan 2005: 216. «So You've Seen the Sea» first appeared in Them 1 (1985): 37; dated 1983 in Tang Xiaodu \& Wang 1987: 208, included in Han 2002: 14. Zhang Zao (2004: 217) calls Han's 1988 poem «Afternoon» (下午, Them 5: 6, Han 2002: 75) another example of writing back to Obscure Poetry. 
influence of Obscure Poetry at the time, with Bei Dao as its leading figure, and said that his own generation's attempt to break free may be called an act of patricide. This tallies with the occasional use of the slogan “Down with Bei Dao!" (打倒北岛!) by younger authors and critics in the mid-1980s. Incidentally, Han recalls that Bei Dao's recommendation was instrumental for publication of «Of the Wild Goose Pagoda» in China (中国) in 1986. ${ }^{10} \mathrm{~A}$ special section in the journal's third issue, endorsed by senior poet Niu Han, constituted official recognition of alternatives and indeed successors to Obscure Poetry as the face of the avant-garde. Before long, the younger generation's rejection of the Obscure poets was epitomized in a brief article by Cheng Weidong in the Literary Gazette (文汇报), entitled "Farewell, Shu Ting and Bei Dao" (别了, 舒婷北岛, 1987). ${ }^{11}$

The act of dissociation is manifest not only in Han Dong' poetry but also in early poetical statements he published from 1985 onward. His dictum that "poetry goes no farther than language" (诗到语言为 止) brings to mind Mallarmé's remark that poetry is made of words not ideas - even if this is a simplification of Mallarmé's poetics - and related statements by other modern authors. Han's words suggest a similar desire to demystify poetry, or minimally to emphasize the ontological primacy of language as poetry's medium, rather than representing poetry as an extension or remediation of anything else. In their local context, they also bespeak the rejection of ideological claims by both literary orthodoxy and early Obscure Poetry.

Han's adage is one of the most frequently cited poetical positions in contemporary Chinese poetry, and has generated many variations and interpretations. Su and Larson translate it as Poetry stops at language. This implies that poetry "stops" before it has "reached" or "arrived in" language, but the original wording indicates that poetry stops only after it has done so. Twitchell-Waas and Huang expand Han's words to Poetry begins and ends in language, in what appears to be a conflation with Shang Zhongmin's claim that "poetry begins in language" (诗歌 从语言开始). Yu Jian combines Shang's and Han's words consciously, when he writes that "Poetry goes from 'begin in language' to 'go no farther than language” (诗 “从语言开始” 到 “语言为止”). Han's original statement likely dates from the mid-1980s, but its origin is un-

${ }^{10}$ Cf Yeh 1992b: 396-397; Han \& Yang 2004 (296, 299), Xu Jingya 1989: 134140, Han \& Chang 2003.

11 Cheng Weidong 1987. 
clear. Characteristically, he has played down its significance by saying that whatever he said was never intended as a theoretical formula, and shouldn't be turned into some kind of "truth.".

If we juxtapose Han Dong's poetry and his poetical statements, the latter stand out by their solemn, grim and heavy tone and by their penchant for abstractions. This doesn't detract from the sensibility and insightfulness of many of his remarks on things like the role of poet, reader and critic, inspiration, poetic form and technique, the social position of poetry and so on. We will return to Han's explicit poetics in chapters Eleven and Twelve.

From 1984 until 1995, Han Dong was the driving force behind the Nanjing-based Them, one of the most widely read and enduring among the unofficial poetry journals that help shape the face of the avantgarde to this day. Them has received insufficient attention in foreign scholarship. Its Chinese name was inspired by the Chinese translation of Joyce Carol Oates' novel Them, but translated back into English as They, on the cover of the fifth issue. The authors at the journal's core started their exchange and cooperation in 1984. They included Han Dong, Ding Dang and Yu Jian, as well as Lu Yimin, Lü De'an, Pumin, Wang Yin, Xiao Hai, Xiao Jun and Yu Xiaowei. Nine paper issues of Them appeared: 1-5 between 1985 and 1989, and 6-9 between 1993 and 1995. The journal's hibernation from 1989 to 1992 coincides with the cultural purge following June Fourth. Since 2002 it has appeared online, as part of the Them Literature Web (他们文学网)..$^{13}$

While this is by no means all there was to it, Them did to some extent derive its identity from being different from Today - and, as we will see shortly, from another eye-catching unofficial journal, which had emerged in Sichuan province, brimming with poetic activity at

12 Su \& Larson 1995: 290, Twitchell-Waas \& Huang 1997: 34, Shang 1988: 229, 232; Yu Jian 1991: 310, Han \& Chang 2003. Han Dong's phrase must have begun to circulate early in 1987 at the latest (Tang Xiaodu \& Wang 1987: 203) and probably after 1985, judging by its absence from the poetical statement in the third issue of Them. Xiao Hai (1998: 19) dates it as "probably from the mid-1980s," and not even conscientious annotator Wu Kaijin can ascertain where it first appeared (1991: 218); Shen Qi (1996: 204) gives no source. In personal communication (March 2003), Han was elegantly evasive about it, saying that he could not recall what exactly he had said but could imagine himself as having said something along these lines.

${ }^{13}$ On Them and its continuation as an online forum, see the surveys of avantgarde poetry listed in chapter One (note 20), Han 1992b, Han \& Malingshu Xiongdi 2004 and the Them Literature Web. 
the time. ${ }^{14}$ Them counts as an early manifestation of a shift away from the grand and exalted toward the simple and quotidian, in form and content alike, thus contributing to the trend from Elevated to Earthly identified in chapter One. Han Dong's «Of the Wild Goose Pagoda» and «So You've Seen the Sea», both published in the Nanjing journal's first issue, are exemplary texts in this regard.

Editorials by Han Dong in the third and fifth issues of Them confirm the journal's dissociation from Today. The cover of the third issue (1986) has this to say, below the names of the ten contributors:

When we first published Them, we didn't make any theoretical statements. It is still like that. But some issues are becoming more and more pronounced, and we need to sum up our views.

We are concerned with poetry itself, with what it is makes poetry poetry, with that form of life in which a sense of beauty is produced by the interaction of language with language. We are concerned with the feeling, the understanding and the experience of entering deep into this world as an individual, with the power of fate as it flows through his (the poet's) blood. While we face the world and face poetry, we depend on nothing, although the glory of all kinds of ideas is projected on our bodies. But we don't want to, and we could not, substitute these ideas for our relationship with the world (including poetry). The world is right here before us, we can reach out and touch it. We don't need the approval of some kind of theory in order to grow confident, and then believe that this world is the real world. If this world weren't right here in our hands, a million reasons wouldn't make us believe in it. Conversely, if this world is in our hands, what reason could there be to make us think it is not real?

These days, silence has become something of an attitude. We will not keep silent as an attitude. But we have always thought that our poetry is the best statement we can make. We do not belittle any theoretical or philosophical contemplation, but we don't place all our hopes on that sort of thing.

Even if it appears that poetry might go farther than language after all, especially the second paragraph shows rejection of the type of poetry and presentation on the literary scene associated with Today. A 1988 reprint of the editorial in Xu Jingya's Overview of Chinese Modernist Poetry Groups 1986-1988 ends on an additional, one-line paragraph that says: "We ask of ourselves to make our writing more authentic" (真实), and Han Dong is credited as its author. ${ }^{15}$

14 Han 1992b: 194-198.

15 Xu Jingya et al 1988: 52-53. Han \& Chang 2003 reconfirms Han's authorship. 


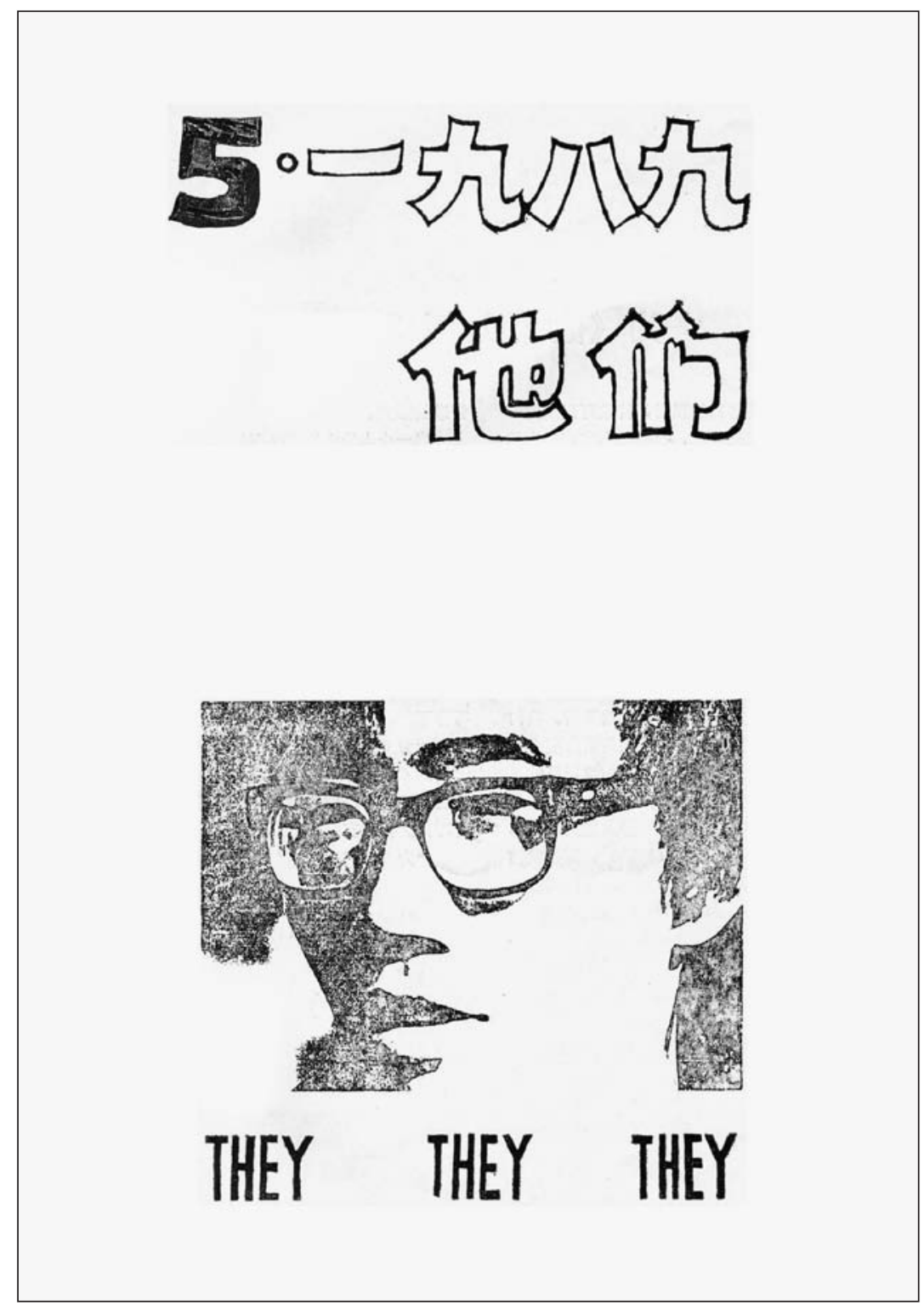

Figure 2.2. Them 5, front cover 
The fifth issue of Them, published late in 1988 or early in $1989,{ }^{16}$ has a portrait of Han Dong on the cover and opens with a selection of his poetry. The inside cover contains an editorial by Han called "Writing for Them":

... Writing for Them is our way of writing, it makes our poetry possible. One can write for pure white paper, or for a good pen. We write for Them. It's the same thing.

The difference with the idealists is that we don't need to write lots of essays on the goal-oriented nature of our journal. We know we should do the right thing, and we must know how to do it right . . .

... We are comrades [同志, literally 'of one mind,' 'of the same intention'] and fellow travelers [同路人, literally 'people on the same road']. Friendship between fellow travelers is stronger than that between comrades...

"Them" is not a literary school, it is merely the possibility to write the way we do.

"Writing for Them" is a symbolic expression. Them, then, is a symbol. In present-day China, it is the only one, and it is pure. The people attracted by it are those who understand what it is to write poetry. "Writing for Them" means no more than that.

Again, even though Han's own mini-essay isn't short on idealism, the "idealists" and the "lots of essays" bring to mind the poets and the extensive critical, theoretical and strategic discourse engendered by $\mathrm{To}_{0}$ day; and, when Han Dong wrote "Writing for Them," by the Sichuan journal $\mathcal{N}_{\text {ot-Not, }}$, which had enjoyed much publicity since its establishment in 1986. Similarly, the assertion that "Them" - in quotation marks, referring not to the title of the journal but to its contributorsis not a literary school (文学流派) creates a contrast with the commonly used "Today School" (今天派) and "Not-Not School” (非非派) as collective names for the authors that published in Today and $\mathcal{N}$ ot-Not. ${ }^{17}$ Whether there was a "Them School" is open to debate, but one difference with the "Today School" and the "Not-Not School" lies in the geographical concentration of the latter two in Beijing and Sichuan and what was perceived as their concomitant regional identities, as opposed to the laid-back encounter of poets from all over the country in

16 The front cover has "Nineteen-eighty-nine" written on it in large characters, but the back cover colophon cites November 1988 as the date of publication.

${ }^{17}$ Cf Wu Sijing 2002: 86. 
Them, often through correspondence rather than physical travel. The pure white paper and the good pen function as simple stage props. They are disclaimers of other things Chinese readers at the time might associate with poetry, and certainly with its presentation in the pages of Today: truth, beauty, righteousness, prophetic vision, a tormented soul, private symbolism and so on. The editorial's closing sentence: "Writing for Them' means no more than that," is vintage Han Dong. It urges the reader to see things in proportion, and specifically to realize that something is in fact less than it is made out to be: less profound or mysterious, less complicated or even special.

In sum, the early Han Dong's poetry and poetics present a forceful commentary on what were then doubtless the most influential works and authors of poetry in China after its emancipation from total political control. As such Han's work augurs the diversity we have witnessed ever since.

\section{An Original Poetics}

No conventional experience of Chinese civilization or the wonders of nature, no bombast or exaltation, no high-sounding ideals, no need for lots of essays, no literary school, "no more than that." While Han Dong's rejection of Obscure Poetry is plain for all to see, there is more to all these negations. They are manifestations of an original poetics that transcends its local literary-historical context.

As regards thematics, scholarship has tended to focus on Han's deconstruction of conventional topoi and on his predilection for the quotidian, for the trivia of everyday urban life. We will see an example of the latter in «A and $\mathrm{B}$ », the last of four poems to be discussed below. One characteristic of Han's poetry that has received little attention is that of a shock effect caused by the interruption of monotony or smoothness, especially powerful when an abrupt turn in the poem's semantics occurs without a change in its prosody or other formal features. In «Mountain People», Han's first attempt at finding his own voice, there is no shock effect, and the poem peters out. We do find it in «Of the Wild Goose Pagoda», in the offhand mention of individuals jumping to their deaths. The contrast with gregarious tourists eager to share in the glory of a public landmark lends their behavior a disturbing significance. This makes the phrase a hero of our time ambiguous, 
beyond its first, ironic reading. The speaker may see the gutsy ones as true heroes after all, since they have the courage to disrupt and indict uncritical worship of Chinese civilization by making the Pagoda the site of their suicide.

In «So You've Seen the Sea», nearly the entire poem is reserved for building up a hypnotic drone through repetition and near-repetition. Then, the speaker shatters the monotony by picturing you as drowning and the sea you likes to romanticize as a killer, without a ripple in the poem's acoustic or visual qualities. Then, too, we realize that the observation but you're not / a sailor, halfway through the poem, was a warning. By association with the sea as a popular image across literary traditions, Han Dong implies an opposition of poet versus sailor as one who speaks of the sea but has no right versus one who has the right but doesn't speak. We will see another of these shock effects in «A and $\mathrm{B} »$.

In addition, Han Dong's presentation of his themes is often enhanced by what appears to be willed superficiality on the part of the speaker. My use of this notion is different from Fredric Jameson's, cited by Su and Larson in their discussion of Third Generation Poetry. ${ }^{18}$ While $\mathrm{Su}$ and Larson focus on superficiality as a sign of the postmodern, I use it to denote a mechanism that causes a fairly straightforward type of defamiliarization, by blocking out conventional lines of reasoning and association. This is part of a general inclination toward "objectivism” (客观主义) noted in Han and other Third Generation authors by Chen Zhongyi. ${ }^{19}$ The flat observations made in «Of the Wild Goose Pagoda», for instance, don't lead to soul-searching or value judgment, and thus subvert seemingly self-evident assumptions: that landmarks like the Pagoda enable individuals to experience their cultural heritage, that poetry is a suitable vehicle for expressing that experience, or - with reference to the classical Chinese tradition - that ascending a high point to take in the view is a suitable theme for a poem. The speaker merely observes that all sorts of people come to the Pagoda, climb up, look around and perhaps enjoy the illusion of being heroes, and then come down again, with the suicides as a terrifying aside whose exploration is left to the reader. The repression of common knowledge and conventional reasoning has a defamiliarizing effect, summed up in

\footnotetext{
18 Jameson 1991: 9, Su \& Larson 1995: 291-292.

19 Chen Zhongyi 1994: 26ff, 45ff.
} 
the question the poem asks in the beginning and again at the end: what do we really know. Crucially, the said "objectivism" doesn't mean that the author or the speaker can or indeed wants to attain any measure of objectivity in representation, and has no designs on the reader, so to speak. We will return to this issue in chapter Seven, in connection with Yu Jian's poetry.

Critics habitually call Han Dong's language usage colloquial (口语). This is one of the most commonly cited characteristics of his art, frequently noted for other contributors to Them as well. Han's style has had considerable impact, in that writing in colloquial language has been among the claims to fame of many Chinese poets since Them first appeared and continues to be high on the critical agenda. Scholarship to date and the poets themselves have pointed out that the language of this so-called Colloquial Poetry is not the same thing as that spoken in ordinary human traffic, but the label is reasonable enough, certainly in its immediate literary-historical context. ${ }^{20}$ It bears emphasis that in this respect, again, the power of Han Dong's poetry lies not just in the rejection of formal or bookish language (书面语) of one kind or another. Positively defined, his usage comes across as measured, focused and controlled. This lends his poetry a quiet confidence and insistence, especially in its employment of (near-)repetition. Han's word choice and the form of his poetry - free verse, with short lines - are well suited to one another.

Perhaps inevitably, the canonization of a small number of Han Dong's early poems as primarily "colloquial" trendsetters away from Obscure Poetry has led to neglect of other aspects of his work in multiple-author anthologies and literary histories. His collection Daddy's Watching Me in Heaven (爸爸在天上看我, 2002), a rich selection spanning the years 1982-2001, shows that there are many more sides to his oeuvre. Below, we will consider three very different poems, none of them captured by canonized descriptions of Han Dong's poetry that simplify what are in fact complex literary texts. Several characteristics of his art come together in the fourth, «A and $\mathrm{B} »$, reviewed in detail toward the end of this chapter.

Let's begin by looking at «Someone in a Riot of Stones» (一堆乱石 中的一个人, 1988): $:^{21}$

${ }^{20}$ E.g. Yu Jian 1989a: 1-2 and Han \& Liu \& Zhu 1994: 119.

${ }^{21}$ Han 2002: 63. 
«Someone in a Riot of Stones»

someone in a riot of stones. some-

one like that, a riot of stones like that

crawler, one hugging the ground

slowly moving, even unmoving lizard

athlete leaping amid riotous stones, or

stone falling down on stones

it's not the one at the foot of an enclosure

the one before the neat and orderly brickwork

stops right there when we stare

transfers one stone's warmth to another

its shape is six stones overlapping

now, as if craving rainwater, crawls

onto the picture

This poem certainly isn't about the trivialities of urban life. Instead, in one possible reading, it allows the imagination to transform a human being into a reptile, then athlete, then stone, then human being again - by negative association: it's not... - and then, from the fifth stanza onward, cold-blooded, crawling animal again. The poem displays no objectivism of any kind. It is syntactically ambiguous, for instance in the connections between the fourth, fifth and sixth stanzas. It is enigmatic, not to say inaccessible: What enclosure? Is the one at the foot of the enclosure inside or outside the brickwork? Who are we? Whose shape is six stones overlapping? What happens next? Yet, the text is intriguing and it invites multiple rereadings. It also invites the classification of images as metaphors, as opposed to the professed whatyou-see-is-what-you-get poetics of authors such as Han Dong himself and his literary soulmate of early days, Yu Jian. Most importantly, the poetic voice expresses tension, complete engagement and anything but irony. While «Someone» is in many ways unlike Han Dong's bestknown works, one thing it has in common with «Of the Wild Goose Pagoda» and «So You've Seen the Sea» as well as with the next three poems studied here is a feeling of palpable concentration. This poem handles its metaphors better than happens in many early Obscure poems and other texts that tend toward the Elevated. The metaphors in 
«Someone» are limited in number, and they don't produce loose ends but feed into one another.

Written in the same year, this is «There Is a Darkness» (一种黑暗, 1988): $:^{22}$

\section{"There Is a Darkness»}

I notice forest darkness

darkness with a difference

darkness like a square, in the forest

darkness made by four people walking off in four directions

darkness between the trees but not inside the trees

darkness rising spreading through the sky

darkness not of underground rocks that share everything

darkness that weakens lights scattered evenly

across a thousand miles to their lowest glow

darkness gone through turns of endless trees, not vanished

there is a darkness that forbids strangers to enter at any time

if you reach out a hand to stir it that is

darkness in a giant glass

I notice forest darkness although I am not in the forest

Just like «Someone in a Riot of Stones», «There Is a Darkness» contains enigmatic, surrealist scenes and literary techniques not normally associated with the demystification that is known as a trademark of Han Dong's poetry: darkness made by four people, darkness gone through turns of endless trees, darkness in a giant glass, and the personification of the underground rocks, in the expression share everything (不分彼此 'not divide thine and mine'). With 12 occurrences in 14 lines, darkness acquires incantatory qualities, at the end of the lines in the original, and anaphoric in the translation. The poem's language is not difficult but not colloquial either: darkness that weakens lights scattered evenly / across a thousand miles to their lowest glow.

An important scene in this poem is that of four people walking off in four directions. Their separation and the increasing distance between them take the form of the darkness that gives the poem its name. Subsequently, these things are projected on the trees that make up the forest: there is darkness between them. This is not, however, because they

22 Them 5 (1988): 7, Han 2002: 69. 
stand close together, like the underground rocks that share everything. The darkness between the trees is of a distancing, mutually unwelcoming kind. The observation that it forbids strangers to enter projects the darkness back from the trees onto human beings and the central scene of the four people walking off in four directions. Finally there is a double distancing, not just among the people in the poem, and among the trees, but also between the people and the trees on the one hand, and the speaker on the other. This is visible in the clinical, objectifying formula I notice (我注意到), in the poem's first line and its last, and most of all in its closing words: I am not in the forest, meaning 'I am not among those people or those trees.' Thus, «There Is a Darkness» questions people's ability to establish and maintain company and contact.

This happens elsewhere in Han Dong's oeuvre too, as we will see in the next two poems. Take «See» (看, 1990), for instance: ${ }^{23}$

«See»

see you

and see him

but neither of you

can see each other

in the middle there's a wall

a tree

or mist

I am beside the wall

above the tree

I am the mist itself

but both of you can

see me at the same time

you can see me

now see the one

then turn to the other

I am the wall

the tree

the mist itself

any thing

${ }^{23}$ Han 2002: 126-127. 
that can both be seen

and used for cover

a bird's

two sides

with my left eye

separate from my right

see you

and see him

only neither of you

can see each other

Look implies stronger agency than see, although this is less clear in Chinese than in English. I have translated 看 'look' as see in order to retain the connection with the resultative 看见 'see' (literally 'look-and-see'), which is the more important expression in this poem.

More insistently than «There Is a Darkness», «See» shows the impossibility of human contact. The obstruction that stands between $I$ and you takes various shapes. Of these, the wall and the tree appear frequently in Han Dong's poetry, for instance in «Someone at the Foot of the Wall» (墙壁下的人, 1988) and «Small Street Scene» (街头小 景, 1999), ${ }^{24}$ both poems that highlight the limitations of mutual perception and understanding. Interestingly, in «See», after taking position beside the wall and above the tree, the speaker changes from a voice-over-like observer into the agent of obstruction, acting as voiceover and protagonist at the same time. The first stanza's final line is almost triumphant: I am the mist itself(我就是云雾本身). ${ }^{25}$ In the third stanza, the speaker-obstructor takes the shape of a bird, whose left and right eye operate independently. A hint of mockery can be detected in the poem's closing lines: [I] see you / and [I] see him / only neither of you / can see each other, although this isn't the only possible reading. In another, unlikely but theoretically possible, the final four lines could be a neutral observation, or even suggest regret. Regardless, «See» concurs with other poems by Han Dong in its disavowal of company, contact and communication, including communication through poetry. This brings to mind a vision of the poem as a type of language

\footnotetext{
${ }^{24}$ Han 2002: 67, 260.

${ }^{25}$ Remarkably, 烟雾 'smoke, mist' in line 7 is followed by 云雾 'clouds, mist' in lines 10 and 18.
} 
that thwarts communication, commonly contemplated by theorizers, critics and poets ever since poststructuralism, and as fascinating as it is unsettling. ${ }^{26}$ «See» is, furthermore, one of several poems by Han in which the speaker explicitly observes the paradox of language thwarting communication and actively partakes in it.

Han's «A and B» (甲乙, 1991) is a fourth and final text that shows there is a great deal more to Han Dong's oeuvre than his early "representative works." It is one of the texts reviewed in Hong Zicheng's Reading Poetry in the Classroom at Peking University (在北大课堂读诗). This book records graduate students and professors' discussions of works by famous Chinese poets, in a course moderated by a senior academic who enjoys widespread respect as a scholar of contemporary literature. As such, and as the product of a leading institution of higher education, Reading Poetry is an object lesson in the ongoing process of literary canonization. It has chapters on Zhang Zao, Wang Jiaxin, Zang Di, Ouyang Jianghe, Zhai Yongming, Lü De'an, Sun Wenbo, Xiao Kaiyu, Xi Chuan, Han Dong, Bai Hua, Zhang Shuguang, Yu Jian and Chen Dongdong - a line-up that illustrates the primacy of the avant-garde in literary historiography, noted in chapter One.

Zhang Xiafang, the main speaker in the session on Han Dong, introduces Han's life and work. On «A and B», he notes that it dismantles traditional poetic sentiment (诗意), drawing attention to what he calls Han's prose-like usage, some central images, and the fact that the poem has comical as well as shocking qualities. Being a record of a classroom exchange, the ensuing discussion is somewhat impressionistic. This doesn't detract from the pertinence of remarks by Leng Shuang and $\mathrm{Hu}$ Xudong on the role of the speaker and Han Dong's technique of depersonalization. Zang Di says that Han knows how to "carry out effective destruction." He also claims that «A and B» was a powerful poem especially when it was written and that what Han does in « $\mathrm{A}$ and $\mathrm{B}$ » was done better later in the 1990s, for instance by Xiao Kaiyu. This appears to be a reference to the contested notion of Poetry of the Nineties as a critical rather than a chronological category, which was among the issues that triggered the Popular-Intellectual Polemic of 1998-2000. According to its proponents in previous years, including Zang Di, the majority of poets studied in Reading Poetry come under

26 Bertens 2001: 126. E.g. Gerbrandy 1999 and Bei Dao’s description of poetry as "a way of keeping secrets" (see chapter Four). 
Poetry of the Nineties, exceptions being Han Dong, Lü De'an and Yu Jian. Toward the end of Reading Poetry, the notion's contested nature is recognized. ${ }^{27}$

Contrary to Zang's claim, the following analysis shows that the literary merit of «A and $\mathrm{B} »$ is by no means limited to its deviation from one-time conventions, traditional or within the avant-garde. ${ }^{28}$

«A and $B »$

two people $A$ and $B$ sit up on opposite sides of the bed

$A$ is tying his shoes. so is $B$, back turned to $A$

in front of $A$ there's a window, so that he looks out on the street

and a horizontal tree branch. the tree trunk is obstructed by the wall

so that, from this obstruction, he must look back

along the tree branch, ever thinner, all the way to the end

after which, before the next stretch of wall, there's still a large

empty space, nothing there, neither tree branch nor street

maybe only empty sky. A (a second time) looks back again

head moving five centimeters leftward, or five centimeters

forward too, or even more than five centimeters leftward and forward

at the same time, anyway, with the aim of looking at more

and more tree branch, and less emptiness. the left eye can look at more

than the right. the distance between them is three centimeters

but the extra bit of tree branch looked at is more than three centimeters

using this disparity, he (A) looks once again at the street

closes his left eye, then closes his right and opens his left

then closes his left again. at this point both eyes

are closed. A looks at nothing. when A ties his shoes

there's no need to look, no need to look at his feet, first left then right

now both are tied. at four he knew how

at five he was commended, at six he was skilled

this is a day in A's life after seven, a day when he's thirty-something or

a day when he's sixty-something, and can still bend over to tie his shoes

it's just that he's neglected B for too long. this is our

(first of all the author's) and A's joint mistake

she (B) sits up on the bed's opposite side, facing a cupboard

27 Hong 2002: «A and $\mathrm{B} »$ is discussed in ch 10, and the notion of Poetry of the Nineties in ch 15. Zang dates «A and B» as from 1992 instead of 1991, a minor inaccuracy that doesn't change the argument.

28 Them 6 (1993): 42, Han 2002: 137-138. 
looks through the glass or the screen and sees dishes that A doesn't see to bring this narration to a close, let it be noted that when $B$ has tied her shoes and stands, sperm trickles down that was once A's

Different from «See», in «A and B» I have stuck with look for 看 'look', and indeed for several instances of 看见 'see'. Look is the more important expression here.

Calling the poem's protagonists A and B-甲乙 in Chinese, the first two of the ten Heavenly Stems, employed as serial numbers for unspecified enumeration - depersonalizes them more effectively than would have been the case had Han Dong used pronouns. The effect is reinforced by simple yet slightly formal and technical word choice. Essentialist distinctions of prose and poetry are of little relevance here, but it is open to debate whether we should call Han's usage prose-like, as Zhang Xiafang does. One could object by pointing to the emphatic repetition of words and phrases, such as so that (lines 3 and 5) and look (throughout). Also, poetic usage, in this case minimally meaning Han's concentrated use of language, doesn't exclude the narrative feel of the poem that Zhang rightly notes. ${ }^{29}$

But back to depersonalization. In an instance of what I have called willed superficiality, the speaker isn't satisfied by noting that A spends a short while looking out the window before bending over to tie his shoes, but describes his every movement in minute detail. For a different plot - say, the operation of hi-tech machinery in preparation for robbing a bank - this type of description could produce tension that builds up to a climax. Here, however, it is as if behavior such as A's, or indeed the very existence of his species, is perceived for the first time and fails to activate any ready framework for the construction of meaning. This explains the speaker's inability to be selective, and the obsessive recording of detail, seemingly to no particular end. All this happens in a language not unlike that of scientific observation: the geometry of A's attempts to see more of the tree, quantification of the shifts in his physical position, the use of expressions such as disparity (差距) and at this point (目前为止). The speaker moves from depersonalization to dehumanization - in other words, to ever stronger defamiliarization - by stating what is the obvious in everyday human

\footnotetext{
29 Hong 2002: 250.
} 
experience. In this respect, Han Dong's literary kinship with Yu Jian stands out.

As in many of Han's poems, one of the central images is that of looking. While the better part of «A and $\mathrm{B}$ » is dedicated to an exact description of the act of looking, its message concerns the limitations of perception. This happens on several levels. First of all the literal: A's look at the tree is stopped by the wall, which he tries to circumvent to see not just more of the tree but also less of the emptiness that is his share if he accepts the wall's restrictions. Secondly, maybe in maybe only empty sky (line 9) and or in through the glass or the screen (line 28) stress the impossibility of knowing what it is that someone else perceives. In this poem, this holds not just for ordinary mortals like A's co-protagonist $\mathrm{B}$, but also for the otherwise all-powerful and omniscient speaker, to whose role we will return below.

In the transition in which A goes from looking out the window to closing his eyes and finishing the tying of his shoes, it is yet again the mechanism of defamiliarization that produces a line of reasoning that is not illogical "in itself" — as reasoning without a reasoner, if there is such a thing - but that we know to be untrue, and somehow find funny to imagine. We are not sure why A closes and opens and closes his eyes again - is he testing his vision? - until we realize that to the speaker, this makes perfect sense. A is done looking out the window, and doesn't need to look at his feet while tying his shoes. He stops looking by switching off his eyes, just like one stops chewing once the food is swallowed and gone from the mouth. The act of shoe-tying casually takes us back to A's childhood, which operates as a miniature for social experience. One learns how to do this or that, is praised if one does it well, becomes good at it - and, in a revised edition of the poem in Daddy's Watching Me in Heaven, gets bored with it and stays bored with it.

«A and $\mathrm{B}$ » shows Han Dong at his most sophisticated in manipulating everyday trivia as poetic material. If we decide to interpret what is offered to us at face value, an important part of the message is that entire worlds may lie behind the tiniest of details, in poetry and possibly elsewhere in life. Another key component of the interpretation, in line with the poems reviewed above, is a cynical view of human togetherness and interaction. In the poem's opening lines, A and B are pictured as sitting with their backs to one another. B disappears from view until the closing scene. There, the speaker observes that A has 
neglected B, and that A and B see different things, and don't see each other. A sees the world outside the window, B sees household chores embodied by the dishes in the cupboard. This is an ironic mobilization of clichéd, reactionary visions of heterosexual marriage, ushered in by the late identification of $\mathrm{B}$ as female in line 27.

A's sperm leaving B's body when she gets up - that is, distancing itself from her - confirms their fundamental separation. This holds in the defamiliarized outsider's view that represses common knowledge, in this case of the physical details of sexual intercourse and mechanisms of reproduction. Neither the physical togetherness of sex nor a possible pregnancy would do anything to change this view, in which human contact is little more than a chance meeting of monads incapable of real interaction. Conversely, any (naive) association of sex with things like romantic love could make the speaker's portrayal of A and $\mathrm{B}$ as ignoring one another after having had sex positively painful, and the ending to the poem (naively) scandalous. As such, in Zhang Xiafang's presentation in the Peking University classroom, the sperm appears as one of Han Dong's shock effects. To illustrate how the poem dismantles traditional poetic sentiment, Zhang says that "it may well give the reader an 'unclean' (不洁) feeling, both psychologically and physiologically." ${ }^{30}$ One may take this as a sign of prudishness on the part of Zhang, or prudishness of the rules for the public documentation of a classroom community at a highly reputed university in China. At any rate, there is more to the poem's final phrase (sperm trickles down that was once $A$ 's) than uncleanliness or scandal. One may also read it as the speaker's ironic satisfaction of a particular type of reader expectation: alright, here's your clue, or your punch line-even though it means nothing.

This brings me to a final observation, for which we must take another look at the speaker, to whom I will refer as male because of the mention of the poem's author (作者) in line 26. The speaker is incapable of sharing in the protagonists' perceptions, but also questions and disparages the relevance of his own words. This happens in the sudden summary (anyway, line 12) of his meticulous report on A's head movements, and in the indifferent remark that while A may be thirty, he might just as well be sixty. Toward the end of the poem, the speaker makes his presence felt more strongly. He explicitly reduces the pro-

\footnotetext{
${ }^{30}$ Hong 2002: 253.
} 
tagonists to puppets on a string, and foregrounds the artificiality of the poem as a textual construct. A's failure to pay attention to B is first of all the author's [mistake]. In addition, by first calling it our mistake, the speaker makes the reader his accomplice. If we follow him in taking the lack of attention to B as failing to see her or indeed avoiding to look at her (neglected), this bespeaks a vision of the writing process in which the author has, or wants, no complete control. If we don't, we see a well-considered authorial strategy instead. Finally, the penultimate line (to bring this narration to a close, let it be noted that) employs a literary meta-consciousness and formal, almost bureaucratic language to create radical differentiation and ironic distance between the speaker and the rest of the poem. ${ }^{31}$

Literary history and criticism to date have paid overwhelming attention to Han Dong's rejection of Obscure Poetry in some of his early, best-known work. This is understandable, but it entails the risk of reducing a versatile poetic oeuvre to a negatively defined commentary on other texts. In Han's case, the danger of early canonization leading to simplification and indeed distortion is acute.

Several features combine to make Han's a distinct and influential voice: quotidian themes, purposefully superficial description, colloquial language, literary meta-consciousness and last but not least, his individuality and sophistication in handling these things. Or, conversely: the deconstruction of heroic themes, the repression of conventional interpretation, the rejection of literary language, and defamiliarization as a fundamental textual attitude.

The first list of features would make Han Dong's poetry one that believes in authenticity and in personal experience as the measure of all things, sometimes to the point of absurdity. The second makes it a poetry that disbelieves in affectation, and in anything that lies outside personal experience. While both perspectives are rewarding, there is one important theme that is impossible to fit into the first list and easy to add to the second. That is this poetry's skepticism regarding human

\footnotetext{
${ }^{31}$ Revision in Han 2002 of the 1993 Them version includes the removal of this line.
} 
contact and communication, including communication through poetry. As such, Han's poetics is one of disbelief.

Han's disbelief is of the existential kind, and as such a "true" disbelief when set off against the early Bei Dao's over-exposed declaration, made in «Answer»: I-don't - be-lieve! (我一不一相一信!). ${ }^{32}$ The latter is really another way of saying $I-d o-b e-l i e v e$, in humanist values such as the dignity of the individual self, who is a member of a community governed by social justice. ${ }^{33}$ «Answer» is typical of Bei Dao's early work, in that it is fundamentally an expression of faith. I-don't$b e$-lieve is a declaration of rebellion but at the same time essentially affirmative in nature, on two levels. First, as part of the poem in its entirety, it operates within a grand narrative that shows the lingering influence of Maoist discourse. Second, beyond the surface of the semantics of the phrase as an isolated one-liner, the scope of Bei Dao's belief is much larger than that of his disbelief. By contrast, Han Dong's existential disbelief permeates his writing from beginning to end.

Han Dong's disbelief is positively defined. It is embodied in an oeuvre that is not just a commentary on other poetries but a complex, primary text in its own right.

${ }^{32}$ Yan Yuejun et al 1985: 1; for a full English translation by Bonnie McDougall, see Bei Dao 1988: 33. My rendition of the poem's most famous line aims to retain the emphatic, four-syllable rhythm of the original.

${ }^{33}$ Cf Zhang Hong 2003: 67-68. 
Maghiel van Crevel - 978-90-47-44273-8 Downloaded from Brill.com $04 / 25 / 2023$ 11:38:45PM via free access 


\author{
CHAPTER THREE
}

\title{
THANATOGRAPHY AND THE POETIC VOIGE: HAIZI
}

Ask any Chinese about the poet Haizi, and the first thing they will say is that he killed himself.

Really? First, not all Chinese people know of Haizi. Second, one doesn't have to be Chinese to remember Haizi's suicide at the mention of his name. That public discourse has had more time for his death than for his writings is not just true in China. Many who haven't read his poetry do know that he was a poet and killed himself, and there is probably no one that has read his poetry and doesn't know that he killed himself. Third, there are some Chinese readers, mostly fellow poets and critics, who resist the domination of Haizi's poetry by the memory of his suicide.

On the other hand: first, Haizi is in fact one of the best-known contemporary Chinese poets, among younger readers even better known than Bei Dao, Shu Ting and Gu Cheng. The latter three are among the Obscure poets who, in the late 1970s and the early 1980s, were more visible in Chinese society at large than any generation or individual poet has been ever since. As noted, what I have called their rock stardom at the time was really an anomaly, occasioned by particular historical circumstances. Gu Cheng's fame further increased because like Haizi, he killed himself. He did so after killing Xie Ye, and publicity surrounding the murder-suicide spread far beyond the literary world. Second, to be sure, the suicides of artists and writers fascinate readers everywhere. This includes those who only "read" the suicide, not what the self-killer wrote, painted and so on, as well as professional critics like Alfred Alvarez and Jeroen Brouwers, whose analysis encompasses both authors and works. Still, as Michelle Yeh has shown, literary suicides particularly enthrall Chinese poets and their audiences - and the number of modern Chinese writers that have killed themselves is remarkable. I have seen Yeh's findings confirmed in many instances of formal and informal critical discourse, a recent example being Mao Jian's The Last Myth: The Riddle of the Poet's Suicide (最后的神话: 诗人自

(C) MAGHIEL VAN CREVEL, 2008 | DOI 10.1163/9789047442738_004

This is an open access chapter distributed under the terms of the Creative Commons AttributionNoncommercial 3.o Unported (CC-BY-NC 3.0) License. 


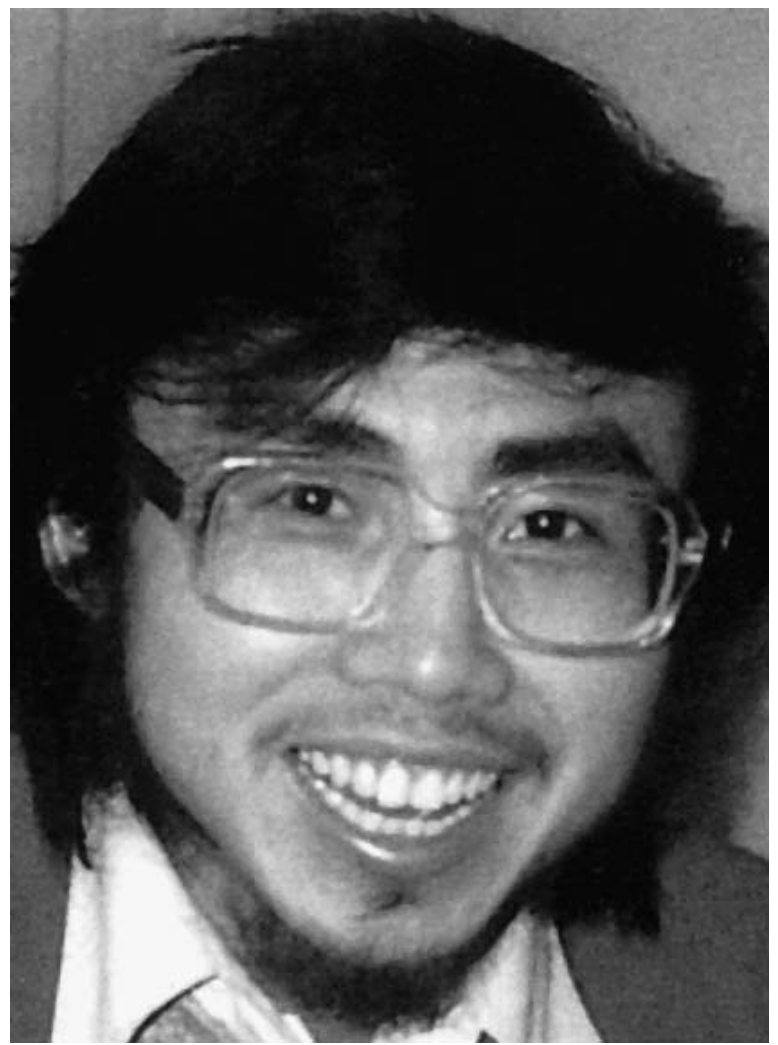

Figure 3.1. Haizi, late 1980s (Haizi 1995, inside cover) 
杀之谜, 2005). And third: yes, there are those who attempt to rescue Haizi's poetry from the popular, near-complete identification with his suicide, but they fight an uphill battle. ${ }^{1}$

A study of Haizi as a literary phenomenon, then, highlights the issue of what we may call creative suicide. Is his suicide a poem, or the poem to end all poems, even if he didn't literally write it, or publicly orchestrate it like Mishima? More generally, is Haizi's life part of his work, and should we view his life and work as one? Elisabeth Bronfen observes that one of the thrilling things about artistic representations of death is that they allow the survivors to experience death by proxy. One can see how this holds all the more for artists who not only produce representations of death but actually "live it" by committing suicide, especially if the suicide is visibly premeditated. Depending on the circumstances, a view of the artist's life and work as one can make it possible for life to mean the artist's death, or more precisely: their death, with the preceding life as a process predestined to lead up to this death and no other. Then, often triggering a deceptive mechanism we may call post hoc inevitability, biography becomes thanatography. That is, the rewriting of a life as first and foremost the build-up to a death. $^{2}$

As a reader, I don't try to retrieve authorial intent or verify the historical authenticity of experiences that the poem evokes. What does the author mean? or Should we identify the speaker in this poetry with the historical figure of the author? are but two of the many questions one may choose to ask once someone releases their poetry into the public domain. Moreover, in Haizi's case, if we let ourselves be swept along by the trend of conflating his life and work, the historically authentic experience we claim to explore is that of an individual's sui-

\footnotetext{
1 Avant-garde authors included in Tong \& Chen 2004, an anthology of mustreads in poetry from all over the world, are Shu Ting, Gu Cheng, Bei Dao and Haizi. Alvarez 1971, Brouwers 1984. Wang (David Der-wei) 2004: ch 7; Yeh 1994 / 1995, 1996a. Yeh 1994 and 1995 are the same essay in Chinese and English, but because the former appears to have been censored, I will hereafter only refer to Yeh 1995. Mao Jian 2005.

2 Bronfen 1992: x. Bronfen calls the field that informs her study that of thanatopoetics, focusing on the conjunction of femininity and death or, in an alternative formula, on the triangulation of femininity, death and textuality (403). Simon Patton, reviewing poetry by Yang Lian that he finds "monotonous in its morbidity," uses thanatography to mean 'a prolonged investigation of death and decay, a literary mortuary' (1995b). In its occasional medical usage, thanatography means 'description of a death.'
} 
cide. I would venture that the state of mind directly preceding the act of suicide - not so much in time as in experience - remains incommunicable in language, beyond a superficial level of essentially meaningless verbalization. As such, discussing actual suicide, always someone else's, is the domestication in words of something unspeakable. Literally so, as it is undergone by human beings of their own initiative but impossible for them to speak of once it takes place.

One of the factors explaining suicide's popularity as a topic for reflection among those who live on is the absoluteness of self-determination by self-destruction. While suicide can be plausibly imagined as such, a vision of killing oneself as an assertion of subjectivity shouldn't block out another, perhaps less thrilling but equally convincing. At the risk of stating the obvious, I mean the possibility of an individual life simply becoming unbearable, for reasons ranging from the grand to the pedestrian: from war guilt to continual shortness of breath. Suicide, in other words, not as an act of strategy but as the embodiment, and the disembodiment, of despair. ${ }^{3}$

The above reservations don't mean that we should limit ourselves to studying the strictly textual dimensions of Haizi's poetry. A work of art can make people curious about its maker and what they learn about the maker can influence their appreciation of the work. In this sense, fascination with the suicides of poets and artists rather than with their daytime jobs as insurance agents, to cite a useful cliché, makes total sense. Especially if the suicide is young and violent, creation and (self-)destruction present a powerful mix. It is hard to maintain that the music of Joy Division didn't change when Ian Curtis hanged himself, or that Haizi's poetry didn't change when Haizi had himself cut in two by a freight train. The retroactive nature of mechanisms such as these is something to marvel at rather than deny, as does Alvarez when he writes that "the suicide adds nothing at all to the poetry," a contestable claim made in an otherwise convincing study of the power that suicide has exerted over the creative imagination. ${ }^{4}$ Central to reflection on these things, especially in professional commentary, is the question where one draws the boundaries of the text and how much space one gives the author, if the author is inside them to begin with. Any answer

3 On the essentially private and desperate nature of many suicides, see Alvarez 1971: 44, 85-90, 144, 206 et passim.

4 Alvarez 1971: 33, 124. 
represents a choice by the commentator that will benefit from explication.

In this respect and others, the case of Haizi tells us much about the avant-garde's metatexts, especially about the extraordinary importance of poethood discussed in chapter One, self-evident to many Chinese poets and critics. In recognition of this point, section 1 of this chapter explores mythifications of Haizi's life as part of his work. These identify his poetry with his suicide and make what he wrote inseparable from everything else he did. As a counterweight, section 2 examines more or less text-immanent features of Haizi's writing, in order to foreground aspects of the poetic voice that have been drowned out in the uproar over the fate of the author.

\section{Thanatography}

Most if not all critical writing on Haizi appeared after his death, and makes explicit reference to his death. This in itself provides evidence for a widespread view of his life as part of his work.

\section{Life}

During his lifetime, however, Haizi didn't go unrecognized as a poet. In 1985 his early writings were given prominent positions in Modern Poetry Materials for Internal Exchange (现代诗内部交流资料) and Contemporary Chinese Experimental Poetry (中国当代实验诗歌), two groundbreaking unofficial journals out of Sichuan province that brought together avant-garde poets of various literary generations and persuasions from across China. Full, multiple-author sections of both journals were named after a poem and a poetical statement by Haizi respectively, the only other poet to have such honor bestowed on him being Bei Dao. Over the next several years, Haizi's work was included in major anthologies drawing attention to the avant-garde's dynamic development beyond Obscure Poetry. He received awards from the Peking University May Fourth Literary Society (北京大学五四文学 社) and the official literary journal October (十月) in 1986 and 1988, and appears in both issues of the unofficial journal The Survivors (幸存 者), as a member of the prestigious poetry club of that name. According to Luo Yihe, about fifty of Haizi's poems had appeared in print 
before he died. His publication record aside, however, what we know of his literary status while alive comes to us in articles and books written after his death. Until that time, he was a poet's poet. ${ }^{5}$

In light of my interest in views of Haizi's life as part of his work, a biographical note is in order. Born in 1964, Haizi stands out in the avant-garde because he came from a rural background. Growing up in a village in Anhui province, he was a precocious child that stunned those around him with his talent for learning, remembered in the anecdote of his victory in a Little Red Book recitation contest, at age ten or so. In 1979, when China's schools and universities were still reeling from the havoc wreaked upon them during the Cultural Revolution and recruiting students of all ages between mid-teens and mid-thirties by scholarly examination rather than political pedigree, Zha Haisheng, as he was then still called, enrolled in the law department of Peking University at fifteen years of age. His student years overlapped with those of literary activist and editor Lao $\mathrm{Mu}$ and poets Luo Yihe and $\mathrm{Xi}$ Chuan, three others who were to contribute to the status of PKU as a breeding ground of modern poetry throughout the twentieth century and beyond. Generally a shy character, Haizi did develop lasting friendships with Luo Yihe and Xi Chuan. Upon graduation in 1983, nineteen years old, he was assigned to the Chinese University of Politics and Law, initially for editorial work and later as a lecturer. $\mathrm{He}$ moved to its new campus in semi-rural Changping, a suburb about thirty kilometers north of Beijing. ${ }^{6}$

Over the next few years, he continued on a track of maniacal reading and writing, with few distractions. Writing was more important to him than anything else. When he traveled to other parts of China, this was for writing projects, too. Calling himself Haizi from 1984, he lived what appears to have been a life of absolute, feverish dedication to poetry and to a grandiose vision of poethood, however consciously or unconsciously his embodiment of this vision took shape. Supporting his family in Anhui, he could afford few luxuries, even if he wasn't

\footnotetext{
5 The said anthologies are Lao Mu 1985, Shanghai Literature \& Art Press 1986, Tang Xiaodu \& Wang 1987, Xiping 1988, Xu Jingya et al 1988 and Chen Chao 1989. Luo's estimate is cited in Liaoyuan 2001: 12. On Haizi as a poet's poet, see Xi Chuan 1991a: 10, Xiao Ying 1999: 231 and Liaoyuan 2001: 187, 195.

${ }^{6}$ Biographical information on Haizi comes from Luo Yihe 1990 and 1997a, Xi Chuan 1991a and 1994a, Wei'an 1994, the diary entries in Haizi 1997: 879-885, Liaoyuan 2001 and Yu Xugang 2004.
} 
poor by Chinese standards nationwide and across social strata. He had few social contacts and apparently suffered heavy blows from ill-fated love affairs. He wrote at an astonishing pace in several genres at the same time, the most important being short, lyrical poems, long, narrative-epic poems and plays in verse. Living by himself, writing at night and sleeping in the mornings, displaying no desire to partake of daily realities in the world around him, eating little and drinking heavily, suffering from depression and in his final months from delusions and pathological symptoms possibly indicating cerebral aneurysm, Haizi was the epitome of romantic poethood.

\section{Deaths}

On 26 March 1989, twenty-five years old, Haizi threw himself under the wheels of a train near Shanhaiguan, a couple of hundred kilometers east of Beijing, close to the sea. On his body, he carried a note: ${ }^{7}$

My name is Zha Haisheng. I am a lecturer in the philosophy teaching and research group at the Chinese University of Politics and Law. My death has nothing to do with anybody. My previous will herewith becomes wholly invalid: my posthumous manuscripts are to be given to Luo Yihe of the editorial office of October, for him to administer.

On 31 May Luo Yihe, Haizi's fellow poet and closest friend and now his posthumous editor, died after developing a brain hemorrhage and entering a coma earlier that month. The story of Luo's death at age twenty-eight, shortly after he and Xi Chuan had begun work on Haizi's literary legacy, was uncanny from the start. The popular view was that Luo had over-exerted himself while working to establish Haizi's memory. Moreover, he had first collapsed on Tiananmen Square, oc-

7 See Yang Li 2004: 16-17 and Liaoyuan 2001: 340. Yang Li 2004 contains Luo's letter to Wan Xia describing Haizi's suicide. Luo cites only the latter two thirds of the note on Haizi's body, leaving out his identification of himself and his employer. Liaoyuan's version of the note differs from its citation by Luo. According to Liaoyuan, the note's penultimate sentence reads: "My previous will remains wholly valid: please give my poetry manuscripts to Luo Yihe of October." Upon Haizi's death, Luo was the one who went to Shanhaiguan to handle the formalities of the situation and was given the note. There is no reason to doubt the reliability of his letter to Wan. The difference between Luo's and Liaoyuan's accounts may be explained by a typo, with remains wholly valid (全部算数) being a miswritten version of the near-homophonous becomes wholly invalid (全不算数). The issue doesn't affect the argument made in these pages. 
cupied at the time by students who had gone on hunger strike as part of the 1989 Protest Movement, and according to some his death was the result of medical complications after he joined in the strike: Luo's fate became all the more dramatic when June Fourth caused many more young deaths soon thereafter. Over the next few years Haizi's and Luo's deaths were followed by the suicides of poets Ge Mai in 1991 and Gu Cheng in 1993, and by a good ten lesser-known suicides, deaths by illness and other violent incidents in mainland Chinese poetry circles. One recalls the phenomenon of "suicide epidemics" such as those following the publication of Goethe's The Sorrows of Young Werther (Die Leiden des jungen Werthers). ${ }^{8}$

\section{Publications and Publicity}

Haizi's suicide triggered an explosion of publications and publicity, on a scale much larger than would have been possible had he lived on. Between 1983 and 1988 he had published several unofficial collections, but evidence of his posthumous rise to fame lies in four official books of his poetry, published between 1990 and 1997, and is reaffirmed by his publication and publicity record at large. This includes the sales numbers of his individual collections, his status in multiple-author anthologies, all manner of commemorative activities and a floodwave of commentary on his life and work, ranging from the scholarly to the sensationalist.

In 1990 the Spring Wind Literature \& Art Press brought out Haizi's The Land (土地), one of seven parts making up the unfinished «The Sun: A Play in Verse» (太阳: 诗剧, 1986-1988), selected by Luo Yihe and $\mathrm{Xi}$ Chuan for stand-alone publication in book form. The Land would have gone to press in 1989, had it not been for the temporary paralysis of avant-garde literature and art after June Fourth. In 1991 the Nan-

8 On the popular view of Luo's death, see Haizi \& Luo 1991: 1, Xi Chuan 1991b: 315 and Zou Jingzhi 1991: 333; on possible medical complications, Day 2005a: ch 11; on the many suicides in the (early) 1990s, Xi Chuan 1994a: 97, Zhang Qinghua 1999: 185, Wang Yuechuan 1999: 80, Mao Jian 2005: 16 and Luo Zhenya 2005: 140. Ge Mai drowned himself in Beijing. Gu Cheng hanged himself on Waiheke Island in New Zealand. There are countless commentaries on Ge's and especially Gu's suicides. On Ge Mai, see Ge 1993: 222-278. For negotiating the huge amount of material on Gu Cheng, Brady 1997 and Li Xia 1999 are useful starting points. See also Wang (David Der-wei) 2004: ch 7. On suicide epidemics, see Alvarez 1971: 95, 174. 


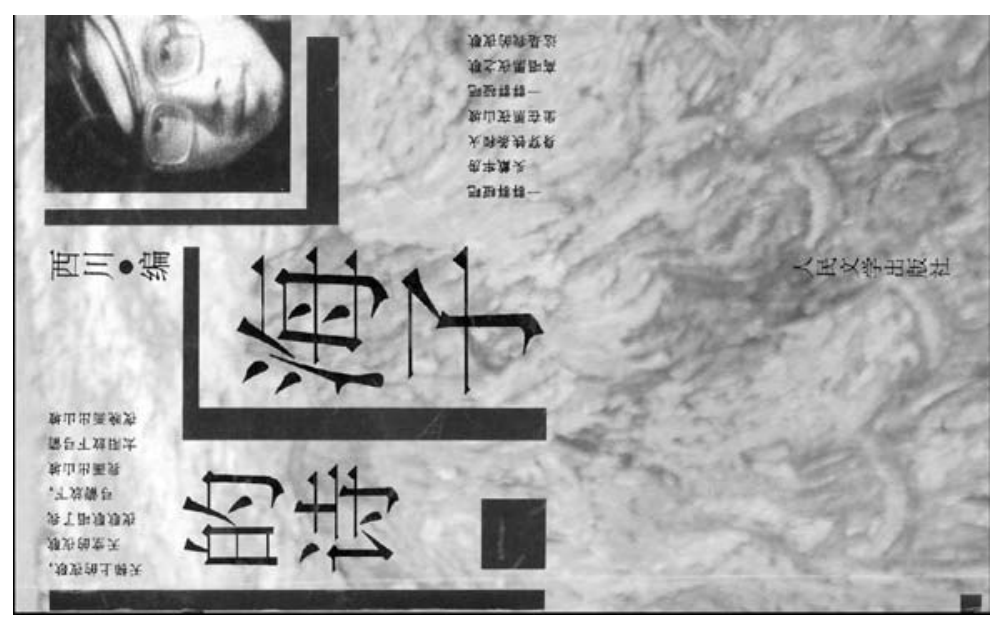

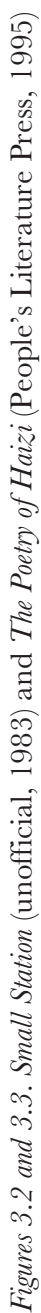


jing Press brought out Works by Haizi and Luo Yihe (海子、骆一禾作品 集), containing selections from every genre that Haizi had practiced. Nominally edited by Zhou Jun and Zhang Wei, Works was in fact a reprint of the second issue of the unofficial journal Tendency, edited by Chen Dongdong, which had appeared in 1990. Also in 1991, the People's Literature Press sought out Xi Chuan to compile a collection of Haizi's short poems, after several other publishers had contacted him with the same request but failed to convince him of their integrity. Because of personnel changes at the Press, The Poetry of Haizi (海子的 诗) didn't appear until 1995. In an afterword to the first print run the publisher is relieved to satisfy at long last the many reader requests for such a book. This was no idle prattle. By the twelfth run in June 2005, as many as 110,000 copies of The Poetry of Haizi had been printed, and in 2006 People's Literature brought out a new edition with minor changes simply called Haizi (海子), in a series entitled Selected Poetry by Famous Contemporary Chinese Poets (中国当代名诗人选集). Finally, in 1997 the Shanghai Triple Alliance Bookstore published The Complete Poems of Haizi (海子诗全编) in 934 pages, edited by Xi Chuan and containing Haizi's short and long poems and all 350 pages of «The Sun», as well as his essays on poetry, forewords and afterwords to individual poems and diary entries. ${ }^{9}$

The Complete Poems is one of four such collections of similar design, published by the Triple Alliance between 1995 and 1999. The other three contain the oeuvres of Gu Cheng, Luo Yihe and Ge Mai. Dead authors lend themselves more naturally than live ones to the publication of their complete poems, but most of the work in three of the four books (Haizi, Luo Yihe, Ge Mai) had remained unpublished while its authors were alive. Clearly, these big, black volumes embody the special status of poets who died young, suddenly and violently, and by their own hand. The suicidal criterion extends to Luo Yihe by association, through his dramatically thwarted editorship of Haizi's legacy. This observation also applies to the very idea behind Works by Haizi and

\footnotetext{
${ }^{9}$ On the immediate effects of June Fourth on avant-garde literature and art, see Luo Yihe 1990: 10 and Yang Li 2004: 16-17. Haizi 1990, 1995, 1997 and 2006, Haizi \& Luo 1991; for Haizi's other books, see Van Crevel 2008a. English translations are found in Tang Chao \& Robinson 1992, Zhao (Henry) \& Cayley 1994, Haizi 2005 and Tao \& Prince 2006.
} 
Luo Yihe, and to early essays by critics and fellow poets such as Li Chao, Zhu Dake, Xiao Ying and Chen Dongdong. Chen writes: ${ }^{10}$

When the one strangled his own song, the other could listen no more; when the one's outstanding voice fell silent, the clamor and the screams destroyed the other's ears.

In view of Luo's personally and poetically intimate relationship with Haizi, it is but a small step from suicide by association to a vision, if only implied, of Luo Yihe having sacrificed himself: for Haizi, or for poetry, as Luo himself maintained that Haizi did. Commentators' factually inaccurate inclusion of Luo Yihe in a list of contemporary poetsuicides has trickled down into literary historiography, foreign and domestic. In a 1999 essay on Mao Dun and Gu Cheng, Raoul Findeisen mentions Luo Yihe, Haizi and Ge Mai as poets "who died early and by suicide," and Chang Li and Lu Shourong's China's New Poetry (中国新诗, 2002) names Luo Yihe and Ge Mai as "two outstanding poets [who] offered their young lives as tribute, just like Haizi." 11

In addition to the huge exposure that Haizi's hitherto largely unpublished poetry received in his own books, a posthumous explosion of publicity is visible in the many commentaries on his life and work since his death. Countless journal articles aside, Haizi receives special attention in surveys, histories and genealogies of contemporary poetry. He was, for instance, the third individual poet to have a series of articles devoted to him in the scholarly Poetry Exploration (诗探索) after its revival in 1994, in what would grow into one of the journal's regular features. The first two were Gu Cheng and Shizhi. A romantic vision of poethood is in evidence yet again: Gu Cheng and Haizi killed themselves, and Shizhi - still known to many as Guo Lusheng - has famously suffered from mental illness ever since the Cultural Revolution, when he wrote the poetry that has brought him so much renown. It is no coincidence that these three names also represent the avantgarde in the Selected Poetry by Famous Contemporary Chinese Poets series mentioned above - in addition to Shu Ting, whose work has enjoyed uncontroversially canonical status ever since Today. As for literary histories, a telling source is Hong Zicheng's Research on $20^{\text {th }}$-Century Chinese Literature: The Contemporary Era (20世纪中国文学研究: 当代文学研究,

${ }^{10}$ Haizi 1997, Gu Cheng 1995, Luo Yihe 1997b, Ge 1999; Li Chao 1999: 60-61, Zhu Dake 1999: 141, Xiao Ying 1999: 231, Chen Dongdong 1991: 339.

${ }^{11}$ Findeisen 1999: 167, Chang \& Lu 2002: 232. 
2001), a survey of (Chinese) scholarship on Chinese literature since 1949. The poetry chapter includes a section entitled "Research on Important Contemporary Poets," which has subsections on Ai Qing, Tian Jian, Guo Xiaochuan and He Jingzhi - and on Haizi, making him the only avant-garde author in this hall of fame. Hong's track record shows that this is no attempt to claim Haizi for the orthodox lineage within the literary establishment. It simply signals Haizi's enormous exposure as compared with most other avant-garde poets. Similarly, Luo Zhenya's On the Avant-Garde after Obscure Poetry (朦胧诗后 先锋诗歌研究, 2005) devotes a full chapter to Haizi, other chapters covering broad topics involving scores of authors, such as Individual Writing in the 1990s and feminist critical discourse. ${ }^{12}$

Furthermore, to date there are at least two edited volumes and four single-author monographs that are exclusively dedicated to Haizi's memory and his poetry through the eyes of others. First of all, the 1991 Works by Haizi and Luo Tihe includes early commemorative essays on Haizi by fellow poets including Luo Yihe - in this book, Luo is both commemorator and commemorated-Xi Chuan, Zou Jingzhi, Han Dong, Chen Dongdong and Zhong Ming, and by critics including Liaoyuan, Wu Xiaodong and Xie Linglan. Second, in 1999 the tenth anniversary of Haizi's death saw the appearance of a commemorative collection of essays, most of them previously published. Edited by Cui Weiping, this beautiful volume contains several dozen photographs of the poet. It is called 不死的海子, a title that is at variance with its English caption: Hai Zi Whose Poetry Will Never Be Dead. The Chinese title really translates as The Undying Haizi and claims immortality for the poet, that is: for his life and work as one. A diverse collection, The Undying Haizi accommodates two skeptical voices (Han Dong and Cheng Guangwei) as well as straightforward mythifications of the self-killing poet (e.g. Xie Mian, Li Chao, Yu Hong and Zhu Dake) and textual analysis with occasional and measured reference to his death (e.g. Yeh, Cui Weiping, Zhang Qinghua and Tan Wuchang).

The four monographs are Liaoyuan's Leopard Pouncing on the Sun: A Critical Biography of Haizi (2001), Gao Bo's Interpreting Haizi (2003) - which claims to focus on the poet's writings rather than the story of his life - Yu Xugang's A Biography of Haizi: Hero of Poetry (2004) and Zhou Yubing's Face to the Sea Spring Warmth Flower Glee: Haizi's

12 Gu Cheng 2006, Haizi 2006, Shizhi 2006. Hong 2001, Luo Zhenya 2005. 
Poetic Life (2005). ${ }^{13}$ Haizi is the second contemporary Chinese poet to have inspired commentators operating in domestic discourse to produce full-fledged, book-length studies, both monographs and edited volumes, and dedicated websites. The first was that other famous suicide: Gu Cheng. ${ }^{14}$

The sheer space that scholars, critics and editors devote to Haizi and the commentarial perspectives they adopt are functions of his suicide. What Yeh has identified as a cult of poetry in contemporary China was conducive to a widespread interpretation of the act as quintessential proof of Haizi's poethood. Moreover, he killed himself - and Luo Yihe was seen to follow in his wake - right when exhilaration in the life of the mind was about to be cut short by a traumatic instance of political violence that could not be publicly discussed: on the cusp of the mind wave, so to speak, shortly before times of mayhem and money would set in, as discussed in chapter One. Retrospectively, his suicide has come to symbolize the beginning of the end of the Eighties. ${ }^{15}$ Repressed lament over June Fourth, then, was doubtless projected on Haizi's and to a lesser extent Luo Yihe's deaths, in poetry as well as commentary. This assumption finds emphatic support in an essay on Haizi by Wang Jiaxin. Michael Day, citing poetry by Bai Hua that foregrounds the fateful year 1989, argues that poems on "personal" suicides are often thinly veiled references to public deaths, with these tactics forced upon the authors by political repression. Chen Dongdong and Gao Bo - again, with reference to Bai Hua - explicitly connect Haizi's and Luo Yihe's deaths to June Fourth, and many others do so implicitly by speaking of unspecified "hard times," "upheaval" and so on. ${ }^{16}$

${ }^{13}$ Haizi \& Luo 1991, Gui 1999a, Liaoyuan 2001, Gao Bo 2003, Yu Xugang 2004, Zhou Yubing 2005.

${ }^{14}$ E.g. Chen Zishan 1993, Xiao Xialin 1994, Huang Lifang 1994 and Jiang Xi \& Wan 1995. Two other biographical works, also prompted by Gu Cheng's death but of narrower scope, are Wen 1994 and Gu Xiang 1994. Like Huang Lifang 1994, Mai \& Xiaomin 1994 is a commemorative volume containing commentaries on $\mathrm{Gu}$ Cheng and samples of his writings. The latter also has a section on other recent suicides in Chinese poetry, specifically Haizi and Ge Mai. Over the years, there have been several websites dedicated to Gu Cheng and to Haizi; for examples, see Works Cited.

${ }^{15}$ As noted in chapter One, my occasional use of the Eighties and the Nineties is with reference to a widely perceived sea change in the intellectual-cultural realm at large, as distinct from the 1980s and the 1990s as neutral indications of calendar time.

${ }^{16}$ Yeh 1996a. Wang Jiaxin 2002: 34, Day 2005a: ch 11, Chen Dongdong 1995, Gao Bo 2003: 4-6 and 2005: 132-133. 
Amplified by reverberations of " 1989 " ever since the massacre, the impact of Haizi's suicide also shows in instances of commemoration and identification, both institutionalized and individual. Remembrance of Haizi at PKU has been institutionalized since the early 1990s by fixing the date of the May Fourth Literary Society's annual poetry readings on or around 26 March, the anniversary of his death. When in the 1994 edition, the MC began to read Haizi's poetry on stage, large parts of the audience joined in, hundreds of people shouting out the lines of poems they obviously knew by heart. The Chinese have a formidable tradition of memorizing poetry but this was a stunning scene nonetheless, with Haizi's poetry recited in an atmosphere like that of collective prayer or the singing of an anthem. In 1999 the University's Theater Society (北京大学戏剧社 or 北大剧社) staged «Regicide» (斌), an acclaimed part of Haizi's «The Sun». In 2001 a group of students traveled to where Haizi killed himself and collectively lay down on the railroad tracks in imitation of his suicide. Incidentally, while Haizi himself hadn't lain down but had thrown himself in from the side, most references to his death use the expression 卧轨自杀 'lie down on the tracks to kill oneself.' His alma mater aside, ever since the appearance of The Poetry of Haizi and The Complete Poems, public commemorative activities - mostly poetry recitals, but also theatrical activities such as that described above - have been taking place all over China. ${ }^{17}$

As for individual instances of commemoration and identification, $\mathrm{Xu} \mathrm{Yi}$, editor of the works of poet Fang Xiang who took poison to end his life at age twenty-seven in 1990, notes in a chronicle of Fang's life that in 1989, he "was influenced by the posthumous manuscripts of Haizi." Fang Xiang may well be the anonymous poet referred to by Xi Chuan when he relates how a young man from Zhejiang province traveled to Haizi's Anhui home to perform memorial rites in his honor before taking his own life. ${ }^{18}$ In light of the poetry cult and the series of high-profile suicides and other deaths in poetry that began with Haizi, stories such as this shouldn't be dismissed as mere legend. And even if they were just that, they would still reaffirm cultish features of the Chinese poetry scene.

${ }^{17}$ I witnessed the recital. The staging of «Regicide» is cited in Liaoyuan 2001: 8. On commemorative activities, see Gao Bo 2003: 131-132.

${ }^{18}$ Fang 1997: 157. See also Mao Jian 2005: 160-166. Xi Chuan 1994a: 97. 
As measured against the impact of Haizi's poetry during his lifetime, commentarial and commemorative practice are disproportionate. This is precisely the position of a small number of dissonant voices, barely audible amid the general eulogy. Cheng Guangwei, for instance, notes in 1991 that

commemoration of the poet cannot take the place of cool-headed criticism, and his biography should no longer serve as reference material for scholarly critiques.

In 1999, in a book called Assassins of Fashion: Three Musketeers Challenging Fashion (时尚杀手: 三剑客挑战时尚), co-authored with fellow poets and literary provocateurs Xu Jiang and Qin Bazi, Yi Sha observes that Haizi's renown is a direct consequence of his death. Yi Sha recalls how as early as 1990, when poets and critics had begun to make Haizi a "martyr of poetry" - in Rimbaud's words - he had made a point of attacking them for advocating Haizi's style and creating an atmosphere that stifled pluriformity in poetry. Yi Sha's own breakthrough as a poet came in 1994 with the appearance of his collection Starve the Poets (饿 死诗人). The title poem is a dig at Haizi, Luo Yihe and other poets in whose work the word 麦子 'wheat' occurs frequently, leading to association with the (Chinese) countryside and the natural world, and with (Chinese) ethno-cultural identity. Yi Sha's satire is also directed at what he perceives as overblown critical acclaim for the "wheat poets." Liaoyuan, for instance, presents Haizi's and Luo Yihe's association with the image of wheat and wheatfields as analogous to Van Gogh's association with that of the sunflower, in an early essay and in his later biography of Haizi. Such praise for the "wheat poets" has by no means disappeared since. In 2005 Mao Jian approvingly describes Haizi's poetry as a "wheat Utopia," Gao Bo organizes several sections of his case study of Haizi around his "wheat" and "wheatfields" imagery, and Liu Shuyuan has this to say: ${ }^{19}$

Haizi's wheatfields are lonely. Lonely wheatfields are the shared background to our lives as a nation of peasants. Once the endless sufferings over wheat in our history enter poetry, they turn into a golden light that refracts all of our lives.

19 Cheng Guangwei 1999: 222. Yi et al 2000: 115-116, Robb 2000: ch 13-15. Examples of Haizi's "wheat" poetry are found in Haizi 1997: 68, 100, 353, 354, 355. Liaoyuan 1991 and 2001: ch 5, Mao Jian 2005: 226, Liu Shuyuan 2005: 202. 
Yi Sha has long taken a different view. Here is a passage from «Starve the Poets» (1990):

the poets have eaten their fill
their bellies are filled with the fragrance
of wheatfields as far as the eye can see
grand idlers from the city
become glorious peasants in poetry
wheat in the name of sun and rain
I call on you: starve them
those fucking poets

Writing on the tenth anniversary of Haizi's death and living up to his notoriety as a polemicist, Yi Sha calls all Haizi's writings other than his short poems garbage. He says that the propagation by others of Haizi's poetics has thrown back the development of Chinese poetry by ten years, taking an entire generation of fledgling poets born in the $1970 \mathrm{~s}$ into the poet's grave, as sacrificial funerary objects. ${ }^{20}$

Also writing in 1999, Qin Bazi asserts that no one dares speak the truth about Haizi's long poems. He calls exaggerated praise for Haizi "cheap" and concurs with Yi Sha's opinion that Haizi's influence has made Chinese poetry regress: no less than two hundred years, according to Qin, who cites Haizi's admiration of European Romanticism. Like Yi Sha, Qin expresses dismay at how the poet's death has meant the birth of a myth and how this myth has been abused in the 1990s by poets and critics whom he calls "countryside intellectuals" — as Haizi once called himself - and "spiritual aristocrats" in their efforts to monopolize the Chinese poetry scene. Qin's essay, entitled 'Criticizing Haizi: Shattering the Myth of the Epic," is part of an edited volume called Criticizing Ten Poets (十诗人批判书), with an outspoken, anticanonical agenda that also attacks other established reputations such as Guo Moruo, Xu Zhimo, Ai Qing, Shu Ting, Yu Guangzhong, Bei Dao and Wang Jiaxin. Around the same time, Xu Jiang takes aim at Haizi by comparing him to Wang Guozhen, whom we briefly encountered in chapter One, in what is a horrible insult to an avant-garde poet: Wang is so popular and well-behaved that his poetry can't be any good. An understanding of these attacks on Haizi's legacy and

${ }^{20}$ Yi 1994: 3-4, Yi et al 2000: 115-116. 
on contemporaries like Wang Jiaxin - by Yi Sha, Qin Bazi and Xu Jiang, but also by Yu Jian, as we shall see below - stands to gain from contextualization in the Popular-Intellectual Polemic of 1998-2000 to which we turn in chapter Twelve, with Yi Sha, Qin, Xu and Yu as representatives of the Popular camp. ${ }^{21}$

\section{Mythification}

As is true for many other modern poetries, romantic notions of poethood featured prominently in the early stages of modern Chinese poetry. The beginnings of this poetry are commonly associated with Huang Zunxian's writings in the closing years of the Qing dynasty and $\mathrm{Hu}$ Shi's early in the Republican era. An important moment in between occurred when Lu Xun published "On the Power of Mara Poetry” (摩罗诗力说) in 1907. Lu Xun's remark that “Poets are they who disturb people's minds" recalls Jonathan Culler's characterization of modernity in poetry as essentially disruptive in nature. According to Kirk Denton, Lu Xun introduces to the Chinese reader "a demonic model for the poet (based on Western Romantics like Byron and Shelley) that was essentially alien to the tradition." In an essay on the image of the mad (狂) poet in Chinese tradition and modernity, Yeh shows that this "Chinese Romanticism" is by no means a purely European or Western, imported affair and that its impact didn't cease after the early years but has persisted. She argues that the motif of the mad poet is "a key to understanding the dynamics of modern Chinese poetry" up to the present day. That Haizi's romantic poethood partook of both indigenous and "foreign" or international discourses would have spurred the process of mythification outlined below. ${ }^{22}$

Whether Haizi's commentators offer praise or blame, none dispute that his suicide did indeed cause the emergence of a myth (神话, literally 'story of things divine'), elevating him to godlike status. It is this mythification that leads to a vision of his life and work as one. The suicide of the poet as the most romantic of public persons provokes

${ }^{21}$ For the "countryside intellectual," see Xi Chuan 1991a: 6. Qin 1999: 227, 234, 248ff. Qin's essay is undated, but he claims to write ten years after Haizi's death (227). While Criticizing Ten Poets (Yi et al 2001) also contains a tongue-in-cheek essay by Yi Sha about Yi Sha (sic), and one by Xu Jiang about rock idol Cui Jian as a poet, Qin Bazi's piece is entirely serious. Xu Jiang 1999a.

${ }^{22}$ Lu Xun 1996: 102, Guller 1997: ch 5, Denton 1996: 69, Yeh 2005: 122. 
curiosity and the desire to identify with a life lived and died to the full, all the more so in cultish quarters of the poetry scene. As such, the audience of the suicide demands the posthumous construction of a public identity for someone they largely failed to notice while he was alive.

The right words are easily available. Haizi's poetry and his explicit poetics contain a wealth of material that invites projection on his life, all the more enticing because that life only caught the public eye in its spectacular finale. His work contains musings on death and burial and on suicide, including the identification with famous role models like Van Gogh, addressed as "my thin older brother." Van Gogh is wildly popular in Chinese literary and artistic circles, for his biography - or, of course, his thanatography - as much as for his paintings. He fits perfectly into what Yeh calls the genealogy of spiritual forebears appropriated by the builders of the poetry cult. The majority are marked by personal tragedy, often suicide: from $\mathrm{Qu}$ Yuan, role model of tragic-heroic poethood in "Chinese" antiquity whose moral-political hues were aestheticized in the modern era, to (early) modern poets from across cultural traditions such as Hölderlin, Tsvetayeva, Rimbaud, Plath, Gelan and many others. Haizi's work also features images of poetry as fire and the sun, source of creation and destruction, giver and taker of life, and of the speaker - easily equated with the historical figure of the poet - as plunging into the fire and consumed by the sun whose son he wants to be. ${ }^{23}$

The process of projection, and more generally of mythification and the conflation of Haizi's life and work, is further constituted by voices that derive authority from their status as Haizi's fellow poets and critics. This holds in particular for Luo Yihe's and Xi Chuan's early commemorative essays. The personal grief they feel as friends and Luo's own death on the heels of Haizi's add to the public tragedy of Haizi's poethood. In the introductory words to his first commemorative essay, Luo Yihe states that Haizi "died for poetry" or "sacrificed himself for poetry” (殉诗, cf expressions like 殉国 “die for one's country'). Luo presents this as a self-evident truth, without explaining what dying or sacrificing oneself for poetry means, much like Wang Jiaxin's remark that Haizi's suicide "expressed his love for poetry per se." Does poetry need poets to kill themselves in order to safeguard its existence? Do

${ }^{23}$ Yeh 1996a: 64-68 and 2005: 135. On Qu Yuan, see Schneider 1980. E.g. Haizi 1997: 4-5, 72, 133-137, 377-378 and 895-897. 
great works of art require the destruction of the artist? Luo calls Haizi a Chinese poet who will live forever, a martyr of poetry and an immortal. In his second essay he explicitly projects Haizi's work on his life, by citing Byron's contention that one should not just write but live the way one writes, and calling this an apt description of the relationship between Haizi and his poetry. ${ }^{24}$

$\mathrm{Xi}$ Chuan is the first to call the myth by its name, in the opening sentence of his 1990 essay "Remembrance" (怀念), when he declares that "The poet Haizi's death will become one of the myths of our time." A few pages on, he writes:

This man who so ardently wished to take flight was doomed to die on earth, but who can say whether his death was not a different way to take flight after all—freeing himself from the long, dark night and his soul's deep-rooted suffering to respond when the Messiah's resounding voice called at daybreak.

Xi Chuan's words reflect the religious experience that poetry was to Haizi and himself in the late 1980s. So does the exclamation, repeated four times, that through their encounter with Haizi, "blessed are" (有 福了) the students who heard him recite, the four girls he loved, the Chinese earth he gave a voice and the new Chinese poetry of his day. Xi Chuan recalls that Haizi identified with Rimbaud as a self-styled martyr of poetry and concludes that Haizi himself has now also entered the ranks of the martyrs. ${ }^{25}$ As is true for many other passages in Xi Chuan's essays on Haizi - emotional, anecdotal, analytical - the notion of the myth recurs in commentaries by various authors in subsequent years. Notably, in 1990 Xi Chuan's attitude toward Haizi's ongoing mythification is anything but questioning, skeptical or critical. Indeed, he can be seen to launch the myth of Haizi in so many words. He does so at the onset of a time of harrowing transition and radical changes to his worldview and his writing that we will examine in chapter Five. These things would compel him to revisit the episode a few years later, as we will see below.

${ }^{24}$ Luo Yihe 1990: 1-2, Wang Jiaxin 2002: 29, Luo Yihe 1997a: 1. Luo's essay, dated 26 April 1989, is one of the earliest written instances of Haizi's commemoration. See Yeh 1996a: 63 for other examples of Haizi's posthumous "martyrdom." The term comes from his poem «In Dedication to Rimbaud: Martyr of Poetry» (献给韩波: 诗歌的烈士, 1987?) (Haizi 1997: 319).

${ }^{25}$ Xi Chuan 1991a: 307, 310-312. 
Mythification of Haizi is in evidence from the early 1990s on, in glorification of his death and representation of his suicide as the ultimate poem and the completion of poethood. Wu Xiaodong and Xie Linglan write: ${ }^{26}$

Haizi's death is nothing less than a divine sign [神示] to Chinese intellectual circles, after they have been fast asleep for thousands of years in the midst of delusion and deception ... Suicide is the only active resistance to the predestined fate of death ... Haizi's death means the ultimate completion of the image of poethood [诗人形象].

Li Chao concludes a review of Works by Haizi and Luo Yihe thus: ${ }^{27}$

[Haizi and Luo Yihe's] death should be given the highest possible appraisal. We cannot do without this indomitable spirit. Such a death is the poet's predestined fate, and indeed the poet's most revered quality.

While $\mathrm{Wu}$, Xie and Li focus on the person of the poet, Yu Hong's glorification of Haizi's death can be seen to establish a connection with his art, in words, language and song: ${ }^{28}$

Blood becomes words, language returns to myth: this is Haizi's offering, at the end of humankind ... Because of Haizi, death has finally become sacrifice, become birth, become song.

Zhu Dake goes further, presenting Haizi as a poeta vates or poet-seer and prophet, and his suicide as a well-planned work of art. His comparison of Haizi's fate to that of Jesus Christ fits religious and cultish features of Chinese poetic discourse at the time. These features - in Haizi and his commentators, but also in numerous other poets and critics - qualify Wolfgang Kubin's claim that "the idea of the poet as a prophet... which Guo Moruo may have borrowed from German and English Romanticism, has survived modernity only in socialist art." ${ }^{29}$ In fact, socialist orthodoxy has left obvious traces in the avant-garde, captured to a considerable extent by the notion of romanticism and that of "literature of euphoria," which Kubin borrows from Broia Sax.

Remarkably, Zhu Dake not only presents art as religion, but also turns religion into art, and Jesus into an artist: ${ }^{30}$

${ }^{26}$ Xi Chuan 1991a: 307, 310-312.

${ }^{27}$ Li Chao 1999: 60-61

${ }^{28}$ Yu Hong 1999: 120.

${ }^{29}$ Kubin 1993: 25.

${ }^{30}$ Zhu Dake 1999: 139-140. 
[Haizi's fate] means a flying leap from poetic art to performance art. Through a careful design of sheer genius, in his suicide he completed the purest articulation of life and the ultimate poem of greatness; in other words, he completed his ballad of death, his song to end all songs [绝唱] in death . . . Haizi's song to end all songs in death was a modern imitation of the great art of Jesus, the difference being that Haizi completed the deed alone. As such he had to shoulder the missions of both hero and traitor by himself.

Xiao Ying's essay “Existence Leading toward Death” (向死亡存在) is reminiscent of Xi Chuan's "Remembrance," in that it contributes to the very process of mythification it identifies. ${ }^{31}$

In an era that has brought us the failure of poetry, the death of the poet in itself becomes a possible form of poetry . . Haizi's poems are an enlightenment of poetry, an enlightenment on the verge of death [绝 命] written by a poet on the verge of death . . . In contrast to his nameless lot while he was alive, poetry circles reacted to the death of the poet in inevitably drastic fashion - overnight, the poet and his poetry were made into myth. Thus, the enlightenment given by the death of the poet to contemporary poetry changes into a conscious, unequivocal sign . . . If poetry were still a possibility and a thing of hope, the poet would never choose death to break off poetry, never put death in poetry's place. Insisting on their desire for poetry, yet having lost the possibility for poetry, the deaths of [Haizi, Luo Yihe and Ge Mai] become a symbol of the night of this age in which poetry withers away - the death of the poet becomes the ultimate poem.

As soon as the world learns of Haizi's suicide and the myth emerges, it becomes thanatography and extends backward to determine the image of the poet in the preceding years. Writing after the event, several commentators mobilize references to his poetry to come up with what we may call post-dictions of his suicide. Thus, in retrospect Haizi's textual production already endows him with potentially divine qualities while alive, and makes the particular death he died his logical apotheosis, literally so: as not just his finest hour, but in fact his elevation to divine status. ${ }^{32}$

Mythification has accompanied Haizi's poetry on its way into English in at least two publications. Wang Yuechuan's "A Perspective on the Suicides of Chinese Poets in the 1990s" is an exercise in righteous

31 Xiao Ying 1999: 231.

32 Zhang Qinghua 1999: 182ff, Liaoyuan 2001: 347ff. On Haizi's apotheosis, cf Yeh 1996a: 63. 
psychologizing. Wang depicts suicide as the inevitable consequence of "pure" poethood "witnessing truth" and hence "facing death" in an age governed by "the logic of commerce," adopting a deceptively simple opposition of poetry and money that is questioned at various points in this study. While decrying a popular tendency to glorify deaths in poetry, Wang himself does just that. His essay was written for Li Xia's 1999 Essays, Interviewes, Recollections and Unpublished Material of Gu Cheng, Twentieth-Century Chinese Poet: The Poetics of Death (1999), a volume whose thanatographical motivation shows in the writings of its editor and several contributors. Zeng Hong's commentary in An English Translation of Poems of the Contemporary Chinese Poet Hai Zi (2005) is also thanatography. While Zeng makes a laudable effort to acquaint Anglophone readers with one of the best-known modern Chinese poets, her introduction of the poet and his poetry is less than balanced. It is, however, a paragon of levelheadedness when read side to side with Zhao Qiguang's preface to her work. Referring to accounts of Haizi's suicide that listed several books he had taken with him on his way to the railroad at Shanhaiguan, Zhao writes:

I was saddened and flattered when I saw the title of the last book that Haizi took to another world, because I compiled, co-translated, and prefaced the Selected Novels of Joseph Conrad. Before leaving for the US in 1982, I handed the manuscript to a publisher and I had scarcely heard anything about it since. Now I received the most overwhelming feedback that an author or translator can expect. Haizi is no stranger anymore. I didn't know I had such a sincere friend and fellow traveler. Together we penetrated the heart of darkness and sailed through a typhoon. We went there together. We both decided we liked the beauty in those places. I left but he stayed there, forever.

This borders on the perverse. Zhao proceeds to call Haizi's death "a gallant and romantic declaration of his passions, devotions and beliefs," and his life a poem - written, of course, in blood. ${ }^{33}$

Other representations of Haizi in what foreign-published scholarship there is to date are less overdetermined by the end to his life and less inclined to mythify and frame his life and work as one, even if he is almost invariably mentioned in connection with suicide. Yeh's essays on death in poetry and the cult of poetry in China are literary-

${ }^{33}$ Wang Yuechuan 1999; Li Xia 1999 - see, for instance, the opening paragraphs of Li Xia's foreword, and the essay by Henry Zhao that gave the book its name (1999); Zeng 2005 and Zhao Qiguang 2005 (ii and v-vi), both in Haizi 2005. 
sociological in orientation and primarily focus on images of Haizi's poet-hood as part of broader discursive practice. When she does engage in detailed textual analysis, in a 1993 essay on Haizi's programmatic poem «Asia Bronze» (亚洲铜, 1984) - in Chinese, but published outside China, in the new Today - this is quite possibly the only commentary written after 26 March 1989 that makes no mention of the poet's death. As such, it pointedly implies a defense of the poetic voice against the thanatographical hullabaloo that threatens to drown it out. David Der-wei Wang mentions Haizi in passing in an essay on the politics and poetics of (Chinese) literary suicides, with Wen Jie, Shi Mingzheng and Gu Cheng as case studies. Wang draws on Yeh's suggestion of the poetry cult's complicity with Maoism, a notion he himself puts forward in his earlier writings on fiction. Like Yeh's work, Wang's offers a wealth of stimulating analysis, although Alison Bailey is right in calling the connections between the case studies tenuous. While Wang is quick to point out that Alfred Alvarez' categories of the "totalitarian artist" and the "extremist artist" are anything but absolute, he shows how thoroughly "political" suicides can in fact be occasioned by romantic desire and seemingly "morbid" suicides may well expose latent political trauma. The parameters of Wang's analysis would, however, be less applicable to Haizi than to Wen, Shi and Gu, if we were still to arrive at what Wang calls the dialectic between late modern Chinese culture and its body politic. Day calls attention to the linkage of Haizi's suicide and June Fourth in poetry and commentary, discussed above. Mi Jiayan examines epistemic reconfigurations of the river as a national symbol contributing to Chinese identity, in the fiction of Zhang Chengzhi and the (epic) poetry of Haizi, Luo Yihe and Chang Yao, duly noting the effect Haizi's and Luo Yihe's deaths have had on the reception of their work. In fact, Mi might have extended this observation to Chang Yao, who took his own life by jumping off a building at age sixty-four, when he was terminally ill. When Chang Li and Lu Shourong include Chang Yao in their discussion of Newborn Generation Poetry, they can only do so by stretching this category considerably, and their lament that the poet's talent was insufficiently recognized while he was alive comes as no surprise. ${ }^{34}$

${ }^{34}$ Yeh 1993a, 1995, 1996a; Wang (David Der-wei) 2004: ch 7 and 1994: 242-243; Day 2005a: ch 11; Mi 2007. Chang Li \& Lu 2002: 250-252, Mao Jian 2005: 16, Liu Fuchun 2004: 592. 


\section{Biographies?}

The most significant, palpable example of Haizi's thanatography is Liaoyuan's 2001 monograph Leopard Pouncing on the Sun: A Critical Biography of Haizi (扑向太阳之豹: 海子评传), prefaced and hence more or less authorized by Xi Chuan, who remarks on unpleasant memories of other, would-be biographers of questionable intentions and style. No one would have thought of writing Haizi's biography if he hadn't killed himself. As such it makes perfect sense that Leopard starts with a brief account of his suicide. The narrative reversal of historical chronology is of course not exclusive to stories of which the end is widely known, and a death foretold can sharpen our perception of the vitality we know it will terminate, thus creating dramatic tension. This is, however, not what happens in Leopard. While Liaoyuan consolidates the myth of Haizi, his book is no hagiography and he commands respect by the way he pulls together information on a scarcely documented life-but from start to finish the foremost level of coherence in his account of Haizi's life is dictated by the poet's eventual suicide. Liaoyuan weaves Haizi's poetry into the rest of his life, on the explicit assumption that his oeuvre can be taken biographically in its entirety. In itself, certainly in light of a traditional Chinese poetics, this is a defensible position, but it makes passages that may be read as pointing toward Haizi's death acquire disproportionate weight.

Liaoyuan's desire for coherence combines with his regard for Haizi's art and a romantic vision of poethood, when he concludes that Haizi “died for poetry" (为诗而死). He bases himself on the note in which Haizi wrote that his death had nothing to do with anybody, which Liaoyuan says was $^{35}$

to stop us from guessing at the reason for his death from any mundane [俗世] angle. And what he expressed about giving his poetry manuscripts to Luo Yihe is in fact a public authorization. On one level his will was about dying; on another it was about poetry. From this it isn't hard for us to experience his words as delivering a mental note to the effect that he cleanly died for poetry.

The argument is uncharacteristically weak, if not a glaring non sequitur. An alternative interpretation of Haizi's suicide note is that he wished to make sure no one would be blamed for his death, but one

35 Liaoyuan 2001: 340. 
surmises that the issue is simply too important. Like Luo Yihe and others who hold that Haizi "sacrificed himself for poetry," Liaoyuan sees the poet's life - again, most of all, his death — as part of his work. Ever since the cult of poetry came to full bloom in mainland China in the 1980s, it has been forcefully challenged. But Liaoyuan's book, published in 2001, shows its continuing impact.

So does Yu Xugang's A Biography of Haizi: Hero of Poetry (海子传: 诗 歌英雄, 2004). Yu, a fine arts student proud of his and Haizi's shared Anhui provenance, presents it as a commemorative document fifteen years after Haizi's death. Innocuous detail on Haizi's childhood has no relevance to the book's thrust as advertized on its back coverhomage to Haizi as a true "emperor of poetry" and "hero of poetry" and merely reaffirms his mythification. The same holds for some of the photographs in A Biography, such as the front covers of "journals that Haizi often read" and textbooks used in law courses he attended as a university student. Both would have had many other readers, who failed to become heroes of poetry. Yu's account is occasionally semifictional, when he includes dialogue and appropriates what he assumes to be his protagonist's perspective. The most striking example is when, in the closing paragraphs of his book, he describes the moment of Haizi's death: ${ }^{36}$

A freight train approached, its whistle screaming.

Haizi fled into the sun!

Yu's book adds nothing of intellectual substance to previous publications, offering instead a sugary and naive account of Haizi's life and work. This is not meant to cast doubt on its author's sincerity or the conscionable nature of his interviews with relatives and acquaintances of Haizi. If anything, it indicates that in 2004 the reputable Jiangsu Literature \& Art Press felt that there was a (non-specialist) readership for another monograph on Haizi - a book that compares to Liaoyuan's work as a light variety of the genre - or that its publication would add to the publisher's prestige.

Zhou Yubing's Face to the Sea Spring Warmth Flower Glee: Haizi's Poetic Life (面朝大海 春暖花开: 海子的诗情人生), published by the Anhui Literature \& Art Press in 2005, is a similar production and another major instance of thanatography. The blurb starts thus:

${ }^{36}$ Yu Xugang 2004: 215. 
Haizi was a dazzling shooting star on contemporary China's poetry scene. In his brief life, he kept a holy and pure, elevated poetic heart. Misunderstood in his time by the people of this world, he bore loneliness and pain. Through his own literary talent and sheer perseverance, he wrote close to two hundred short lyrical poems and seven long poems. When, like maxims and holy songs, lines from his poetry were collectively recited by university students in the square, included in junior high school teaching materials, used for profit by real estate business in advertising slogans for seaside homes.... people recalled with emotion this "son of the wheatfields," this "hero of poetry."

Like Yu Xugang, Zhou underpins his status as biographer by identifying himself as a fellow Anhuinese of the poet. The many pictures in his book include a prominently placed, sorrowful portrait of Haizi's mother and images of a well-maintained house with a plaque that reads "Haizi's Erstwhile Residence" over the front door. ${ }^{37}$ Face to the Sea is a romanticized, tear-jerking account of Haizi's life. Zhou rehearses all well-known anecdotes about Haizi and, like Yu, semi-fictionalizes his biography. He provides detailed, empathetic descriptions of Haizi's fateful love life and of dreams that he portrays Haizi as having had, for instance of his suicide. The narrative is set up to take the reader unerringly toward Haizi's death. Zhou's description of Haizi's final moments - "he slowly lay down, his back pressing against the ice-cold iron rail"- is at variance with Luo Yihe's letter to Wan Xia, based on the freight train crew's report, that said Haizi had thrown himself under the train from the side. It is not unlikely that Zhou saw this letter before completing his manuscript. If so, his decision to make Haizi "lie down slowly" in readiness for the approaching train may bespeak a desire to orchestrate the climax in style, as the glorious end to a tragicheroic life. Zhou's version of events is of course easier to picture as a ritual "sacrifice" than Luo's.

\section{Demythification}

Just like there are a few voices that question the uncritical celebration of Haizi's poetry, there are some that refuse to go along with a simplistic, abstract reading of his suicide as a "death for poetry." Writing in 1991, poet Han Dong, disbeliever in high-blown representations of

37 Zhou Yubing 2005: 154, 215. 
poetry and poethood, first remarks on contemporary poets' inclination for "experiment" (实验):

Taken to extremes, they even deny that the material of which poetry is composed must be that of language. The use of paper and pen, too, is strictly unnecessary or optional. At this point, poetry can be body art, or action art. In order to distinguish poetry from daily life, action artists continually seek action that is out of the ordinary, and free from the mundane. They get drunk, fight, womanize, drift around and cultivate eccentricities, so as to prove that they are poets. In the end they discover that not only have they failed to escape from the mundane, but their situation is in fact getting worse and worse. Now the only thing they haven't tried is death.

Yeh rephrases Han's words as follows: "In other words, self-willed death seems to offer a new way, even the ultimate way, of asserting one's identity as a poet." Notably, however, Han Dong continues by dissociating Haizi from the "experimenters":

It goes without saying that Haizi's death means a lot for the establishment of their self[-image]. But none of this has anything to do with Haizi himself.

In any case, Yeh doesn't take speculation on the cause of Haizi's suicide further than the suggestion that it cannot be separated from his poetry, specifically that the self-imposed pressure of an overly ambitious poetics may have been too much to bear. ${ }^{38}$

Han Dong accepts the possible validity of a biographical reading of Haizi's poetry, but takes a "death for poetry" to mean something radically different from its usual interpretation: ${ }^{39}$

Haizi's death only counts as evidence of the misery and internal conflict in which the poet found himself. We cannot proceed from his death to establish the origins of his poetry; we can only try to discover in his poetry the secret of why he went to meet his death. If we say that Haizi died for poetry, that must mean that his creativity faced an impasse. Death then becomes a way out, not elevation in any sense . . I insist on believing that Haizi was someone who, when he could no longer write poetry, would rather die-although it is highly likely that such was not the concrete cause of this death.

\footnotetext{
${ }^{38}$ Han 1991: 335, Yeh 1995: 55, 45.

39 Han 1991: 335-336.
} 
Gui Weiping's “In Memory of Truth" (真理的祭奠, 1992) ends on a thanatographical note, and the section "Split and Rupture of the Self” in "The Myth of Haizi" (海子神话, 1992) was likely inspired by Haizi's physical rupture on the railroad track. On the whole, however, Cui's analysis is based on textual evidence, not all-powerful visions of poethood and of the poet's life and work as one. Toward the end of "The Myth of Haizi" she wonders whether a sense of calmness and resignation in Haizi's poems from his final months points to a resolve to end his life, or to a quiet spell preceding a new outburst of creativity. But she interrupts her own speculations: ${ }^{40}$

Be all that as it may, it remains impossible to draw any conclusions about the reason why on 26 March 1989 he suddenly chose to leave this world. There was a crisis all along, but its outcome was by no means necessary. In the end, to go by his poetry for drawing conclusions on the cause of his suicide is not all there is to it - and to go by his suicide for an understanding of his poetry makes even less sense. His fate harbored a few more secrets (they may be very simple ones) that he has taken away with him forever.

The most powerful instance of demythification is Xi Chuan's "Afterword to Death" (死亡后记, 1994). This is a different voice from that in "Remembrance," forceful yet reluctant and sometimes angry, intimating that "Afterword" was difficult to write, and was perhaps written not out of the urge to continue speaking but from a sense of duty to the memory of a friend and fellow poet, that had taken on a life all of its own-spurred, incidentally, by Xi Chuan's own earlier commentary as much as by others.

$\mathrm{Xi}$ Chuan begins his intervention with critical reflections on the publicity that Haizi's death unleashed. He then gives a systematic account of "what he knows and what he conjectures" about possible reasons for Haizi's suicide. The first is Haizi's "suicide complex." Haizi had apparently attempted suicide in 1986 and was fascinated by the popular idea that artistic talent or genius often brings a young death (天才短命、天才早天). The second is Haizi's disposition, which Xi Chuan calls pure, stubborn, sensitive, puritan and sentimental among other things, and generally gentle but "leopard-like" when he was angered. Liaoyuan's biography of Haizi presumably took its name from

${ }^{40}$ Cui 1999b: 98, 1999c, 1992b: 101, 110. Zhong Ming's reflections are similarly inspired by the fact that Haizi had himself physically cut in two (1991). 
"Afterword," which occupies a central position among commentaries on Haizi, even if it expresses what is clearly a minority viewpoint. $\mathrm{Xi}$ Chuan cites Haizi's lifestyle as a third possible reason. He recalls that Haizi lived in seclusion and kept social contacts at bay for fear of distraction from his art, and as a result suffered from loneliness and lacked a social network that might have kept him from killing himself. Allegedly, Haizi once asked the owner of a Changping restaurant for drink in exchange for a public recital, and the owner replied that he could drink all he wanted, as long as he did not read any poetry. In poetry circles, the anecdote has become something of a classic, if only because it is well suited to serve as an illustration of the "marginalization" of poetry or indeed its being in "crisis" as measured against social trends of consumerism, commercialization and so on.

Xi Chuan's fourth category is that of "the issue of honor" (荣誉 问题), meaning public acceptance of one's art. He depicts Haizi and all other Chinese avant-garde poets as facing mistrust by society at large and conservative forces in literature, calling this "not a literary but a political problem." In addition, he remembers Haizi as vulnerable to infighting within the avant-garde, a famous example being poet Duoduo's and others' scathing criticism of Haizi's epic poetry at a gathering of The Survivors poetry club at Wang Jiaxin's home in central Beijing, late in 1988. The event reputedly left Haizi devastated. Wei'an, writing around the same time as Xi Chuan, also associates it with his suicide. Wang Jiaxin, reminiscing in 2001, disagrees. ${ }^{41} \mathrm{Xi}$ Chuan goes on to note that on one occasion, a better-known poetwhom he calls "LMN," in a series of alphabetically veiled attacks ("poet AB," "poet CD") on those who wronged Haizi in one way or another - plagiarized a typescript Haizi had sent around to friends, fellow poets and editors, and got away with it. The fifth category is Haizi's fascination with qigong, a traditional Chinese technique to control one's vital energy, mostly through controlled breathing and meditation. Qigong is associated with exceptional physical abilities, such as in martial arts and medicine. According to Xi Chuan, when Haizi felt that he was entering higher stages of qigong he began to suffer from delusions. Specifically,

\footnotetext{
${ }^{41}$ Wei'an 1994: 107; Wang Jiaxin 2002: 33-40, esp 37.
} 
he felt there was someone speaking into his ear all the time, which made him unable to write. And to Haizi, being unable to write meant thoroughly losing his life.

Here, Xi Chuan's words recall those of Han Dong, an author whose poetry and poetics could hardly be more different from his own, but who shares his belief that Haizi was someone who would rather die than live with the concrete, physical inability to write. Recognizing that toward the end of his life Haizi showed signs of terrible confusion, $\mathrm{Xi}$ Chuan still questions his official medical diagnosis as "schizophrenic." In the sixth section of "Afterword," he suggests that the trigger of Haizi's suicide - as opposed to its deeper causes - may have been the guilt he felt about having said disrespectful things about a former girlfriend in a bout of drunkenness, although Haizi's companions at the time insisted that he had not. In the seventh section Xi Chuan points out that "Haizi was fully dedicated to writing. There was no distance whatsoever between living and writing." This formula makes Haizi's life and work seamlessly contiguous if not indistinguishable. Xi Chuan concludes, however, by saying that Haizi could have written more and better poetry if he had handled his talent differently.

Having noted the impact of "Afterword," we see how a voice that launched the myth of Haizi in 1990 retains its authority a mere four years later, when it takes others to task over their contributions to that myth. The explanation lies, again, in the speaker's status as a personal friend of Haizi and in his own rapid rise as an acclaimed poet. For the present analysis it is important that Xi Chuan's claim that Haizi had somehow mishandled his talent invalidates the notion of his suicide as the poem to end all poems.

\section{Reading the Poet}

In light of the overwhelming conflation of Haizi's life and work in critical discourse, it stands to reason that thanatography extends from the poet to his poetry. Haizi's death, in other words, is projected backward to determine not just his life but also his writings. For biographer Liaoyuan the one-on-one relationship of life and work goes both ways. He takes Haizi's poetry as biographical documentation but also reads evidence from other spheres into the poetry. Textual analysis by other commentators, too, displays a vision shaped by Haizi's extratextual death. We find a telling example in the first edition of Chen 
Chao's Critical Anthology of Chinese Explorative Poetry (中国探索诗鉴赏词 典, 1989). Chen completed the manuscript in 1988, when Haizi was still alive. It contains discussions of two of his poems. In his comments on «Clasps a White Tiger and Crosses the Ocean», Chen is puzzled by the phrase mother leaning towards death but then notes that Haizi presents life and death in equilibrium. He concludes: ${ }^{42}$

The poem avails itself of the form of a dream, and reveals the true nature of life: that magnificent, great force, duty-bound not to turn back, conquering death.

Ten years on, in the revised and expanded edition of his Critical Anthology (1999), Chen adds discussions of three more of Haizi's poems. He inserts them between his two previous mini-essays, abruptly placing a posthumous eulogy for the poet at the head of the first of his new commentaries, which is the second of the full set. All three newly added poems had received much exposure in the years following Haizi's death. Disregarding a possible contradiction with his earlier characterization of "the true nature of life" emanating from Haizi's poetry as "conquering death," Chen says that in the 1987 poem «Ancestral Land (Or: With a Dream for a Horse)», Haizi prophesied his fate. With or without reference to the Chinese tradition of equating speaker and author, this is a reasonable claim, as we shall see below. Still, the fact remains that canonization of «Ancestral Land» was only triggered by Haizi's fulfillment of the "prophesy," by the author doing what the speaker had said. Chen's anthology has a predilection for individual poets' "representative works": «Ancestral Land», then, only became a representative work, in the anthology's second edition, once it was endorsed by the poet's life - that is, by his death. Chen's commentary confirms this when he compares the poem, in its "tragic emotion and holy purity" (悲慨与圣洁), to an epitaph. It is no surprise that he finds that Haizi's play in verse «The Sun» ${ }^{43}$

was in a sense "completed" after all, and that the poet gave his life as a final record of inspiration toward [the poem's and his own] completion.

In closing, Chen approvingly cites Luo Yihe's Byronesque vision of Haizi's life and work and says that, among other things, reading

${ }^{42}$ Chen Chao 1989: 615.

${ }^{43}$ Chen Chao's phrasing is ambiguous: 这部大诗还是 “完成” 了, 诗人是以生 命作为最后的启示录完成的(1999: 1161). Chen Chao 1999: 1158-1166. 
Haizi's poetry brings about a sacred (神圣) feeling, while being firmly rooted in the concrete world of humankind.

One commentary that deserves special mention, if only because it presents itself as questioning Haizi's mythification, is Gao Bo's Interpreting Haizi (解读海子, 2003). The motivation of Gao's book-and of the case study of Haizi in his Modern Poets and Modern Poetry (现代 诗人和现代诗, 2005) - is akin to that of the present chapter in that Gao questions a vision of Haizi's writings that is determined by his suicide. Gao's discussion of central images in Haizi's poetry is certainly worthwhile, as are his reflections on Haizi's rural provenance and his affinity with folk art and popular cultural forms, and his contextualization of Haizi in twentieth-century Chinese poetry. ${ }^{44}$ Still, Interpreting Haizi fails to reach its professed goal of clarifying matters and keeping people from "misreading" mythified versions of Haizi, largely on account of a reading attitude that is similar to that of Haizi's biographers. Gao tends to take Haizi's poetic genius as a given that precedes any textual analysis, and Haizi's explicit poetics as the unassailable truth about the poet's own writings. To Gao, the historical Haizi's intellectual and emotional experience is self-evidently knowable, and its acute relevance is beyond a shadow of a doubt. This limits his textualinterpretive space.

We have seen that the great majority of Haizi's domestic commentators mythify his life as part of his work, identify his poetry with his suicide and make what he wrote inseparable from everything else he did. In itself, this is perfectly understandable. After deduction of some rhetorical exaggeration, there is no reason to doubt the accuracy of Haizi's image as a worshiper of poetry, as one absolutely dedicated to and indeed possessed by poetry, and hence, in a romantic vision, as the embodiment of poetry who wanted, in his own words, to "speed up the pace of life and death." Nor is there any reason to deny that certain passages in his work lend themselves to a biographical reading. There is textual evidence to that effect that is more concrete than a general compatibility of mood or temperament between the poet's personality and his writings. Several of his poems feature a protagonist called Haizi, and there are phrases and words that fit biographical fact, such as the names of places Haizi visited and a reference to a family of six,

${ }^{44}$ Gao Bo 2003: e.g. 91, 96ff, 113-125 and 169ff. Gao Bo 2005: 132-179 (there is considerable overlap with Gao Bo 2003). 
like his own. ${ }^{45}$ More importantly, a biographical reading is defensible if not self-evident because Chinese literary practice continues to reflect a biographist, traditional view of literature to this day, even as it vies for influence with contemporary socio-political circumstance and all manner of foreign and indigenous modernities in literature and art.

To readers not natively steeped in Chinese literary traditions, however, the case of Haizi shows biography as not just one of several possible reading strategies that is occasioned by a particular textual situation. It is rather something like a fundamental assumption which stipulates that when all is said and done, the poem is a means to the end of getting to know the poet - or, in Stephen Owen's words cited earlier, that reading the poem is reading the poet. As Michel Hockx has shown, this assumption holds all the way into the new media of today's Chinese literary production. Notably, Chinese biographism is different from the eponymous nineteenth-century European method that mobilized endless "facts" about the author's life as tools for interpreting their writing and became anathema in the twentieth century. ${ }^{46}$ Gao Bo's Interpreting Haizi is perhaps the best example, precisely because it claims to set out from the primacy of the written text but ends up interpreting the author instead. In Chinese scholarly-critical discourse on contemporary poetry, the biographist component of a heterogeneous reader's intent competes with many others but effortlessly comes to the fore once the need arises. That is what happened when Haizi killed himself and has kept happening ever since, without much reflection on the vision of his suicide as the said particular textual situation - a poem, or the poem to end all poems - or on the implications of this vision for Haizi's representations in literary history.

\section{The Poetia Voice}

As a counterweight to the trend outlined above, I will now examine some of Haizi's poems and attempt to hear the poetic voice in its own right, without necessarily linking it to the fate of the author. This presumes no ability to unlearn Haizi's biography and block out associations with his suicide, nor does it make his suicide in itself any less

45 Diary entries in Haizi 1997: 879-885. Poems that fit biographical fact: Haizi 1997: 107, 157, 174, 178, 347, 375-376, 414, 470 .

${ }^{46}$ Owen 1979: 232-234 and 1992: 26-28, Hockx 2004, Levie 2004. 
shocking. Notably, the questions I have raised about conflations of his life and work do not invalidate biographical readings per se, as long as they are based on textual evidence - nor do such readings reduce his poetry to documents of "mere" human interest.

Haizi himself found his long poems the most important, calling them "the only real poetry." His commentators differ in their assessment. The posthumous publication of The Land shows that Luo Yihe especially admired his epic poetry, and the same is true for Liaoyuan. Tan Wuchang, too, while recognizing that Haizi's epics provoked fiercely negative reactions among his fellow poets, maintains that they deserve a prominent position in literary history. Luo Zhenya calls Haizi's efforts toward the epic "legitimate" but concludes that his ambitions were not realized. Cheng Guangwei is critical of Haizi's failure to structure or limit his torrential outpourings of language, and Qin Bazi, as we have seen, calls Haizi's epic poetry fundamentally unfit for the age. I concur with Cheng Guangwei. Large parts of «The Sun», for instance, present clichéd megalomania and unexplained allusions to private experience in a bombastic mix that simply fails to gel, notwithstanding the beauty of passages such as those in the part called «Night Song» (夜歌). ${ }^{47}$

I find Haizi's short, lyrical poems easily the best part of his oeuvre. Many contain archetypal subject matter and imagery from the natural and rural worlds. This includes the sun, the earth, the moon and the stars, the sky and the sea; fall, winter and spring - but not summer; dusk, nightfall and night, darkness, dawn and daybreak, light; fire and water, wind, rain, snow and sunshine; grasslands, rivers; the soil, wheat and wheatfields, grain, farming villages, harvest, shepherds, livestock; blood and death. The poems usually unfold from the perspective of a first-person speaker, in whose mood moments of euphoria stand out against a keynote of depression: sad, somber, sometimes downright bleak. Haizi's usage combines pompous expressions with colloquialisms and moments of intimacy. Most of his poetry is in free verse. Yet, critics of various persuasions agree that he made a major contribution to reestablishing the phenomenon of song (歌唱) in contemporary po-

${ }^{47}$ Haizi 1997: 888. His preference for "big" and "epic" poetry and poetry "of greatness" is evident throughout his explicit poetics (869-918, esp 898-901). See also Xi Chuan 1994a: 94 and Luo Yihe 1990: 2-3. Luo Yihe 1990, Liaoyuan 2001: 277, Tan Wuchang 1999: 197ff, Luo Zhenya 2005: 116-126, Cheng Guangwei 1999: 222, Qin 1999. Haizi 1997: 799-866. «Night Song» is found on 840-841. 
etry, with Wang Yichuan making an especially strong case. ${ }^{48}$ Form and content are in agreement in that both are often unconstrained. This is frequently a weakness and rarely a strength, and directly reflected in the sheer amount of poetry Haizi has to his name.

Piet Gerbrandy proposes a matrix for the classification of poetry with the attributes "open" and "closed" on one axis, and "accessible" and "inaccessible" on the other. For an open text, he writes, "however compelling its language, one still feels that it could just as well have contained more of fewer lines." Through association with Gerbrandy's approach, in which most of Haizi's poetry would be open and accessible, we may call his poetics extremely receptive. It wants to accommodate a range of things of great magnitude, from the heritage of ancient civilizations and mythologies to the pinnacles of "world literature" and art and to profound, individual emotion, and it displays constant exaltation in the process. In the modern Chinese context, obvious precursors are Walt Whitman and Guo Moruo, in addition to orthodox Political Lyricism. On the spectrum from Elevated to Earthly, Haizi sits squarely at the Elevated end. His work confirms the connection between the sublime (崇高) on the one hand and ethnocultural identity and ambitions on the other, noted by Wang Ban. ${ }^{49}$

Those among Haizi's short poems that strike me as the strongestfour of the five considered here - are not at all megalomaniacal or bombastic, but individual, private and introspective instead. In contrast to the unconstrained parts of Haizi's oeuvre, they employ structuring devices such as repetition and rhyme, to appreciable effect. The 1986 poem «Clasps a White Tiger and Crosses the Ocean» (抱着白 虎走过海洋) is an example of Haizi's rare attempts to impose formal limitations on his writing. An earlier version in an unofficial collection of poetry, published jointly with Xi Chuan, reveals that Haizi must have consciously moved toward the poem's eventual strict form at some later stage..$^{50}$

${ }^{48}$ Wang Yichuan 1999b. Cf Gao Bo 2003: 169-178 and Luo Zhenya 2005: 134-137.

${ }^{49}$ Gerbrandy 1995: 15, Xi Chuan 1991a: 9, Abrams 1971: 3-29, Wang Ban 1997: 69-70. For a more elaborate English-language introduction to Gerbrandy's criteria for the classification of poetry and their relevance to contemporary Chinese texts, see Van Crevel 2004: 105-107.

${ }^{50}$ Haizi 1997: 123, Haizi \& Xi Chuan 1986: 11-12. 
"Clasps a White Tiger and Crosses the Ocean»

Mother leaning toward magnificence

clasps a white tiger and crosses the ocean

On the land are five chambers

a sickbed lies down in her hometown

Mother leaning toward her hometown

clasps a white tiger and crosses the ocean

The sons coming out in spite of their sickness

open the door and gaze at the sun of blood

Mother leaning toward the sun

clasps a white tiger and crosses the ocean

The maidservant on the left is life

the maidservant on the right is death

Mother leaning toward death

clasps a white tiger and crosses the ocean
抱着白虎走过海洋

倾向于宏伟的母亲 抱着白虎走过海洋

陆地上有堂屋五间 一只病床卧于故乡

倾向于故乡的母亲 抱着白虎走过海洋

扶病而出的儿子们 开门望见了血太阳

倾向于太阳的母亲 抱着白虎走过海洋

左边的侍女是生命 右边的侍女是死亡

倾向于死亡的母亲 抱着白虎走过海洋

I include the Chinese original to show that all its lines are visually and aurally of the exact same length: eight characters $=$ syllables, without any punctuation. The final syllables of each stanza rhyme. The poem's semantics, too, are tightly and indeed formally controlled. The poem's first line takes its cues from the second, fourth and sixth stanzas for mechanical rewritings in the third, fifth and seventh by the replacement of one word, followed each time by a repetition of the first stanza's second line, which is also the poem's title. The central scene, of mother clasping a white tiger and crossing the ocean, is mystifying. The word translated as clasps is 抱 'hold,' 'embrace,' meaning that mother is sitting on the tiger's back, with her arms around its neck. While crosses (走过) doesn't specify the means or mode of transportation, an image of the tiger walking or running across the water comes to mind. The scene's mythical qualities are enhanced by the maidservants that represent life and death, and by the vision of mother as a powerful presence interacting with the formidable entities of "magnificence," the hometown (故乡 'place of origin,' an important constituent of Chinese identities), the sun and death, all of which recur throughout Haizi's oeuvre. The sick sons vis-à-vis the sun are familiar, too-we will encounter them again below-but the dynamics of their relation 
to mother remain unclear. An alternative reading proceeds from the image of mother holding the tiger the way one holds a child, and carrying it rather than riding it across the ocean. The homophony of the poet's name and 孩子 'child" ${ }^{51}$ may then lead to identification of the poet-speaker with the white tiger, portraying the poet-both the historical figure of Haizi and the abstraction of poethood - as a species that is dangerous and rare. The form of «Clasps a White Tiger» makes it a remarkable, catchy text. It sticks in the reader's memory, because it combines these qualities with stubbornly repeated riddles that spur the imagination.

«Moved» (感动)—as in 'experiencing profound emotion'—was also written in 1986. It is in free verse, and closer to Haizi's usual style than «Clasps a White Tiger». ${ }^{52}$

«Moved»

\begin{abstract}
Morning is a dappled deer
that tramples my forehead

what a wonderful world

wild flowers in the mountain cave

go along my body

burn all the way to the light of day

burn all the way out of the cave

what a wonderful world
\end{abstract}

But night, the deer's

master, entered long ago

into the depths of the soil, leaning on tree roots

to redirect some kind of

happiness you cannot possibly see

${ }^{51}$ In Mandarin, three differently intoned pronunciations of 海子 are possible: third + neutral tone, as in the dialect expression meaning 'lake'; second (through tone sandhi) + full third tone; and second (through tone sandhi) + neutral tone. The latter two would be personal names. Depending on its position in the sentence, Haizi's name is commonly if not invariably pronounced in the second + neutral tone, just like 孩子 'child.' Xi Chuan (1994a: 92) recalls a fellow student at PKU ridiculing Haizi when handing him a series of newly arrived letters, and switching from identifying the addressee as "Haizi/child.... Haizi/child.... Haizi/child...." (háizi, which Xi Chuan writes as 海子 but interprets as 孩子) to calling him "grandchild.... grandchild... grandchild....” (孙子 'grandson'). Its literal meaning aside, 孙 子 is a term of abuse.

${ }^{52}$ Haizi 1997: 129. 
wild flowers underground

burn all the way up above ground

Wild flowers burn onto your face

burn you and hurt you

what a wonderful world

morning in a mountain cave

is a man-trampling dappled deer

Formally, the poem is held together by the modified return of the first couple of lines in the last couple of lines and indeed by the resonance of the entire first stanza in the last, with the significant addition that the wild flowers turn out to burn you and hurt you (烧伤) - just like in «The Wheatfields and the Poet» (麦地与诗人, 1987), the speaker is scorched and hurt (灼伤) by the unforgiving wheat that other people ... find mild and beautiful..$^{53}$ The flowers burning to the light of day and out of the cave denote more than just bright colors. Dramatic tension between their loveliness and the pain they inflict on the speaker-protagonist echoes the role of the dappled deer, with its trampling of the speaker's forehead and face destroying connotations of pretty innocence and any pristine qualities of the morning hour it is said to represent. Elsewhere in Haizi's oeuvre, too, the speaker's relation to the natural world is ambiguous, involving opposing forces such as creation, nurture and comfort on the one hand, and violence and destruction on the other. In light of his pain, the speaker's repeated exclamation what a wonderful world, which strengthens the cohesion of the first and last stanzas, invites an ironic reading. In this poem and throughout Haizi's oeuvre, however, the tone of the poetic voice is one not of irony but of utmost sincerity. As such the said exclamation conjures up an experience of ecstatic self-destruction. I take the first-person and second-person pronouns to refer to the same, passive speaker-protagonist, who moves from individual experience, in my forehead and my body, to omniscient observation in happiness you cannot possibly see and beyond. In the second stanza, the action moves into the soil, connected by the wild flowers to the cave where the speaker finds himself. «Moved» derives its strength from the conjunction of loveliness and horror.

Let's now turn to a text that is much more famous than «Clasps a White Tiger» or «Moved», presumably because it suits a romantic

\footnotetext{
${ }^{53}$ Haizi 1997: 355-356.
} 
poetics that is widespread in contemporary China and because it lends itself to commemorative uses. For a short poem, it is rather long and extremely unconstrained: two full pages holding 38 lines, some of as many as 25 characters. It brings to mind Haizi's long poetry in other ways as well, in qualities discussed above that I sum up as an inclination toward clichéd megalomania. I am referring to «Ancestral Land (Or: With a Dream for a Horse)» (祖国[或以梦为马], 1987), one of the poems that triggered the collective recital at PKU in 1994, and one of those in which, according to Chen Chao and others, Haizi prophesied his death. Here are the opening and closing stanzas: ${ }^{54}$

I will be a loyal son of faraway parts

and short-lived lover of things material

Like all those poets with a dream for a horse

I cannot but go the same road as martyrs and clowns

...

The sun is my name

The sun is my life

On the sun's mountain peak is buried poetry's corpse - a millennial kingdom and $I$

riding a five-thousand-year-old phoenix and a dragon called "horse"-I must fail

but poetry itself, being the sun, must emerge victorious

«Ancestral Land» is not original or subtle by any standard, in content or form. It doesn't suggest experience but announces it instead. It harbors no ambiguity or paradox and doesn't generate any dramatic tension. It is composed of big words on big themes such as the pain of human existence and the identification of the speaker with nature and the universe. These themes, however, are not stimulated to emerge in the reader's mind but explicitly asserted, on the assumption that a tormented, self-aggrandizing soul has poetic value in itself. The poem doesn't require an active reading attitude, leaving the reader little room for initiative. As regards a possible concern with poetry or language per se, it makes manifesto-like statements which the reader is asked to accept without what we may call artistic arguments in modern poetry: things like original imagery, defamiliarization and discernible rhythm on the level of lines or stanzas. The centrality of the first-person

\footnotetext{
${ }^{54}$ Haizi 1997: 377-378.
} 
speaker doesn't grant him, or the poem, any individuality. On that note, the line I plunge into this fire (我投入此火, in a passage left untranslated here), recalls establishment poet Guo Xiaochuan's «Plunge into the Fiery Struggle» (投入火热的斗争, 1955) - just like Haizi’s «In the Fall, Remember the Pain of Spring And Remember Lei Feng» (秋日想起春天的痛苦 也想起雷锋, 1987) echoes the «Song of Lei Feng» (雷锋之歌, 1963) by that other figurehead of Political Lyricism, He Jingzhi. ${ }^{55}$

These things call attention to an interface of avant-garde textsincluding famous works of early Obscure Poetry as well as Haizi's work - with Maoist orthodoxy in their shared predilection for solemn, deeply ideological grand narratives, a connection that Yeh has characterized as one of subtle literary complicity. ${ }^{56}$ Haizi's intertextuality with Guo is especially interesting because while his style in «Ancestral Land» is similar to that of Guo's collectivist Political Lyricism of the 1950s, he employs it to preach a kind of social heterodoxy in which the $I$ is an ill-adjusted figure by mainstream standards. And yet, in its loudness and its appeal to ethno-cultural identity - references to China as the birthplace of a new poetry "of greatness" (伟大) occur throughout Haizi's writings - this poem seeks a kind of social endorsement, a measure of approval within the avant-garde.

Judging from its present status, it has succeeded. Witness, for instance, the fact that its subtitle (With a Dream for a Horse) is the name of a multiple-author anthology edited by Chen Chao, part of a 1993 six-volume set with obvious canonizing ambitions, edited by Xie Mian and Tang Xiaodu, called A Review of Trends in Contemporary Poetry (当代 诗歌潮流回顾). ${ }^{57}$ In addition to its potential for a romantic reading, supported by Haizi's biography - in phrases like short-lived lover of things material, poetry's corpse and I must fail - this is explained by the manifestolike characteristics of the first stanza. The line like all those poets with a dream for a horse recurs in penultimate position in the first eight of its nine stanzas. Its semantics fit the said romantic poetics perfectly. In addition, the original is rhythmically beautiful and the line's central word group, with a dream [mèng] for a horse [mă] (以梦为马), contains a powerful alliteration in two of four equally stressed syllables. Last but

\footnotetext{
${ }^{55}$ Guo 1985: 45-51, Haizi 1997: 364, He Jingzhi 1979: 366-426.

${ }^{56}$ Yeh 1996a: part 2.

57 Chen Chao 1993, Xie Mian \& Tang 1993.
} 
not least, the concept of the ancestral land (祖国) and the fate of the nation is a favorite topos throughout the history of Chinese poetry, classical and modern alike. «Ancestral Land» is typical of Haizi's grandiloquent side. Qua poetry, I find it much less successful than the other poems in this section. I have discussed it in recognition of its popularity in China.

«Spring: Ten Ghildren Haizi» (春天, 十个海子, 1989) is radically different from «Ancestral Land», but equally famous. My rendition of 海子 'Haizi' as child Haizi is motivated by the homophony of the poet's name and 孩子 'child,' noted above. It is inconceivable that any sinophone reader - or writer - would be unaware of the ambiguity, not just when hearing the poem recited and knowing its author's name but also when reading it on the page..$^{58}$

\section{«Spring: Ten Children Haizi»}

Spring: ten children Haizi all come back to life in a landscape of light laughing at that one wild, wretched child Haizi you slept a long, deep sleep, but what was it for

Spring: ten children Haizi and their deep, angry howl surrounding you and me, dancing and singing tearing at your black hair, straddling you, speeding off, dust flying the pain when you're chopped open spreads across the earth

In spring, that wild and weretched child Haizi

is the only one left, the last one left

this is a child Haizi of night, immersed in winter, admiring death unable to free himself, burning with love for the hollow, cold countryside

There, the grain is piled up high, blocking out the windows they use half on the mouths of a family of six, their eating and stomachs and half for farming, their own reproduction winds blow from east to west, from north to south, defying night and daybreak you spoke of the light of dawn, but what does it mean

Most if not all of the manuscripts in Haizi's legacy were meticulously dated, noting the year, month and day the poem was written, completed or reworked from earlier drafts. «Spring» is dated "14 March 1989,

\footnotetext{
${ }^{58}$ Haizi 1997: 470.
} 
in the small hours, 3 to 4 am," the specificity of the moment before dawn contributing to the romantic image of the poet. By all accounts, it was the last poem Haizi wrote. Zou Jianjun's admiring, exclusively biographical = thanatographical reading - he says the poem shows Haizi "going bravely unto his death"-illustrates how such information can reduce the poem to a document of human interest and fail to do it justice as literature. Poet-critic Yu Jian, one of Haizi's most vociferous detractors, does something similar, but in derogatory fashion. He refuses to take the image of ten children Haizi as anything but an instance of megalomania and vanity on the part of an author whose poetic oeuvre he calls "The Flowers of Evil, grown in the Mao Era," calling attention to the interface with orthodoxy with much aggression and little nuance. Yu presumably borrows Baudelaire's phrase to summarize his assessment of Haizi's work rather than point to any textual kinship with the French symbolist's oeuvre..$^{59}$

As is true for «Ancestral Land», there are textual triggers in «Spring» that lead to association with Haizi's life, and with his suicide: a family of six, ten children Haizi come back to life and a child Haizi ... admiring death, as well as the poem's general tone of despondency. The last line, for instance, yields two distinct readings. One intimates that in spite of what you said, the light of dawn doesn't appear. The other questions the light of dawn as an archetypal moment of hope and new beginnings, which Haizi does in a 1986 diary entry as well: "Daybreak is not at all a beginning, she should be the last one to get there, the one that clears away the night's corpse. $" 60$

But if the said textual triggers may be seen as another "prophesy of death," this is where the similarity with "Ancestral Land» ends. I find «Spring» an infinitely better poem, hard-hitting with an entirely different kind of power, which I attribute to its original imagery and its personal, private style, as well as to a sense of proportion. The speaker produces no clichéd, predictable phraseology, but lays out despair without marshaling the loud and none too subtle strategies of persuasion encountered elsewhere in Haizi's oeuvre. As such, of the three

59 «Peach Blossom» (桃花) is dated 15 March 1989, but should be taken as part of the "peach blossom" and "peach tree" series commenced in 1987 (Haizi 1997: 448-455). Zou Jianjun 1999: 236-237. Yu Jian's presentation at the International Institute for Asian Studies Workshop on modern Chinese poetry (Leiden, September 1995) and personal communication (February 1997), Yu Jian 1995c: 140-141.

${ }^{60}$ Haizi 1997: 880. 
poems discussed above, «Spring» is closest to «Moved», but it has a stronger sense of urgency. Authenticity is a tricky notion, but «Spring» and «Moved» come across as authentic in that the poetic voice isn't on a quest for social endorsement or even understanding - and yet leaves a lasting impression, in spite of or indeed thanks to the poem's weirdness and its casual embrace of diverse semantic domains, moods and protagonists. Just like in «Moved», one senses the possibility of transfer between them: the various children Haizi, both come back to life and wretchedly still alive, as well as you and me. Different from Yu Jian, I hold that the astonishing image of ten children Haizi and their return to life (复活 'come back to life,' 'resurrection [of Jesus Christ]') does in fact steer clear of megalomania. This is because any self-aggrandizement is undercut by the cruel scenes in the rest of the first and second stanzas and because of the poem's questions at two crucial moments, their dejection visible in the absence of question marks: but what was it for . . but what does it mean.

The canonization of «Spring» is evidenced by its appearance in numerous multiple-author anthologies, including those covering orthodox poetry as well as the avant-garde. ${ }^{61}$ Its reception history is inseparable from the issues raised in the first half of this chapter. "Spring» is one of Haizi's best poems, but not because it was the last thing he wrote before he killed himself. ${ }^{62}$

Haizi wrote a good number of ode-like poems in dedication to various addressees, including someone identified as "S," the Pacific Ocean and "the last night and the first day." Two are simply called «Poem in Dedication» (献诗, both 1989). Dedication as a fundamental attitude, regardless of its application to any particular object, or perhaps dedication to poetry itself, both fit the exaltation that Haizi's poetry and poetics exude. These are the opening and closing stanzas of «In Dedication to the Dark Night»(黑夜的献诗), written in February 1989

61 Xie Mian \& Meng 1996: 456.

62 In the title and the first line of «Spring», there is a curious echo of Wu Shaoqiu's «Spring: There Is a Child Falls in the River» (春天, 有一个孩子掉进河里). Wu's work appears in Born-Again Forest (次生林, 1982), an unofficial collection of avant-garde poetry compiled by Zhong Ming, using the pen name Shi Jile (1982), which Haizi is likely to have read. Wu's poem contains this long line: The child has not got up again.... as if there were footprints, together with the rivulet, slowly wriggling, slowly coming back to life... But the intertextuality is strictly lexical (spring, child, coming back to life), and fragmentary at best. 
and with the additional caption "in dedication to the daughter of the dark night": 63

The dark night rises from the earth

blocks out the brightest sky

on the bleak earth after harvest

the dark night rises from inside you

You come from afar, I must go afar

the long road comes through here

there's nothing at all in the sky

why does that comfort me

Flocks of birds like dark raindrops

fly from dusk into the dark night

there's nothing at all in the dark night

why does that comfort me

Walk down the road

and sing out loud

wind across the mountains

above it all the endless sky
黑夜从大地上升起 遮住了光明的天空 丰收后荒凉的大地 黑夜从你内部上升

黑夜, literally 'black night' or 'dark night,' is conventional poetic usage, usually best translated as night. I have added the adjective-and made the English heavier, perhaps clumsier, than the Chinese - in order to retain the contrast of darkness and brightness in the first stanza, the resonance of dark night in dark raindrops (黑雨滴) and so on.

The first stanza is another example of the effective formal organization that is visible in a small number of Haizi's poems. Just like in «Clasps a White Tiger», all four lines in the original are eight characters long and unpunctuated. There is end rhyme in lines 1 and 3, and lines 2 and 4. These qualities enhance the effect of typical Haizi imagery - night, earth, sky, harvest - in that they make it cohere. Night falls, or rather, it rises, when the daughter of the dark night in the poem's motto arrives and the speaker leaves on a journey afar. What follows in the third and fourth stanzas, left untranslated here, is rural scenes in which the harvest is equated with bleakness, logically yet

${ }^{63}$ Haizi 1997: 319, 359, 472-478. For the «Poem[s] in Dedication», see 474 and 476; for «In Dedication to the Dark Night», see 477-478. 
paradoxically, both in the fields and in the granaries, and the speaker claims to see the eyes of Yama, the Chinese-Buddhist King of Hell, inside it. Throughout the poem, the speaker undergoes an ever stronger, yet ambiguous identification with the rural and the natural world, beautifully captured in the penultimate stanza through more patient variations on dark night. The original of the first two lines of the final stanza shows Haizi’s ability to fit powerful plain words (大白话) to poetic, song-like form. Like «Ancestral Land», «In Dedication» is made of big words on big themes. Here, however, they derive powerful effect from the poem's musicality and from the thoughtful, repeated negotiation of central imagery. Rather than announcing this or that type of "greatness," «In Dedication» evokes an intensely personal vision that is at once vulnerable and detached, and hence capable of generating profound emotion. Just like in «Spring», a question without a question mark suggests that the speaker doesn't expect any answers: there's nothing at all in the dark night / why does that comfort me.

$*$

Inasmuch as Haizi's writing can be characterized as a poetry of exaltation located at the Elevated end of the spectrum, his work is akin to Obscure Poetry, and specifically to its ethno-cultural streak in Jiang He and the early Yang Lian. Also, Haizi took part in a late 1980s discursive move by Xi Chuan, Chen Dongdong and others, embodied by the journal Tendency, which aimed to counterbalance colloquializing and vulgarizing trends that had challenged the Obscure poets' primacy within the avant-garde. ${ }^{64}$ Yet, Haizi's work is fundamentally different from Obscure Poetry in that it moves away from socio-political ideology and toward the establishment of a truly individual lyrical subject - that is, when it doesn't indulge in clichéd megalomania. Also, it contains much less "difficult" imagery, quite aside from the question to what extent such imagery ever functioned as camouflage for a political message in Obscure Poetry.

Haizi's significance in Chinese poetry is easy to deduce from his publication and publicity record, meaning both what he wrote himself and how well it has sold, and what others have written about him.

${ }^{64}$ Van Crevel 2007. 
That things would have been different had he not killed himself is another matter. His poetry and his poetics present an amalgam of diverse material and influences, including Chinese history, mythology and language as well as the (Chinese) natural and rural world; and predecessors in literature and art from a wide range of times and places, most of them foreign, as they came to him in Chinese translation. While traceable influences in the works of many contemporary Chinese poets and their reading histories display an international outlook, most of them also cite (classical) Chinese poetry as a source of inspiration and pride. Haizi, however, felt little regard for classical or modern Chinese poets to date. He makes an exception for $\mathrm{Qu}$ Yuan, who qualifies for poetic "martyrdom" as the tragic-heroic founding father of Chinese poetry and poethood - even if he lived in the kingdom of Chu and had his Chineseness imposed on him only retrospectivelyand, of course, as one said to have drowned himself. ${ }^{65}$ Also, the occasional echo of Maoist Political Lyricism such as that practiced by Guo Xiaochuan and He Jingzhi is unmistakable in Haizi's work. Perhaps his tendency toward self-aggrandizement, exaltation and a romantic vision of poethood is the flipside of what I have called the receptiveness of his poetics. Be that as it may, the best parts of Haizi's oeuvre will stand the test of time by virtue of their sheer intensity, and his current popularity in China reaches far beyond the avant-garde inner circle and exceeds that of most other authors. Finally, as much as his material and influences may be historically identifiable and regardless of any inclination to demythify his life and work, we shouldn't lose sight of the individual impulse that lies at the root of his art — without taking recourse to mythologies of an all-powerful creative genius whose very existence annuls the need for critical, intersubjective reflection on the work it leaves behind.

Thanatography is presumably as old as suicide itself. This doesn't disqualify it as a topic for continuing reflection. For Haizi's poetry, I hope to have shown that the poetic voice deserves more attention than it has hitherto received.

${ }^{65}$ Haizi 1997: 880. See Schneider 1980 for a fascinating discussion of the myth of $\mathrm{Qu}$ Yuan through the ages, including its rewritings in early modern era and contemporary times. 


\section{CHAPTER FOUR}

\section{EXILE: \\ YANG LIAN, WANG JIAXIN AND BEI DAO}

Exile and its manifestations in literature are of all times and places. Examples from Chinese literary history include the archetypal exilecum-poet $\mathrm{Qu}$ Yuan, banished to the countryside of Chu in antiquity, and large-scale wartime migration from the mainland to Taiwan in the 1940s. For the People's Republic of China, the government's crackdown on the 1989 Protest Movement dramatically heightened the relevance of literatures of exile (流亡) and related categories such as banishment, diaspora, and wandering or drifting overseas through foreign lands (放逐、流放; 流散、离散; 漂流、漂泊; 海外、异乡), with a prominent role for poets. ${ }^{1}$

When the tanks rolled into Tiananmen Square, Yang Lian (1955), one of the authors studied below, had been away from China for almost a year, on visits to Australia and New Zealand. Bei Dao (1949), who features most prominently in this chapter, was in Germany on what should have been a longish trip taking him to a conference in the United States followed by several months in Northwest Europe. Duoduo's story is comparable to Yang's and Bei Dao's, although he left China after June Fourth, on one of the last planes out of Beijing before the airport was shut down under martial law. His departure on what turned out to be a momentous day in modern Chinese history had been arranged months earlier, following invitations to the Rotterdam Poetry International festival and a conference at the London School of Oriental and African Studies. He had planned to travel in Europe afterward, for a few months at the most. As Yang, Bei Dao and Duoduo joined in the international outrage over violence in the

\footnotetext{
${ }^{1}$ Images of Qu Yuan as embodying dissent and eccentricity and hence exile in the broadest sense, inclined if not bound to express itself in literature, remain influential to this day; Schneider 1980, Leys 1978: xix, Yeh 1991a: ch 2, 1996a and 2005. In addition to the material used in the present chapter, scholarship and other writing on exiled poets from the PRC includes Lee (Gregory) 1993b, Li Xia 1999, Hawkes 2007, Huang Yibing 2007a and 2007b, and Porter 2007.
}

(C) MAGHIEL VAN CREVEL, 2008 | DOI 10.1163/9789047442738_005

This is an open access chapter distributed under the terms of the Creative Commons AttributionNoncommercial 3.o Unported (CC-BY-NC 3.0) License. 


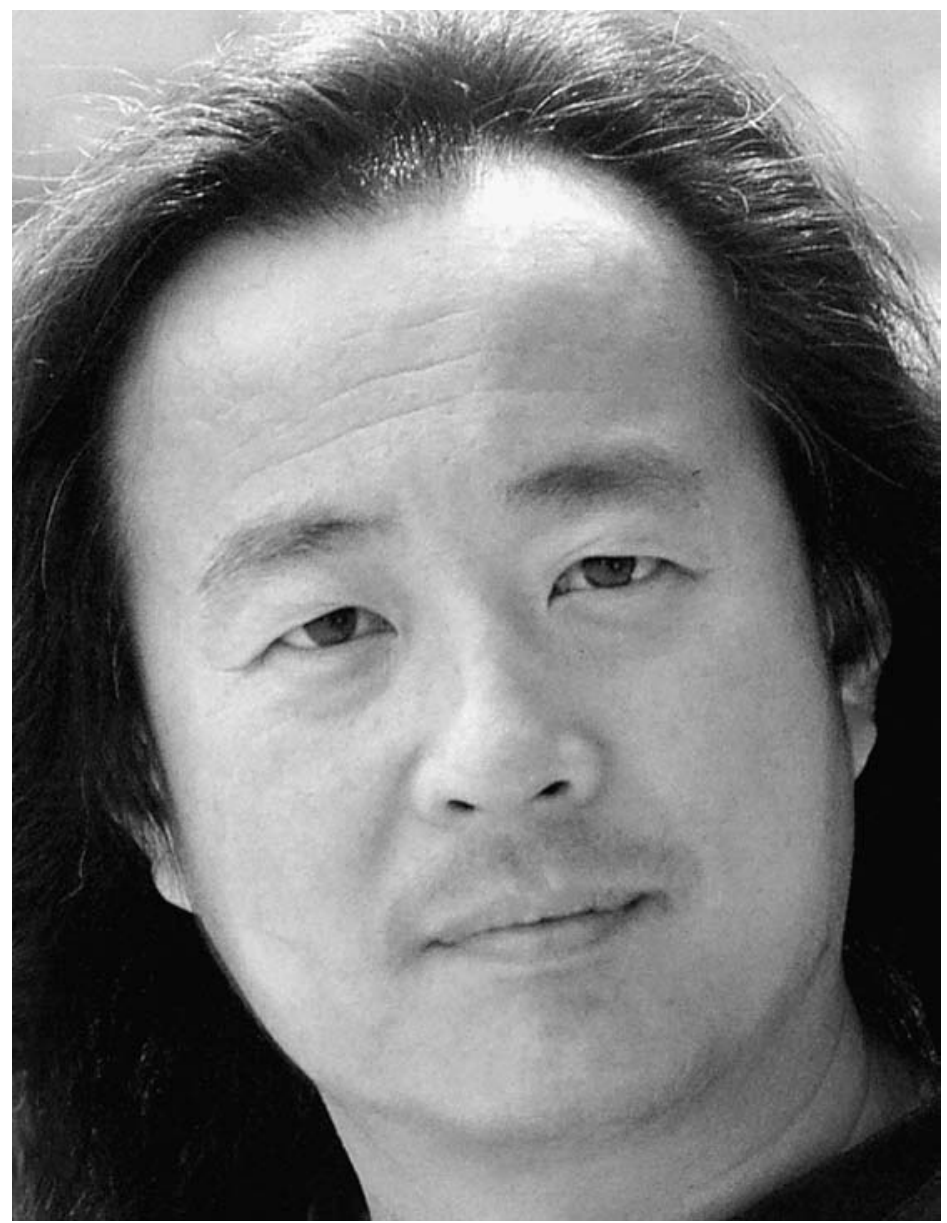

Figure 4.1. Yang Lian, 2004 (photograph by Song Zuifa) 
name of law and order in their native land - Duoduo as one of the first witnesses of the mayhem in Beijing to arrive in the West-all three became enmeshed in an uncontrollable media discourse that tended to portray them as exiled political dissidents rather than poets. Contrary to plan, they ended up staying abroad. Other mainland-Chinese poets had moved to foreign countries from the mid-1980s onward, including Zhang Zhen, Yan Li, Zhang Zao, Jiang He, Beiling and Gu Cheng, in roughly chronological order. I cite Yang Lian, Bei Dao and Duoduo as examples because they were overtaken by the events at home while journeying abroad. Partly as a result, they enjoyed — or suffered — high visibility as exiles. Each traveled widely and lived in various countries before settling in the UK, the USA and the Netherlands respectively, and later making the occasional short-term visit to China, now as holders of foreign citizenship. Duoduo eventually returned to live in China in 2004.

During the cultural purge after June Fourth and later in the 1990s, yet more poets went on long sojourns or settled abroad, most if not all in Western countries. Wang Jiaxin (1957), the third poet discussed in this chapter, lived in the UK in 1992-1993. Others include Jingbute, Xue Di, Hu Dong, Song Lin, Zhai Yongming, Ouyang Jianghe, Huang Xiang, Meng Lang and Xiao Kaiyu: again, in roughly chronological order, from soon after the massacre until the turn of the century. Several had had their brushes with the Chinese authorities, with experiences ranging from intrusive surveillance to imprisonment. If this was usually on account of political protest or intellectual and cultural activism that were incompatible with state-sanctioned orthodoxy, that is not to say they were all "dissidents" who happened to write poetry, an infelicitous description of the sort that has often been applied to Bei Dao and others. For their subsistence many Chinese poets abroad have relied on adoption by cultural and academic networks, as writers in residence and sometimes as teachers. Such support has been motivated by their post-June-Fourth status as exiles among other things. I second Haun Saussy's rebuttal of Zhang Xudong's disparagement of the integrity of institutions outside China that have supported them, and of their poetry, as noted in chapter One. Zhang shows little regard for the development of their art over the years. ${ }^{2}$

\footnotetext{
${ }^{2}$ Cf Duckworth 1991 and Zhang Zhen 1999b: 65. Saussy 1999, Zhang Xudong 1997: 136.
} 


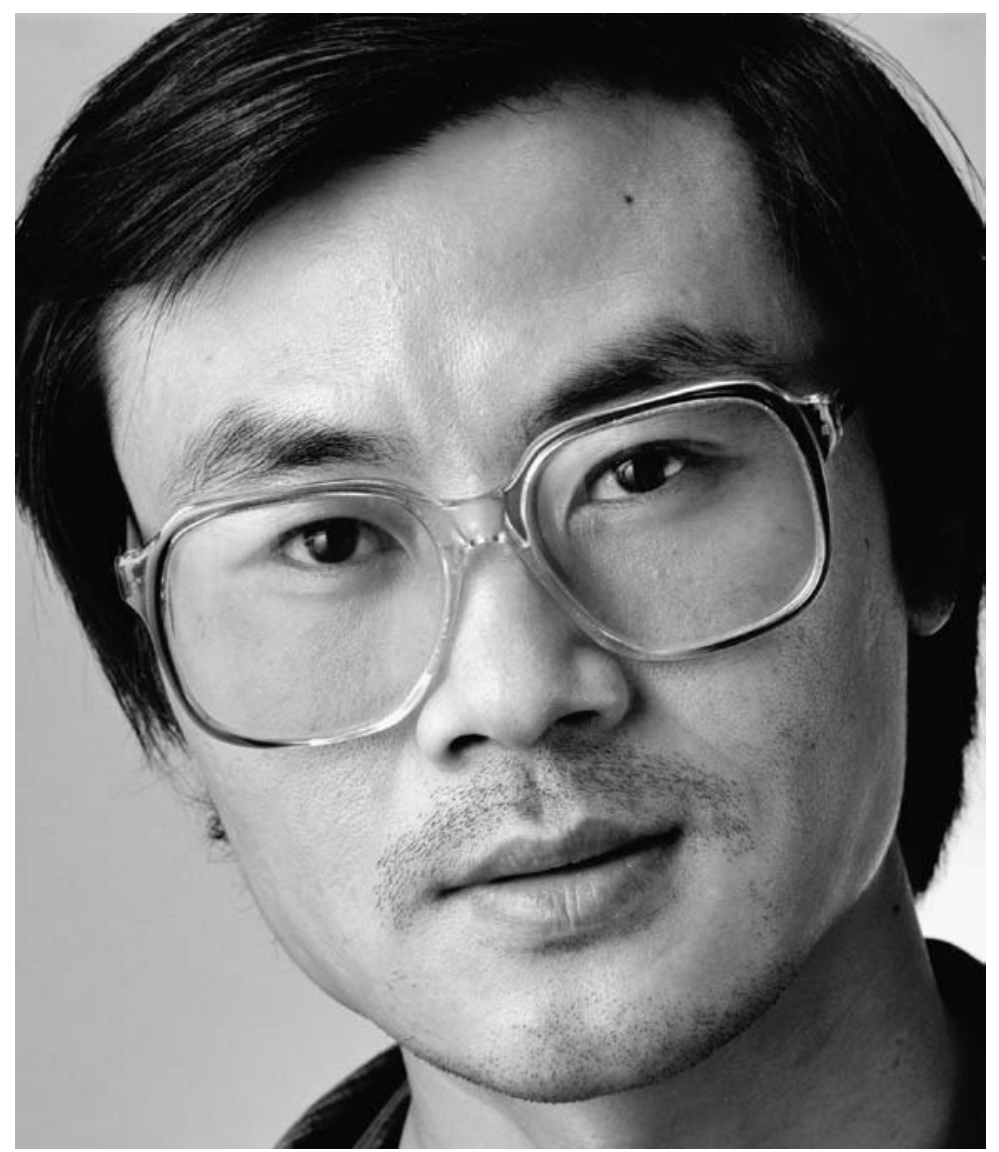

Figure 4.2. Wang Jiaxin, 1992 (photograph by Pieter Vandermeer) 
The presence of poets in mainland-Chinese exile literature is visible in the 1990 revival of Today outside China, with its editors scattered across continents. The new Today emerged in response to June Fourth and contributors were initially envisaged as mainland-Chinese authors abroad, but the journal soon cast its net wider. Smuggled into China from day one, in the early 1990s it counted as blacklisted material. While the journal has since become less dangerous or even "sensitive" (敏感) to have in one's possession, postal delivery inside China remains erratic. Like the old Today, it carries fiction, drama and criticism as well as poetry, but many of its associates are poets - editor-in-chief Bei Dao, for one - and it continues to be primarily identified with poetry. Two other foreign-based journals with PRC roots and centrally featuring poetry are Yan Li's New York-based First Line (一行, since 1987), and Beiling's Tendency (倾向, 1993-2000). Both journals dissociate themselves from orthodox PRC-domestic discourse, and Beiling and Meng Lang have emphatically linked Tendency to underground and unofficial writing inside China, and made it part of their (personal) exile narratives. Yet, neither journal has the (perceived) exilic-literary identity of the new Today. ${ }^{3}$

The notion of exile is as common in popular and scholarly discourse as it is complicated. Does exile presuppose physical displacement, or is it a "homeless" state of mind that can befall one "at home" as well as elsewhere - or, an actively sought-after distance from centers of power and authority and from collective identities? If exile presupposes physical displacement, must this come about as a consequence of political persecution or coercion, economic need, danger? Is the exile's habitat always forced upon them, as the lesser of two evils at best? Is exile always involuntary or should we make room for what Robert Edwards calls the overlay of compulsion and will? Are exile and happiness mutually exclusive? Is exile always terrible to experience, in the words of Edward Said, or can it become comfortable, perhaps even turn into a preferred mode of existence? Does exile have creative potential - might it even be, in whatever form, a prerequisite for originality? Bringing in literature gives rise to additional issues, some

${ }^{3}$ See the editorials to Today 1991-1 and 1991-2, Bei Dao \& LaPiana 1994 and Bei Dao \& Zha 2006: 78. The classification of First Line as an exile journal in Wan Zhi 1997b: 81 is post hoc and, interestingly, doesn't occur in the original Chinese edition (1997a: 72). Cf the discussion of Yang Lian's self-presentation in English, below. Beiling 2006 and 2007, Meng 2005. 


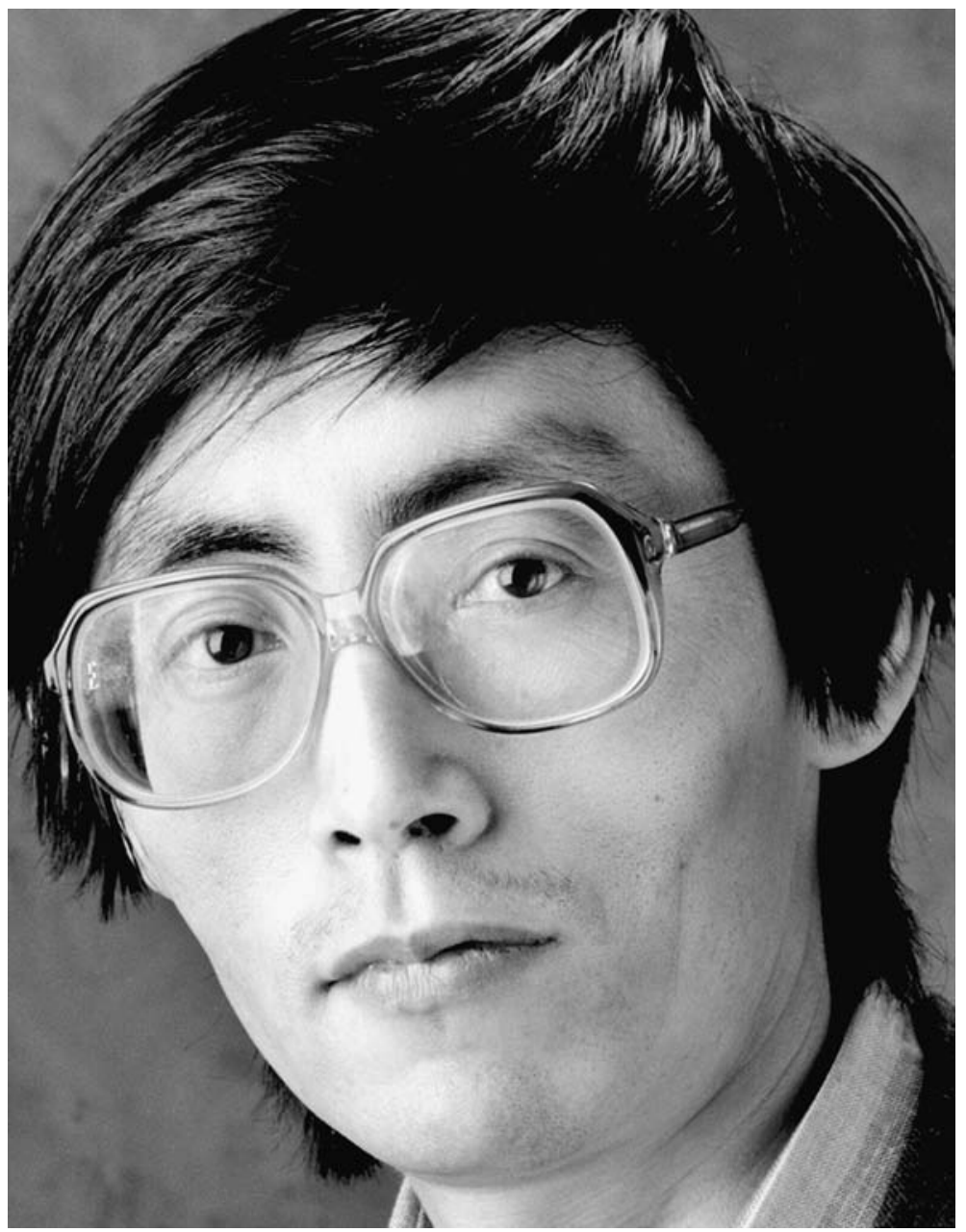

Figure 4.3. Bei Dao, 1988 (photograph by Pieter Vandermeer) 
of them analogous to those surrounding categories such as women's literature, as David Bevan remarks. Do writers in exile automatically produce exile literature? Can one write exile literature inside one's native land? How do audiences fit into definitions of exile literature? What about literary content and form?

Paul Tabori points out that the question is who does the defining. This point holds for exile and exile literature alike, all the more so since conceptualizations of exile have grown in scope and currency over the past several decades. In this light, we should work less than ever toward closure or generalization, and instead reflect on definitional choices and their potential for inclusiveness; and emphasize the possibility of reading for exile rather than essentializing texts or authors. ${ }^{4}$

My argument starts from the observation that Yang Lian, WangJiaxin and Bei Dao have been called poets in exile or explicitly associated with the status of exile, by others and by themselves. This has mostly happened in popular and scholarly texts published outside China. If the term rarely occurs inside China, this is at least partly because it has at times been "sensitive" or politically incorrect by orthodox standards and must often fall victim to (self-)censorship, except when used sarcastically. ${ }^{5}$ Below, in section 1, I take a closer look at Yang's, Wang's and Bei Dao's exile designations, using a theoretical framework proposed by John Glad. In section 2 I read for exile in their poetry. Exile and diaspora have obvious interfaces, but my analysis doesn't aspire to contribute to diaspora studies of Chinese literature or Chineseness as constituting ethnic or cultural identity. Following William Safran and Tom Cheesman and Marie Gillespie, I take diaspora as having

\footnotetext{
${ }^{4}$ Edwards 1988: 18, Said 2001: 173, Bevan 1990: 3, Tabori 1972: 35-36, Hanne 2004: 1-6.

5 The term 流亡 'exile' doesn't appear in Keywords in Contemporary Chinese Literature (中国当代文学关键词), a book whose editors are known for their receptiveness to new trends (Hong \& Meng 2002). It is also conspicuous by its absence in Zhao Xun 2002 (on Wang Jiaxin) and Yang Siping 2004: 238-249 (on Bei Dao, with the chapter heading referring to his post-1989 career as去国 'leaving the motherland'). Personal communication by several poets and critics working in PRC poetry scenes and comments in Zhao (Henry) 1997a: 116 (or 1997b: 133) and Bei Dao \& Tang 2003: 164 also point to the "sensitivity" of 流亡 'exile,' and its vulnerability to censorship. These things fluctuate: Yiping 2003, Zhang Hong 2003: 98-103 and Tang Xiaodu 2006 do speak of 流亡 'exile.' Of course, 流亡 'exile' is also in competition with other terms like 海外 'overseas' and 流散 'diaspora,' as in the 2003 Overseas Diaspora Literature Series (海外流散文学丛书) edited by Henry Zhao for the Hundred Flowers Literature \& Art Press.
} 
stronger connotations of social formation than exile. Diaspora is more about being in networks of others of similar origin, however comfortable or uncomfortable, powerful or powerless, who are living in two or more foreign regions; and exile is more about the individual's not being in the homeland, and often fundamentally alone. ${ }^{6}$

The aim of this chapter is twofold. First, for Yang, Wang and Bei Dao, I hope to clarify a label with loaded and controversial connotations. Outside China "exile" will frequently lend the poet an aura of heroic victimhood, whether they embrace this or reject it. Inside China, on the other hand, identifying with exile or being cited as having exile status abroad often provokes dismissive comments - not only or even primarily from orthodox quarters, but from within the avantgarde. The ingredients typically include the charge that the poet has sold out to foreign audiences and at the same time bamboozled them by claiming to be the victim of political persecution, arrogated the right to speak on behalf of all of China, lost touch with their mother tongue and so on; incidentally, such allegations have also been exchanged between poets abroad. ${ }^{7}$ Especially in the first few years after June Fourth and continuing until the late 1990s, a breakdown of communications between domestic and exile poetry scenes was perhaps inevitable for reasons both material and psychological, with members of each scene scoffing at texts and people in the other of whose situation they hadn't necessarily kept abreast, until long-distance telephone and the Internet became widely available. To some extent, domestic and exile scenes have been competing for the stamp of authenticity and Bourdieuian legitimacy in present-day Chinese poetry. An interesting in-between case is that of Zhang Zhen, who left China on her own initiative in 1983 and later felt that some poets whose exile was linked to June Fourth perceived her as unauthentic in her capacity of Chinese poet abroad. ${ }^{8}$ This is one of many individual stories that complicate any simple inside-outside dichotomy.

\footnotetext{
${ }^{6}$ E.g. Tu 1991, Ang 2001, Chow 1993, Wong (Lisa Lai-ming) 2001 and Teng 2005. Safran 1991, Cheesman \& Gillespie 2002.

${ }^{7}$ Cf Lovell 2002: 66-67 and 2006: 144-152; e.g. Yu Jian \& Zhu 1994: 133 and Yu Jian \& De Meyer 1995: 30; Huang Xiang 2005.

${ }_{8}^{8}$ See chapters Eleven and Twelve for domestic denigrations of exile poetry, and Yang Lian 1996 and 1998c and Gao Xingjian \& Yang 1994: 313-314 for dismissive comments by Yang Lian on domestic scenes. Bourdieu 1993: 38ff. Zhang Zhen 1999b: 61-63.
} 
Second, in an approach that is akin to that laid out in the previous chapter, I hope that my readings of poems by Yang, Wang and Bei Dao help counter the dominance of biography and historiography in the reception of poetry written in exile. If much (Western) scholarship politicizes poetry from the PRC, this is understandable in light of the Chinese government's active involvement in cultural matters, and justified as long as the argument is based on evidence and methodologically sound. By contrast, popular media and non-specialist audiences often simply display overwhelming interest in the poet's personal history, which becomes a political history in that it is automatically taken to be the product of institutionalized repression. This involves a prejudice that does no justice to the subtleties of the literary text and is boosted in press releases and blurbs by foreign publishers, who know that suffering sells better than symbolism. Yang Lian says of this: ${ }^{9}$

For Westerners, if a Chinese writer writes in China, he must be "underground"; if he lives abroad, he must be an "exile." If a Chinese poet is introduced to a Western audience, as soon as the word dissident is mentioned, the audience immediately relaxes - the poet's opponents have guaranteed that the poems must be good.

Other examples occur in Bei Dao's bilingual poetry collections. David Hinton, translator of Forms of Distance (1994), begins his introduction thus: "Bei Dao is by now well known as the most prominent literary voice in China's political opposition." The blurb on the back cover of Unlock (2000) starts in similar fashion: ${ }^{10}$

Bei Dao, the internationally acclaimed Chinese poet, has been the poetic conscience of the dissident movements in his country for over twenty years. He has been in exile since the Tiananmen massacre of 1989 .

Bei Dao's is a literary voice, what it says is often poetic, and his oeuvre contains texts that may justifiably be called political, although they are hardly fit for policy-making or, for that matter, appreciation beyond the high-cultural niche in which the avant-garde finds itself- but to make these qualities mere attributes of his alleged primary status as activist is to turn things on their head. It also disregards Bei Dao's literary track record over the last three decades, and what he has said about his role as a poet. The order of things is as follows. First, he is a poet.

\footnotetext{
9 Yang Lian 1998c: 18.

10 Bei Dao 1994: vii and 2000.
} 
Second, this has occasionally enabled him - and perhaps, following a traditional Chinese poetics, made him feel obliged - to remonstrate with the rulers of his native land. ${ }^{11}$

As for my focus on Yang, Wang and Bei Dao, we will return to this in section 2. There are of course other poets from the PRC to whose life and work the present inquiry could have extended. Duoduo, for instance, is generally recognized as having had exile status during his fifteen years abroad, and Wang Jiaxin isn't the only one whose exile status is open to debate. But on Duoduo and exile, I have written elsewhere; and Wang's case is interesting precisely because it is controversial. $^{12}$

\section{Poets in Exile}

Even though they have visited China since their effective displacement in 1989, Yang Lian and especially Bei Dao are clearly poets in exile. As for Wang Jiaxin, there is a case to be made for viewing his sojourn in England as a period of exile too. ${ }^{13}$

For these claims, I base myself on John Glad's model of writing literature in exile, which sidesteps some of the less objectifiable aspects of exile literature. The editor of a volume of essays by starkly different voices that somehow hang together, Glad defines literature in exile as literary creation outside the boundaries of one's native land, taking the writer's physical displacement as his point of departure. Glad's approach is akin to that adopted by John Spalek and Robert Bell, who specifically assess how the physical exile experience affects the writer's style and means of expression - with Adrienne Ash's contribution arguing forcefully against prejudiced views of poetry as less suited to the negotiation of exile than fiction. Examples of research on modern Chinese literature with a similar outlook to Glad's and Spalek and Bell's

${ }^{11}$ For the traditional Chinese poet's "solemn duty" of remonstration, see Idema \& Haft 1997: 48; for the continued impact of traditional views of literature on PRC writers, see Link 2000: ch 3.

12 Van Grevel 1996: ch 4 and 221-234.

${ }^{13}$ Biographical and bibliographical detail draws on Yang's, Wang's and Bei Dao's publications (including “chronicles" [年表], interviews and prose writings such as Yang Lian 1998b and Bei Dao 1998 and 2004) and those of their commentators, and on personal communication over the years. 
are Oliver Krämer's work on writers publishing in the new Today and Lawrence Wang-chi Wong's study of Wen Yiduo in the USA. ${ }^{14}$

In its turn, we might define exile literature as foregrounding the experience or the notion of exile, regardless of its author's whereabouts at the time of writing and their biography at large. Accordingly, section 2 of the present chapter examines issues that Glad's model doesn't initially highlight. These include literary content and form, and a vision of exile as the (modern) poet's fundamental state of mind - and as such the stuff that modern poetry is made of to begin with. But let's first consider Glad's dimensions for literature in exile.

\section{i. Circumstance}

Certainly up to the mid-1980s, Yang Lian's work was controversial inside China. A recent claim that makes him co-founder of the old Today is inaccurate, but he did contribute to the journal's last two issues in 1980. ${ }^{15}$ Yang has since counted as a core author of the Obscure Poetry that was central to politically charged debates on the arts over the next few years. He was among those targeted by the 1983-1984 government campaign to Eliminate Spiritual Pollution and experienced trouble publishing his work in $1984 .{ }^{16}$ Following trips to Hong Kong and Europe in 1986, he left China together with his wife Yo Yo in August 1988, for a six-month visit to Australia, whence they moved on to New Zealand. As the Protest Movement took shape in Beijing and other cities in China, Yang publicly voiced his support for the student demonstrators. When, in the early days of June 1989, the massacre made headlines around the world, Yang and Gu Cheng published an impassioned indictment of the Chinese government, in a pamphlet entitled Words of Mourning (悼辞). Subsequently, Yang remained active to denounce the suppression of the Protest Movement. Inside China, later in 1989 collections of his poetry and essays were still formally published, but their circulation was withheld or severely limited. The essay collection is difficult to pinpoint as the censor's trigger, since it

\footnotetext{
${ }^{14}$ Glad 1990: ix-x; Krämer 1999 and 2002; Spalek \& Bell 1982: xiv; Wong (Lawrence Wang-chi) 1993.

${ }^{15}$ On the back covers of Yang Lian 1999 and 2002b. Yang's work appeared in Today under the pen name Fei Sha.

${ }_{16}$ On Yang Lian's and Bei Dao's problems during the campaign, see Edmond 2006: 115 and McDougall 1993: 81-82.
} 
was banned as part of a multiple-author book series called Toward the Future (走向未来) that was terminated in its entirety. As for Yang's poetry collection, a number of copies did actually reach their readers and made it into domestic and foreign libraries. In any case, there is every reason to believe that at the time he was on a censorial blacklist of sorts. The fact that such lists are difficult to obtain, verify or evaluate doesn't make their existence any less real. ${ }^{17}$ Had Yang gone back to China in the first few years after June Fourth, he could have expected problems with the authorities and would have been unable to write and publish without their interference. He first returned for a visit late in 1993, with New Zealand citizenship, and has since regularly gone back. He has said that toward the end of 1989, the trouble surrounding the publication of his two books and a failed attempt to renew his Chinese passport made him realize that his original intention to travel and return had to be superseded by a decision to live in exile and view the People's Republic as a foreign country unless it should see political change. ${ }^{18}$

Has Yang Lian perceived and presented himself as an exile? As noted by Krämer, at one point in the early 1990s Yang resented the Chinese term 流亡 ‘exile' and preferred 漂泊 'wandering. ${ }^{19} \mathrm{He}$ has, however, continued to use both terms, and the Chinese part of his website speaks of his literary career in exile (流亡生涯). Presumably in consultation with his translators, he has stuck with exile in English and its cognates in other European languages. This may be because of its currency in general usage, or, in Barmé's words, the "bankability of packaged dissent." Examples include numerous newspaper and journal publications, the English part of Yang's website and the title of a dialogue he originally conducted with Gao Xingjian in 1993. The dialogue appeared in German and Italian in 2001 as What Has Exile Brought Us? (Was hat uns das Exil gebracht?) and The Bread of the Exile: Chinese Literature before and after Tiananmen (Il pane dell'esilio: La letteratura cinese prima e dopo Tienanmen), and was excerpted in English for Index on Censorship in 2002, as "The Language of Exile: When Pain Turns to Gain." Interestingly, its 1994 domestic publication in Chi-

7 Beach 2001: 13-15.

18 For Words of Mourning, see Yang Lian 1990: 41-42. Mabel Lee's translation is entitled "In Memory of the Dead" (3-4). Yang Lian 1989a and 1989b are the books whose circulation was withheld or limited.

19 Krämer 1999: 168. Krämer translates 漂泊 as floating. 
nese is called "What Have We Gained from Wandering?” (漂泊使我 们获得了什么?) and has 漂泊 ‘wandering' and 流浪 'roaming' in the main text, but on Yang Lian's website, a later reference to the Chinese title has 流亡 'exile' instead. In sum, Yang has frequently referred to his circumstances as exile in the popular, concrete sense of banishment. Indeed, biographical fact is occasionally obscured by an exile label that expands as time goes by — not just forward, but backward as well. The blurb on his 2002 bilingual collection $Y_{i}$ claims: "His work was banned in China in 1983, and he has since lived in exile as a citizen of New Zealand." This is, quite simply, misleading. Of course, authors and translators are not necessarily responsible for blurbs in their final form. ${ }^{20}$

On a final note concerning his self-perception and self-presentation, Yang Lian has used the word 流亡 'exile' in poems written after June Fourth-and in semi-fictional prose, such as the powerful "Ghostspeak" (鬼话, conventionally meaning 'lies'). So have Bei Dao and Wang Jiaxin. In section 2, we will consider the relation of literary text and authorial biography in this respect. ${ }^{21}$

Bei Dao's relationship with the authorities was tense from the start of his literary career in the late 1970s, when he was editor-in-chief of the old Today, outside the confines of state-sanctioned literature. A few years on, like Yang Lian, he was among those individually attacked by orthodox critics during the campaign against Spiritual Pollution, and was banned from publishing well into 1984. In the mid-1980s Bei Dao became China's best-known modern poet, making several trips abroad and living in the UK as writer in residence at Durham University in 1987-1988. In February 1989 he drew up a public petition to the National People's Congress and the Communist Party Central Committee on behalf of 33 intellectuals and artists, in which he expressed support for Fang Lizhi's open letter to Deng Xiaoping requesting amnesty for political prisoners. When, later that month, government security personnel prevented Fang from attending a dinner hosted in Beijing by USA president George Bush, Bei Dao spoke

${ }^{20}$ Barmé 1999: ch 7. Yang Lian website. Gao Xingjian \& Yang 1994; see Gao Xingjian \& Yang 1994: 320ff and 2001a: 91ff for the use of 漂泊 and 流浪 in the Chinese edition, and exil in the German edition. On the $Y i$ blurb, cf Twitchell-Waas 2005: 334-335.

${ }^{21}$ Yang Lian \& Yo Yo 1994: 217-221 and Yang Lian 1998b: 15-20; for an English translation, see Renditions 46 (1996): 92-96. 
up again, this time by himself, urging China's rulers to get used to "hearing different, even discordant, voices." 22 Over the next months he was harassed by the police and came under the credible threat of arrest. It may well have been only because of the emergence of the Protest Movement in April and the media attention that came with it that his mid-1989 trip to the USA and Europe could go through. During the Protest Movement students publicly cited Bei Dao's poetry. ${ }^{23}$ After June Fourth, like Duoduo and Yang Lian, he found himself on foreign soil and took part in public protests against the Chinese government's brutal action. Had he gone back to China, he would have got in serious political trouble.

From this point onward Bei Dao's work was thoroughly banned from domestic publication. In 1991, for instance, the entire print run of Wang Bin's Critical Anthology of China's New Poetry in the Twentieth Century (二十世纪中国新诗鉴赏辞典) was confiscated when the books were about to reach the bookstores, with only a couple of copies slipping through into private libraries, the reason being that this tome of a book, some 1500 pages long and featuring 443 authors, contained six short poems by Bei Dao. The fact that all had been previously anthologized any number of times makes the incident a poignant illustration of the retroactive workings of ideological assessment and censorship. When a new version of Wang's original project appeared in 1998, Bei Dao's poetry had been duly removed. ${ }^{24}$

Bei Dao's family was torn asunder in the years after June Fourth. In 1989 his wife, the painter Shao Fei, and their daughter Tiantian were kept from boarding a plane at Beijing Capital Airport that would have taken them toward reunion. In the following years Shao Fei and Tiantian were never granted exit visas at the same time. In November 1994 Bei Dao's effective banishment by the Chinese government was confirmed when he flew to Beijing from the USA but was stopped at the border and summarily deported.$^{25}$ Between 2001 and 2005, he was allowed a number of short-term visits - the first when his father was critically ill — on condition of keeping a low profile and only leaving

\footnotetext{
${ }^{22}$ On a series of such petitions and similar activities in the first months of 1989 , see Barmé \& Jaivin 1992: 23-30.

${ }_{23}$ Bei Dao \& LaPiana 1994, Li 1995: 11, Yeh 1996b, McDougall \& Louie 1997: 430, Saussy 1999.

${ }^{24}$ Wang Bin 1991 and 1998.

25 See Van Crevel 1996: 97-98.
} 
Beijing for domestic travel with official permits. In «For Bei Dao» (给 北岛, 2004), Shizhi recalls one such visit: ${ }^{26}$
At parting, when you turned and walked away from me
a gust of wind lifted your coat up high
taking you along to drift through foreign lands
unceasing worry made me set pen to paper that night

In 2005 the authorities suspended the intermittent permission they had given Bei Dao to visit China and restore something of a "real" domestic presence. On the level of a single individual, this illustrates the PRC authorities' tactics of alternate release (放) and restraint (收) in their exercise of political control, lucidly analyzed for the realm of literature by Perry Link. ${ }^{27}$ Bei Dao's conditional right of entry was suspended after he refused to comply with demands for ideological submission and politically correct behavior, as measured by the Communist Party's position on issues such as June Fourth and, more generally, human rights.

As for Bei Dao's self-perception and his public presentation, whereas he appears less committed to maintaining a strong media presence than Yang Lian, and has - like Yang - often vented his frustration at the politicization of his poetry that the word exile almost invariably entails, he has also referred to himself as a poet in exile ever since June Fourth. Barely a month after the massacre, in an interview with Suizi Zhang-Kubin, he outlined the future of PRC literature in three compartments: official, underground and exile. When invited to write an autobiographical essay for the Amsterdam cultural center De Balie in 1990, he called it “An Exile Looking Back" (一个流亡者的回顾). There are many more such examples. ${ }^{28}$

The circumstances of Wang Jiaxin's sojourn abroad are less clearcut than those of Yang Lian or Bei Dao. Wang appeared on the heels of the early Obscure poets featured in Today that include Bei Dao and Yang Lian. He counts as one of the most senior of a younger generation - or, depending on historical and critical perspectives, as a junior associate of the Today poets, with whom he established contact early on, during his student days in Wuhan. In the second half of the 1980s,

26 Shizhi 2006: 221-222.

27 Link 2000: ch 2. See also Pollard 1985: 655.

${ }^{28}$ Bei Dao \& Zhang-Kubin 1989: 57-58, Bei Dao 1990, Bei Dao \& WedellWedellsborg 1995 (conducted in 1992), Bei Dao \& LaPiana 1994. 
having moved to Beijing, Wang was an editor at the influential Poetry Monthly and a respected poet in his own right. Both in the Poetry offices and in important anthologies like Selected Contemporary Experimental Chinese Poems (中国当代实验诗选, 1987), which he co-edited with Tang Xiaodu, he played an instrumental role in publishing younger avant-garde authors. ${ }^{29}$ After June Fourth, when the authorities tightened their grip on education, the media and cultural life, the Poetry editorial board was reshuffled, and in 1990 Wang lost his job. Positive motivations aside - a wish to see the world beyond China's borders, as Yang Lian and Bei Dao had done in the 1980s - Wang's two-year stay in England in 1992-1993 may well be viewed as the result of a conscious decision to lie low during a time of intense political repression, when finding new, meaningful employment after having left $P_{0-}$ etry would have been exceedingly difficult. He began planning to leave the country and in fact left it before there was any hint of the relative political relaxation that arrived in mid-1992, three long years after June Fourth.

Wang Jiaxin hasn't presented his time in England as an instance of exile forced upon him by the Chinese authorities. Yet, several avantgarde poets inside China-Shen Haobo, Yi Sha, Xu Jiang, Song Xiaoxian, Tang Xin - have mounted scathing attacks on him for making unjust claims to exile status, summed up in Yi's words as Wang's "pseudo-exile" (伪流亡). The explanation may lie in their resentment of Wang's habit of citing near-exclusively foreign greats as kindred souls in literature, coupled with his self-assigned "fate of exile" in a 1994 poetical statement, and this description of himself in the preface to a 1997 collection of his poetry:

Always on the road. Always running, then held up again without recourse or hope; always get to the end only to find that it is but a beginning; always take to the road inside one's words, but forever without a home to return to; always between native soil and foreign lands.

The book's title, Moving Cliffs (游动悬崖), alludes to the rocks called the Wanderers in Homer's Odyssey, one of the dangers on the long way home of Odysseus, an archetypal exile in Western literary traditions. A couple of pages on, Wang cites an adage saying that "when you finally come home, you will be a stranger" to explain his feelings upon

${ }^{29}$ Tang Xiaodu \& Wang 1987. 
returning to China early in 1994. Also, 流亡 'exile' frequently occurs in the poetry he wrote during his time abroad and in earlier poems such as his 1990 homage to Pasternak. The pseudo-exile charge, however, is part of larger diatribes by Shen, Yi Sha and company delivered during the 1998-2000 Popular-Intellectual Polemic, with Wang as the favorite Intellectual target of Popular hellraisers. ${ }^{30}$

\section{ii. Place of Publication}

Glad's second question is whether the writer publishes in the home country, legally or clandestinely, or with foreign publishers. As noted, two of Yang Lian's books were banned or had their circulation impeded in China in 1989; the new Today, to which he has contributed from the start, was clandestine when taken into China, especially in the early years; also, as pointed out by Jacob Edmond, Yang has continued to publish in the domestic, unofficial circuit, which is not clandestine but stands in fluctuating opposition to the official publishing world and censorship. In 1991, however, an official, joint production of Yang's long poem $F_{i}(\mathbb{R})$ and a commentary by Yufeng was published by the Hunan Literature \& Art Press in Changsha, and in 1998 and 2003 the Shanghai Literature \& Art Press put out surveys of his oeuvre to date. Edmond sees the 1998 publication as signaling Yang's "reengagement with the official Chinese literary market" after June Fourth. In China, “provincial” (外省) publishers and other cultural institutions are less susceptible to political strictures than those in Beijing. Edmond argues that also in the capital, increased acceptability of Yang's work in the PRC had already been visible in a 1994 collection of essays by him and Yo Yo, published by the Central Editions \& Translations Press. Another Chinese-language collection by Yang appeared in the same year with the Taiwan Modern Poetry Press in Taipei, but for present purposes this counts as a publication abroad. Over the years, in several countries and languages outside China, Yang has built up a long list of journal and book publications of his poetry in translation, some also containing the Chinese originals. ${ }^{31}$

${ }^{30}$ Shen Haobo 1998, Yi 1999b, Xu Jiang 1999b, Song Xiaoxian 1999, Tang Xin 2000, Yemen 2001: 305. Yemen appears to be a pseudonym of Yi Sha. Wang Jiaxin 1994: 99 and 1997: 2-5, 64-66.

${ }^{31}$ Edmond 2006: 111, 113 et passim; Yang Lian 1991, 1998a, 1998b, 2003; Yang Lian \& Yo Yo 1994, Yang Lian 1994a. 
Bei Dao's publishing record is similar to Yang's, although his work has been censored more harshly inside China. Early in 2003, following journal publication of some of his short prose, survey anthologies of Bei Dao's poetry by the South Sea Press and the Hundred Flowers in Literature \& Art Press marked the end of a fourteen-year domestic publication ban, albeit with several instances of (self-)censorship. The opportunity was not lost on scholars and critics, who began publishing the commentaries on his poetry that had been out of bounds since June Fourth. The presentation of Bei Dao's two new books, published in Haikou and Changchun, was extremely cautious. Aside from the actual poetry, in the glaring absence of prefatory essays by one respected critic or another that would have accompanied the work of this one of China's greatest poets under different circumstances, all they contain is minimalist blurbs on the inside cover noting the author's residence abroad and his earlier book publications. In the meantime an impressive series of journal publications and books of Bei Dao's poetry had appeared with major publishers outside China, both in Chinese, in Hong Kong and Taiwan, and in other countries and languages. Like Yang Lian's foreign publications, some of these books are bilingual. In fact, while Bei Dao had published an unofficial collection as early as 1978, his first official book had also been a bilingual edition, edited and translated by Bonnie McDougall and published in the USA in $1983 .{ }^{32}$

Wang Jiaxin's (official) publication record inside China shows a relatively quiet spell in 1992-1993, when he was living abroad, but his work was not banned, nor has it ever counted as particularly "sensitive" in comparison to other avant-garde poetry. In the fall of 1993, the Southern Poetry Review (南方诗志), an unofficial journal out of Shanghai, carried a special feature on his work; so did the official, scholarly journal Poetry Exploration in 1994, after Wang had returned. Outside China, in addition to foreign-language publications in journals and multiple-author anthologies, the Wellsweep Press brought out a bilingual computer disk containing a selection of Wang's poetry with English translations by John Cayley, and sound recordings of Wang's recitation of the Chinese texts. ${ }^{33}$

${ }^{32}$ Bei Dao 2003a and 2003b. Yiping 2003, Bei Dao \& Tang 2003, Yang Lihua 2003, Zhang Hong 2003: 63-106, Yang Siping 2004: ch 13. Bei Dao 1978 and 1983.

${ }_{33}$ Wang Jiaxin 1993. 


\section{iii. Intended Primary Readers}

Before anything else, we should note that none of the three poets ever switched to writing in a foreign language, in poetry or other genres. Their intended primary readers, then, would be readers of Chinese and probably those "back home," in Glad's words: that is, in mainland China. They have also published in other sinophone settings, and geopolitical boundaries such as those between the PRC and Taiwan shouldn't automatically determine literary classification. Yet, everything from the poetic texture of Bei Dao's, Yang Lian's and Wang Jiaxin's work to its reception shows their locus of belonging to be the PRC avant-garde and its readers, regardless of the censor's success in denying them access to what we may call their native readership. Also, Wang didn't have the exposure outside China that would have warranted realistic hopes for a foreign primary audience. In Bei Dao's and Yang Lian's case, such hopes are less outlandish.

In a 1990 review of The August Sleepwalker, a 1988 collection of Bei Dao's poetry in English translation, Stephen Owen contemplated the possibility of the poet writing with translation in mind, and using "fungible" words to facilitate their future foreign renditions. The August Sleepwalker led William Jenner to opine that the contemporary Chinese language is unfit for writing poetry. Suffice it here to note that Owen's review displays a vision of the creative writing of both originals and translations that is difficult to comprehend, especially coming from the supremely accomplished translator that he is himself. As for Jenner's claim, any informed look at contemporary Chinese poetry will show that it is hard to take this seriously, just like his simplistic vision of (Chinese) poetry's (un)translatability. Then again, sweeping statements like Jenner's are something of a genre unto themselves. Another example, which ironically complements Jenner's assertion, is the early Bei Dao's contention that the formal requirements of Chinese ancient-style poetry "make it hard to express anything more complex than nostalgia or the parting of friends." 34

Should we wish to consider the possibility that Bei Dao and other Chinese poets really write for foreign audiences or in an inherently unpoetic language, with reference to Glad's model it is worth noting that this ordeal is apparently unconnected to their whereabouts, for

${ }^{34}$ Owen 1990, Jenner 1990, Bei Dao 1999. 
The August Sleepwalker is largely a product of Bei Dao's pre-exile years. This still holds if we take his 1987-1988 sojourn in the UK as a time of pre-1989 exile, even though at the time, he hadn't been literally banished from China. Bei Dao has recounted his initial euphoria at the "golden years" of 1985-1986 for literature and art in the PRC, and cited disappointment and weariness at Hu Yaobang's fall from power and yet another curtailment of cultural liberalization early in 1987 as one of the reasons for his first long stint abroad..$^{35}$

\section{iv-v. The Way of Life and the Language of the Host Country}

Glad's fourth and fifth dimensions compare the way of life and the language of the host country to those of the country of origin. For ways of life, Glad offers a scale from roughly comparable (Germany to Scandinavia) to significantly different (Hungary to Austria) to radically different (USSR to USA) to overwhelmingly different (Somalia to France). In this scheme of things, for all three poets, the ways of life of their host country or successive host countries would be radically different from China; and the language, overwhelmingly different. This makes their decision to continue to write in Chinese more or less self-evident, especially since they had had limited exposure to foreign languages before leaving China. ${ }^{36}$

\section{vi. Repatriation}

Glad calls repatriation the most emotional dimension, and asks whether the writer accepts or rejects it, if it is available to them to begin with.

For Wang Jiaxin, repatriation was indeed an available option, if not the only one. Considerations of livelihood, political status and immigration procedures combined, it is impossible to say if he could have continued to live in the UK or elsewhere outside China. Also, Wang 77.

35 On the arguably exilic nature of Bei Dao's time in the UK, see Bei Dao 1990:

36 After some early work in Chinese, Li Li has primarily written in Swedish, and only recently translated some of his poetry into Chinese. He is, however, an émigré rather than an exile (Krämer 1999: 167). Li is not well known as a poet in China. Cf note 46 . 
had planned to live abroad for an extended period but not indefinitely, which makes his "acceptance" of repatriation a moot point.

Not so for Yang Lian and Bei Dao, as the above discussion of their circumstances shows. Since 1993 Yang has visited China freely, albeit on a foreign passport. Other such "foreigners" have been denied entry to their country of origin - Bei Dao, for example - and the 1998 and 2003 publications of something very close to a collected works would seem to imply the possibility, however uncertain or qualified, of Yang going back to continue his literary career in his native land. Without condoning any degree of censorship, I note that textual differences of Yang's 1998 domestic survey anthology with his publications abroad that point to (self)-censorship are limited to things like the removal of massacre (大屠杀) from the title of one poem, of the year nineteen eighty nine (一九八九年) from that of another - incidentally, this phrase does occur in the title of a published poem series by Ouyang Jianghe - and of the prose poem «The Square», full of direct references to June Fourth, in its entirety. ${ }^{37}$ Many foreigners are now living in China, and many of those previously in exile have returned, whether as Chinese or as foreign citizens, including Duoduo. Yang Lian has, however, rejected repatriation on political grounds, stating that he doesn't wish to be part of China under its current political system and this system's current implementation. Whether his exile could be called "enforced" as late as 1999, as on the cover of his bilingual English-Chinese collection Where the Sea Stands Still, is open to debate. None of these considerations cast doubt on Yang's exile status per se.

Bei Dao's 1994 deportation from the Beijing airport made him what Glad calls a "true exile," in that repatriation hasn't been an option, regardless of whether he would want to resettle in China. True enough, 2003 saw the domestic publication of two rich collections of his poetry, but the conditional nature and the recent revocation of his right of entry belie any assumption that the authorities have developed a tolerance for his presence and his writings. Witness, for instance, his otherwise inexplicable exclusion from the Selected Poetry by Famous Contemporary Chinese Poets series mentioned in chapter Three.

${ }^{37}$ On (self-)censorship of Yang's post-1989 poetry for official publication in China, see Edmond 2006. On literary censorship in the PRC, see McDougall 1993 and Link 2000: ch 2 and 2002. Ouyang 1997: 123-130. 
How does the sixth dimension qualify the writer's exile status? Arguably, the most exilic situation occurs when a writer is banished and wants to repatriate but is barred from doing so by the authorities in the country of origin. The other dimensions can be seen to work in similar ways. The stronger the tension between the desire to belong to a - geographic, ethnic, cultural, linguistic - community of origin or "home" on the one hand, and the impediments to such belonging on the other, the greater the multi-dimensional distance and the farther into exile one travels, in the figurative as well as the literal sense. The operative notion is that of distance. As long as one experiences "here" and now as meaning away from "there" and then, the predicament of distance will only end if "there" should somehow fade or disappear. Seen thus, the relative poignancy of exile is a function of the enduring relevance of "there," meaning a place where one is no longer. Hence, the frequent association of exile with nostalgia. According to this interpretation of Glad's dimensions, the farthest one can travel into exile would be by being forced to leave one's native land for a deeply different, "alien" host country and barred from returning; and continuing to write in one's native language but being unable to publish in the community of origin. The utter loneliness of this situation - as an abstraction, aside from the writer's individual experience - is wrapped up in the fact that the actual, foreign audience is not the one the writer primarily wants to address.

\section{Shades of Exile}

In sum, Yang Lian's and especially Bei Dao's status as poets in exile is more than a transient label or a mere blip in literary or media discourse. One can see why Li Dian calls Bei Dao "the face of contemporary Chinese poetry in exile," and why the blurb on Yang Lian's $Y i$ says that the author "stands with Bei Dao and others as one of the major living Chinese exiled poets."

The complexity of exile makes assessing the "true" nature, the "authenticity" or the "legitimacy" of individual cases a tricky business, not made any easier by the phenomenon of groups or individuals engaging in the strategic packaging of dissent and, more generally, privileged

${ }^{38}$ Li Dian 2006: 37, Yang Lian 2002b. According to Li, Bei Dao has managed to make a living in this capacity, and is the only Chinese poet in exile to have done so. 
types of marginality and victimhood. ${ }^{39}$ Still, without taking recourse to romantic hierarchies of tragedy, freedom, adversity, heroism and so on, one observes that Wang Jiaxin's story is less exilic, because his time away from China was shorter than Bei Dao's or Yang's and his work was never attacked by domestic orthodox critics. Then again, the sequence of events that led to his sojourn in the UK-June Fourth and the subsequent cultural purge - and the vast differences between China and England as well as his personal account of his time abroad justify his designation as a poet in exile for the years 1992-1993. Especially for Wang, we need to bear in mind what Tabori calls the dynamic nature of exile, including the possibility of its termination, and hence its hindsight description as temporary. ${ }^{40}$

If I consider Bei Dao's, Yang's and Wang's designation as poets in exile justified, and proceed to read for exile in their poetry, this is not in order to claim ultimate or exclusive validity for the exile label as "capturing" the poets or their work, but rather to adopt one possible, significant perspective.

\section{Exile in Poetry}

The original motivation of this chapter lies in my desire to write about Bei Dao's work. Accordingly, while I only discuss a small number of his poems, my treatment of his poetry is more elaborate than that of Yang Lian and Wang Jiaxin. A look at Yang and Wang, however, is worthwhile not just because of the quality of their writing, but also because their coordinates and those of Bei Dao overlap. All three are avant-garde poets from the PRC in exile after June Fourth and most of the poetry cited below is from the early 1990s. How do its authors differ in their negotiation of the exile factor? For all the damage it may do to individual lives, crudely summarized as an all-pervading sense of loss - of "home" in the broadest possible sense, of the self, indeed of life itself ${ }^{41}$ - the experience of exile has powerful creative potential, as many of those living it and their commentators have observed.

\footnotetext{
${ }^{39}$ Lagos-Pope 1988: 10, Glad 1990: xii; cf Buruma 2000, Teeuwen 2004.

${ }^{40}$ Li Dian classifies Wang as such, calling him one of Bei Dao's fellow poets in exile (2006: 30-31). Li's implied, similar categorization of Shu Ting is less convincing. Tabori 1972: 34 .

${ }^{41}$ Cf Edwards 1988: 16, Bevan 1990: 4.
} 
Tabori's central thesis, for instance, is that throughout history exiles have made important, lasting contributions to their host countries in a range of fields, including literature and art. If Said, in "Reflections on Exile," is at pains to debunk glorifications of exile and stresses its mutilations instead, he too recognizes its creative potential. He focuses on the individual, lived experience of exile rather than its literary manifestation, extending his vision to the millions of displaced people who are not famous poets, artists, scientists, dissidents, activists and so on - not enough, though, to pacify Ian Buruma's critique of the devaluation of exile by postcolonial theory. More germane to the present discussion, Said does note the major role exiles have played in modern cultural production; and here Buruma concurs with him. Joseph Brodsky, without glossing over exile's horrors, points out that it can stimulate the writing process, paradoxically intensifying one's experience of the native language from whose primary habitat one is removed. Bevan, echoing Said's terminology, shows that mutilation and invigoration co-occur within single individuals. Similarly, according to Eugene Eoyang, dépaysement - in the sense of disorientation - is both a calamity and an opportunity. Exile and Creativity: Signposts, Travelers, Outsiders, Backward Glances, edited by Susan Suleiman, and Creativity in Exile, edited by Michael Hanne, constitute major contributions to the discussion. The former came out of a 1996 special issue of Poetics Today that expressly asks whether exile is a spur to creativity. The essays in Exile and Creativity offer a resounding yes, centrally featuring the unique benefit of distance after separation from one's origins. Contributor Svetlana Boym concludes that "estrangement is a survival kit," and "[exile] is not just a misfortune - it is also a cultural luxury." Hanne's volume shows how the notion of exile has expanded since the Second World War and the Cold War, and now encompasses evergrowing numbers of nameless refugees and displaced people as well as the high-profile intellectual experience; and how the expression of creativity in exile avails itself of a range of different media, in addition to (literary) language. ${ }^{42}$

42 Tabori 1972: 12, Said 1984: esp 49-50, Brodsky 1990: 106-108, Buruma 2000 (see Teeuwen 2004 for an interesting response to Buruma 2001), Bevan 1990: 4, Eoyang 1998: 219, Suleiman 1998, Boym 1998: 260, Hanne 2004. My emphasis on exile's creative potential doesn't detract from the legitimacy of "demythologizing" exile (Zhang Zhen 1999b: 64). 
Practitioners and critics of PRC literature, too, have remarked on exile as a positively productive force. To be sure, they lament the ordeal of the individual and remark on specific problems encountered by writers in exile from the PRC and other places ruled by culturally intolerant, authoritarian regimes, which Edward Brown outlines succinctly in the context of Soviet-Russian literature. In addition to removal from the habitat of one's native language, such problems include the sudden absence of champions of government-sanctioned orthodoxy as safely despicable antagonists; the commodification, commercialization and mediatization of literature in the West, as forces that disfigure new-found freedom of expression; and the dissipation of one's social significance as a writer. For poets exiled from the PRC, all three points were of higher relevance in the years around June Fourth than later on, when high culture in mainland China was increasingly subjected to the interrelated forces of marketization and social marginalization. ${ }^{43}$ In the face of such adversity, however, authors such as Gao Xingjian, Yang Lian and Bei Dao note that exile has advanced their creative manipulation of language and jolted their writing into new territory. Scholars including Cheng Guangwei, Wolfgang Kubin, Yang Xiaobin, Leo Ou-fan Lee, Yiping, Zhang Zao and Li Dian have shown that the exile experience has enriched PRC literature and Chinese literature at large. ${ }^{44}$

Whether speakers and protagonists in the poems under scrutiny should be identified with their historical authors is not my primary concern - but while I try not to let author biographies dictate my readings, it would be a forced exercise in formalism to block out their occasional, compelling coincidence. This informs the use of male personal pronouns in the following pages.

\section{Yang Lian}

There is no dearth of commentaries on Yang Lian's poetry. In addition to insightful introductions and afterwords by his translators, Yang Xiaobin, Lin Xingqian, Jacob Edmond, Hilary Chung, Tang Xiaodu

${ }^{43}$ Brown 1984: 55-57, Kubin 1993, Bei Dao \& Wedell-Wedellsborg 1995: 233ff, Lee (Gregory) 1996: ch 5, Li Dian 2006: 29.

${ }^{44}$ Gao Xingjian \& Yang 1994: esp 315ff, Bei Dao \& Tang 2003: 164, 171. Cheng Guangwei 1993: part 3, Kubin 1993, Lee (Leo Ou-fan) 1995: 19, Yiping 2003: 163, Zhang Zao 2004: 194, Li Dian 2006: 32-37. 
and Tan Chee-Lay are among those who dwell on exile and related notions in their research on Yang Lian. ${ }^{45}$

Of two bilingual books of poetry Yang published in 1990, in Mabel Lee's translation, one is called The Dead in Exile. It contains poems written before Yang left China in 1988 as well as texts that explicitly respond to June Fourth. The violence of that historical moment jumps out at the reader, in an idiom easily recognized as an extension and indeed an intensification of Yang's earlier work.

This point calls for a brief digression. Significantly, it shows June Fourth and Yang's ensuing exile functioning as catalysts of an individual track of poetic development that had started a decade earlier. Something similar holds for other mainland-Chinese authors, including Bei Dao and Wang Jiaxin, but also for broader trends in the intellectual and cultural sphere: disenchantment with government ideology and the attendant discourse, the ebbing of the high culture fever, and commercialization of the cultural realm at large. Arguably, then, June Fourth can be seen as an exceptionally powerful catalyst of the emergence of PRC exile literature itself - as one of several concurrent trajectories of cultural change - rather than its root cause. In addition to the poets mentioned earlier, practitioners of other genres had also settled abroad in the 1980s, under exilic circumstances. Two well-known examples are playwright-novelist Gao Xingjian and Liu Binyan, the doyen of PRC reportage literature. ${ }^{46}$ Knowledgeable about foreign literature and having come up against censorship in the early stages of his career - for "spiritual pollution," like Bei Dao and Yang LianGao declined to return to China while on a visit to France in 1987. A domestic ban on his work remains in force today. Liu's exposure of corruption in the Communist Party and social abuses had put him through many ordeals inside China before his effective banishment

${ }^{45}$ For Yang Lian's individual books of poetry in Chinese and for bilingual English-Chinese editions, including those not cited here, see Van Crevel 2008a; Yang Lian 2002a and 2006 are monolingual English-language editions. English translations of some early poems are included in Renditions 19/20 (1983) and 23 (1985), and in Soong \& Minford 1984. Yang Xiaobin 1994, Lin Xingqian 2001, Edmond \& Chung 2006, Tang Xiaodu 2006, Tan Chee-Lay 2007, Edmond 2008a and 2008b. Other scholarship includes Yip 1985, Golden \& Minford 1990, Lee (Mabel) 1990 and 1993, Zhuang 1993: ch 7, Bruno 2003, Edmond 2004, 2005a, 2005b and Edmond 2006, and Twitchell-Waas 2005.

${ }^{46}$ Authors of PRC provenance living abroad who write in other languages than Chinese (and had settled abroad when they started writing) such as Ha Jin, Dai Sijie and $\mathrm{Li} \mathrm{Li}$, are beyond the scope of the present inquiry. See also note 36. 
to the US in 1988. His prestige in post-1989 PRG exile communities is evident from a collection of essays by several tens of writers and intellectuals, entitled The Undying Exile (不死的流亡者). This important book, edited by Zheng Yi, Su Wei, Wan Zhi and Huang Heqing, is dedicated to "big brother Binyan" on the occasion of his eightieth birthday in February 2005 - in the nick of time, as Liu died in December. While The Undying Exile has June Fourth as its most conspicuous point of reference, the editors show that the history of PRC exile literature starts long before 1989. They leave room for various conceptualizations of exile and their earlier (Chinese) manifestations, including the domestic variety forced upon many PRC citizens during political upheaval such as that of the Anti-Rightist Campaign and the Cultural Revolution.

But back to Yang Lian. In an atmosphere that is unrelentingly nightmarish, many of Yang's poems from 1989-1990 present an astonishing, sometimes unmanageable density of images of bodily violence, death, mutilation and rot. They frequently feature the unborn or newborn child, conventionally a carrier of innocence and the promise of vitality, in ways that would count as perverse by everyday standards. These things have remained regular features of his work in later years - Simon Patton writes that Yang's fascination with death makes his collection Non-Person Singular "monotonous with morbidity"47_but in the aftermath of June Fourth, they relate directly to the massacre. Following a reprint of Yang and Gu Cheng's Words of Mourning, which assumes preface-like qualities, several poems in the book's opening sections engage with exile in outraged, sometimes bizarre scenes that cry out to be read as restagings of the carnage on and around Tiananmen Square. Examples include «To a Nine-Year Old Girl Murdered in the Massacre» (给一个大屠杀中死去的九岁女孩, 1989), «Bloodstains in Heaven» (天堂的血迹, 1989?), «Missing» (失踪, 1989?), «The Dead in Exile» (流亡的死者, 1990) and «The Year Nineteen Eighty-Nine» (一九八九年, 1990).

These poems speak a tormented language whose fury breathes an anxiety of powerlessness in the face of the horrors that had occurred in historical "reality." They address the event that led to the status of exile for many mainland Chinese, rather than the state of exile itself. Perhaps a better way of putting it is that outrage over the event makes

\footnotetext{
${ }^{47}$ Patton 1995b.
} 
it impossible to focus truly on the experience of exile: any realization of being "here" now irrepressibly mobilizes the memory of the massacre over "there." If we consider its author's individual situation, the distance increases and the anxiety of powerlessness widens in scope. Yang Lian's experience of June Fourth, on another continent, thousands of miles away, was mediated by radio, $\mathrm{TV}$, print media and probably the occasional live eyewitness account. As such it was fundamentally removed from a reality that was at the same time deeply confrontational. One surmises that the author must have experienced his activism in faraway foreign media and literary circuits as essentially different from "actual," on-the-spot engagement with it all, from being "there."

Notably, in itself, an analysis such as this - of the experience of exile in the author's life, inasmuch as it is visible in the public domaindoesn't suffice to explain exile poetry qua poetry, be it Yang Lian's or someone else's. Any account of the desperate, near-maniacal tone of Yang's writing in the first half year or so following June Fourth should take cognizance of his individual style, which had been aggressively exuberant from the beginning, in both his poetry and his explicit poetics, and sometimes tumid and megalomaniacal. His commentators differ on this point. Yang Xiaobin finds Yang Lian's "grand diction" productive in that it harbors a tension between the text's aspirations to the eternal or godly and its historical and human limitations. Lin Xingqian, whose analysis centers on The Dead in Exile, speaks of Yang's occasional "hysteria" and notes that his "hot-blooded" style isn't always conducive to the success of his work. ${ }^{48}$

But the opening sections of The Dead in Exile also contain a text called «The Book of Exile» (流亡之书), dated January 1990, that negotiates the exile factor in relatively quiet, reflective fashion: ${ }^{49}$

"The Book of Exile»

You are not here these strokes of the pen

barely writ down when mad winds sweep them away

emptiness like dead birds soars above your face

${ }^{48}$ Yang Xiaobin 1994: 118. Lin Xingqian 2001: 52, 61, 56, 46-54.

${ }^{49}$ Yang Lian 1990: 51 and 1998a: 310. The date of composition is only recorded in Lee's English translation (Yang Lian 1990: 14). For Yang Lian and Bei Dao, whose work has appeared in (Taiwan, Hong Kong and PRC) Chinese-language as well as bilingual editions, I include reference to Chinese-English editions wherever possible. 
funereal moon a severed hand

flips back your days

back to the page where you are absent

you write and all the while

you relish your deletion

Like anyone else's voice

bones crushed and spat in a corner just like that

the hollow voice of water on water

entering breath just like that

entering a pear without looking at anyone else

floor covered in skulls and each of them you

grown old overnight between the lines

as your poetry travels the world in hiding

«The Book of Exile» sustains Yang Lian's obsession with images of death and the body - diseased, violated, mutilated, killed - in the funereal moon and the severed hand in the first stanza, and the bones and skulls in the second. The poem doesn't, however, explode with physical disintegration and destruction, and it is much more contemplative than Yang's other poems. In addition, even though its author's biography as part of recent Chinese history — or recent Chinese history as part of its author's biography - may bring June Fourth to mind, this poem is not about June Fourth but about experiences of absence, disappearance, emptiness, insignificance, removal, loneliness, concealment and exile, as its title announces.

These things emerge in scenes that are part of an imagined, surrealized process of fruitless writing, throughout the first stanza and toward the end of the second. Also, in the first line of the second stanza, the voice, in a poem about writing, leads to association with recitation, but without the unique qualities normally ascribed to individual performance: like anyone else's voice, instead. A vital — and, deadly - identification of you with the act of writing occurs. You is because you writes and vice versa, and the absence or disappearance of the one means incapacitation or termination of the other at this moment, in the "here" and now of exile (here . . these strokes of the pen). ${ }^{50}$ The severed hand that flips back your days embodies an attempt to retrieve a past in which you was present, and the act of writing could still mean that strokes of the

${ }^{50}$ Cf Edmond \& Chung 2006: 19. 
pen would remain and not be swept away. But there is no way out of the "here" and now of exile, as you ends up back on the page where you are absent.

An alternative reading of the latter line is that the state of exile retrospectively disables or even annuls the past, with displacement disrupting a sense of continuity that might have been maintained had one still been "there," but is exposed as an illusion by the physical distance from "there" to "here." Thus, the past gains in importance at the same time as becoming out of reach and indeed questionable, not to say unreliable or deceptive. As a consequence, you grows old between the lines, or, as a literal translation might read, in the characters and between the lines, of a poetry that may travel the world but hides itself or is hidden, presumably from readers of other languages than its own - or from all readers. The ill-fated identification of you and writing, both in exile, expands on the identification of exile and writing. ${ }^{51}$ It is reinforced by the fact that the modern Chinese word 书 'book,' echoed in书写 'write' in the penultimate line of the first stanza, means 'to write' in classical Chinese. This would generate an alternative translation of the poem's title as «The Writing of Exile» or «Writing Exile», if only for academic purposes.

In the meantime, it turns out that Yang Lian has written exile with considerable success, as measured by his publication record. This leads me to propose what may be an unexpected reading for the final paragraph of «The Square» (广场), dated December 1989. «The Square» is a powerful prose poem, also included in the opening sections of The Dead in Exile. As noted, it is one of the few texts that were excluded from Yang's later survey anthologies published in Shanghai. It starts like this: ${ }^{52}$

In this your statement, you leave the month of June behind, and you leave that person behind.

The word rendered as statement (交代材料) literally means '[written] material accounting for [one's actions].' Mabel Lee translates it as confession. While it is definitely part of a semantic set including words like 检讨 and 自我批评 'self-criticism,' and 自白(书) and 口供 'confes-

${ }^{51}$ Cf Lin Xingqian 2001.

52 Yang Lian 1990: 58. Again, the date is provided with Lee's translation (Yang Lian 1990: 22-23). 
sion,' the interpretation of «The Square» as a confession is open to debate. If we imagine the text as a document determining its author's treatment at the hands of the authorities, what it does is to help him survive by denial. If there is anything to which it confesses indirectly, this would have to be complicity with the perpetrators of the violence in Tiananmen Square.

In «The Square», in the statement that is the poem, you systematically denies that June Fourth ever happened, describing the square as empty and paradoxically noting in great physical detail how people were not shot and did not die, to powerful effect. The poem's final paragraph reads:

You replace the paper, and the screams go far away. Write yourself up as another, and you will live. Writing stroke by stroke, you personally erase one month from the years of your life. You are lighter than before, you feel empty inside. That person has gone. Long before the square was covered in characters miswritten, it had been torn to pieces. Shreds of paper flying, fluttering down. The locust trees have always had white leaves.

The most plausible interpretation makes you a resident of Beijing who was in Tiananmen Square when the army opened fire; and, in order to survive, is later forced to deny that there ever was a massacre, thus betraying both the victims of the violence and that person, a former self that saw them being shot. The identification of you with the act of writing, and the image of the past as (mis)written - in this case, Tiananmen Square as an unspeakably or unwritably painful lieu de mémoire - operate just like they do in «The Book of Exile», composed barely a fortnight later.

At the same time, however, a pivotal moment in the final paragraph invites an alternative reading. The sentence Write yourself up as another, and you will live reverberates with Yang Lian's biography, even if that means cutting it off from its local context. By way of justification, the image captures what happened to the poet precisely around the turn of that fateful year, when the decision to stay abroad was forced upon him.

\section{Wang Jiaxin}

The fatefulness of 1989 is palpably present when Zang Di, writing in 1994, shows how "the year 1989" both redirected and catalyzed Wang 
Jiaxin's poetry. As noted in previous chapters, textual and metatextual discourse contain thinly veiled signals of censorship surrounding representations of June Fourth, and the cataclysm of change from the 1980s to the 1990s with June Fourth at its center. Ouyang Jianghe's essay "Writing Poetry inside China after '89: Indigenous Disposition, the Marks of Middle Age and Being an Intellectual" (89后国内诗歌 写作: 本土氣質, 中年特徵與知識份子身份, 1993) is a conspicuous example. This illustrates that censorship is a face-saving exercise among other things: we all know that we all know, but we just cannot say that we do. In addition to Zang, other critics who comment on exile and related issues in Wang Jiaxin's work are Cheng Guangwei, Chen Chao and Zhao Xun. Since Wang is less well known than Yang Lian and Bei Dao, especially outside China, I will provide some background before turning to the exile factor in his poetry. ${ }^{53}$

Without detracting from the avant-garde's pluriformity, there are a few crudely generalizable differences between Obscure Poetry on the one hand and the work of many younger poets on the other, especially those of Earthly inclination. One is that the rich, sometimes incomprehensible yet fascinating imagery found in the former - words that flaunt their metaphoric potential - is absent from the latter. We have seen, for instance, that the paucity of imagery in Han Dong is part of a poetics of disbelief and demystification, with a self-styled aversion to grand ontologies of poetry, and with much room for irony and "trivial" realities of everyday life.

While Wang Jiaxin's poetry displays little disbelief or irony, the above generalization does apply. Some of his finest poems contain few evident metaphors, if any. His overall presence on the poetry scenephilosophically inclined, serious if not solemn, introverted yet ambitious - displays kinship with authors such as the early Xi Chuan and

${ }^{53}$ Zang 1994; cf Zhang Hong 2003: 63-106, 135-139. Ouyang 1993a; while this first appeared in the new Today, it quickly entered domestic circulation through copies of the journal that made their way into China, and was frequently reprinted in domestic publications, recent examples including Wang Jiaxin \& Sun 2000: 181-200 and Chen Chao 2003: 165-185. Cheng Guangwei 1993, Chen Chao 1994, Zhao Xun 2002. Two rich collections of Wang's poetry are Wang Jiaxin 1997 and 2001. English translations are found in Tang Chao \& Robinson 1992, Zhao (Henry) \& Cayley 1994 (under the pen name Zi An) and Wang Ping 1999. Other commentaries include Chen Chao 1989: 295-300, Zang 1994, Geng 1999, Xi Du 2000: 107-110 and Liu Shuyuan 2005: 209-213. A combined reprint of Chen Chao 1989 (295-300) and 1994 is found in Chen Chao 1999: 515-531. 
Mo Fei. He has also been grouped together with Chen Dongdong and Ouyang Jianghe, as fellow Intellectual poets, and associated with 1990s Narrative (叙事) poets such as Zhang Shuguang, Sun Wenbo and Xiao Kaiyu, but he can in fact hardly be pigeonholed as belonging to any one group or trend in the avant-garde. Wang's work was marked early on by its quiet, flowing tone and by its melancholy atmosphere. «Autumn in Europe» (欧罗巴的秋天, 1993) is a good example from his years in exile: $:^{54}$

«Autumn in Europe»

When autumn comes to Europe

people holidaying on the seaside start going back

with warm skies looking weary

When autumn comes to Europe

amid the falling leaves adrift, there are those

who sit in sorrow on a park bench reading this or that

and there are those, on the streets of London or Paris

who step in dogshit

There are those, at the thin hour of nightfall

who are retrieved by Chopin's Nocturnes, and there are those

who go out to mail a letter that will never arrive

there are those who register for the new term at the Chinese department

and there are those, in the west wind suddenly rising

whose words will rhyme with Shelley's verse

When autumn comes to Europe

there are birds that fly up, and fly off to southern lands

and there are those who paint another journey in their hearts

there are those who want to cry for no reason at all

and there are those who return to that same old bar

to wait for a miracle

Now together with autumn I set out

and with the autumn winds I cross the English Channel

because of the earth's emptiness, and because of

guitar music drifting through the subway entrance

I become the last insomniac in Paris

${ }^{54}$ Wang Jiaxin 1997: 104-105. 
- when, across from the hotel, there lies a graveyard

in my homeland it's raining, inside me....

This is entirely different from the exile factor in Yang Lian's poems. And while representativeness is a tricky notion, «The Book of Exile» and «Autumn in Europe» are recognizably works by Yang and Wang, reminding us once again that exile will only make poetry in the hands of poets - and, therefore, will do so in varying ways. The difference between Yang and Wang is one of verisimilitude above all else. In Yang Lian, exile sets in motion a tense dynamic of the imagination. In Wang Jiaxin, on the other hand, it appears in basically "realist" scenes from the lives of outsiders and, more specifically, people experiencing a type of loneliness that is the direct result of being in a foreign country. They relate to their alien surroundings in ambivalent ways: from misery in everyday life - sorrow, dogshit, mailing a letter that will never arrive - to consolation in music and literature. Even if the speaker's perspective is not automatically linked to its author's biography or to the fact that the original is in Chinese, he is an outsider to Europe as a whole, not just London or Paris. The birds flying off to southern lands make the outsiders yearn to journey - home? - themselves. The view from the hotel room, surrogate home to the traveler, is that of a graveyard and by implication of a death on foreign soil, especially once we read the poem's final line. There, the exile factor becomes an explicit exile marker, in in my homeland it's raining, inside me. This recalls the closing stanzas of «The Rivers of Amsterdam» (阿姆斯特丹的河 流), a famous poem by Duoduo, written late in $1989:{ }^{55}$

after the autumn rain

that roof crawling with snails

- my homeland

slowly sailing by on the rivers of Amsterdam

In several other poems Wang Jiaxin wrote in England, the exile factor is similarly explicit or directly implied in related words such as 异 国 'alien land,' 哑语 'sign language' but literally 'the language of a mute,' and 流亡 'exile' itself. The first, short prose poem in the series

55 Today 1990-1: 26; included in Duoduo 2005: 158-159. 
«Another Landscape» (另一种风景, 1993), called «England»(英格 兰), begins and ends like this: ${ }^{56}$

England, empty, with no one there. Wherever you go, there's only the sky for a companion... As it turns ever gloomier, it responds to the language of a mute, in the soul of an exile....

Even more emphatic, becoming almost expository in nature, are these passages from «Prague» (布拉格, 1993) — this time echoing Duoduo's «None» (没有, 1991): ${ }^{57}$

The exile carries his homeland on his body

there is no homeland, only dusk bursting from the wounds of the earth

...

There is no homeland

the homeland has risen to the skies, taking its giant rocks with it

the homeland is but a momentary, painful flash

the homeland is above, higher and farther away

pressing down on you to the end of your days

Another series of short prose poems called «Moving Cliffs» (游动悬 崖, 1993) includes a poem that repeats the final line of «Autumn in Europe»: ${ }^{58}$

«Soil»)

When you're homesick, it's not in foggy London but in your homeland that it's raining, inside you. It's not the driving rain, it's some kind of soil inside you that flows down heavy: it will almost make you fall over paralyzed, to touch death, and that lost earth....

This is the most helpless moment of your life: the soil is dragging you back. Who will you ask for help? - In that relentless driving rain, you sink deeper and deeper into the thing that makes you ever darker, and moves you ever further beyond redemption....

«Soil» (泥土), again, contains explicit exile markers: homesick and homeland. At the same time it shows Wang Jiaxin tapping into the potential of the imagination, in the soil inside you that flows down heavy and is

${ }^{56}$ Wang Jiaxin 1997: 114-127.

57 Wang Jiaxin 1997: 106-107. Today 1992-2: 143-144; included in Duoduo 2005: 174-175.

${ }^{58}$ Wang Jiaxin 1997: 129-142. 
dragging you back. The image operates - and this is how the poem fits seamlessly into Wang's oeuvre at large - not as something substituting for reality, but rather in natural conjunction with the "realist" scenes noted earlier. This happens in the oppositions of foggy London and the driving rain on the outside, and the homeland and the soil on the inside. The exile markers in the poem and its author's biography turn 泥土 'soil, clay, earth' into an evocation of that other archetypal exile marker: 乡土 'native soil.' «Soil» thus derives its quiet forcefulness from literary sophistication. That is, it does so from the suggestion of exile's connotations, rather than their declaration.

\section{Bei Dao}

When avant-garde poetry from China first appeared in Western translation and scholarship in the early 1980s, Bei Dao occupied a central position, in line with his domestic prominence. To date, he is probably still the most widely translated modern Chinese poet, with Yang Lian a close second. As is true for Yang, Bei Dao's translators have contributed much to the critical discourse on his work. Scholarly studies with attention to exile in Bei Dao's poetry include essays by Jiangjiang, Wolfgang Kubin, Ouyang Jianghe, Michelle Yeh, Yang Xiaobin, Leo Ou-fan Lee, Lin Xingqian, Ronald Janssen, Yiping, Yang Lihua, Zhang Hong, Yang Siping, Zhang Zao and Tan Chee-Lay, and a book-length monograph by Li Dian. ${ }^{59}$ The majority find common ground in the observation that the exile experience has spurred Bei Dao's development as a poet from a relatively public to a more subjectivized, interiorized voice that is profoundly aware of the powers of language beyond its "neutral" representation of historical realities.

Just like Wang Jiaxin's, Bei Dao's oeuvre contains both declarative and suggestive moments, and they make for very different types of poetry. ${ }^{60}$ The declarations are especially fit for satisfying what

${ }^{59}$ For Bei Dao's individual books of poetry in Chinese and for bilingual EnglishChinese editions, including those not cited here, see Van Crevel 2008a; Bei Dao 1988 is a monolingual English-language edition. Jiangjiang 1990, Kubin 1993, Ouyang 1993b and 1996a, Yeh 1993b and 1996b, Yang Xiaobin 1994, Lee (Leo Ou-fan) 1995, Lin Xingqian 2001, Janssen 2002, Yang Lihua 2003, Yiping 2003, Zhang Hong 2003: 63-106, Yang Siping 2004, Zhang Zao 2004: ch 7, Tan Chee-Lay 2007, Li Dian 2006; other scholarship includes Malmqvist 1983, McDougall 1985, Tay 1985, Zhuang 1993: ch 6 and Jiang Ruoshui 1997.

${ }^{60}$ Cf Li Dian 2006: 39. 
I have called the audience's overwhelming interest in the poet's personal history. The poem becomes a metonym for its author, enabling straightforward empathy with a historical human being, rather than interpretation and appropriation of the text by the individual reader. Here, historical circumstance bolsters the lingering influence of an aspect of traditional Chinese poetics earlier summed up as reading the poet - and reaffirms that such strategies are not solely practiced by Chinese readers. Bei Dao's declarations of exile can additionally be seen to offer relief from the (in)famous "difficulty" of his work.

These things help explain the frequency with which Bei Dao's commentators cite and praise the more declarative of his poems. «Local Accent» (乡音), hailed by Leo Ou-fan Lee, Li Dian and others as a stellar example of exile poetry, is a case in point. ${ }^{61}$ Bei Dao doesn't date his poems, but publication details suggest that it was written soon after his forced settlement abroad, in 1989 or $1990 .{ }^{62}$

«Local Accent»

I speak Chinese to the mirror

a park has its own winter

I put music on

in winter there are no flies

I make coffee, at my leisure

flies don't know what your homeland is

I add some sugar

your homeland is your local accent

at the other end of the phone line

I can hear my fear

A local accent evokes the image of one's (local, native) dialect or language marking one's speech with a foreign accent, of making one a stranger, someone who is "here" but not "from here" —or, of one's dialect or language, spoken in dialogue with a distant interlocutor, as a painful reminder of the "there" that is out of reach except by calling it on the phone, as a surrogate for physical presence.

61 Lee (Leo Ou-fan) 1995: 18-19, Li Dian 2006: 41-42.

62 Bei Dao 1991: 50 and 2003: 114. The table of contents in Bei Dao 1995 confirms this estimation of the date of composition. Cited in Kubin 1993, Lee (Leo Oufan) 1995, Yiping 2003, Zhang Hong 2003, Yang Siping 2004, Zhang Zao 2004, Li Dian 2006 and Tan Chee-Lay 2007. 
«Local Accent» is a conspicuously constructed text. The original carries its mechanical repetition of the first-person singular pronoun through to the last of lines 1-3-5-7-9, and doesn't have $I$ in line 10-where the translation cannot do without it. A word-by-word translation of lines 9-10 reads I at the phone line's other end / have now heard my fear. If unzipped, the poem's two interlocking sequences in lines 1-3-5-7 and 2-4-6-8 fail to connect:

I speak Chinese to the mirror

I put music on

I make coffee, at my leisure

I add some sugar a park has its own winter
in winter there are no flies
flies don't know what your homeland is
your homeland is your local accent

Launched by the exile marker of speaking Chinese to the mirror, the first sequence acquires meaning beyond the inane description of a cozy household scene only by alternation and contrast with the second. For all the poem's ingenuity - the repetition of $I$, for instance, may well be read as purposefully awkward - one wonders whether its effect is not diminished when the tension is explicitly resolved in lines 9-10, as the local accent takes center stage: at the other end of the phone line I I can hear my fear.

Something similar happens in the equally oft-quoted «He opens his third eye....»(他睁开第三只眼睛), written around the same time as «Local Accent», soon after June Fourth. ${ }^{63}$ The first two stanzas contain vintage Bei Dao imagery, strong enough to carry the none too concrete notion of freedom, which the poem calls the golden lid on one's coffin, sealing the image of a he that is fixed in place aboard a ship, in an underwater cabin, like ballast. The poem ends on a solemn one-line stanza that reads

the word's exile has begun

Not only has the compound word 流亡, meaning '(go into) exile' or more literally 'wander in escape,' acquired somber connotations over time, the character 亡 'flee into hiding, die, perish' by itself posits a terrible vision of exile. ${ }^{64}$ While the potential of a new beginning also lends the ending to the poem a defiant tone, its declarative, explana-

63 Bei Dao 1991: 24, 2003a: 106, 2003b: 160. Cited in Kubin 1993, Lee (Leo Ou-fan) 1995, Zhang Zao 1999 and 2004, Lin Xingqian 2001, Song Lin 2002, Yiping 2003, Yang Siping 2004, Li Dian 2006 and Tang Xiaodu 2006.

64 Lee (Leo Ou-fan) 1991: 212-213. 
tory style affects the text's vitality, if only in a poetics that privileges types of literature that show rather than tell - without any intention of downplaying the suffering of the historical person called Bei Dao. At any rate, the poem remains eminently capable of moving the reader, as a text that consciously inserts itself into a public discourse that includes the biography of its author. As McDougall notes, the poetry that Bei Dao wrote soon after June Fourth reflects "[his] grief at the time of the massacre, and his anguish as the separation from his family was prolonged."65 This recalls the desperate tone of Yang Lian's work in late 1989 and early 1990, and Lin's characterization of some of Yang's poems as exuding hysteria. Lin's analysis bespeaks an ultimate preference for Bei Dao's exile poetry, on account of his success in balancing the Dionysian and Apollonian forces in his art, in the Nietzschean sense.

Bei Dao's oeuvre after June Fourth contains more declarations of exile and of the forces that brought it upon him, especially in the early years. For some, it is likely (self-)censorship that excluded them from his 2003 domestic anthologies. An obvious example is «Mourning the Dead: For the Victims of June Fourth» (悼亡一为六・四受难者而作, 1989?): publication in China would trigger repressive action by the authorities until such time as the official government position on June Fourth is revisited. ${ }^{66}$ «Morning Story» (早晨的故事, 1990?) is another poem whose declarative hues invite citation. It is cited nearly as often as «Local Accent» and «He opens his third eye....». This is the first stanza: ${ }^{67}$

\section{One word exterminates another word \\ one book orders \\ the burning of another book \\ a morning erected on the violence of language \\ changes how, in the morning \\ people sound when they cough}

In the entire passage, the sound of coughing is the only image that leaves room for interpretation. One could, for instance, read the coughing as representing routines of daily life that are affected by

\footnotetext{
65 Bei Dao 1991: xi. Cf Lee (Leo Ou-fan) 1995: 14.

66 Bei Dao 1991: 10; not in 2003a or 2003b.

67 Bei Dao 1991: 26; not in 2003a or 2003b.
} 
ideological terror. Zhang Hong broadly takes it as signaling political intention. ${ }^{68}$ In the rest of the poem, poetic imagery - as opposed to pamphletish diction - more or less holds its own. But the poem lays out its overall orientation in no uncertain terms when we read, in the second stanza:

in obtuse crowds of people

the government finds its spokesman

Yang Xiaobin cites «Morning Story» as highlighting a symbolic totalitarian discourse of dictatorial words, to illustrate Bei Dao's reflection on the problematic of language as a means to narrate history ${ }^{69}$

Strictly speaking, the poem contains no exile markers. The reader has to invoke the author's biography in order to make it exile literature - or, in the terms used in chapter Three, draw the boundaries of the text in such a way as to give the author some space inside them. Invoking the author's biography is precisely what many of Bei Dao's (foreign) readers would have done, after encountering it in Old Snow, his first (bilingual) collection of poetry after June Fourth. The book's contents are divided into three parts called "Berlin," "Oslo" and "Stockholm," accurately advertised as "poignant reminders of the restless and rootless life of the exile" on its back cover. ${ }^{70}$

(Self-)censorship thus appears to come into play for Bei Dao's 2003 domestic anthologies when his poetry refers to June Fourth and the type of political repression that caused his exile, not for poems that foreground the experience of exile as such. «Poison» (毒药, 1992?) is an example of the latter, with strong declarative overtones: $:^{71}$

\section{«Poison»}

\section{Tobacco holds its breath}

The exile's window aims at

wings set free from the depths of the ocean

winter music sails closer

like faded banners

It is yesterday's wind, it is love

\footnotetext{
68 Zhang Hong 2003: 97.

69 Yang Xiaobin 1994: 108.

70 Cf Patton 1995a: 142.

71 Bei Dao 1994: 42, 2003a: 140, 2003b: 188.
} 
Remorse comes down like heavy snow

when a stone reveals the end

I cry here and now for what's left of my life

Give me another name

I mask myself in misfortune

to block my mother tongue's sun

In this chapter, when translating from the Chinese, I use mother tongue rather than native language or native tongue, because the Chinese 母语 literally means 'mother language,' and the signified of these various terms - one's “own" language - is central to the exile experience.

In exile and my mother tongue, «Poison» has straightforward exile markers. Less explicitly, a sense of nostalgia runs through the poem, from the faded banners to yesterday's wind - as the force propelling the wings and the music that are visible and audible through the exile's window - to remorse and the notion of what's left of my life. The asking for another name, the masking or disguising (伪装) of the self and the obstruction of the mother tongue bring to mind Yang Lian's words: Write yourself up as another, and you will live.

It has often been noted that the physical exile of poets from the PRC who lived abroad at one time or another was preceded by a "spiritual" or "inner" or "internal" exile that was required for and reinforced by poethood inside China to begin with. ${ }^{72}$ Here, rather than what they actually wrote, the notion of poethood signifies what it meant to belong to the avant-garde in terms of social status. A few authors enjoyed exceptional popularity soon after the Cultural Revolution, for works that were readily interpretable as the expression of widespread sociopolitical grievances. Beyond that historical moment, however, outside a small if well-positioned audience, avant-garde poets have consistently been marginal and controversial figures - when measured against official cultural policy and popular taste, that is.

Inner exile, as an exilic retreat into the mind, is not specifically Chinese or exclusive to the modern era. Cicero, for instance, is one of those who have remarked that exile can occur without one's being driven from a home. As regards inner exile in response to political

${ }^{72}$ For terminological clarity, physical exile inside the nation's borders might be called domestic exile instead of inner or internal exile. The latter usage occurs in Daruvala 1993: 35, Zhang Zhen 1999a: 312 and Liu Tao Tao 2001: 342ff. 
repression, one is reminded of the "internal emigration" by intellectuals and writers in Nazi Germany, which Rosemarie Morewedge convincingly classifies as a "real" type of exile. More generally, many moments in poethood the world over have involved inner exile in the sense of self-assigned outsider status, as both cause and effect of the rejection of socio-cultural convention or political strictures. This is sometimes called "metaphorical exile," in a neutral sense. Authors such as Boym, Buruma and Rudolphus Teeuwen put metaphorical exile and exile as metaphor to polemical use, to question an intellectual-cultural discourse that they see as trivializing "real" exile, that is: physical banishment. Inner or metaphorical exile can co-occur with physical displacement, but it can also happen at home. Beginning in Eastern and Western antiquity with authors such as Qu Yuan and Ovid, it has in fact been cited as a prerequisite for original art. ${ }^{73}$

Yang Lian, Wang Jiaxin and Bei Dao have all described exile as inherent in poetry. In a 1993 interview by post with Chen Dongdong and Huang Canran, during Wang's time in England, he speaks of "a kind of 'exile' that started long ago, inside the words." Brodsky's depiction of exile as "an absolute perspective," meaning "the condition at which all one is left with is oneself and one's language, with nobody or nothing in between," comes to mind when Bei Dao, in a conversation with Anne Wedell-Wedellsborg, calls exile "an extreme clarification of every poet's situation." Bei Dao argues that writing poetry always constitutes a challenge to the dominant language and culture; that the poet is hence never really at home anywhere; and that in this sense, poetry and exile are almost "synonymous concepts." As for Yang Lian, whose "conception of poetry as an exilic art form" is underscored by Jacob Edmond and Hilary Chung, the title of his 2002 essay "In Search of Poetry as the Prototype of Exile" says it all. The central question recurs in the preface to Yang's bilingual collection Notes of a Blissful Ghost, published in the same year: "When did this "self-exile" begin? What true poet who touches upon the true nature of poetry is not in spiritual exile?"’74

${ }^{73}$ Cicero is cited in Edwards 1988: 21. Morewedge 1988: 115. Lagos-Pope (1988: 9) uses metaphorical exile as more or less synonymous with inner (and domestic) exile. Boym 1998: 243-244, Buruma 2000, Teeuwen 2004. Schneider 1980, Edwards 1988: 22.

${ }^{74}$ Wang Jiaxin \& Chen \& Huang 1993: 44, Brodsky 1990: 108, Bei Dao \& Wedell-Wedellsborg 1995: 229, Edmond \& Chung 2006: 9-10, Yang Lian 2002c: 37 
There is no simple equation of poetry with exile. For one thing, not all (physical) exiles write poetry. Yet, the metatextual association of exile and poetry is clear, with exile as a state of mind that can contribute to poetry, or as an overarching framework for non-mainstream poethood in the PRC - and, for (modern) poethood at large. In Bei Dao's case, in addition to these things, the expression of exile in the actual texts of his poetry has consistently been a feature of his art, starting long before his life in physical exile. To isolate inner exile from the writer's experience in Spalek and Bell's terms - that is, the experience of physical exile as a literary determinant - the first place to look would be in works written before the writer settles abroad. As it turns out, for the notion of (inner) exile, Bei Dao's poetry from before June Fourth contains declarative moments too, just like his later work. One of the most straightforward occurs in «To the world....» (对于世界....). This poem's inclusion in The August Sleepwalker helps explain some of Owen's bafflement in his review: ${ }^{75}$

To the world

I am an eternal stranger

I do not understand its language

it does not understand my silence

what we exchange

is mere disdain

as if meeting in a mirror

To myself

I am an eternal stranger

I dread the darkness

but use my body to obstruct

that one and only lamp

my shadow is my lover

my heart the enemy

The text bears little commentary, inasmuch as it arguably is commentary itself - poetical or otherwise - and employs words such as world,

and 2002a: 10. Commentaries that link avant-garde poethood or literary eccentricity in the PRC to (inner) exile include Yip 1985: 121, Lee (Leo Ou-fan) 1991: 219221, Yeh 1993b, Lee (Gregory) 1996: 128, Zhang Zao 1999: 9, 22 and Yiping 2003: 144 .

${ }_{75}$ Bei Dao 1987: 148 and 2003b: 111, without stanza division; not in 2003a. 
stranger, language and disdain that remain unwieldy for want of imaginative usage. Considered alongside other poems by Bei Dao, early and late alike, it is immature. Yet, as an explicit poetical statement it reaffirms the significance of inner exile and outsider status as a state of mind, regardless of the author's physical surroundings: say, a crowded city in his native land. Zhuang Rouyu speaks of self-estrangement (自 我疏离感), Zhang Hong of separation from (隔膜) and opposition to (对立) both world and self. ${ }^{76}$

More importantly, while in «To the world....» itself, the literary expression of these things is far from subtle, it draws attention to a larger, quintessential thematic in Bei Dao's best poems. This is a thematic of alienation, as an umbrella notion that covers categories like difference and otherness; distance, removal, and displacement; and absence, isolation and silence. Notably, Bei Dao's negotiation of these things often involves images of spoken or written language. Without wishing to speculate on the writing process as it works for this particular poet, it is easy to see how this thematic, which takes shape in his work long before 1989, can incorporate the lived experience of physical exile, as recognized by Ronald Janssen and Zhang Hong. Bei Dao's thematic of alienation manifests itself not only in more or less paraphraseable content but also in his style. If style is an intangible thing, let me clarify this point by contrasting Yang Lian's exuberance with what one might call Bei Dao's reticence. This is especially visible in his later writings. It is captured by the poet in his adage that "poetry is a way of keeping secrets" and by Yiping's characterization of Bei Dao's work as "the predicament of standing alone." $" 77$

To illustrate the thematic of alienation that runs through Bei Dao's oeuvre, noted by McDougall as a feature signaling its development beyond the incipient stages ${ }^{78}$ let's first turn to some early examples. «Spite makes a drop of water troubled....» (积怨使一滴水变得混浊) is one of Bei Dao's untitled poems from the 1980s: ${ }^{.9}$

Spite makes a drop of water troubled

I am tired - as the storm

${ }^{76}$ Zhuang 1993: 165ff, Zhang Hong 2003: 84-85.

77 Janssen 2002: 264-270, Zhang Hong 2003: 63-106. Zhang-Kubin 1989: 58, Van Crevel \& Van Toorn 1990: 126, Bei Dao \& Wedell-Wedellsborg 1995: 230-233. Yiping 2003.

${ }_{78}$ McDougall 1985: 245.

${ }^{79}$ Bei Dao 1987: 116. 
runs aground on a sandy beach

the sun hit by the ship's mast

is a prisoner of my heart, while I've

been banished by the world it shines on

and on the reef, black pagan altar

there is nothing left to worship

but myself, about to open or close

the deafening book

This poem contains a declarative exile marker in the banishment (放 逐) of $I$. As an observation of textual fact, this is unchanged by its date of composition, before Bei Dao's physical exile and, indeed, his banishment. The declaration of banishment is, however, an integral part of the body of the poem, and as such less overbearing than the concluding statements in «Local Accent» and «He opens his third eye....», whose position at the very end of the text can lead to closure of the interpretive process. Again, this is not to deny those two poems their power but to note the decisive impact of their concluding lines on the reading process.

Some unconstrained specimens of early Obscure Poetry generate a feeling of loose ends or unfinished ideas rather than productive ambiguity - but in the quick sequence of images in «Spite», the imagery coheres: storm, beach, sea, sun, reef. The alienation of the speaker is anchored, to stick with the poem's vocabulary, in (written) language, embodied in the deafening book - just like Chinese spoken to the mirror, the word's exile, the mother tongue's sun, and the language of the world and silence (沉默, meaning silence as opposed to speech) in the poems cited earlier.

These are the opening lines of «Notes Taken in the Rain» (雨中纪 事), a longer poem that may serve as another example of alienation in Bei Dao's early work: ${ }^{80}$

When I awake, the window on the street

retains of glass

that perfect, peaceful pain

while slowly clearing in the rain

the morning reads my wrinkles 99.

${ }^{80}$ Bei Dao 1987: 134. A full translation by McDougall is found in Bei Dao 1988: 
the book lies open on the table

rustling, just like

the sound that fire makes

«Notes» has the familiar elements of distance between the $I$ and a world out there, on the street, and the speaker's proximity to (written) language in the book. The first four lines of the final stanza also constitute a declarative moment of the type encountered above:

One who paints fruit on the earth

is doomed to go hungry

one who dwells among friends

is doomed to be lonely

tree roots show, outside of life and death

what the rain washes away

is the soil, is the grass

is the sound of lament

Just as in «Spite», however, the declaration of alienation - in this case of difference, rather than distance or absence - is embedded in the poem's body, not attached as a conclusion. This softens the effect of closure.

We started from declarations of exile in Bei Dao's later poems. Bearing in mind distinctions of physical and inner exile and some critical junctures in the poet's biography, we then moved back in time to related textual moments in his earlier work. In so doing, we have situated his literary expression of exile within a larger thematic of alienation that is already present in the $1980 \mathrm{~s}$. To conclude, let's return to Bei Dao's later work for a discussion of two poems that also feature this thematic. Crucially, however, they do so in suggestive, not declarative, fashion. «Whet the Knife» (磨刀) was written late in 1989 or in $1990:^{81}$

"Whet the Knife»"

By the glimmer of dawn, I whet the knife

and find that its back grows ever thinner

and its edge remains dull

as sunlight flashes

${ }^{81}$ Bei Dao 1991: 46 and 2003: 111. The table of contents in Bei Dao 1995 confirms this estimation of the date of composition. 
Out on the street, the crowd

is a forest on a giant billboard

as silence roars

I see the needle edge along

growth rings in a tree trunk

and slide toward the core

If we read for alienation, the image in the poem's title or, more precisely, its elaboration in the first stanza, is grist to the mill: whetting the knife surrealistically leads to the opposite of its known effect. The description of the crowd that is out on the street as a forest on a giant billboard is central to the way the poem unfolds. Physically, it is hemmed in by parallel phrases that point to the blinding and deafening of sight and hearing: as sunlight flashes and as silence roars. This recalls the deafening book in «Notes Taken in the Rain», and the mother tongue's sun as an unbearable blaze that needs to be blocked in «Poison». The equation of the crowd to a forest shows that the speaker is aware of his deviation from "normal" perception: aware, in other words, of seeing things differently from what they "really" are. The word rendered as billboard is 楃窗, 'display window, showcase' or 'glass-fronted billboard.' Positioned out on the street and with a glass surface it presents another echo of «Notes», emphasizing the distance between the speaker and the world around him, with a window in between. The poem's title builds tension: whet the knife in order to do what? So does the image in the final three lines, as the phonograph's needle travels back in time, from the outer growth rings to the inner. Once it reaches the core, the music will cease. In an instance of iconicity, this is where the poem ends.

«Whet the Knife» is literature in exile, in Glad's definition, since it was written outside the author's native land. For its qualification as exile literature - that is, as foregrounding the experience or the notion of exile — we would minimally need to bring in Bei Dao's biography.

The final poem discussed in this chapter is «Borrowing Direction» (借来方向). In addition to its date of composition, likely in 1994 or 1995, some of its imagery leads to association with the physical exile factor, including the frequency of Bei Dao's relocations and travels since 1989. This poem, however, qualifies as exile literature even if we draw the boundaries of the text as tightly as possible, regardless of any association with its author's biography. The poem itself, in the strict 
sense, can be seen to foreground exile as a specific category of alienation. To this reader, the fact that it does so by suggestion rather than declaration, less directly than some of the earlier examples, makes it one of the finest specimens of exile poetry from China. ${ }^{82}$

«Borrowing Direction»

A single fish has a life

full of holes

holes in flowing water oh froth

is what I speak

Borrowing direction

the drunk travels through his storied echoes

but the heart is a watchdog

forever facing the lyric core

Music underway

is shattered in an accident

skies cover

our emotional life from the other side

Borrowing direction

birds break out of my sleep for the trek

lightning strikes in everybody's glass

he that speaks is without guilt

«Borrowing Direction» is a poetic reflection on difference, distance and absence, as component parts of alienation in Bei Dao's work. In froth is what I speak, the speaker's otherness - specifically, his inability to communicate with others - is foregrounded in the image of ineffectual or futile language, just like in the Chinese spoken to the mirror in «Local Accent», and the world and $I$ failing to communicate through language in «To the world....». As for the poem's title, twice repeated, a direction one borrows is not one's own. It hints at removal from a locus of origin, and lack of control over one's destination. Tang Xiaodu, in an interview with the poet, wonders whether the image represents an ironic, anti-ideological stand. Bei Dao affirms this by saying that a direction is temporary, like an assumption, as opposed to the unequivocal and definitive nature of ideology, which he calls

${ }^{82}$ Bei Dao 1996: 88, 2003a: 188, 2003b: 239. 
revolting. Both readings tie in with the sense of dislodgment in the subsequent image of a drunk who travels. A constant throughout his travels, however, is a (poet's) heart watching over the lyric core; this echoes the core in «Whet the Knife», as a point from which music - or poetry - emanates and to which it returns. If we let the indirect exile marker of the travels evoke Bei Dao's biography, the accident that shatters the music - or poetry - that is underway (行进中, literally 'advancing' or 'in operation') could lead one to think of June Fourth. The last thing this poem needs, however, is the reductionist force of such historical context. Its potential lies in the ability to address the experience of exile at large, not the forces that sent its author into physical exile. The final stanza offers a powerful, indirect exile marker in the time-honored image of the migratory birds that we also encounter in Wang Jiaxin's work, and that Zhang Zhen invokes to sum up her border-crossing experience since the early 1980s. The birds rise from the speaker's sleep - from his dreams? - as the embodiment of the urge both to leave and to return..$^{83}$

The poem's last line, he that speaks is without guilt (言者无罪), is a near-literal citation of a phrase from "The Great Preface" (大序) to the Book of Songs, one of the canonical sources of early Chinese poetics: 言之者无罪 'he that speaks it is without guilt,' with it referring to admonitions of authority whose literary form gives them license to violate social taboo. ${ }^{84}$ In other words, according to a traditional Chinese poetics, the poet has the right to remonstrate with the ruler, as long as the remonstrations are well put. Of course, while he sees himself as a poet not a dissident, Bei Dao's biography can be used or abused to interpret his poetry as political protest. One need only think of the founding of Today, his 1989 open letter requesting amnesty for political prisoners and his consistent refusal to let himself be silenced by the threat of political repercussions. ${ }^{85}$ Yet, again, «Borrowing Direction» can do without all that qua poetry. He that speaks is without guilt presents, above all, a reassertion of the (poet's) right to speak his poetry, aside

${ }^{83}$ Bei Dao \& Tang 2003: 164-165, Zhang Zhen 1999b.

${ }^{84}$ See Owen 1992: 46. Owen renders the full string as When an admonition is given that is governed by patterning (wen), the one who speaks it has no culpability. My translation aims to bring out the intertextuality with Bei Dao's poem.

${ }^{85}$ Bei Dao 1990: 78. 
from any socio-political message it may or may not bring — or, in the "other words" that poetry is, even if froth is what I speak.

$*$

I have tried to clarify conceptualizations of exile: of poets, and in poetry. The narrowest variety has been that of the physical exile of Yang Lian, Wang Jiaxin and Bei Dao, three Chinese avant-garde poets after June Fourth. The broadest, that of exile as the (modern) poet's state of mind or the stuff that (modern) poetry is made of. On a third level of engagement, I have focused on exile as it is foregrounded in actual texts written by the said three poets. For Bei Dao, this demonstrates that a central thematic of alienation that is present in his oeuvre from the early years facilitates incorporation of the exile factor. For all three, it shows that in any poetry that will hold its own, independent of historical contextualization, the order of things is incorporation of the exile factor in an individual poetics, not the other way around. This is not a new idea, and one could call it a specification of long-standing definitions of (modern) literature that grant pride of place to the text's aesthetic qualities over effectiveness in conveying a paraphraseable message. But it bears textually argued reiteration, if only to balance biography and historiography's penchant for turning art into documentation, with literature from China as an easy victim. 


\section{CHAPTER FIVE}

\section{MIND OVER MATTER, MATTER OVER MIND: XI CHUAN}

Periodization entails simplification. A summary in three words and two decades - mind, mayhem and money, "the Eighties" and "the Nineties" and beyond - does no justice to the complex dynamics of the social, political and cultural context of contemporary Chinese poetry. It's not as if the switch from high culture fever to all-pervading commercialization can simply be explained by pointing to June Fourth, or as if the transition from one era to the next took place instantly in the summer of 1989. Anecdotal evidence is provided by the spoken pun that told people to wăng qián kàn or xiàng qián kàn. This can mean 'look forward' (往前看、向前看), as in political rhetoric, but also, written differently, 'look to the money' (往钱看、向钱看), and it had begun to circulate as early as the mid-1980s. June Fourth, then, was a catalyst of change rather than its root cause, as noted in the preceding chapters. Yet, from the periodizer's point of view, catalysis was swift and powerful enough to make it likely that the contrast of the 1980s and the 1990s will go unchallenged for a while. Avant-garde poetry, for one thing, shows a contrast of extraverted collectivism in the 1980s and Individual Writing in the 1990s that is striking enough to make the advantages of periodization outweigh its drawbacks.

Since the 1990s, Xi Chuan (1963) has been one of the two most prominent poets writing inside China, the other being Yu Jian. Xi Chuan had been well known on the poetry scene ever since the mid-1980s, but his breakthrough came in 1992, when he published the poem series «Salute» (致敬). In section 1 of this chapter, after supplying some coordinates for situating Xi Chuan within the avant-garde at large, I review early and mid-1990s commentaries that proceed from an opposition of mind and money, pitting what they perceive as the Elevated spirituality of Xi Chuan's poetry and his poethood against the vulgarity of Earthly trends in poetry and of an increasingly materialist society. In section 2, after noting that Xi Chuan's 1990s writing 


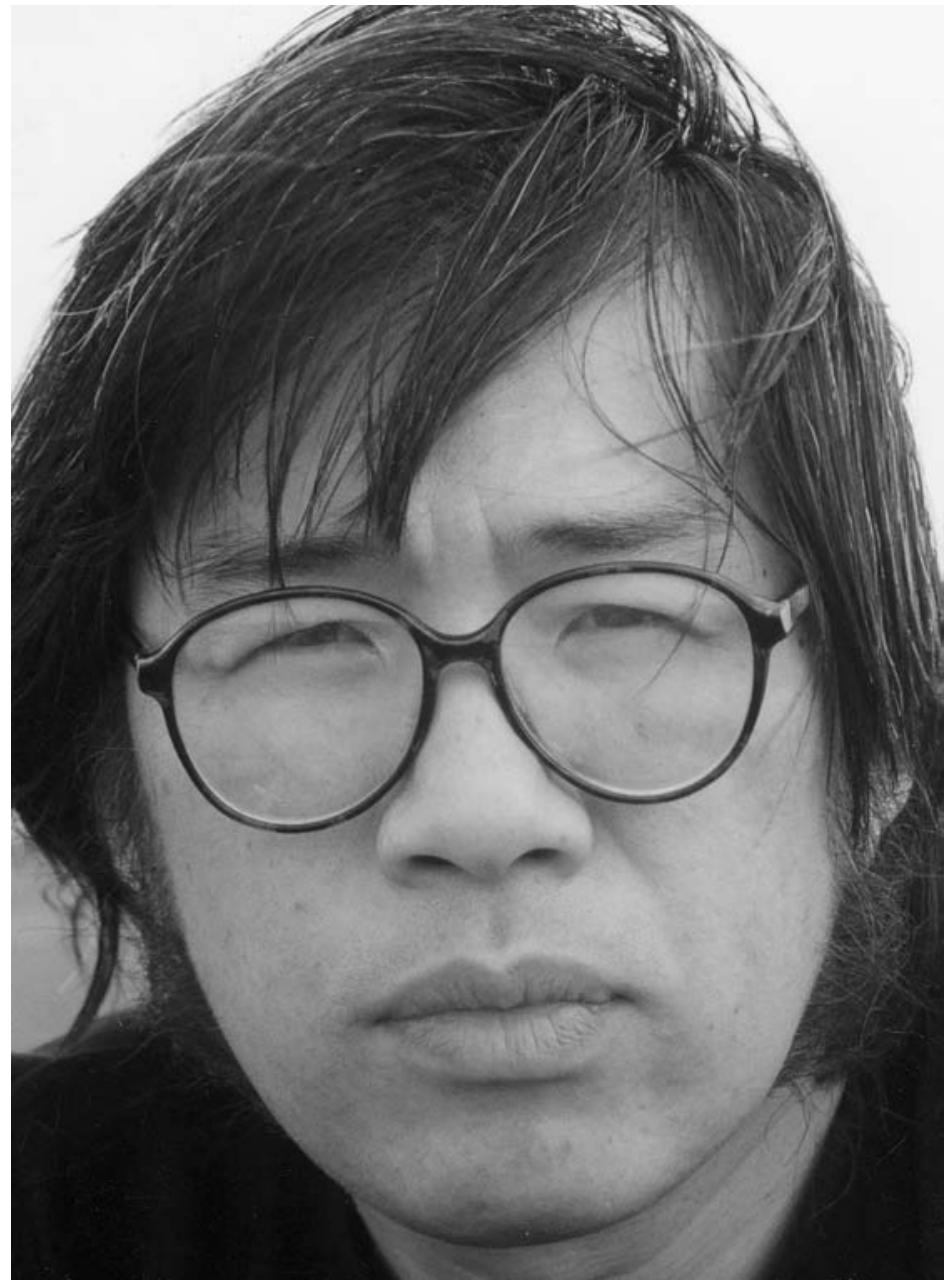

Figure 5.1. Xi Chuan, 2000 (photograph by Maghiel van Crevel) 
is radically different from his early work, I present a close reading of «Salute» that questions this dichotomy of the spiritual and the material. While «Salute» appears to reaffirm Elevated visions of poetry's capacity for transcendence, it simultaneously displays a creative type of indeterminacy, which results in the subversion of Elevated notions of poet-hood, by stressing the poet's physical mortality. In section 3, I discuss later works by Xi Chuan that take us to other aspects of the concept of indeterminacy as theorized by Marjorie Perloff, specifically what she identifies as the tension between reference and the compositional game. I hold this tension to be a key feature of Xi Chuan's writing.

\section{Spirituality versus Materialism AND the Barbarians}

Xi Chuan began to write during his student days in the early 1980s. He graduated from the Department of English at Peking University with a thesis on Ezra Pound's encounters with Chinese poetry, with attention to mis-understandings in that famous instance of cross-cultural literary production. Since the mid-1980s he has built a formidable record in both unofficial and official circuits, publishing mostly poetry but also essays and travel diaries, and translations of Borges and Pound among others. Following the publication of several long, innovative prose poems that uniquely define his style, he has participated in numerous international festivals and other literary programs from the mid-1990s onward. His work has been translated into many languages and he is by now a poet of international renown. ${ }^{1}$

As noted in chapter Three, Xi Chuan was personally and poetically close to Haizi and Luo Yihe, when all three studied at PKU; and in the late 1980s, together with Chen Dongdong, Ouyang Jianghe and Haizi, he was a core member of a group of poets associated with the unofficial journal Tendency who consciously reacted against colloquializing and vulgarizing trends that had challenged Obscure Poetry's primacy within the avant-garde. This doesn't make Xi Chuan's early

\footnotetext{
${ }^{1}$ For Xi Chuan's individual books of poetry, including those not cited here, see Van Crevel 2008a. His work has appeared in scores of multiple-author anthologies. English translations include those in Renditions 37 (1992) and 51 (1999), Barnstone 1993, Zhao (Henry) \& Cayley 1996, Wang Ping 1999, Zhao (Henry) et al 2000, Seneca Review xxxiii-2 (2003), Tao \& Prince 2006, The Drunken Boat 6-I/II (2006, online), Sentence 5 (2007) and the DACHS poetry chapter.
} 
work a return to Obscure Poetry anymore than Ouyang's, Chen's or Haizi's. Just like their work, Xi Chuan's poetry lacks the humanist, socio-political engagement of the Obscure poets. Like Chen's and Haizi's, his early work bespeaks a vision of poetry as a religious experience. As such, and on account of its generous use of imagery, it is inclined toward the Elevated rather than the Earthly, and clearly part of the cult of poetry. While it contains the occasional reference to Chinese history, Xi Chuan's poetry displays little kinship with RootSeeking. Early labelings of his work include the illuminating category of the Xi Chuan Style (西川体), in the upbeat exercise in pigeonholing that is the Overview of Chinese Modernist Poetry Groups 1986-1988 edited by Xu Jingya and company, Li Fukang and Eva Hung's 1992 classification of his poetry as "visionary," and Michelle Yeh's association of his work with Stream-of-Consciousness (意识流) poetry in the same year, following domestic critical discourse. Although Xi Chuan's poetry has transformed itself since its early days, the slogan of Intellectual Writing (知识分子写作), first aired at the 1987 edition of the Poetry Monthly Youth Poetry Conference (青春诗会) and embodied in Tendency in 1988, is still a defensible description of his art. This is perhaps even more so than when it was first coined, as long as we block out possible interference from the 1998-2000 Popular-Intellectual Polemic, in which the term was frequently turned into a travesty of its original usage. To clarify this claim, I quote from a broadside Xi Chuan delivered in 1995 against "pretty literature" (美文学), meaning writing that is characterized by frivolousness rather than authenticity:"

[Pretty literature is] opposed to creativity, imagination, irony, metaphor, the spirit of experiment and doubt, it is opposed to the difficulty of writing [写作的难度]....

And Xi Chuan is opposed to pretty literature. Authors' ideas about their own work don't automatically hold water, nor do they necessarily carry more weight than receptions by other readers - for it is only in the latter capacity that authors can speak of their work once it is written. But in this case the author's commentary tallies well with his poetry, as will hopefully be substantiated in the rest of this chapter.

${ }^{2}$ On Tendency, see Chen Dongdong 1995 and Xi Chuan 1997c: 293-294; on the cult of poetry, Yeh 1996a; on Wholism and Han Poetry, Day 2005a: ch 9; Xu Jingya et al 1988: 360-362; Li Fukang \& Hung 1992: 97; Yeh 1992b: 394-395; Xi Chuan 1995: 64. 


\section{Image of a Poet in the Age of Money and Anti-Culture}

Xi Chuan's image in the Chinese literary world is that of a modern-day man of letters (文人) — or, depending on who is talking, a bookworm: an erudite bibliophile whose interests extend beyond literature and art to history and philosophy. The above outline of his coordinates within the avant-garde may serve as background to some remarkable commentaries on his work in the early and mid-1990s. First, let's look at an exhortation by Yang Ke and Wen Yuanhui for poetry to fall in step with the materialist zeitgeist, on the assumption that resistance is futile: ${ }^{3}$

Postmodern commodity society has attacked the arts in a destructive manner. Since money's charms now delude people to unprecedented degrees, the humanist spirit communicated in poetry is obviously at odds with present-day material desires of the masses. Poetry's attention to lasting values appears as an attitude that is "divorced from reality," and is unable to satisfy consumer society's need for sensory delight ... If today's poets are not to feel shame in the face of posterity, a joint effort by this generation is needed, so as to make numerous words presently lacking in emotional flavor - such as commodities, business, oil, steel, police, politics, tax invoice, instructions, software and so on - finally embody the cultural connotations of this new age ... The purest poetry is a poetry that pays attention to the reality of subsistence, that doesn't flee from the dual violence of society and commodities, that punctures fictions and illusions of "letting poetry return to poetry itself" - for beyond subsistence, no poetry exists.

Other critics writing around the same time are less impressed with the new gold rush and don't share Yang and Wen's belief that poets should catch up with the times. Instead, they reassert what they see as the unique value of poetry vis-à-vis materialism, specifically of a noble, spiritual type of poethood epitomized by Xi Chuan. Their outlook exemplifies Bourdieu's notion of the field of cultural production as the economic world reversed, and specifically what Hans Bertens sums up as a vision of poetry - also found in other literary histories than the Chinese - as a line of defense against mundane vulgarity, and things like rapid social and technological change. It also implies defensive moral judgment, sometimes of an idolizing kind. The implied request of the reader to take sides on issues of morality reflects the continuing

\footnotetext{
${ }^{3}$ Yang Ke \& Wen 1996: 76-77.
} 
relevance of traditional Chinese views of literature as well as orthodox Maoist poetics, summed up in the time-honored expression that "the text is like the person" (文如其人); in other cultural contexts, judgment of the author's personality might fall outside the scope of textual criticism. Dwelling on Xi Chuan's work up to 1994, Yang Changzheng writes: ${ }^{4}$

Xi Chuan's disposition has always been both gentle and tenacious. How much wisdom and soul does it take to sustain such gentleness and tenacity in this mortal life with all its disasters, its unpredictable changes and its endless temptations? Gazing at the starry sky, Xi Chuan says that he doesn't want to press himself into being a holy man, but that only true writing can give him peace of mind. Xi Chuan realizes that of money one can make a thousand and thousands more, and then a million and millions more, but that works of literature must be written with single words, one by one.

Liu Na makes the following claim, in a dense review article that is part of a section devoted to Xi Chuan's work in a 1994 issue of Poetry Exploration: ${ }^{5}$

In an age when commodity prices are going up and spiritual culture is devaluating, Xi Chuan and some of his poetry friends [诗友] stand guard over the classical spirit of poetry, protecting with dignity the seriousness of art.

In a 1997 issue of Literary Criticism (文学评论), Wu Sijing makes an especially resounding statement, extending textual analysis to the author's personality as do Yang and Liu: ${ }^{6}$

Naturally, it is not only old poets who hold their own in the midst of loneliness. In the face of surging commercialization and the temptations of money, not a few young poets have also displayed personal integrity ... Xi Chuan is a graduate of the Department of English at PKU and the great majority of his classmates have gone abroad, but he has stayed in China, for poetry's sake. He first worked for Globe Magazine [环球杂 志]. In the general fever of literati "going to sea" [to do business], he too left Globe - not for a high-paid, luxurious job at a foreign company, but to teach at a much poorer institute for the arts so as to have ample time for reading and writing, and the opportunity to engage in a mutually beneficial exchange of views with young artists studying there.

${ }^{4}$ Bourdieu 1993: passim in parts I-II, Bertens 2001: ch 1, Yang Changzheng 1994: 48.

${ }^{5}$ Liu Na 1994: 82.

${ }^{6}$ Wu Sijing 1997: 80. 
The word translated as poor is 清贫, explained in the Dictionary of Modern Chinese (现代汉语词典) as "poor (formerly often used to describe scholars)," and rendered in John DeFrancis' ABC Chinese-English Dictionary as "poor but honest." The New Age Chinese-English Dictionary (新时代汉语大词典) example sentence says it all: "Father and son maintained their personal integrity despite reduced circumstances." Paradoxically, then, the moneyfication of society at large would have meant reduced circumstances for poets.

In these passages, poet-scholar Xi Chuan is invoked to ward off demons of material greed. But it isn't only money that he is pitted against by literary critics. Within the avant-garde, some view him as a defender of "culture" against the barbarism of trends like "non-culture" (非文化) and “anti-culture" (反文化), referring to mid-1980s trends that made themselves heard through unofficial journals such as Them, Macho Men and Not-Not. Writing in 1994, Lan Dizhi concedes to the barbarians that "one's culture can indeed turn into a heavy burden," but proceeds to make his loyalties to "culture" abundantly clear:"

However, pray do not misunderstand me, this is certainly not to say that it is best for a poet not to be cultured, it is certainly not to say that for writing poetry one can do without reading, and it is certainly not to say that the glory of poetry can be established in a cultural desert. It seems to me that the case of Xi Chuan reminds us of the need to view the issue in its full complexity. For Xi Chuan is an ardent lover of books and an ardent lover of culture, and has received high-level and profound cultural training, but his accomplishments in writing poetry are recognized by all.

The but in the final sentence signals the relevance of the ElevatedEarthly divide, and specifically the anti-intellectual hues of the Earthly discourse that Lan attacks. Lan praises Xi Chuan for continuing to employ original imagery, unfashionable among the barbarians:

"No Imagery" has been among the pursuits of this new generation of poets for a long time. They feel no interest in any imagery whatsoever, pursuing instead the flow of language, of poetry, of rhythm, pursuing the original state of language and a new type of sentence. Face to face with this current, [Xi Chuan] has by no means taken to disliking and avoid-

\footnotetext{
${ }^{7}$ Zhongguo Shehui Kexueyuan 1996, DeFrancis 1996, Wu Jingrong \& Cheng

${ }^{8}$ On "non-cultural" and "anti-cultural" features of Them and Not-Not, see Wang Guangming 1993: 216-224. Lan 1994: 85, 89.
} 2000. 
ing imagery. All this goes to show that he has an independent mind and great courage.

Lan's representation of Xi Chuan's poethood is that of a beacon in dark times, much like Yang Changzheng's characterization of the poet as "a fortress on the contemporary poetry scene." Cui Weiping had earlier voiced similar sentiments when she wrote, in 1992: ${ }^{9}$

Among modern writings full of hullabaloo, strangeness, loss and the feeling of being torn, Xi Chuan is miraculously neither torn nor confused, and in fact exudes qualities of harmony, contemplation and light.

After these quotations, it should come as no surprise that in the mid-1990s, as Xi Chuan was coming into this stride amid contested notions of poetry against a backdrop of rapid social change, some appraisals of his work contain explicit acts of canonization of both text and author. Liu Na's essay opens with this candidly idolizing abstract: ${ }^{10}$

$\mathrm{Xi}$ Chuan is one of the most serious and determined among those writing poetry in China since the mid-1980s.

Xi Chuan's poetry has become a contemporary Chinese literary phenomenon that cannot be overlooked.

$\mathrm{Xi}$ Chuan's poetry is in the first stages of acquiring normative significance.

\section{A Different Voige: Poetry Rising, Poets Falling}

The above commentaries show how acutely the tension between the spiritual and the material was felt by the critics concerned. Yet, it is surprising that their reviews aren't more cognizant of spectacular developments in Xi Chuan's writing since the early 1990s, that occurred amid far-reaching changes in contemporary Chinese poetry at large.

\section{From Faith and Structure to Doubt and Deconstruction}

To bring out the contrast with Xi Chuan's early work, let's first consider «In Hairag, Gazing at the Starry Sky» (在哈尔盖仰望星空), written in 1985 and revised in 1987 and 1988. Yang Changzheng alludes

\footnotetext{
${ }^{9}$ Yang Changzheng 1994: 47, Cui 1992: 120.

${ }^{10}$ Liu Na 1994: 75.
} 
to this poem in his depiction of Xi Chuan as a noble, cultured spirit withstanding money's temptations, cited above. ${ }^{11}$

"In Hairag, Gazing at the Starry Sky»

There are mysteries that are beyond your control

you can merely play the part of an onlooker

letting their mysterious force

emit its signals from afar

radiate light, pierce your heart

just like tonight, in Hairag

far from the cities, in this desolate

place, on the Qinghai-Tibet plateau

outside a railway station the size of a broad bean

I look up and gaze at the starry sky

no sound now from the River of Stars, birds are scattered

grass is growing madly toward the stars

horses forget what it means to fly

the wind blows through this spacious night as it blowes through me

the wind blows through the future as it blows through the past

I am becoming someone, becoming some

plain little oil-lamp-lit room

and the ice-cold roof of that plain little room

turns into a sacrificial altar under the feet of myriad stars

I am like a child receiving holy communion

mustering up its courage but holding its breath

For all the calm, contemplative elegance of this text, one is struck by its conventionality, and by the absence of any element of surprise. «In Hairag» is a formally unremarkable poem in free verse, with irregular rhyme in the original. The mysteries (the night sky, and Time) are clichés that put urban, human life in predictably humbling perspective. This romanticism of the natural world extends to the plain little oil-lamp-lit room, and culminates in the innocent speaker's (I am like a child) initiation in a religion of the universe. We may view the speakerprotagonist as a poet, and the poet's inspired writings as offerings to a Muse that is this universe - and even if we don't, the poem's spiritual conviction stands unchallenged, as does its faith in structure rather than

${ }^{11}$ Xi Chuan 1997a: 181-182. 
arbitrariness or chaos. By contrast, as we will see below, starting in the early 1990s Xi Chuan's poetry frequently replaces faith and structure with doubt and deconstruction. After a quiet spell, he reemerges as a different voice, recognizable yet transformed. What happened?

The preceding chapters have shown that the year 1989, meaning June Fourth and its aftermath, was a turning point for the life of the mind in China. The violent drama in Beijing and other cities put an end to what had been culturally the most liberal and exciting years in the history of the People's Republic. This left large parts of the intelligentsia bitterly disappointed if not downright cynical. It led many who had immersed themselves in the late 1980s cultural carnival to give up their literary aspirations or put them to commercial use - even though in retrospect, it turns out that poets' visibility in the 1980s had been an anomaly and that more and better poetry has arguably been written in the 1990s and beyond. In Xi Chuan's case the social trauma and disillusionment of June Fourth had been preceded on a private level by the deaths of Haizi and Luo Yihe in March and May, both of them his close friends. This would have made the rest of the deaths-in-poetry discussed in chapter Three - including the 1991 suicide of Ge Mai, yet another friend and fellow poet from PKU - especially uncanny and traumatizing, a supposition which draws support from Xi Chuan's public comments on those turbulent years. ${ }^{12}$

Declarations of authorial intent and autobiographical detail aren't automatically "true," but that doesn't mean we should turn a blind eye to what authors - again, as readers of their own work - have to say about their state of mind and how they believe it informs their writing. The gist of Xi Chuan's statements on the shocking experiences of 1989 and the following years can be summed up in two words: grief and soberness. The latter may be especially pertinent to the change he has identified in his creative writing. The early Xi Chuan was a staunch advocate of "pure poetry" (纯诗). Notably, in 1980s PRC discourse the notion of pure poetry was less to do with things like the self-referential nature of literary language - as in poésie pure - than with the unequivocal, logical and lofty character of a world constructed in literary texts that rejected all concern with mundane affairs. In 1980s China there was room for such pure poetry to make sense, ethically

${ }_{12}$ E.g. Xi Chuan 1991a, 1994a and 1997b: 6; Xi Chuan 1997c: 294-295, Maas 1995. 
and aesthetically, especially in the more cultish quarters of the poetry scene, even if it harbored little dramatic tension. From 1989 on, however, the deaths around Xi Chuan, both public and private, made him feel that life didn't work in unequivocal, logical and lofty ways. Purity became an increasingly hollow, deceptive concept to him, harmful to the authenticity and the vitality of literary works. Unwavering in his dedication to literature, he became less sure of what poetry was or should be, other than that it was imperative for his writing to establish some relationship with a "reality" on which pure poetry would turn its back.

Whatever the cause of the changes in Xi Chuan's writing at the turn of the decade, «Salute» and his later prose poems of the 1990s make it impossible to characterize his voice as unequivocally dignified, courageous, serious, determined, normative and so on, to use some of the vocabulary employed by the critics cited above - or, as unequivocally Elevated. Similarly, it becomes difficult to represent his poethood as an emblem of reliability any longer, as a familiar stronghold in times of norms and values changing in unsettling fashion and at unsettling speed. Such representations sociopoliticize his art to an unwarranted degree, as regards both its presumed intent and its presumed effect. In addition to the continuing influence of premodern and modern Chinese literary orthodoxies, they reflect the critics' own uneasiness vis-àvis contemporary social trends as much as anything else.

In fact, to stick with the metaphors used by Lan, Cui and Yang, starting in the early 1990s the beacon may mark a dangerous reef instead of a safe haven and cracks cut through the walls of the fortress as a part of its very design. From this point onward Xi Chuan's writing derives much of its power from the alternation and the coexistence of opposites, and it displays a capacity for dilemma, contradiction, paradox and indeed impossibility that is hard to reconcile with Cui's observation of harmony and the absence of confusion in his work. ${ }^{13}$ This doesn't hinge on either "transparent" or "obscure" imagery but emerges as a general mood that subverts clarity, certainty and straightforward direction in most if not all of the text's dimensions. I refer to this mood as the quality of indeterminacy, and will connect this to Perloff's use of that concept toward the end of this chapter.

${ }^{13}$ Cf Wang Guangming 1999 and 2003: 626-628. 
Indeterminacy operates at critical junctures in «Salute». Recalling the discussion of exile poetry in chapter Four, this is not to say that the following analysis aspires to do anything like framing the series in its entirety. It adopts one possible perspective, to respond to the views of the critics cited earlier and offer other avenues into Xi Chuan's work.

The publication history of «Salute» runs from The Nineties (九十年 代), one of the small-scale, unofficial poetry journals out of Sichuan that showed the poetry scene's resilience during the cultural purge after June Fourth, to the large-scale, official all-genre journal Flower City (花城), and from Xi Chuan's individual poetry collections to authoritative multiple-author anthologies, both of the contemporary era and of the entire twentieth century. Some textual differences between these editions are clearly misprints. Others must be the result of Xi Chuan changing his mind from one edition to the next, or from editorial intervention. My analysis is based on the text published in The Nineties, with corrections and changes made by Xi Chuan in November 1993 - that is, the latest authorized version before the publication of his 1997 collection This Is the Idea (大意如此), which follows the said corrections and changes with very few exceptions. There are minor discrepancies with the Flower City text, the most widely available source of the Chinese original, and I will note those which are of interest. I quote extensively from all constituent poems in the series. An English translation of the full text is found in Renditions 51 (1999). ${ }^{14}$

\section{«Salute»): Form}

«Salute» consists of eight sizable constituent poems, each a very full page in length, with numbered headings and individual titles: «One: Night» (一、夜), «Two: Salute» (二、致敬), «Three: Abode» (三、居 室), «Four: The Monster»(四、巨兽), «Five: Maxims»(五、箴言), «Six: Ghosts» (六、幽灵), «Seven: Fourteen Dreams» (七、十四个 梦) and «Eight: Winter» (八、冬). Xi Chuan has said that the series is neither a poem nor a prose poem nor a narrative text. While its author is unwilling to categorize «Salute»—although he did once call it a long

14 The Nineties, 1992: 94-106, Flower City 1994-1: 88-96, Wan Xia \& Xiaoxiao 1993: 236-243, Xie Mian \& Meng 1996: 545-549, Xi Chuan 1997c: 159-174, Renditions 51 (1999): 87-102. 
poem (长诗) — there are good reasons for calling it a prose poem. ${ }^{15} \mathrm{We}$ will return to this point in chapter Six.

$\mathrm{Xi}$ Chuan's poetry stands out by its sound. In written form, his texts contain many things one will immediately see and indeed hear during a silent reading, such as parallelism and rhyme, and Xi Chuan is an expert reciter with a growing list of high-profile public readings to his name. While «Salute» has no strict metrical patterns, it does have a great deal of rhythm and it abounds with internal rhyme. Here is an example, in transcription:

Duō xiăng jüàohăn, dàn yào jìnliàng bă shēngyinn yāà̄, bù néng xiàng mànmà, ér yīng xiàng qídăo, bù néng xiàng dàpào de hōngming, ér yīng xiàng fêng de hüxiào.

(多想叫喊, 但要尽量把声音压低, 不能像谩骂, 而应像祈祷, 不 能像大炮的轰鸣, 而应像风的呼啸.)

Rhythm is more subjectively perceived than meter or rhyme, and for its realization more dependent on who is reading. In Xi Chuan's recitation of «Salute», rhythm can intersubjectively be seen to operate on the levels of both sentence and stanza. ${ }^{16}$

Within each stanza, both the written sentence (ending in a full stop, a question mark, or an exclamation mark) and its component phrases (separated by dashes, semi-colons, colons, commas) operate as rhythmic units. The line is irrelevant in this respect. I focus on rhythmic effects on the levels of phrase length and sentence length as well as repetition and parallelism. Take the first stanza of «The Monster»:

[1] The monster - I have seen it. The monster has bristly hair and razor-sharp teeth, it is close to going blind. The monster breathes its husky breath and shouts of misfortune, but its feet move without a sound. [2] The monster has no sense of humor, like someone trying hard to cover up humble origins, like someone destroyed by a calling; it has no cradle offering memories, no goal offering direction, not enough lies to defend itself. [3] It beats on tree trunks, it collects infants; it lives like a rock, it dies like an avalanche.

Repetition and parallelism feature throughout, punctuating and structuring long, dense stretches of text. In part 1, phrases and sentences

\footnotetext{
15 Yang Changzheng 1994: 48, Xi Chuan 1997c: 295.

161995 Rotterdam Poetry International festival.
} 
become progressively longer. Length adds to the text's momentum, and part 1 serves as a springboard for part 2: the phrases in this sentence are longer than those in part 1 , and the sentence as a whole is so long as to leave the reader out of breath. In part 3, the speaker relieves some of the pressure, reverting to shorter phrases and a shorter sentence. This generates a jagged rhythm, coming to a halt in avalanche at the end of the stanza.

Dividing the first stanza into three parts accords with its content. Part 1 describes the monster as seen by the speaker; in part 2, the speaker dwells on the monster's character; and part 3 tells us what the monster does and relates this to the natural world. The mutual reinforcement of form and content doesn't end here. The first, long stanza is abruptly followed by a single-line stanza, which also heralds a surprising jump in the poem's content:

The crow seeks allies among scarecrows.

Rhythm on the sentence level in «Salute» is hard to overlook. As for rhythm on the stanza level, the above example - a long stanza followed by a short - is typical of patterns that are discernible in the greater part of the series. In each of its eight poems long (l) and short (s) stanzas alternate. If long means having three or more lines in the original, «Salute» can be charted like this: ${ }^{17}$

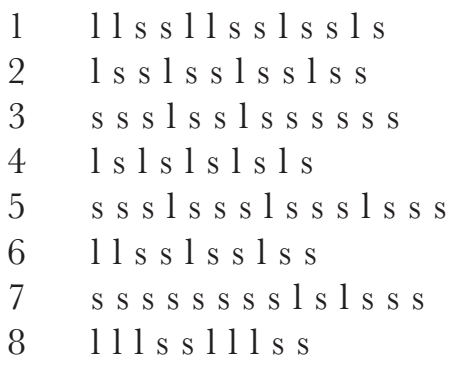

The short stanzas are interruptions of a veritable outpouring of words, which builds up speed in the space provided by the long ones. The first, second, fourth, fifth and eighth poems make effective use of this

${ }^{17}$ The third short stanza in the fifth poem is part of the text printed in Wan Xia \& Xiaoxiao 1993 and among Xi Chuan's corrections to the text printed in The Nineties. 
mechanism. The alternation of long and short works best if no two long stanzas are adjacent, while the short ones in between are not so many as to make the text lose its flow.

In «Salute», rhythm on the stanza level compensates for the absence of poetic-formal regularities such as division in lines and number of lines per stanza, but this mechanism doesn't operate consistently throughout the text. In the realm of form, then, indeterminacy is easy to detect. In his other major poems of the 1990s and beyond Xi Chuan has continued to experiment in this respect.

\section{Content: General Remarks}

Form and content are harder to distinguish than their frequent appearances in literary criticism and other languages suggest. Does the typography of a poem in the shape of a swastika come under form or content? Equating the two renders both concepts meaningless. Perhaps this is what the adage "form is content" is meant to do: blot out an artificial distinction. But it is art that we are dealing with, and while neither form nor content exists without the other, this doesn't make them the same thing. Common sense and everyday usage justify their distinction, as long as they constitute a closed circuit. They are the two ends of a scale, and if the transition between them is gradual, as in the first stanza of «The Monster», form and content can amplify one another, and form can act as an icon for content rather than its stylization, as in the case of the swastika. When form contributes directly on the level of content, it can indeed be seen to acquire necessity.

Let's now turn to questions located at the content end of the scale. «Salute» taps semantic reservoirs that also inform other poetry by Xi Chuan. After briefly touching on imagery, diction, atmosphere, speaker and protagonist, we will look at one semantic domain of special importance, that of poetry itself.

«Salute» is full of imagery. To regard words as images and images as metaphors implies that literal, surface meanings don't say all there is to be said. It presupposes the desire or indeed the urge to interpret, and not to take the text at face value. Some texts stimulate these things more than others. Not everything that appears as imagined, however, necessarily represents - or signifies, or "hides" - something else, to be dis-covered by the reader. The sheer presence of the image can make the search for such true identities misguided, especially if the text ema- 
nates a palpable joy of language, as does «Salute». Also, an image doesn't have to mean the same thing throughout an oeuvre, perhaps not even throughout a poem as long as «Salute», whose component parts can be read by themselves. In the rest of this section and the beginning of the next, I give in to the urge to interpret. I then complement this approach by returning to the surface of Xi Chuan's poetry, which turns out to be an important motive of the interpretive energy that his work releases in the reader - and that it frustrates at the same time.

Diction in «Salute» is generally at a far remove from the colloquial. Xi Chuan's language is highly aestheticized, often literary and ornate, using arcane and archaic expressions. At the same time - and here, again, there is an appreciable difference with his early work - this literariness is interspersed with samples from other linguistic registers, such as the language of Communist Party bureaucracy and everyday speech. Thus, irony undermines seriousness and solemnity, though not to the point of making the stylistic structure collapse altogether. It will become clear that as such, Xi Chuan's language is frequently an icon for his subject matter.

Large parts of «Salute» take place in a dreamlike atmosphere, far from the hustle and bustle of everyday life, evoking an Old World of myth and fairytale. Terrible and wonderful things happen there, but as a whole the series doesn't demand strong emotional involvement on the part of the reader. This aspect of Xi Chuan's work has led some critics to work from binary oppositions of mind versus heart, and of rational and moral contemplation versus mad passion. ${ }^{18}$ In the case of «Salute», perhaps this is so because the text is not laid out as a pressing reality, but as an expertly performed show of make-believe. The speaker drifts in and out of the poem's stories, shifting back and forth between being a protagonist and an omniscient narrator. When the speaker is also a (male) protagonist - the only one that is constantly present - he comes across as an outsider who scarcely interferes with his surroundings and delivers surprised reports on his own and others' adventures. All sorts of things are done to him but he is not victimized. He is naive, not pretentious or ambitious, but he has a clever and independent mind. In the face of adversity he shows dignity, resilience, and humor. Explicitly conscious of the literary text in its capacity as

${ }^{18}$ Yang Changzheng 1994: 47, Liu Na 1994: 82. 
a discursive framework, he creates a certain distance between himself and the reader, as an expression of humility vis-à-vis a wondrous existence - or, again, as an expression of doubt and of the desire to question the seemingly self-evident.

«Salute» ventures into various semantic domains. A rewarding reading is one with an eye on the domain of poetry itself, and of poetics: one which takes «Salute» as poetry about poetry, while noting other types of subject matter as well. To some extent, the series does uphold the opposition of the spirituality of poetry to material wealth asserted by critics such as Yang, Liu and Wu. It does so in a paradoxical way, by incorporating the issue into its subject matter. But especially with regard to the status of poetry and poets amid realities of everyday life, it turns out that things are much less straightforward than that - or, that they are much more indeterminate.

\section{Content: A Close Reading}

My point of departure is the title of the series. At first glance, the second poem has special status because it is also called «Salute», and the title word occurs in the tenth stanza:

A man goes deep into the mountains and miraculously survives. In winter he hoards cabbage, in summer he makes ice. He says: "One who will let nothing move him is not real, neither where he comes from nor in his present life." Therefore we crowd around the peach blossom to sharpen our sense of smell. Face to face with the peach blossom and other things of beauty, one who knows not how to doff his hat in salute is not our comrade.

This mountain hermit flaunts all sorts of rules. He has retreated from human society and he is given to normally impossible undertakings (making ice in summer). Combined with the rest of the stanza, this brings to mind a romantic image of the poet - denoting an abstraction of poethood, as distinct from historical persons - to whose imagination great powers are ascribed. He calls the capacity to feel a criterion for authenticity. We are his disciples, who do their best to learn how to feel beauty, to have objects of beauty trigger their emotions. To be literally of one mind (同志, 'comrade') with us - with the debunking of Communist ideology, this expression is also an instance of self-mocking irony - one must salute beauty. I take this to refer to the act of writing poetry, in a reading inspired by the poem series itself and enhanced 
by the echo of Rimbaud's $A$ Season in Hell (Une saison en enfer). ${ }^{19}$ If we, poets, live for beauty by writing poetry in order to feel and to express feeling, the poem's last two stanzas make sense:

But we hope not for an outcome in which souls are made to lie idle and words blackmailed.

Poetry guides the dead and the next generation.

Other passages in the series confirm these hints at a high-blown, cultish poetics, even if they regularly do so in tongue-in-cheek fashion. This happens, for example, when the poet's receptiveness to signals from a Muse-like, supernatural source is outlined in the seventh stanza of «Night»:

I have brought you a searchlight, there must be fairy maidens flying over your head at night.

$I$ and you can be read as two sides of the same person, one a rational daytime creature and the other the nighttime poet. While the poet is prompted by an external inspiration (fairy maidens), raw materials are provided by his own experience, converted to memories. From the fifth stanza of «Night», and the eighth of «Salute»:

\section{Memory can create brand-new things}

and

\section{Memory: my textbook.}

As for spectacular products of the poet's imagination, the impossible is frequently possible in «Salute». The following passage, from the fourth stanza of the series' eponymous second poem, invites quotation all the more because it expresses the wish to provoke feelings in steel, conventionally symbolizing a type of heartlessness that comes with strength: ${ }^{20}$

To want to scream, to force the steel to shed a tear, to force the mice used to living in secret to line up and appear before me.

19 Coelho 1995: 132.

20 The text published in Flower City has sound an echo for shed a tear; the latter occurs in Wan Xia \& Xiaoxiao 1993 and is one of Xi Chuan's corrections to the text in The Nineties. 
If the scream miraculously provoking feelings is poetry, the next sentence- earlier cited in transcription for its acoustic qualities - may describe this poet's style:

To want to scream, but in the softest possible voice, not like curses but like prayers, not like the roar of cannon but like the whistle of the wind.

Throughout the series, there is a close association of poetry and night. At night, fairy maidens will hover over one's head. And two stanzas before that:

A youth is singing in the basement, surpassing himself . . It's night, needless to say.

The penultimate stanza of «Night» connects the night, emotion and writing, and contrasts them with the daytime:

How powerless the heart when lights go out, when street sweepers get up, when crowes take off into the sunlight shining on this city, proud to have their sumptuous wings no longer confused with nighttime writing.

The quotations from «Night» clarify why this poem, written later than the others, ended up being the first poem of the series. ${ }^{21}$ It sets the stage, like a preface to a book, written after the main text is completed. The self-referential nature of poetry is asserted in the closing stanza of «Night», immediately after the night has ended and the day begun:

The bugle blows, dust trembles: the first note always sounds bad!

The last phrase, taken as a comment on the poem it concludes, shows the speaker attempting to distance himself from - or, "indetermining" his relationship to - the literary text of which he must remain part, again drawing attention to his consciousness of that text as a discursive framework.

More examples of the association of poetry, or writing, and night are found elsewhere in the series. Toward the end of «Abode», we read:

The lilac in the ink well is slowly turning blue. It hopes to remember this night, it would do anything to remember this night, but that is impossible.

\footnotetext{
${ }^{21}$ See the dates provided for the individual poems in Wan Xia \& Xiaoxiao 1993: 236-243.
} 
and in the first stanza of "Winter":

a spare-time writer stops writing and starts to prepare food for the birds of dawn.

In the sixth stanza of «Winter», $I$ wakes up at night, when the fire in the stove goes out. $I$ gets up, pokes the ashes and makes the fire flare up once more:

For the one just now dreaming of wolves, my lighting the fire means rescue.

In the scheme of things that emerges from this reading it comes as no surprise that poetry and dreams also belong together, and fire can be added to the list because the moment of waking up coincides with its extinction. Rekindled, it saves the dreamer-poet. Again, the speaker and the dreamer in this passage are different identities of the same person, to whose duality we will return later.

The dreamer takes us to the seventh poem, «Fourteen Dreams». Indeed, «Fourteen Dreams» strengthens the connection of poetry on the one hand, and receptiveness, emotion, imagination, night, dream, on the other - within a reading of the series in its entirety as poetry about poetry, that is, for «Fourteen Dreams» itself never makes this explicit. But eleven of its fourteen stanzas begin with the words I dream, and one with In my dream, and there are good grounds for identifying the speaker in this series with the poet or someone close to the poet.

«Fourteen Dreams» also draws attention to another, central component of the multifarious subject matter in «Salute». That is, the intrusion of death, as the crudest of everyday realities, into the unworldly realm of poetry. If one expects to see stylized versions of death anywhere at all, poetry and discourse on poetry would be a good place to start looking. Against the backdrop of the Chinese avant-garde, one recalls the mythification of Haizi, and the glorification of his suicide. By the seventh and eighth stanzas, however, halfway through «Fourteen Dreams», death is anchored in a very real, less than glorious reality that is embodied precisely by Xi Chuan's erstwhile fellow poets and friends:

I dream of Haizi, grinning at me and denying his death.

I dream of Luo Nihe, luring me into a garage, its floor covered in oil stains. In a corner stands a single bed with white sheets. That is where he sleeps, every night. 
Xi Chuan has named Haizi's and Luo Yihe's sudden deaths as part of the forces that reshaped his worldview and his poetics between the spring of 1989 and the early 1990s. This is confirmed by their appearance in «Fourteen Dreams» and by other scenes in «Salute» and elsewhere in Xi Chuan's 1990s work. In the passage quoted above the speaker wards off the reality of Haizi's death through dream and poetry, if only momentarily - but to no avail, for the fact of the matter is that Haizi is dead, and Xi Chuan has publicly reflected on Haizi's death more than once. In that sense, «Salute» occupies a transitional position between Xi Chuan's first commemorative essay, which was written soon after Haizi's death and effectively launched the Haizi myth, and his demythifying intervention called "Afterword to Death" some four years later, both reviewed in chapter Three.

Three stanzas down there is a morbid ambiguity in «Fourteen Dreams»:

I dream of a child [孩子 háizi] falling from a high-rise. Without wings.

As noted earlier, the Chinese word meaning 'child' resonates in the name Haizi, and Xi Chuan has related an anecdote of someone playing on their homophony; and the háizi in the tenth stanza dies a violent death. Finally, there would be no need to assert that this háizi has no wings unless there exists, somewhere, the outlandish assumption that he has wings. They must be the wings of the imagination, or Heine's wings of song (Auf Flïgeln des Gesanges....), or those said to be confused with nocturnal writing earlier in «Salute». They fail, however, to make this háizi transcend gravity or an ordinary human death, whether such transcendence would take place through poetry or through an extraordinary human death, that is: through suicide.

With hindsight the references to Haizi and Luo Yihe affect the meaning of remarks on death in the first, second, and sixth poems of the series. In «Night», the speaker says:

For the soul that cannot sleep, there is no poetry. One needs to stay awake and be on guard, but in the face of death one cannot ponder.

Certainly in a Chinese cultural context, a soul that cannot sleep could be that of someone who died an untimely death, as Haizi and Luo Yihe did. After the reality of death has made its way into Xi Chuan's poetry, it overrules their identity as poets. They are doomed to wakefulness, 
but even the rationality that being awake would normally bring is denied them. Death leaves them empty-handed altogether.

In the seventh stanza of «Salute», we read:

On this endless road, there is no asking where the journey leads. When the moth flies into the flame, that is no time to talk of eternity and it is hard to find proof of a man's moral flawlessness.

If the road stands for a life of writing - we have seen that Haizi, for one, was by all accounts a dedicated poet, to the point of being obsessed - the traveler is not to wonder about a destination while alive. Read thus, this statement calls for soberness on the poet's part. It takes exception to a view of creative writing as defying mortality, or claiming eternity for the oeuvre that will outlive its author. Here, let me stress once more that such views were widespread on the late 1980s and early 1990s Chinese poetry scene, and remind the reader of Haizi's «Ancestral Land (Or: With a Dream for a Horse)».

Again, in «Salute» aspects of such a romantic poetics of transcendence are shoved aside by death, specifically the compulsive self-destruction of a moth, emblem of transience. And although Xi Chuan's moth kills itself, everyone else is said to be implicated. This thought is made explicit in the third stanza of «Ghosts»:

The death of others makes us guilty.

The greater part of «Ghosts» is about the relationship between the living and the dead. The speaker finds fault with the living for their inability to deal with death, and for their lack of consideration for the ghosts of the dead. In the fifth stanza he defies the taboo of indecent deaths, a decent death presumably being that of old age:

There is to be no death by lightning, no death by drowning, no death by poison, no death in battle, no death by disease, no death by accident, no death by unending laughter or unending crying or gluttonous eating and gluttonous drinking or an unstoppable flow of words until one's strength is exhausted. Well-how then is one to die? Noble death, ugly corpses; a death without a corpse is impossible.

This instance of iconicity - the first sentence is itself an unstoppable flow of words - demonstrates that people's attempts to domesticate death are in vain, as are the poet's attempts to romanticize it. $\mathrm{Xi}$ Chuan's irony extends to this somber area in the eighth stanza of «Ghosts»: 
How will the ghosts appear? Unless hats can be transformed into hat ghosts and clothes be transformed into clothes ghosts, flesh-turned-ghost must be naked, but the appearance of naked ghosts is not in keeping with our current morality.

In the penultimate stanza, the speaker again sets himself apart from other living human beings, and affirms his affinity with the ghosts of the dead in a playful encounter with them:

In the dark, someone reaches out a finger and taps me on the nose.

To return to my reading of «Salute» as poetry about poetry: the poem suggests that poetry is powerless in the face of death, although more negotiable aspects of reality will leave it in peace. Whereas examples of this type of indeterminacy - not poetry or reality, but poetry and reality - are scattered across the series, poetry does remain exempt from many rules of daytime life, accepting a socially "marginal" status in return. In «Night» for instance, the youth singing to his heart's content doesn't do so for a paying audience but in the basement, unseen and unheard. In «Salute», this statement:

\section{Illusions depend on capital for their preservation}

may first appear to forge an unexpected bond between dreams and money, but it is followed in the same poem by the instrumental passage on the mountain dweller who calls the capacity to feel a criterion for authenticity. According to this authority the realm of poetry is real, not its unfeeling counterpart. In other words, illusions are associated with material wealth. Incompatibility of material wealth with emotional and spiritual wealth, hammered home by the critics quoted earlier, also comes to mind when in «Maxims» the speaker admonishes a general audience: ${ }^{22}$

don't sleep with your wife in your arms while dreaming of high profits; don't light lamps during the day, don't do business with the night.

Finally, the opposition of poetry and the truths of daytime life finds good-humored, ironic and equivocal expression in this scene from «Winter», the last poem in the series:

${ }^{22}$ The last phrase of this passage (don't do any business with the night) occurs in Wan Xia \& Xiaoxiao 1993 and is among Xi Chuan's corrections to the text in The Nineties. 
The taxi covered in snow is pure white, like a polar bear. Its engine doesn't work, its body temperature is dropping to zero. But I can't stand watching it give up, so I write "I love you" on one of its windows. As my finger moves across the glass, it makes a happy, squeaking sound, just like the forehead of a girl expecting a kiss will start to glow.

The speaker literally writes the life back into a victim of the cold with what must be one of the most fundamental and hackneyed phrases from his art.

I have twice referred to the speaker's dual personality. This is illustrated by the following quotations from the first, fourth, and sixth stanzas of «Abode»:

What I will not allow has happened: I am slowly changing into someone else. I must call out three times, I must call myself back . . .

The world in the mirror is my world's equal but its opposite, too: if it isn't hell, it must be heaven. A man exactly like me, but my opposite too, lives in that world...

This often happens: Liu Jun makes a phone call to find another Liu Fun. As if I am talking to myself, cradling the phone.

Liu Jun is Xi Chuan's official name. He could have used his pen name, as he did for Haizi, but he did not. Perhaps he thought it unbecoming or distracting, or he saw no need for a general readership to connect the above scenes with their author. Be that as it may, by using his own name he makes them autobiographical, no matter how many Liu Juns exist in historical reality. In the context of «Salute», which depicts poetry in opposition to daytime life, this splitting of a personality on the phone to itself refers to a double identity of poet and daytime person.

I have not yet quoted from «The Monster», the fourth and longest poem in the series, with a dominant "monster" protagonist at its center. To read that conspicuous presence as a metaphor is thrilling, and it is a radical instance of the decision to interpret. The reading of «Salute» that has emerged in the preceding pages, however, offers good grounds for doing so. Moreover, toward the end of the poem, the monster is called a "metaphor of a monster" (比喻的巨兽).

«The Monster» is perhaps the strongest poem in the series. A story well told and delineated in form and content, it exemplifies the ability of effective imagery — and of expertly manipulated language - to gen- 
erate a presence all its own, without constantly raising questions of the type What does this really mean? I quote this poem in full to illustrate this point, and to provide a substantial example of what I have called a joy of language. At the same time I will in fact interpret the poem, as before: without attempting full coverage of the text, and with a focus that is directed by my reading of the series as poetry about poetry.

«Four: The Monster»

The monster-I have seen it. The monster has bristly hair and razor-sharp teeth, it is close to going blind. The monster breathes its husky breath and shouts of misfortune, but its feet move without a sound. The monster has no sense of humor, like someone trying hard to cover up humble origins, like someone destroyed by a calling; it has no cradle offering memories, no goal offering direction, not enough lies to defend itself. It beats on tree trunks, it collects infants; it lives like a rock, it dies like an avalanche.

The crow seeks allies among scarecrows.

The monster hates my hairdo, hates my smell, hates my regret and my overcautious ways. In short, it hates my habit of dressing up happiness in pearls and jade. It bursts through my door, tells me to stand in a corner, will not let me explain and falls through my chair, shatters my mirror, rips my curtains and all protective screens around my private soul. I beg it: "When I am thirsty, don't take away my teacup!" Right then and there it digs out water from a spring: that must be its answer.

A ton of parrots, a ton of parrot talk!

For the tiger we say "tiger," for the donkey we say "donkey." But how do you address the monster? It has no name, so its flesh melts into its shadow, so you cannot call out to it, so you cannot determine its place in the sun nor foretell the good or ill luck it may bring. It should be given a name, like "sorrow" or "shyness," it should be given a pond to drink from, it should be given a roof over its head for shelter from the rain. A monster with no name is scary.

A thrush bumps off all the king's men!

The monster is exposed to temptations too, but not those of the palace, not those of female beauty and not those of sumptuous candle-lit banquets. It is coming toward us, but surely there is nothing about us to make its mouth water? Surely it will not try to suck emptiness from our bodies? What kind of temptation is that! 
Sideways through a shadowy passageway, the monster collides head-on with a glint of steel, and that smallest of injuries teaches it to moan - to moan, to live, not to know what faith is. But as soon as it calms down, it hears the sesame stalks budding once again, it smells the Chinese rose's fragrance once again.

Across a thousand mountains flies the wild goose, too timid to speak of itself.

This metaphor of a monster goes down the mountainside, picks flowers, sees the reflection of its face in the river, in its heart of hearts feels unsure who that is; then it swims across, goes ashore, looks back at the haze above the water, finds nothing, understands nothing; then it charges into the city, follows the trail of a girl, comes by a piece of meat, spends the night under eaves, dreams of a village, of a companion; then it sleepwalks fifty miles, knows no fear, wakes up in the morning sun, discovers it has returned to its earlier place of departure: still that thick bed of leaves, hidden underneath the leaves the dagger still - what is about to happen here?

Dove in the sand, you are awakened by the shimmer of blood: the time to fly has come!

I take the monster to be a metaphor for poetry in a broad sense, including all aspects of artistic creation. The $I$ in the poem's opening line is one side of the dual personality identified above. Accordingly, as the poem proceeds, his relationship with the monster proves to be ambiguous. The statement:

The monster-I have seen it

implies that the monster isn't visible to all. In a romanticist poetics, the attributes ascribed to the monster in the rest of the stanza are familiar traits of poetry too, which rub off on the poet: dangerous, proud of a calling but destroyed by it, and truthful (not enough lies to defend itself). Thus, from the start, the monster fits in well with the dreamlike, romantic world of poetry. In the fourth stanza, among the things the monster hates are regret, overcautious ways, and façades drawn up around one's heart and heartfelt feelings: it advocates the unbridled expression of individual emotion. Curtains and protective screens around the soul are part of the speaker's appearance in daytime life. Two stanzas down, there are evident associations with poetry again, as that which cannot be named and defies straightforward expression and control. The speaker suggests "sorrow" as one possible name, in- 
voking truisms to the effect that good poetry is more likely to have suffering than happiness as its source. The stanza's closing sentence: ${ }^{23}$

\section{A monster with no name is scary}

takes the reader back from romantic poetry at large to its concrete manifestation in this poem. The temptations to which the monster is said not to be exposed point to poetry's social "marginality": that is, as measured against political power, sexuality, and material wealth (the palace, female beauty, sumptuous banquets). After the now explicitly metaphorical monster's wild ride through the ninth stanza, the text ends at daybreak, just as in «Night», the first poem of the series. The day begins with a hidden dagger, a promise of violence, and the shimmer of blood that awakens the dove in the sand comes to stand for the colors of sunrise. In another similarity with «Night», the last line of «The Monster» is a reference not to an abstraction called poetry, but to this poem itself. When the dove flies off, the poem is over.

The dove is the last of a series of birds interrupting the monster in the short stanzas that alternate with the long ones, in another example of form acting as an icon for content. The short, airy stanzas feature birds, while the long, heavy stanzas are the domain of the monster itself, of human beings, of the tiger and the donkey, all earthbound and unable to fly. If the birds are not poetry itself, they may be messengers from the realm of poetry or its overseers. There is evidence to that effect elsewhere in «Salute» and in other poems by Xi Chuan, and in his explicit poetics. $^{24}$

My reading of the monster as a metaphor for poetry is motivated by its immediate surroundings, the other seven poems in «Salute». Especially if the fourth poem stands by itself, as it has at various times in its publication history, the monster has broader resonances. It can be seen as an anarchic, uncontrollable force of an emotional or imaginative nature, further interpretation depending on what individual readers bring to the text. To cite three examples, the monster could represent the artist's inspiration - as Xi Chuan has suggested - or

${ }^{23}$ This statement, added by Xi Chuan to the text in The Nineties, also occurs in Wan Xia \& Xiaoxiao 1993; there, it is followed by the phrase it is a force we can't control.

${ }^{24}$ See, for instance, «Birds» (鸟, in Xi Chuan 1999a: 89-90), and the opening and closing stanzas of «Near View and Far View» (近景和远景, in Xi Chuan 1997c: 217-236); and chapter Ten of this study. 
social rebellion, or the power of fate. Cui Weiping has invoked the monster to illustrate her observation that Xi Chuan's later work no longer claims to know how things will end and hints at forces that lie beyond our grasp. ${ }^{25} \mathrm{In}$ this respect, the terms in which she comments on Xi Chuan's work are akin to the notion of indeterminacy, even if the monster is a less indeterminate presence than the romantic poet embodied by Haizi.

At first sight, then, a reading of «Salute» as poetry about poetry yields a romantic opposition of poetry and everyday reality, reaffirming views of Xi Chuan's poethood held by several critics. Poetry, in close association with night and dreams, provides a prideful alternative to daytime life. The value of emotion, imagination and spirituality is set off against the limitations of rationality and despicable materialism. Thus, the poem's time and place of origin brings to mind social change in China, specifically on the poetry scene and in the intellectualcultural climate at large, in the rapid transition from the Eighties to the Nineties, with those two decades representing not just periods in time but distinct, incompatible mindsets. But as we read on and reread, it transpires that things are not as clear-cut as that. There is one aspect of reality from which poetry offers no escape, manifest in the appearances of Haizi and Luo Yihe: death, oblivious to any order of things but its own. Death will invade the realm of poetry and kill poets, no matter how immortal their poetry. In the words of Joseph Brodsky: ${ }^{26}$

With neither grimace nor maliciousness

death chooses from its bulging catalogue

the poet, not his words, however strong,

but just - unfailingly - the poet's self.

«Salute» owes much of its charm to its speaker-cum-protagonist, apt at putting both reality and poetry in perspective. While recognizing the compulsory, universal truth of death, he reserves the right to create an optional, personal truth in art. He is better at questioning answers than at answering questions. Especially in his indeterminate portrayal of poethood and related matters, this character is a worthy companion to tragic heroes, low-key demystifiers, loud taboo-slayers and vulgarizers and other voices that operate in the avant-garde's texts. The poem's

\footnotetext{
25 Xi Chuan 1995: 66, Cui 1992: 122-123.

26 Brodsky 1973: 99; translation by George Kline.
} 
power, within a framework of modern Chinese poetry and beyond, lies in meticulous and confident wording, in the balanced combination of divergent registers and subject matter, and in the dramatic tension between disrespect for inflated notions of poethood on the one hand, and poetry's miraculous survival on the other.

\section{Words Capturing Images, Images Capturing Words}

Since «Salute», Xi Chuan has produced several other long poem series, including «Misfortune» (厄运, 1996) and «What the Eagle Says» (鹰的话语, 1998). ${ }^{27}$ Both share with «Salute» an experimental, explorative feel and the quality of indeterminacy in various dimensions of the text, from typography to sound to linguistic register and so on. There are interfaces between the three texts on the level of subject matter, too. All are concerned with issues of identity, relations of self and other, transformation and metamorphosis - and with images of poetry and poethood.

$\mathrm{Xi}$ Chuan's poetry is of the kind that stimulates the urge to interpret. Giving in is easy, so to speak. Below, I give in once again, this time to several passages from «What the Eagle Says». This leads toward some thoughts on the limits of interpretation that are inspired by the surface of his poetry rather than its "deep meaning," and by the interaction of these two levels of the poetic experience.

\section{Some More Deep Meaning}

Just like «Salute», «What the Eagle Says» has eight constituent poems; for an English translation of the full text, the reader is referred to the Seneca Review xxxiii-2 (2003). Each poem's stanzas are numbered, for a total of ninety-nine in the entire series. The eight titles are worth joint citation, as a nutshell characterization of Xi Chuan's style in the late 1990s:

"One: Of Thinking, As Harmful As It Is Fearful"

"Two: Of Loneliness, That Is Desire Unsatisfied»

"Three: Of False Causality and Real Coincidence in the Dark Room»

"Four: Of Dreary Good and Contentious Evil»

\footnotetext{
${ }^{27}$ Xi Chuan 1997c: 175-198 and 1999b.
} 
"Five: Of My Intimate Experience of Things»"

"Six: Of Fighting, Tearing and Biting, and Death"

«Seven: Of the Appearance of Truth»

"Eight: Of My Meaningless Life»

《一、关于思想既有害又可怕》

《二、关于孤独即欲望得不到满足》

《三、关于黑暗房间里的假因果真偶然》

《四、关于呆头呆脑的善与惹是生非的恶》

《五、关于我对事物的亲密感受》

《六、关于格斗、撕咬和死亡》

《七、关于真实的呈现》

《八、关于我的无意义的生活》

«What the Eagle Says» contains many moment of metamorphosis. Take this stanza in «Of My Intimate Experience of Things»:

56/ Thereupon I shun my flesh and turn into a drop of perfume, actually drowning an ant. Thereupon I turn into an ant drilling my way into an elephant's brain, upsetting it so that it stamps all four of its legs. Thereupon I turn into an elephant, my entire body exuding a great stench. Thereupon I turn into a great stench, and those who cover their noses when they smell me are men. Thereupon I turn into a man, and a plaything of fate.

But metamorphosis doesn't quite cover what is going on here. I appears to be a mental-linguistic agency, autonomous but without a home of its own. Roaming from one body to another, animate or inanimate, $I$ can occupy divergent points of view:

58/ Thereupon I turn into my posterity and let the rain test if I am waterproof. Thereupon I turn into rain, and splash upon the bald head of an intellectual. Thereupon I turn into the intellectual, detesting the world and its ways, and I pick up a stone from the ground and hurl it at the oppressor. Thereupon I turn into stone and oppressor at the same time: when I am hit by me, that sets both of my brains roaring.

In addition to metamorphosis, then, we may speak of metaphor, in its literal meaning of transfer. Apparently, it is not just $I$ that is capable of transfer, but others as well. In «Of Fighting, Tearing and Biting, and Death», we read:

$64 / . .$. I need but feign to be an eagle, and a man will feign to be me. 
In the final stanza of «Of My Meaningless Life» and of the series as whole, the poem intimates that the chain or the poetic spell of metamorphosis and metaphor can be broken, with the same sort of literary self-consciousness we have encountered in «Salute»:

99/ So please allow me to stay in your house for an hour, because an eagle plans to reside in a chamber of my heart for a week. If you accept me, I will gladly turn into the image you hope for, but not for too long, or my true features will be thoroughly laid bare.

These are some of the things we learn about the speaker-protagonist. What of the eagle itself? The poem's title suggests humanization, for 话语 'what ... says' is inseparably linked to human language, and cannot be used in phrases like The cat says miaow. In the poem, the eagle doesn't say a thing, but in Chinese, as in English, what the eagle says can also mean 'what the phenomenon or the story of the eagle has to tell us,' or indeed 'how one could speak of the eagle.' This ambiguity extends to the eagle as it appears in the body of the poem, reaffirming clichés only to subvert them. In «Of Thinking, As Harmful As It Is Fearful», the eagle is a sign that doesn't carry the weight of thinking, evoking a conventional vision of animal instinct, determined of itself and untroubled by existential doubt. Soon thereafter, however, the eagle is called shy. For all its unlikeliness, this all too human imperfection somehow endears the animal to the reader. As such, it is akin to the monster in «Salute», when the latter is said to have no sense of humor and hate the speaker's hairdo.

Moving on from there, we find a regular alternation of a sovereign, clichéd eagle, abstracted into eaglehood, and an individual animal. The cliché flies on high, flying of itself, like its own shadow. It even becomes a point of calibration in the universe, for when it spreads its wings ... it is the earth begins to fly. Our shy eagle of flesh and blood, however, neglects to eat and is too weak to get off the ground. It dies - the cliché is of course immortal - and falls prey to maggots, and its feathers end up in the living room of a white-collared beauty. In the context of present-day China, this may well bring to mind the new rich, unimpressed by eaglehood but happy to pay for a stuffed eagle as a piece of interior design. Although there is nothing like one-to-one overlap here, the distinction between abstract eaglehood and the eagle of flesh and blood leads to an association with that between transcendent poetry and mortal poets in «Salute». 
Thus, the dismantling of the Elevated image by vulgar, material reality takes us back to the earlier series, where Haizi falls to his death from a high-rise and we read that the death of others makes us guilty. In «What the Eagle Says», Xi Chuan expands this observation to include the animals:

... not metaphysical death but death of the flesh: wounds festering, the body rigid. That is death of the flesh, and we partake in it.

Subsequently, in a poetical statement - the naming of things in order to neutralize them - we read that if I describe an eagle, this is in order to cut off its head. The same stanza contemplates the possibility of the eagle's biblical rebirth, thus reverting to cliché once again. Any temporary death of eaglehood would be strictly metaphysical, and only have a use for festering wounds and so on as stage props.

But in the end, metaphysics lose and what weighs heaviest is feathers, festers, the identification of man and beast and their mutual metamorphosis or trading of places. The eighth and final poem in the series «Of My Meaningless Life», begins as follows:

88/ Among men there are men who are not men, just like among eagles there are eagles that are not eagles: there are eagles that are forced to pace up and down the alleyways, and there are men who are forced to fly through the air.

Some eagles are really men, and some men eagles. This must be why in "Of Fighting, Tearing and Biting, and Death», I cautions that one shouldn't be too quick to put eagle meat on the menu. That to be an eagle is not nearly as exciting as the cliché would have it is another one of $\mathrm{Xi}$ Chuan's inferences from the blurring of the boundaries between man and beast. For if man doesn't revel in his walking, why should the eagle revel in its soaring?

\section{Back to the Surface}

I have said that Xi Chuan's poetry makes it easy to give in to the urge to interpret. The actual process of interpretation, however, is difficult - that is, if one expects anything like complete coverage of the text, or coherence in an all-encompassing symbolic structure, or even the identification of one particular, exclusive deep meaning for central images such as the monster or the eagle. Thus, while this poetry invites 
interpretation, at the same time, it actively resists any interpretation that leads to semantic closure. How does this work?

«What the Eagle Says» frequently strikes an expository pose. It does so through the deliberate, aestheticized repetition of sentence patterns, a mechanism we find in «Salute» as well. From «Maxims»:

A book will change me, if I want to take it in; a girl will change me, if I want to sing her praises; a road will change me, if I walk it to the end; a coin will change me, if I want to own it. If I change someone else who lives beside me, I change myself: my single conscience makes the both of us suffer, my single selfishness makes the both of us blush.

This mechanism occurs more frequently as Xi Chuan's poetry develops through the 1990s, in texts such as the above-mentioned «Misfortune» and especially in «What the Eagle Says». ${ }^{28}$ We have seen several examples, but there are more, such as this stanza from «On Loneliness, That Is Desire Unsatisfied», which lays out nothing less than an itinerary through life:

25/ Shall we not read the map? At sorrow lies the first crossroads, with a road to song and a road to bewilderment; at bewilderment the second crossroads, with a road to pleasure and a road to nothingness; at nothingness the third crossroads, with a road to death and a road to insight; at insight the fourth crossroads, with a road to madness and a road to silence.

Intra-sentence and inter-sentence patterns such as these remind one of ancient philosophical-literary texts from East and West, such as Zhuangzi and Heraclitus, suitable for analogy and contrast, mirror image and opposition; and they prompt the reader to engage in a cognitive discourse with the text. And true enough, Xi Chuan's poetry has thought-provoking, serious things to say about thought-provoking, serious subject matter such as that identified above-identity, self and other and so on - and about the human condition. Crucially, however, upon closer inspection the semantics of his poetry often stray from the rules of expository and other logics, celebrating ambiguity, paradox and indeed contradiction instead. Inasmuch as it is philosophically inclined, his poetry turns out to be pseudo-philosophy (伪哲学), in the author's words - which, yet again, present a defensible descrip-

${ }^{28}$ For Andrea Lingenfelter's English translation of excerpts from «Misfortune», see Sentence 5 (2007). 
tion of his art. ${ }^{29}$ His poetry's resistance to interpretation, then, stems from the primacy of the poem's actual texture, that is: the materiality, including the musicality, of its language. Summed up in a reversal of the conventional expression that the words of a poem serve to capture images, what happens here may well be described as images attempting to capture words.

The concept of indeterminacy as I have used it, especially in section 2, denotes a general mood that subverts clarity, certainty and straightforward direction in most if not all of the text's dimensions. This largely overlaps with the scope Marjorie Perloff assigns to it in The Poetics of Indeterminacy: Rimbaud to Cage. Notably, Perloff points out that indeterminacy is not the same thing as vagueness, or the multiplicity of meanings one may read into a single poem, or an assumption that any poem can be made to mean anything - and hence, one might add, to mean nothing at all. Perloff's employment of the concept hinges on the fact that while the surface of a particular type of (post)modern poetryJohn Ashbery's, for example - "endlessly generates the impulse that makes the reader yearn for completion and understanding" and invites one to probe its depths, doing so will not lead to the ability to determine any stable deep meaning. Using Roger Cardinal's imaginative terminology, she shows how the language of such poetry always seems to be on the point of revealing its secrets but at the same time re-veils them, in simultaneous disclosure and concealment. According to Cardinal, "to read such a text is like being given a key only to find that the locks have been changed." In a chapter on Gertrude Stein, Perloff observes that indeterminacy comes about through "repetition and variation, sameness and difference, a rhetorical pattern of great intricacy," and that this pattern is "set up so as to create semantic gaps." This analysis very much applies to the aestheticized quality of Xi Chuan's writing. Xi Chuan's particular performance of what Perloff summarizes as tension between reference and the compositional game, or between a pointing system and a self-ordering system, is a

${ }^{29}$ Xi Chuan 1997c: 5; cf Xi Chuan 2001: 224, entry 19. 
key feature of this poetry and its unique contribution to modern Chinese literature. ${ }^{30}$

On the metatextual level of critical discourse, my reading of «Salute» shows that representations of Xi Chuan's poetry in the moneyfied 1990s as asserting a unidirectional prevalence of mind over matter or Elevated over Earthly are incomplete at best. His poetry can equally be seen to show up the prevalence of matter over mind, in the deaths of poets and otherwise. These two expressions also apply on the level of our immediate engagement with his work: mind over matter in that interpreting this poetry more or less contentwise can be extremely rewarding, and matter over mind in that the formed materiality of his language takes the lead in this poetry's realization. This duality is one of the ways in which the synergy of form and content that is typical of poetry can make itself felt.

${ }^{30}$ Perloff 1999: 27-32, 72, 84, 97, 98, 261-263 et passim. 
Maghiel van Crevel - 978-90-47-44273-8 Downloaded from Brill.com $04 / 25 / 2023$ 11:38:45PM via free access 


\section{CHAPTER SIX}

\section{FRINGE POETRY, BUT NOT PROSE: XI CHUAN AND YU JIAN}

Xi Chuan's poetry and Yu Jian's are widely seen as representative of the Elevated and Earthly aesthetics respectively, and as reflecting diametrically opposed poetics. Bearing this in mind, I like to think of the present chapter - preceded by one on Xi Chuan and followed by one on Yu Jian - as bridging a stretch of nobody's land from one end of the avant-garde textscape to another. I hope the reader will excuse my use of this clichéd image, if only to question a moralizing you-must-take-sides criticism that is occasionally practiced in both Elevated and Earthly camps and focuses on the incompatibility of various poetics within what I have called a single Easthopian discourse, rather than celebrating diversity and interconnectedness. I proceed from the observation that two early 1990s texts, one by Xi Chuan and one by Yu Jian, stand out by their sheer length, and by their testing of the boundaries between poetry and prose - or, analogous to the image used above, by their forays into nobody's land between the two genres. Perhaps, for Xi Chuan and Yu Jian and for poetry and prose, we shouldn't merely speak of nobody's land, but of middle ground as well. The texts in question are Xi Chuan's «Salute» (致敬) and Yu Jian’s «File 0» (0 档案), both written in 1992. For aspects of «Salute» reviewed in chapter Five, I will offer the occasional summary rather than repeating the argument.

Within the avant-garde, «Salute» and «File 0» count as milestone texts and have acquired canonical status, even if «File $0 »$ remains controversial to this day. Their publication history shows that readers in China and elsewhere tend to classify both texts as poetry. In addition to bibliographical detail on «Salute» outlined in the previous chapter, I note that Yu Jian has consistently referred to «File 0 » as a long poem; after unofficial circulation in 1992-1993, it was officially published in China in the poetry section of the literary journal Grand Master (大家) in 1994, accompanied by a review by He Yi that emphatically confirmed its classification as poetry, in fact ascribing to it a leading role in the development of the genre; in 1995 both text and commentary

(C) MAGHIEL VAN CREVEL, 2008 | DOI 10.1163/9789047442738_007

This is an open access chapter distributed under the terms of the Creative Commons AttributionNoncommercial 3.0 Unported (CC-BY-NC 3.0) License. 
were republished in Taiwan in Modern Poetry (现代诗); it is included in The Poetry of 1 u Fian (于坚的诗, 2000), and so on. That «File 0» was adapted for the theater by Mou Sen's Beijing Theater Workshop (戏 剧车间) in 1995, and as such acquired the additional status of a script and performance that interact with the original publication, doesn't alter its continuing existence as a poem. ${ }^{1}$

This chapter is concerned with distinctions of poetry and prose, but it doesn't aim to categorize «Salute» and «File 0» as unambiguously being one or the other. Rather than essentializing either the genres or these particular texts, I note that although both texts have counted as poetry from the start, they highlight and problematize the said distinctions. «Salute» has poetic, formal regularities in parallelism, rhyme and rhythm on the level of sentences and stanzas, but its lines cover the full width of the page. Conversely, lineation and line-internal division into short strings separated by blanks make «File 0» look typographically poetic, but its prosody is less than spectacular and its division into sections is modeled on extremely prosaic examples. «Salute» makes a poetic appeal to the imagination and abounds with ambiguity, contradiction and paradox, encouraging interpretation, even if we have seen that the actual process of interpretation is difficult. «File 0» seemingly claims to have but one semantic level, that of objective observation with some respect for the logic of everyday life, but it generates poetic tension by thoroughly defamiliarizing and contrasting language and "reality." Both texts foreground an uneasy relationship between sheer length and the phenomenon of poetry, but in other aspects of the literary experience they are so unalike that one might ask whether calling the one poetry means calling the other prose. My answer to that question is no. Both are indeed poetry, albeit of an unusual kind-but each for different reasons.

Section 1 looks at some issues surrounding the definition of poetry. Section 2 presents a text-based analysis to clarify the poetic status of «Salute» and «File 0». Section 3 considers the evident viability of long poems in contemporary Chinese literature.

${ }^{1}$ Yu Jian 1994, 1995a, 2000: ch 4, He Yi 1994. Yu Jian \& Zhu 1994, Yu Jian 1998b: 4. On the Theater Workshop adaptation (Yu Jian 1995b), see Lin Kehuan 1995, Yeh 1998a, Zhang Ning 1999 and Huot 2000: 80-82. 


\section{A Wonderful Inadequacy of Definitions}

When asked, people will commonly say that they know what poetry is - and therefore also what prose is: the rest, the unmarked case, the default mode of linguistic usage in literary expression. It is only when they are asked to describe or define poetry that they become less assured. This holds not just for those with no professional interest in the subject. For the specialists, too, distinctions of poetry and prose are less than absolute and indeed contested. There are no universally accepted, clear-cut definitions of prose, poetry and what lies between them or outside their combined scope. Be that as it may, poetry and prose are different things, perhaps so different as to enable meaningful distinctions of prosaic poetry and poetic prose, bringing to mind Northrop Frye's scale from metric verse to free verse to free prose to prose. ${ }^{2}$ I will begin by adding to the confusion, through a look at some statements on the elusive genre of prose poetry, or 散文诗 in Chinese.

With regard to nineteenth-century European as well as twentiethcentury Chinese traditions, various poets, scholars and critics agree that texts labeled prose poetry find themselves in a transitional zone, a grey area, nobody's land between poetry and prose-but whether they define such texts negatively as no longer bound by the rules of either genre, or positively as enjoying the best of both worlds, the bottom line tends to be that they come under poetry not prose. They are, in other words, a special kind of poetry and not a special kind of prose, as the following examples show. John Simon, in his dissertation on nineteenth-century French, German and English literature, recognizes how difficult it is to chart the territory between poetry and prose, but doesn't hesitate when ultimately classifying his material as poetry. Wang Guangming, writing on modern Chinese literature, states unequivocally that in essence the "modern lyrical literary form" of prose poetry comes under poetry not prose. Taiwan poet Xiaoxiao, in a survey of prose poetry from Taiwan and its history in Chinese literature since $\mathrm{Qu}$ Yuan, quotes several Chinese authors as saying that the texts under review are poetry that has incorporated selected features of prose, not the other way around. He takes issue with the dissenting voice of Luo Qing, who proposes that poetic prose (诗散文) would do the

\footnotetext{
${ }^{2}$ Frye 1965: 886, discussed in Perloff 1996: ch 6, esp 143.
} 
job equally well. Xiaoxiao doesn't engage with Lin Yiliang's claim that prose poetry is a true borderline case and belongs with neither prose nor poetry, perhaps because Lin's essay is included in a book called $L$ in Yiliang's Poetry Talk (林以亮诗话). In an anthology of French texts in Dutch translation, Menno Wigman speaks of poetic prose only once, otherwise of prose poems. ${ }^{3}$

One could argue that the issue is that of the bottle being half full or half empty. Does it matter what you call it? But such distinctions of perception - and indeed of intent - can be crucial, certainly in the realm of art. Poetry and prose don't exclude each other, or lay claim to all-encompassing generic classification. Still, they are the two ends of a scale that co-determines how we approach literary texts, and the reasons why we assign certain coordinates to certain texts are of scholarly interest. One notable thing about the consensus among the authors cited above is that while most pay homage to Baudelaire's Paris Spleen: Little Poems in Prose... (Le spleen de Paris: petits poèmes en prose....), they take little note of the fact that Baudelaire himself, in his letter to editor Arsène Houssaye, speaks of "the miracle of a poetic prose," not of prose poetry or prosaic poetry. Wigman does mention Baudelaire's initial designation of his writings, but Wang Guangming has removed the inconvenient opening words (struck through below) of Baudelaire's famous description of the texts, and quotes only its second half: ${ }^{4}$

the miracle of a poetic prose, musical without rhythm and without rhyme, supple enough and choppy enought to fit the soul's lyrical movements, the undulations of reverie, the jolts of consciousness.

One wonders if prose poetry and 散文诗 would have eclipsed poetic prose and 诗化散文 or 诗性散文 as the name of the genre if the title of Baudelaire's collection hadn't eclipsed the letter that has often served as its foreword.

The authors cited above have done more in the way of defining than reaffirming a label. Xiaoxiao identifies two characteristics for prose poetry: it must have fictional intent and produce an effect of horror. He names four ways to achieve this. These are the intermingling of fiction and reality, the crisscrossing of time and space, the reversal of

${ }^{3}$ Simon 1987: 3-4 and 697-698, Wang Guangming 1986: 687, Xiaoxiao 1998: 315-317, Lin Yiliang 1976: 45, Wigman 1998: 13-18.

${ }^{4}$ Baudelaire 1943: 4 and 1989: 129, Wigman 1998: 15, Wang Guangming 1986: 688. 
feelings and situations and the rotation of "the world" and "I." Xiaoxiao's theory is problematic in its failure to address the issue of form. Moreover, it would have to apply to a variety of works unanimously recognized as either prose or poetry that no one would dream of calling prose poetry.

In a discussion of prose rhythm in the introduction to The Prose Poem as a Genre in Nineteenth-Century European Literature, Simon defines rhythm as "the sound that ... seems apposite to, and co-expressive with the meaning." Toward the end of his study, when he tackles the distinction between (prose) poetry and (poetic) prose once again, he writes: ${ }^{6}$

This is what poetry, and therefore prose poetry as well, must do: in the sound, in the syntax, in the cadences of the rhythm, repeat, illustrate, intensify the idea - provide the body, the soma that fits the psyche of the particular utterance. Then, again, emotional charge has something to do with it all . . . certain topics almost ineluctably gravitate towards poetry: memories, dreams, the passing parade of great names, the awareness of mortality. But there is more, there is Mme Durry's 'proprement l'ineffable.' It is something, lastly, in the rhythm of the statement that makes the heart leap up, or race along, or — almost - stop, overcome ... Is it a rhythm, here, that associates itself to something from our childhood, that echoes, perhaps, the rhythm of our thoughts or passions? I do not know. In the last analysis, it is the very problem of beauty: why is this face lovely to all, or almost all, who behold it? Geometry, physiology, psychology and aesthetics will come forward with their sundry explanations, and, as far as they go, they will be good explanations. But there will always be something more: the sheer inexplicable beauty of that face. Ultimately, a prose poem is a prose poem because it is more beautiful than prose.

I have quoted Simon at length for two reasons. First, to point out a contradiction between his discussion of prose rhythm on the one hand and his identification of rhythm as a distinguishing characteristic of poetry on the other. Second, because he allows the notion of beauty to enter the discourse - the experience of beauty is instrumental in bringing people to literature and art, but unfortunately often perceived as unfit for the classroom or critical discourse at large - and because he concedes a degree of undefinability. This concession doesn't invalidate what we do manage to define, and we don't need it out of dogmatic respect for some mystery or other. Language enables us, or we en-

\footnotetext{
Xiaoxiao 1998: 324-337.

6 Simon 1987: 13, 697-698.
} 
able language, to create things that intensify language and yet defy it. These things may be supremely personal and yet experienced as intersubjective, even if we cannot account for everything we feel about them by mobilizing yet more words.

The undefinability of poetry is illustrated by the number of its definitions through the ages. Depending on context - literary, scholarly, aphoristic - divergent criteria are brought to bear. To name a few archetypes, in addition to what we have seen so far:

(A) Definitions through bootstrapping, in abstractions, such as "poetry is (the expression in words of) the ineffable," "poetry is saying the unsayable," or couched in imagery and thus mere examples of what is to be defined: "poetry is a mirror."

(B) Definitions that beg the question, such as "poetry is the literary expression of beauty," or Coleridge's "poetry = the best words in the best order," or Shelley's extraordinary claim that "poetry is a record of the best and happiest moments of the happiest and best minds."

(C) Canonical, abstract definitions such as the traditional Chinese "poetry articulates what is on the mind intently" or "poetry verbalizes emotion," or Wordsworth's "poetry is the spontaneous overflow of powerful feelings." Without wanting to misconstrue their meaning and disregard the cultural context and the connotations of either phrase, it is easy to produce doubtful instances of poetry thus defined.

(D) Definitions based on the text's visual qualities, such as "poetry is literary texts whose lines don't cover the full width of the page," or "for poetry, the author determines where on the page the words end up, not the typesetter." ${ }^{8}$ While statements such as these can be useful to make widespread assumptions about poetry explicit, their limitations are obvious. They focus on what the text looks like and pay no attention to its sound. This problem may to some extent be remedied: for instance, by saying that poetry has rhyme. But that is an unsatisfactory solution, for there can clearly be such a thing as musicality in prose, meaning rhyme and rhythm in their broadest sense. Also, these statements attach disproportional importance to line breaks, which are but one feature of certain kinds of poetry from certain times and places.

Significantly, there has always been much less ado about definitions of prose. This makes sense if we bear in mind that, generally, prose

\footnotetext{
7 Preminger 1965: 640, 644.

${ }^{8}$ Krol 1982: 3-4.
} 
is closer to the patterns of everyday speech - so that in prose, literary usage is at the shortest possible distance from non-literary languagewhile poetry derives its generic status from deviation from and, indeed, disregard for those patterns.

Half a century ago, Simon noted that prose poetry had become harder to define, indeed harder to find, since the times of Baudelaire: ${ }^{9}$

When poetry and prose have acquired the flexibility and inclusiveness they now enjoy - thanks, in part, to the prose poem - the need for a tertium quid decreases.

We have since come through another fin de siècle, characterized by happy disrespect for boundaries of all kinds in the realm of literature and elsewhere. Simon's "flexibility and inclusiveness" for poetry and prose ring true more than ever for Chinese and other literary traditions. It may be no exaggeration to say that an exclusive definition of the genre of prose poetry is less than ever possible — or, desirable. This doesn't make reflection on distinctions of poetry and prose obsolete or meaningless. For one thing, it may help us take a fresh look at literature and its subsets as functional not ontological categories - in the words of Terry Eagleton - that we ourselves invest with identity and meaning. ${ }^{10}$

Below, I will examine «Salute» and «File 0» from a series of angles that are germane to these distinctions, namely their look and sound; their subject matter, style and interpretation; the reading attitudes they require; iconicity; and, with reference to a perspicacious essay by Gerrit Krol, an opposition of presence and progression in literary texts.

\section{2. «SAlute» AND «FILe 0»: Poetry or Prose?}

In Chinese literature from the Republican era, two names associated with prose poetry are those of Liu Bannong, for his groundbreaking translations of the 1910s, and Lu Xun, as the author of Wild Grass (野 草, 1926). In the second half of the twentieth century, the genre has been robustly alive since the early 1960s, with Shang Qin, Su Shaolian and Liu Kexiang as some of its most important authors. ${ }^{11}$ By con-

\footnotetext{
9 Simon 1987: 700.

${ }^{10}$ Eagleton 1996: 8.

11 Hockx 2000, Kaldis 2000, Yeh 2000b.
} 
trast, prose poetry doesn't manifest itself in literature from the People's Republic until the mid-1980s. Orthodox traditions in PRC literature contain many examples of poems that could be called prosaic, such as Li Ji's «Wang Gui and Li Xiangxiang» (王桂与李香香, 1946), He Jingzhi's «Song of Lei Feng», and Luo Gaolin's «Deng Xiaoping» (邓小平, 1996), ${ }^{12}$ but the features that lead one to do so-length: tens and indeed hundreds of pages of more or less linear narrative, lack of original metaphor and ambiguity - are not those that characterize prose poetry in the broad Baudelairean tradition. If we loosely define the latter as short texts with conventionally poetic features but without line breaks, experiments with prose poetry can be seen to occur again in China from the 1980s onward, in the works of authors including Yang Lian, Ouyang Jianghe, Xue Di, Liao Yiwu, Chen Dongdong and Xi Chuan.

As we have seen, Xi Chuan's use of the prose-poetic form in the 1990s appears to be structural rather than incidental, in texts such as «Salute», «Misfortune» and «What the Eagle Says». Further to the close reading offered in chapter Five, an analysis of the prosaic and poetic qualities of «Salute» stands to gain from contrasting it with $\mathrm{Yu}$ Jian's «File 0», and vice versa. Both texts call attention to distinctions of poetry and prose, but in very different ways. Chapter Five has provided some context for situating $\mathrm{Xi}$ Chuan in the avant-garde at large, and chapter Seven will do so for Yu Jian. Here, we go straight to the texts. For «File 0», the analysis is based on the 1994 Grand Master edition.

«Salute» consists of eight constituent texts with separate headings containing numbers One through Eight and the individual titles «Night», «Salute», «Abode», «The Monster», «Maxims», «Ghosts», «Fourteen Dreams» and «Winter». In translation, the text totals over 3200 words. «File 0 » consists of seven parts: a prologue called «The File Room»(档案室), five Books (卷一、卷二 etc, some with subdivisions): «Book One History of Birth»(卷一 出生史), «Book Two History of Growing Up» (卷二 成长史), «Book Three History of Romantic Love» (卷三 恋爱史), «Book Four Daily Life» (卷四日常生活) and «Book Five Forms»(卷五 表格), and an

12 Li Ji 1982, vol 1: 1-55; He Jingzhi 1979: 366-426; Luo Gaolin 1996. «Wang Gui and Li Xiangxiang» predates the founding of the PRC but is a product of the lines laid out in Mao Zedong's 1942 "Talks at the Yan'an Forum on Literature and Art" that would determine PRC cultural policy for decades to come (McDougall 1980, Denton 2003). 
epilogue entitled «Last Book» (卷末) containing “no main text” outside «Appendix One: File Production and Storage» (档案制作与存 放). The text totals over 5000 words in translation. For «Salute», I will illustrate large parts of the discussion with examples taken from «The Monster», cited in full in chapter Five. For «File 0», I will do so with reference to a representative excerpt from «History of Growing Up», cited overleaf. To conclude my argument, I will return to both texts in their entirety. A full English translation of «Salute» is found in Renditions 51 (1999); one of «File 0», in Renditions 56 (2001).

\section{Look and Sound}

«Salute» has no line breaks, but when it appeared in Flower City the editors or the typesetters must have viewed line length as an essential feature of the text, which suggests that they went some way toward classifying «Salute» as poetry "proper." They strictly adhered to the number of characters per line in the text's first, unofficial publication, and they made sure that most lines did cover the width of the page. If the absence of lineation adds to the prosaic qualities of «Salute», its visually poetic status emerges in the stylized alternation of long and short paragraphs, or stanzas. In its regular alternation of long and short, «The Monster» exemplifies patterns that are discernible throughout the series, although they are not equally obvious in each of its constituent parts.

«File 0 » does have line breaks, but its lines tend not to be "broken" until considerable time has passed. This makes one feel that the line, paradoxically, wants to continue but cannot bear the prospect of being cast in the typesetter's mold. In this sense, translation into alphabetic script does more justice to the spirit of the text than the original. Because alphabetic writing takes more space than Chinese characters, if the visual integrity of «File 0 » is to be respected, the translation has to be in landscape format, drawing extra attention to the text's width. This is precisely how Renditions has consistently printed translations of Yu Jian's poetry. Regrettably, in this chapter and the next, I must occasionally resort to indentation to show that the line is longer than will fit on these pages - even if I use smaller type, following the example of the 2004 Collected Works of Yu Fian (于坚集). Something else that will likely catch the reader's eye is that «File 0 » is punctuated not by conventional marks such as commas and full stops, but by blanks the 


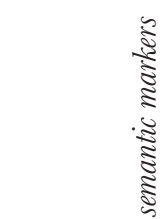

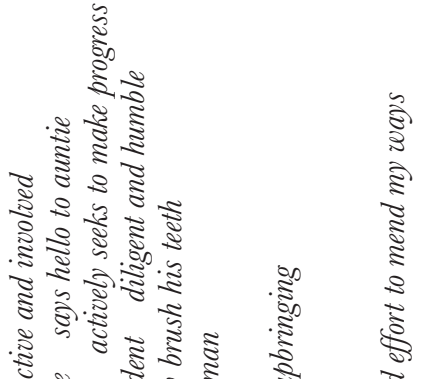

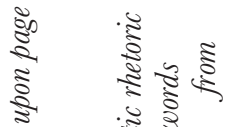

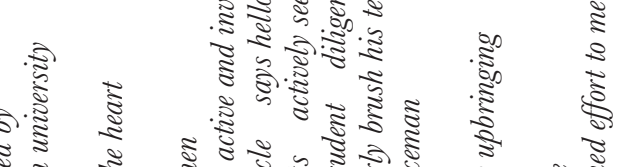

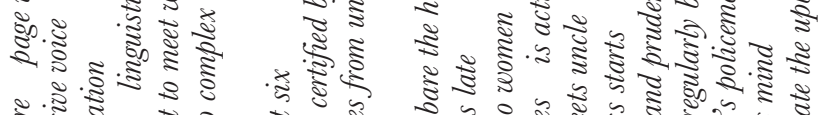
:

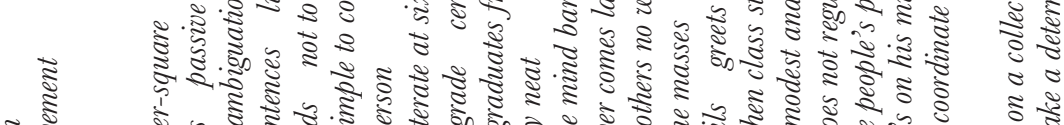

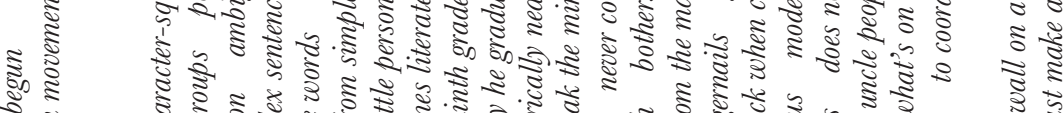
ป.

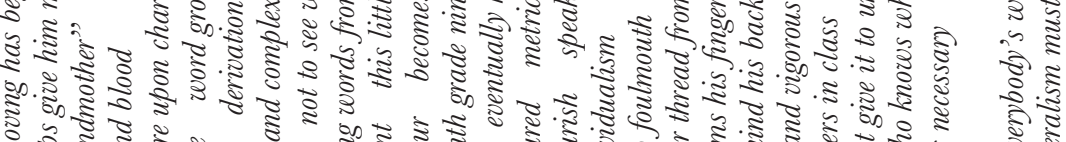

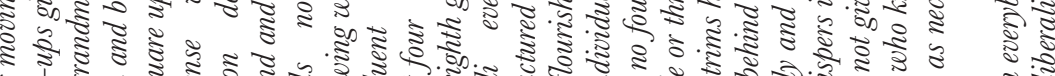

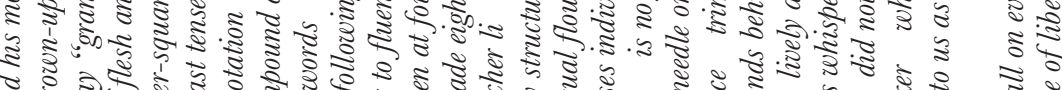

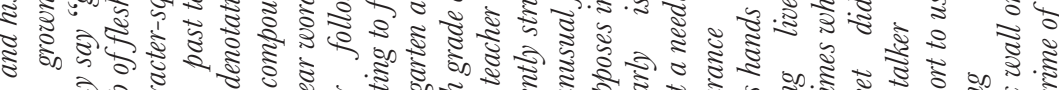

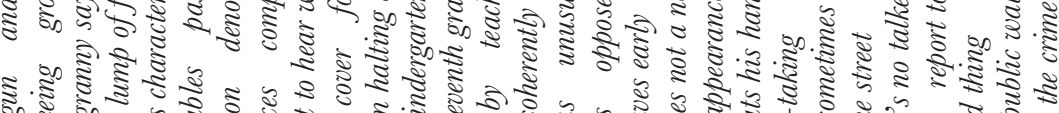

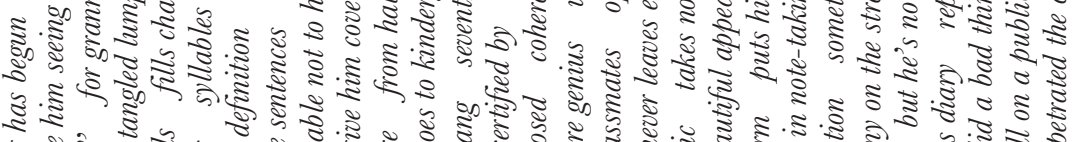

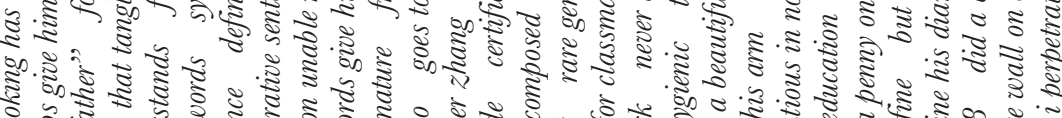

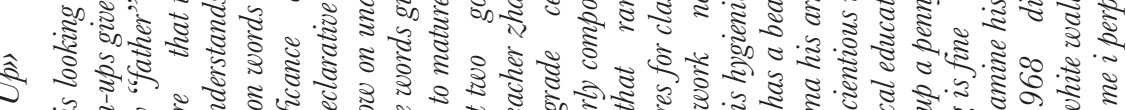

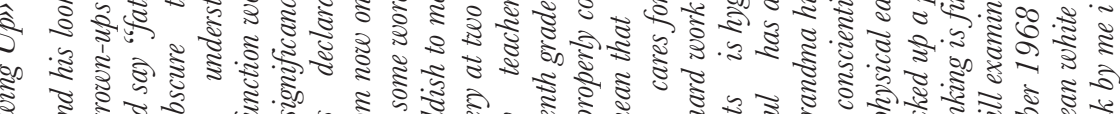

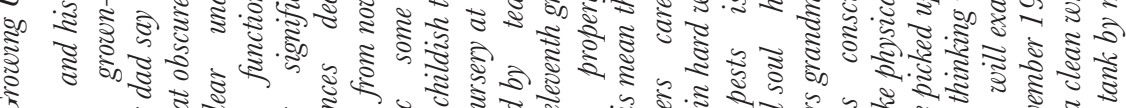

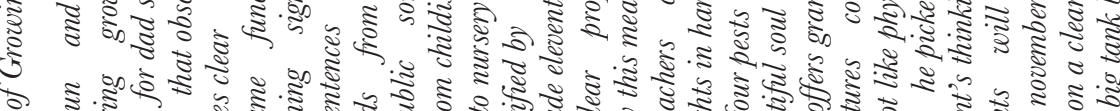

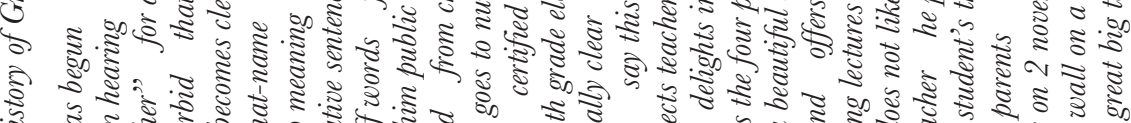

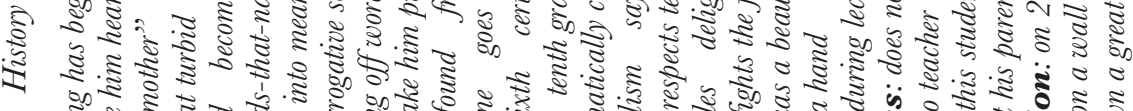

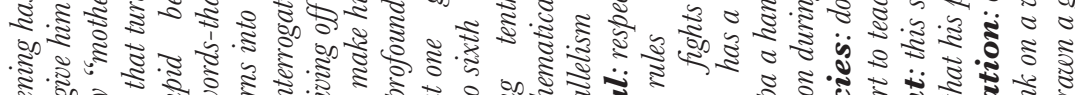

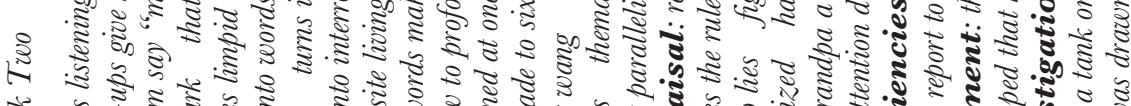

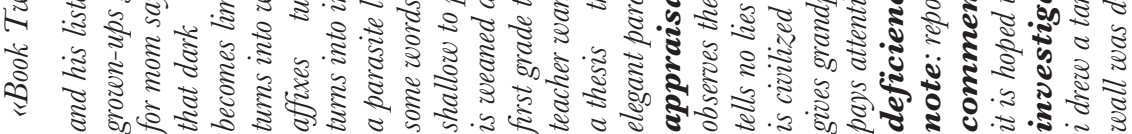


size of one Chinese character. The text thus shows a double discontent with conventional line breaks. While it exceeds each line's "normal" quota, it also deconstructs the notion of the line per se, through the use of line-internal short strings and the breaks between them. Thus, as measured against typographic convention, the lines are excessively long and the strings are excessively short. We will return to the significance of this form in chapter Seven.

«File 0» also features breaks above the level of the short string and the line, but I would hesitate to speak of stanzas. Each sequence of lines has its own title and every blank line signals the end of a sequence. Of the seven parts of «File 0», four have no subdivisions. The longest has as many as 54 lines. The other three parts of the text are subdivided into smaller, separately entitled sections, the shortest containing a mere five lines. In the longer sequences, another visual instrument used is that of boldface type, as visible in the excerpt from «History of Growing Up».

In sum, it is not the lines that make «Salute» look like it does but the stanzas, and it is not the stanzas but the short strings and the lines that do so for «File 0». On levels above that of the stanza, both texts are visually structured in what should perhaps be referred to as chapters, in view of their numbering and their individual titles. The sheer size of the texts in their entirety will be discussed toward the end of this section. Let's defer assessment of their status as (poetic) prose or (prosaic) poetry until we have reviewed them from some other angles.

Now to sound. In chapter Five, we have seen that «Salute» stands out by its acoustic qualities, both on the page and in recitation, through devices such as rhythm and parallelism on the sentence and stanza levels, and by rhyme in phrase-internal and end-of-sentence varieties. Below is a generous portion of citation in transcription, to bring out the acoustic richness of the text. The second passage is a more extensive version of that cited in chapter Five.

Zuòwéi chéngkè de niǎo. Zǔduàn de hédào. Wèi dànshēng de érnü. Wèi chéngxing de lèishur. Wèi kāishı̌ de chéngfá. Hùnluàn. Pínghéng. Shàngshēng. Kòngbái.

...

Dūo xiăng jiàohăn, pòshř gāngtiě liúxià lèishuř, pòshř xíguàn yú y̌̌nmì de láoshǔ lièdùi láidào wǒ de miànqián. Dūo xiăng jiàohǎn, dàn yào jìnliàng bă shêngȳ̄n yāā̄, bù néng xiàng mànmà, ér ȳ̄ng xiàng qídǎo, bù néng xiàng dàpào 
de hōngmíng, ér yīng xiàng fềng de hüxiào. Gèng qiángliè de xīntiào bànsúizhe gèng dà de jìjìng, yănkàn cúnzhù de yúshǔ jijiàng bèi hēguāng, jiàohăn ba! A, wǒ dūo xiǎng jiàohăn, dāng shù băi zhī wūyā guōzào, wǒ méi yǒu jīn kǒu yù yán-wǒ jiù shi bù xiáng zhī zhào.

(作为乘客的鸟. 阻断的河道. 未诞生的儿女. 未成形的泪水. 未 开始的惩罚. 混乱. 平衡. 上升. 空白.

多想叫喊, 迫使钢铁发出回声, 迫使习惯于隐秘的老鼠列队来 到我的面前. 多想叫喊, 但要尽量把声音压低, 不能像谩骂, 而 应像祈祷, 不能像大炮的轰鸣, 而应像风的呼啸. 更强烈的心跳 伴随着更大的寂静, 眼看存咜的雨水即将被喝光! 啊, 我多想叫 喊, 当数百只乌鸦聒噪, 我没有金口玉言一我就是不祥之兆.)

The acoustic qualities of «File 0 » are remarkable but not sophisticated in what would conventionally be called a poetic way, and transcribing the Chinese original would add little to the argument. Where there is rhyme it seems coincidental, and where there is rhythm, that really is another word for an insistent repetition and parallelism. The text displays a mechanical, enumerative rhythm throughout, usually with a noticeable, rigid beat and sometimes fairly maniacal. The resulting monotony comes across as being of a purposeful kind and ties in well with other aspects of the text that are reviewed below. The opening lines of the excerpt from «History of Growing Up» may serve as an example.

and his listening has begun and his looking has begun and his moving has begun grown-ups give him hearing grown-ups give him seeing grown-ups give him movement

for mom say "mother" for dad say "father" for granny say "grandmother" that dark that turbid that obscure that tangled lump of flesh and blood

There are many such examples throughout the text, often with a constant number of characters $=$ syllables for each short string in a given passage, ranging from one to six or seven. Against this backdrop, a small number of unpunctuated lines in a total over over 300 stand out, aurally and visually. The final two lines of the excerpt, for example:

$i$ drew a tank on a wall on a clean white wall on a public wall on everybody's wall on a collective

wall was drawn a great big tank by me i perpetrated the crime of liberalism must make a determined effort to mend my ways 
As regards their sound, then, «Salute» and «File 0» are no less different than in the way they look. By itself, neither criterion warrants confident classification of either text as poetry or prose.

\section{Subject Matter, Style and Interpretation}

Whether they are poems or prose poems or something else, both «Salute» and «File 0» are big texts, and neither author appears to have tried to limit their subject matter. «Salute» contains scenes and images from the natural and the human world, which are regularly presented as being in opposition or at least at cross-purposes; it has room for loose ends, for scattered, fragmentary ideas and situations which are not brought to conclusion, albeit less so in «The Monster» than in other parts of the series; and while it appears to posit a romantic image of transcendent, immortal poetry in opposition to the vulgar domain of everyday reality, this clichéd dichotomy is undermined by the real, physical death of the mortal poet. These things are presented in a highly literary style, occasionally interrupted by other linguistic and discursive registers, with shifts in language accompanying shifts in subject matter. Arguably, then, «Salute» is a text that positively demands interpretation - not just because it calls the protagonist of «The Monster» "this metaphor of a monster," but also because the reader may take recourse to interpretation in order to reconcile the text's imaginative aspects with instances of verisimilitude. That the actual process of interpretation turns out to be a complicated, potentially inconclusive affair doesn't change this.

In «File 0», the most extreme instance of its author's unwillingness to limit his subject matter is found in the second half of «Forms», entitled «Inventory of Objects» (物品清单). Yu Jian has said that this sequence goes back to a text called «A Poet's Inventory of Objects» ( 个诗人的物品清单), which he wrote in the $1980 \mathrm{~s} .{ }^{13}$ The «Inventory» in «File 0» lists the contents of the protagonist's room in considerable detail. I will but quote five of the 48 lines:

${ }^{13} \mathrm{Yu}$ Jian \& Tao 1999: 77-78. 
15 kilos of old magazines 5 kilos of old wall calendars 20 kilos of waste paper unit price for old magazines 0.20 yuan per kilo (same price for wall calendars and waste paper)

...

2 old mao suits 3 old zip-up jackets 1 pair of bell bottoms (frayed at the hem)

2 pairs of jeans (halfway worn) old socks (7 pairs) shorts singlets towels some of each

1 guitar (as good as new broken strings brand name hongmian)

Suffice it to say that these objects and the accompanying commentary are in tune with the rest of the room as it is depicted in the text.

The penchant for accumulation in «File 0» isn't restricted to the material world, as this passage shows:

turns into words-that-name function words syllables past tense word groups passive voice

affixes turns into meaning significance definition denotation derivation ambiguation

turns into interrogative sentences declarative sentences compound and complex sentences...

..

is weaned at one goes to nursery at two goes to kindergarten at four becomes literate at six

first grade to sixth certified by teacher zhang seventh grade eighth grade ninth grade certified by

teacher wang tenth grade eleventh grade certified by teacher li eventually he graduates from university

Especially if considered alongside «Salute», the most striking thing about the subject matter of «File 0 » is its obsessive recording of things that usually count as unspectacular, self-evident or trivial. These are offered with reasonable coherence, fleshing out the skeleton of an anonymous urban life in contemporary China that emerges from the titles of the Books that are so expertly stored in the File Room. In its apparent lack of ambition to describe anything "unusual," this aspect of the subject matter of «File 0» is best summed up as prosaic - or, of course, as ironic.

On a higher level of abstraction «File 0 » is about the phenomenon of personal files (人事档案) that institutions in the PRC keep on their members, employees and so on, and that can determine how individual lives take shape, in areas ranging from material circumstance 
to parenthood to political rights. A time- and place-bound reading, then, could bring to mind Kafkaesque traits of life during the Cultural Revolution, when banal information on the most minute and private of one's daily movements could mean the difference between life and death - and found its way into personal files. But the interpretation of «File 0 » doesn't hinge on recent Chinese history, for the power of files is of all times and places. Systematicity is the enemy of individual style: files can maim the people whose lives they write up and reduce them to numbers, and a meticulous record of one's activities, including the less glamorous, will find every human being vulnerable.

No less important, «File 0» addresses issues such as the incompatibility of public and private discourse, and the capacity of language to shape "reality" and not to serve it or document it: of the file to write the life, as it were, not the other way around. ${ }^{14}$ The concrete workings of language - or, people's illusions of having control over languageare equally part of its subject matter, as the above enumeration of linguistic terminology shows. With regard to the many challenges that «File 0 » presents to the translator, I decided on the literal rendering of 动词 'verbs' and 名词 'nouns' as words-that-move and words-that-name after realizing how important these categories are, and how literally they operate, in the original and in Yu Jian's oeuvre at large. ${ }^{15}$

I have tacitly passed over the question whether «File $0 »$ should be interpreted at all, which is of special interest in light of Yu Jian's avowed aversion to metaphor and symbolism and the presentation of his own writing as what-you-see-is-what-you-get, to which we will return in chapters Seven and Eleven. If more than the above remarks is needed to justify interpreting «File 0», we should remember that in the last analysis, it is the reader not the author who decides what is metaphor and what isn't. Moreover, throughout the text, defamiliarization on every level suggests that this text "says not what it says," in the words of Martinus Nijhoff, ${ }^{16}$ and that it actively engages in dissimulationagain, to be more exact, that it can be seen to do so by the reader. If presented as a literary text, the driest institutional language cries out for deconstruction: to be read, for instance, as an indictment of

14 Cf He Yi 1994.

15 See Van Crevel 2001.

16 Nijhoff 1978: 216. My translation is motivated by the wish to retain the exact duplication of staat in the original (er staat niet wat er staat), for the crux of the matter is that Nijhoff's words apply to themselves as much as to other poetry. 
institutionalization. In this respect as in others, Yu Jian's method is one of brute force and of what I have called purposeful monotony. He exhibits endless examples of politically correct "official" or mainstream language (提法) to represent various kinds of social traffic, and alternates these with curious, incredulous, parodying comments and would-be objective, disinterested depictions of "unofficial" realities of human behavior. For «File 0», issues of subject matter, style and interpretation may be summed up as follows: this text is not only about a file, it is a file itself; and it not only has a style, but it is about style as well.

Dividing lines between issues of form and content in literary writing are hardly ever clear. Still, it is safe to say that what «Salute» and «File 0» are about, as distinct from what they look like and what they sound like, gives us grounds for calling both texts poetry. Again, they are given the same classification for different reasons: «Salute» primarily for its imagery, «File 0» primarily for its irony and the means it employs to achieve this irony. Both the use of imagery and that of irony are inextricably tied to their respective authors' expert manipulation of language.

\section{Reading Attitudes}

Comparison of the reading attitudes that «Salute» and «File 0» require provides further clues. If poetry foregrounds the musical qualities of language and spurs the imagination beyond the confines of "reality," and if it doesn't invite the reader to engage in goal-oriented communication toward the primacy of a paraphraseable "message," or indeed discourages them from doing so, then «Salute» is definitely poetry. The case presented by «File 0» is less simple. One would hardly call a plethora of trivial information on an unspectacular, ordinary urban life a message. Then again, the reader may well pick up an abstracted message of the kind discussed above, for example on systems of control exercised by files and their keepers, and by implication on ideological and political repression. But can this message lay claim to primacy in «File 0»? For the reader who finds that it cannot, the previous paragraphs have shown that the peculiar presentation of «File 0» compensates for this by offering alternative attractions, even if it doesn't employ conventionally poetic language. 
If a poetry-reading attitude is sensitive to things like ambiguity, contradiction, paradox and (unresolved) tension, both «Salute» and «File 0» qualify as poetry again - and once more, unsurprisingly, in different ways. As we have seen in chapter Five, «Salute» has plenty of room for these things, subsumed under the overarching notion of indeterminacy on every level of the text. In «File $0 »$, on the other hand, the real tension is between the text and its subtext, generated by its defamiliarization of language and reality. For a time- and place-bound historical interpretation, the reader will benefit from extra-textual knowledge of life in contemporary China, something that is much less true for «Salute».

What about the act of reading itself? What does a poetry reader do? Obviously, there is no single, accurate answer to this question, and if texts as different as, say, Li Ji's «Wang Gui and Li Xiangxiang» and Bei Dao’s «Borrowing Direction» can both count as poetry, generalizing is unwise. Yet, inasmuch as modern poetry in various cultural traditions and social settings - media, education - has generally elicited slower, more thorough and more interpretive reading strategies, it is legitimate to ask whether «Salute» and «File 0» lend themselves to any degree of close reading, bearing in mind the specific description of this notion put forward in chapter One.

Is this the type of reading that «Salute» and «File 0 » require? For «Salute», I would say that it is, for reasons outlined in the above discussion of subject matter, style and interpretation. But this creates a problem, for it is difficult to close-read a text of over 3200 words with the intensity, constancy and purposefulness of the immediate encounter with the full text that is enabled by short poems - even if the effort can be worthwhile, as I hope to have shown in chapter Five. «File 0» doesn't demand a microscopic reading, one striking aspect of the text being that large parts consist of mechanical enumeration. In fact, a hurried, diagonal reading of «File $0 »$ might well be reasonably gratifying, something that is unthinkable for «Salute». In this sense, «File 0» is less poetic than «Salute», and that is just as well in view of the fact that «File 0 » is an even longer text. From this reader's point of view, the very size of the two texts makes them not prose, but poetry with a problem. 


\section{Iconicity}

Let's recall one of Simon's claims for poetry, made in the spirit of Roman Jakobson: ${ }^{17}$

This is what poetry, and therefore prose poetry as well, must do: in the sound, in the syntax, in the cadences of the rhythm, repeat, illustrate, intensify the idea-provide the body, the soma that fits the psyche of the particular utterance.

By iconicity I mean mechanisms that allow form to contribute directly to content, which generally operate in poetry more than in prose and make form an icon of content rather than its more or less arbitrary stylization. Iconicity is not an especially salient feature of «Salute», although Xi Chuan's diction is often an icon for his subject matter. As noted in chapter Five, one concrete instance of iconicity in not just the acoustic but also the visual realm is found in «The Monster», in the alternation between long, heavy stanzas populated by earthbound organisms, and short, airy stanzas populated by birds. This wouldn't have worked if the long stanzas had featured the birds instead. The brevity of the bird stanzas is what makes them "light," so that one can imagine them as taking off, upward, away from the heavy stanzas. In this respect, «The Monster» resembles Mallarmé's famous «Winter Shiver» (Frisson d'hiver), in which long stanzas alternate with short ones that feature spiders living close to the ceiling. ${ }^{18}$

«File $0 »$, on the other hand, clearly displays iconicity in that it is laid out as, and largely written in the style of, the file that it is about. In this sense, one could think of it as an objet trouvé, a ready-made - but modified - work of art in the tradition of Duchamp, or a collage of countless bits of ready-made language. It may be no exaggeration to say that iconicity is its most effective feature, especially since «File 0 » is in fact about the reinforcement and the taking over of content by form, or the taking over of reality by representation. The criterion of iconicity certainly doesn't make either of the two texts prose, and it makes «File $0 »$ more markedly poetic than «Salute».

\footnotetext{
17 Simon 1987: 697; e.g. Jakobson 1960: esp 368-369.

18 Mallarmé 1935: 111-115.
} 


\section{Presence versus Progression}

To conclude this section, I will examine both texts with extensive reference to Gerrit Krol's essay Free Verse (Het vrije vers, 1982), an engaging piece on distinctions between poetry and prose. On the issue of visual layout, indulging in some excusable generalizations, Krol says: ${ }^{19}$

A distinguishing characteristic of poetry is that not all of its lines are of the same length. In prose, most or all lines are of the same length. And there is another clear difference: the length of the work itself. Poems are usually shorter than stories. We can even observe that the average poem is shorter than one page, and the average story is longer ... A poem may be viewed at a glance.

This is nothing new, but Krol's quasi-naive observation on the poem's viewability at a glance takes on added importance as we read on:

We generalize the following proposition: a work of art is a unity. By this, we mean that what we imagine the work of art to be ... is a unity: it may be recorded in one memory, in one emotion. This holds for poems and stories alike. But the difference is that this sensation of unity, if evoked by a poem, has a direct representation in another unity: that of the page ... Of a poem, the unity is directly visible in the one page, while of a story, the unity is in-directly visible: in a sequence.

«Salute» and «File 0» can each be recorded in one memory or emotion, and their (imagined) unity as works of art isn't contingent upon internal sequence in time or in logic, but neither can be viewed at a glance. Both texts exceed the size of Krol's average poem by so much that the concept of the page becomes irrelevant. Still, while neither is contained in a single page, both possess the unity of a poem, according to Krol:

[A poem], for all its truth, can lay no claim to logic and is not necessarily consistent. It is a unity nonetheless. We could call something like that 'coherent.' Things cohere, and that is why they are true: $a$ and $b$ are true, not because one is a consequence of the other, but because they are similar: $a \approx b$ [not $a \rightarrow b]$. Poetry is the place where the world meets itself in comparisons, images situated in different layers, constituting each other's meaning and, moreover, exchangeable.

As observed at several points in this study, poetic coherence need not achieve anything like complete "coverage" of the text. Accordingly,

${ }_{19}$ The following quotations come from Krol 1982: 10-14. 
the notion of a unity need only apply to whatever parts of the poem cohere. This, however, doesn't detract from the contrast of coherence on the one hand, and consequence + consistency (the original has consequentie, which can mean both) on the other. If we consider how Krol's $a \approx b$ and $a \rightarrow b$ manifest themselves in concrete literary texts, and think, for instance, of metaphor for $a \approx b$, and of plot or character development for $a \rightarrow b$, both «Salute» and «File 0» reflect the former mechanism much more than the latter.

At the same time, on this count there emerges another appreciable difference between the two texts. In the line-up of the Books (birth, growing up, romantic love, daily life, forms), there is a sociochronological side to «File 0» which «Salute» lacks altogether. This chronology, however, doesn't build toward a resolution of any kind and none of its stages are presented as the consequences of earlier ones. Rather, its parts appear alongside one another, almost as arbitrary accumulation rather than a meaningful composition toward the description of a life: in fact, one of the points that «File 0 » makes is precisely that of the absence of meaningful order in this life. Just like the file is in many ways no more than a heap of words thrown together, so the life it contains is but a blind exercise in the piling up of unconnected situations that will not result in any overall direction. This makes it possible to start reading, and certainly to start re-reading, more or less anywhere. The same is true, by and large, for «Salute». This is not to say, however, that the series' constituent texts can be reshuffled with impunity. Especially the first and the last, «Night» and «Winter», are anchored in their positions, and there is a development of the atmosphere in the series that would be affected by rearranging its parts.

As elsewhere, we find that in Krol's scheme of things neither text can be immediately classified as poetry. At the same time, according to Krol, the ability to enter both texts at various places and enjoy a fruitful, partial (re)reading invalidates a classification as prose. About novels, he writes:

The order on a page is constituted in two ways: horizontally (words $\rightarrow$ line) and vertically (lines $\rightarrow$ page). Since a poem consists of no more than one page, these are the only two principles of order. In a story, they are joined by a third (pages $\rightarrow$ book) ... Of the threefold ordering made possible by novels, only one type is used: the order of the words, as determined by the author. A novel is in fact one long line ... What puts me off in almost every novel is the need to start reading on the first page. Like a painting that would only be visible if you started looking in 
the top left corner . . . Self-evidently, a novel shouldn't be compared to a painting but to music: everything comes in a certain, predetermined sequence ... If, years later, you want to reread a beautiful page . . . you must first remember what has preceded that page.

We know that «Salute» and «File 0» are not novels. And yet, the tongue-in-cheek quality of this passage aside, the phrase one long line strikes me as an appropriate description of the unrelenting bombardment of language that is «File 0 ». I have observed that its lines feel as if they want to continue but cannot bear the prospect of being cast in the typesetter's mold. In the words of Simon Patton, Yu Jian tries to explode the line. ${ }^{20}$ This poem would be one long line, if only that could be physically realized: ideally one biting its own tail like a snake, to complete the vicious circle of the 0 in its name and rule out escape from the world it contains.

The snake takes us back to Baudelaire. He used the image in his letter to Houssaye to market qualities of his innovation that Krol might recognize as belonging to poetry: ${ }^{21}$

We can stop wherever we want, I my reverie, you the manuscript, the reader his reading: for I do not bind the latter's recalcitrant will to the endless thread of a superfluous plot. Remove one vertebra, and the two pieces of that tortuous fantasy will reunite without difficulty. Chop it up into many fragments, and you will find that each one can exist separately. In the hope that some of those segments will be lively enough to please and to divert you, I dare dedicate to you the entire serpent.

As is true for most of the angles adopted earlier in this section, Krol's and Baudelaire's remarks do not locate either «Salute» or «File 0» squarely on the side of either prose or poetry. Yet, both gravitate toward poetry. Crudely put, this is because they are not narrative, internally sequential texts. This is of course a relative assessment, for there are such things as narrative, sequential poetry — we will see a Chinese example in chapter Eight-and non-narrative, non-sequential prose.

In sum, I see plenty of reasons for calling both «Salute» and «File 0» poetry, albeit of an unusual kind. The most important reason is akin to Krol's contrast of coherence and consequence + consistency. I would, however, use another pair of terms for contrasting the essence of the poetic with that of the prosaic experience, and draw attention to the

\footnotetext{
20 Personal communication, May 1998.

21 Baudelaire 1989: 129.
} 
presence of poetry as opposed to the progression of prose. In both «Salute» and «File 0 » presence has been spread thin and stretched to the point of resembling progression-but one can more or less enter and exit anywhere, and enjoy a worthwhile engagement with the text.

If only to reclaim kinship with music for poetry, in response to Krol's provocative linkage of music and prose, I will end this section by suggesting an analogy with works by two masters of the jazz saxophone. The bebop solos of Charlie Parker must travel by the harmonic progression of fixed chord sequences, commonly called the changes, but large parts of the solos Steve Coleman plays with the Five Elements materialize over the constant harmonic presence of one chord. Parker's astonishing melodic versatility and coherence within the time reserved for any one chord or scale are undeniably poetic; but harmonically, across chords, contrary to what Loss Pequeño Glazier claims, he must remain prosaically in sync with a compelling, linear, (con)sequential structure that assigns to each moment a relative value and cannot be reshuffled. ${ }^{22}$ By contrast, many of Coleman's compositions generate unchanging, non-linear harmonic environments, with temporal limits set by on-cue termination at the bandleader's discretion, not completion of a harmonic narrative. As long as the analogy is with free verse, harmonically and in their entirety, Coleman's solos are more poetic than Parker's.

\section{Fringe Poetry}

Ever since their publication, both «Salute» and «File 0» have been called poems. As much as from their textual qualities, this classification may stem from the metatextual fact that both Xi Chuan and Yu Jian were well known as poets when the two texts appeared. I hope to have shown that the text-based classification of both works as poetry rather than prose is justified but by no means straightforward, and that this classification must be complicated and conditional instead. To add another spatial metaphor to those used at the start of this chapter, one could think of «Salute» and «File 0 » as fringe texts within the overall scope of poetry. What separates them from the heartland is most of all their length. Length comes in for every single one of the angles we

${ }^{22}$ Glazier 2002: 26. 
have adopted above to examine both texts, from their look and sound to their position on the scale of presence and progression.

Length has often counted as incompatible with good poetry. Goethe famously held that restraint shows the master's hand, and Poe called a long poem a contradiction in terms, for "a poem is such, only inasmuch as it intensely excites, by elevating, the soul; and all intense excitements are, through a physical necessity, brief." ${ }^{23}$ Length, however, linewise and pagewise, is a conspicuous feature of much poetry from China, from extreme cases such as Luo Gaolin's 278-page «Deng Xiaoping» to poems the size of «Salute» or «File 0», and many others of two or three pages that cannot be viewed at a glance.

What lies at the root of the sheer size of many poems from China is not the focus of this chapter. Yet, at this point we may recall how much needed to be said in the late 1970s and the early 1980s, right after the Cultural Revolution, as noted in chapter One. Also, while the avant-garde's modes of presentation, readership and social position differ vastly from those of Maoist orthodoxy and its legacy, the tradition of big poems as practiced by avant-garde authors shows a lingering influence of the Maoist discourse that held sway from the 1940s until the 1970s, also remarked upon in chapter Three. A third source of the remarkable length of many contemporary Chinese poems might be the 1980s Root-Seeking tradition, the historical and mythological components of which made for generously sized texts as well. These lines of thought need not exclude each other or any further explications. Additionally, we could look into reading attitudes within the avant-garde - and writing attitudes, and their interactions - and in doing so perhaps pay special attention to the negotiation of imagery, specifically to strategies of interpretation. While recognizing the dangers of generalization, I contend that close reading hasn't been the dominant trend in criticism and scholarship in China-or close writing, the dominant trend in literary production. If this is so, it helps explain the acceptability, or indeed the desirability, of long poems.

«Salute» and «File 0 » are poems with prosaic qualities, not the other way around. They should be considered prose poems rather than

${ }^{23}$ Poe 1973: 552, discussed in Perloff 1996: 158. 
poetic prose. John Simon pronounced the prose poem dead in the 1950s - even though later, he conceded that it might still be "the occasional 'aside' of writers whose essential utterances take other forms" and in the Chinese world of letters, Lin Yiliang urged young writers to stay away from prose poetry, which he considered to be neither fish nor fowl. Research by Marjorie Perloff and others shows that Simon's claim has proven untenable for Western literatures in later years. ${ }^{24}$ As for Lin's worries, they didn't prevent the emergence of successful prose poetry in Chinese, starting in the 1960s in Taiwan. That the prose poem is alive in Chinese, just as in other languages, is reaffirmed by literary practice in mainland China since the 1980s, with the work of $\mathrm{Xi}$ Chuan and Yu Jian as powerful examples.

${ }^{24}$ Simon 1987: 700 and 1965: 665, Lin Yiliang 1976: 44, Perloff 1996: ch 6. 


\section{OBJEGTIFICATION AND THE LONG-SHORT LINE:}

$$
\text { YU JIAN }
$$

In contemporary China, there are many fiction writers with all manner of collected works (文集、作品集、小说展示) to their name while they continue to write. Can Xue, Chen Ran, Chi Li, Mo Yan, Wang Shuo and Yu Hua are but a few of those whose books have been on prominent display in the bookstores for years on end. Especially their short and medium-length pieces (短篇、中篇) tend to be frequently re-published in new, reshuffled arrangements between equally new book covers. Things work differently for poetry, if we disregard the Complete Poems of Haizi, Luo Yihe, Ge Mai and Gu Cheng that were occasioned by three suicides and one suicide-by-association, as discussed in chapter Three. Republication of the kind that signifies the re-confirmation of earlier success - as it does for fiction writers - has occurred for few poets, primarily in the Blue Star Poetry Treasure House series (蓝星诗库, People's Literature Press), an open-ended project running since the mid-1990s. The stand-alone collections by Yang Lian and Bei Dao mentioned in chapter Four are special cases, in light of their status as "dissident" poets in exile, which made domestic publication in the 1990s difficult for Yang and impossible for Bei Dao. The Blue Star books are anthologies that survey individual, previously well-published poetic careers. Different from fiction, however, the reconfirmation of earlier success is embodied in a single anthology for each poet and not in multiple re-issues by multiple publishers. Other recent series such as the Midnight Subway Poetry Series (零点地铁诗从, Qinghai People's Press), the Dark Skin Poetry Series (黑皮诗从, Northern Mountains Literature \& Art Press) and the Epoch Poetry Series (年 代诗从, Hebei Education Press) constitute the overdue recognition of poetic oeuvres whose unofficial reputation had not been matched by their official publication track record to date, rather than reconfirming earlier success. ${ }^{1}$

\footnotetext{
${ }^{1}$ For bibliographical detail on series and stand-alone collections, see Van Crevel 2008a.

(C) MAGHIEL VAN CREVEL, 2008 | DOI 10.1163/9789047442738_008

This is an open access chapter distributed under the terms of the Creative Commons AttributionNoncommercial 3.o Unported (CC-BY-NC 3.o) License.
} 


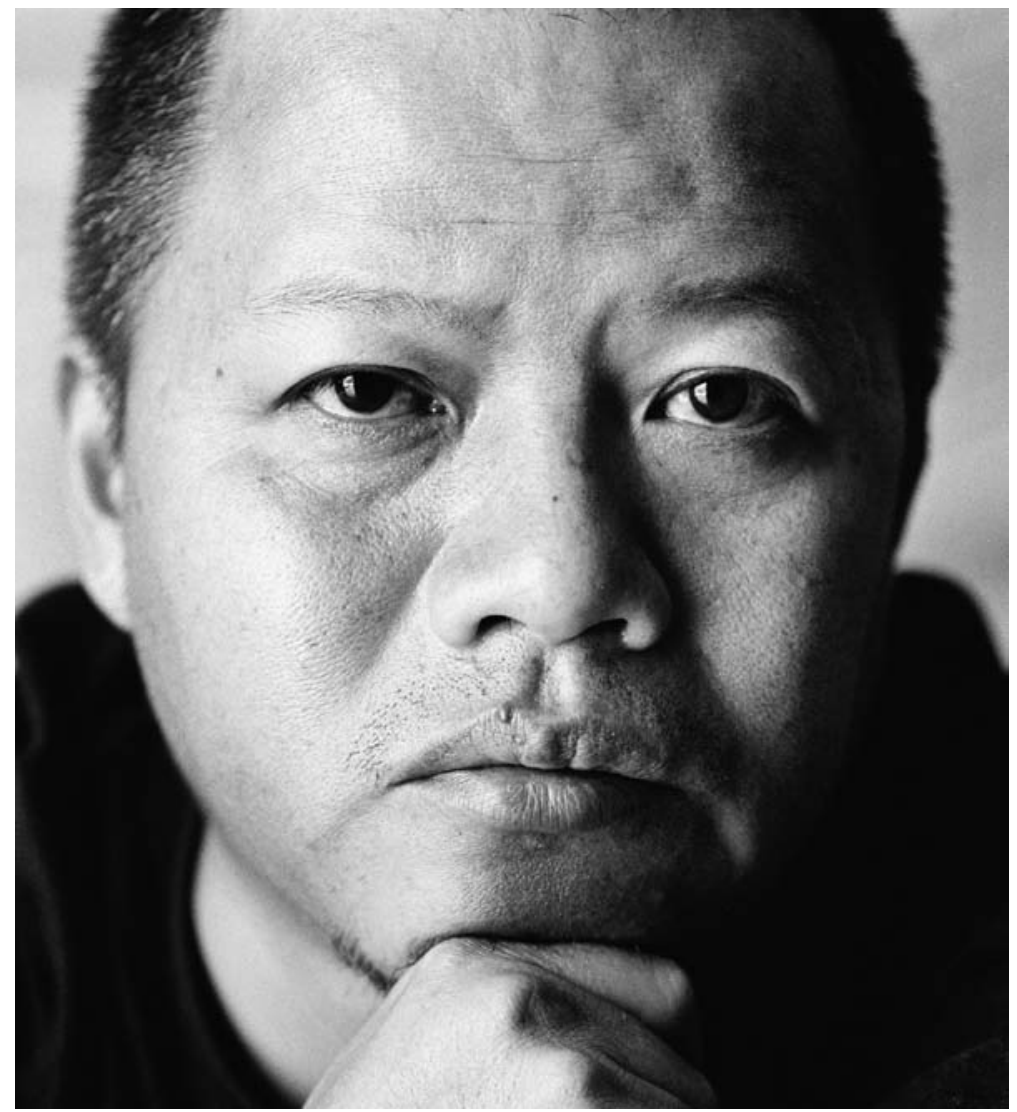

Figure 7.1. Yu Jian, 1997 (photograph by Pieter Vandermeer) 
Yu Jian (1954) is one of the poets whose work has been anthologized as a Blue Star book, in The Poetry of Yu fian (于坚的诗, December 2000), other authors in the series including Shizhi, Shu Ting, Gu Cheng, Haizi, Xi Chuan, Wang Jiaxin, Sun Wenbo and Xiao Kaiyu. Barely three years after The Poetry of Yu Fian, which surveys the years 1982-2000, the Yunnan People's Press brought out the five-volume Collected Works of Yu Fian (于坚集, January 2004). The first two volumes total almost seven hundred pages of poetry from roughly the same period, but starting in 1975. The other three contain Yu's short prose and his critical writing, as well as high-profile interviews conducted with the poet over the years. The appearance of Yu's collected works is even more remarkable if we bear in mind that in September 2003, yet another substantial book of his poetry had been put out by the Qinghai People's Press: Poems and Images, 2000-2002 (诗集与图 像, 2000-2002); and that in 2001, the Yunnan People's Press itself had brought out his Poetry: Collected Notes, 1996-1999: 1-216 (诗歌便条集, 1996-1999: 1-216), a collection of very short poems. And the story doesn't end with the Collected Works: a mere two years after their appearance the Long March Press published Only the Sea, Vast Like a Canopy (只有大海苍茫如幕, 2006), containing poems from the years 2003-2006, and Poetry News (诗歌报) brought out Eighty-Eight Notes: Selected Notes 1996-2005 (八十八张便条: 便条集1996-2005选), in cooperation with the Walt Whitman Literature Fund. The Fund, whose Chinese name is 惠特曼出版社, is based in New York but appears to have readers in China as its primary audience.

Prior to this explosion of publicity in China, a collection of Yu's work entitled A Nail through the Sky (一枚穿过天空的钉子) had been published in 1999 by the Tangshan Press in Taiwan, in a series of mainland-Chinese poetry collections edited by Huang Liang; this is also the subtitle of the first volume of the 2004 Collected Works. Further back, Yu's domestic publication history includes two unofficial booklets, one containing the long poem «Flight» (飞行), published when he won the first Wang Zhong Culture Award in 1998, the other a reprint of substantial excerpts from the equally long «File 0» and photographs of its adaptation for the theater (1995); and The Naming of a Crow (对一 只乌鸦的命名, 1993), by the International Culture Press; and three unofficial, slim collections in 1989-1990; and Sixty Poems by Ru Fian (于 
坚诗六十首, 1989), by the Yunnan People's Press. ${ }^{2}$ In addition, Yu Jian's poetry has appeared in scores of influential journals since the mid-1980s. Examples range from the unofficial Them to the official $P_{0-}$ etry Monthly. His poetry also features in all multiple-author anthologies that can lay claim to being representative of contemporary China.

$\mathrm{Yu}$ Jian, then, is domestically the most widely published avantgarde poet - and since the 1990s, his poetry has been translated into languages including Danish, Dutch, English, French, German, Italian, Japanese, Spanish and Swedish. ${ }^{3}$ His 2004 Collected Works are unique for their sheer size. Each volume is exquisitely produced: the binding is good, the off-white paper is of high quality, the photographs are beautifully reproduced and the occasional, meticulous use of smaller type ensures that even the longest of Yu's long lines are not broken prematurely. Bearing in mind that the Collected Works constitute a type of republication that is exceptional for poetry, one assumes that they were published with lavish external sponsorship of the sort discussed in chapter One - and wonders whether the poet's fiftieth birthday provided the occasion.

$\mathrm{Yu}$ Jian's impressive publication history is matched by his reception history. Numerous commentators have registered everything from admiration to denunciation of his work. Both his poetry and his explicit poetics have generated controversy more than once, his pièce de résistance «File 0 » being the most conspicuous example. Soon after publication in March 1994, it was the subject of one of Xie Mian's poetry seminars at Peking University, following widespread disagreement concerning its literary merits and the question of whether this text was poetry at all, and commentators have since continued to lock horns over a text that elicits fanatical support and equally fanatical opposition. He Yi holds that it is "a groundbreaking effort, linguistically and otherwise," and that "this work can rescue our poetry." Chen Qufei sets out on a long, systematic search-and-destroy mission leading to the conclusion that "misbehaving" apparently suffices to make one "avant-garde." Cai Yi declares that "this poetry stinks," and that "it lacks any and all

${ }^{2}$ By date: Yu Jian 1989a, 1989b, 1989c, 1990, 1993, 1995b, 1998b, 1999a, 2000, 2001a, 2003, 2004, 2006a and 2006b.

${ }^{3}$ English translations of Yu's poetry include those published in Morin 1990, Renditions 46 (1996) and 56 (2001), Wang Ping 1999, Patton 2003b, the DACHS poetry chapter $(\rightarrow$ China's Second World of Poetry $\rightarrow$ related material $\rightarrow$ translations), Tao \& Prince 2006, The Drunken Boat 6-I/II (2006, online) and Full Tilt 1 (2006, online). 
aesthetic feeling and literary value." Zhang Ning calls «File 0» "a concentration camp of words," and ascribes "enormous significance" to its effect of "cleaning up the vocabulary of the contemporary Chinese language." Li Zhen sees it as capable of "dismantling the structure of an entire world," in an essay that favorably compares Yu Jian with Ouyang Jianghe, as representatives of the Earthly and the Elevated aesthetics respectively - and so on and so forth. As regards Yu's explicit poetics, two of the many bones of contention have been his dismissal of metaphor and his role in the 1998-2000 Popular-Intellectual Polemic. $^{4}$

Commentary on Yu's work, then, includes pieces by scholars whose poetics are utterly incompatible with that of the poet, such as Chen Qufei and Cai Yi - and which are of interest precisely for that reason, contributing as they do to a bigger picture of Chinese poetry today. Conversely, there are those who worship $\mathrm{Yu}$ and repeat his teachings like disciples. Xie Youshun's reception of Yu Jian's poetry, for instance, shows the effectiveness of Yu's interventions as a critic who delivers the preferred commentarial vocabulary together with his poetry. Something similar holds for critics Hu Tingwu and Xia Yuanming. Such extremes aside, more insightful commentaries on Yu Jian's poetry and his broader cultural career include essays by Chen Zhongyi, He Yi, Hu Yan, Xin Yue, Jan De Meyer, Wang Yichuan, Michelle Yeh, Simon Patton, Huang Liang, Liu Shijie, Wang Zheng and Xiaohua, Zhang Ning, Glaire Huot, Li Zhen, Cosima Bruno, Gao Bo, Yu Liwen and John Crespi. ${ }^{5}$

The above reflections on Yu Jian's publication history draw attention to his activism on the poetry scene. The Chinese word is 操作 'operate,' in itself a neutral term but nowadays frequently used to describe whatever artists and writers do beyond their work in the strict sense to maximize fame and material gain, with connotations of conscious

${ }^{4}$ Shen Qi 1995; He Yi 1994, Chen Qufei 1995, Cai 1997, Zhang Ning 1999, Li Zhen 2001a: 201-214 (which, in light of his earlier writings such as 1994 and 2001b, should be viewed in the context of the Popular-Intellectual Polemic, discussed in chapter Twelve).

5 Xie Youshun 1999, Hu Tingwu 2004, Xia 2005; Chen Zhongyi 1994: 156ff and 2000: 305ff, He Yi 1994, Hu Yan 1995, Xin 1995, De Meyer 1996, Wang Yichuan 1998 (115ff, 261ff) and 1999a, Yeh 1998a, Patton 1998, 2003a and 2003b, Huang Liang 1999, Liu Shijie 1999: 89ff, Wang Zheng \& Xiaohua 1999, Zhang Ning 1999, Huot 1999: 209-214 and 2000 (78-82, 192-194), Li Zhen 2001 a: 201214, Bruno 2003: 137ff, Gao Bo 2005: 180-242, Yu Liwen 2006, Crespi 2007a. 
manipulation toward increasing one's status. Yu is singularly active, and seems to relish being part of a poetry scene that has been caught up in metatextual battles since the early 1980s. What lies at the core of his success, however, is doubtless his poetry itself.

Following the discussion of «File 0» in chapter Six, this chapter focuses on other salient texts, in chronological order. Section 1 presents a content-oriented analysis, and prepares the ground for a discussion of the synergy of form and content in section 2. Yu's poems tend to be long; for some, the present context only allows for partial translation. All references are to the Collected Works. There are occasional, minor differences with earlier editions of cited poems, but they don't affect the argument put forward here.

\section{Objectification and Subjectification}

$\mathrm{Yu}$ Jian was one of the two major voices in the colloquializing trend that challenged the primacy of Obscure Poetry within the avant-garde from the early 1980s onward, the other being Han Dong. As noted in chapter Two, that $\mathrm{Yu}$, Han and other poets associated with the type of poetry first published in Them have been called Colloquial poets is understandable, but their "colloquial" usage presents but one aspect of their art. As such, perhaps inevitably, this appellation is a simplification. Commentators have further noted that Yu's poems have a lot of time for concrete and conventionally trivial, non-poetic aspects of the daily lives of "ordinary" people, in both serious, partisan and humorous ways, as we have seen in chapter Six: Chen Zhongyi calls this quotidianism (日常主义). ${ }^{6}$ Then there is Yu's avowed rejection of metaphor, meaning roughly, according to the poet himself, that what you see is what you get. In an example taken from Yu's poem «Event: Writing» (事件・写作, 1989/1994), a bald eagle is a bald eagle, not an instance of symbolism feeding on clichéd cultural codes that will turn it into a eulogy of power. In all, within the avant-garde, Yu counts as a leading representative, if not the leading representative, of the Earthly aesthetic.

Not all commentators accept the non-metaphorical status of $\mathrm{Yu}$ Jian's language as a given, or something that is the poet's to deter-

\footnotetext{
${ }^{6}$ Cf Chen Zhongyi 2000: ch 14.
} 
mine. At the very least, however, they agree that Yu has gone further than most of his contemporaries in creative reflection in his poetry on language as the material (物性), formed (具象) medium of that poetry as a linguistic construct, and on its relation to being (存在) and reality. With reference to traditional Chinese poetics, several critics have remarked that $\mathrm{Yu}$ Jian does not engage in culturally conditioned "expression of emotion and articulation of what is on the mind intently” (抒情言志) or writing literature to convey the Way. Instead, they argue, his cool-headed observation and examination of the physical world defamiliarize human experience, thus establishing objectivity or objective representation. Ideally, this leads to the ability to rename that world or, truer to the register of the original, to "name it anew" (重新命名).

Discussions of Yu Jian's poetry in terms such as the above are very much to the point. Rather than objectivity and objective representation, however, my analysis centers on the notion of objectification, which I consider to be a mechanism that operates centrally amid the distinguishing features of Yu's work. Here, objectification doesn't mean the denial of subjectivity in an Other, such as the reduction of woman to a lust object under the male gaze. Objectification in the poetry of $\mathrm{Yu}$ Jian is the presentation of human experience as dislodged from socially determined, conventional and habitual perception and interpretation. It denotes the process of objectifying and an attempt at objectivity, rather than its attainment, which is particularly impossible in contexts such as those of literature and art. For the made thing that is poetry, the notion of objectification only works if we recognize that it is artificial and indeed a manipulative intervention on the part of the poetand as such, ultimately, an expression of the poet's sub-jectivity. With these qualifications, objectification offers a rewarding perspective on Yu Jian's oeuvre. The mechanism of objectification is of course by no means unique to Yu's poetry, but his particular employment of it is worth a closer look.

Notably, as a global force in Yu's oeuvre, objectification is locally complemented by something I will call subjectification. That is, Yu Jian's imaginative, personifying attention to (inanimate) objects that makes them subjects in their own right: say, raindrops and bottle tops, to borrow Patton's well-chosen examples. ${ }^{7}$ Together, objectification

\footnotetext{
7 Patton 1998.
} 
and subjectification question the relevance of subject-object distinctions and hierarchies. While I will not explore such distinctions and hierarchies per se, this effect is worth noting because it resonates in $\mathrm{Yu}$ Jian's deconstruction of hierarchies of the lofty and the lowly, which we will encounter below.

To set off the mature Yu Jian against his earliest years, let's first have a look at an untitled poem from $1981 .{ }^{8}$ Few may know that $\mathrm{Yu}$ Jian started out by writing poetry like this:

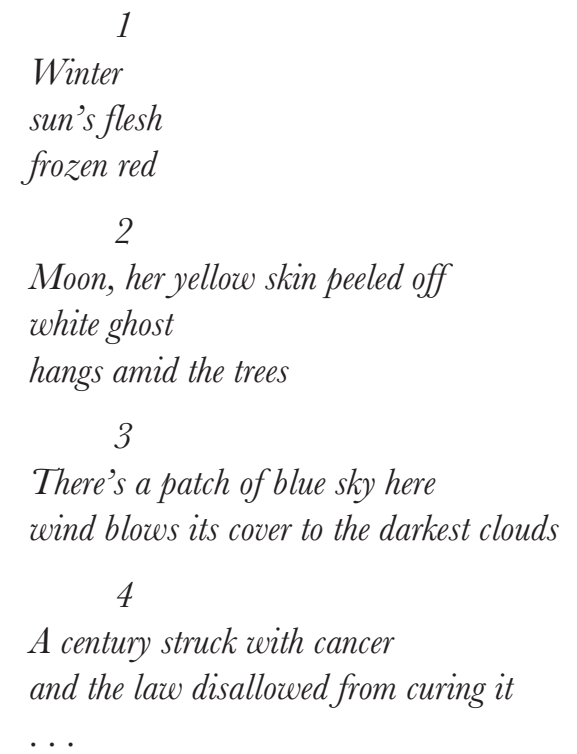

Those familiar with the Obscure Poetry associated with Today will recall famous poems such as Mang Ke's «Sky» (天空, 1973) and Bei Dao's «Notes from the City of the Sun» (太阳城札记, 1979?). Like «Sky» and «Notes», Yu's poem consists of a series of numbered stanzas or mini-poems. In addition to this particular form, it also shows the influence of early Obscure Poetry in a distinctly metaphorical language anchored in a historical frame of reference that brings to mind the Cultural Revolution. The image of the sick, lawless times, for instance, can be seen to portray the Cultural Revolution as a particularly painful excess of the pathology of China's turbulent twentieth century. Another example of Yu Jian's initial Obscure leanings, his «Don’t Be-

\footnotetext{
${ }^{8}$ Yu Jian 2004a: 16-18.
} 
lieve....» (不要相信...., 1979), recalls the early Bei Dao's best-known line $\left(I-d o n ' t-b e\right.$-lieve.) and his imagery, in lines like these: ${ }^{9}$

Don't believe that star

when it says it's the eye of love

and

Don't believe my strong hands

will steady the little boat of love

A completely different voice emerges in «Luo Jiasheng» (罗家生, 1982), which stands at the beginning of Yu Jian's original development. Even though this poem explicitly features the Cultural Revolution, it could hardly be farther removed from his earliest work: ${ }^{10}$

\section{"Luo Fiasheng»}

every day he'd ride an old bicycle

and come to work

as smoke was rising from the chimney

cruise past the office buildings

cruise past the workshop

cruise past the warehouse walls

and step inside that little wooden makeshift shed

workers standing at the workshop entrance

would see him and say

luo jiasheng's here

no one knew who he was

no one asked him who he was

the whole plant just called him luo juasheng

\footnotetext{
9 Mang Ke 1988: 8-11, Bei Dao 1987: 21-24, first published in Today 1 (1978): 28-30 and 3 (1979): 37-40, respectively; Bei Dao 1987: 25-26, first published in Today 1 (1978): 31-32; Yu Jian 2004a: 14-15.

10 Yu Jian 2004a: 36-37. Whereas all other editions have a stanza division between tie and when, the Collected Works edition does not. The functionality of stanza divisions in the poem suggests that this is a misprint.
} 
the workers would often knock on his shed

and ask him to fix a watch fix an electric clock

ask him to fix a radio

during the "cultural revolution"

he was chased from the plant

in his trunk

they'd found a tie

when he came back to work

he was still riding his old bicycle

luo jiasheng

had quietly married

without inviting anyone

and at forty-two

become a father

right that year

he died

a furnace exploded

blew a big hole in his head

scary stuff

on the day he was buried

his old lady didn't show up

a couple of workers carried him up the hill

they said he was a little fellow

easy to carry

once he'd fixed your watch

it'd be better than new

smoke is rising from the chimney

workers standing at the workshop entrance

luo jiasheng

hasn't come to work

By all accounts, «Luo Jiasheng» is the poem that established Yu Jian's reputation, and it remains one of his most cited works to this day. Early 1980s readers had recently encountered Obscure Poetry with its daring and sometimes overstretched metaphors, and Root-Seeking trends that featured solemn references to Chinese history and mythology. To them, «Luo Jiasheng» opened up a new orientation, much 
like Han Dong's «Of the Wild Goose Pagoda», discussed in chapter Two. The two poems are alike in their attention to ordinary people's lives, their short lines and their colloquial, minimalist usage, and in the casual shock effects they deploy. In Han's, this is someone committing suicide by jumping off the proud symbol of Chinese-national culture that is the Pagoda, rather than dutifully taking in the view and descending by the staircase. In Yu's, it is LuoJiasheng's violent, utterly meaningless death by an accident at work.

«Luo Jiasheng» exhibits Yu Jian's skillful employment of the lowkey style that set the new trend apart amid its literary environs. The final two lines, for instance, are a powerful understatement in light of what has gone before, precisely because of their flat, unmarked diction: luo jiasheng / hasn't come to work. The poem's composition also contains features that are typical of Yu's art. It smoothly conjoins the moving burial scene described by a detached narratorial voice with what appears to be a personal memory experienced by Luo's fellow workers: once he'd fixed your watch / it'd be better than new. Objectification is visible in the willed superficiality of the speaker's observations. This recurs throughout Yu's oeuvre and makes for another similarity with Han Dong; as in chapter Two, I use the notion of superficiality not as a sign of the postmodern but to denote a mechanism that causes defamiliarization by blocking out conventional lines of reasoning and association. The causal relationship between the necktie and Luo Jiasheng's brutal removal from work, for instance, is not made explicit. First, this implicitly mobilizes the reader's knowledge of the Cultural Revolution: say, the fact that a tie could count as signaling bourgeois mentality or Westernization. Second, it makes the event "objectively" defamiliar, not to say absurd. Third, this in its turn does in fact imply the opinionated, moral judgment in which the text pretends not to engage.

Lest the notion of objectification limit our vision of an oeuvre that is versatile within its unmistakable style, let's consider a very different text. «A Wall» (墙, 1983) is another early poem, but thoroughly dissimilar to «Luo Jiasheng»: ${ }^{11}$

${ }^{11}$ Yu Jian 2004a: 75-76. 


$$
\text { «Wall» }
$$

a wall without seasons

a wall that the sun doesn't reach even at noon

a wall with no trace of human presence

a wall with all sorts of shadows on it

a wall suddenly stripped naked by floodlights

a wall that has "no through road" written on it

a wall with windows tightly closed

a wall without a sound a wall that is earsplitting deafening

a wall where a murder was committed

a wall that's eaten the windows

a wall written on the wall by a professor

a wall below her eyelashes

a wall sitting across from you sleeping next to you

a wall hidden in shorts

a wall made up of writing

a wall produced by eyeballs a wall behind a tongue

a wall that laughs a wall that is expressionless

a wall in the wilderness a wall at sea

a wall with a calendar on it a wall with the dragon as its zodiac sign

a wall between here and the parents' bed

a wall that's died a wall in memory a wall that's immortal

a wall coming into the world with a cry every second

a wall disguised by a sofa and a tapestry

a wall from which it is impossible to flee

a wall that whichever way you look

remains unspeakable impossible to unmask and criticize

a wall that makes describing the above walls

feel like holding a pen is clutching a pickaxe

a wall

In the original, each line ends in 墙 'wall,' with the exception of the last five, where the modifiers that precede the noun extend to two and three lines, respectively. In the translation, a wall stands at the beginning of each line, but the effect of the insistent repetition is comparable. In the first ten lines (down to eaten the windows), the wall appears to be outside, as opposed to the walls inside a house that appear in the poem's final one third. Observations presented as more or less empirical in lines 1-7 go together with claims of personal perception in lines 5 and 8-10, 
both sensory (earsplitting deafening) and imaginative, personifying and metaphorical (suddenly stripped naked, murder, eaten the windows). In lines 11-17 and possibly 18, the wall-as-metaphor represents inaccessibility, including that of academic writing, of body language and of sexuality. The last third of the text is technically less cohesive than the first two thirds, as the wall invites alternating literal and metaphorical readings and the poem works toward its conclusion in an all-encompassing abstraction of its central image.

Two things about «A Wall» are typical of Yu Jian's poetic oeuvre at large. First, there is the patient, repeated examination of a single word and, inasmuch as we wish to allow for the referential function of poetic language, a single thing. This allows for the combination and confrontation of separate if not incompatible experiential domains. I would venture that if it has to be either, «A Wall» examines a thing, rather than a word. A poem, conversely, that could be argued to examine a word rather than the thing to which this word claims to refer is «The Naming of a Crow» (1990), the title poem of one of Yu's poetry collections mentioned in the beginning of this chapter. ${ }^{12}$ Second, «A Wall» breathes a sense of humor that is characteristic of other authors who rejected the solemnity of Obscure Poetry and went on to appropriate contemporary poetry in their various ways: Han Dong, but also, often in cruder ways, poets such as Macho Men Li Yawei and Wan Xia, and Not-Not poet Yang Li. ${ }^{13}$ This sense of humor finds more elaborate expression in Yu's oeuvre in later years.

If there is any text from Yu Jian's early years as a published poet that can compete with «Luo Jiasheng» in terms of canonical status, it must be «No. 6 Shangyi Street» (尚义街六号, 1985). In «No. 6 Shangyi Street», the historical address of that name in Yu's native city of Kunming - where he has lived all his life, and with which he strongly identifies - is the home of $\mathrm{Wu}$ Wenguang. $\mathrm{Wu}$ is a historical person now resident in Beijing, who has made a name for himself in the worlds of Chinese documentary movie-making, theater and more generally avant-garde culture. In the poem Wu's home is where a group of male friends hang out. Here is a first, long excerpt: ${ }^{14}$

${ }^{12}$ Yu Jian 2004a: 228-230.

13 See Day 2005a: ch 4 and ch 10.

${ }_{14}$ Yu Jian 2004a: 130-133. The poem is dated June 1985 in Them 2 (September 1985) and in Yu Jian 2004a. In Yu Jian 1993 and 2000, it is dated June 1984. 
we'd often pay our visits at dusk

open our cigarette cases open our mouths

open the window

there was a painting by yu jian nailed to the wall

many people disapproved

they only knew van gogh

old ka's shirt was like a crumpled piece of cloth

we'd use for wiping the fruit juice off our hands

while he leafed through some dirty book

later he fell in love

and the two of them would often show up together

do their fighting there do their flirting there

one day they announced that they'd split up

their friends relaxed felt happy

but the next day he sent around wedding invitations

everyone was immaculately dressed went to attend the banquet

the table was always covered with zhu xiaoyang's manuscripts

his handwriting went every which way

that bastard he watched us like the police

facing those red eyes of his

all we could do was be a bit vague

just like the poetry that was all the rage

li bo's slippers would sit on fei jia's shoes

he was already famous had a blue-sleeved membership card

he'd often lie back and rest his head on it

while he was telling us how to wear our shoes

how to take a leak how to wash our shorts

how to cook cabbage how to sleep and so on

in 82 he'd come back from beïing

in a new overcoat more profound than before

he had the inside stories from the literary scene

sounded like the chairman of the writers' association

the tea was old wu's the clock was old wu's

the floorboards were old wu's the neighbors were old wu's

the missus was old wu's the stomach medicine was old wu's

the phlegm the cigarette butts the air the friends were old wu's

The reader is asked to forgive my translation of 打开灯 'turn on the light' as open the window. A literal rendition would be open the light; hence, 
the replacement in translation of the light by another household object, that can be opened in English. The repetition of one word (打开 'open') in a variety of contexts exemplifies Yu Jian's habit of playing with everyday linguistic usage. Here, the effect is that of putting inanimate devices such as cigarette cases and electric lights on a par with the mouth, by "opening" each in quick, mechanical succession, in a clear instance of subjectification. This complements the objectification that occurs in downplaying the mouth's conventional association with language as a distinguishing characteristic of human beings and their imagination and creativity - which is visible in poetry, among other things. There are another two examples of such repetition in the above passage, with a comparable effect of good-natured ridicule. First, we read about Li Bo telling the others how to go about several tasks in "trivial" daily business, including the act of sleeping, usually seen as something that comes to one naturally rather than having to be taught. Next, the speaker lists Wu Wenguang's "possessions," ranging from household conveniences to waste products and fellow human beings with whom he enjoys various degrees of intimacy. The willed, superficial realignment of conventional categories is clearest in this enumeration: the phlegm the cigarette butts the air the friends were old wu's.

As for the names of historical persons in the poem, including that of Yu Jian himself, one might be tempted to take these as evidence of this poetry's "authenticity," as Xie Youshun and other critics have done, in the sense of documenting historical, lived experience. ${ }^{15}$ If this recalls traditional Chinese notions of the relation of world, author and text, the difference is that the experience laid out here doesn't contribute to a vision of the author's behavior or position in the world as appropriate for the traditional man of letters. ${ }^{16}$ «No. 6 Shangyi Street» is but one of many poems by $\mathrm{Yu}$ that contain the names of historical persons, often those of other people active on the cultural scene. «When Friends Come from Afar» (有朋自远方来, 1985), ${ }^{17}$ for instance - its title taken from the opening lines of the Confucian Analects (论语) - features Them poets Han Dong and Ding Dang. There, the appearance of "real people" in the text has little added value. In «No. 6 Shangyi Street» it entails reflection on things like the artist's rise to fame, and on the

15 Xie Youshun 1999.

${ }_{16}$ See Owen 1979, esp 232-234.

17 Yu Jian 2004a: 134-135. Notably, Yu Jian 1989a: 40-42 and 2000: 211-213 have 从 for 自 in the title; the Analects has 有朋自远方来. 
opposition of a public persona and the pedestrian qualities of a private life:

lots of faces first appeared in that place

if you go into town today and ask around

they're all celebrities now

outside a drizzle was falling

when we set foot in the street

as for the empty public toilet

this was the first time he used it by himself

Perhaps the authenticity of «No. 6 Shangyi Street» doesn't depend on our ability to establish whether the poem ever "really happened," but rather on the convincing, mocking description of the ordinary-guy, male mateship experience as something that could have happened and that the poet could have been a part of. Be that as it may, the private histories as they appear in the poem are casually linked to verifiable public history in the literary world. In the lines all we could do was be a bit vague I just like the poetry that was all the rage, the Chinese word rendered as vague is 朦胧 'obscure,' 'dim,' 'hazy,' and the epithet of the Obscure poets from whom $\mathrm{Yu}$ Jian and like-minded authors had been busy dissociating themselves for some time when «No. 6 Shangyi Street» was written. Also, protagonists Wu Wenguang, Fei Jia, Li Bo and Zhu Xiaoyang all contributed to the Kunming-based, unofficial Highland Poetry Compilation (高原诗辑, 1982-1983), as did Yu Jian under the name of Dawei. The fourth issue, incidentally, contains a 1983 poem by Wu called «Highland Poets» (高原诗人) that may well have been a direct source of inspiration for Yu's «No. 6 Shangyi Street». ${ }^{18}$

And there is still more literary history here, most of it presented in sarcastic fashion. Li Bo's inside stories make him into a Mr Know-ItAll, and further down we read:

yu jian wasn't famous yet

and would constantly be lectured

on an old newespaper

he'd write down lots of profound pen names

A central mood in the poem is that of nostalgia, for

${ }_{18}$ See Van Grevel 2007. 
... the years of wisdom

full of conversations that if they'd been recorded

could have made a famous book

those were the years when it was all happening

When the mates go their separate ways, these happy times inevitably come to an end, as does the poem:

wu wenguang you're gone

where do $i$ go to bum my dinner tonight

after some grumbling and some shouting

everyone finally split

all that was left was a bunch of old floorboards

like an old record that sounds no more

in other places

we often bring up no. 6 shangyi street

saying that one day many years from now

children will go there on sightseeing tours

The "real," historical no. 6 Shangyi Street may not have become a cultural landmark, but the poem certainly has.

Yu Jian's oeuvre contains a set of poems with titles made up of the word event (事件) followed by a specification, all but one from the period 1989-2002: for instance, «Event: Power Outage» (事件・停电, 1991) and «Event: Snoring» (事件・呼噜, 2000). Both A Nail through the Sky and The Poetry of Yu Fian anthologize them together, in separate "event" sections; Yu's individual collections include a total of seventeen such titles. As is true for other parts of Yu's oeuvre, including his verse-external explicit poetics, he has done some rewriting here. A 1982 poem entitled «Three Passengers» (三乘客) in The Naming of a Crow is retitled «Event: Three Passengers» (事件 • 三乘客) in The Poetry of Yu Fian, and one entitled «Experience no. 5: In Search of Waste Land» (经历之五・寻找荒原, 1989) in one of his unofficial collections is retitled «Event: In Search of Waste Land» (事件・寻找荒原) in $A$ Nail, The Poetry of Yu Fian and the Collected Works. ${ }^{19}$ At some point after 1993, when The Naming appeared, Yu must have adopted the "event" formula as a distinct category of texts within his oeuvre and expanded it backwards. He had earlier done so for the “opus" (作品) formula in

${ }^{19}$ Yu Jian 1993: 164-167 and 1990: 3-4. 
the titles of several dozen poems from 1983-1987, such as «Opus 1» and «Opus 108», not strictly in numerical order. Both formulas contribute to the mechanism of objectification: the "opus" poems because they are nameless except for the hard numbers, and the "event" poems because they suggest a vision of poetry as documentation or reportage. They remove poetry from things like romantic inspiration and the notion of high art, by portraying it as one of many other activities whose output is organized along similar lines: running a bureaucracy, for instance, that will produce matter-of-fact, documentary reports designed to fit a particular format. In addition to their titles, objectification and subjectification are in evidence throughout many of the "event" poems in their entirety.

Let's first consider the subjectifying impulse in these poems' imaginative attention to (inanimate) objects. «Event: Power Outage» contains minute descriptions of people's physical familiarity with their surroundings at home as they move about in darkness when electricity fails them. In «Event: Death of a Palm Tree» (事件・棕榈之死, 1995), the speaker's exhaustive description of the tree reminds one of the ancient Chinese genre of poetic exposition (赋). The death of the tree is caused by a lack of respect accorded to it by human beings who plan to build a shopping mall where it stands. There are several more titles that speak for themselves, such as «Event: Three Tennis Balls near the Compound Wall» (事件・围墙附近的三个网球, 1996) and «Event: Floorboards Sticking Out» (事件・尧起的地板, 1999). Conversely, in the context of the "event" series, especially when presented together as in A Nail and The Poetry of Yu fian, titles such as «Event: Birth» (事件 • 诞生, 1992) and «Event: Wedding» (事件・结婚, 1999) put moments that normally count as existentially and emotionally important in human lives on a par with things like a burnt fuse, the felling of a roadside tree, the loss of tennis balls and imperfect carpentry. Thus, Yu Jian realigns divergent experiential domains in the titles of the "event" poems, just as he does on other levels throughout his oeuvre, down to that of the single line in «No. 6 Shangyi Street». ${ }^{20}$

Another example on the level of titles is «Event: Writing», writing being an activity that is conventionally viewed as more worthy of literary representation than an "event" such as snoring, certainly in the context of a poetic oeuvre. In the body of the poem, Yu Jian works toward

${ }^{20}$ Yu Jian 2004a: 249-250, 281-285, 306-309, 346-347; 254-255, 337-339. 
objectifying the phenomenon of (written) language usage, through attention to its concrete tools (ink, pen, paper) and literary and linguistic terms such as metaphor, subject and adverbial modifier. The effect, however, is weakened by passages that seem grandiloquent and pompous when compared to other "event" poems. The lines are exceptionally long, even by Yu Jian's standards; from here on, as in chapter Six, citations are in smaller type and occasionally require indentation. ${ }^{21}$

writing this is the most glorious event of an era the death and revival of words highway or pitfall

magnificent details right where a word emerges from obstruction its original form fully revealed to reach a predestined position in fate

In «Event: Writing», the intensity and commitment that shape $\mathrm{Yu}$ Jian's reflection on his art get in the way of his poetic talent. The poem never quite takes off in the way that other "event" poems do, weighed down as it is by abstractions, conceptualizations and explanations. It is theory rather than practice and explicit poetics rather than poetry.

The "event" formula is highly effective in «Event: Paving» (事件 • 铺路, 1990), because this poem shows rather than tells: ${ }^{22}$

«Event: Paving»

walking on the newly paved road the workers push the tool cart

dragging sledgehammers behind them shovels pickaxes wobbling on their heads

every road is now paved coming into town

this is the last bit of bad road a tear in the beautiful carpet

threatening the feet raising worries for actions like strolling comfortably

everything must be flattened roads and the falls and crashes that stem from them

old words like medicinal liquor barefoot mudhole and caved-in

will be replaced by even and regular both shining with bitumen brilliance

this is a good thing it's in the plan the workers get to work

wielding tools meticulous measurements devoted as if paving new vistas

this road is uneven full of bumps and holes its geology isn't constant either

with some stretches guarded by basalt some places harassed by water

in one spot the twisted roots of an old tree that took 300 years to raise this clan

the hoe is a wonderful thing it will dig out anything flatten it out

turn high into low even out any cavities

${ }^{21}$ Yu Jian 2004a: 278-279.

${ }^{22}$ Yu Jian 2004a: 240-241. 


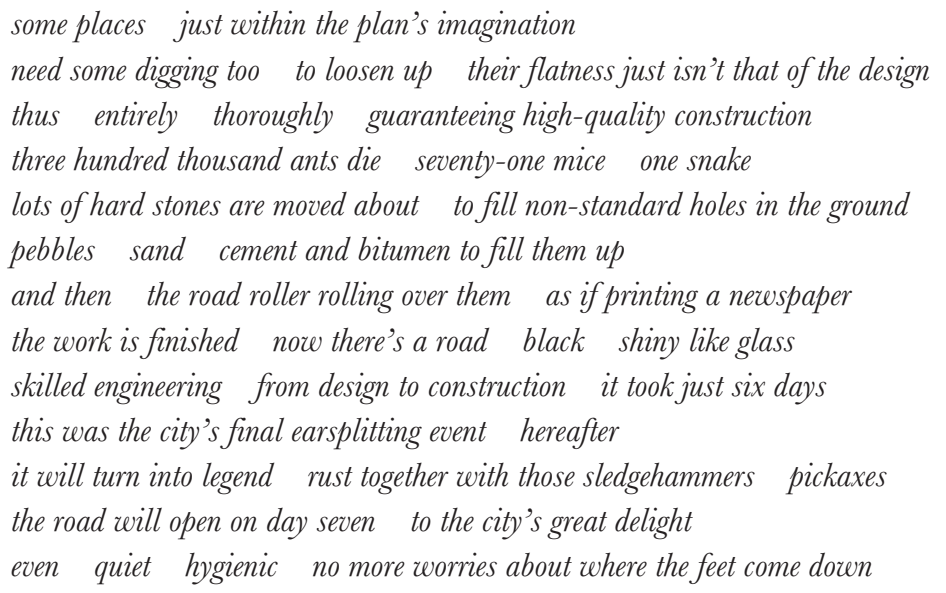

«Event: Paving» offers a balanced elaboration of cohesive, concrete imagery: tools, machinery and human-made materials such as cement and bitumen on the one hand, and authentic "objects" displaced and damaged such as tree roots, mudholes, stones, animals and bare human feet, on the other. Just like «Event: Death of a Palm Tree», the poem is an indictment of a modernization that carries with it destruction and disregard for the human body as part of the natural environment, even if the future invoked to justify these things is presented as a protection of that body, in this case against the falls and crashes that stem from bad roads. As such, «Paving» is easily related to the destructive side of urban transformation in China since the 1980s, on which $\mathrm{Yu}$ Jian has commented in his short prose, especially with reference to Kunming. ${ }^{23}$ The message is driven home because the deaths of ants and mice, animals that normally don't "count" in human deliberations, are noted in precise numbers, in a pseudo-neutral, understated observation rather than an angry $j$ 'accuse.

In spite of Yu Jian's declared rejection of metaphor, there are good grounds to take «Paving» in its entirety as just that, and to interpret it as an expression of resistance to the erasure, or the flattening, of local and individual identity by centralization and standardization. Yu's most significant subject matter in this regard is that of language, which he addresses in dichotomies of foreign or "Western"- usually meaning English - versus Chinese, and domestically of the Standard Lan-

${ }^{23}$ E.g. Yu Jian 1997b: 99-107. 
guage (普通话) versus regional languages or “dialects” (方言) such as those of Yunnan or Kunming. In both cases, the former encroaches upon the latter. He sees "linguistic" issues such as the disappearance or indeed the repression of Chinese and regional idiom as expressions of the hegemonic ambitions of English in the world and the Standard Language inside China; and English and Standard Language idiom as part of discourses that ultimately represent dominant positions of political power. In his verse-external, explicit poetics, Yu Jian presents these views passionately and polemically. In his poetry he does so by alternating laid-back, informal usage with phrasings that feed on the politically correct language of government-sanctioned publications, in other words: by alternating private and public discourse, and the "unofficial" and "official" realities they represent, as we have seen in chapter Six. In «Paving», official discourse resonates in a tear in the beautiful carpet and everything must be flattened and guaranteeing high-quality construction and skilled engineering, as well as, humorously, non-standard holes in the ground. The effect, exemplified in their flatness just isn't that of the design, is one of all-pervading irony that combines cheerfulness with sadness, despair and bitterness between the lines.

$\mathrm{Yu}$ Jian's cheerfulness is a rarity in contemporary Chinese poetry, exceptions being the more provocative, devil-may-care varieties found in Macho Men poetry of the 1980s, and in trends such as Lower Body poetry and other examples of what I have called extreme manifestations of the Earthly aesthetic since the turn of the century. In «Event: Conversation» (事件・谈话, 1990/1992), the undertones of Yu's cheerfulness are different from those in «Paving». Whereas below its disciplined surface «Paving» challenges modernization and its sociophysical impact, «Event: Conversation» has no such ideological ambitions. This poem is a positively clownish account of a visit to the speaker by an acquaintance who brings along a stranger, thus making an "intrusion" into the speaker's home, for shelter from the rain. The poem's clownishness derives, again, from the combined effects of objectification and subjectification. After the setting has been outlined as a very wet July, we read: ${ }^{24}$

${ }^{24}$ Yu Jian 2004a: 256-258. According to Yu Jian 1990: 1-2 and 1993: 13-16, the poem was written in May 1990; the revised version in 2004a is dated 1992. 
we all stay at home only the rain is taking a stroll still circulating on the roads this is good home is home rain is rain the one doesn't exist for the other's sake the door stops moving to consecrate its position but we expect an intrusion pores wide open after dinner in licentious loneliness we identify noises outside seven pm the weather report is finished the rain will go on for another week someone pays a visit a fat person or a thin with a black umbrella or a red can't remember the intruders' faces dry or wet we never pay attention to concrete facts

The phrase we never pay attention to concrete facts reads as a dig at an "overall," dominant discourse (总体话语) that Yu never tires of attacking for what he sees as its manipulation of abstractions to the detriment of concrete experience, especially in the politics of culture. In «Conversation», the said phrase specifically leads into a portrayal of language as a ritualized, semantically empty type of social intercourse that is at best phatic in nature. Viewed less optimistically, it is boring if not grotesque, and absurd in its arbitrariness:

the conversationist suddenly vanishes into thin air only the mouth remains the gums and the root of the tongue all inflamed

when the conversation picks up again it's drifted onto different waters

this time the syntax is if... then and if only.... then all would be well and then now what? and what would that mean?

if only the rain fell toward the sky then all would be well this would mean rescue well put fascinating there's always someone to point out the crux of the matter followed by a broad grin the mouth cruelly flashing to both sides at once to dodge an explosion of teeth but.... when that crucial word comes out this indicates a climax is near someone's going to get angry someone's going to spit out their tea

someone's going to rethink the whole thing but let's have some more tea first clear our throats

have another cigarette a full set of actions gymnastics of conversation possessing the order and the beauty of music

(moderato) (andante) (grave) (con brio) (allegro)

(con spirito) (largo tranquillo) (three-four time) (crescendo) (da capo)

normally three to seven ears will climb one mouth while a few others

have long ago got on their motorbikes and disappeared without a trace faces with ears on them

watch the conversation a line-up of subjects verbs objects complements modifiers attributes burst forth through the teeth 
and dry up on the surface of things right away no matter how dry the host must manage his own ears

listen intently nod sigh smile pour fresh tea show that he's taking it all in this excites the conversationist who expertly uses labiodentals rounded vowels and nasals

as if correcting a night school student's homework here drawing a red line

writing? somewhere else and at the end the assessment says the theme still lacks profundity

the rain is still falling something starts to seep through never mind the conversation must once more transfer to a new topic

communication starts to be difficult luckily this room is dry so we converse on dry things

dry furniture dry marriages dry extramarital affairs and wages dry washrooms dry tos and magazines dry weekends dry holidays spent in dry places

The conversationist, or the one "making conversation" (谈着话的), is reduced to a free-floating mouth that produces linguistic structures such as syntactic patterns (if... then and if only....) and sounds that conform to the phonology of the language used (labiodentals, vowels, nasals). To call this metonymy would be problematic because what $\mathrm{Yu}$ does to the mouth is to make it autonomous: it no longer represents or substitutes for the conversationist. The poem makes the employment of the if only... pattern in a well-behaved conversation look meaningless, in contrast to its imagined use as representing an impossible situation that would be truly significant (if only the rain fell toward the sky then all would be well this would mean rescue), unlike the inconsequential chatter that goes on between the speaker and the visitors.

The clichéd nature of language usage is also manifest in the predictable patterns of dialogic interaction. If only to postpone the visitors' exit back into the rain, the social desirability of harmony overrules semantics that should really lead to disagreement. Impending conflict signaled by the conjunction but.... is quickly averted by more tea, cigarettes and the awkward clearing of throats: gymnastics of conversation possessing the order and beauty of music. The protagonists opt for compromise over confrontation, and there is a good deal of sarcasm in phrases like well put fascinating there's always someone to point out the crux of the matter and the host show [ing] that he's taking it all in, while what is happening is no more than the mechanical operation of empty structures. The speaker likens these things to the rules that govern formal 
education, a theme that recurs in Yu Jian's poetry, by citing some of the most hackneyed words a teacher can write down when marking papers. There is no first-person singular in the poem, but since the speaker's perspective frequently overlaps with that of the host receiving the visitors we may speak of the protagonists' self-portrayal in the eyes of the host: as one of ordinary people, not heroes, in a type of selfmockery that is indulgent rather than judgmental.

The passage that starts with normally three to seven ears will climb one mouth combines a ludicrous instance of Yu's imaginative attention to objects with a vision of conversation as a wet, physical element whose association with moist air or saliva bursting forth through the teeth is obvious. From the conversation we return to the rain, through the echo of the theme still lacks profundity in the next line: the rain is still falling. As the rain continues to fall, ominously, something starts to seep through, and the only way to keep this something out is to start all over again and talk about something else. Here, conversation becomes human behavior intended to neutralize frightening manifestations of the natural world. We encounter another instance of the realignment of divergent experiential domains and the repetition of one word in a variety of contexts: $d r y$ furniture dry marriages and so on. While the dry things listed in this line and the next differ in experiential status - from the institutionalization of human relationships to consumer itemsthey are all plausible topics of informal conversation. Soon afterwards, the poem ends:

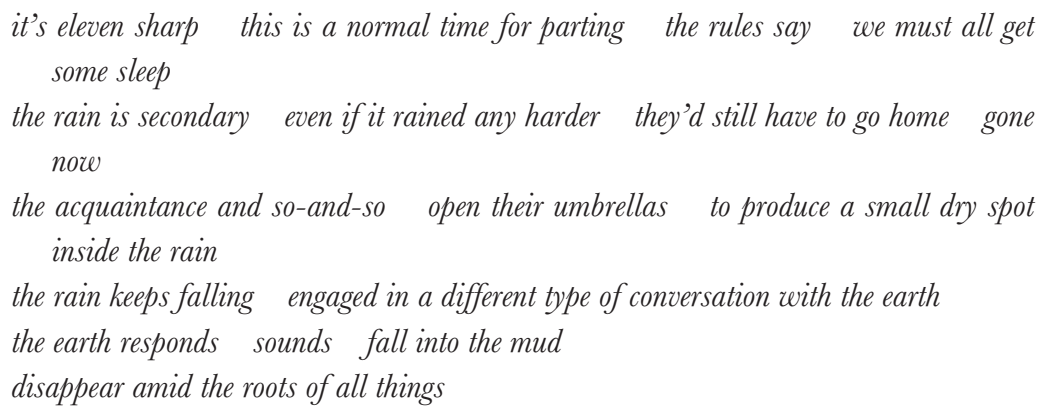

Just like the conversation, the guests' arrival and their departure are determined by conventional patterns: after dinner and at eleven pm, respectively. This vision of social intercourse as entirely mechanical is reinforced by the avuncular cliché that we must all get some sleep. In its final few lines, after a vintage Yu Jian description of the function of 
umbrellas, the poem can be seen to wax philosophical. Perhaps the conversation that takes place between the rain and the earth, with the powerful image of sounds that fall into the mud, is more meaningful than that between the human protagonists - but there is no way of knowing for sure.

We get a closer look at the rain in «Outside the Poet's Scope: Observation of the Life of a Raindrop» (在诗人的范围以外对一个雨点 一生的观察, 1998). «Outside» is yet another long poem. Here are the first 38 of its 71 lines: ${ }^{25}$

right it's going to rain

the poet on a bar stool in the coffee shop

shoots a glance at the sky quietly mumbles

and his tongue withdraws into the dark

but back in those dark clouds its life its

drop-by-drop tiny story is only just beginning

how to say this this sort of small thing happens every moment

i'm concerned with bigger things says the poet to his female reader

obedient to that invisible straight line coming down

maintaining consistency with surroundings equally perpendicular to the earth

just like the poet's daughter always maintains consistency with kindergarten

and then in skies twisted by pedagogy

becoming twisted it cannot but become twisted

not in order to graduate but in order to retain its wetness

it has not yet the ability to choose its locus

it does not know as of yet that whatever its choice

to fall down is all that is within its rights or maybe it knows

but then again how to stop here

everything is going down

happy little princelet in self-styled coronation

on the verge of an overcast sky lithely flashes by

divorces itself from the ranks turns into a tiny tail

stuck upward flattened out twisting up again

lashing out experiencing the freedom

and the unreliability of open space

now it seems that it can do as it pleases

in a small space in the world neither up nor down

${ }^{25}$ Yu Jian 2004a: 327-329. 
junior high student out of class on the road between home and the classroom the poet maintains his composure sizing up his reader's chest like an honest man but it dares not indulge in enjoyment of this wee bit of freedom in the end having to become an appendage of something else in the end having to team up with one colossus or another petty lowly luminophor

firefly fearful of individualism

longing for surveillance by the lights of summer nights

just like the poet at the same time as writing poetry

also serves in a certain association he has a membership card descending faster now losing all freedom

Starting in the poem's title and continuing throughout the text, the conventionally lowly, inanimate object that is the raindrop is set off against the conventionally lofty human being that is the poet. The effect is not just, shall we say, an ontological upgrade of the raindrop, but also an ontological downgrade of the (male) poet, prepared in the irony of the preceding lines (this sort of small thing happens every moment I im concerned with bigger things says the poet to his female reader). An instrumental moment comes in line 9 (obedient....), when there occurs the first of several shifts from the poet to the raindrop as the grammatical subject that remain unmarked by personal pronouns. Yu Jian could have used the neuter third-person singular '它 'it' but chooses not to, and the reader discovers the shift only in retrospect. This is the reflection in syntax of objectification and subjectification combined.

Subsequently, the dis-similarity of the poet and the raindrop turns into the similarity of the raindrop and the poet's daughter. Both are obedient to an invisible straight line produced by the larger systems of which they are a part and that will ultimately disallow their independent existence: the laws of nature and those of education. This subject matter is familiar in Yu Jian's oeuvre, and so is the mixing of linguistic registers. Again, this pointedly implies that language is by no means a transparent, neutral and reliable tool that describes "reality," and that its potential for shaping and distorting experience is greatest in institutionalized discourses such as formal education and political ideology. The passage in which the raindrop divorces itself from the (revolutionary) ranks (脱离了队伍) is a case in point.

The next step takes us back not to the poet and the raindrop but to the raindrop and the poet, in that order. The raindrop with its appar- 
ent freedom - and its lack of courage to indulge in this freedom - is now the point of calibration, and something to which the poet is likened. That is where the second and truly ingenious unmarked subject shift comes in, in line 38 (descending....). The first, in line 9, has prepared the reader for the seamless shift from the poet back to the raindrop (descending faster now). However, once we read the next half of line 38 (losing all freedom), and because of the proximity of the poet's description in lines 36-37 as serving in a certain association at the same time as writing poetry, the preceding twenty or thirty lines, outlining the incorporation of individual existence into larger systems, come to apply to not just the raindrop and the poet's daughter but also to the poet himself. After the laws of nature and those of formal education, we may now justifiably think of the literary world as a third such system. It could be a contemporary Chinese literary world, if we take freedom as meaning political freedom or freedom of speech, and note that the raindrop-poet is fearful of individualism and the People's Republic has a government-sponsored Writers' Association that would easily qualify as a "colossus," but the poem's effectiveness doesn't hinge on this specification.

In line 41 (in a passage left untranslated here), the raindrop has finally caught hold of an iron-wire clothes-line. The equation of raindrop and poet recurs in lines 50-57:

... it seems that it can choose anew

this right moves it to flaunt its talents and possess its own form

while doomed to fail for want of the final touch the weight of this form

has long ago determined that it's all downward a heaven-granted pitfall

just like our poet rebels howls

and then becomes legitimate moves up in the world

with his aestheticist pen giving his reader an autograph

desperately grasping at everything within reach

As earlier (line 35), there is a straightforward simile in line 54: just like our poet. The inevitable, downward fall of the individual raindrop is now literally likened to the poet's "upward" social mobility. We recall the flippant supposition in «Event: Conversation»: if only the rain fell toward the sky this would mean rescue.

Bearing this in mind, we may take the poem's closing lines, when the raindrop and the poet meet, as asserting not just their coincidence but their inextricability or indeed their fundamental sameness: 
it has remained wet throughout

in this life its victory is never to have been $d r y$

its time meanswater retention up until it

turns into other water splashed on the bottom of a trouser leg

of the poet who has just left the coffee shop to leave a wet mark

\section{Long Lines AND BLAnKs}

Who would want objective literature, if there were such a thing to begin with? I have stressed that objectification doesn't lead to anything like "true" objectivity, that it is artificial and a manipulative intervention on the part of the poet, and that as such it is an expression of sub-jectivity. This is evident from the sympathy for Luo Jiasheng in the poem of that name, and for the all too human protagonists of «No. 6 Shangyi Street» and «Event: Conversation», as well as from the indictment of standardization and modernization in «Event: Paving». Objectification, then, is of course a particular type of irony, in its basic meaning of dissimulation or feigned ignorance. After the Maoist years, starting in the 1980s and coming into full swing in the 1990s, the resurrection of irony is among the most significant developments in contemporary Chinese poetry, with Yu Jian and Xi Chuan as two early contributors, each in their own way. As we have seen, Yu's irony often targets conventions of social intercourse and hierarchies of the lofty and the lowly, be they human beings or objects, poets or raindrops. Proceeding from the content-oriented analysis in the preceding pages, to conclude this chapter I will elaborate on the proposition that objectification and the broader category of irony in Yu Jian's poetry also draw on the formal qualities of his work, and that they are in fact contingent upon these qualities.

The most striking thing about the form of Yu Jian's poetry is what he calls the long-short line (长短句, with no obvious relation to this term's denotation of aspects of the Song-dynasty lyric [词]): long lines, punctuated not by conventional marks such as commas, full stops, (semi-)colons, dashes and so on but by blanks roughly the size of a Chinese character. Here is an example from «Event: Conversation», with the translation in especially small type, to make it fit the original: 
十一点整 这是通常分手的时间 规距 大家都要睡觉 雨是次要的 再大的雨 都要回家 走掉了

it's eleven sharp this is a normal time for parting the rules say we must all get some sleep the rain is secondary even if it rained any harder they'd still have to go home gone now

Let's first consider the issue of line length. In the Collected Works, «A Song for People from Our Time» (唱给同时代人的歌, 1981) contains lines of up to 20 characters. From then on, Yu's oeuvre regularly includes examples of such visibly big poems, their frequency and their length - as in the number of lines - generally increasing during the 1990s and after, although the poems in his recent collection Only the Sea, Vast Like a Canopy are noticeably smaller in both respects. Exceptionally long lines occur in texts such as «Fable Exodus» (寓言 出埃 及记, 1985/1994) and «Event: Wedding», each poem spilling across three large pages and containing lines of up to 38 characters. ${ }^{26}$

As for the blanks that punctuate $\mathrm{Yu}$ Jian's poetry, they are also there from the beginning. The first blanks in the Collected Works occur in «Rainy Night» (雨夜, 1976). In the early years, the blanks are few and far between, and their usage is rather wooden. They make for a pompous, dramatic effect not unlike that created by varying indentation in the work of orthodox poets from the Maoist era, such as Guo Xiaochuan and He Jingzhi, whose echoes in the early avant-garde have been noted at other points in this study. Specifically, the blanks often function as alternative exclamation marks when they follow words like ah (阿) in phrases like ah the setting sun and ah eternal imperishable wind, in «Judgment Day» (末日, 1976), for example. These are the very "poetic" exclamations that Yu himself later ridicules in «Event: In Search of Bleakness», when the speaker says about western Yunnan: ${ }^{27}$

a flock of bright red goats (i mean the soil) with no one keeping watch prehistoric omens everywhere and $i$ as a poet one forcing his way in stood there outside them not knowing if $i$ should start from ah or from oh

The flock of red goats followed by the reading instructions in (i mean the soil) is, of course, a send-up of the type of metaphor Yu Jian delights in "rejecting," and leads into tongue-in-cheek self-reflection by the speaker-poet who worries about the proper interjections.

\footnotetext{
26 Yu Jian 2004a: 19-21, 263-265, 337-339 and 2006.

27 Yu Jian 2004a: 6; e.g. 8, 9, 11, 19-21, 23, 24, 26; 11; 218.
} 


\section{事件・结婚}

总会在某个下午 当城市放松了腰带 在落日中酿造着黄色啤酒 五点半 在大街的拐弯处 川味饭店门口 撞见 这喜气洋洋的一对 套在 新衣服里的 木偶人 被父母的线奇着 差差答答 豉出在人群的边缘 犹如 两颗 刚刚镶进喜剧的假牙 传统的黄昏 对于你 只是千篇一律 一份含有 味精和洗涤剂的 日程表 的 复印 你和昨天一样 得赶回去买菜 做饭 接小孩 应付家庭中 日益猖㢸的女权主义 在别人 却是全新的五点半钟 印在赑金的 红纸上 值得隆重纪念的良辰吉日 值得把过节的那些花样 于 统统搬来 还不是 那一套 就是那一套 永远的一个套 套住了世界上的红男 坚 绿女 彩车 假花 鞮炮 喜榶 红包 酒席 胡闹 冷场 带点儿色情的 元笑 集 新娘和新郎的三头六臂八面玲珑 应醂造抢 狼狈临了杯盘狼藉 席终人散

总是 男的 灰西装 女的 红旗袍 小舅子扛着摄像机 露出斜囨着的左眼

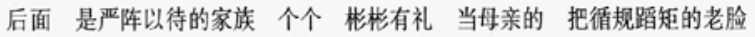
凑近新人 交代这样 记住那些 最后 又红着脸 说出一直骨䚙在鯸 难以启齿 的一点 “第一个晩上……垫单上要铺一块白布, 这是老规矩。” “什么? ” 新郎和新娘像猴子一样 困惑 “听種了没有” 明白人想说明白 又找不到 说得明白的比方 老框框中 许多名堂 从来不知道人们是否明白 是否当真 是否心甘情愿 是否早已腐烂 是否早已过期 每一次 都事无巨细 照旧节省 照旧浪费 照旧心疼 每一次 都要 面面俱到

总是 担心着找不着媳妇 老青年的心病 在中国社会上 孤独是可耻的 国家的套间 只分配给成双成对者 人生的另一本护照 通向婚姻的小人国 东市置家具 西市照合影 北市买棉被 南市配音响 从此 他有恃无恐 可以继续做人 堂堂正正地做人 聚精会神地做人 紧紧地奔着他的新娘子 像是牵着一只可以耀祖光宗的孔雀 来见父老乡亲来见同事朋友 来见

\section{7}

Figure 7.2. Small type: a page from «Event: Wedding» (Yu 2004a: 337) 
«Event: In Search of Bleakness» is the first of a few dozen poems from the 1990s and since that combine long lines with the regular insertion of blanks, thus constituting what is the most typical form of Yu Jian's poetry. What does this form do? In addition to things like the "clean" or "bare" feeling of texts without punctuation marks, what is the effect of the blanks, in comparison to their function in Yu's earliest work and in relation to the exceptional line length in his later work?

One possibility that comes to mind is that in his later work, Yu Jian uses blanks where he might previously have used line breaks. Technically, this is plausible enough, in that it would be the replacement of one kind of break by another. By way of an illustration, let's make a few such replacements in a passage from «Luo Jiasheng»:

during the "cultural revolution" he was chased from the plant

in his trunk they'd found a tie

when he came back to work he was still riding his old bicycle

luo jiasheng had quietly married without inviting anyone and at forty-two become a father

If carried through, this rewriting of «Luo Jiasheng» would substantially reduce the number of lines in the poem. With Yu Jian's gradual lengthening of line, however, the number of lines doesn't go down and indeed tends to go up - as does the total number of words per poem, almost exponentially. It doesn't matter which was first: the poet's active appropriation of a bigger space to fill with words, or the opportunity to use more words per poem that came with the decision to lengthen the line.

Expansion on the level of the line highlights another possible interpretation of Yu Jian's typographical development. This is closely linked to the feeling, explained in chapter Six, that the individual lines in «File 0 » would prefer not to be broken at all, and would rather be one endless, circular line instead. Seen in this light, we may take Yu's long lines, or perhaps we should say his wide lines, as a compromise. The fundamental component of most poetry that is the line is pushed to its limits, but Yu retains the right to decide where it eventually breaks. The alternative would be for him to pour that one endless line into the space available on each page and have the typesetter or the word processor wrap it rather than break it himself, which would make his work - certainly the longest poems - more unambiguously like prose poetry. But with lineation, too, the sheer length and width of 
his big poems make them visually massive. More generally speaking, as is true of Yu's verse-external poetics, his big poems come across as positively wanting to be there and appropriating discursive territoryin contradistinction to the work of that other famous Colloquial poet, Han Dong, whose writings in both genres may be characterized as exercises in disappearance. Yu Jian, quite literally, has a lot to say and tends to fill his pages in a way that leads to association with physical stacking and storage. The reader will recall the «Inventory of Objects» in «File 0 ».

How do these things lead to a relation of form to objectification and the broader category of irony in Yu Jian's poetry? The answer lies in the physical experience of conventional punctuation marks on the one hand and blanks on the other. Commas and full stops, and to a lesser extent (semi-)colons, question marks and exclamation marks, are unspoken accessories to what we might call the words themselves, which can decelerate and terminate the physical momentum of these words. Witness the influence of punctuation marks on intonation, timing and rhythm in reading aloud - and in the "silent," inward-aural experience of those things that takes place when we read without orally reproducing what we see on the page. By contrast, the absence of conventional punctuation marks forces the reader to continue moving without being able to stop, or to land, so to speak.

How are the poems under scrutiny different in this respect from texts without any punctuation at all? Without the blanks, the earliercited two lines from «Event: Conversation» would read

\section{十一点整这是通常分手的时间规距大家都要睡觉 雨是次要的再大的雨都要回家走掉了}

it's eleven sharp this is a normal time for parting the rules say we must all get some sleep

the rain is secondary even if it rained any harder they'd still have to go home gone now

One difference is that unpunctuated text has added potential for syntactic ambiguity, certainly in Chinese, and indeed for ungrammatical readings. If such problems - if that is what they are - do not seem acute in the above example, we should bear in mind that our reading is guided by the memory of these two lines and their translation with the blanks. 
More important, however, is the rushed feeling that unpunctuated text exudes. In poems that are punctuated by blanks, the absence of conventional punctuation precludes the coming to a halt of the words themselves, and hence their closure and reification; but the blanks also function as moments that invite reflection. If unpunctuated text is breathless, then blanks in a text without conventional punctuation marks are places to hold one's breath. They offer space for a literal distancing from the words and, of course, suggest pauses in the reading process, whether silent or aloud; but without conventional punctuation's effect of decelerating and terminating the words' momentum, such as in the falling intonation triggered by the anticipation of a full stop. The reflection that can take place during the blanks is of a kind that disallows or discourages the reader from interrupting the flow of reading, from landing: it is unresolved and irresolvable.

Crucially, in its unwillingness to reify the words, the materiality of the poem leads the reader to suspect that its surface is dissimulative in nature, and that any defamiliarizing ignorance it may display - of hierarchies of the lofty and the lowly, and conventions of social intercourse, for instance - is feigned ignorance. The typical Yu Jian form, then, challenges readers to mobilize their thinking and to open their minds, just as these poems are open-minded or pseudo-naive vis-à-vis the world as we know it, or think we do.

There are two final points that support this analysis. The first is that the peculiar form of Yu Jian's poetry has an appreciable effect on its reciters, both the poet himself and others who read his work aloud, such as students in the classroom and those who read translations of his work at literary events outside China. In my experience, its reciters immediately identify the blanks as requiring special recitative treatment, and tend to sustain an "unnatural," more or less level pitch that rarely descends to a "natural," sentence-final low. As a result, their recitation comes across as questioning and searching, and resisting the intonational urge toward conventional pitch patterns - and, toward conventional perception and interpretation in the broad rhetorical realm. This reinforces the mechanism of objectification, both as defined at the start of section 1 and as a particular type of irony.

Secondly, our examination of what I have called the most typical Yu Jian form brings to mind a remarkable moment in «File 0 » that was flagged in chapter Six for its disruption of the poem's overall rhythm. 
That the poet is conscious of the effect of both the blanks and their sudden removal is evident in this passage: ${ }^{28}$

deficiencies: does not like physical education sometimes whispers in class does not regularly brush his teeth

note: report to teacher he picked up a penny on the street did not give it to uncle people's policeman

comment: this student's thinking is fine but he's no talker who knows what's on his mind

it is hoped that his parents will examine his diary report to us as necessary to coordinate the upbringing

self-criticism: on 2 november 1968 did a bad thing

$i$ drew a tank on a wall on a clean white wall on a public wall on everybody's wall on a collective

wall was drawn a great big tank by me $i$ perpetrated the crime of individualism must make a determined effort to mend my ways

The final two lines are the first of a mere handful in over 300 that contain no blanks. Notably, they are also the only two in the entire poem that contain the first-person singular pronoun 我 'I.' And whereas the second half of the second line-i perpetrated the crime of individualism must make a determined effort to mend my ways - is especially ironic in its employment of politically correct, formulaic language, the preceding description of the "bad thing" works differently. Many of the modifiers in $i$ drew a tank on a wall on a clean white wall on a public wall on everybody's wall on a collective wall was drawn a great big tank by me do occur in the official discourse that $\mathrm{Yu}$ Jian is in the habit of parodying. But at the same time, in their exasperated, breathless succession, these phrases come across as a non-reflective burst of deeply involved, individual excitement or anger that has no time for blanks.

The typical $\mathrm{Yu}$ Jian form is an icon of objectification on the content level, and the effectiveness of the mechanism of objectification hinges on this iconicity. These things are essential to a poetic oeuvre that is of striking originality, within the framework of Chinese literature and beyond - and worth a Collected Works while the poet is alive and continues to write.

${ }^{28}$ Yu Jian 2004b: 31-32. 


\section{NARRATIVE RHYTHM, SOUND AND SENSE: SUN WENBO}

As a distinguishing characteristic of poetry, the synergy of form and content has come up more than once in the preceding chapters. It features again in this chapter, now with attention to narrativity (叙事性) in the work of Sun Wenbo (1956). Critical discourse to date presents narrativity as an important trend in Chinese avant-garde poetry in the 1990s, contrasting it with lyrical trends in the 1980s, but it has focused on content and had little time for form.

A native of Chengdu, Sun began to write in the early 1980s and was recognized as a distinct voice within the avant-garde in the early 1990s. Since the mid-1990s he has spent most of his time in Beijing. His track record includes many journal and book publications, frequent citation in domestic criticism and invited readings abroad. He is one of those whose work has been anthologized in the Blue Star Poetry Treasure House series, discussed in chapter Seven. Invariably associated with Xiao Kaiyu's and Zhang Shuguang's poetry but also akin to that of Wang Jiaxin, Sun's work is characterized by a relative paucity of imagery, a thoughtful mood and a forceful, flowing tone. On the scale from Elevated to Earthly, Sun, Xiao and Zhang display a greater affinity with the former than with the latter, although all three make room for "realist" representations of the quotidian in their writing.

Their style has been invoked by critics such as Hong Zicheng, Cheng Guangwei, Li Shaojun, Tang Xiaodu, Luo Zhenya and Wei Tianwu - and by poet Xiao Kaiyu in his capacity as a critic - to help identify a so-called Poetry of the Nineties, a contested notion briefly mentioned in chapter Two. Aside from its particular, controversial usage in the Popular-Intellectual Polemic, which we will examine in chapter Twelve, an oft-cited feature of Poetry of the Nineties is that of narrativity. The concept of narrativity has been stretched to fit a mixed bag of texts, but one can see how it applies to the poetry of Sun, Xiao and Zhang, and how it led to their labeling as Narrative poets in the mid-1990s, with Zhang generally recognized as having pioneered the

(C) MAGHIEL VAN CREVEL, 2008 | DOI 10.1163/9789047442738_009

This is an open access chapter distributed under the terms of the Creative Commons AttributionNoncommercial 3.0 Unported (CC-BY-NC 3.0) License. 


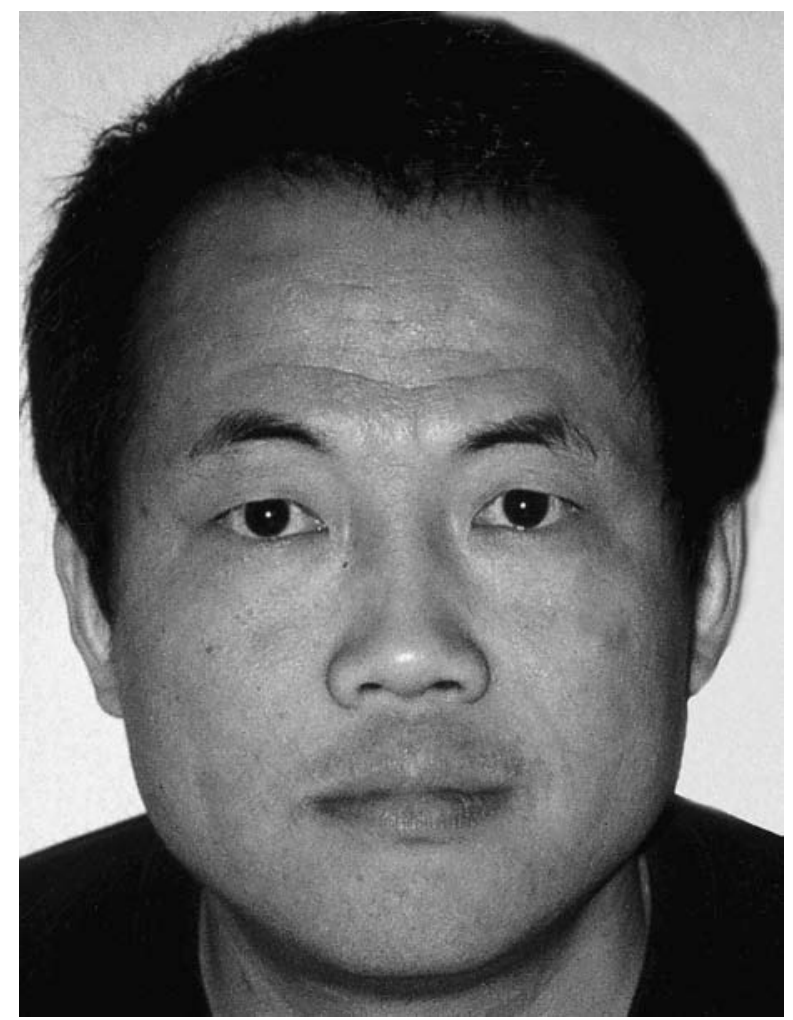

Figure 8.1. Sun Wenbo, 2000 (photograph by Maghiel van Crevel) 
narrative style in the late 1980s. As is true of the other angles adopted in the case studies in this book - exile, indeterminacy, objectification and so on - this chapter's focus is not meant to reduce the poetry under scrutiny to one-dimensionality. On that note, John Crespi comes to Sun's poetry and that of Yu Jian from the opposite direction, by asking how poetry provides non-narrative ways of remembering the Cultural Revolution - non-narrative when compared to the typically narrative genres of fiction, memoir and film, that is. ${ }^{1}$

It is perhaps unsurprising that critics have discussed narrativity in the oeuvres of Sun, Xiao and Zhang with near-exclusive reference to content. In a narrow, common sense, narration means the construction or the telling of stories. This easily leads to association with paraphraseable aspects of the literary work rather than things like the materiality of the poem's language. As such, the concept of narration is wont to direct the reader toward content-again, in a narrow, common sense - rather than to form, and in practice toward the poem's plot, to consider "what the poem says" or "what happens in the poem." Moreover, Xiao Kaiyu, metatextually the most vocal of the Narrative poets, has encouraged such thinking in his explicit poetics. While the trend from what to how identified in chapter One has had its advocates throughout the avant-garde textscape ever since the balance shifted from the message to the medium in the mid-1980s, Xiao holds that contemporary Chinese poetry's predicament is in fact summed up in the question of what to write (写什么), and that this takes precedence over the question of how to write (怎么写). ${ }^{2}$

To be sure, there is a clear content side to the narrativity of Sun's, Xiao's and Zhang's poetry. Yet, it is high time for attention to the possibility that the narrative character of their work, defined as its resemblance to the telling of a story, is also realized by something else than paraphraseable content. How is this poetry narrative? This question is prompted by Sun Wenbo's «The Program» (节目单, 1994), a long

${ }^{1}$ Most published sources cite 1959 as Sun's year of birth. This inaccuracy stems from biographical notes accompanying his poetry in the Hong Kong newspaper Thumb (大拇指) of 15 July 1986 (see Sun 2001b). Sun 2001a, Xiao Kaiyu 2004 and Zhang Shuguang 1998 are substantial collections of Sun's, Xiao's and Zhang's work; see Van Crevel 2008a for others. Hong 1998, Cheng Guangwei 1997a, 1997b and 1998b; Li Shaojun 1998, Tang 1999, Wang Guangming 2003: 632-636, Luo Zhenya 2005: 172-188, Wei 2006: ch 5, Xiao Kaiyu 1997a and 1997b. Crespi 2007a.

2 Xiao Kaiyu 1997b: 97. For an outline of Xiao's, Sun's and Zhang's views on narrativity, see Cao 2002: 299-303. 
poem that is representative of Sun's writing at its strongest. «Sequel to the Program» (续节目单, 1999), for instance, fails to meet the standard set by its predecessor in terms of narrative complexity, interpretive space and acoustic quality. ${ }^{3}$

As a preliminary to the analysis, section 1 draws attention to the phenomenon of content bias. Section 2 submits that while «The Program» derives content narrativity from the sophistication of its plot, it simultaneously realizes poetry's lyrical potential through its use of apostrophe. In section $3 \mathrm{I}$ argue that crucially, narrativity in «The Program» is not just of the content kind but is generated in synergy with the poem's sound and its visual appearance on the printed page. This happens on two levels: that of objectifiable formal features and that of rhythm, less objectifiable but no less relevant. Section 4 shows how the notion of narrativity employed in 1990s criticism can be seen to reinforce content bias as it has been conditioned by the particular context of modern Chinese poetry at large.

\section{Content Bias}

As noted in chapter Five, the inseparability of form and content doesn't justify their equation, nor does it detract from the usefulness of their distinction for examining poetry. As Veronica Forrest-Thomson writes in Poetic Artifice: A Theory of Twentieth-Century Poetry: ${ }^{4}$

Too many literary theorists have taken [the observation that form must support content] to mean that form and content are fused in such a way as to make it impossible for us to distinguish levels in a poem or to find it good on one level though ill on another. If form must support content, it is no less necessary ... that content should support form . . . [Form and content] must be different, distinguishable, in order that their relations may be judged.

Among the countless definitions of poetry, of special interest to us here are those that address the dynamic relation of form and content, of sound and sense. One such definition is proposed by Derek Attridge, with characteristic attention to what he calls the physical stuff of language: ${ }^{5}$

\footnotetext{
3 Sun 2001a: 219-222 and 256-259.

4 Forrest-Thomson 1978: 121.

5 Attridge 1981: 228, 244.
} 
Poetry represents not a minimization of the arbitrariness obtaining between signifier and signified, as a semantically oriented approach to verse would imply, but an enforcement and exploitation of it: our rush for meaning is impeded, and we are obliged to acknowledge the independence and value of the linguistic properties we are usually so eager to leave behind.

The work of Amittai Aviram addresses similar issues, albeit from a very different perspective: one that is particularly useful for the present analysis, as we shall see below. Aviram defines poetry thus: ${ }^{6}$

A poem . . . . is an utterance designed to draw the reader's or listener's attention simultaneously in the opposed directions of mere sound and meaning, and thus to afford a sustained feeling of tension.

Sections 2 and 3 of this chapter travel in these opposed directions, section 2 in that of meaning and section 3 in that of sound-and of vision.

As Aviram points out, while rhythm is central to the poetic experience, it is often neglected in criticism. For one thing, this is because it is far from evident how rhythm can be verbalized. More generally, disregard for rhythm and other elusive formal qualities of the poem can be traced to insufficient sensitivity and indeed indolence in poetry reading, acquired in the referentially driven culture of schools and universities, and to the phenomenon of content bias at large. By content bias I mean disproportionate attention to paraphraseable parts of the poem, to what may appear to be a straightforward, semantic message that can be re-told with impunity. ${ }^{7}$ By way of an example, let me recall that a content-biased translation of Yu Jian's lines 打开烟盒 打开嘴 巴 // 打开灯 would read open our cigarette cases open our mouths / / turn on the light, instead of open our cigarette cases open our mouths // open the window. My rendition of 灯 'lamp' as window stems from the conviction that in this case, retaining the repetition of 打开 'open' in three grammatical phrases in current English usage is infinitely more important to the realization of the text qua poetry than any semantic "faithfulness" on the level of single lexical items. If this comes across as form bias, let me reiterate that I subscribe to the position that in poetry, form is of the essence. This doesn't mean that every question we ask

\footnotetext{
Aviram 1994: 51.

7 Aviram 1994: 54-57 et passim. On content bias, cf Frye 1973: 77, Forrest-Thomson 1978, Attridge 1981, and Zhang Longxi 1992: 179.
} 
of poetry must be to do with form, but it does mean that we should realize which of our questions require answers that give pride of place to issues of form.

For formal poetry, the adverse effects of content bias are obvious. Content bias would, for instance, reduce Li Bai's time-honored if overexposed «Thoughts on a Quiet Night» (静夜思) to a Tang-dynasty description of a traveler's melancholy. If this poem's semantics are less than spectacular, violated as they are by their extraction from its formal levels of operation, this only helps to prove the point. By way of another Chinese example, this one from the early modern era, Wen Yiduo's «Dead Water» (死水) would amount to no more than national-allegorical musings on stagnancy and rot, in disregard of the dramatic tension generated by the contrast with the poem's well-formed appearance. Such informationalization of literature begs the question of form. Why did these poets go to the trouble of coining metrical phrases of equal length containing rhyme, parallelism and so on, to begin with? Or, conversely, can the content of their work be considered without taking into account its emphatic formal qualities - does it even exist without these qualities? In one of Forrest-Thomson's illustrations of a reprehensible type of criticism that she calls "bad naturalization," why didn't Eliot just say "Life seemed so futile" instead of writing «The Waste Land»? Moving closer to our own time and faced with contemporary Chinese poetry's overwhelming inclination toward free verse, «The Program» being a case in point, we may invoke Eliot the critic to caution that no verse is free for the one who wants to do a good job. ${ }^{8}$

Content bias is partly explained by the fact that semantic paraphrase provides a seemingly easy and unconstrained way of talking about poetry, an activity that becomes notoriously difficult as soon as it ventures beyond the safe confines of mere rewording. ForrestThomson makes a frontal assault on content bias, in her attempt ${ }^{9}$

to talk about the most distinctive yet elusive features of poetry: all the rhythmic, phonetic, verbal, and logical devices which we may group together under the heading of poetic artifice.

She takes the issue further by claiming that it is precisely those aspects of poetry that are most difficult to talk about that most clearly mark

\footnotetext{
8 Forrest-Thomson 1978: xi, 133 et passim. Eliot 1990: 37.

9 Forrest-Thomson 1978: ix.
} 
it as poetry - and by proceeding to write an inspiring study that reaffirms the value of the second voice, in the words of Tonnus Oosterhoff, cited in chapter One. Cross-cultural and cross-linguistic literary scholarship, insofar as it is of a translatory nature in the broadest sense, and certainly as a part of Area Studies - talking in language X about poetry in language $\mathrm{Y}$, talking in culture $\mathrm{X}$ about poetry in culture $\mathrm{Y}$-is especially prone to content bias, but intra-cultural and intra-linguistic scholarship by no means guarantee due regard for form either.

For modern Chinese poetry, content bias is aggravated by the interference of history and politics in Chinese cultural life. The twentieth century brought social upheaval, ranging from war and revolution to starvation and the horrors of totalitarian rule. Coupled with the sociopolitical engagement of the traditional Chinese poet and the importance that Chinese rulers have attached to literature through the ages, be it as censors or as sponsors, this situation has reinforced visions of the literary work as the reflection if not the logical product of circumstance - and hence, as eminently paraphraseable. Consequently, domestic and foreign commentary have often treated modern Chinese poetry as rhetorically frilled social documentation, as noted in chapter Four in connection with the exile scene. Examples include Donald Finkel's and Tony Barnstone's anthologies of poetry from the PRC in English translation. Their content bias is visible in what I would like to call, after Forrest-Thomson, bad historicization of the literary text. This is particularly disturbing because they address a general audience that has no access to the original texts, contexts and metatexts, and comes away thinking of modern Chinese poetry, including the contemporary avant-garde, as primarily political in nature. There are of course counter-examples, especially in research on formal poetry, such as Cyril Birch's study of meter in Xu Zhimo and Lloyd Haft's work on the Chinese sonnet; and with regard to free verse, Peter Hoffmann's monograph on Gu Cheng. In all, however, especially research on modern Chinese free verse requires a continuing attention to the interdependence of form and content. It is in this area that the present chapter hopes to make a contribution, in line with some of the others in this study. ${ }^{10}$

${ }^{10}$ Finkel 1991, Barnstone 1993, Birch 1960, Haft 2000, Hoffmann 1993. 


\section{2. «The Program»: Content and Plot}

An aside on terminology is in order here with regard to four related words used in this chapter: content, plot, sense and meaning. Content is, according to Jaap Oversteegen, the subject matter present in a given form, or the poem's more or less paraphraseable aspects, with the constellation of its constituents intact, in the linear order of reading. ${ }^{11}$ The poem's plot is the same thing after it has been paraphrased, rearranged in the analysis and so on, and with less attention to its amplification by formal aspects. Sense is one half of the duad sound and sense, an elegant characterization of what the complex thing that is poetry has to offer, and a subset of form and content, for there is more to form than sound. In this chapter, especially in the latter half of section 3, the large and potentially vague notion of meaning functions specifically as part of Aviram's contrast of meaning and sound, cited above, and largely overlaps with content. More broadly, meaning denotes content after interpretation - and at that stage, it has also taken form into account.

Like many of Sun Wenbo's poems, «The Program» is a sizable text: 72 lines, neatly divided into nine numbered stanzas-cum-episodes. The translation below is more rigidly "faithful" to the original than its literary rendition, published elsewhere. ${ }^{12}$ My concern has been to ensure that each line contains the same word groups as its Chinese source, if possible in the same order, to let the text unfold to its Anglophone reader in similar fashion to the original. This is to do with the paramount importance of the line as an organizational unit in Sun Wenbo's work, on which I will elaborate later.

\section{"The Program»}

\section{1}

Leafing through the beautifully printed program, you see

a fiction of night: with a moon like a face ravaged by cholera.

He sits on a stone bench in the garden. Grief over the loss of his father

stirs his soul as would cheap liquor. You see

his depressed stare at the withered chrysanthemum.

When the orchestra strikes up, he starts, on the stage,

\footnotetext{
11 Oversteegen 1983: 29-31.

12 HEAT 1997-5: 144-149, The Drunken Boat 6-I/II (2006, online).
} 
to walk back and forth. He sees you. You and he know that to define positions for the actors and the audience means: confusion.

2

One step, just one step, and you have crossed the audience's line. You have even seized the main character's role.

You have taken his position now, and set foot on an avenger's road. Compared to him, you know better who the enemy is, you would almost madly shout the enemy's name. You, brandishing the sword that was once his, on the stage dash toward the highest point. You are directing the extras, wanting them to bring the enemy before you, right there you want to chop off his head.

3

Does he tolerate your behavior? He seems so dejected!

He has quietly withdrawn to a corner of the stage, his hands restlessly tugging the edge of the curtain. And the rest of the plot, how should it be handled? How will a larger scene combine with this scene to form a full-fledged act? He doesn't know now. How can the time of two hours be whiled away in only half an hour?' And there should be schemes yet, and conspiracies, betrayal, and someone's love.

4

Thereupon, time quivers in the crowd's eyes: clouds rush like mad dogs over the crowd's heads; rivers fall, revealing glossy cobbles; bats at dusk swoop to and fro 'round humming electricity lines. Thereupon, you start stating details from a book: a sentence read out loud, downcast retroflex sounds. They turn into a play within a play, on death, on a tale come back to life from death. Thereupon, 5

the crowd sees a shocking episode: on a street corner, in a busy inn, a bunch of blind-drunken soldiers are loudly talking smut. Between two of them a quarrel arises, over comments made about a woman. This leads to knives being drawn, to the inn being smashed up as they fight. In this madness, all those present lunge into tangled warfare. And people die. Just how satisfying is this smell of blood?

The audience is watching, wide-eyed and trembling with fear. 


\section{6}

And the sentimental are now sobbing. And a bereft

woman has now fainted in her seat. Time seems

to glide to one side now. You seem to walk into another life now.

"Daytime cities, let them vanish like froth.

Rise, rise. But not rise like steam, no,

rise like a rocket, screaming and in flames."

You are satisfied with those sobbing; as for the ones that have fainted, them you curse: you frail souls, what good is it that you exist?

\section{7}

Well what about him?' He has left, in a gloomy state of mind. He has entered an out-of-the-way side street of reality. Under pale yellow streetlights, he walks with lowered head. Above his head, the wind makes noises, like a thiefjiggling the edge of a roof. $\mathrm{He}$

knows that to quit this time means to quit forever. A man, how could he spend a lifetime inside a play? Props for wine will not resemble wine for long. As he turns and strides into a small wine shop, he shouts: waiter, bring out the wine.

\section{8}

Oh, but you're drunk with being on stage. Tou're like the crown prince who sees the throne unoccupied. At this moment, what your eyes

see is a scene happier than paradise: all of the

extras are like stage props in your hand. You fiddle

with them, as if fiddling with pencils. Chairs and tables talking?

You make the chairs and tables talk. Can walls and trees walk about? You make them look like leopards on stage, and walk about. "The stage in its greatness is a gorgeous dream."

\section{9}

But you, how will you make the final curtain fall? One climax after another has not just spurred feverish waves in the hearts of the audience, but also pushed you to the center of excitement. In their eyes, all you see is the glint and flash of knives and swords. The music keeps working to construct a splendid future. Bread-like swollen desire makes you reach out your hand time and again. You have forgotten yourself, and forgotten him. You have become a usurper. You now think that whatever you lay hands on is just that. 
«The Program» comes to us in the words of an omniscient speaker, whose critical distance from the poem's protagonists is clearest at the midpoint (stanza 5: line 7, Just how satisfying is this smell of blood?') and in the poem's final three lines (You have forgotten yourself, and forgotten him ... You now think that whatever you lay hands on is just that). There are two main protagonists: you and he. On level one in the diagram overleaf, you reads the program of a theater play featuring $h e$. Subsequently, on level two, you enters into the play and into interaction with he, forcibly taking his place (1:7 and 2). Within the play embedded in «The Program», you creates (4:5-7) another play (4:8 and 5:1-7). Within this innermost text on level three, the encounter and the struggle on levels one and two between you and he find a parallel in a fight between two soldiers. This could generate a reading of their blind drunkenness and talking smut on the stage as metaphors for theatrical and hence for literary usage, backed up by the observation in stanza 8 that you is drunk with being on stage. More pertinent to the present interpretation is the expansion of the said parallel by the audience's (all those present) engagement with the actors (the two soldiers). This is precisely what has happened in stanzas 1 and 4, with you initially as part of the audience. After the pivotal interjection of the play-within-the-play in stanza 5-halfway through the text, at its core - it is also what continues to happen in stanza 6 . But now you is an actor, and indeed the director and judge of both play and audience.

In the diagram, italicized words are literal quotes from the poem. The outer circle contains «The Program», the middle circle contains the play embedded in the poem, and the inner circle contains the play-within-the-play, created by you in the process of usurping him and becoming he. Arrows indicate (inter-)action that results in a change of status or identity; double lines, projection from one level onto another.

As we read on in the poem's time toward its final lines, we are on our way back from the inner to the outer shells. This movement doesn't stop at the text's boundaries. You is severed from previous identities of you and he and their relationship, and what you has usurped (9:8) is arguably he. You, who started out as an audience, has become he. He, who started out as an actor, is thrown off the stage into reality, which might also mean that he is pushed over the poem's edge. At the same time, the poem suggests that - from outside its textual boundaries- 


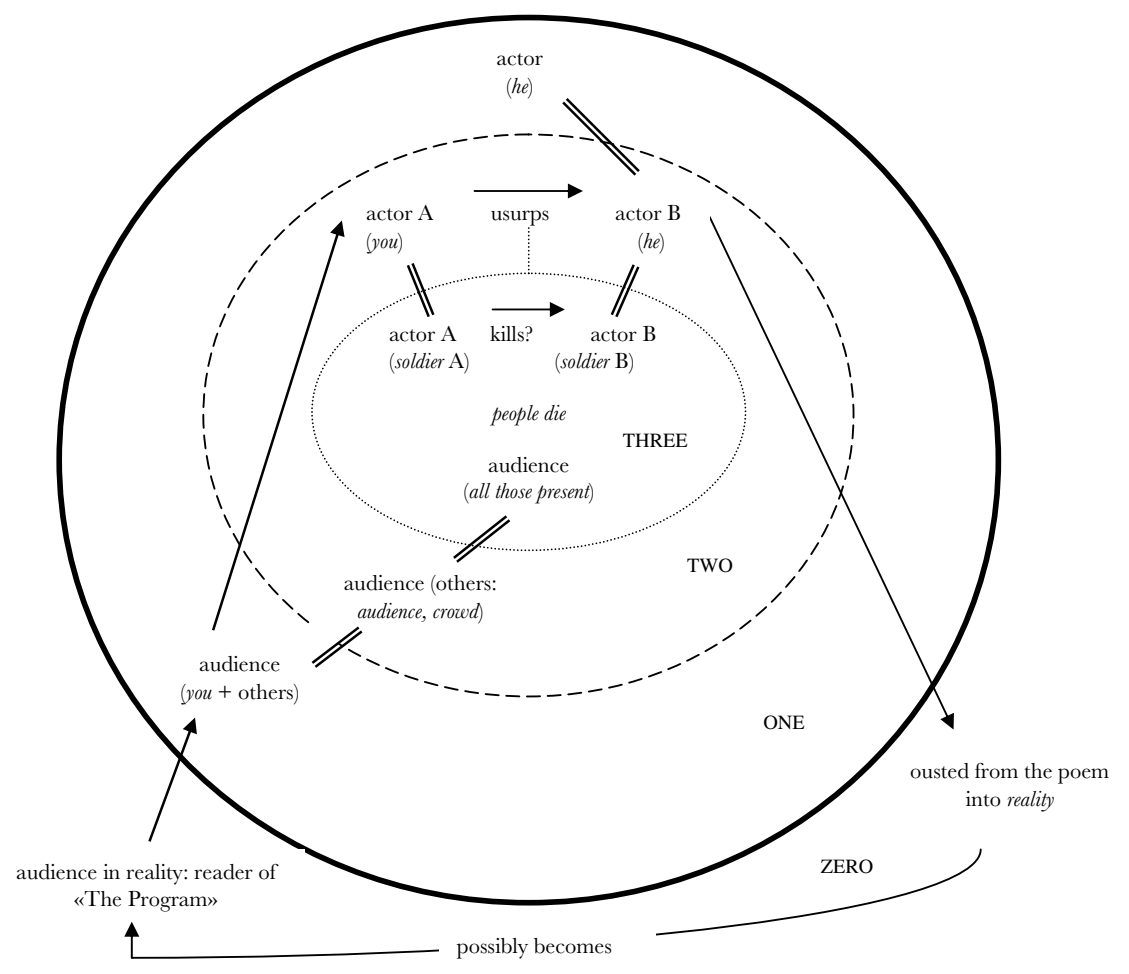

Figure 8.2. «The Program»: Content and Plot

you, reader of «The Program», take the place of you, protagonist and reader of the beautifully printed program (1:1), and are drawn into an eerie if not grotesque and violent event. The play-within-the-play and its aftermath, for example, show that terrible things befall the audience. When the poem is next read, the process starts anew. The reader will become you, you will become he, and he will be ousted. Notably, in a side street of reality, he might become you, the poem's next reader. «The Program» —or, the program - continues endlessly and relentlessly, going around in circles, cyclical and resonating in itself as poetry does.

The namelessness of the oft-repeated personal pronouns suggests that they represent ineluctable, inherently repetitive patterns of social interaction rather than moments that involve individual choice. This impression is reinforced by emphatic repetition on the level of form, 
as we shall see below. It is as if these mechanisms become operational as soon as the next person - including an "innocent" reader - appears and is slotted in. In the abstract, then, «The Program» is also about interpersonal, social roles and their transgression and rotation (crossing the audience's line, taking somebody else's position, entering another life, entering reality): from reader to protagonist, audience to actor, actor A to actor B, inside the play to outside - and possibly back in again. These roles include the categories of subject and object, with he the subject acting upon you the object, and you the subject making he the object of the audience's gaze.

But there is another dimension to the interpretation of the poem's protagonists. Throughout stanza 1 and in the poem's closing sentence, the second-person protagonist you suggests identification with the reader-narratee. This highlights the sophistication of the poem's plot and its content narrativity. Most occurrences of you, however, are manifestations of apostrophe, a mechanism whose centrality in the lyrical-poetic experience has been established by Jonathan Culler. That is, they address a second person that is not the reader, with the poet "turning his back on his listeners"-reflecting the Greek etymology of apostrophe - and being "not heard but overheard," in the words of Northrop Frye and John Stuart Mill. ${ }^{13}$ By the discursive temporality of the here-and-now of the address, as opposed to that of narrated time, these occurrences of you draw attention to the poem as an event, as a speech act, and to its lyrical qualities. A dual identity of you as both reader-narratee and the addressee of the apostrophe is by no means excluded, for example in its first and last occurrences (1:1 and 9:8). In the closing sentences of stanza 1 and the opening of stanza 2, you can be seen to change gradually from the reader-narratee into the addressee of the apostrophe. You remains so through stanza 8 and some way into stanza 9. Only there does the reader-narratee resurface, flustered and set off against the speaker's cool-headed distinction between reality and make-believe - or, between real life and the theater - that takes us back to the start of the text. The overall picture, then, is of two distinct but inextricable identities of you. Their duality doesn't subvert the poem's content narrativity in itself. On the contrary, it heightens narrative acuity by reminding us of the lyrical in the middle of the nar-

\footnotetext{
${ }^{13}$ Culler 1981: ch7, Frye 1973: 5 (Mill citation), 249-250.
} 
rative. This thematizes the text's very status as a poem, making it poetry about poetry, or an outstandingly poetical text: it says what it is.

\section{3. «The Program»: Form}

As with most other poems, the primary formal feature of «The Program» is its sound, but its visual appearance merits attention too. Indeed, we shall find that the poem's overall formal effect hinges on the interaction of the acoustic and the visual.

\section{Objectifiable Features}

«The Program» has nine numbered stanzas of eight lines each. The identical size of its component parts is typical of large parts of Sun Wenbo's oeuvre. A striking example is his «Narrative Poem»(叙事 诗), in 23 stanzas, also of eight lines each. ${ }^{14}$ In «The Program», line length varies from 13 to 18 characters. All nine stanzas end in long lines and all but the first two begin with long lines - in the original more clearly so than in the translation - which gives them a cyclical feel. For a narrative poet like Sun, we should remind ourselves that the poet determines where the line ends, not the typesetter. This presents one of several interfaces with the analysis in chapters Five, Six and Seven, another being that while Sun's «Narrative Poem» is almost three times as long as «The Program», both texts far exceed the single page and fail to meet Gerrit Krol's poetic criterion of viewability at a glance. On the whole, as an orderly line-up of robust blocks of writing whose width exceeds their height, «The Program» looks solid and regular if not monotonous, repetitive and long drawn out. There is a patient insistence about the look of «The Program» — and, as we shall shortly find, about its sound.

How does «The Program» sound? Like much contemporary Chinese poetry in more or less free verse, it has no structural rhyme to speak of, be it end rhyme, internal rhyme or alliteration. The poem does, however, employ the device of repetition to considerable effect. Stanza 4, for example, begins with thereupon, ends with thereupon and literally hinges on thereupon, as the first word of its second half. The crowd's

14 Sun 1997: 109-118. 
eyes (人们的眼睛 rénmen de yănjīng) resonates in the crowd's heads (人们 头顶 rénmen tóuding). We can read the asymmetry (no 的 in the latter) as the conscious avoidance of monotony or as indicating that the text has little regard for detail in this respect. Repetition also occurs on the level of syntax. Each of the stanza's first three lines ends with a noun phrase ushering in a new sentence (clouds, rivers, bats), standing out because of its position between a punctuated pause and a line break. The focus of the present analysis requires a slight terminological adjustment as compared to chapter Five: here, a sentence is defined as (implied) noun phrase + verb phrase, so that it can end on a comma or a (semi-)colon. The effect of the noun phrase in line-final position depends on the poem's manner of recitation, for there are sharply different ways of acoustically negotiating enjambment - and on its being visually read, that is: seen, in addition to being heard. Easily the most effective instance of repetition throughout «The Program» is that of the singular pronouns you and he as the first word of a sentence or a line. Section 2 has shown the importance of these pronouns from the viewpoint of content. Excluding pronouns that don't refer to the protagonists, there are as many as 38 cases. Their density is highest at the poem's start and end, and lowest in its middle third (stanzas 4-6), in the play within the play.

After rhyme and repetition, let's now turn to meter, meaning the regular arrangement of stressed and unstressed or long and short syllables into fixed patterns such as feet. At this point, it won't surprise the reader that «The Program» displays no strict meter. Nevertheless, a look at stress patterns in the text is worth our while. Here is stanza 1 in transcription, with stressed syllables underlined:

Fān-käà yìn-zhì de jēng-mě̀i de jüé-mù-dān, ň̌ kàn-jian

yi-ge xu- -gòu de yè-wăn: yuè-liang xiàng huò-luàn bìng-rén de miàn-kòng.

$\underline{T a}$ zuò zai huā-yuán de shí-y̌̀ shàng. Shì-qu fû-qin de bè-i-shāng

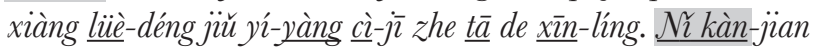

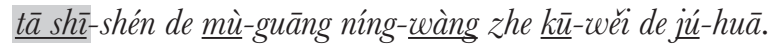

Dāng bàn-zòu de yuè-qǔ xiáng-qŭ, tā käă-shř zài weǔ-tái shàng

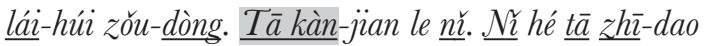
yăn-yuán hé guān-zhòng de wèi-zhí de què-ding, yì-wèi zhe: hùn-xiáo.

In assigning stress, I have worked along the following lines. A toneless second syllable in a compound word is unstressed: e.g. jian in kàn-jian, 
liang in yuè-liang and dao in zhì-dao. ${ }^{15} \mathrm{~A}$ fourth-tone second syllable of a compound word with a first syllable in second or third tone is stressed: e.g. yàng in yíyàng (with yí realized in second tone through tone sandhi), wàng in ning-wàng and dòng in zǒu-dòng. Stress is assigned with attention to syntactic sentence structure rather than lineation: $y i$ in line 2 remains unstressed. Stress within the sentence is relative: xiang in lines 2 and 4 and dang in line 6 remain unstressed. This may appear problematic, for where does one draw the line? But if we agree that calling all but the toneless syllables stressed would defeat the purpose of the exercise, minimal regard for prominence and said special cases results in a pattern of six to eight mostly trochaic and dactylic feet per line.

Notably, exceptions occur in six places spread evenly through the stanza, highlighted in the above citation. All mark the beginning of a new sentence, as defined above, in a monosyllabic pronoun ( $n \iota$ ' 'you' and $t \bar{a}$ ' $h e$ ') immediately preceding the stressed first syllable of another

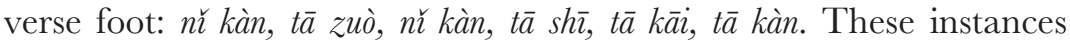
of stress on two consecutive syllables add effective syncopation to an overall rhythm that can be traced throughout the entire poem. Form and content-interaction of the poem's protagonists, you and he, as well as thematization of the dual identity of you - iconically connect and reinforce one another.

In Mysterious Music: Rhythm and Free Verse, Burns Cooper submits that rhythm is essentially a perceptual and therefore subjective but not an arbitrary phenomenon. Its perception may to some extent be culturally and linguistically determined. I will not speculate on similarities and differences between perceptions of «The Program» by native speakers of Chinese, non-native speakers of Chinese and people who don't speak Chinese, and merely observe that my analysis of the written text is supported by Sun Wenbo's recitation, in my non-native Chinese perception. ${ }^{16}$

As regards phrase length, with the phrase defined for present purposes as what lies between any two punctuation marks - which is not necessarily a noun-verb sentence - Sun strictly follows the written text, audibly pausing at each punctuation mark and nowhere else. Disregarding lineation, his recitation yields the following sequence of phrase length

\footnotetext{
${ }^{15}$ In addition to Sun Wenbo's recitation, I go by DeFrancis 1996, in light of this work's primary concern with true-to-life transcription.

${ }^{16}$ Cooper 1998. 1998 Rotterdam Poetry International festival.
} 
in characters $=$ syllables in stanza 1: 11-10-10-9-20-17-8-11-5-16-3-2. If we do take lineation into account, the longest phrase has 14 characters. The stanza-final phrases of five, three and two characters are conspicuous in their brevity. Combining the character count and punctuation patterns with the stanza's syntax, we find that of these three, the middle one is closely linked to the preceding 16-character phrase, justifying emphatic pauses around the five- and two-character phrases in lines 7 and 8. Again, there is a connection with the poem's content, in that both phrases, he sees you and confusion, have a high specific gravity in the stanza. This connection is reaffirmed if we include short phrases with line breaks instead of punctuation as their right boundary, in lines 2, 4 and 7. In linear order, the short phrases build a content skeleton for the stanza and the poem: you see [the scene] . . y you see [him] ... he sees you ... you and he know ... this means . . confusion.

We have noted that Sun Wenbo employs enjambment. In this respect, as in others, «The Program» is representative of large parts of his oeuvre. Only a third of the line breaks in the poem coincide with the completion of a sentence, always marked by punctuation. For all line breaks in the other two thirds of the text, from the viewpoint of syntax we must read on. There are three degrees of enjambment. The first, accompanied by punctuation (nine cases), is that exemplified in lines 5-6 of stanza 2: You, / brandishing the sword. The second degree of enjambment (27 cases, or more than one third of the full text) is seen, for instance, in lines 1-2 of stanza 1: you see / a fiction of night and in lines 7-8 of the seventh: strides into / a small wine shop. The line break interrupts the sentence, but respects the integrity of noun and verb phrases. We find enjambment to the third degree where the line break also cuts through the middle of a (compound) noun phrase or verb phrase (12 cases), as in lines 1-2 of stanza 2: the audience's / line and lines 3-4 of stanza 5: a quarrel / arises (in the original, a four-character inchoative verb compound, one word broken in two: 争吵 / 起来). Last but not least, there is a conspicuous case of enjambment bridging a stanza division (between stanzas 4 and 5): Thereupon, // the crowd sees ...

Enjambment is remarkably frequent, to where run-on lines become the default mode. As a result, end-stopped lines with breaks that coincide with the punctuated completion of a sentence gain in emphasis and finality, a typical example being the poem's last sentence and closing statement: You now think that whatever you lay your hands on is just that. Conversely, sentence-final lineation is systematically undermined. 
The narrative character of Sun Wenbo's work - in contradistinction to its lyrical elements - thus partly derives from enjambment, that is: from one of this poetry's formal features. The poem sounds like a story, quite aside from the sense we have made of it in section 2. As above, we should note that for its effect, it hinges on the text being seen and preferably heard at the same time, in the reader's voice or someone else's. This is less so for poetry with sentence-final line breaks, for example that of Ouyang Jianghe; and for poetry without line breaks, such as that of Xi Chuan.

Objectifiable formal features of «The Program» show that content aside, the oft-cited narrativity of Sun Wenbo's poetry is generated by its look and sound, as well as their interaction in near-ubiquitous enjambment. We will return to the role of enjambment in a discussion of the relation between rhythm, sound and sense toward the end of this section.

\section{Rhythm}

With critical reference to an array of literary, linguistic and cultural theories (Jakobson, Nietzsche, Freud, Lacan, Abraham, Kristeva, Lacoue-Labarthe), Amittai Aviram's Telling Rhythm: Body and Meaning in Poetry presents a theory of poetry built on the principle of rhythm, defined as the repetition of discontinuous elements, which controls both the meaning and the sound of the poem. As noted above, to the latter one might add the poem's visual appearance, and indeed any other sensory features it may have. Poetry can then be read as ${ }^{17}$

an allegory of the sublime power of rhythm to manifest the physical world to us. It is a way of infusing words with a power that is not itself in words, a way of saying the ineffable.

If "saying the ineffable" comes under what I have called definitions through bootstrapping in chapter Six, the mobilization of rhythm makes it that much more concrete and operational.

Seen thus, poetry not only tells of unrepresentable experience but also of the impossibility of conveying such experience by way of words and symbols. One of the strengths of Aviram's argument lies in its

\footnotetext{
17 Aviram 1994: front flap et passim, esp part I.
} 
negotiation of an issue that is acutely pertinent to the study and indeed the definition of poetry, summed up in the question of why Li Bai, Wen Yiduo, Eliot and countless others went to so much trouble to write what they wrote in the particular way that they did. If poetry were merely another way of doing what prose can arguably do better-say, transmitting information, even if this includes information of the imaginative, the aestheticized, the non-goal-oriented kind-then why bother? Rhythm, then, is an origin of poetry, not an ornamental or rhetorical device attached to or even worked into a prior message. Rhythm compels affect, which triggers an attempt on the part of poet and reader to think of words and images to address it. This approach also informs Aviram's stimulating treatment of the relation between form and content or, in his terminology, sound and meaning. Here, their order is not hierarchical but ontological, and determined by the primacy of rhythm. Poetry valorizes and energizes reality by using its own material reality, its own material being-pure rhythmic sound that allows us to witness the failure of language to address the power of the very material out of which its signs are made. Notably, this failure can be realized in exquisitely crafted form and content. There is, in other words, no contradiction between the primitive power of rhythm and the sophistication and complexity of a poem like «The Program».

Here lies an interface with the discussion of poetic form in crosscultural and cross-linguistic frameworks. Building on Jan de Roder's work on the unmeaning - betekenisloosheid, what Aviram calls the meaningless or the non-sensical and Forrest-Thomson the non-meaningful-I have elsewhere suggested a definition of form that challenges content bias and the dominance of the cognitive in literary criticism and education: ${ }^{18}$

Form is everything about the poem that may be perceived by one who doesn't know the language of which the poem partakes.

With some exaggeration, one could proceed to a view of the actual realization of content or meaning as a cultural-linguistically determined aspect of poetry, on the assumption that rhythm, by contrast, is universal. We need only think of musical-rhythmic differences between, say, Indian, Australian Aboriginal and Middle-Eastern traditions to

${ }^{18}$ De Roder 1999, Forrest-Thomson 1978: xi et passim; after Van Crevel 2000: 5. 
recognize that universality of rhythm lies not in historically specific interpretation but in what Aviram calls its catchiness and in its affective access to the human body. Further exploring what is self-evident in everyday experience, the universality of rhythm is shown by association with things like heartbeat, breathing, sex, swimming-crawlingwalking-running-flying, night and day, the seasons, birth and death and so on. Incidentally, this forges a connection with the thematics of death, famously universal - that is, significant in every single culturallinguistic habitat - in the realm of meaning but equally so in that of rhythm. The reader will recall that in «The Program», death makes its advent in the pivotal stanza 5 , the play within the play, at the heart of the text.

Aviram presents his theory primarily with reference to conventionally metrical texts, ranging from classical, canonized high culture to contemporary popular forms like rap. While it may work especially well for these types of text, this need not detract from its applicability to free verse. Indeed, if in comparison to metrical poetry, free verse is closer to prose, Aviram's questions and his answers become all the more pressing. At any rate, the theory of poetry as telling rhythm can advance scholarship on free verse without claiming exhaustive or exclusive analytical power.

Returning to «The Program», we find that Sun Wenbo's poetry is not strictly metrical and employs little rhyme, but that it does display systematic, formal regularities that distinguish it from radically free varieties of free verse. Its acoustic and visual qualities combine on the levels of word group, sentence, line and stanza to produce a patiently insistent surface beat. In verse feet, lines and stanzas, acoustically as well as visually, the poem's rhythm is easily discernible, and so - albeit more cognitive and mediated - is the rhythm's manifestation in the poem's content.

To conclude this section, I will pull together my earlier remarks on the relation of form and content. First, the ineluctable repetition of interpersonal and social role patterns mirrors the poem's orderly, monotonous flow of words. From its initial affective status, the poem's patient insistence is cognitivized into a verbal representation of behavioral patterns. Conversely, the poem's calm, balanced formal features produce a stark contrast with the violence at the heart of the text. This exemplifies Aviram's definition of poetry as affording a sustained feeling of tension by drawing the reader's attention simultaneously in the 
opposed directions of sound - and vision - on the one hand, and of meaning on the other.

Second, when you and he generate syncopation, this disrupts and challenges the rhythm's surface manifestation. Subsequently this surface manifestation is time and again restored to reaffirm not just itself, but also the futility of the protagonists' efforts to take charge. For all their efforts at individual agency, they are subjected to predetermined mechanisms. Similarly, enjambment subverts the visual surface rhythm of the poem's lines, which is only disciplined in the nick of time at the end of all but one of the stanzas, including the last. Here, I invoke Aviram's observation that rather than thinking of poetic rhythm as a sign representing something, we should see it as a function that is doing something. It manifests the physical world to us and underlies poetry's knowingly doomed attempts at saying what cannot be said. One thing the text's inadequate representation of poetic rhythm can do is to register anxiety over the fact that the power of rhythm cannot be controlled - by lineation, for instance, or by division into stanzas.

Third, in the poem's content, the said role patterns emerge on different levels. Reading linearly we first move inward, from the outer world to levels one, two and three in the diagram on page 292. At this point, reading on means moving out again. Levels two and one, and level zero or the world outside the poem, are like ripples around a stone cast in water. Especially in the first stanza and the last, ever larger and more self-aware, levels two, one and zero are cognitivizing spheres sent forth by the painfully physical, central scene on level three, in the fifth stanza. The message of mortality and the rhythm of death are driven home in minimal, immediate words: people die (有人 死亡).

These are three ways in which words, including their syntax, and images in «The Program» tell of the poem's rhythm.

\section{Narrativity and Its Context}

Let's return to the question asked earlier and recapitulate our findings. The analysis shows that «The Program» has strong narrative components. Its narrative acuity is heightened by the dual identity of the second-person protagonist, setting narrativity off against lyricism and thematizing the contrast as a poetical statement. But what are the nar- 
rative components of Sun Wenbo's poetry, or how exactly is his poetry narrative? The answer opens up the full width of the sliding scale between content and form, with referential, cognitive matter at one end and non-referential affect at the other.

«The Program» has conventional story-like qualities. It ostensibly relates a chronologically unfolding course of events and their internal dynamics. One could with some justification approach the text using structuralist narratological concepts like narrator and focalization. Alternatively, Monika Fludernik's "post-classical” narratological concept of experientiality could also apply to «The Program». According to Fludernik, narrativity occurs, that is: the reader views a text as a story, upon encounter with any anthropomorphous agency that accumulates and evaluates recognizable, "real" experience and displays emotional involvement. ${ }^{19}$ Especially in modern literature, there is no reason why theory designed for one conventional genre cannot be applied to another. Still, to explore and explain narrativity in «The Program» as poetry, narratology would at best offer incomplete insights. More is to be gained from adopting Aviram's view of poetry's sensory features and its meaning as combining and interacting to tell of the power of the poem's rhythm.

Of equal importance to its paraphraseable aspects, then, the poem's essential affective impact may be gleaned in its tone and rhythm. The extension of the protagonists' audience within the text to its "outside" reader establishes a direct relationship with this reader. Narrative hues thus acquired on the level of tone are reinforced by "prosaic" diction in words like and, thereupon, now, but in sentence-initial position and by formulas like the expository this leads to and the phatic Well. As for the text's rhythm, its conventionally poetic, semi-metrical qualities are clear, but on this level its narrativity is decisively enhanced by the absence of rhyme and by enjambment in most of the line breaks. Referential matter in an abstract, neatly structured plot aside, the poem almost sounds like the telling of a story. This is no less important for its narrative status than the issues of content that have dominated the discussion of narrativity in the avant-garde to date.

Content bias in scholarship on twentieth-century Chinese poetry has its culturally and historically specific contextual reasons, previously mentioned at several points in this study: traditional Chinese ideas

\footnotetext{
${ }^{19}$ Cited in Herman \& Vervaeck 2001: $146 \mathrm{ff}$.
} 
about the poet's social responsibility, coupled with social upheaval in the modern era. The verse-external, explicit poetics of the three poets identified with Narrative Poetry in the 1990s points in the same direction. At the start of this chapter we noted as much for Xiao Kaiyu, the most systematic theorizer of the three and a champion of the whatto-write school, even though in one of the more light-hearted of his essays, he remarks on the "even pace" of the language of Sun Wenbo's poetry and - perhaps not in earnest - offers biographical explanations for Sun's characteristic rhythm as stemming from his experience as a soldier (marching), a factory worker (machines) and a city resident living close to a railroad (train wheels).

Neither does Sun Wenbo's own explicit poetics do much to dispel content bias; Zhang Shuguang is the only one who dwells, albeit fleetingly and inconsistently, on the phenomena of tone and rhythm as lying at the heart of the matter. All three emphatically situate their writing in its social context of life in present-day China, including its less than glamorous and its positively banal moments. In 1997 Xiao proposed the original notion of Transitive Writing (及物性的写作), meaning writing whose motivation and consciously limited, focused subject matter stem from personal, lived-through experience. Linked to the concept of narrativity, this has proved influential in historical and critical survey works of later years, such as those by Luo Zhenya and Wei Tianwu. These present Transitive Writing as contributing to the deconstruction of a utopian lyricism found in poetry of the 1980s, ranging from early Obscure Poetry to Root-Seeking trends and poetry as religion in the work of Haizi. ${ }^{20}$

In sum, according to Chinese poets, scholars and critics writing in the 1990s, content reflecting a real world outside the poem is indispensable. It is confirmed as such in the oeuvres of the Narrative poets. Content, however, acquires prominence and sustains it beyond a particular historical moment only if the poem satisfies Archibald MacLeish's request that A poem should not mean / But be -or, in Aviram's

${ }^{20}$ Xiao Kaiyu 1995: 158-159. Sun 1998b, 2001b. Zhang Shuguang 1999, esp 245-246; the said inconsistency is with his answer to the first two questions, on 235236. Xiao Kaiyu 1997a: 221. Luo Zhenya 2005: 172-188, Wei 2006: ch 5. 
words of similar import, if it tells of the power of rhythm, which is precisely what «The Program» and many other Narrative poems do. ${ }^{21}$ Especially in light of China's turbulent twentieth century it is important that we remind ourselves that narrativity comes in various kinds, and more generally that poetry is not social documentation.

${ }^{21}$ MacLeish 1985: 106-107. 


\section{THE LOWER BODY: YIN LICHUAN AND SHEN HAOBO}

At the start of the twenty-first century, the most talked-about thing in avant-garde poetry in China was a controversial group of authors called the Lower Body (下半身). Section 1 of this chapter is a critical introduction to their poetry, poetics and poethood, with special attention to the work of Yin Lichuan and Shen Haobo. We focus on the years 2000-2002, when two book-like issues of the unofficial journal named after the group appeared and its members made their way into a wide range of other publications. The Lower Body has since ceased to be active as a group but secured a place in literary history, even if this is fiercely contested. In addition, its legacy lives on through the individual literary careers of some of its one-time members, including Yin, Shen and Duoyu. Section 2 sketches the Lower Body's lineage within the avant-garde, from three angles summarized as demystification, bad behavior and social concern. As regards the third, although the Lower Body is an extreme manifestation of the Earthly aesthetic, a feature it shares with texts across the full spectrum from Elevated to Earthly is that it regularly positions literature as a medium for the expression of such concern. This confirms that while the Elevated and the Earthly provide useful points of reference for discussing the avantgarde, they are not pigeonholes and they do not constitute a binary opposition.

The Lower Body's reception in literary circles is sharply divided. If some critics dismiss it out of hand as immoral, this is evidence of a mismatch of critical expectations and actual poetic production more than anything else, as in the crisis discourse identified in chapter One. As this chapter hopes to show, shock value doesn't suffice to explain the publicity generated by the Lower Body. Nor does the fact that Lower Body poetry is grounded in the social realities of contemporary China make awareness of these realities indispensable for enjoying this poetry as art.

(C) MAGHIEL VAN CREVEL, 2008 | DOI 10.1163/9789047442738_010

This is an open access chapter distributed under the terms of the Creative Commons AttributionNoncommercial 3.0 Unported (CC-BY-NC 3.0) License. 


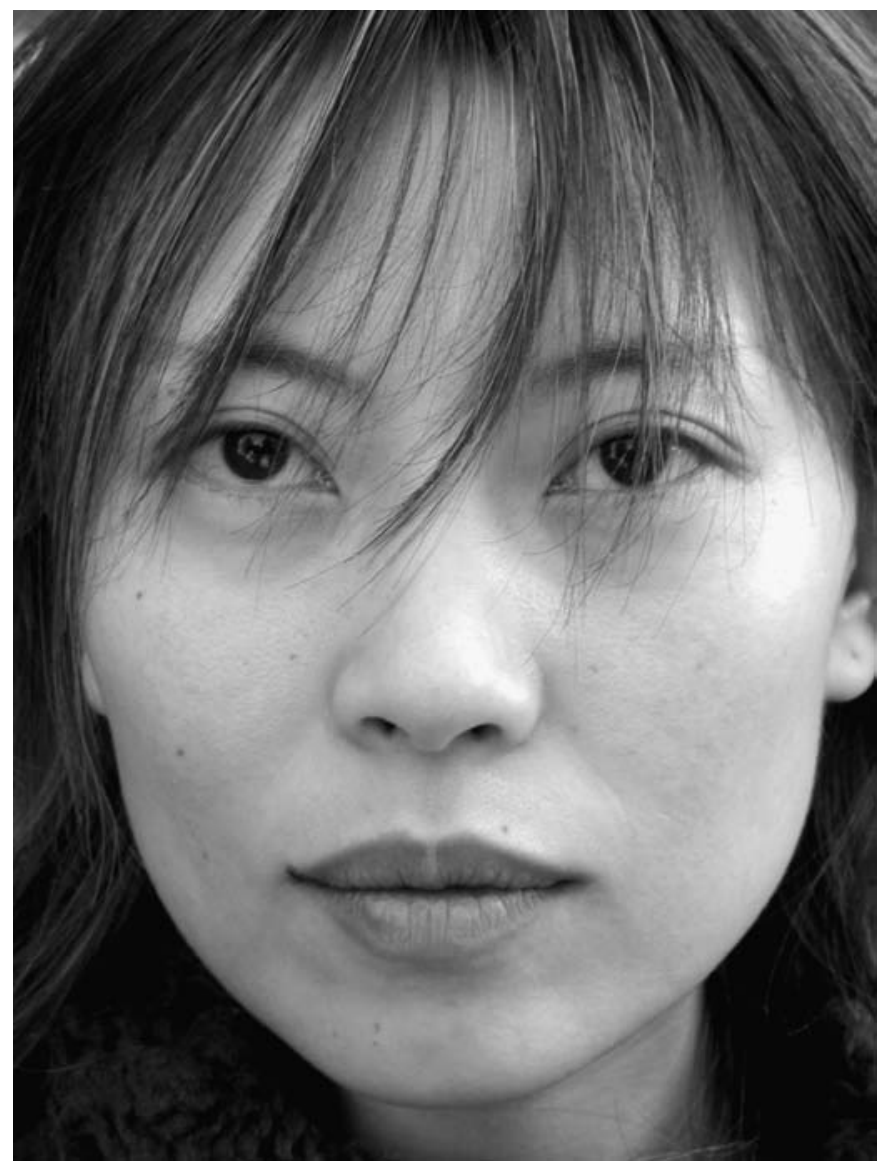

Figure 9.1. Yin Lichuan, 2004 (photograph by Martin de Haan) 


\section{Lower Body Poetry}

Here's a Chinese poem from the year 2000, Yin Lichuan's «Why Not Make It Feel Even Better» (为什么不再舒服一些): ${ }^{1}$

"Why Not Make It Feel Even Better»

ah a little higher a little lower a little to the left a little to the right

this isn't making love this is hammering nails

oh a little faster a little slower a little looser a little tighter

this isn't making love this is anti-porn campaigning or tying your shoes

ooh a little more a little less a little lighter a little heavier

this isn't making love this is massage writing poetry washing your hair your feet

why not make it feel even better huh make it feel even better

a little gentler a little ruder a little more Intellectual a little more Popular

why not make it feel even better

What is this about? Sexual intercourse, sure - but how does one have sex in an intellectual or popular fashion?

"Why Not Make It Feel Even Better» appeared in the first issue of The Lower Body, in July 2000. It is dated January 2000, when the Popular-Intellectual Polemic that had raged through the Chinese poetry scene the previous two years was coming to an end. We will take a closer look at the Polemic in chapter Twelve; for now, suffice it to note the following points. Having started as an inner-circle affair that involved numerous prominent poets and critics, the Polemic soon spilled over into the general media outside the poetry scene. Older scholars and critics in particular considered this a loss of face for literature. Their indignation over what many appeared to see as contemptible behavior on the far side of an unbridgeable generation gap was fueled by the feeling that those fanning the flames were carelessly endangering hard-won literary freedoms. After all, it was not long before that ubiquitous censorship and most of all self-censorship had set strict limits for literature, and original metaphor could lead to political interference by the authorities in the form of publishing bans, general harassment, disciplinary measures and so on. A fracas within the avant-garde, which had quickly grown and diversified since the

\footnotetext{
1 The Lower Body 1: 58-59.
} 


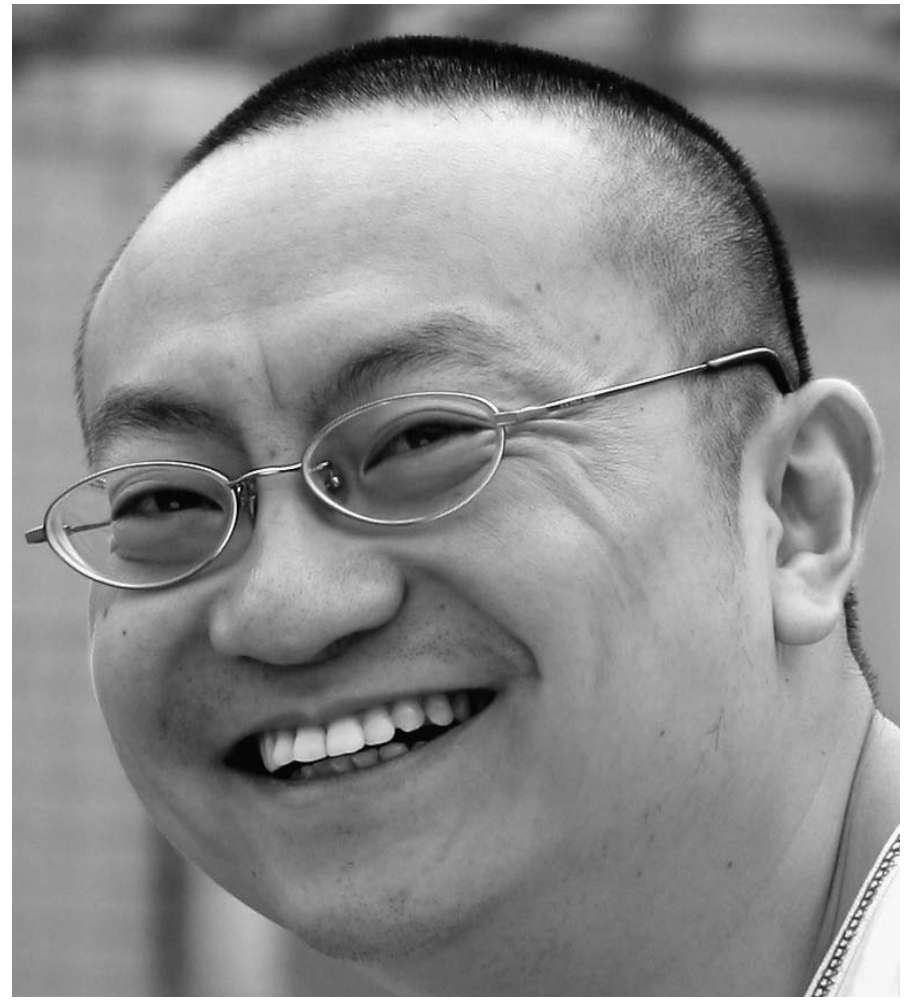

Figure 9.2. Shen Haobo, 2006 
Cultural Revolution, might just give its traditional enemy the wrong ideas. In addition, while the Polemic definitely spurred reflection on the state of the art, it also moved many to lament the damage done to poets' and critics' personal and professional relations and to the atmosphere on the scene at large, especially after the debate truly escalated during the April 1999 Panfeng Poetry Conference.

And then, early in 2000, when a sense of closure is about to descend, someone does a send-up of the whole thing. Both proud banners, carried by famous poets - such as Yu Jian, Han Dong and Yi Sha (Popular), and Wang Jiaxin, Ouyang Jianghe, Xi Chuan and Sun Wenbo (Intellectual) - appear at the end of a series of directions to get as much pleasure as possible out of sex. They do so not as the poem's focal point, but as a casual addition, almost an afterthought. This is vintage Yin Lichuan, just like the rest of the poem: derisive, tired, cynical, playful yet tough. The effect is strengthened by a dogma that holds everywhere but is particularly deep-rooted in China, certainly if one bears in mind a good two millennia of literary history: public, detailed description of sexuality is scandalous, especially if the author is a woman. ${ }^{2}$ To make matters worse, the speaker in «Why Not» is an immoral woman, whose carnal ecstasy is not the spin-off of soulmateship or love but emerges in lazy instructions to a man portrayed as a tool to satisfy female lust.

Yin Lichuan (1973) and Shen Haobo (1976) were leading members of the Lower Body group, which created a sensation from the summer of 2000 until late in 2001. Several commentators have read the metaphor of the lower body as a synonym for genitals, and equated Lower Body poetry with pornography. It is, however, too frequently ironic and insufficiently focused on sex and sexual arousal to justify this classification. There is much more to it: in its own, inimitable way, Lower Body poetry reflects "dark" sides of life in China's big cities, viewed from within the ideological vacuum surrounding urban youth who cannot find it in themselves to live conventional lives. It showcases their alternative lifestyles, which are informed by a bitter-cheerful feeling of No Future, paradoxically coupled to the sense that for the happy few in China's big cities, everything is possible. This finds expression in cynical, unconcerned individualism and hedonism, be it Punk or commercial or both. Incidentally, these are aspects of youth culture

\footnotetext{
${ }^{2}$ Idema \& Grant 2004.
} 
that are also seen in other countries, and within the mainland-Chinese socio-cultural framework their literary and artistic expression is certainly not limited to the genre of poetry.

\section{Yin Lichuan}

In Yin Lichuan's writings, then, more is to be found than the voice of an immoral woman. In the People's Republic a title like «Old Man Zhang, Retired Worker» (退休工人老张, 2000) evokes the image of a Socialist-Realist hero enjoying well-deserved retirement, or perhapsafter Colloquial poets such as Han Dong and Yu Jian - that of a quiet man from among "the common people" minding his own, daily business. But not so: ${ }^{3}$

\section{"Old Man Zhang, Retired Worken»}

when he opens his eyes, in the ceiling

there's a nail. he looks at it for ten minutes straight.

as soon as he opens his eyes, he sees this nail, in the ceiling

it's been like that for ten years straight.

so ten years ago, the nail was in the ceiling

not in his eye.

back then, as soon as he'd opened his eyes, he'd go to work - no, to the loo.

now he doesn't go to work, and he doesn't need the loo, so once he's awake

all he does is stare at the nail. the nail drops down, into his left eye.

his left eye is kaput, and can't see the nail. his right eye ain't kaput

and can't see the nail either, because the nail is now gone from the ceiling.

there's a hole in the ceiling, just like in his left eye

there's a hole. so at that hole in the ceiling

he looks with his right eye. he'll be a long time looking

before the alarm goes off, at the first glimmer of dawn

The trivial texture of everyday life - not grey hairs or other solid symbols of respectable issues in exemplary lives, but the troublesome, the hopeless, the awkward, the undignified - has been accepted subject matter in Chinese poetry since the 1980s. Yin Lichuan's power lies in her dispassionate report, in cool chatter while what happens is enough to make one cringe. Then there is her detached play with the attri-

\footnotetext{
3 The Lower Body 1: 60.
} 
butes: the nail, a left eye, a right eye, a hole in the ceiling, a hole in the left eye. The scene following the nail's descent into Old Man Zhang's eye is absurd. It revolves around the wrong eye, and asks us to believe that Zhang, nail in eye, will patiently continue to lie in bed until the alarm goes off, just as he does everyday.

Tension arises here between two types of language. One is the language of official reality as a product of socialist ideology, normally the home of people like the Old Man Zhang that appears in the poem's title. The other is the language of Yin Lichuan, who drags him away from there and into her irreverent edition of his life, in the body of the poem.

A similar stylistic twist occurs in «Man Throwing Up» (呕吐的男 人, 2000), in lines 6 and 12:4

«Man Throwing Up»

the suit is black, with filth like cream

at night a man squats in our midst and throws up

quiet and coy, everyone's most pleased.

neon dancing, women dancing

drinks dancing, music stumbling

one must be serious, thorough and fully committed.

throw up some bones

throw up some skin

throw up some fluids

throw up your last bit of vigor

and do continue. the crowd is awfully pleased.

and for the climax, pray throw in your heart and soul, my dear.

The picture is one of nightlife euphoria, intoxication and tender cruelty. An example of such tenderness, the intimacy of my dear complicates the poem's effect. This is irony, to be sure, but in Yin Lichuan's "debauched" universe - this being the sort of description typically meted out to her by detractors of the Lower Body - these words could be of the utmost sincerity.

Yin has also written sympathetically and compassionately about "unclean" characters that appeared in China's big cities late in the

\footnotetext{
4 The Lower Body 1: 63-64.
} 
twentieth century: junkies, prostitutes, petty criminals and so on. For example, in «Small-Time City Thief» (城市小偷, 2000): ${ }^{5}$

"Small-Time City Thief»»

out of a fistful of last year's snow

you squeeze a lump of black mud

empty as air. you can't find a stone to kick

and so you hold to the straight and narrow line

the streets are swept too well to offer shelter anymore

the buses are no longer crowded

you just can't get used to the girl selling shoes saying

how are you, or the shop

selling hamburgers instead of steamed rolls

fuck! all these things have changed

and no one's talking to you

big brother's gone to vietnam for big bucks

brother two's a gangleader now, brother three's been taken in

brother four was run over and killed, brother five's gone back to work the fields

and you've no place to go. in '68, you were born here

you're from the city, you've made your own life since you were small

you're no cheat no robber no rapist you're chaster than a monk

you walk past the police, careful now

but they don't even bother to look

you slow your step, people swirling

past you all the time. you set yourself down

in the city park, the fence pinching your ass

for the first time you question your beloved trade

nobody needs you now. you were born at the worng time

In addition to her ability to combine a sense of humor with credible moments of melancholy, what makes Yin one of the better Lower Body poets is her regard for poetic form, in ditty-like, playful repetition, near-rhyme and beautifully flowing rhythm. In «Wet with Paint» (油漆未干, 2001), seven consecutive lines (3-9) are syntactically and rhythmically identical, and end in the same character (度): ${ }^{6}$

\footnotetext{
5 Yin 2001: 183-184.

6 Blue 6 (2002): 112-113.
} 
"Wet with Paint»"

- dedicated to so-and-so, so-and-so and so-and-so

reach out your hands

tear off your face

measure its depth

increase its strength

rule out its filth

master its truth

shorten its length

adjust its width

reject its worth

then put it back on

(handle with care)

fix its expression

aim it at nothingness (that is, all mortal beings)

and be so kind as to stick out your tongue

to feel if your face is still there

and whether or not it is there

right where it is right then

please place your palms together

and you will certainly feel

your own devout and valiant expression

like a signboard wet with paint

on which everyone wants

to leave a pawprint

To retain the original's formal features, I have taken more translatory license than usual and rendered 湿度 'wetness' or 'dampness' as filth, 尺度 'yardstick' or 'measure' as truth and 风度 'style' or 'proud bearing' as worth.

After reach out your hands, the perfect cliché to announce a sentimental vision of love or charity, tear off your face is of shocking brutality. The image of one's presentation to the world as a mask leads into issues of identity. Is the face-mask still there? Can one see oneself? Has the mask taken over? Can one be oneself? Just like «Man Throwing Up», «Wet with Paint» has a powerful, slightly mystifying ending. The final scene bespeaks disgust at being touched by others wanting to leave their mark, whether literal or figurative. 


\section{Manifestations and a Manifesto}

Lower Body poets without university degrees were advertised by their companions as not "polluted by knowledge." A fair number of them, however, had willingly absorbed such pollution in earlier years. Yin Lichuan studied French at Peking University, the flagship of Academe in China, and film at the École Supérieure Libre d'Etudes Cinématographiques in Paris. Four others - including Shen Haobo, the group's driving force - studied Chinese at the highly reputed Beijing Normal University. This didn't keep them from scoffing at formal education as a bastion of highbrow culture. As such, in its Earthly antiintellectualism Lower Body poetry follows on seamlessly from many Popular contributions to the Polemic. Yi Sha and Xu Jiang, two Popular polemicists who have offended just about everyone who is anyone in Chinese poetry since the early 1990s, and who are held in high esteem by the Lower Body poets, are also BNU graduates. By way of an example of the above-mentioned generation gap, the BNU connection would have contributed to Lan Dizhi's angry outburst against the Polemic at a conference entitled Chinese Literature from a Cultural Viewpoint (文化视野中的中国文学), at Tsinghua University in August 2001. It is easy to see how Lan, one-time professor of Chinese at BNU, might have felt as if he had nurtured a nest of vipers in his bosom. ${ }^{8}$

In Chinese universities, many students and professors write poetry, especially though not exclusively those in the humanities. It is not uncommon for professors or high-level administrators to encourage salon-like meetings where students "learn to write poetry." The phrase implies a different vision than that exuded by most avant-garde poetics and exhibits the continuing influence of traditional Chinese views of poetry as a skill that can be acquired rather than something requiring radical creativity and original innovation, if not deviation from the norm. Universities such as PKU and BNU produce journals and anthologies of students' poetry, recitals and awards. Such student poetry rarely rises above well-behaved, conservative burbling, in lyrical evocations of the changing of the seasons, unrequited love and weltschmerz. The original voices of the few who stand out and rise to nationwide

\footnotetext{
7 See Shen Haobo's manifesto, below.

${ }^{8}$ Cf Zhu Dake 2006: 278-279.
} 
fame guarantee a royal reception at their alma mater. Say, Han Dong at Shandong University, Wang Jiaxin at Wuhan University, Xi Chuan at PKU or Yu Jian at Yunnan University.

Accordingly, in December 2001, on account of the Lower Body's BNU antecedents, they met an expectant crowd of approximately four hundred at the seventh edition of the Chinese Department's Iron Lion's Cemetery Poetry Festival (铁狮子坟诗歌节); but they quickly outstayed their welcome by offending large parts of the audience. During the recital, several members of the audience walked out in protest while others voiced raucous support, until the event turned into a shouting match on the nature of poetry. A bizarre moment came when, from the high backbenches in the auditorium, a visibly enraged elderly gentleman made his way to the microphone, carrying a sword. His outfit suggested that he had come from a martial arts workout and his weaponry was for exercise rather than battle; and aside from some angry body language, his contribution was strictly verbal, amounting to a denunciation of what he saw as a disgrace to BNU and to poetry. Still, under the circumstances his sword acquired symbolic value, if only as a traditional response to the (toy) hand grenade in Diane Arbus' famous photograph of a child in New York's Central Parkwhose lower body, upside down, graces the cover of the first issue of The Lower Body. ${ }^{9}$

The journal opens with a manifesto written by Shen Haobo, entitled "For Lower Body Writing \& Against the Upper Body." The Lower Body phenomenon has been identified with these few pages to the point of eclipsing other texts, including the poetry itself. Perhaps understandably so, if only because of the manifesto's brazen style and the discrepancies between Lower Body "theory" and practice, noted by sympathizers and criticasters alike ${ }^{10}$ - even though there is no law that says an author's poetry and their explicit poetics must be consistent in order to be interesting. Here are some salient passages from the manifesto: ${ }^{11}$

\footnotetext{
${ }^{9}$ I witnessed the recital. The incident was reported in several places, e.g. Shen Haobo 2002: 101.

${ }^{10}$ E.g. Yi 2001a: 125-126 and Xi Yunshu 2001: 57-58.

11 The Lower Body 1: 3-5.
} 


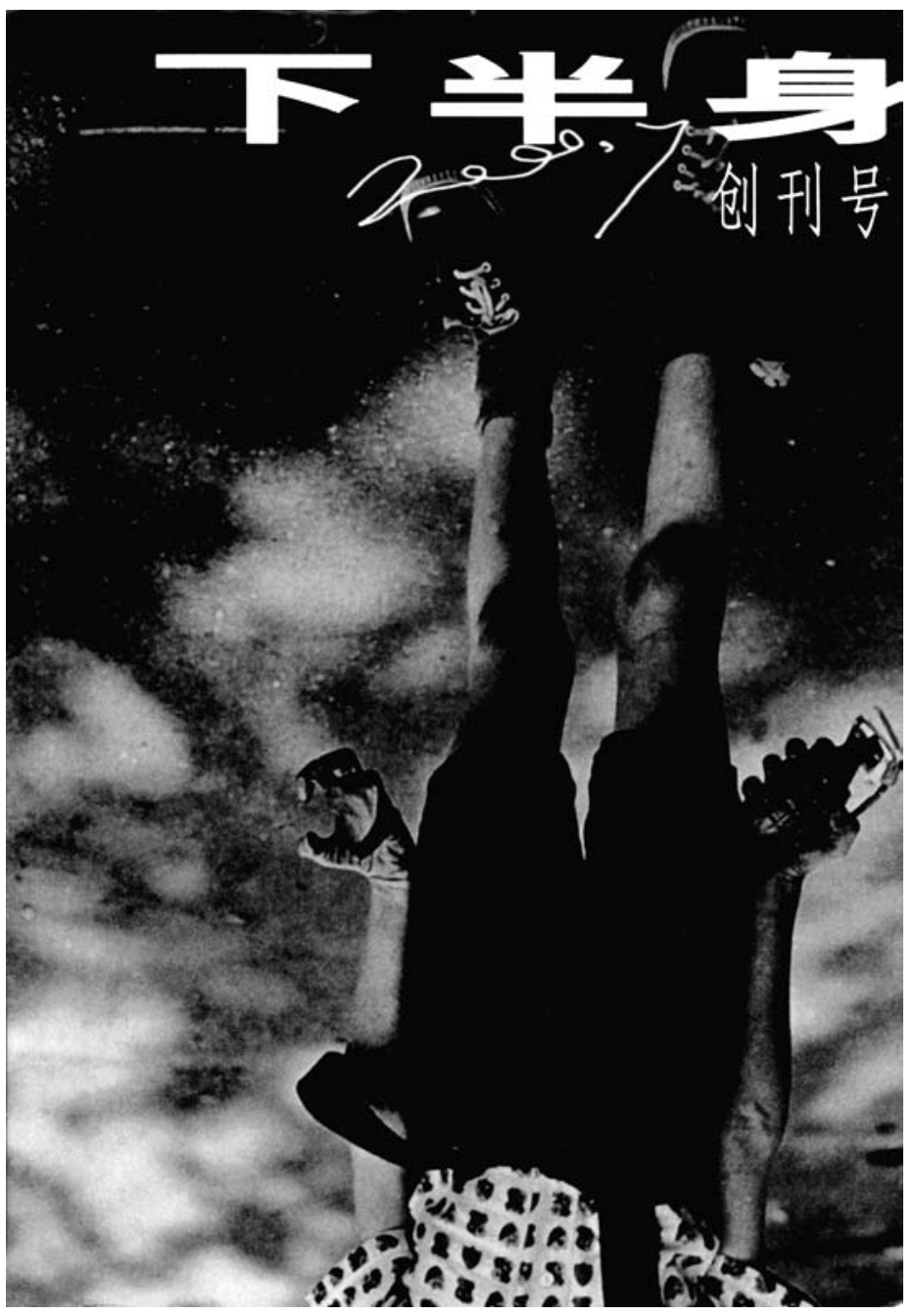

Figure 9.3. The Lower Body 1, front cover 
Emphasis on Lower Body writing means first of all the eradication of the upper body factor in poetry writing.

Knowledge, culture, tradition, poetic sentiment, lyricism, philosophy, contemplation, commitment, calling, mastership, canon ... All these words belong to the upper body and have nothing to do with art. They are entries in a humanist dictionary and have nothing to do with avantgarde poetry of the here and now.

And what is so great about the tradition of Western modern art? Nothing really. We have seen with our own eyes how an entire generation of Chinese poets have crawled before it and never stood up straight since.

As regards poetic sentiment from the Tang and Song dynasties, we are simply not satisfied with any poetic sentiment whatsoever. We are going to make poetic sentiment die a very ugly death.

Only those who can't find joy go looking for thought. Look for thought in poetry? Are you sick or something? Don't tell us you didn't know that abstruse poets are frauds. It's all the same thing: only those who can't find the body go looking for lyricism, for the sobs of a weakling. Disgusting.

Let all that upper body business go to the devil . . . We want only the lower body. That is real, concrete, tangible, exciting, wild, sexy, unimpeded.

So-called Lower Body writing means a firm worldly stand. ${ }^{12}$

So-called Lower Body writing pursues a palpable presence of the flesh. That is: of the flesh [肉体] not the body [身体] . . . For externalia such as tradition, culture and knowledge have deeply alienated, polluted and defiled our bodies. Too many people have nothing like the flesh, only a weak cultural soma, no lower body like that of animal existence, only the upper body of a pitiful thing called "human being." But to return to the flesh and to pursue a palpable presence of the flesh means to let our experience go back to that of the essential, original animal flesh. We are each of us ourselves the flesh. As the flesh happens, so poetry happens, and as the flesh makes its presence felt, so poetry makes its presence felt. That's all.

12 The word rendered as worldly is 形而下, literally 'below the form(ed),' an antonym of 形而上 'metaphysical,' literally 'above the form(ed).' 形而下 has been used for years in social-science discourse and elsewhere, but not attained the status of a regular dictionary entry. 形而上 as the received translation of metaphysical further complicates the matter. According to the English term's Greek etymology, the antonym to metaphysical would have to be physical, if anything - metaphysical being defined in contradistinction to physical to begin with - and not involve value-laden concepts such as above and below. 
Does poetry really go no farther than language? Wrong, the time of language has come to an end, and the time of the awakened body has begun.

We lay our lower body bare, the men their hilts and the women their holes. This is how bad it is, so what have we to be scared of?

The manifesto is typical of Shen Haobo's style as a literary activist. Its recalcitrance, aggression and anti-intellectualism and the phrase $a$ palpable presence of the flesh lead to association with the atmosphere surrounding the Popular-Intellectual Polemic, as well as with Yi Sha's and Yu Jian's style in their capacity as commentators rather than poets. ${ }^{13}$ Making poetic sentiment die an ugly death is the sort of thing many self-styled innovators of artistic traditions the world over have set out to do in the age of modernity.

Even if literary manifestoes are exempt from academic assessment, Shen's argument is conspicuously flawed. Announcing that as the flesh happens, so poetry happens, he leaves one without a clue as to how this is supposed to work, a question which gains in significance if the time of language has really come to an end. The latter statement is an attack on a renowned Earthly predecessor, delivered as an aside: as noted in chapter Two, the claim that "poetry goes no farther than language" is the best-known summary of Han Dong's poetics. If one takes Shen's animal dreams seriously, problems arise as soon as he avails himself of that accursed language, especially for writing more or less expository text. Animals have no language in the human, let alone the literary sense. If human expression is figuratively animal-like, this would have to be in other art forms than literature: say, in music. The image of original animal flesh also sits uneasily with the urban-decadent style of the Lower Body group, in both life and work. In a more domesticated piece for Poetry Exploration Shen follows kindred souls such as Yi Sha, $\mathrm{Xu}$ Jiang and Hou Ma when he calls his preferred poetic usage Post-

\footnotetext{
13 See Zhongdao 1998, a partial but rich and informative collection of Yi Sha's poetry and related matter (interviews and so on), and numerous comments on his work by others; and Yu Jian 2001b, following the corporeal orientation of Yu's earlier writings such as 1999b. In Yi 2001b Yi Sha's focus on the flesh becomes a caricature, perhaps because he addresses a primary audience consisting of admirers (cf Shen Haobo 1999 and 2001b, and Duoyu 2000): the editors of The Lower Body, who likely asked him for a contribution.
} 
Colloquial (后口语). Here, too, Shen's vigor leads to little more than unproven assertions, not of the original or stimulating kind. ${ }^{14}$

Shen's first individual collection of poetry, A Handful of Tit (一把好 乳, 2001), is a garish, professional-looking unofficial publication. Its material quality reflects the fact that Shen makes a living in the publishing business as one of the many book brokers operating in newly graphomanic China, to borrow Geremie Barmé's term. ${ }^{15}$ Shen's second collection, Great Evil Hidden in the Heart (心藏大恶), banned almost immediately after its (official) publication in 2004, suggests macho sexuality through the cover photograph of a man's bare abdomen rising from a pair of jeans, his crotch at the center of the picture. ${ }^{16}$ In a preface to A Handful called "My Poetry Makes Sense" (我的诗歌有道 理), Shen claims that foreign sinologists will never understand poetry like his and neither will most Chinese critics, because they only have access to learned, intellectual, formal types of language and cannot get at the nuances of the spoken word.

It is difficult to determine the limits of one's own perception, and I am aware that the native and non-native experience of any poetry is likely to differ substantially — although generalization of this issue disregards the individual reader's engagement with the literary text that is essential to its realization. At any rate, I would wager my dictionaries that foreign readers are not as powerless as Shen makes them out to be. On the contrary, Lower Body poetry is easier for foreign readers and translators than most other avant-garde texts. This is because of its one-dimensionality or, in a related image, its textual shallowness; and because of its loose composition on the levels of word, phrase and sentence, which make the translator less obliged than usual to be "faithful to the original" in the narrow sense. Both Yin Lichuan and Shen Haobo have stated that they are less concerned with translatory word-to-word meticulousness than with getting across the "meaning" or the "intention" or indeed the "gist" (意思) of their work. ${ }^{17}$ One surmises that this attitude also holds for their poetry's domestic travels, so to speak, and that critical misapprehensions of Lower Body poetry are to do with the incompatibility of the poet's and the critic's

14 Shen Haobo 1999. The invention of the term is generally ascribed to Yi Sha (e.g. Luo Zhenya 2005: 212).

15 Barmé 1999: x.

16 Shen Haobo 2001a and 2004.

17 Personal communication on several occasions in 2001-2003. 
respective poetics rather than anyone's insufficient command of the Chinese language, including its colloquial or post-colloquial varieties. More generally, Shen's low appraisal of Chinese and foreign critical ability - and of much avant-garde poetry to date - appears to be part of mechanisms of differentiation and dissociation from what has gone before which typically come into play when a new trend seeks to establish itself in the literary field.

Clear-cut distinctions between high and popular culture have been effectively challenged in the past several decades, and so has the automatic evaluation of high as good and popular as bad. Still, I wish to note that the aforesaid one-dimensionality and shallowness are not value judgments or euphemisms for bad poetry. Successful Lower Body texts combine a particular flow, colloquial or theatrical or both, with the effective evocation of an extra-literary, acutely relevant context. This context is an urban jungle, home to insatiable industries of consumption and entertainment, in a society witnessing the rise of money, social mobility, inequity and sex as something no longer linked to wedlock, love or procreation. These things are proportionate to the collapse of Chinese-socialist ideology and its institutions in all spheres of life: material austerity, the iron rice bowl, puritanism and so on. In Lower Body poetry the new New China is experienced through the senses of hip, free-floating youths who fail to meet society's conventional expectations but who are smart and well-connected enough to get by, with a keen eye for both misery and happiness.

\section{A Comparison with Glamlit}

The Lower Body is firmly grounded in the turbulent social realities of contemporary China outlined above. If, as part of the poetry scene, it emerged in a climate that had been generated by the Polemic, this is only one of several possible angles from which to approach these texts. Hence, before we proceed to examine Shen Haobo's poetry, a quick comparison with related developments in fiction - much better researched to date - is in order.

Following the relaxation of government cultural policy in late 1970s China, Obscure Poetry and, for fiction, Scar Literature (伤痕文学) embodied a transition from orthodox Maoist poetics to experimental 
or avant-garde types of literature. ${ }^{18}$ Both poetry and fiction have since thoroughly problematized their status as high art. Anti-intellectualism, the celebration of "hooligan" (流讯) lifestyles and the exploration of sexuality beyond current convention are manifestations of the shock value of literature that has foregrounded the city and the body as prominent themes, during the 1980s and especially since the 1990s. For fiction, scholars such as Robin Visser and Lu Jie have shown that the city is a site of both glamor and ugliness, and of the alienation and anxiety that modernity and globalization bring. ${ }^{19}$ The (sexual) body becomes extra significant in women's writing, because of age-old sexist bias coupled with traditional biographist views of literature that equate the speaker in the literary work with the historical person of the author. All this takes place against a backdrop of the sweeping commercialization of culture and the arts.

Going on from there, let's compare Lower Body poetry with fiction by the equally controversial women authors known as Glamlit Writers or Beauty Writers (美女作家), specifically Weihui's Shanghai Babe (上海宝贝, 1999) and Mian Mian's Candy (糖, 2000), with reference to research by scholars including Megan Ferry, Sabina Knight, Sandra Lyne and Kong Shuyu. ${ }^{20}$ There are similarities in that Yin Lichuan's, Shen Haobo's and Weihui's allegiance with youth culture and their anti-intellectual and "hooligan" claims are complicated by the strategic downplaying of their own formal training - Mian Mian is the only one without a degree from a prestigious university - and by the fact that their readers far exceed the scope of youth culture and include many intellectuals and few hooligans. This brings to mind the ambiguities in Hooligan or Thug Literature (流讯文学、㾂子文学) godfather Wang Shuo's relation to high culture, as noted by Wang Jing, even if it would have been unrealistic to expect a seriously hooligan readership for Wang Shuo's work to begin with. ${ }^{21}$

Neither the Lower Body nor Glamlit fiction make sexual passion a substitute for political, Maoist-revolutionary passion, an operation identified by Wendy Larson in Anchee Min's Red Azalea. ${ }^{22}$ In the work

\footnotetext{
${ }^{18}$ Yeh 2003: 525, Knight 2003a: 528-529.

19 Visser 2002, Lu 2004.

${ }^{20}$ Weihui 1999, Mian Mian 2000, Ferry 2003, Knight 2003b, Lyne 2002, Kong 2005: ch 4.

${ }^{21}$ Wang Jing 1996, chapter 7: e.g. 284.

${ }^{22}$ Larson 1999.
} 
of Yin Lichuan, Shen Haobo, Weihui and Mian Mian, politics is largely irrelevant. At the same time, their individual focus on low-life and lawless losers, decadent consumers of sex \& drugs \& rock-n-roll and other inhabitants of the new urban jungle is inseparable from social change in 1990s China. This, in its turn, has a political dimension, if only in the debunking of political ideology as one of the primary factors shaping social policy.

The emancipatory potential of sex, also discussed by Larson, is central to Ferry's and Knight's research and features in Kong's investigation into the commercialization of literature. Here, we find important differences between the Lower Body and Glamlit. At the same time as raising questions of womanhood, ethics and morality, Weihui and Mian Mian ultimately reinforce stereotypes of female sexuality, against a backdrop of the continuing repression of women. Shen Haobo's rude machismo works differently in that it can alternatively be read as a sarcastic indictment of male chauvinism. Similarly, Yin Lichuan plays with female stereotypes, in caustic and triumphant ways that enhance female literary agency and self-representation - whereas Glamlit fiction undermines these things, as Ferry shows. We find another sexuality-related contrast between Glamlit and the Lower Body in Lyne's classification of Shanghai Babe as yet another example of the long-standing, exoticizing sexualization of Asian women, catering to the demands of the (foreign) male gaze. This is not at all how female sexuality appears in Yin Lichuan's poetry. Incidentally, in contrast to Weihui's active stimulation of sex-related publicity for her work, Yin notes that there is only so much one can say about sex, remarking that the Western media hype surrounding Shanghai Babe was motivated by an interest in social issues rather than literature. ${ }^{23}$

Related to the previous points, a major difference between Lower Body poetry and Glamlit is that (international) publishing market forces are a powerful factor spurring Glamlit fiction and its graphic depictions of sexuality, and that the publishers are not just after the prestige - including, of course, notoriety - but after the money. In this respect, the situation of Lower Body poetry is captured in the observation that most of it appeared in print and online unofficial circuits, which never involve financial profit, and that all of it belongs to a literary genre that is financially unmarketable, to which we now return.

${ }^{23}$ Yin \& That's Beijing 2004. 


\section{Shen Haobo}

Shen Haobo's drive finds more felicitous expression in his poems than in his expository prose. In «Fucking Cabdriver» (他妈的出租司机, 2000), the speaker is behind the wheel of one of the seventy thousand taxis that were operating in Beijing at the turn of the century: ${ }^{24}$

\section{"Fucking Cabdriver»}

"all this fucking traffic from liulichang to majiapu on yangqiao $i$ was stuck for a full fucking hour it's fucking stop-n-start today"

“the lady i just dropped off she's got herself a fucking lover

that old girl $i$ know her she's at the fucking trade center"

"at night they're fucking everywhere see those big trucks driving so fucking fast you going somewhere stay in shijiazhuang what the fuck you in beijing for"

"now what you standing in the road for you shouldn't fucking stand anywhere this time of night why the fuck you causing trouble"

"it's really fucking fucked a shitty bridge like that nine months it ain't done yet they fucking fleecing me and you the ringroad fly-over just took six fucking months"

"see that tree with the dirty great dent a fucking toyota hit it just the other day you get sleepy you take a break right it's like he wanted to fucking die ain't it"

"but if he'd really fucking died he wouldna had to worry about the car broke the fucking axle that fella's gonna have to spend a lot of money"

"said they were gonna fix this road but nothing's happening

it's a real fucking pain now that's a job in hand eh"

"you live in fucking majiapu man you've found yourself some place

right out in the sticks how'd you fucking find it"

Taxi drivers rave and rant everywhere, in taxi driver language: politically incorrect, riddled with expletives, in monologues that are something of a natural genre in other solitary yet interactive professions too-hairdressers, shopkeepers and so on. Something very close to a Duchampian ready-made, Shen Haobo's taxi driver is no exception. Most of Shen's other poems also require little knowledge of China from the reader. His thematics include a hatred of teachers and edu-

24 Shen Haobo 2001a: 93-94. 
cation, the horrors of marriage and pedestrian middle-class existence, the new rich, emotionally indifferent sex, thugs, whores, street gang violence and so on. Shen's poems are occasionally funny and usually aggressive, and contain many colloquialisms, not idiosyncratic or experimental but delivered with considerable panache. The lines are either very short or very long; let's first consider an example of the former. «Huang Si's Ideals» (黄四的理想, 2001) makes one or two references to Chinese realities, but in such a way that a modicum of historical knowledge on the part of the reader will suffice: ${ }^{25}$

"Huang Si's Ideals»

huang si and $i$

sit on his balcony

drinking beer

playing dice

huang si is always

lucky at dice

just like he's been

lucky in business for years

he blowes into his hands

and says

if $i$ throw a six

i'll realize

my first ideal

before the year's out

buy a cadillac

and drive across the square

of heavenly peace

he blows again

and if then

$i$ throw another six

i'll also realize

my second ideal

then i'll pay a million

or two million

to book our high school teacher

that woman

25 Shen Haobo 2001a: 59-60. 
called xu chunping

the old girl

for all of two months

i'll peel off her clothes

and squeeze her

shriveled tits

while $i$ make her

tell me about

marxist-leninist thinking

One can imagine the words being uttered in stops and starts between sips of beer and throws of the dice, and this is in fact how Shen Haobo recites the poem, with end-stopped lines throughout. ${ }^{26}$ Elsewhere, Shen's and other Lower Body poets' short lines are little more than a gimmick. They are most effective when their form contributes to a content of aversion, refusal, denial and so on, whether blunt and straightforward or through irony, as in the sarcastic portrayal of idealism. One could call this type of writing rejective - again, without passing value judgment.

Shen's long-line poems are few, and generally better than his stops and starts. «And We Push» (我们拉, 2001), ${ }^{27}$ with pushing-for the Chinese 拉, literally 'pull' — denoting defecation, as in 拉屎 'take a crap,' has a recurrent chorus that both friends and foes of the Lower Body will cite to vindicate themselves. So does «All Hail the Clap» (淋病将至, 2001). Its line length is extreme even by Chinese standards and the translation below-just like Yu Jian's poetry, in smaller type and with indentation - has two more line breaks in each stanza than the original. The poem has close to a dozen sizable stanzas, maintaining a breathless speed throughout. I cite it in full so as to give the reader a sense of what one may call its aggressive size.

The bookstore in line 1 is Fangzhou (方舟书店), near Baiwanzhuang in Beijing, which sold all manner of subcultural and countercultural products in the 1990s. The rock club is the Joy Garden (开心乐园), near Wudaokou, which hosted underground rock bands until the Beijing demolition specter put an end to that, or budget problems, or both. Early in the twenty-first century this location lay in ruins, surrounded by car repair shops and illegal CD vendors. There

${ }^{26}$ Q \& A session, De Centrale (Gent, Belgium), May 2004.

27 Shen Haobo 2001a: 14-15. 
starts Shen's tirade: about money, the hunt for a green card, the tainted Tiananmen Square as a metonym for the poker face of China's autocratic rulers, faded lust, provincial officials on their junket to the sinful big city, and of course uninvolved sex: you've got yours and i've got mine just one more kiss and nothing else. The entire poem bespeaks social concern - albeit of the rough-edged kind and alternated with shameless, hard-boiled cynicism - which is visible in lines such as migrant workers on the run and that thing squatting by the road is a man not a dirty dog. The image is part of Shen's description of the gigantic construction site that Beijing has been for years, covered by deafening machines and blinding floodlights and kept running day and night by migrant workers without much in the way of labor rights. The speaker himself ends up like all the others who have no home to go to, that is: in the street and dripping with rain-yet the poem exudes undaunted resilience throughout. ${ }^{28}$

\section{«All Hail the Clap»}

and the hippest bookstore has closed

and the hippest rock club has quit

and your old man's smashed up that hard-earned bass guitar

and your childhood mates have learned to make money

and young artists have no home to go to

and they're out on the street and they're dripping with rain

drip drip drip drip drip drip drip-a-drip

dripping and dripping

now all hail the clap

and the world trade center's collapsed

and the pentagon's been bombed

and the statue of liberty's been forgotten

and the yanks look at foreigners with green eyes

and green card holders have no home to go to

and they're out on the street and they're dripping with rain

drip drip drip drip drip drip drip-a-drip

dripping and dripping

now all hail the clap

${ }^{28}$ Shen Haobo 2001a: 155-159. 
and it'll soon be national day

and then they'll cordon off the square again

and the neighborhood guards will be carrying truncheons

and they'll deal with whoever's up to no good in the parks

and migrant workers on the run have no home to go to

and they're out on the street and they're dripping with rain

drip drip drip drip drip drip drip-a-drip

dripping and dripping

now all hail the clap

and those yellowed cheekbones are sticking out more and more

and those wrinkles covered in eye-shadow are spreading

and those tight leggings make you look like a hillbilly

and the lads on the bus can't bring themselves to touch your ass

and faded women their looks swept off in a beijing dust storm have no home to go to

and they're out on the street and they're dripping with rain

drip drip drip drip drip drip drip-a-drip

dripping and dripping

now all hail the clap

and the gum in your eyes gets thicker and thicker

and you've had two abortions already

and dear min dear y a dear lan dear mali you're all so dumb

and grown men are no good have you figured it out now

and little girls one fag left in their pockets have no home to go to

and they're out on the street and they're dripping with rain

drip drip drip drip drip drip drip-a-drip

dripping and dripping

now all hail the clap

and the north wind makes the windows rattle

and birch trees shiver with cold

and old men in overcoats hunch their shoulders

and made-up mothers and aunties have nowhere to dance

and long-skirted birds that'll flaunt it at good old houhai have no home to go to

and they're out on the street and they're dripping with rain

drip drip drip drip drip drip drip-a-drip

dripping and dripping

now all hail the clap 
and at twenty you get fat

and at thirty they cut out your gall-bladder

and at forty you're out of breath after doing it once with a crumpet

and at fifty you're dead in the street

and dumb shits who squander their prime like booze have no home to go to

and they're out on the street and they're dripping with rain

drip drip drip drip drip drip drip-a-drip

dripping and dripping

now all hail the clap

and the beijing madam talks down to you

and this here ain't no backwater like your own

and one shot'll cost you three hundred no less

and if you've got dollars that's even better

and countryside deputy heads of department have no home to go to

and they're out on the street and they're dripping with rain

drip drip drip drip drip drip drip-a-drip

dripping and dripping

now all hail the clap

and he's sent his daughter to harvard

and rich daddy himself drives a big old mercedes

and from the fourth ring road you can see the fifth

and a big old au-di will take you straight to the au-lympic village

and the motherland and the people have reached an understanding

and the poor and the artists spoil the city's pretty face

and why not chase'em all into the street dripping with rain

drip drip drip drip drip drip drip-a-drip

dripping and dripping

now all hail the clap

and who says time flies when you're having fun

and who says steamed buns are good when you're hungry

and that thing squatting by the road is a man not a dirty dog

and why all the gullies below every highway

and $i$ write and $i$ write and $i$ 'm just about getting high

and a little hurt if you call me affected

and why not chase bastards like me into the street dripping with rain

drip drip drip drip drip drip drip-a-drip

dripping and dripping

now all hail the clap 
and $i$ met this woman called cao yuan we got a little tipsy

and she sang me some shaoxing opera from "the broken bridge"

and $i$ should know now what is meant by roaming eyes

and orchid fingertips scratching the night light

and you've got yours and i've got mine just one more kiss and nothing else

and $i$ slung on my bag and turned and walked downstairs

and all those me's shaved heads in threads in the night streets dripping with rain

drip drip drip drip drip drip drip-a-drip

dripping and dripping

now all hail the clap

dripping and dripping

now all hail the clap

drip drip drip drip drip drip drip-a-drip

dripping and dripping

now all hail the clap

dripping and dripping

now all hail the clap

now all hail the clap

now all hail the clap

now all hail the clap

now all hail the clap

Especially if read aloud and with the appropriate, relentless drive, such as during the BNU recital in 2001, "All Hail the Clap» is truly typical of Shen's style. It gives a memorable voice to the human experience at the root of Lower Body poetry: hopeless, yet irrepressible.

It also serves to remind us - with reference to the above discussion of one-dimensionality and textual shallowness - that many Lower Body poems are very much suited to the immediacy of recitation. As for their realization on the page, this is highly worthwhile too, even if it doesn't mobilize close-reading strategies in the reader. Lower Body poetry doesn't trigger the painstaking interpretation of syntactic ambiguity or original metaphor, or the identification of sophisticated intertextualities. This does not invalidate its artistic potential, as long as we allow it to activate the appropriate reading expectations; nor does it make the context evoked any less relevant and disturbing. On the 
contrary, the very presentation of these texts as poetry can deepen our understanding of contextual issues such as those laid out above-life in the urban jungle and so on-by offering alternative, unusual angles to complement what we learn through other media and genres. At the same time it leads to reflection on the nature of poetry and reaffirms one of the genre's fundamental features, as we shall see below.

\section{Production and Reception, Cast - But Why Poetry?}

The Lower Body is the first event in Chinese poetry that is inseparably linked with the Internet, which was the perfect medium and milieu for these texts and their authors to find their readers and develop. ${ }^{29}$ The Internet invites swift, nonchalant textual production, and for the censor it is even harder to keep up with than printed matter in the People's Republic, although visions of the web as incapacitating censorship have failed to materialize. As noted in chapter One, online varieties of the literary experience are fast gaining ground in China and may well be the default situation for the youngest generations, but there are many authors and readers for whom one measure of success for such Web Literature (网络文学) continues to be its eventual appearance in print. Accordingly, while the importance of the Internet for the emergence of the Lower Body is beyond all doubt, it has also left an impressive paper trail, including scattered translations into various languages since roughly $2003 .^{30}$

In 2002 Fu Mahuo compiled Poetry Vagabonds: Selected Web Poetry from 2001: The Avant-Garde Poetry Files (诗江湖: 2001网络诗歌年选: 先锋 诗歌档案), a multiple-author anthology whose allegiance lies with the Lower Body's literary lineage. The book is officially catalogued under this title in its Chinese Publications Library (中国版本图书馆) colophon. Much more visibly, however, the cover has Poetry Vagabonds: The Avant-Garde Poetry Files. This shorter name glosses over the web factor, reinforcing the impression that print publications have by no

${ }^{29}$ For avant-garde poetry websites, see the DACHS poetry chapter and Inwood 2008: ch 2. On Yin Lichuan as "internet poetess" and "bloggeress," see Blume 2005, Yin \& Bradbury 2005 and Hirsch 2007: ch 1.

30 Cf Inwood 2008: ch 2. On the continuing significance of publication in print, see Hockx 2004: 121 and Inwood 2008: ch 3. For English translations of Yin's and Shen's poetry, in addition to publications in The Drunken Boat 6-I/II (2006, online) and Full Tilt 1 (2006, online), see Index on Censorship 35-4 (2006). 
means lost their edge in terms of status for all authors and readers. The cover also appropriates the metaphor of the lower body for a range of authors far exceeding the group of that name in an advertising slogan that reads "the lower body of Chinese poetry." The Lower Body group itself, too, boasts a series of old-fashioned paper publications. First of all, there are the two issues of its book-like journal, from July 2000 and March 2001. In 2001 Yin Lichuan and Shen Haobo each published their first individual collection - Yin's is called Make It Feel Even Better (再舒服一些) and also contains fiction and short essays, Shen's is A Handful of Tit, mentioned earlier. The second issue of Wu Wenguang's exquisite Document (现场) series, and the sixth issue of Blue (蓝), a poetry journal put out by Chinese living in Japan, ran special features on the Lower Body in 2001 and 2002 that included poetry, biographical and bibliographical notes, interviews, verse-external explicit poetics, criticism and so on. In 2004 Shen published the abovementioned Great Evil Hidden in the Heart, which the authorities banned, retroactively classifying The Lower Body as an illegal publication in the process; and a survey collection of Yin's poetry called Cause and Effect (因果) appeared in 2006. By then, the Lower Body was no longer active as a group but Yin had become an author of considerable renown, with several readings abroad to her name. Publications featuring other Lower Body poets include anthologies such as Huang Lihai's Selected Poems by Post-70 Chinese Poets ('70后诗人诗选, 2001), Fu Mahuo's Poetry Vagabonds and many more in recent years; and unofficial journals such as Poetry Reference (诗参考), Sunflower (葵), Poetry Text, Poetry and People (诗 歌与人), Original Writing (原创性写作) and Poetry Vagabonds (诗江湖), the precursor of Fu's eponymous anthology. ${ }^{31}$

The original of the phrase poetry vagabonds is 诗江湖, literally 'poetry rivers and lakes,' 江湖 'rivers and lakes' being an age-old, somewhat sentimental term for a world of wanderers and drifters living by their wits and their prowess, on the periphery of law and order or beyond: fortune-tellers, traveling actors, prostitutes, knights and desperadoes. While the image of the poetry scene as one of vagabondage is by no means exclusively linked to the Popular-Intellectual Polemic, it has been a favorite with advocates of Earthly types of poetry ever since the first blows were exchanged. Xu Jiang, for instance, addresses the Intel-

${ }^{31}$ Fu 2002, Yin 2001, Shen Haobo 2001a and 2004, Yin 2006, Huang Lihai 2001. 
lectuals using a rhymed saying in popular martial arts fiction (武侠小 说) style: “Go ahead, wander rivers and lakes in this life, and we'll see who's the first to fall prey to my knife!” (尔等但在江湖飘, 看谁先挨 我的刀!). . $^{32}$

As for its reception, the Lower Body was the most talked-about thing in Chinese poetry in the first few years of the twenty-first century, with recorded discourse sharply divided in its tone and overall assessment. This ranges from anonymous praise and blame on the web to long essays by well-known critics in literary and scholarly journals and books. Let's consider a few examples.

Ma Ce's "The Death of Poetry: On the Need to Guard against the 'Lower Body' Poetry Group Running Wild on a 'Crash-Hot' Road' (诗歌之死: 主要是对狂奔在 “牛 B” 路上的“下半身” 诗歌团体的 必要警惕) is a furious piece, published in Lotus (芙蓉) early in 2001. The word rendered as crash-hot is 牛B, literally 'cow's cunt,' a profane expression of enthusiasm or admiration that Ma uses sarcastically, echoing Lower Body self-advertising slogans; upper case $B$ and the character 逼 are homonyms used to circumvent the taboo on the slang expression for vagina in writing. Ma contextualizes the Lower Body within Chinese poetry and indicts it for self-indulgent tendencies and the explicit aim of creating a stir. He warns that the Lower Body's predilection for profanities is pushing poetry toward the abyss of hedonism. In line with this vision he remains unreceptive to anything about the Lower Body that might possibly be worthwhile. Writing in Poetry Exploration later that year, Xi Yunshu remarks unfavorably on web-related features of the contemporary scene, and on literary activists' lack of background knowledge behind their sloganeering. Xiang Weiguo, author of Shouts from the Margins: A Genealogy of Poets of Modern Han Poetry (边缘的呐喊: 现代性汉诗诗人谱系学, 2002)-with Han referring to the Chinese language rather than ethnicity, just like the unofficial journal mentioned in chapter One - sides with Ma Ce. Xiang also notes that the first section in Yang Ke's 1999 Yearbook of China's New Poetry (1999中国新诗年鉴) already singles out a number of poets later associated with the Lower Body group, and that as such the Lower Body is less "new" than it would like to believe itself to be. He expresses disbelief at the claim, made in the journal Poetry Vagabonds,

${ }^{32}$ Xu Jiang 1999b: 90. The original idiom runs 人在江湖漂, 谁能不挨刀! 'Wandering rivers and lakes in this life, who can avoid falling prey to the knife!' 
that the collective name they later adopted substantially changed their writing styles. ${ }^{33}$

Other critics are much more positive, continuing a trend of growing literary tolerance across the history of the avant-garde at large, as observed in chapter One. They view the Lower Body as not just a particularly irreverent offshoot of Earthly poetics and a force challenging stagnation and incrowd culture but a real contribution to literature. Yi Sha and Xu Jiang are themselves poets and representatives of the Earthly aesthetic that includes the Lower Body. If they cannot be called disinterested parties, this doesn't automatically disqualify them as commentators. Writing in the same issue of Lotus as Ma Ce, both support the Lower Body cause, while warning against the dangers of the general hullabaloo's obstruction of poetry itself (Yi Sha), and of wanting to be cool for cool's sake (Xu Jiang). Xu calls Shen Haobo a poetry freak, with regard to his astonishing activism: authorial, editorial, critical, organizational and so on. Xie Youshun, writing in Flower City, also in 2001, mobilizes an impressive amount of theory to make a case for the Lower Body. This ironically recalls the desire of the Lower Body and related trends to tear down ivory towers in literature and criticism, and confirms their allegations that professional readers tend to speak incomprehensible jargon. In itself this need not invalidate Xie's argument. He outlines a fundamental opposition of the Lower Body on the one hand and Haizi - as the epitome of a larger, "lyrical" trend - on the other. The latter's "martyrdom" and mythification, following his suicide, continue to infuriate Yi Sha and Xu Jiang as well, as we have seen in chapter Three. Xie cautions against a narrow vision of the Lower Body, meaning too much attention to genitals and sex. Writing in Poetry Exploration in 2002, Chen Zhongyi lists corporealized writing (肉身化写作) as one of four important directions in contemporary poetry. He expands this section of his survey in another positive review, published in the same year in the Lower Body special feature in Blue, with the unofficial status of this journal allowing him greater candor on Lower Body subject matter and language. Chen advocates a balance of the corporeal and the mental, of the senses and the mind; and he sees Lower Body poetry as inseparable from social change and web culture. Zhang Qinghua's preface to China's Best

${ }^{33}$ Ma 2001, Xi Yunshu 2001, Xiang 2002: 173-176, Yang Ke 2000, Shen Haobo \& Yin 2001. 
Poetry of 2001 (2001年中国最佳诗歌, 2002) is an inspirational essay that portrays the Lower Body as a sign of innovation and the core of a literary generation that had just been identified in Chinese-domestic criticism at the time: Post-70, meaning that the authors in question were born after 1970. Zhang reminds the reader that avant-garde shifts away from the Elevated and toward the Earthly, which started in the mid-1980s, have never yet managed to enter the vision of the "common" people and that all avant-garde writing remains part of elite culture.

In recent years, the Lower Body has secured a place in literary history. By way of an example, Luo Zhenya's 2005 survey history On the Avant-Garde after Obscure Poetry dedicates a full chapter to Post-70 poetry, with the Lower Body as the top-of-the-bill act (领衔) mentioned in the chapter's title. Luo presents a balanced account that recognizes the Lower Body's significance as the main representative of Post-Colloquial Writing, the other constituent of Post-70 poetry being what he calls the Academicized Writing (泛学院化写作) of authors including $\mathrm{Hu}$ Xudong, Jiang Hao, Jiang Tao, Wang Ai and Zhou Zan. Within the Post-70 framework, these two strands can be seen as affiliated with the Earthly and the Elevated, respectively. Luo rightly notes that one of the Lower Body's distinguishing features - and of Post-70 poetry at large - is that it has produced many "happy texts" (快乐的文本) and displays little suffering (痛苦) of the kind one may encounter in other poetry. He concludes that publicity-wise, Post-70 poetry, with the Lower Body as its trailblazer, has enough of a presence to pose a real challenge to previous literary generations such as the Third Generation and Poetry of the Nineties, but that its promise needs yet to materialize. Another instance of recognition of the Lower Body as part of contemporary culture - and, within that culture, of a lineage of bad behavior, to which we turn below-is found in Zhu Dake's The Hooligan Banquet: Contemporary China's Hooligan Narrative (流讯盛宴: 当代中国的流讯叙事, 2006). Zhu comments approvingly on Yin Lichuan's poetry. He writes of Shen Haobo's work in disparaging terms, but does note the force of Shen's literary activism. ${ }^{34}$

Of the damning reactions sampled above Xi Yunshu stands out in that he cites his own astonishment in the face of recent develop-

${ }^{34}$ Yi 2001a, Xu Jiang 2001, Xie Youshun 2001, Chen Zhongyi 2002a and 2002b, Zhang Qinghua 2002, Luo Zhenya 2005: ch 4, Zhu Dake 2006: 283-287. 
ments, realizing that an incompatibility of critical expectations and actual poetic production cannot be blamed exclusively on the poets. Such incompatibility and the resulting crisis discourse are of course nothing new, in China or elsewhere. Wu Sijing has suggested that in the contemporary Chinese case, the mismatch of poetry and criticism and the particularly acute crisis discourse of the late 1990s go back to the mid-1980s. Then, the new poetry's sheer abundance and its extraverted presentation began to drown out and ignore its commentators or, in Wu's words, struck them speechless - not least because it produced aesthetic trends that were incomprehensible and unacceptable even to critics who were generally sympathetic to the avant-garde..$^{35}$

The defining publications of the Lower Body show them as including twelve authors, all born between 1970 and 1980, two of them women: Shen Haobo, Yin Lichuan (ㅇ), Sheng Xing, Li Hongqi, Nanren, Duoyu, Wu Ang (P), Zhu Jian, Ma Fei, Xuanyuanshike, Li Shijiang and A Fei. Loosely organized as it was - on the basis of a broadly defined literary affinity - the group can also be seen to include the work of other authors: Shu, for instance, who made a well-received contribution to the BNU recital. That most of the poets are men helps explain their macho-sexist style, which became self-perpetuating as the Lower Body gained momentum. In their turn, women poets Yin Lichuan and Wu Ang did little to subvert conventional gender patterns, if we recognize that images of femmes fatales do not advance female emancipation. A remarkable thing about the Lower Body was that the authors put forth a consciously hip visual presentation, which was uncommon in literary circles at the time but has since spread far beyond the unofficial journals that initiated it. This was very much a sign of the times, with visual media encroaching on the hegemony of the written word, as noted in chapter One: impossible camera angles, flippant postures, wild hairdo's, Yin Lichuan lighting cigarettes with her face averted, Shen Haobo's "Record of a Head Shave" (剃头记) and so on. These and similar images are part of a literary undertaking that is playful and dedicated at the same time.

For all their loudness and self-indulgence, the Lower Body poets by no means saw their undertaking as the measure of all things and were more inclined to self-mockery than most of their contemporaries. They happily accepted that many of their poems were little more than

${ }^{35}$ Wu Sijing 1996. 


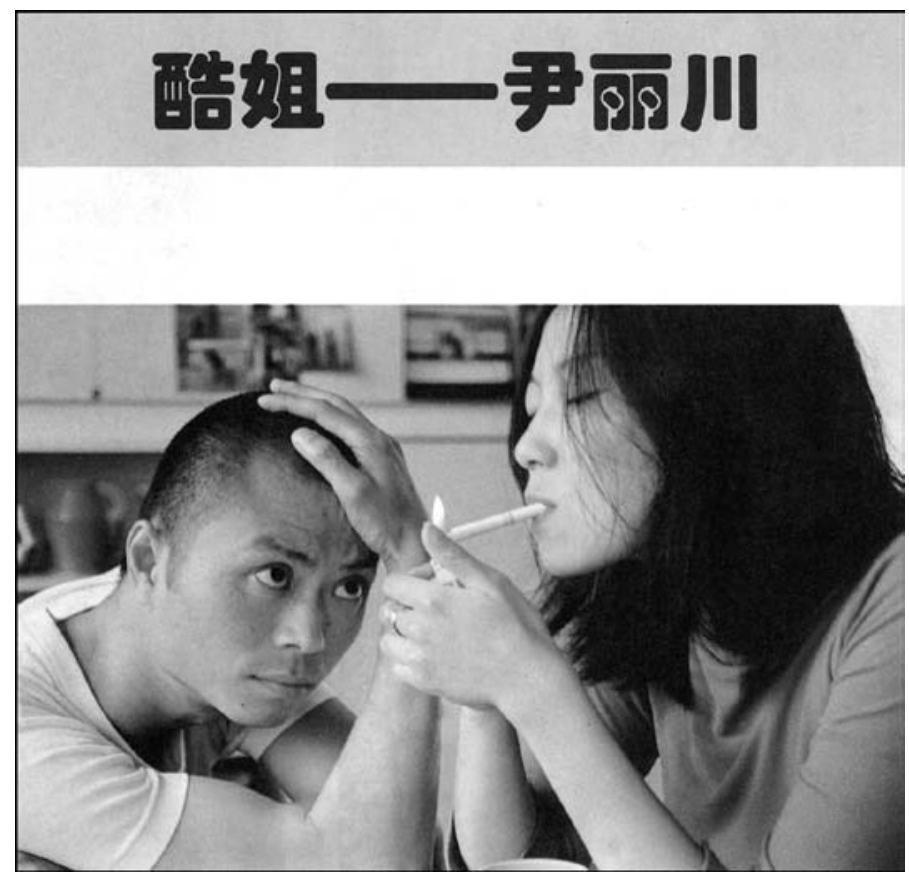

Figure 9.4. "Cool sister" Yin Lichuan (Poetry Text 4 [2001]: 10)

fleeting ideas and impressions written up with line breaks: provocative, perhaps even shocking or absurd, worth reading but not rereading. This would make their texts little more than zeitgeist commentaries that could just as well have availed themselves of genres other than poetry, such as political pamphlets, newspaper editorials and social science reports.

Or could they? For the Lower Body's best poems it is precisely the fact that their authors did not write pamphlets, editorials and reports that leads one to reflection on the genre of poetry and reaffirms that the Lower Body is more than a succès de scandale, in spite of censorial reflexes such as Ma Ce's. These have always befallen lawless literature, and they always will.

Why poetry? Contrary to Shen Haobo's manifesto, the Lower Body has all sorts of things to do with knowledge, culture and tradition, and even with poetic sentiment, albeit in a new time and a new style; and maybe with lyricism and philosophy as well, for even a minimalist poetics makes poetry the precipitation of such things, conscious or un- 


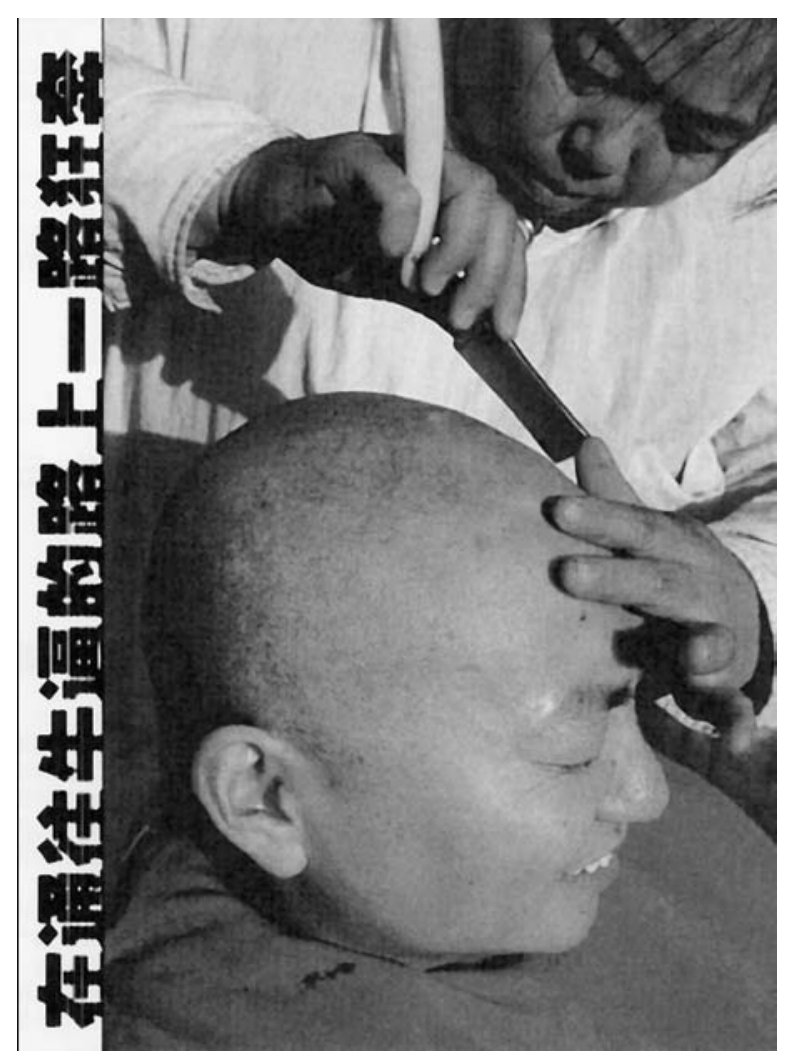

Figure 9.5. "Running Wild on a Crash-Hot Road": Shen Haobo's "Record of a Head Shave" (Poetry Vagabonds 1 [2001]: 12)

conscious. The Lower Body's alleged unconcern is debatable along similar lines. One who is truly unconcerned doesn't write - unless one writes for the money, but Lower Body poetry is financially even more unmarketable than most other avant-garde texts. In fact, Lower Body poetry does display a palpable concern with not just the horrors of a time of radical social change but also its pleasures. But the crux of the matter is poetry's ability to be about something else and yet, as an artifact, be about itself and draw attention to itself: to connect with others and yet stand alone. Lower Body poetry happens on the interface of its rootedness in the reality of its surroundings and art's right to be elsewhere. It couldn't do without either. 


\section{A Poetia Lineage}

Lower Body poetry didn't appear out of nowhere. Below, I will briefly sketch its lineage within the avant-garde, with reference to the Elevated and Earthly aesthetics - again, not as pigeonholes but as coordinates in a multidimensional body of texts and metatexts, to help us to identify overall trends within the avant-garde and kinship between individual oeuvres.

For positioning themselves during their heyday in the years 2000-2002, Lower Body poets often referred to the notion of the Popular as this had been advertised during the Polemic in 1998-2000. For them, the Polemic derived its status as a frame of reference from the fact that it had brought the divergence of the Elevated and the Earthly to a head during their formative years as poets. Incidentally, Shen Haobo was by no means uncritical of the Popular, but his discontent in this respect pales in comparison with his vicious attacks on anything that could be remotely associated with Intellectual Writing. ${ }^{36}$ At any rate, the Lower Body is one of several extreme manifestations of the Earthly orientation in the early twenty-first century, two others being the Trash School and the Low Poetry Movement of subsequent years, studied in recent research by Heather Inwood and Michael Day respectively. ${ }^{37}$ Explicit poetics and other comments by Lower Body authors confirm its affinity with the Earthly. For outlining its provenance we focus on three salient features.

\section{Demystification}

What I have called the rejective quality of Lower Body poetry is also visible in Shen Haobo's manifesto, as one of many deconstructions of high-blown images of poethood by Shen and others. As such the Lower Body partakes in a poetics of demystification and indeed desecration that is discussed at various points in this study. This poetics goes back to authors such as Han Dong, Yu Jian and Yi Sha and journals such as Them and Not-Not. In its early stages, it is to some extent negatively defined as the rejection of Obscure Poetry. Later, it finds itself in opposition to many of the categories on the Elevated side in the list

\footnotetext{
36 For Shen's criticism of the Popular, see Shen Haobo $2001 b$.

37 Inwood 2008: ch 2, Day 2007a.
} 
of dichotomies that make up the contrast of Elevated and Earthly outlined in chapter One: the "lyrical," the "mythical," the "utopian," the "Westernized" and so on. It bears reiteration that the poetry of demystifiers from Han Dong to Shen Haobo far transcends their resistance to other poetries, as I hope to have shown in the preceding pages.

By way of concrete examples, some of which have been previously discussed, Han Dong's «Of the Wild Goose Pagoda» and «So You've Seen the Sea» effectively deconstruct canonical landmarks of Chinese civilization and clichéd, inflated imagery. Yi Sha's poetry does something similar, famous texts being «As the Train Crosses the Yellow River» (车过黄河, 1988) and «Starve the Poets», with the latter specifically targeting Haizi and his epigones. More explicitly than Han Dong in «So You've Seen the Sea», Yi Sha proceeds from a perceived abuse of poetic imagery to contempt for the arrogance of poet-hood. Yu Jian's oeuvre, most notably «File 0», extends demystification to the sacred status of poetic language. ${ }^{38}$

\section{Bad Behavior}

Another feature of Lower Body poetics that builds on earlier trends in its literary surroundings is that of being unruly and offensive in conventional terms. That is, conventional within the avant-garde, to say nothing of government-sanctioned literary orthodoxy. This poetics of bad behavior manifests itself in the systematic breaching of (socio-)sexual and other bodily taboos such as prostitution, substance abuse, masturbation, defecation, urination, disease and violence; in the denigration of education and learning, often through association with these taboos; and in the shameless display of sexism, specifically misogyny, homophobia and a general machismo. Here, too, there are well-known precedents and parallels, overlapping with the category of demystification. Yet again, one thinks of Yi Sha. Other, earlier authors that come to mind include Macho Man Li Yawei and Not-Not poet Yang Li. Notably, the impact of their bad behavior went well beyond poetry. According to Zhu Dake, the cradle of "hooligan discourse" in other literary genres and art in contemporary China stood in avantgarde poetry of the 1980 s. $^{39}$

${ }^{38}$ Han 2002: 10, 14; Yi 1994: 5, 3; Yu Jian 1994.
${ }^{39}$ Zhu Dake 2006: ch 6. 
«The View Is Limitless» (风光无限, 1999), the first poem in Yi Sha's second officially published collection of poetry, opens with the joys of defecation linked to the classical-literary topos of ascending a mountain to take in the view. This and other taboos occur throughout his oeuvre, such as in "Address at a Seminar on Women's Literature» (在女性文学研讨会上的发言, 1997) and «My [Academic] Advisor and I» (我和我的导师, 1996). An early instance of the denigration of higher education is Li Yawei's «The Chinese Department» (中文系, 1984). Simultaneous with the emergence of the Lower Body, Yang Li published «Fire the Cannon» (打炮, 1999?), a long-drawn out account of mostly prostitutional sex, firing the cannon being phallocentric slang for intercourse and ejaculation. The poem first appeared in 2000 in Poetry Reference. In addition to many other types of poetry, this influential, long-standing unofficial journal has consistently given the poetics of bad behavior opportunities for publication. So has Original Writing, which carried «Fire the Cannon» in 2001. ${ }^{40}$

\section{Social Concern}

Of special interest in this literary-genealogical exercise is Lower Body poetry's expression of social concern. I use this broad notion specifically to refer to the fact that many Lower Body poems engage with issues of social justice and discontent that result from present-day China's radical transformation. One example is the widening gap between urban and rural lives and livelihoods, and generally between haves and have-nots and the powerful and the powerless. Another is young people's rejection of socialist ideology and its institutions, not to say their indifference to these things, certainly since the 1990s. This is starkly visible in an overall incompatibility of experience from one generation to the next, in areas ranging from norms and values for social relations to tastes in fashion, music, literature and so on. Shen Haobo's and Yin Lichuan's poetry illustrates this point, which is driven home by the astonished reactions of several of their critics.

Not just since the 1990s, a decade that has inspired views of China as a postsocialist and jungle-capitalist society, but in fact ever since the avant-garde's early years there have been many examples of socially

${ }^{40}$ Yi 1999a: 1-44, 125; Zhongdao 1998: 259; Li Yawei 2006: 6-11; Original Writing 2 (2001): 4-9. 
concerned authors of Earthly persuasion. This includes those writing in Them in the mid-1980s as well as authors associated with the Low Poetry Movement whose sense of social responsibility has been pointed out by Day, and self-styled philosopher and musician Wenmang (1977) - a name meaning 'illiterate' - who describes the inside of a psychiatric institution in «Burn to Death All You Fucked-Up People» (烧死你们这些狗日的, 2002). ${ }^{41}$ Wenmang's belligerent title addresses the institution's authorities, not the patients: he portrays the latter with compassion. Notably, however, unlike demystification and bad behavior, the poetics of social concern is not at all exclusive to oeuvres that can be subsumed under the Earthly orientation. It is something the Lower Body has in common with authors from across the array of styles that have made up the avant-garde in the past decades - and there is, of course, an interface here with traditional Chinese views of poetry.

The best-known example of social concern at the Elevated end of the spectrum lies in the humanist orientation of much late 1970s and early 1980s Obscure Poetry, in texts such as Bei Dao's «Declaration», Shu Ting's «Motherland, My Beloved Motherland» and Jiang He's «Monument». In hindsight these poems, which marked the transition from Maoist orthodoxy to the avant-garde, border on socio-political pamphleteering. Later, artistically sophisticated examples of Elevated social concern are Wang Jiaxin's «Pasternak» (帕斯捷尔纳克, 1990) and Xiao Kaiyu's «The People's Bank» (人民银行, 1997). ${ }^{42}$

A final example of social concern as a notion bridging the gap between the Elevated and the Earthly - and one of particular relevanceis that of Yan Jun, in «Against All Organized Deception», which we will examine more closely in chapter Thirteen. Yan's poem is truly contemporary with the Lower Body and the similarities are striking. «Against» is anchored in present-day, rough-edged Chinese realities. It is streetwise, angry and energizing, but it also displays self-mockery and humor. Its social concern is visible in Yan's depiction of things like the abuse of police power, the growing dominance of consumerism and entertainment culture, and ecological disaster. Unlike the Lower Body, however, «Against» is anything but cynical or decadent. It is a contemplative and seriously political poem with anarchist overtones.

${ }^{41}$ Original Writing 3 (2002): 39-41.

${ }^{42}$ Yan Yuejun et al 1985: 19, 42-43, 190-192; Wang Jiaxin 1997: 64-66, Xiao Kaiyu 2004: 57-58. 
As for literary technique, it employs an abundance of associative and imaginative imagery in a prose-poetic form that strongly recalls $\mathrm{Xi}$ Chuan's work. In this respect, it also displays kinship with the Elevated aesthetic. $^{43}$

Poets like Shen Haobo and Yan Jun have more to say than can be handled within an "autonomous" realm of literature. As such, their predecessors in modern times range far and wide, from Liang Qichao in China to Marinetti in Italy, to name but two examples of roughly a hundred years ago. The work of Liang comes to mind because it stands at the beginning of modern Chinese literature; that of Marinetti, because the texts of Futurism, just like Shen's and Yan's, are driven and defiant if not aggressive, and marked by the phenomenon of learning and culture ostensibly turning on themselves. Crucially, both Liang and Marinetti consider art that explicitly positions itself in relation to its extra-literary surroundings capable of effecting social change. In fact, especially for Liang but also for Marinetti, the projection of social change is a point of departure for literature rather than its possible conclusion. ${ }^{4}$

As a common feature of diverse oeuvres in the Chinese avant-garde, and one that transcends the dichotomies that have led me to identify the Elevated and Earthly aesthetics, social concern is firmly rooted in today's extra-literary realities. In many other places contemporary poetry tends to function as a buffer against the world outside literature instead. In China, poetry as the expression of social concern stands in a long, strong tradition that makes it a self-evident extension of the poet-official's involvement in governing the state and actively contributing to the well-being of society. In spite of modern poets' declared dissociation from China's literary past, this aspect of traditional poetics is one of several factors that inform the work of numerous authors from the Republican and Maoist periods, and from the early years of the Reform period - as well as that of younger generations such as the Lower Body poets, albeit irregularly and in provocative, noninstitutional or indeed anti-institutional fashion.

\footnotetext{
43 Yan Jun 2001: 149-152.

44 Martin 1973, Weber 1960: 241-246.
} 
Different from their predecessors, the Lower Body poets and authors like Yan Jun forgo claims to poethood as a means of speaking for others and something that confers high status. At the same time they pursue personal publicity and fame, or at least they don't eschew these things. Their glamor is that of being hip and disaffected but still making a difference in terms of social engagement. Any easy dismissal of this duality in their work turns a blind eye to fascinating relations between social change and cultural development in China today. 
Maghiel van Crevel - 978-90-47-44273-8 Downloaded from Brill.com $04 / 25 / 2023$ 11:38:45PM via free access 


\section{CHAPTER TEN}

\section{NOT AT FAGE VALUE: XI CHUAN'S EXPLICIT POETICS}

The previous case studies have by and large focused on text, with large metatextual and contextual components in chapters Three and Four. Starting with the present chapter, the next three shift to metatext. This chapter and chapter Eleven look into the explicit poetics of individual poets, meaning their view of literature and specifically of poetry, as expounded in so many words. Chapter Twelve examines the PopularIntellectual Polemic.

Explicit poetics can include creative writing, or "primary" texts, as well as verse-external, critical discourse, or "secondary" texts, for one can speak of poetry in poetry as well as in essays, interviews and so on. One's verse-external poetics, then, is a subset of one's explicit poetics. I have cast my net wider than the verse-external, in order to extend the analysis to a text by Xi Chuan that is difficult to classify as either primary $\approx$ creative or secondary $\approx$ critical, and that is neither a poem nor an essay.

Good clean curiosity aside, why would we want to know about poets' explicit poetics, verse-external or otherwise? As far as I am concerned, with reference to what I have said about authorial intent, research such as this is not to test practice against theory or to ask whether poets are reliable readers of their own work, much less to check whether they keep their promises or realize their professed ideals. The answers to such questions may tell us that a given author's poetry and their poetics match or that they don't, but this doesn't necessarily add much to our appreciation of either. As noted in the previous chapter, there is no law according to which an individual's poetry and their poetics must be consistent in order to be interesting. Conversely, if someone's explicit poetics turns out to be indispensable for a successful reading of their poetry, it arguably takes on the status of text rather than metatext - but again, these things can overlap. More generally, we may wish to view a given author's explicit poetics in part or in whole as extensions of their poetry, because there is a difference

(C) MAGHIEL VAN CREVEL, 2008 | DOI 10.1163/9789047442738_011

This is an open access chapter distributed under the terms of the Creative Commons AttributionNoncommercial 3.0 Unported (CC-BY-NC 3.0) License. 
between poets and other artists talking about their art. For painters, musicians and so on, the language in which they speak of their work is a truly secondary medium. For poets, however - and of course for fiction writers and dramatists - language is the shared medium of both primary and secondary texts, of both creative writing and critical discourse, and the boundaries are easily blurred. This is most obvious when poetical statements are couched in metaphor. We shall see that in the case of Xi Chuan, the conventional relationship of primary and secondary texts is occasionally inverted, when his poetry clarifies his poetics instead of the other way around.

My attention to metatext is also motivated by the scope and intensity of metatextual activity in contemporary China. There are frankly stunning amounts of metatext by avant-garde poets, foregrounding what Bourdieu calls the specific principle of legitimacy, or consecration of artists by other artists: a large number of Chinese poets whose work constitutes a canon in the making have also published on poetry. ${ }^{1}$ From among them, I have chosen to write about Xi Chuan in the present chapter, and about Han Dong and Yu Jian in the next. As poets, all three have exerted a palpable influence on the development of the avant-garde beyond its initial stages, and they have some of the most interesting metatextual writing to their names. Furthermore, $\mathrm{Xi}$ Chuan is widely seen as a leading representative of the Elevated aesthetic, and Han and Yu count as quintessentially Earthly authors. While this is understandable, it is important to note - as elsewhere in this study - that neither Xi Chuan nor Han and Yu are anything like "pure" in this respect.

If this chapter is shorter and ranges less widely than the next, this is because Xi Chuan has produced much less metatext than Han Dong and especially Yu Jian. In addition, contentwise, Han's and Yu's metatexts contain much more commentary on the actualities of the avant-garde scene than Xi Chuan's. As regards the organization of this chapter and the next, although there is considerable overlap between the topics explored in Xi Chuan's poetics on the one hand and in Han's and Yu's on the other, their differences are substantial enough to justify structuring each chapter according to its own material rather than adhering to exactly the same subdivisions. In both chapters, I have opted for thematic discussions that move back and forth

\footnotetext{
${ }^{1}$ Bourdieu 1993: 50-51.
} 
through time and include much literal citation so as to give the reader an immediate sense of the discourse. My aim has been to outline $\mathrm{Xi}$ Chuan's, Han Dong's and Yu Jian's poetics and reflect on this material mostly from within its self-assigned frames of reference, rather than set it off against other possible conceptualizations of poetry or against the practice of poetry in contemporary China. Yet, the selection of what I perceive as significant topics and representative passages is in itself of course an act of interpretation.

Below, in section 1, I consider three substantial explicit-poetical pieces by Xi Chuan (using in-text references to avoid inordinate numbers of near-identical footnotes), with occasional reference to other sources. In section 2, I offer a brief classification of Xi Chuan's poetics with reference to $\mathrm{M} \mathrm{H}$ Abrams' typology of theories of poetry and A L Sötemann's application thereof to the explicit poetics of individual poets, followed by tentative remarks on Xi Chuan's representativeness for the avant-garde at large. As in chapter One, my generalization of masculine pronouns for the poet reflects the near-exclusive male dominance of the metatextual arena, all the more remarkable in light of women poets' important contributions in the textual dimension.

\section{Explanations, Issues and Alghemy}

A medicinal prescription may be expected to be clear, unambiguous and meaningful in the sense of being useful, and is to be taken at face value. At the other extreme lies poetry, with the prerogative of the enigma, ambiguity and indeed - in the terminology of Jan de Roder, cited in chapter Eight - an inclination toward the unmeaning; and of being "useless," although not meaningless. As such, it is not to be taken at face value, and may give rise to a strong interpretive impulse instead. Xi Chuan's metatexts underscore this feature of poetry. In addition, just like his poetry, his metatexts are themselves of the kind that triggers the urge to interpret.

My analysis revolves around three texts: a short piece called "The Author's Explanation of His Art” (艺术自释, 1986), included in Xu Jingya's 1988 Overview of Chinese Modernist Poetry Groups 1986-1988, the long article "On Nine Issues in Poetics" (关于诗学中的九个问 题, 1995), first published in the literary journal Mountain Flower (山 花), and a remarkable series of poetical statements called "The Al- 
chemy of Poetry" (诗歌炼金术), written in 1992-1993 and published in Poetry Exploration in 1994 but substantially revised and expanded in 1999 for publication in one of Xi Chuan's books, entitled Water Stains (水渍, 2001). ${ }^{2}$ The former two ("Explanation" and "Issues" for short) are straightforward expository discourse about poetry. The latter ("Alchemy 1" / "Alchemy 2") is something between a secondary and a primary text, between critical and creative writing. I wouldn't confidently call it verse-external, if only because it somehow borders on the poetic mode, visible in things like the use of imagery and a language usage that may be called affected in the neutral sense, or at least selfconscious. As such it is the least "reliable" of the three-if we were to look for the reliability associated with medicinal prescriptions, that is.

I will examine Xi Chuan's poetics according to the subject matter that is covered in these three pieces, in the following order: poethood, inspiration, poetry's relation to reality, technique, form, and poetic language and poetry itself. As for the final item, the fact that in $\mathrm{Xi}$ Chuan's metatextual writing poetic language and poetry itself are difficult to disentangle can be taken as a resonance of his textual production, especially with regard to the issues reviewed in chapter Five; but in light of the preceding paragraphs, the reader won't be surprised if I refrain from drawing any conclusions from this observation-say, on the consistency of his texts and his metatexts.

\section{The Poet}

In Xi Chuan's explicit poetics, the poet features but isn't terribly important. An early description in "Explanation" endows him with supernatural powers in religious terms:

The poet is both God and Devil.

"Alchemy 1" $(1-2)^{3}$ contains a more down-to-earth and modest claim:

\footnotetext{
2 Xi Chuan 1988, 1995, 1994b and 2001: 223-228.

3 Parenthesized numbers following "Issues", "Alchemy 1" and "Alchemy 2" refer to the numbered entries in the texts. After "Alchemy 2," the abbreviation prev, meaning 'previously,' indicates that the passage in question also occurs in "Alchemy 1." E.g. "Alchemy 2" (46 prev 31) means "entry 46 in "Alchemy 2," previously found as entry 31 in "Alchemy 1 ".'
} 
The poet is neither a commoner nor a noble; the poet is an intellectual, a thinking person.

The poet is a laborer.

This is revised to read more cautiously in "Alchemy 2" (1-2):

The poet is neither a commoner nor a noble, but one affected [感受] by thought and expression.

The poet is one type of intellectual, an alternative laborer.

This change may have been informed by renewed sensitivities surrounding the notion of the intellectual (知识分子), to whose painful history under Maoism was added a quirky chapter in the late 1990s during the Popular-Intellectual Polemic. The importance of the intellectual side to poetry is further toned down by Xi Chuan's emphasis on its affective complement.

Xi Chuan isn't the first poet from China or elsewhere to celebrate poetry's undefinability, or to call the definition - by poets - of poetry undesirable. In "Alchemy 2" (87), he writes:

If at all possible, the poet should avoid defining poetry.

As an utterance that is part of his explicit poetics, this is a conspicuous instance of irony, more specifically of self-subversion. In practice, $\mathrm{Xi}$ Chuan happily fails to heed his own warning against the dangers of definition: not just for poethood, inspiration, the writing process and so on but also for the phenomenon of poetry itself, as we shall see below.

In "Alchemy 2" (65), the poet's divine qualities as asserted in "Explanation" are superseded by the magical:

When the strong poet touches iron, it turns to gold.

Both the poet as God and the Devil and his successor, the poet as alchemist, possess special powers. However, the following admonitions in "Issues" (4) and "Alchemy 2" (5) critically address the cult of poetry in contemporary China as identified by Michelle Yeh, of which I have observed that it is in many ways a cult of poet-hood:

There are even those who announce that although they do not write poetry, they are poets.

In the writing of poetry, do not be concerned with your poet status. 


\section{Inspiration}

In accordance with the above injunction, Xi Chuan has more to say about various aspects of the writing process than about poethood. Let's first look at his ideas about inspiration, in "Alchemy 2" (46 prev 31):

Inspiration is the same thing as discovery. Penetrating discovery.

Discovering something that already exists - even if discovery triggers an act of creation - is notably different from a concept of "pure" creation from nothing. Xi Chuan makes only one reference to another, less easily grasped type of inspiration, in "Issues" (9):

Since ["Why I Write"] is a mysterious question, all we can do is to answer it in mysterious fashion.

Here, in what is an expository essay on poetry with much room for rational argumentation and linkage to concrete literary practice, he likens the drive to write to the mythical messenger that knocked on Mozart's door to request the writing of a requiem-Mozart's own?that the sickly, impoverished composer would never finish. Xi Chuan refers to the messenger as "the man in black":

Some venture that he is God, some that he is the Devil, some that he is death [死神, literally 'the god of death'], but I would venture that he is poetry [诗神, 'the god of poetry'].

This mysterious, somewhat overbearing fellow is not the same as the nine Muses on the Olympus as we know them. Those girls, idle and unoccupied, both dignified and generous, both wise and clever and deft, have as their special task to fan cool air to sophisticated natural talents. But the one that truly compels us to write is this man, whose identity is unclear. He represents the myriad things in the universe, history, humanity and that blind force carried by each of us as individuals, a force of dying and living, a force of song and silence. Face covered, he appears at our side, stunning us out of our wits, leaving us at a loss with our hands thrown in the air. To calm down, all we can do is lay out the writing paper in front of us. 


\section{Poetry's Relation to Reality}

Another aspect of the writing process is poetry's relation to reality. In "Alchemy 2" (61, 22), Xi Chuan highlights two distinct roles for reality, or the world outside the poem. That of a frame of reference:

... Make nature and human life the frame of reference for writing and that of raw material to be processed:

Knowledge that constitutes the resources for writing is reformed in writing.

Reality's latter role is supported by several other statements $(11,35$ prev 21, 86):

As regards the transmission of culture, people attach too much importance to the relation of poet (poem) and poet (poem), overlooking that of poet (poem) and non-poet (non-poem).

First, one must love life; then, one must scorn life. To love life makes poetry plentiful, to scorn life makes poetry refined.

There exists no poetry in isolation from myth, history and existence, just as there exists no language in isolation from myth, history and existence.

And most succinctly, in a 1997 essay called "On the Road" (在路 上): ${ }^{4}$

Literature doesn't have to reflect life, but certainly has its source in life.

Similarly, "Issues" (5) states that in order to discover poetic sentiment in all things - that is, in order to be inspired - the poet must

cut into life, and be in touch with all things.

All of the above stress the importance of reality as indispensable raw material for poetry.

By contrast, as noted in chapter Five, the early Xi Chuan advocates a "pure" poetry that stands aloof from reality. "Explanation," for example, makes no reference whatsoever to poetry's relation to reality. The radical change in his views on the matter in 1989 and the early 1990s can be gleaned from both editions of "Alchemy" (42 prev 27):

Pure poetry excludes [拒绝], humane poetry includes [包容].

\footnotetext{
${ }^{4}$ Xi Chuan 1997e: 69.
} 
According to "Alchemy 2" (62), reality may be indispensable raw material, but it isn't poetry: it needs to be transformed in order for poetry to emerge. The following statement still leaves reality intact, and can mean that the distinction of reality and poetry is simply one of perspective:

The language of poetry is not everyday language; even if the poet uses everyday language, it is not in the everyday sense.

But Xi Chuan also presents the distinction of reality and poetry as an opposition, so that the one can flourish only to the detriment of the other (61 prev 39$)$ :

Let language test its strength against nature, let language test its strength against human life...

In the same vein, with a rare, politically impassioned cry from the heart in "Alchemy 1" (60), Xi Chuan declares that

Poetry will never bow its head to any non-poetic force

and in "Alchemy 2" (98) he adds that

this is to reaffirm the independence of writing.

In late 1990s China, the need to assert the independence of writing brings several things to mind. First, a Maoist vision that has in many ways become an anachronism but continues to inform official cultural policy, and that sees literature as accountable for its social effect and as subordinate to politics. Second, a traditional poetics summed up as literature to convey the Way in the broadest sense, with the Way denoting dominant socio-political ideology in a given historical situation. Third, and perhaps most urgently, the sweeping commercialization of cultural life in China as a force threatening the integrity of literature and art - although here, we should bear in mind that things are less simple than quick dichotomies of the spiritual and the material suggest, as noted in chapters One and Five.

\section{Technique}

Poetic technique is another part of the writing process. Xi Chuan has clear ideas about technique, with equally clear implications for his view of poethood. If we take things like (scholarly) knowledge (知识, 
as in 知识分子 'intellectual') and erudition as components of poetic technique, our attention is drawn to this entry in "Alchemy 2" (21):

To respect ignorance as power is the greatest ignorance.

This statement - which recalls Lan Dizhi's defense of learning in his comments on Xi Chuan's poetry - is likely inspired by the PopularIntellectual Polemic, and perhaps by anti-intellectual trends of the Mao era. But Xi Chuan has consistently emphasized the importance of other aspects of technique as well. Early on, in "Explanation" he writes of

... the pursuit of perfection in structure, sound, imagery

and evaluates poetry according to

how consummate are the poem's internal structure and its technique.

\section{Form}

Closely related to this proposition is of course the matter of poetic form. As we have seen, Xi Chuan's regard for form in his poetry is audible and visible in several ways: rhythm and rhyme, and more generally, his idiosyncratic "stanzas" or paragraphs of prose poetry. As for his explicit poetics, in "Alchemy 2" (68 prev 43, 73) he writes:

The poem's form is the same thing as its music.

One type of poetic quality: sound effects, wild with joy, attained by language at its highest.

Another remark on form leaves the reader, characteristically, with more questions than answers (69 prev 44):

The poem's external form can be used time and again, but each poem's internal form can be used only once.

External form probably means objectifiable formal features. Internal form might mean something like the poem's unique individual dynamics within these features.

\section{Poetic Language and Poetry Itself}

In light of several of his comments examined so far, it need not surprise us that Xi Chuan's view of poetry is not one of spontaneous, 
uncontrollable outbursts of creativity or emotion, not even in the early "Explanation":

Please let me practice moderation.

Note the prayer-like formula please let me, repeated several times in this short piece: to the early Xi Chuan, poetry is like religion. The later $\mathrm{Xi}$ Chuan holds that powerful feelings can, in fact, damage poetry. "Issues" (4) contains this passage:

I do not believe in writing without practice . . But in China, under the mistaken guidance of "poetry verbalizes emotion," many people think that for good poetry, all you need to do is verbalize emotion, that to be a poet, all you need is passion [激情] . . . Writing poetry is first of all a skill, and only then an art . . I have never believed things like "Li Bai drinking to his heart's content, poems by the score" [李白斗酒诗百篇], I have never believed that poethood comes from a poetic way of life.

In chapter One, I cited both Stephen Owen's and Zhang Longxi's English renditions of 诗言志 (poetry articulates what is on the mind intently and poetry verbalizes emotion, respectively). In the above passage I follow Zhang, in light of Xi Chuan's interpretation of 志 as passion.

"Alchemy 2" (43 prev 28) shows that it is not that Xi Chuan has no time for passion, but that he is particular about its uses:

One must foster the passion of imagination, to produce not an outpouring of it but a sculpture.

Then there is Xi Chuan's denunciation of "pretty literature," meaning writing that is characterized by frivolousness rather than authenticity, made in "Issues" (6) and earlier cited in chapter Five:

Pretty literature is opposed to creativity, imagination, irony, metaphor, the spirit of experiment and of doubt: it is opposed to the difficulty of writing.

This passage points to important if abstract components of Xi Chuan's normative view of poetry: everything that pretty literature is said to oppose. It is on poetry itself, rather than on poethood or the writing process, that $\mathrm{Xi}$ Chuan has produced the most abundant, ramified and original discourse, and that his development over time is most profound. Initially, in "Explanation," he writes that

Facing poetry is like facing religion

and 
Different classes of poetry occur in three dimensions: (1) resourcefulness, (2) wisdom, and (3) truth. But what I call truth is surmise: its source lies in wise thought and resourceful expression.

The early Xi Chuan does little more than reaffirm well-behaved canonical values and conceptualizations of poetry, in his above-mentioned "pursuit of perfection." A poem's success, for instance, is measured against four criteria, the first of which is the most striking example of his views at the time:

... how close it gets to eternal truth.

His views change considerably in the early 1990s, as we have seen. Further to Xi Chuan's dislike of pretty literature, let's first look at what, according to "Alchemy 2" (48), poetry is not.

That which can be subsumed under one's attitude - things like anger, reverence, eulogy, scorn and so on - is not where the power of poetry resides.

As for what poetry is, "Alchemy 1" (29) contains the following questionable dichotomy according to which female poet-alchemists produce one thing and male poet-alchemists another:

Let women express their mood, let men express their wisdom.

This doesn't reappear in "Alchemy 2." What does reappear is $\mathrm{Xi}$ Chuan's categorization of poetic language ( 54 prev 36 ):

As to its language, poetry is divided into three kinds: songlike poetry, theatrical poetry, and narrative poetry. One who is able to synthesize these three may be said to have gathered all that is good.

Incidentally, Xi Chuan's prose poetry of the 1990s and beyond goes some way toward such synthesis. We could simply take his categorization as evidence for the fact that - perhaps primarily for his own writing - he is not overly concerned with divisions into literary genres such as poetry versus prose or fiction and so on, ${ }^{5}$ and rather with literary modes like narrative and song. While the differentiation of song, theater and narrative is not in itself remarkable or original, through its presentation of the poem as a "made thing," as artifice, it does aid the interpretation of this piece of advice to poets in "Alchemy 2" (53):

\footnotetext{
${ }^{5}$ Cf Yang Changzheng 1994: 48.
} 
Do not declare that you have attained "authenticity"; "authenticity" is the poet's nightmare, brought on by theory.

This is a prime example of profound development in Xi Chuan's poetics, not just from his $1980 \mathrm{~s}$ "purity" to a much more complex vision in the 1990 s, but also from "Alchemy 1" to "Alchemy 2."

Within the broad subject matter that is poetry itself, Xi Chuan discusses an "I," a "self," that should probably be taken not as a protagonist in the usual sense but rather as a songlike / theatrical / narrative perspective embodied by the speaker. Here, my reading of Xi Chuan's poetics is informed by his poetry rather than the other way around, specifically by stanzas 56, 58, 64, 88 and 99 of «What the Eagle Says», cited in chapter Five, where I called the speaker a mental-linguistic agency, autonomous but without a home of its own. In "Alchemy 2" (16-17-18) Xi Chuan offers an explanation of the composition of this "I," and by extension of the words that it produces and by which it is produced itself - that is, the poem:

"I" is composed of "external I" and "internal I."

"Internal I" is composed of "I of logic," "I of experience," and "I of dreams."

Inevitable self-contradiction.

These statements bring to mind the contrast in «Salute» of night-time poetry and dreams with daytime reality and rationality, even though these cannot be separate worlds and the poem subverts their easy opposition.

In "Alchemy 2," the passage on "I" is followed by one on its maker, the poet (19). Yet, this claim is not so much about poethood as about poetry itself:

The poet believes to be inspiring and secretly transmitting truth. Rather than philosophy and religion, the poet needs pseudo-philosophy and pseudo-religion.

This passage and its subsequent explanation (20):

Pseudo-philosophy discovers cracks in thought, pseudo-religion points out the aesthetic value of faith

are central to Xi Chuan's explicit poetics of later years, and indeed helpful for interpreting his poetry, as we have seen in chapter Five. They are playfully supported by these two remarks (59 prev 7, 44): 
In the best possible case, if the poet talks nonsense, that is good poetry too.

Baloney is permitted.

One more of Xi Chuan's comments in "Alchemy 2" on poetry itself deserves mention here (28 prev 16):

Poetry is a winged animal.

This is one of several passages in Xi Chuan's explicit poetics that are couched in metaphor. Other examples include the central image of poetry as alchemy. We are faced with a conceptually recursive situation when Xi Chuan uses metaphor to discuss metaphor or, in light of metaphor's centrality to the poetic experience, poetry to discuss poetry. There is a striking parallel, here and throughout large portions of "Alchemy," with traditional Chinese criticism's predilection for poetic diction that is closely related to notions of citation as an art in itself, meaning the ability to highlight the operative passage in a given text so as capture its essence in the most direct manner possible. According to Zhang Longxi, the explanation of this aspect of traditional criticism lies in radical doubt concerning the adequacy of (expository) language, which he calls a deep-seated cultural notion in the Chinese mind. Zhang duly notes that such doubt - bespoken by both Xi Chuan's poetry and his poetics - is not unique to premodern traditions in China or elsewhere. ${ }^{6}$

Let's take a closer look at the winged animal (飞翔的动物) in Xi Chuan's poetics. In an interview with Canadian poet Fred Wah, he says: ${ }^{7}$

... birds are animals that I love. Now the highest animals I can see with the naked eye are birds. On the face of the earth roams the monster, above the earth fly birds. Stars I cannot see birds can see, the God I cannot see birds can see. So, birds are an intermediary [中介] between me and the stars, the universe, God.

Most clearly in the notion of the intermediary, the above passage tallies with Xi Chuan's views on matters like the origin of poetry, inspiration and so on; the birds and the monster allude, of course, to «Salute». In comparison to a view of the poet as an intermediary between divinity

\footnotetext{
${ }^{6}$ Zhang Longxi 1992: 55.

7 Xi Chuan 1997b: 284.
} 
in the broadest sense - wisdom, beauty, truth, mystery - and its representation as human language, Xi Chuan adds another layer. Poetry still originates in the divine, but passes through two media, bird and poet, before becoming text.

"Alchemy 1" (62) concludes with a final, metaphorical entry:

I have always tried to describe a mirage.

In "Alchemy 2" (104), the final entry reads

I once exerted myself to view, from afar, a mirage. I once tried to travel through Utopia. I once tried to enter the Tower of Babel.

These recollections are clarified in a speech Xi Chuan delivered when he received the Aiwen Award for Literature in February 1999. These were his closing words: ${ }^{8}$

I once tried like a blind man to describe a mirage, like a traveler to pass through Utopia, like a sleuth to enter the Tower of Babel.

Rather than reminding us of blind poets like Homer or Hettinga, the blind man, in a handicapped, powerless capacity, adds to the implications of the words once, exerted and tried. Description of the mirage, travel through Utopia and bringing to clarity what goes on inside the Tower of Babel - that is, ending a confusion of tongues or restoring a non-arbitrary, uniform relation of language to the world, of signifier to signified - have failed, and may be inherently futile.

This additional conclusion to Xi Chuan's richest and most interesting explicit-poetical text reaffirms and deepens a disillusionment with the Utopian that has been part of his poetics ever since its transformation in 1989 and the early 1990s. Thus, it opens up new perspectives on poetry, poethood and so on. One such perspective emerges in scattered comments connected by their contempt for things that are real, true, sincere, sensible and unconcealed - or, to return to the opening paragraphs of the present chapter, for what can be taken at face value. In "Explanation," Xi Chuan still advocates truthfulness, sincerity and so on:

I am opposed to the faces of phony sages on the present-day Chinese poetry scene, and their deliberately mystifying pseudo-truths.

${ }^{8}$ Xi Chuan 2001: 221-222. 
Later, however, the notion of poetry as religion from his early days is replaced by that of pseudo-religion coupled with pseudo-philosophy, for a poet who now believes to be secretly transmitting truth. "Truth" almost appears to be a slip of the pen, if we consider this entry in "Alchemy 2" (51 prev 34):

Only the insincere need to discuss sincerity; don't let sincerity harm the poem.

In plain words, never let facts get in the way of a good story-baloney is permitted, and Xi Chuan's attitude toward truth has been complicated from the start. In "Explanation" he writes:

... what I call truth is surmise.

But perhaps truth is alright as long as it is secret, for in "Alchemy 2" (23 prev 11) we read:

A literature without secrets will not travel far through time [不能传之 久远].

Xi Chuan's original phrasing is closer to classical than to modern Chinese. The passage is reminiscent of a statement ascribed to Confucius in the Zuozhuan (左传), which holds that "if the language lacks patterning, it will not go far” (言之无文, 行而不远), in Owen's rendition. What is on the mind (志) is complemented by language (言), which is in turn complemented by patterning or "literature" (文). Beneath the outer shell of Confucius' written patterning lie language and innermost ethical disposition, inevitably visible to the one who knows how to read the poet; but beneath Xi Chuan's outer shell of literature (文学) lie secrets. ${ }^{9}$ In light of the indeterminate nature of "deep meaning" below the surface of his poetry, discussed in chapter Five, one is tempted to ask how real these secrets are envisaged to be-if one can get to them to begin with.

In poetical discourse, that which cannot be taken at face value leads to association with the phenomenon of imagery and specifically metaphor, which is central to Xi Chuan's art. For instance, the metaphor of turning iron into gold in both editions of "Alchemy" (25 prev 13):

Between faith and superstition, the poet is an alchemist.

\footnotetext{
${ }^{9}$ Owen 1992: 29-30.
} 


\section{A Bigger Pigture}

In The Mirror and the Lamp: Romantic Theory and the Critical Tradition, M H Abrams presents his typology of literary theories as comprised of reflection on four key elements: the universe - that is, reality or the world outside the poem - the audience, the artist and, centrally, the work of art. Depending on their primary orientation toward each of these coordinates, Abrams distinguishes mimetic or world-oriented, pragmatic or reader-oriented, expressive or artist-oriented and objective or work-oriented theories. His model has been influential across cultural traditions, as evidenced by its adaptation in James Liu's Chinese Theories of Literature. Explicit poetics of the kind we encounter in this chapter and the next are not theories of poetry, but they do constitute a type of metatext to which Abrams' categories can be applied. This is precisely what A L Sötemann does in "Four Poetics" (Vier poetica's), an essay on the poetics of various nineteenth-century and twentiethcentury authors. Sötemann employs a typology similar to that of Abrams, albeit with some adjustments and in different terminology. ${ }^{10}$ He speaks of romantic rather than expressive, symbolist rather than objective, realist rather than mimetic and classicist rather than pragmatic.

With some qualification, Abrams puts forth a more or less linear "historic progression": mimetic $\rightarrow$ pragmatic $\rightarrow$ expressive $\rightarrow$ objective. Sötemann, however, shows that typologies such as Abrams' and his own are conceptually powerful, but that no clear-cut chronological periodization of literary history necessarily follows from them and that, as time goes by, their constituent categories are in fact ever more likely to co-occur. He first pairs off realist and classicist poetics to one side, and romantic and symbolist poetics to another. The former two are characterized as down to earth, rational, imitative, generalizing, moral, direct and concrete, the latter two as metaphysical, anti-rational, creative, strictly individual and suggestive. From a different angle, he contrasts the romantic and the realist with the symbolist and the classicist. Here, the first two set great store by carefree spontaneity and impulsiveness, and the latter two by consciously acquired skill and clarity. Sötemann rightly notes that authors of different types of poetry may subscribe to remarkably similar poetics, and that, conversely, contemporaries subscribing to different types of poetics may display

${ }_{10}$ Abrams 1971: 3-29, Liu (James) 1975: 9-13, Sötemann 1985. 
remarkable stylistic affinity in their poetry. He also points out that individual poetics often belong in more than one of the four categories, and that they are subject to change during individual literary careers. His observations very much apply to the contemporary Chinese avantgarde, with Xi Chuan's writings as a case in point.

$\mathrm{Xi}$ Chuan's poetry requires an active, imaginative and indeed creative reader, but his explicit poetics rarely discusses the reader or poetry's interaction with its audience. As such, his poetics cannot count as pragmatic - or classicist, in Sötemann's terms - in any sense. There is a mimetic, or realist, side to his poetics in that it portrays reality or the world outside the poem as indispensable. Xi Chuan does not, however, see poetry as a straightforward reflection of life, and stresses that for life to yield poetry a profound transformation is required. Hence his low regard for authenticity and his fascination with its subversion through pseudo-religion, pseudo-philosophy, pseudo-reason and indeed pseudo-truth, that is, surmise. Also, his recognition of the world outside the poem as having a direct bearing on poetry occasionally comes across as an abstraction at best and lip service at worst, and comes nowhere near the intense engagement of this issue by authors such as Han Dong and particularly Yu Jian. While Xi Chuan's poetics questions the self-importance of poethood, it is expressive-or romantic - in its presentation of the poet as a deity and an alchemist, and in its emphatic portrayal of the writing process as an elaborate act of creation. Finally, his poetics is objective, or symbolist, inasmuch as its overarching orientation is toward poetry itself. Notably, however, he frequently focuses on poetry's process of becoming, rather than on what it is once it has become.

Before we move on to the next, more extensive chapter on Han Dong's and Yu Jian's poetics, a few remarks to situate Xi Chuan's poetics in a larger discourse are in order. First of all, as a product of the avantgarde, Xi Chuan's poetics differs fundamentally from traditional Chinese and Maoist poetics, both of which attach considerable value to poets' lived-through experience, their intention, their truthfulness and authenticity, their social responsibility and literature's subordination to affairs of state. Xi Chuan's assertion of the independence of writing 
and his declaration of the futility of travel through Utopia offer additional points of contrast with Maoist and more generally politicizing poetics. The latter point, however, presents an ambiguity in that what he calls Utopia should perhaps primarily be taken as a reference to the 1980s avant-garde notion of "pure" poetry from which he turned away in 1989 and the early 1990s. These two readings are not mutually exclusive but rather bring to mind what Yeh has called the subtle complicity of certain 1980s avant-garde texts with Maoist orthodoxy, discussed at several points earlier in this study. Conversely, Xi Chuan's metatext exhibits notable interfaces with (modern) Western poetics: not least in his central metaphor of poetry and especially the making of poetry as alchemy, which brings to mind Mallarmé and Rimbaud, among others. ${ }^{11}$

Traditional Chinese poetics, Maoism and foreign literatures aside, are Xi Chuan's ideas representative of the contemporary Chinese avant-garde? First, we should caution ourselves in light of the sheer abundance and pluriformity of metatext-by-poets. In addition, the question of representativeness becomes especially difficult if we take into account ongoing, far-reaching changes in the metatextual dimension brought about by the Internet since roughly 2000.

With these two caveats, Xi Chuan's poetics may be called representative in its high regard for the Individual Writing that characterizes much poetic practice of the 1990s, which was not controlled by collective agendas of the socio-political or literary kind. His statements to this effect can be seen to reflect the recent memory of China's decades-long history of active political interference with literature - and, as suggested above, vexation and anxiety over the commercialization of literature in the 1990s and beyond. Another feature that his poetics has in common with that of many other avant-garde authors is a conspicuous lack of reader-oriented discourse on things like the actual realization of the poem at the moment of the text's unique encounter with its individual reader.

As regards Xi Chuan's disapproval of the self-importance of poethood, one can only call his poetics representative of significant trends in the avant-garde with some qualifications. To be sure, the deconstruction of high-blown images of poethood has been a regular feature of metatext-by-poets ever since the colloquializing and vulgarizing

${ }^{11}$ E.g. Michaud 1953: 67-72, Coelho 1995: 121-122, 127-132. 
trends of the early 1980s, especially on the Earthly side of the spectrum. On the whole, however, while neither Xi Chuan's poetry nor his explicit poetics are unequivocal in this respect, he shows greater affinity with the Elevated aesthetic, according to which the poet selfevidently enjoys some sort of extraordinary status, and his comments on poethood warn against extreme self-aggrandizement rather than reducing the poet to humble, average proportions. The matter is complicated further by the fact that in practice, champions of the Earthly who claim to assume no more than such proportions for the poet have simultaneously produced metatexts that belie this position.

We shall shortly encounter the latter, in chapters Eleven and Twelve. If Xi Chuan is less loud, prolific, activist and generally "heavy" in his metatextual production than Han Dong and certainly than Yu Jian, his original contribution lies in his exploration of the border areas between creative and critical writing. 
Maghiel van Crevel - 978-90-47-44273-8 Downloaded from Brill.com $04 / 25 / 2023$ 11:38:45PM via free access 


\section{CHAPTER ELEVEN}

\section{DESEGRATIONS? HAN DONG'S AND YU JIAN'S EXPLICIT POETICS}

Before anything else, I should remind the reader that the previous chapter's introductory remarks on the study of explicit poetics in this book also hold for the present chapter. I have noted as one of my reasons for writing on Xi Chuan's, Han Dong's and Yu Jian's poeticsfrom among the many poets who have substantial metatextual writings to their name - that Xi Chuan is widely seen as representative of the Elevated aesthetic, and Han and Yu count as Earthly authors; and that, while these designations make sense, we should be wary of their essentialization. With regard to the combined presentation of Han's and Yu's metatexts in this chapter, there is an additional point. On the whole, these two poets have constituted something of a joint presence on the poetry scene ever since the early 1980s, even if in the late 1990s their relationship soured and they entered into semi-public conflict. They count as the two foremost Colloquial poets and contributors to Them, one of the most enduring and widely read of the unofficial journals that help shape the face of contemporary poetry in China to this day; one of their early metatexts is the joint publication of a dialogue they conducted in Taiyuan in 1986, at the annual Poetry Monthly Youth Poetry Conference; extensive interviews with both Han and Yu appeared back-to-back in Them in 1994; they were, each in their own way, important representatives of the Popular camp in the 1998-2000 Popular-Intellectual Polemic, which serves as the backdrop to some especially fiery passages in their metatextual writings, and so on.

Desecrations? in the title of this chapter points to two things. First, Han and $\mathrm{Yu}$ are well known as desecrators, or demystifiers at the very least, of the self-aggrandizing tragic heroism of the early Obscure Poetry of the late 1970s and the early 1980s, and of similar features in authors associated with the cult of poetry in later years. At the same time, while Han's and Yu's Earthly desecration of the Elevated discourse surrounding poets like Yang Lian and Haizi is successful, if only rhetorically, they themselves can be seen to construct an Earthly

(C) MAGHIEL VAN CREVEL, 2008 | DOI 10.1163/9789047442738_012

This is an open access chapter distributed under the terms of the Creative Commons AttributionNoncommercial 3.0 Unported (CC-BY-NC 3.0) License. 
cult of their own, over and above what Michelle Yeh calls their anticult behavior in reaction to the Elevated. ${ }^{1}$ Han and $\mathrm{Yu}$ ascribe a kind of regular-guy authenticity to the poet, but at the end of the day their vision frequently proves to be as high-blown as that of the poetry worshipers and the Intellectuals they claim to oppose. As such, this vision constitutes a cult of ordinariness - as a positive, indeed a sacred quality of an undertaking that requires unconditional loyalty. Hence, the question mark.

My sources are a series of publications by Han Dong and Yu Jian that cover two decades, from the mid-1980s to the mid-2000s. In comparison with Xi Chuan's poetics, the phenomenon of poethood-what a poet is, and what it means to be a poet - is highly significant to both Han and $\mathrm{Yu}$. Section 1 of this chapter examines images of the Chinese poet as he appears in their writings, overarching other, interrelated aspects of their poetics. Section 2 shows that for all their poetical kinship, Han and $\mathrm{Yu}$ display markedly different styles in the metatextual arena. As before, my use of masculine pronouns reflects the male monopolization of this arena.

\section{Poethood Agcording to Han Dong and Yu Jian}

As in chapter Ten, I have organized the discussion along lines suggested by the material itself. Overall, the subsections move from questions concerning what we may call the ontology of poetry and the poet toward commentary by $\mathrm{Han}$ and $\mathrm{Yu}$ on actualities of the Chinese poetry scene that bring to mind literary-sociological issues highlighted elsewhere in this study.

\section{Where Does Poetry Come From?}

In Han Dong and Yu Jian's “Conversation in Taiyuan” (在太原的谈 话, 1988), Yu asserts that what matters is not where poetry appears, but through whom: ${ }^{2}$

\footnotetext{
1 Yeh 1996a: 78.

2 Yu Jian \& Han 1988: 77.
} 
[Good poetry requires] for the poem not to choose a fashion or a culture or a philosophy or a history or the West or the East and so on, but to choose the poet himself.

The notion of poetry as an abstraction that precedes the poet and avails itself of him as a medium recurs in the writings of both authors. Han discusses this most elaborately in "Two Thousand Words on Poetry" (关于诗歌的两千字, 1997): ${ }^{3}$

The poem originates long before the poet appears. It exists before the poet but is in no hurry to alight amid human beings. The poem chooses the poet and is born through the poet, who is but the channel of this birth. And the poets, having gone through the throes of birth, wrongly assume that it is they who have created the poem, and try to appropriate the result of this act of reproduction, just like the fathers and mothers of human beings naturally own their sons and daughters. But sons and daughters are not born of fathers and mothers. Their souls, their predetermined forms and the procedure of their production all stem from Heaven and go back to a mystery. Fathers and mothers are but common workers at the assembly line, they are not the designer, the machinist or the boss, they work mechanically and are moved by a force outside themselves: such is the poet's fundamental character, that of a worker ... For the poet to take advantage of poetry or apply it toward his own achievements is a despicable act, and to think that poetry is an individual construction of and for oneself is a psychological obscenity . . . Truly great poetry belongs to no man, all it does is borrow the poet and his name to descend into a concrete time. This is verily an honor incomparable to anything else - the question is whether we are ready for it.

\section{The Poet's Innate Receptiveness and His Divine Qualities}

Of the two authors, Han is also the one who has most to say about the qualities that make the poet receptive to poetry's advent: ${ }^{4}$

Narrow-minded, headstrong, arrogant, self-satisfied people and the like have no predestined relation to poetry ... This is all the more so for those who hesitate and waver, carelessly running hither and thither, opportunistic and bent on intrigue, and without peace of mind. Poetry will not flutter down like a leaf off a tree onto their deceitful heads. As poets,

${ }^{3}$ Han 1997. 被动, literally 'be moved,' is usually translated as passive. In itself, this would work well here: "they work mechanically and passively...." I have rendered it as are moved by a force outside themselves in light of Han's play on the ambiguity later in this passage, when he dwells on the poet's "potential for being moved."

${ }^{4}$ Han 1997. Cf Han 1995a: 85. 
we need first of all to concentrate and never be the least bit indolent, and then to vacate ourselves, just like vacating a house, not leaving any preconceived ideas in there ... Whether or not the poem will alight is a matter for it to decide, a mysterious matter from high up and far away. All we can do is hope to be the lucky ones, and hold out our bodies of flesh and blood to take in its arrow-like, brilliant rays of light.

This is one of several occasions where Han's imagery echoes the very grandiloquence he sets out to deconstruct in the work of others, through his poetry and his poetics alike. What appears to be the earliest record of his poetics is included in Young Poets on Poetry (青年诗人谈 诗, 1985), edited by Lao Mu. Han's contribution was likely written in the early 1980s. He may well have had the Obscure poets in mind for this indignant outburst: ${ }^{5}$

Spiritual life in poor China of all places has now produced this bunch of unbearably vulgar noblemen. Laughable? Lamentable! Where are the poetic qualities of being plain and unadorned, and of being at the source of things? How to explain that the popular and the primitive possess continuing, immense artistic charm? How to explain what it means to "return to the real and revert to the simple"?

In order to be among those who may hope to find themselves exposed to what Han calls poetry's brilliant rays of light, one must be endowed with qualities of poethood that are innate. In an interview with Liu Ligan and Zhu Wen (1994), Han says: ${ }^{6}$

The poet's character, his potential, the particular factor he embodies from the very beginning, that mysterious thing comes to him naturally [天然, literally 'in heavenly manner'] . . . Our efforts are merely to release these things to the fullest possible extent.

$\mathrm{Yu}$ Jian pays more attention to what happens once poetry has chosen the poet. Throughout his poetics, Yu's primary concern is with language and its relationship to the poet. Early on, in a contribution to $\mathrm{Po}_{0}$ etry Monthly following the 1986 Youth Poetry Conference, he puts forth the notion of the feel of language (语感) as the poet's distinguishing characteristic, which Han Dong accepts and supports in their "Conversation." Yu concurs with Han on the innateness of poethood: ${ }^{7}$

${ }^{5}$ Lao Mu 1985b: 125.

${ }^{6}$ Han \& Liu \& Zhu 1994: 114.

Yu Jian 1986; see also 1989a: 1-2 and 1988. I follow Simon Patton's translation of 语感 as the feel of language (Yu Jian 1996: 65). 
The most important thing in poetry is the feel of language ... The feel of language is not an abstract form, but a meaningful form poured into the rhythm of the poet's inner life...

The feel of language is not something one obtains through searching or cultivation or reconceptualization. It is something one is born with. It belongs only to the true poet.

The poet's innate qualities — what Han Dong calls the poet's potential and $\mathrm{Yu}$ Jian the feel of language - are more than just a talent: they make the poet a godlike being. In the concluding paragraphs of "After Three Worldly Roles” (三个世俗角色之后, 1989), Han writes: ${ }^{8}$

The poet doesn't exist as a person bound to any historical moment, he is an emissary of God, of the divine. His link to the earth is not horizontal but vertical, from up there to down below, from heaven to the human world to hell and back ... The barriers he encounters are those of the flesh because these keep him from living the life of an immortal. But his real goal is not that of the flesh ...

The poet is like God in that he forever creates being from nothingness, he deeply loves illusory things, forever facing the infinite un-arrived and un-known. The only difference is that God took just six days to create the world (resting on the seventh), but the poet will take a lifetime to write a book of poetry, and to make the most of that rare divine quality of his.

As to the poet's divine status, Yu Jian says in "Rebuild the Spirit of Poetry" (重建诗歌精神, 1989): ${ }^{9}$

The poet's role is no longer that of the model personality of God or of a pastor, he is the reader's friend . . . He doesn't instruct, instead merely expressing his own most authentic life experience.

In "Rebuild," Yu Jian partakes in a favorite activity of Chinese poets throughout the modern period when he announces the advent of a new era starting with his own generation. According to $\mathrm{Yu}$, features of the new poetry include cool objectivity, intimacy and ordinariness, as well as the reflection of authentic life experience, even if it be oppressive, lowly and vulgar. He sets these things off against aspirations to loftiness and purity on the part of unnamed fellow poets whom he relegates to a past that begins with "May Fourth" literature but doesn't stop in, say, 1942, with Mao Zedong's 'Talks at the Yan'an Forum on

${ }^{8}$ Han 1989: 20. I have rendered 未来 ['the future'] 和未知 as the un-arrived and un-known to retain the parallelism of the original.

${ }^{9}$ Yu Jian 1989d: 63-64. 
Literature and Art," or in 1949, when the Maoist view of literature became government policy in the People's Republic; it doesn't stop even in 1978, with the emergence of the avant-garde in the pages of Today. Thus, Yu effectively lumps together poets from the Republican era, state-sanctioned Maoist orthodoxy and the 1980s as obsolete, a powerful rhetorical move that he repeats more or less explicitly in several of his other essays. ${ }^{10}$ Among his fellow 1980s poets he clearly targets Obscure Poetry, but most of all authors associated with the Elevated cult of the late 1980s, which was at a high point when he wrote the essay.

Yu's comments on the poet's divine status are typical of his own and Han Dong's poetics, in that both distinguish implicitly between an abstract, idealized concept of the poet on the one hand, and its (in)authentic manifestations on the other. According to $\mathrm{Yu}$, inauthentic poets "whose role is no longer that of God" lose the godlike status they have arrogated to themselves; authentic poets of the new era, including Yu Jian, don't seek after such status to begin with.

A few years on, in “What Should the Poet Do?" (诗人何为, 1993), Yu appears much less adverse to notions of the poet as god: ${ }^{11}$

It looks as though in this world, the poet always plays the role of one offering spiritual redemption. I certainly won't deny that today, at a time when the dominant discourse and the set of values it has constructed are on the verge of collapse, there is a need for new gods to guide us ...

Great, healthy poetry will guide us to escape from the spiritual hell of utopianism, and to return in health and freedom to man's "here and now."

Utopianism is one of the attributes that constitute the Elevated aesthetic in the eyes of its critics, as discussed in chapter One.

In 1994, in an interview with Zhu Wen, Yu describes the mature poet as one of divine vigor (神性奕奕), a rewriting of the expression 神采奕奕 'glowing with health and vigor. ${ }^{12}$ In "The Light of Poetry, Cutting through the Chinese Language" (穿越汉语的诗歌之光, 1999) Yu calls poets divinities (神灵) and emissaries of the divine who operate language. "The Light" was one of the key texts in the Popu-

10 Esp Yu Jian 1998a.

11 Dated 1993 and likely a journal publication around that time. Included in $\mathrm{Yu}$ Jian 1997b: 235-238.

12 Yu Jian \& Zhu 1994: 129. 
lar-Intellectual Polemic: note the derogatory use of intellectual in the passage cited below. In the same essay, Yu also presents the notion of Poets' Writing (诗人写作), presumably as undertaken by the “true poet" we have encountered earlier. This confirms the poet's divine status: ${ }^{13}$

How could there be any kind of writing that is even higher than Poets' Writing? Poets' Writing is writing that sits atop all other types of writing. Poets' Writing is a divine not an intellectual type of writing.

\section{The Making of the Poem}

The actual making of the poem is a subject on which Han Dong has little to say. We recall his description of the poet as someone who is under the illusion of having engaged in an act of creation, but is really no more than a mechanical, passive medium. Han's "Ten Aphorisms or Sayings on Poetry” (关于诗歌的十条格言或语录, 1995) includes similar observations: ${ }^{14}$

The direction of poetry is from above to below. It drifts through the air, dimly discernible, and because of gravity caused by the waiting and longing of the one who writes [写作者], it lands amid men. Poetry isn't downward digging, it isn't coal. The one who writes is not a laborer. He must abandon any attitude of using force.

Without detracting from the importance of the poet's innate receptiveness to poetry, $\mathrm{Yu}$ Jian gives him a much more active role and depicts him as engaged in an activity that does in fact lead to association with the downward digging Han Dong says is useless. In "The Light," Yu offers this illustration of Poets' Writing: ${ }^{5}$

A few days ago, in Kunming, in the area around Wucheng Road, I picked up a carved, wooden window frame from amid some rubble. At the time, a few people standing around nearby disdainfully watched me as I tied the decrepit old thing onto my bicycle - maybe they thought I meant to take it as firewood. Having been exposed to long years of smoke, it had become pitch-black. The next day at noon, in the sun, I cleaned it ... and the original window, long obscured from view under a thick layer of soot, emerged at last. Only then did I discover that in

\footnotetext{
${ }_{13}$ Yu Jian 1999b: 13-16.

${ }^{14}$ Han 1995: 85. Simon Patton has translated this essay in its entirety (Han

${ }_{15}$ Yu Jian 1999b: 10.
} 2007). 
between the regular squares, the carving included several flowers . . . That's when I suddenly heard the sound of the chisel in the hands of the carpenter who had long ago created [创作] the window, and I saw the flowers opening up one by one under his hands. My state of mind at the time, I believe, was the same as that of the carpenter. It was one of creation [造物 'the divine force that created the universe,' 'Nature'], of having removed any obstructions to seeing the true nature of the world. In the eyes of others a piece of wood is but a piece of wood, a window or just firewood - but in the eyes of the poet it is a flower garden. Now that is a poet, and that is poetry ...

Poets' Writing is a thing of humility and ordinariness ...

This passage is consistent with the following pronouncement made in “Retreat from Metaphor: Poetry as Method" (从隐喻后退: 作为方法 的诗歌, 1997), an essay foreshadowed in "Tradition, Metaphor and Other Things" (传统, 隐喻及其他, 1995) ${ }^{16}$ — and equally deceptive in its concreteness, since Yu speaks in the very metaphors from which he urges retreat, by likening poetry to carpentry. "Retreat" is typical of his incessant attacks on Elevated, tragic-heroic and romanticist poetics, and of his overriding concern with language: ${ }^{17}$

The poet is no talented scholar [才子], not a so-called king of the spirit, nor one who endures suffering bearing a cross on his back. The poet is a craftsman in his workplace, a specialized manipulator of language.

The concrete act of writing implies a rejection of the traditional inclination to represent writing as a mystery (in China, many poets will declare they can only write in autumn or by the light of the moon) ...

The cross on the poet's back is one of several examples of the use of Christian imagery and terminology in contemporary Chinese poetics, and is part of a larger discourse of poetry as religion, noted by Yeh in her discussion of the Elevated cult of poetry. ${ }^{18}$ But it occurs in Earthly quarters too, reinforcing their own (re)construction of the sacred in poetry: for example, in Han Dong's reference to the biblical story of Genesis, cited earlier.

Incidentally, we should make no easy assumptions about the meaning - in the broadest sense - of Christian imagery and terminology within the particular discourse of the Chinese avant-garde or (modern)

\footnotetext{
16 Yu Jian 1995c.

7 Yu Jian 1997a: 72.

18 Yeh 1996a, esp 53-57.
} 
Chinese culture at large and their historical context, since "Western" and "Chinese" usage may differ substantially in this respect. But this issue lies outside the scope of the present inquiry.

\section{Language Usage}

The making of the poem brings us to the issue of language usage. In chapters Two and Seven we have seen that as poets, Han Dong and $\mathrm{Yu}$ Jian are best known for their employment of so-called colloquial language, as opposed to formal or bookish language, and that they are often referred to as Colloquial poets, even if this label represents a simplification of their art. In the interview with Liu and Zhu, Han Dong says: ${ }^{19}$

The basic language of my poetry is the modern Chinese spoken language ... Of course, you can't say my language is the exact same thing as everyday conversation, but its fountainhead clearly lies in the spoken language ... If our language were the result of inbreeding within the written language, it would progressively lose its usability, wither and become insipid and move toward extinction...

$\mathrm{Yu}$ Jian, too, has commented at length on the virtues of the colloquial. He links the opposition of formal versus colloquial language on the one hand with an opposition of the Standard Language versus regional languages (普通话 versus 方言, usually translated as Modern Standard Chinese and dialect $)^{20}$ and an opposition of the North versus the South, on the other. This passage comes from the opening paragraph of "The Hard and Soft of the Tongue of Poetry: On Two Different Directions in the Language of Contemporary Poetry" (诗歌之舌的硬 与软: 关于当代诗歌的两类语言向度, 1998): ${ }^{21}$

Especially in the South, the Standard Language may have effectively made its way into the written language, but it has never thoroughly done so for the spoken language. Dialect is always capable of effectively dispelling the Standard Language: indeed, this has become an everyday language game among people ... The Standard Language has hardened

${ }^{19}$ Han \& Liu \& Zhu 1994: 119.

${ }^{20}$ Regional language is the preferred scholarly translation of 方言. Hereafter I render it as dialect to situate the issue within the popular socio-political and cultural discourse of which it is a part and to avoid using language in the translation of both terms, which Yu employs contrastively.

${ }^{21}$ Yu Jian 1998a: 1. Cf Inwood 2008: 218-224. 
a certain part of Chinese, while the soft side of Chinese has been maintained through the spoken language. These are two states of one and the same tongue: hard and soft, tense and flaccid, narrow and broad....

$\mathrm{Yu}$ Jian is one of remarkably few contemporary Chinese poets who engage in more than a fleeting way with linguistic, political and artistic implications of national language policy. The considerable differences between the Standard Language and various dialects clearly have a bearing on the poetic practice of native dialect speakers. Some feel that they inevitably "switch to the Standard Language" when writing poetry, which ultimately makes recitation in their native dialect problematic. Recent years, however, have seen a rise in the status of dialect writing and recitation, as well as growing interest in the poetic potential of the Chinese script as a regional quality distinguishing Chinese from other languages.

$\mathrm{Yu}$ depicts the Standard Language and those who allow the Standard Language to rule their poetic practice as having hegemonic ambitions. The issue is linked to his vision of modern Chinese poetry as having become a rigidified, all-encompassing and ultimately politically motivated system of clichés in which the distance between signifier and signified has reached unacceptable lengths. For the presentation of these ideas in "Retreat," his use of linguistic and literary terminology is questionable. Rather than as scholarly writing, however, we should take the essay as a rhetorical intervention.

This is clear from the opening paragraphs, when $\mathrm{Yu}$ tells a story that is as infectious as it is nonsensical, and contingent on the peculiarities of (modern) Chinese rather than any intrinsic qualities of poetry. He relates how the first human being to see the sea 海 hăi uttered the near-homophonic 烸 $h \bar{a} i$, an exclamation which is normally equivalent to heave ho but is here presented as one of surprise and awe at the sight of the sea, and an expression of authentic experience. By way of a counter-pun, we might translate 烸 as “See!". As soon as the original seer - the resonance in this image of the poeta vates is more appropriate than Yu's reputation as desecrator might suggest - passes this sound on to others whom he tries to tell about the sea, the word is dislodged from the thing, (poetic) expression is alienated from authentic experience, and the rule of "metaphor" (隐喻) begins. In Yu Jian's usage, metaphor can mean anything from simile, symbol and imagery at large to fixed expression or cliché. These things are presented in con- 
tradistinction to the original act of naming (命名) and naming anew (重新命名), with the latter two notions denoting good poetry.

In spite of glaring holes in the argument, the message is clear when $\mathrm{Yu}$ laments the fact that whereas the original namer said "Sea/e!", modern poets have been conditioned to exclaim "Eternal and vast!" (永恒而辽阔!) instead. Thus, Yu writes, conventional representation in language controls the poet, in a system rooted in a massive literarycultural history that is a millstone around his neck.

According to $\mathrm{Yu}$, things should be the other way around. As he says in the interview with $\mathrm{Zhu} \mathrm{Wen}:^{22}$

The mature poet isn't manipulated by the magical powers of language; he soberly, coolly, rationally controls those powers instead. His method is to construct language amid its deconstruction.

In "Retreat," Yu Jian extends the deconstruction of language to that of metaphor, reconfirming that in his scheme of things, the two are difficult to disentangle. Here are some of the operative passages: ${ }^{23}$

Poetry is a language game that exterminates metaphor ...

Poetry is the dissection of language.

To reject metaphor is to reject the metaphor hegemony of our mother tongue, to reject the dominant discourse. Rejecting the metaphor system it imposes, the poet should write from inside a position of questioning and resisting the mother tongue's heaven-granted powers. Writing is the disposal and elimination of metaphor trash ...

As a subjective, made-up world, the poem offers a linguistic reality that constitutes a method for removing the imagination, for removing illusions and romanticism, for removing Utopia and the beauty of evil [恶 之美] ...

With regard to poetry's fundamental direction of writing, there are two kinds. One is poetry made of words that "advance" [前进], the other is poetry made of words that "retreat" [后退].

"The beauty of evil" is a reference to Baudelaire's The Flowers of Evil (Les Fleurs du Mal), one of several oft-cited foreign influences on contemporary Chinese poetry, whose alleged worship by Intellectual poets is a source of anger to $\mathrm{Yu}$ Jian - as noted in chapter Three, he has called Haizi's oeuvre "The Flowers of Evil, Grown in the Mao Era."

${ }^{22}$ Yu Jian \& Zhu 1994: 129-130. See also Yu Jian \& De Meyer 1995: 29.
${ }^{23}$ Yu Jian 1997a: 71-73. 
The word translated as advance also means 'progressive,' with strong connotations of PRC political orthodoxy. Yu's notions of advance and retreat run parallel to the analogous oppositions in his essay on the hard and the soft, noted above: the formal versus the colloquial, the Standard Language versus dialect and the North versus the South.

\section{What Is the Poem to the Reader?}

What is the poem once it has been written, that is: to the reader? How does the encounter of poem and reader work? In "Ten Aphorisms," Han Dong says: ${ }^{24}$

Poetry has nothing to do with learning ... For their communication, the one who writes and the one who reads [阅读者] rely on innocence, not learning. It is certainly not the case that a good writer has more of a right to speak on poetry than a good reader ... A good reader is definitely superior to a second-rate writer.

But as is true for other contemporary Chinese poets, neither Han Dong's nor Yu Jian's poetics is reader-oriented. In a somewhat contradictory formula, $\mathrm{Yu}$ holds that ${ }^{25}$

the mature poet definitely doesn't aim at readers or other poets from his own time, he doesn't even see those people, he only writes for language, he forces the reader to accept his way of speaking, but he does so by "caress"...

Nor do Han and $\mathrm{Yu}$ expect the reader to bring the poem to life or, more generally, consider the possibility of slippage or discrepancies between authorial intent and the reader's experience. According to $\mathrm{Yu},{ }^{26}$

In the poet's subconscious, there is a living sediment formed under the influence of the society in which he finds himself, and the politics, culture and religion of the times as well as his family's hereditary features, history, aesthetic values and all that he has personally observed ... All the poet needs to do is combine his intuitions into a meaningful form, into the feel of language, and his life will find expression ...

\footnotetext{
24 Han 1995a: 85.

25 Yu Jian \& Zhu 1994: 129-130.

26 Yu Jian 1986.
} 
Yu thus emphatically situates expression of the poet's life in a social context. Similarly, in their 1986 "Conversation," he says to Han: ${ }^{27}$

The poet's view of human life and his social consciousness . . . will all naturally be revealed in his language ...

Recorded around the same time, Han Dong's words in the Youth Poetry Conference report in Poetry Monthly recall a traditional Chinese poetics even more strongly: ${ }^{28}$

In a truly good poem we can see the author's soul, his way of life and his understanding of the world.

Han doesn't see poetry as a vehicle for conveying content that can somehow be isolated from the rest of the poem:

All this must blend into the poem, as opposed to being expressed through the form of poetry.

“Miracles and Foundations" (奇迹和根据, 1988) shows that Han attaches central importance to poetic form, albeit in abstract terms: ${ }^{29}$

Poetry isn't established for the perfection of one type of culture or another... Poetry has more profound goals, namely to bestow form on the world. To explain poetic form one may need the help of culture. Alternatively, it is possible that such explanation only exists within the entity we call culture. But explanation cannot replace form ... Poetry as the existence of form is transcendental and independent of anything outside itself. It is related directly to the soul of humankind, it is the soul's activity and its need ... It is the formed existence of the emotional relation between humankind and the world.

In "Conversation," Han reiterates the inseparability of form and content. Here, he speaks not of the soul of humankind, but of that of the individual - or rather, of the souls of two individuals, in a modern-day version of the traditional Chinese notion of the poem as a means to the end of getting to know the poet: ${ }^{30}$

When you read a truly good poem, you will feel the intimacy of another heart. This is not just a resonance ... you use your soul to experience the authenticity of another soul, a living soul. Poetry doesn't express anything, it is in itself a person's soul, it is life. And even if it expressed

27 Yu Jian \& Han 1988: 76.

${ }^{28}$ Han 1986.

${ }^{29}$ Han 1988: 51.

${ }^{30}$ Yu Jian \& Han 1988: 76. 
anything, that thing could only be expressed in this particular form. The entire sense of beauty in poetry is instilled in it by individual life, and then experienced by another concrete life. Otherwise, poetry has no meaning whatsoever. I cannot conceive of a poetry that doesn't bear the signs of life yet has aesthetic value.

\section{The Poet Vis-à-Vis His "Worldly" Surroundings}

Whereas both Han Dong's and Yu Jian's ideas lead to association with a traditional Chinese poetics in that they situate poetry and its interaction with the reader in a social context, they insist that the poet is under no obligation to take on any social role, and that he should in fact actively avoid doing so. In "After Three Worldly Roles," Han finds fault with his contemporaries for being "political, cultural and historical animals," even if this status is to some extent forced upon them by their environment. He exhorts them to break free. The essay is a caustic, bitter piece: ${ }^{31}$

In a politicized country, everything can be understood from a political angle. Developments outside politics in the sphere of art often remain unknown. People aren't interested, and they don't have the energy. So Chinese and foreigners trying to understand things Chinese all believe that there is no art in [contemporary] China ...

Bei Dao's success has been misconstrued in precisely this manner. Bei Dao himself recognizes that his success derives in large part from political pressures. Later, we were disappointed by the way he took advantage of the situation. Then again, all efforts toward subsistence and immortality as a human being are permitted...

Bei Dao never took advantage of the Chinese, but he did take advantage of the Westerners, and this is essentially the same thing ...

If we want to cast off the tragic role of the political animal, we must also discard all attempts to gain fame and fortune from it ...

Westerners don't know about China, and they have no wish to know. Westerners harbor colonialist demands of China to this day. To make this claim for the spiritual realm is by no means an exaggeration. The Chinese are still taken as rare cultural animals that live on a patch of ancient earth for strictly decorative purposes. This is all there is to the Westerners' view of the Chinese.

\footnotetext{
${ }^{31}$ Han 1989: 18-19.
} 
Chinese human beings can only adopt the standpoint of Chinese human beings. Anything else falls outside their lot. The standpoint of human beings per se is the monopoly of the West ...

This is how the Chinese have been stripped of their right to be human beings. If you are not contented with being a lower animal, fine: then you can be a richly mysterious cultural animal - that's what the Chinese are. That's how A Cheng has gained the Westerners' trust ...

Once we have cast off the two roles of the brilliant political animal and the mysterious cultural animal, we arrive at the forefront of artistic creation. Here lies another pitfall: the role of the profound historical animal.

Like certain other claims by $\mathrm{Han}$ and $\mathrm{Yu}$, especially the more polemical, Han's comments on Bei Dao and A Cheng are debatable, not to say untenable or at best misleadingly incomplete. As for Bei Dao, much has been said about the politics of his poetry in every sense of the word, in detailed studies of his work such as those by Bonnie McDougall and Li Dian as well as in the debates on the issue of uneven exchange between modern Chinese literature and other literatures mentioned in chapters One and Four. ${ }^{32}$ Suffice it to note that in 2003, fourteen years after his comments on Bei Dao in "After Three Worldly Roles," Han Dong says in an interview with Chang Li that his own generation's attempt to break free from the overwhelming influence of Bei Dao and Obscure Poetry in the 1980s "may well be called an act of patricide." 33

In the interview with Liu and Zhu, Han reiterates his disapproval of Chinese poets who make political repression their selling point. At the same time, he acknowledges that political pressure on poets in China is real, and a terrible thing. Asked about avant-garde poets as "dissidents" holding radical political views, he says: ${ }^{34}$

This is first of all determined by political life in our country. If a poet doesn't toe the line and insists on his own artistic position, he will be misunderstood by the outside world, and hated by jealous fellow poets ... An important feature of political life in our country is its regard for stability and unity. Anything alien, unusual, outstanding or rebellious constitutes a threat to the political order. Hence, if our poetry doesn't fit in with mass [culture] and has its own ideas and individuality, per-

32 McDougall 1985, Li Dian 2006.

33 Han \& Chang 2003.

34 Han \& Liu \& Zhu 1994: 114-115. Cf Han \& Zhu 1993: 69. 
haps even wants to give expression to unconstrained abnormalities and demands to be circulated and spread around, this will of course lead to commotion ... Unconventional avant-garde literature's conflict with politics is a totally normal thing ... Under these special political circumstances, those who insist on their individual artistic pursuits will in fact run into problems ... The obstacles and the pressure can be formidable, even deadly.

In “The Life and Times of Them" (《他们》, 人和事, 1992), which first appeared in the post-1989 revival of Today outside China and was later excerpted for domestic publication in Poetry Exploration (1994), Han asserts again that the poet has absolutely no "non-poetic"-political, social, moral - responsibilities, and that writing "to establish poetry in its own right" is by no means a form of escapism. In one of the most solemn, moralizing parts of a poetics that regularly bespeaks the romanticist, tragic heroism Han has a reputation for condemning in others, he writes: ${ }^{35}$

In an era full of temptations, it is all the more important that the poet adopt a stance of rejection and a lonely countenance. He must return to writing by himself. Any act or thought inspired by his judging the hour and sizing up the situation or being zealous for the common weal will damage his character as a poet. He is out of keeping with the times, he has no foundation to fall back on, and what's more, he will never adapt. His cause is God's cause, the creation of being from nothingness but without any practical use. He has no support and no one responds to him. And if these things do happen, they have nothing to do with him. He must understand all this. His writing is for the soul, it is art, it is absolute, and that's all there is to it. He must treasure and respect himself.

Yet, typically, Han warns against self-importance on the poet's part:

The relation of the poet and the reader should really be that of the poem and the reader. There's no need for the poet to appear. To read your poetry the reader need not know about your life, about what you are and do outside your poetry. If a poet actively seeks a part in poet-reader relations I feel that he's after a kind of stardom that is way beyond his reach.

Yu Jian, too, habitually remarks on the poet's roles and characteristics throughout his poetics. In “The Poet and His Fate” (诗人及其命运, 1999), he decries the fact that starting in the Song dynasty, the poet

${ }^{35}$ Han 1992b: 199-200. Cf Han \& Zhu 1993: 71-72. 
began to "ascend" (上升) and see himself as being "higher" than the poem, as he became conscious of the heaven-granted right to speak that had been his since antiquity but had until then not been considered his "abstract privilege," that is: something that made him special. Yu finds that in certain quarters this trend continues into the present, "making the poet more important than the poem," as manifest in the disproportional attention paid to "the death of the poet." This is one of Yu's regular allusions to the media hypes following the suicides of his contemporaries Haizi, Ge Mai and Gu Cheng.

In contrast to what he describes as the poet's unjustified self-importance, $\mathrm{Yu}$ Jian paints a grim picture of current social (dis)regard for the poet: $^{36}$

The poet is a man of magical powers. When as a young man I traveled through Yunnan Province, I saw many indigenous tribes. I learned that the sorcerers in these tribes on the Yunnan earth constituted the soul of the tribespeople, their history, the presence of their mother tonguebut a soul that resided outside everyday life and only functioned any longer on the occasion of festivals and celebrations, to recall people's memory, their shame and their dignity, their gratitude and their fears. The difference with the sorcerers of antiquity was that then, too, they were the organizers of activities to establish contact with ghosts, but all other members of the tribe would also take part in those activities. But things are different now. Either the sorcerer occupies a position above all others in the tribe or he has been completely forgotten. I saw not a few Yunnan sorcerers and they were invariably the poorest and loneliest people in the tribe. That is the poet's fate - and a matter in which he has no choice...

Earlier in "The Poet and His Fate" and in other essays, Yu claims somewhat questionably that poetry was a central, ubiquitous element of ordinary people's everyday life in traditional Chinese societies up to the Song dynasty.

He goes on to predict that in a globalizing world the first person to be forgotten will be the poet, who has become "a tour guide in a museum." However,

The real poet should resist the poet's fate as it takes shape in this our time ... The poet should refuse to ascend, and sink low [值落] instead. Sinking low is a word that moves [动词] for which one needs a certain weight. It is harder than ascending.

${ }^{36}$ Yu Jian 1999c: 81-83. 
My rendition of 动词 'verb' as word that moves is informed by Yu's conscious, literal employment of linguistic terminology in his poetry and his poetics alike, as noted in chapter Six. His use of 邽落, which often means 'degenerate,' is presumably intended to ridicule the poet's noble calling, in the eyes of others, to "ascend" to higher spheres.

While Han Dong's variety of the poet's loneliness is of the proud and glorious kind, $\mathrm{Yu}$ considers it part of a miserable fate that the poet should work to turn around. He agrees with Han on the practical uselessness of poetry - which, in a reference to Zhuangzi, makes it ultimately useful on less tangible, superior levels: ${ }^{37}$

Poetry should be useful to human life. In the use of being useless lies the use of poetry [无用之用, 就是诗歌之用].

\section{Enemies of Poetry and of the Authentic Poet}

We noted earlier that Han Dong and Yu Jian distinguish implicitly between an abstract, idealized concept of the poet and this concept's (in)authentic manifestations on the contemporary poetry scene. Especially the latter prompt them to dwell frequently on what Han Dong identifies in "On the Popular" (论民间, 1999) as three "big beasts" (庞然大物) threatening the real, right kind of poetry. "On the Popular" was a key text in the Popular-Intellectual Polemic, and typical of what I have called an Earthly cult of poetry. The big beasts are: the System, the Market and the West. The System denotes official cultural policy, orthodox literature and state-sanctioned ideology; the Market, the all-pervading commercialization of Chinese life; and the West is emphatically inclusive of foreign sinologists. Especially Han's and Yu's anti-Western sentiments have strong anti-intellectual overtones that were made more acute by the Polemic. Let's review some enemies of poetry - and hence of the authentic poet, as poetry's true disciple - as they are perceived by $\mathrm{Han}$ and $\mathrm{Yu}$.

Yu Jian, interviewed by Zhu Wen, feels that in China the corruption of traditional views of poetry has led to insufficient respect for the genre. This is visible in the arrogance of those who cannot claim true

\footnotetext{
37 Chuang-tzǔ 1981: 75. I follow Graham's translation of 无用之用.

38 Han 1999: 7, 10. Han frequently uses 民间 as a noun.
} 
literary skills yet continue to write - including political leaders - and, by extension, in types of literature sanctioned by the System: ${ }^{39}$

The Chinese tradition takes poetry as a type of everyday karaoke for expressing emotion and articulating what is on the mind intently. People will not lightly engage in dance, musical composition, painting or writing novels, but no one feels any inhibitions about writing poetry ... In this millennia-old poetry country, poetry is no longer a specialized art. From leaders to common folk, it is an everyday laxative they "love to hear about and use themselves." In China, among those that have gone to school, there are but few who haven't written a couple of poems.

By contrast, reporting on his impressions of the 1997 Rotterdam Poetry International festival, Yu writes: ${ }^{40}$

There, the poet isn't the object of sarcasm from the masses, nor a karaoke artist performing for the masses and much less an obsequious servant to the throne - but one possessing deeply revered wisdom that is both ancient and novel.

As for commercialization, Han Dong launches into a characteristically grim, didactic exposition in response to Liu Ligan and Zhu Wen's questions: ${ }^{41}$

The bigger picture behind commercialization is something to disapprove of ... In ancient times the standpoint of the artists was one of opposition to commercialization, but nowadays they're reduced to a handful of people who are out of keeping with the times. It is definitely not as some people claim: "What's wrong with commercialization? Commercialization makes those who were unfit for writing to begin with go into business, and those who persevere will prove to be born artists" ... This is nothing but a rationalized explanation ... If a poet has a strong desire for money and is a gifted artist, under the present circumstances his desire for money will of course harm his writing. Commercialization is doubtless an obstacle to writing in every respect. What are the intentions of people who attempt to come up with rationalized explanations? One problem is that under the pressures of commercialization, one's energy for writing is scattered ... and completion of the work will be manipulated by principles that are external to art. If you have no readers, your work cannot turn into money and consequently has no value ... Many people will invoke supporting evidence to say that in Western countries, every single artistic act is to do with commerce and is realized inside a commercialized system, and hence China's ongoing commercialization

${ }^{39}$ Yu Jian \& Zhu 1994: 129-130.

${ }^{40}$ Yu Jian 2004d: 302.

${ }^{41}$ Han \& Liu \& Zhu 1994: 122. 
is not a bad thing for the poets and is indeed entirely reasonable and necessary. Something that is so common in the West cannot be questioned: the West's today is China's tomorrow. It's hard to believe that poets' and politicians' judgment of historical values is in fact totally consistent ...

As it happens, Yu Jian is one of those who "come up with rationalized explanations." In the interview with Zhu Wen he says: ${ }^{42}$

Commercialization cannot subjugate poetry. It will in fact subjugate a whole bunch of "talented scholars." Only in a commercialized society will the real poetry survive.

As for the West as an enemy of poetry, Han and Yu often object to what they see as admiration for, submission to and slavish imitation of Western models on the part of contemporary Chinese poets, rather than to the West or Western poetry per se. In "Brushtalk at the Old Sluice” (古闸笔谈, 1993), co-authored with Zhu Wen-brushtalk meaning a dialogue in writing-Han says: ${ }^{43}$

Every writer must start from reading. Well, these days the works that possess the most authority and persuasive power are of course translations. We all deeply feel that we have no tradition to fall back on: the great classical Chinese literary or written tradition seems valid no longer ... we have become orphans in the literary tradition.

To seek consolation, as if by prior agreement everyone has turned to the West. How to graft oneself onto the Western literary tradition has become the main orientation in the efforts of many poets these days, so as to make themselves strong, and to "march toward the world." Sadly, these efforts can only reach their goal indirectly, through translation. For our writing we study translations and then imitate them to write the same sort of thing. And then, this has to be translated yet again into English or other languages, to occupy the "international market" . . . they cunningly replace the literary traditions of humankind with the Western literary tradition, and believe it to be incomparably superior, purely to advance their own interests.

In "Starting from My Reading” (从我的阅读开始, 1996), however, Han no longer takes a dim view of Western influence: ${ }^{44}$

Works by Western authors constitute a large portion of the literature that I've read . . . Therefore, some people have designated our generation as one "raised on wolf's milk" ... but this expression has no real

\footnotetext{
42 Yu Jian \& Zhu 1994: 134.

43 Han \& Zhu 1993: 71.

44 Han 1996: 35.
} 
significance for the debate and it may even confuse the issues that we are faced with.

He emphasizes that all his reading, wherever it "comes from," is in the modern Chinese language. Citing fellow Nanjing poet Lu Yang, he notes the possibility of Western literature in modern Chinese translation being less "foreign" to present-day Chinese readers than texts in classical Chinese.

Of the two poets, Yu makes the more fiercely anti-Western statements, in the sense outlined above. One of his favorite targets is (Chinese) exile poetry: ${ }^{45}$

I'm afraid this is not exile literature like that of Joseph Brodsky. When poets of the Chinese language go to countries of the English language, they must necessarily form their own small clique and be their own audience ... Aside from the Westerners' respect for the word exile, I'm afraid there are few people who actually realize that the exile poets are poets. For Chinese poets, exile mostly means fleeing from their existence ... Brodsky didn't want to leave but was forced to leave. For Chinese exile poets, it's the opposite: they consider it an honor to be in exile in Europe and America, they will scramble to get in and worry about being left out. Why don't they go into exile in Vietnam, or Burma, or Tunisia? Taking pride in exile shows that deep down, their mindset is that of colonized men of culture.

Stilted as the phrase countries of the English language (英语国家) may be, it retains the contrast with the syntactically parallel poets of the Chinese language (汉语诗人). "English" is, of course, a questionable metonymy for a range of foreign languages.

In a 1995 interview with Jan De Meyer, when De Meyer asks whether June Fourth was a turning point for poetry, Yu says: ${ }^{46}$

I think it is wrong to link poetry and politics together. There is a limit to the influence that changes or revolutions exert on poets. After Tiananmen I got letters from several poets informing me that they would never write again. I don't understand attitudes like that at all. I wrote quite some good poetry in 1989. Whatever happens in the world around me, I remain a poet before anything else. That doesn't mean I subscribe to an ivory-tower mentality - not at all. As a citizen, as the man in the street, I am of course concerned about what happens and I will voice my opinions, but as a poet I cannot let myself be dominated by every political change of course in China. Since 1989 a good number of poets have

\footnotetext{
${ }^{45}$ Yu Jian \& Zhu 1994: 133.

${ }^{46}$ Yu Jian \& De Meyer 1995: 30.
} 
left China, but I don't understand them. Look here, Chinese history has seen numerous great poets and many of them lived in times of extreme brutality and cruelty. Yet they continued to write.

Whatever happened, these people consistently made sure they didn't lose touch with their mother tongue. If a poet allows himself to be separated from his mother tongue, how can he write any longer? As a poet, I need direct contact with China, its people and its language. That benefits my poetry. You know, for some writers Tiananmen was just an excuse to get out of China. I find that irritating. However badly things may be going politically, that should never be an excuse for a poet to flee. And there is something else: it's often precisely the ones in exile, who have severed their ties with China, who present themselves in the West as authorities, as spokesmen for what is happening in literature in China. And foreign countries accept them more or less automatically in this capacity. Makes you wonder, doesn't it?

$\mathrm{Yu}$ presents his view of the West and related issues at length in an interview with Tao Naikan called "Clutch a Stone and Sink to the Bottom" (抱着一块石头沉到底, 1999). The title is a reference to Qu Yuan, said to have drowned himself and invoked by Chinese poets through the ages as the epitome of extraordinary qualities gone unrecognized: moral uprightness in officialdom and-later - patriotic poetic genius, even if the latter image requires the retrospective appropriation of $\mathrm{Qu}$ Yuan's Chu provenance by a "Chinese" identity. The interview shows Yu's style growing ever more belligerent, rambling and logically problematic, not to say uninformed and opportunistic. Some of his tirades appear to aim for rhetorical intimidation of other players on the poetry scene and sheer, "loud" visibility, as much as for clarification of the issues. Notably, Yu certainly has helped clarify the issues over the years. His consistent attention to language as a key component of poetics is but one example of his contributions in this respect.

What Yu Jian says about the West and Chinese poetry when his implied audience is domestic is rather different from his occasional communications addressed to foreign readers. After much uncritical celebration of foreign literatures and literary theories in the 1980s, in the 1990s the relationship of the avant-garde and the West became the uneasy subject of critical reflection involving issues of (Chinese) identity. Seen in this light, $\mathrm{Yu}$ has a point when he takes some of his contemporaries to task for their extreme eagerness to seek foreign publishing opportunities to "connect" (接轨) with the West-a fashion- 
able phrase with a connotation of manipulative self-advancement. ${ }^{47}$ Incidentally, Yu himself has always welcomed and indeed solicited foreign interest in his work. In 1990, for instance, he acknowledged his indebtedness to Longfellow, Whitman and Frost in an English preface to the third of his unofficial, privately-produced poetry collections in Chinese. ${ }^{48}$ This is but one example of his active courting of foreign attention over the years - and of his familiarity with foreign literatures in Chinese translation. There's nothing wrong with the ambition to address an audience larger than the domestic readership. One who writes wants to be read, and to be read as widely as possible. But as Wang Jiaxin points out, it is remarkable how $\mathrm{Yu}$ finds fault with others for transgressions against a vaguely nationalist code that apparently doesn't apply to himself. ${ }^{49}$

For his domestic audience Yu reserves a different type of rhetoric, as seen in the following passage from the interview with Tao: $:^{50}$

To non-native speakers English is a second-rate language, but its position is that of Esperanto, of the Standard Language of the world. It leads toward set patterns for communication, toward standardization, and is turning into a computer language, a language that every human being can use. I feel that today's Chinese still retains the poetic nature it had in antiquity ... Unlike English, it is not a language that anybody anywhere can simply control. Chinese constitutes an older kind of wisdom, a language that's been poetic in nature ever since it came into being. To master it you need an animal intelligence [灵性]. I feel that Chinese per se presents a challenge to global integration and materialization.

$\mathrm{Yu}$ alludes to the second language that English is to many Chinese when, in a casual twist, he calls English "a second-rate language" (二流语言). By subsequently comparing it to the failed project of Esperanto (世界语, literally 'world language'), he turns the global significance of English on its head. At the same time, he hints at its (global) hegemonic ambitions through association with the Chinese-domestic role of the Standard Language:

Modernization through the English language [英语现代化] leads to "cloning," to duplication in the fields of economy, culture and modernization - isn't that what the world is coming to right now? Ultimately it

${ }^{47}$ E.g. Yu Jian 1998a and 1999b.

${ }^{48}$ Yu Jian 1990.

${ }^{49}$ Wang Jiaxin 1999: 48-49.

${ }^{50} \mathrm{Yu}$ Jian \& Tao 1999: 80. 
will mean the duplication of human beings. The Chinese language, on the other hand, by virtue of its special and regional features and its fivethousand-year-old poetic nature, cannot become a linguistic tool used throughout the world. Chinese is a language that . . . is capable of arriving at another world view than that of Western logic . . . and guiding human civilization in a different direction. English provides access to the computer; Chinese, to human beings . . . While English leads people to move forward toward modernization and turns them into slaves of the material, Chinese makes them stay in touch with nature, with the traditions of antique civilizations and with the old world of all living things.

In “What All True Writing Does Is to Retreat" (真正的写作都是后 退的, 2001), written together with fiction critic Xie Youshun, who joined the Popular ranks during the Polemic, Yu Jian expresses a similar concern about modernization as a process of copying or derivative reproduction (复制): ${ }^{51}$

Other people do the creative work, and only then do you get to share in it. Now if a high school student who worships the Nike swoosh thinks like that, or an old lady in a butcher shop who dreams of sending her grandson to America to study, or an official in the foreign trade ministry, this isn't necessarily something to hold against them. The problem is that today, those guys availing themselves of the Chinese language to write poetry think like that, too . . . There are even poetry professors at universities who declare that Chinese poetry must force its way [into "international writing"], and the standards are controlled by the sinologists in the developed world . . My anger is the anger of a poet. If, in this country, nationalism now meets with the disdain of all intellectuals, then the poet should be the last nationalist. He is the guardian and the creator of our mother tongue! I am a mother-tongueist nationalist . . . I will forever reject so-called "international writing."

In the following passage from the interview with Tao, leaving the caricature of "the West" aside, one could argue that it is precisely the colonized mindset of which $\mathrm{Yu}$ Jian accuses his fellow poets that leads him to call a series of countries from Ireland to Latin America "the margins." His identification of the Cultural Revolution as a determining factor for contemporary Chinese poetry sits uneasily with his earlier admonitions to separate poetry from politics: ${ }^{52}$

${ }^{51}$ Yu Jian \& Xie 2001: 32.
${ }_{52}$ Yu Jian \& Tao 1999: 80. 
Having been abroad myself, the feeling I get is that the West is a society that has already reached completion, where people enjoy high position and live in comfort. Concerns in the early stages of modernization matter less and less. Very few of their poems will excite me, as far as their expression of human life and human nature goes. They're mostly word games. In my opinion the good poetry from the West was all written before the 1960s. Now, outstanding authors in this world all come from the margins, like Ireland, the Czech Republic, Russia, Poland, Latin America.... Contemporary Chinese poetry is in fact truly excellent, it's just that it is cultivated inside the boudoir and no one knows about it . . China is a society on which work remains to be done and which therefore still brims with creative vitality and all manner of potential. Having gone through the terrible totalitarianism of the Cultural Revolution, Chinese poets' experience of human life is especially profound ...

In the Chinese context, poetry inside the boudoir brings to mind women's writing in imperial times. But whereas premodern women and their writing were in many ways effectively kept from public exposure by men, it is unclear who should be the ones that imprison the-predominantly male - Chinese poets in the contemporary period. In spite of the incompatibility of avant-garde poetry with orthodox cultural policy, most poets have ample publishing opportunities, in unofficial and official circuits alike.

In "The Light," published around the same time as the interview with Tao, Yu says: ${ }^{53}$

In the final two decades of the twentieth century, the world's most outstanding poets have dwelled in the Chinese language. But on this point we remain silent, we keep it a secret and don't spread the word.

A possible reading of this strange declaration and the image of the boudoir is that $\mathrm{Yu}$ Jian transforms his frustration over what he feels is insufficient recognition for contemporary Chinese poetry into an assertion of its splendid isolation.

One wonders, who is Yu's intended audience here? Obviously not foreigners who don't read Chinese. He is also unlikely to have sinologists in mind, whom he has classified as operating on the level of children in primary school, albeit in the provocative context of the 1998 Rupture (断裂) project, which had Han Dong and Zhu Wen as its driv-

\footnotetext{
53 Yu Jian 1999b: 16.
} 
ing force. ${ }^{54}$ In Rupture, contemporary fiction writers and poets, several of them socially controversial, responded to a questionnaire evaluating established individuals and institutions in the literary field, from Lu Xun to the Chinese Writers' Association to foreign sinologists. The project encouraged iconoclastic responses and dissociation from the official literary-historical canon. Here's what Han had to say about sinologists at the time: ${ }^{55}$

Unless we make contemporary [Chinese] literature stoop to the level of alphabetic transcription, the idea that sinologists possess any authority is ridiculous. Sure, they can make certain things happen, but they more often do serious damage out of naivety. The sinologists are a bunch of troublemakers.

Later, Han clarifies what he means by the concession that sinologists can make certain things happen: they can help Chinese poets ${ }^{56}$

travel to foreign countries to join pen clubs or be poet-in-residence at some university ...

In "Ten Aphorisms" Han depicts sinologists as ignorant of the achievements of contemporary Chinese poetry, not without some justification. We should perhaps add that their numbers are negligible when set off against the vast majority of the Chinese domestic reading public, who share this ignorance - without succumbing to easy images of marginalization, discussed in chapter One. Han holds that in China, contemporary poetry "has been given the cold shoulder," 57 but he probably doesn't include himself in the "we" that appears below: ${ }^{58}$

Modern Chinese extends farther than classical Chinese. Classical Chinese lives inside modern Chinese, not the other way around. Modern Chinese poetry is not to classical Chinese poetry as ever weaker descendants are to a once-formidable empire on the wane. Classical poetry is to modern poetry but an honorable point of departure. These are two radically different views of history. Western sinologists are invariably in happy agreement with the former, and we, in our turn, are in happy agreement with the sinologists. This is a twofold passivity, misunderstanding and humiliation.

\footnotetext{
54 See Zhu Wen 1998, Han 1998c, Wang Jifang 2000 and Berry 2005. Yu's remark is found in Wang Jifang 2000: 264.

55 Han 1998b. Also included in Wang Jifang 2000: 264.

56 Han \& Chang 2003.

57 Han \& Chang 2003.

58 Han 1995: 85-86.
} 
The critical angle that $\mathrm{Yu}$ Jian and Han Dong frequently take on contemporaries that they see as corrupted manifestations of poethood is best illustrated through some examples of their anti-intellectualism. When asked by Zhu Wen about his reputation for being an "angry poet," Yu responds: ${ }^{59}$

When I occasionally lift my head, sunk in the depths of poetry, to the surface of the poetry scene and see so much flotsam and jetsam and trash making a racket, there's no way I can not be angry. In China's poetry circles, especially in the so-called avant-garde clique, I regularly have this feeling of being forced to find my place between the others to squat in a public toilet. You must write, but at the same time you must ensure that your value is in evidence vis-à-vis a big heap of trash . . . When you keep hearing that Mr So-and-So, a man of extraordinary poetic talent, has recently published a book by cutting-and-pasting some of his erudition, and bought himself a new pair of shoes, for 500 Yuan; or that ... this or that poet has run off to this or that foreign country to be a dishwasher, you get this feeling inside of having been sold out. It's as if in this country, there's never anyone that takes poetry seriously ... The image of the poet has by now changed to one of an idler who holds forth about culture, whose talents go unrewarded, joyless and depressed, pallid and thin, a suicide who cuts down others with an axe ... and I, as the poet that I am, often find myself lumped together with all that by naive, muddle-headed and disingenuous readers.

The image of the suicide who cuts down others with an axe is a reference to Gu Cheng's murder of Xie Ye before he killed himself.

In 2004, when interviewed by Malingshu Xiongdi, Han Dong is similarly outraged: ${ }^{60}$

The affected, boastful, self-emotionalizing and hypocritical behavior of those who insist on their status as "intellectuals" is disgusting to my instincts. In my opinion, the biggest evil is not evil per se but hypocrisy.

In the opening paragraphs of this chapter I noted that in the late 1990s Han and Yu entered into semi-public conflict. An interview conducted with Han Dong by Yang Li in 2001 shows that by that time, Han's angry criticism comes to extend to $\mathrm{Yu}$ Jian, the other figurehead in the battle against the Intellectuals, with whom Han had frequently been mentioned in the same breath throughout the 1980s and 1990s. Han finds fault with $\mathrm{Yu}$, especially in the latter's famously long poems,

\footnotetext{
${ }^{59}$ Yu Jian \& Zhu 1994: 125-126.

${ }^{60}$ Han \& Malingshu Xiongdi 2004: 100.
} 
for being too ambitious and "squandering language," instead of being meticulous about every single word: ${ }^{61}$

That sort of stuff you don't even need to read anymore ... It only wants to show how crash-hot this person is ... Yu Jian is refuting the intellectuals in an intellectual way ... He has lost his own language ... he wants to prove he's more learned and knowledgeable about the past and the present and more cultured than [archetypal "intellectual"] Xi Chuan. When talking about poetry, he will just carry on about that Tang and Song dynasty stuff . . . Aesthetically, too, he has changed direction, he wants to prove that he is more cultured and broader-minded than the other contenders, he wants to make it bigger than them. Essentially, he is a traitor, self-satisfied and smug, he has entered that order of things ... I feel that his poetry changed a lot in the 1990s and I feel that this change is intellectual in its orientation.

The striking thing about this torrent of incrowd abuse is the image of the traitor - which, in turn, recalls its victim Yu Jian's feeling of "having been sold out." For all Han Dong's Earthly, desecrating credentials, his words depict the poet as one involved in a sacred cause. The legitimacy of this involvement, in the Bourdieuian sense, requires unconditional loyalty.

\section{Metatextual Styles}

The conflict between Han and Yu emerges around the time of the Popular-Intellectual Polemic of 1998-2000. It is noteworthy, for instance, that "On the Popular," Han's most substantial contribution to the fracas, contains not a single reference to Yu Jian, who counted as the foremost representative of the Popular camp. Yu's conspicuous absence tallies with the fact that throughout the essay, Han cultivates an image of the true poet - and by implication of Han himself - as a lonely warrior. ${ }^{62}$

Yu Jian, in his turn, works hard - in fact, harder than Han - to create a similar image for himself, more specifically that of a warrior who is not just very lonely but also very tough, in romantic fashion. We recall his exasperation at having to "ensure that your value is in evidence vis-à-vis a big heap of trash" and being "lumped together"

61 Yang Li 2004: 302-309.
62 Han 1999. 
with all the wrong poets. Yu portrays himself as an outsider from the beginning, for instance in Tang Xiaodu and Wang Jiaxin's Selected Contemporary Experimental Chinese Poems (1987): ${ }^{63}$

I belong to "the generation that stands off to one side of the table." God has arranged a kind of outsider's treatment for me. I'm used to being overlooked by the times and by those with experience. There's nothing I can do about it, it's been like that all my life. As far as literature goes, the status of an outsider may well be an important factor in the making of a master. It means he'll always keep a certain distance from life, the better to observe it.

In "All True Writing," the essay jointly written with Xie Youshun in 2001, at a time when his own and other polemicists' publications are becoming riddled with vulgarities, Yu writes: ${ }^{64}$

Here's a thing that sometimes makes me lose the desire to write: is it worth it to be so solemn and serious about writing, in an age whose vision of the poet is that of a dumb shit? Not a few friends have woken up to all that and wised up. They are through with being dumb shits. I am the last incurable poet. I write for the past.

And in an interview with Duoyu, recorded around the same time: ${ }^{65}$

In Kunming I'm really just an ordinary guy without any crowd around me, and barely have any contact with literary circles. Hardly any of my friends are in literature ... And in national poetry circles I'm obviously becoming ever lonelier: the leftists criticize me at every turn, and the China Times [华夏时报] recently carried an article calling me “an enemy of poetry." Those engaged in "Intellectual Writing" are abusing me too. Who knows? In the end I might even offend the young.

In 2002 interviewer Jin Xiaofeng is impressed by Yu's report of his participation in the 1997 Poetry International festival in Rotterdam. She cites him as describing a student of Chinese poetry in attendance at the festival who said that reading Yu's work made her sad because she felt it wasn't very graceful, to which he had replied:66

I am not in the business of making enamelware. What I do has a rocky surface. That sort of thing is very rough. It will hurt you.

${ }^{63}$ Tang Xiaodu \& Wang 1987: 153.

${ }^{64}$ Yu Jian \& Xie 2001: 31.

${ }^{65}$ The interview is dated 2001 and included in Yu Jian 2003 and Yang Li 2004.

This citation comes from Yu Jian 2003: 279.

${ }^{66} \mathrm{Yu}$ Jian \& Jin 2002: 216. 
From Yu’s “Brown Notebook” (棕皮手记), a common appellation for his short prose over the years, comes this passage, reinforcing the image of his loneliness and depicting him as being out of others' reach: ${ }^{67}$

For many years I've lived in a big old compound on the Cui Lake North Road. I've never moved house and the compound has never changed. But the house number has changed five [sic] times, from 2 Cui Lake North Road to 1 Cui Lake North Road to 25 Cui Lake North Road to 3 Cui Lake North Road, with the result that we wouldn't even get our mail any longer. It's just like everyone around a person has changed and he is the only one that hasn't. At this point those who once knew him won't be able to find him anymore.

The lonely warrior is like many images of poethood according to Han and $\mathrm{Yu}$ - both implicit and explicit, several of them discussed abovethat point to the said Earthly cult of poetry and poethood, over and above any anti-cult behavior in reaction to Elevated trends. While claiming ordinariness for the poet, and contrary to their warnings against self-aggrandizement, Han and Yu ultimately view poethood as a superior quality of extraordinary importance and social relevance. This is exemplary of the way modern and contemporary Chinese poets have sustained the importance of poethood by cherishing it as an abstraction, made concrete and interpreted in different ways that succeed one another or co-exist and are often rooted in romantic notions of the artist, as noted in chapter One. In Han's and Yu's writings, the said superior quality appears in the poet's divine status and his moral goodness, especially in Han; and in his significance as one battling ubiquitous corruption of the art, especially in $\mathrm{Yu}$.

While we have noted the occasional difference between the two poets' views of poethood and related issues, across the board their poetics are compatible in many respects. Their styles of operation in the metatextual arena, however, are markedly different. Metaphorically speaking, Han Dong is the abstemious of the two, and $\mathrm{Yu}$ Jian the gluttonous. Alternatively, we might sum up Han's general presentation as one of Verneinung, and that of Yu Jian as one of Bejahung, notwithstanding the latter's de(con)structive slant on poetic practice of which he disapproves. Han Dong is the Great Negator, as he himself realizes: ${ }^{68}$

${ }^{67}$ Yu Jian 2004e: 80.
${ }_{68}$ Han 1998a. 
When discussing poetry, I'm in the habit of speaking in negative [排斥 性] terms, such as what poetry is not, and what the poet is not. All claims about what poetry $i$, and how the poet should act, are biased .. .

Typically, when asked by Malingshu Xiongdi whether he writes to get closer to people or to remove himself farther from them, Han answers: ${ }^{69}$

It seems that it's neither [似乎都不是].

Of his 1980s adage that "poetry goes no farther than language," discussed in chapter Two, Han says: $:^{70}$

it has a negative intent [排斥性的意向]

and $^{71}$

it wasn't a theoretical formula ... when a one-time saying like that turns into a truth, this is very scary.

$\mathrm{Yu}$ Jian has had considerable success in advocating the "rejection of metaphor" and the "deconstruction of language" and, often together with Han, waging war on whatever big beasts he spots on the Chinese poetry scene. Yet, as noted in chapter Seven, in spite of the many negations he utters, Yu produces not just poems but also metatexts that come across as wanting to be there and appropriating discursive territory. By contrast, many of Han Dong's writings in both genres strike one as exercises in disappearance, written in spite of themselves, as it were-reluctant and reticent, often attempting to reason their very subject out of existence.

That the voices of both Han Dong and Yu Jian carry weight in the metatextual arena of contemporary China is evident in their authorship of flagship essays in multiple-author anthologies, reproductions and citations of their work and so on. ${ }^{72}$ Perhaps predictably, the contrast noted above also finds expression in their productivity in terms of sheer volume. While Han Dong has a respectable list of publications to his name, $\mathrm{Yu}$ Jian has generated astonishing amounts of metatext. This is not just because he has so much to say - which he does - or because he wants to make money, or because many of his pieces appear to

${ }^{69}$ Han \& Malingshu Xiongdi 2004: 103.

${ }^{70}$ Han \& Zhu 1993: 69.

${ }^{71}$ Han \& Chang 2003.

72 E.g. Han 1999 and Yu Jian 1999b. 
have been edited only carelessly if at all, or because he has no difficulty repeating himself. This happens, for instance, in "Poetry Articulates the Body" (诗言体, 2001) — with the title alluding to the traditional notion that "poetry articulates what is on the mind intently" — which subsumes a jumble of earlier, well-publicized ideas under an opposition of the cerebral and the corporeal. ${ }^{73}$ It is also because $\mathrm{Yu}$ displays exceptional activism in recycling his output, even by the standards of the frenzied publishing world that has emerged in China since the mid-1990s.

When recycling his writings $\mathrm{Yu}$ occasionally fails to make clear that one publication is a reprint of another: by omitting titles, for instance. A striking example is the fifth and final volume of his collected works, Reject Metaphor: Brown Notebook, Criticism, Interviews (拒绝隐喻: 棕皮手 记、评论、访谈, 2004). In the first eighty or so pages of the book, literal or near-literal reproductions of several of the publications discussed above appear without being identified as such. They are part of a continuous flow of musings on poetry and other things divided into large chunks ascribed to periods of a few years each, sometimes not even marking the transition from one original piece to the next by so much as a blank line. They contain equally unmarked textual revisions that are not without significance: say, from Chinese as the poetically richest language to one of the poetically richest languages in the world. ${ }^{74}$ Other examples of recycling are the omission of interviewer Zhu Wen's name upon publication in Them of a conversation previously circulated as an unpublished typescript that did acknowledge Zhu, and the relegation of co-author Xie Youshun to the status of interviewer when, in 2003, "All True Writing" was reprinted in Yu Jian's Poems and Images, 2000-2002 (诗集与图像: 2000-2002). ${ }^{75} \mathrm{Yu}$ Jian is not just a highly productive author, but also one who actively engages in image-building to support his status as such.

$*$

Different as their styles may be, in a framework of poetry and its metatexts as contained between the Elevated and the Earthly, both

\footnotetext{
73 Yu Jian 2001b.

74 Yu Jian 1999b: 15 and 2004e: 75.

75 Yu Jian \& Zhu 1993 and 1994, Yu Jian 2003: 257-268.
} 
Han Dong and $\mathrm{Yu}$ Jian sit at the Earthly end of the spectrum and actively work against the Elevated. Yet, they are anything but "pure" in this respect, as evidenced by their own (re)construction of poetry and poethood as sacred things.

Their many comments on the actualities of the Chinese poetry scene suggest that Han's and especially Yu's metatextual output are more strategically motivated than Xi Chuan's, meaning that they more demonstrably aspire to influence the development of the avant-garde. We will return to the issue of strategic behavior in the next chapter, which considers the Popular-Intellectual Polemic. 
Maghiel van Crevel - 978-90-47-44273-8 Downloaded from Brill.com $04 / 25 / 2023$ 11:38:45PM via free access 


\section{WHAT WAS ALL THE FUSS ABOUT? THE POPULAR-INTELLECTUAL POLEMIC}

In the final years of the twentieth century, countless Chinese poets and critics partook in a protracted Polemic (论争) of Popular Writing (民间写作) and Intellectual Writing (知识分子写作) to which I have often referred in the preceding chapters. The Polemic made headlines in specialist and general media, and involved prominent players including Cheng Guangwei, Shen Haobo, Yu Jian, Yang Ke, Tang Xiaodu, Sun Wenbo, Wang Jiaxin, Han Dong, Xi Du, Xu Jiang, Yi Sha, He Xiaozhu, Chen Chao, Zhongdao and many others. All major protagonists were men. As noted more than once in this study, the male dominance of the avant-garde's metatextual arena is all the more remarkable in light of the significance of Women's Poetry as a textual category of widely acknowledged impact.

If we allow for some generalization, it would doubtless be possible to arrive at a textually argued contrast of so-called Intellectual and Popular poetry as written by the individuals associated with each side. The reader will recall that intellectual and popular form one of the dichotomies that constitute the overarching contrast of the Elevated and Earthly aesthetics within the avant-garde outlined in chapter One. However, literary texts per se played a negligible role in the Polemic. Instead, contributors put forward verse-external poetics more than anything else. What's more, for all their mutual hostility, Popular and Intellectual contributions to this particularly large and intense metatext exhibit some notable similarities. So, what was all the fuss about?

Section 1 of this chapter offers a critical inventory of over one hundred such contributions to outline what the issues were, that is: what people talked about. Section 2 considers geographical-cultural, institutional and biographical dividing lines and ties of allegiance (关系) between authors, and reflects yet again on the sociology of modern Chinese poethood, in order to identify what was at stake, that is: why people talked about what they talked about. The Appendix to this

(C) MAGHIEL VAN CREVEL, 2008 | DOI 10.1163/9789047442738_013

This is an open access chapter distributed under the terms of the Creative Commons AttributionNoncommercial 3.0 Unported (CC-BY-NC 3.0) License. 
chapter contains a chronological bibliography of the Polemic, as a palpable record of its emergence and development and to facilitate future research. References to items \#1-120 are to the Appendix (in an in-text format to avoid drowning in bibliographical detail during the analysis); other literature, referred to in the footnotes, is found in the regular list of works cited for all chapters.

The Polemic was a defining, multi-faceted moment in discourse on the avant-garde. It was different from earlier tussles with the literary establishment as regards both the avant-garde's (self-)image and things like interpersonal relationships on the poetry scene, publication patterns and so on. There is an abundance of material and for developing a real sense of what it was all about, nothing less than immersion in the sources will do. To this end I will dwell on all key texts and make summary reference to many others. Hence, section 1 is long and dense, and some readers may wish to skip to section 2 (p441); but I have wanted to avoid jumping to conclusions on what was a rhetorically charged affair, and the material is well worth it. The analysis reaffirms a point that has come up several times in the preceding pages: on the contemporary Chinese poetry scene, images of poethood are of exceptional importance.

\section{What Were the Issues?}

The Polemic generated a plethora of publicly available material in multiple-author anthologies of poetry and criticism, scholarly publications, official and unofficial literary journals and regional dailies and weeklies. Research for this chapter doesn't extend to the Internet. Aside from the general disclaimer made in chapter One, this is because the explosive growth of Internet use on the poetry scene came after the Polemic "proper" had come to an end early in 2000.

\section{Cheng Guangwei's Appropriation of a Decade: "Chinese Poetry from the West"}

In February 1998 Beijing-based critic Cheng Guangwei published an anthology entitled A Portrait of Years Gone By: Literature of the Nineties, Poetry Volume (岁月的遗照: 九十年代文学书系, 诗歌卷, \#1). Literature of the Nineties (\#3) editor Hong Zicheng rightly calls attention to a change of mood in the 1990s as compared to the 1980s in a foreword (\#4) 
to the series, reaffirming that 1989 was a turning point between two distinct periods in contemporary poetry. Reflecting on the social status of (high) literature in the 1990s, which was much less self-evident than in the 1980s, Hong concludes on a note of cautious optimism, saying that in spite of poetry's low visibility some very good works have been written. Portrait also contains an introduction by volume editor Cheng Guangwei, entitled "Journey with Unknown Destination" (不知所终 的旅行, \#2). This essay had appeared by itself a few months earlier in Mountain Flower. Already at that time it must have raised some eyebrows, but it was as the introduction to the poetry volume in the Literature of the Nineties series that it sparked off the Polemic.

In "Journey," Cheng claims the concept of Poetry of the Nineties (九十年代诗歌) for a particular literary persuasion, which seemingly comes to monopolize what was in reality a decade of multifarious writing. ${ }^{1}$ Poetry of the Nineties then comes to denote the work of poets of Cheng's personal-professional preference, whom he frequently calls his "friends." Meanwhile, as his adversaries would be quick to point out, he ignores authors whose significance is beyond doubt, as evidenced by their publication record. Any anthology bears its maker's mark and subjectivity is the anthologizer's prerogative, and Cheng is by no means the only critic whose idea of "the Nineties" blurs the boundaries between aesthetics and calendar chronology, ${ }^{2}$ but the introduction to Portrait and its selection of poems are blatantly partial. This is borne out by an appendix listing Cheng's recommendations in poetry and criticism on the book's final page. All things considered, it is hardly surprising that the anthology gave rise to heated debate.

For his vision of Poetry of the Nineties, Cheng takes his cue from the work of Wang Jiaxin. This passage (p2) ${ }^{3}$ is reprinted on the book's back cover:

\footnotetext{
${ }^{1}$ As noted in chapter One, my use of the Eighties and the Nineties is with reference to a sea change in the intellectual-cultural realm at large, as distinct from the 1980s and the 1990s as neutral indications of calendar time. This distinction is acutely relevant to the present chapter.

${ }^{2}$ Cf Luo Zhenya 2005: 172-188 and Wei 2006.

${ }^{3}$ Page numbers are those of first publications. Cheng Guangwei's "Journey" is one of three exceptions $(\# 2,63,86)$. Reference is made to the article in its capacity as the introduction to Portrait, because it is as such that it triggered the Polemic.
} 
I was shocked by the feeling of grief in [Wang's] poems, and I felt that it was not just him, but that all this encompassed shocking changes deep inside the souls of our entire generation. I had a premonition that the Eighties were over. Or, perhaps, that what used to be knowledge / intellect, truth, experience, no longer constituted "models" to regulate, to guide, to control what poets write, and at the very least these things no longer provided any norms for writing.

My rendition of 知识 'knowledge' as knowledge / intellect is motivated by its various uses by various parties in the debate, and by its connection with the Chinese 知识分子 'intellectual.'

According to Cheng Guangwei, knowledge / intellect is a good thing, even if it found itself floundering throughout the 1990s. As noted in chapter Five, following the 1987 edition of the Poetry Monthly Youth Poetry Conference at Shanhaiguan, several up-and-coming poets had advocated an "intellectual spirit" for poetry and arranged for their ideas to materialize in the unofficial journal Tendency the following year. With reference to this self-assigned label, Cheng Guangwei calls his favorite poets Intellectuals. Judging from the space he devotes to them in his introduction to Portrait, in addition to Tendency founders Chen Dongdong, Xi Chuan and Ouyang Jianghe-from the mid-1980s, Ouyang had played a particularly prominent part in the theorization of "serious" or "intellectual" poetry" - they include Wang Jiaxin, Zhang Shuguang, Xiao Kaiyu, Sun Wenbo, Bai Hua, Zhai Yongming and Zang Di. Cheng holds that (p17)

Nineties writing requires the writer first of all to be an intellectual with independent views and taking an independent position, and only then to be a poet.

Die-hard supporters of Maoist literary policy aside, it would be difficult to find anyone in post-Cultural-Revolution China who disagrees with the need for the writer to hold independent views and take an independent position, but the primacy of intellect over poethood is of course open to debate.

In principle, many voices on the poetry scene might have concurred with Cheng's moralizing (p15-16):

I respect the efforts of those few poets of the Eighties who were serious about their writing . . What we call poetry of the Nineties . . is

\footnotetext{
4 Day 2005a: ch 8.
} 
an extremely strict artistic standard, it is a moral issue in the writing of poetry.

The problem was that Cheng appropriated the full breadth of a decade for only one of many poetic practices that co-existed at the time.

One thing that angered many was Cheng's negotiation of an issue which has remained controversial ever since Huang Zunxian's experiments with the vernacular in the final years of the nineteenth century, namely Chinese poetry's relationship with foreign and especially "Western" literature. First, Cheng lists numerous foreign influences, but without textual evidence, so that this amounts to little more than name-dropping. When discussing Zhang Shuguang, whose poem «Ulysses» (尤利西斯, 1992) is included, Cheng mentions Yeats, Rilke, Miłosz, Lowell and Pound; for Wang Jiaxin, whose «Pasternak» and «Kafka» (卡夫卡, 1992) are included, Yeats, Miłosz, Pasternak and Brodsky; for Zhai Yongming, Sylvia Plath; for Xi Chuan, whose «Rereading Borges' Poetry» (重读博尔赫斯诗歌, 1997) is included, Borges, Neruda and Pound; for Chen Dongdong, Apollinaire and Breton; and for Xiao Kaiyu, "certain American poets" and Pound. The echo Cheng hears of Chinese traditions moves him to no more than one mention of Republican-era poets Li Jinfa and Dai Wangshu in connection with Chen Dongdong, and one of Tang and Song dynasty poets Li Shangyin, Wen Tingyun and Li Yu in connection with authors of lesser prominence in his anthology.

A second bone of contention was Cheng's depiction of Chinese poetry's relationship with its Western precursors and examples. This is the operative passage (p18):

There is a notion that traditional Chinese poetry never offered modern poetry a suitable aesthetic space, and that therefore one can say that modern Chinese poetry has grown and developed in another aesthetic space, that is: within the Western poetic tradition. Such a notion presents us with the hypothesis that people could only discuss Poetry of the Nineties within the boundaries of Western taste. I do not doubt that our poets have wanted to dedicate themselves to modern Chinese poetry with all the sincerity and responsibility contained in the greatness of their character; but I do doubt whether the ordeal of their dilemma has contributed to the rational development of our modern poetry. On the one hand we look to Pound, Eliot, Auden, Yeats, Miłosz, Mandelstam, not to mention the biases and ever-changing tastes of foreign sinologists, and we attempt to establish what is in fact the fiction of a "tradition" of modern poetry in Chinese; on the other, in our heart of hearts, in the insight 
into Han culture and language that is carved into our bones, we lack any and all confidence regarding this "tradition," which is built on sand. We are sufficiently vigilant vis-à-vis the "international poetry stage" but at the same time yearn for recognition on that very stage, to use this as a standard for greatness in poets. On the one hand we want to be Don Quixote charging enemy lines; on the other, even if we have taken a hundred steps forward, we are still but an irresolute, hesitant Hamlet. Our education and our nature preclude all this being more than fruitless exercises in the realm of art.

Tellingly, Cheng concludes this passage by references to Don Quixote and Hamlet, and not, say, Sun Wukong and Ah Q. In 2001 his views on the matter were brief and simple: modern Chinese poetry comes from the West. ${ }^{5}$

Third, Portrait takes its title from an eponymous poem (1993) by Zhang Shuguang, which opens the anthology (p1-2):

"A Portrait of Years Gone By"

Over and over again I see you, friends from childhood days still lively, cheerful, with your jokes that border on the vulgarit seems the years have failed to play their tricks on you or you've somewhere found a prescription for staying young and the trees, the sky behind you still retain their original shape, not a hint of change, as if bravely withstanding time and all that time brings. Oh young knights, we once saw days of glory, drank and womanized or stayed up all night to talk about a poem or a novel. We played Hamlet, now imagine crossing the waste land, looking for the long-lost holy grail near the campus flower beds at dusk, chasing Eliot's lonely silhouette. At the time I didn't like Yeats, didn't understand Lowell or Ashbery and of course didn't know you, merely saw you every day hurrying along that little road to the church or the canteen, your expression grave or melancholy. I went mad for the illusion of an image, called out for spring only to be cast deeper into valley snow until my soul was exhausted. Of the squirrels back then some are now dead some toothless left with no more than the occasional angry cry to prove that they're here and we've made peace with our fathers, or become fathers or fallen into even deeper traps in life. And do they really exist those beautiful hours that we yearn for, gone forever? Or

\footnotetext{
${ }^{5}$ Personal communication, July 2001.
} 
are they but dreams, or ideas we entertain within our pain?

Perhaps we're only witnesses to time, just like these old photographs

yellowed, cracked, but holding events, people

once called history, yet never real-

The poem's second half is stronger than its first. What concerns us here is these lines:

to talk about a poem or a novel. We played Hamlet, now imagine crossing the [W] aste [L] and, looking for the long-lost holy grail near the campus flower beds at dusk, chasing Eliot's lonely silhouette.

At the time I didn't like Yeats, didn't understand Lowell or Ashbery

There is no reason why a Chinese poet shouldn't refer to Western traditions. Also, the text holds not a single clue regarding the cultural identity of the speaker, unless we want to take the fact that it is written in Chinese as such. Should we perhaps envisage the speaker as a Westerner, precisely because he speaks of Hamlet and the rest? The casual transition from public, historical, literary Westerners to an anonymous, personal presence (you) in his life doesn't make this a likely reading. Be that as it may, without condoning cultural nationalism and protectionism, it is understandable that the combination of the anthology's subtitle, Cheng Guangwei's introduction and his naming of the book after Zhang's poem rubbed many readers the wrong way.

\section{Shen Haobo's Angry Response: "The Occupation of the Poetry Scene"}

An elaborate rejoinder to Cheng Guangwei's anthology and its introduction would appear early in 1999, in what may well be called a counter-anthology edited by Yang Ke, with a counter-essay by Yu Jian. But let's first take a look at an earlier contribution by Shen Haobo, who would soon take the lead in the Lower Body movement. In October 1998 Shen - then calling himself Choushui-had published “Who's Fooling “the Nineties” (谁在拿 “九十年代” 开涮, \#8) in the May Fourth Literary Journal (五四文学报) at Beijing Normal University, where he was a student at the time. It was first reprinted in Oriental Culture Weekly (东方文化周刊), and then, in January 1999, in the widely read Friends in Letters (文友). The article, sometimes more like an open letter to Cheng Guangwei, starts off in bold, vituperative terms (p20): 
... I mostly want to talk about these people: Cheng Guangwei, so-called "famous" poetry critic, whom I have always disliked; Hong Zicheng, professor at Peking University, whom I once respected but whose behavior I now find most dubious; Ouyang Jianghe, high school graduate bragging all day long about being an "intellectual"; Wang Jiaxin, forever jabbering foreign names like "Pasternak" and "Brodsky," words like "exile" and "grief"; Sun Wenbo, who has written a hundred bad poems, all with the same face, but is still trying hard to establish himself in Poetry of the Nineties; Chen Dongdong, whose pages are strewn with exquisite expressions but who can't string together a single good poem; Xiao Kaiyu, who is in no way worth mentioning but now affects sudden fame; and those lower down, like Zhang Shuguang, Zang Di and Xi Du and their ilk.

Shen Haobo is a skilled polemicist. That is, for all the ostentatious subjectivity of his allegations, they are put forward with enough panache to leave a lasting impression. He sounds both threatening - toward the end of the article, when he addresses Cheng Guangwei directly - and sardonically funny, as in this attack on Wang Jiaxin (p21):

. . Granted, Wang Jiaxin's «Pasternak» is a good piece of work, but that's all. In most of his poems, the best lines are always those in quotation marks (and what he quotes is other people's poetry!). He is always in London or in Russia, always pouring out his Brodsky, his Pasternak, his Kafka - he simply doesn't grow on Chinese soil! All day long, over and over again, he says "exile" "exile" "exile," but the problem is: who is it has exiled you, Wang Jiaxin? You're not Bei Dao, you're not Duoduo, you're not Brodsky, and you will always be that overcautious Wang Jiaxin, imitating the Russians with that big scarf'round your neck, Wang Jiaxin!

Shen feels that Cheng Guangwei and poets, critics and editors of similar inclination have "occupied" important channels for publication in the 1990s and intentionally "suppressed" worthy poets such as Yu Jian, Yi Sha, A Jian, Mo Fei, Hou Ma, Xu Jiang, Han Dong and Wang Xiaoni. His words contain some of the charges against the Intellectuals that were to recur throughout the Polemic: Westernization and the lack of an indigenous spirit, affected, mystifying diction, and manipulation of opportunities for publication and public relations of the poetry scene. 


\section{Yu Fian's Two Camps in Poetry: "The Light of the Chinese Language"}

Early in 1999 Guangzhou-based poet and editor Yang Ke put out the 1998 Yearbook of China's New Poetry (1998 中国新诗年鉴, \#12). For its coverage of one year, the 1998 Tearbook is an ambitious project. In fact, its selection of poetry by close to a hundred authors and of essays by a dozen critics includes entries from earlier years. Yang Ke's anthology was followed in April by another yearbook, edited by Beijing-based critic and editor Tang Xiaodu, entitled 1998 Yearbook of Modern Han Poetry (1998 年现代汉诗年鉴, \#17). Tang's book, with a broad vision but more meticulously organized than Yang's, contains works by well over a hundred poets and three appendices of specially recommended poems, criticism and events in poetry in 1998; as we have seen in earlier chapters, the Han in Modern Han Poetry denotes the Chinese language rather than ethnicity. Tang's choice of material for the appendices would likely have reaffirmed the discontent Shen Haobo felt at what Shen perceived as the occupation of the poetry scene by certain poets and critics.

The successive appearance of Yang's and Tang's yearbooks in Guangzhou and Beijing, the composition of their editorial committees and Yang's postscript (\#13) all point toward what would soon be one of the central issues in the Polemic: a dichotomy of North and South, and of Beijing and the provinces. Yang Ke's is arguably a counteranthology to Cheng Guangwei's A Portrait of Years Gone By, and it is spearheaded by a counter-essay by Kunming poet Yu Jian. Yu's essay, entitled "The Light of Poetry, Cutting through the Chinese Language" (\#14), amounts to a declaration of war.

"The Light" was written in the fall of 1998. A year earlier, when Cheng's Portrait had just come out, important elements in "The Light" had been foreshadowed in Yu's "The Hard and the Soft of the Tongue of Poetry: On Two Different Directions in the Language of Contemporary Poetry" (\#5), published in Poetry Exploration; we encountered both essays in chapter Eleven. "The Hard and the Soft" is less truculent than "The Light," presumably because it went to press before Cheng Guangwei's book claimed the 1990s for the poetics of Cheng's preference.

In "The Hard and the Soft," Yu Jian examines the development of contemporary poetry through a contrastive comparison of the Standard Language and regional languages. In Yu's words, there is 
a connection of the Standard Language, Maoist discourse, central state-sanctioned ideological and literary orthodoxy, official realities of propaganda and the public sphere, utopianism, abstraction, metaphysical spirituality, formal diction, foreign-influenced literary elitism, Intellectual Writing and so on - what he calls a hard (硬) type of language - with works by orthodox Political Lyricists He Jingzhi and Guo Xiaochuan, Obscure and Post-Obscure poets such as Bei Dao, Yang Lian, Wang Jiaxin, Haizi, Ouyang Jianghe and Xi Chuan, and poet of the masses (大众) Wang Guozhen. The obvious implication is the relegation of Bei Dao, Yang, Wang, Haizi, Ouyang and Xi Chuan to an orthodox and artistically hackneyed position, in spite of their generally perceived avant-garde status. Yu Jian writes that, on the other hand, regional languages, life in the (Southern) provinces, marginality, unofficial realities, relaxation, humor, playfulness, intimacy, concreteness, physicality, indigenous culture, colloquial diction, Popular Writing and so on - in what he calls a soft (软) kind of language - are found in works by Third Generation authors such as Han Dong, Yu himself, Lü De’an, Zhai Yongming, Yang Ke, Zhu Wen, Lu Yimin and Yang Li. In itself Yu Jian's attention to differences between the Standard Language and regional languages is entirely justified, but the leaps and bounds that lead to his literary genealogy remain unsubstantiated.

Still, "The Hard and the Soft" is a paragon of reason and clarity when compared to "The Light" and to several of Yu's later contributions. Yu Jian offers original ideas but his style is often gratuitous, chaotic and aggressive. Like Shen Haobo, he achieves considerable effect because he excels at invective, has an unfailing instinct for what is hip in artsy and "ordinary" circles, and can be very funny. "The Light" suffers from a questionable internal logic, but it contains most of the core elements of the Popular-Intellectual Polemic.

Before we proceed to review these, another translatory note is in order, on 民间 'popular,' 'folk,' 'of the people,' 'among the people,' 'people-to-people,' 'non-governmental,' rendered as Popular throughout this study. This rendition has an unfortunate overlap with popular as in 通俗读物 'popular reading matter' in the sense of pulp fiction. On the other hand, rendering 民间 as of the people would lead to unwarranted association with 人民 'the people,' a key term in PRC political discourse, in phrases like 人民共和国 'the People's Republic' and 人 民群众 'the masses of the people.' People-to-people or non-governmental only cover a small part of the connotations of 民间 in the Polemic. 
Furthermore, as we shall see, Yu Jian and others use 民间 in two different ways, which further complicates its translation. Hence, Popular remains the preferred option after all, with upper-case $\mathrm{P}$-and uppercase I in Intellectual - flagging usage that is specifically linked to the Polemic. The possibility of throwing up our hands at an instance of untranslatability and simply transcribing it as minjian is denied us, because the word's usage in the Polemic is equally problematic in the original. ${ }^{6}$

But let's return to the scathing criticism of Cheng Guangwei's scheme of things put forward by Yu Jian in "The Light." Yu expands the scope of the conflict to that of total warfare between two camps in poetry, one of Intellectual Writing and one of Popular Writing. Notwithstanding his 1993 statement that an intellectual standpoint was a minimal condition for mature poethood, ${ }^{7} \mathrm{Yu}$ presents himself as a champion of the Popular. His argument hinges on a rhetorically clever usage of Popular that invests it with two profoundly different implied meanings, one institutional and the other aesthetic, along the lines of a similar ambiguity in the term unofficial, discussed in chapter One. In Yu's essay, Popular sometimes takes on the institutional meaning 'published outside state control,' as a proud epithet of groundbreaking journals such as Today, Them and $\mathcal{N}_{\text {ot-Not. }}$. At other times he uses Popular in an aesthetic sense, so that the question What is Popular poetry? is implicitly rephrased as What is good poetry? or What is poetry that matters? He contends that good poetry is inherently opposed to knowledge / intellect, and describes Popular poetry as a reflection of the experience of everyday life, craftsmanship like that of a carpenter, the movement of language which cuts through forgetting and returns to the home of being, the light emitted by wisdom and the soul, and so on. Other, equally vague and high-blown definitions abound. The most interesting among them spring from Yu Jian's concern with language itself rather than things like truth and beauty.

Yu's impassioned advocacy of Popular Writing in both the institutional and the aesthetic sense implies the identification of Intellectual Writing with state-sanctioned orthodoxy on both counts. If Intellectual Writing is presented as alien to Popular Writing in the aesthetic sense, the non-specialist reader may well assume that institutionally, it had

\footnotetext{
${ }^{6}$ Cf Wang Guangdong 2002.

Yu Jian \& Zhu 1993, published as 1994: Question 5.
} 
no part in the avant-garde's history either, which would retroactively make its authors disappear from the unofficial journals that have been instrumental in this history. As the avant-garde was originally defined in opposition to orthodoxy and has effectively outshone it since the mid-1980s, hostile identification with orthodoxy is a damaging imputation for any avant-garde author.

$\mathrm{Yu}$ Jian characterizes Intellectual Writing as elitist, artificial, alienated and fake, and Popular Writing as sensitive, honest, accessible and authentic, and belonging to ordinary people. In line with his ideas on the hard and the soft, Intellectual Writing is located in the North, more specifically in Beijing and the Standard Language, as the center of orthodox, political ideology; and Popular Writing is located in the provinces, more specifically the South and its regional languages, as the heartland of Chinese culture. The opposition of North and South extends into one of foreign and Chinese. Yu ties Intellectual Writing to foreign-colonial traditions and what he calls the slavish Europeanization of a Chinese language that draws on Western-language resources (西方语言资源). Exile poetry doesn't count as Chinese. Popular Writing, in its turn, taps into the Chinese experience and into pride taken in indigenous traditions, such as the classical poetry of the Tang and Song dynasties. He concludes with a remark on the possibility that some languages are better suited to certain tasks than others (p16):

For poets of the Chinese language, English is a language for the web, a Standard Language for the cloned world that leads the way in our time's economic activities. But for poetry the world needs Chinese to take the lead. The historical consciousness of the Chinese language and its natural poetic qualities make it a poetic language par excellence that can effectively maintain human memories of the earth and the connection of humankind's spirit with the old world. I am of the opinion that in the final two decades of this century, the world's most outstanding poets have dwelled in the Chinese language. But on this point we remain silent, we keep it a secret and don't spread the word.

As noted in chapter Eleven, the assumption appears to be that foreigners don't read Chinese, and one wonders why those parts of the world that lie outside China should be kept in the dark if the world's best poets are really writing in Chinese. These things sit uneasily with the importance $\mathrm{Yu}$ Jian ascribes to the Chinese language for the wellbeing of humankind. Then there is the sad lot of languages which are neither English nor Chinese, disabling them for leadership in matters 
economic and poetic alike: say, Swahili, Finnish, Turkish, Portuguese, Hindi, Russian, Arabic....

The above passage is typical of Yu Jian's disregard for argumentative logic or nuance. Sometimes this rhetorical havoc appears to be intentional, as in the distortion of Cheng Guangwei's opinions. The struck-out words are those that Yu Jian leaves out when he quotes Cheng (p8):

Nineties writing requires the writer first of all to be an intellectual with independent views and taking an independent position, and only then to be a poet.

"The Light" and Yu Jian's other essays are cluttered with untenable claims: historical events such as the founding of the People's Republic and June Fourth are irrelevant to the development of literature, poetry was part of the everyday experience of ordinary people in the Tang and Song dynasties, something similar is currently true for Popular poetry by $\mathrm{Yu}$ and others, and so on. A conspicuous feature of his contributions and of the Polemic at large, mostly in the Popular camp, is the echo of Maoist literary discourse, or perhaps we should say its resuscitation in a vastly changed context. This is manifest in the negative stereotyping of Intellectual status, and in the overall tendency toward moralizing, righteous verbal assault in a manner that recalls the preaching of political ideology. It is disconcerting if we bear in mind some of the less pleasant experiences forced on intellectuals in the Maoist years, and the avant-garde's tense relationship to a cultural orthodoxy that theoretically still adheres to Maoist literary ideas. Yu Jian displays a curious anti-intellectualism in passages like the following (p8):

The inherent deficiency of [contemporary] criticism has led it to rely solely on the "Intellectuals" for its theoretical resources, in the end losing the independent standpoint of criticism and degenerating to a level not much different from that of poetry authorities such as those rigid, "bookish" poetry professors in universities, poetry critics, Chinese Departments and anthologies.

Yu's anti-intellectualism combines Maoist overtones with an opposition of the creative and the critical in literature. Notably, this opposition springs from a modern, romantic vision of the artist that is incompatible with Maoist theory. In addition, whenever it supports their argument, $\mathrm{Yu}$ and his comrades-in-arms use Intellectual to mean 
'having completed a certain level of formal, higher education.' This is awkward because many in the Popular camp hold degrees from universities of repute. Yu Jian and Shen Haobo are graduates of Yunnan University and $\mathrm{BNU}$ respectively, and $\mathrm{BNU}$ is also alma mater to $\mathrm{Xu}$ Jiang and Yi Sha, whom we will encounter below. Xie Youshun and Han Dong, another two Popular polemicists of note, are graduates of Fujian Normal University and Shandong University.

We have noted the Popular emphasis on the value of indigenous culture and its rejection of Westernization. Of course, especially in modern times, there is no such thing as a purely Western or a purely Chinese culture. Incidentally, the reader will recall that $\mathrm{Yu}$ Jian has identified Walt Whitman's and other foreign poetry as having had a tremendous impact on him in his years as a budding poet, also mentioning Pushkin, Lermontov, Shelley, Byron and Tagore as examples of the Western literature he read during the Cultural Revolution, usually in a deserted library in Kunming. Yu's extensive if eclectic acquaintance with foreign literature in translation doubtless continued afterward, as it did for most Chinese authors who rose to prominence in the 1980s and 1990s. ${ }^{8}$ While it may be an exaggeration to charge the Popular cause itself with nationalism in any serious sense, as Wang Jiaxin (\#23) has done, authors such as Sun Wenbo (\#81) and Geng Zhanchun (\#6) have a point when they observe that Popular ideas ride the tide of reemergent nationalism in China at large. These are the closing sentences of "The Light" (p17):

Poetry in Chinese of the last twenty years goes to show that my dreamof rebuilding a dignity that the Chinese language had nearly lost since [the Opium Wars], of letting modern Chinese obtain anew the glory that the Chinese language once had, in the poetry of the Tang and Song dynasties - that my dream is not at all a dream, but a magnificent road to travel.

\section{Xu fiang's Vitriolic Clowning: "Ordinary People's Right to Poetry"}

Poet Xu Jiang shares Yu Jian's nostalgia for the glory of classical Chinese language and poetry. In his "One Man's Polemic" (一个人的论 争, \#71), Xu writes (p97):

\footnotetext{
${ }^{8}$ Yu Jian \& De Meyer 1995: 28.
} 
As a poet of the Chinese language, my sorrow lies in not having been born in the days of [Tang and Song dynasty poets] Li Bai and Su Shi.

Like $\mathrm{Yu}$ Jian, too, $\mathrm{Xu}$ is ready to do battle on behalf of his ideals:

I have a responsibility to protect the soberness, cleanliness and fairness of the Chinese poetry scene, and I cannot let a small handful of pedantic literati slackly gain undeserved reputations, while destroying literature and the Chinese language.

The phrase a small handful of pedantic literati takes us straight back to the spring of 1942 in the Communist base areas, when Maoist literary policy was taking shape, and the same is true for Xu Jiang's fondness for calling the Intellectuals comprador-poets (买办诗人). The echoes of orthodoxy also run through Xu's “Ordinary People's Right to Poetry" (俗人的诗歌权利, \#25) and through his most substantial and acrimonious contribution to the Polemic, “The Noxious Poetry Scene” (乌烟 瘴气诗坛子, \#16). This long article appeared in the March 1999 issue of Friends in Letters. Having earlier published Shen Haobo's "Who's Fooling "the Nineties," this monthly magazine would continue to support the Popular side. In "The Noxious Poetry Scene," conjuring up the image of a miasma rising from the swamps of literature, $\mathrm{Xu}$ levels wide-ranging accusations at the Intellectual camp and blames Cheng Guangwei for leaving the reader with this impression (p6):

All Chinese poets of the Nineties are a bunch of sickly aphasia patients, not one of them can speak in plain words! . . If it weren't for the fact that I write poetry myself, even I would almost believe what he has to tell us: poets aren't normal people!

The article is divided into three parts, with subheadings "Those Anthologies," "Those Poetry Awards" and "Those Poets." The first contains yet more devastating criticism of Cheng's anthology. The second is about the corruption $\mathrm{Xu}$ Jiang perceives behind poetry awards conferred in the name of Liu Li'an, also known as Anne Kao, patroness of the avant-garde at the time and perceived by some to be partial to the Intellectuals. The third is a remarkable call to poets to behave themselves (p7):

[The poets] are lacking in discipline-long-haired or with shaved heads, living vagrant lives, giving speeches, reciting poetry, cadging meals, talking all sorts of strange prattle, presumptuous and full of themselves. 
Xu's rhetorical talent is on display when he sums up the relationship between these undisciplined poets and other, presumably "normal" people. In a nutshell: in the 1970s people were afraid of poets, in the 1980 s they were curious about them and in the 1990s they were annoyed by them. That Xu Jiang subsumes murder under annoying behavior is persuasive enough, in an oblique reference to $\mathrm{Gu}$ Cheng's killing of Xie Ye before taking his own life. That suicide should also count as annoying, rather than give cause for concern, is less selfevident. Judging by Xu's other publications, out of several suicides in avant-garde poetry since the late 1980s we should probably be thinking of Haizi here. Members of the Popular camp recognized Haizi's talent, but they still associated his life and work with the self-aggrandizement and the estrangement from everyday Chinese life for which they took the Intellectuals to task. Finally, Xu Jiang chides Poetry Monthly's editors for including their own names in a list of influential authors, as an illustration of Chinese poets' flagrant indulgence in self-promotion. Then he promptly names one of his own collections, this one in joint authorship with Hou Ma, among the ten best books of poetry of the past twenty years.

$\mathrm{Xu}$ Jiang's contributions to the Polemic are notable not so much for their substance as for their linguistic register. His choice of words and his overall tone of voice are rude and clownish at the same time. "Playing Chinese Poetry” (玩弄中国诗歌, \#11), preceding “The Noxious Poetry Scene" by a month and containing sideways allusions to the early stages of the Polemic, is a case in point. Here, $\mathrm{Xu}$ describes contemporary poetry as a sport, laying out the rules and various types of players to comical effect. The rude and the clownish merge when he admonishes aspiring critics to (p21)

put forward incessant, long articles on the work of women poets that nobody has ever heard of.

The 1999 issue of Poetry Reference includes Xu Jiang's "This Is My Standpoint" (这就是我的立场, \#72). This article makes clear how far $\mathrm{Xu}$ is willing to go in his diatribes against the Intellectuals. He accuses Wang Jiaxin of plagiarizing Pasternak, and lambastes him for (p87)

his sudden realization that for exile poetry, you don't need to go abroad.

$\mathrm{Xu}$ Jiang obviously feels no need to reflect upon niceties such as the scope of the notion of exile literature beyond its most "common- 
sensical" interpretation. The poet's whereabouts aside, Xu also has clear ideas about the preferred geographical location of their subject matter, reproaching Wang for writing about Auschwitz rather than the Nanjing massacre or the Cultural Revolution.

As we have seen in chapter Nine, on the "rivers and lakes" of the poetry scene Xu Jiang is a close companion of Xi'an-based poet Yi Sha, who has generated more controversy than anyone else since his famed collection Starve the Poets, and whose contributions to the Polemic we will address below. ${ }^{9}$ Yi Sha's and Xu Jiang's willful notoriety for abusing fellow literati and artists is captured in a March 2000 interview with Shen Haobo, using the name Shen Lang, with the tonguein-cheek title "Carry Abuse Through to the End" (将骂人进行到底, \#91). This headline is a typical parody of orthodox political jargon. It makes Yi's, Xu's, Shen's and others' penchant for seriously using such language elsewhere all the more remarkable.

\section{Xie Youshun's Cheerless Aggression: "The True Face of Poetry"}

Nevertheless, while Xu Jiang's and Yi Sha's diction is regularly reminiscent of orthodox discourse, it is also interspersed with other types of language: humorous, populist, vulgar and so on, and it leaves plenty of room for creative originality. This doesn't hold for the critic Xie Youshun. Xie specializes in fiction, but contributed several articles to the Polemic. "What Does Poetry Relate to?" (诗歌与什么相关, \#15), published in the March 1999 issue of Poetry Exploration, boils down to the assertion that poetry should be about "real life." Xie proceeds from a narrow-minded biographism, and his view of literature is almost anticreative when he presupposes a simple, one-on-one relationship between reality and art. His style, a prime example of the aforesaid echo of Maoist literary discourse, is cheerless and aggressive throughout.

One piece that elicited a fiery response from Intellectual quarters is Xie's “The Inner True Face of Poetry" (内在的诗歌真相, \#20), a rave review of Yang Ke's 1998 Yearbook carried by Southern Weekend (南方周末). Xie wonders if writing poetry is not a comical thing to do in an age of materialism, and observes that jokes about poets abound among ordinary people. He finds this especially lamentable in light of the proud poetic traditions of the Tang and Song dynasties. According

\footnotetext{
${ }^{9}$ Yi 1994.
} 
to Xie, the public has forsaken poetry because a number of poets have turned it into knowledge / intellect and abstruse learning. He advertises Yang Ke's yearbook as an attempt to countervail this trend. Following $\mathrm{Yu}$ Jian, as he does in most of his contributions to the Polemic, he sees two prominent types of poetry. Popular Writing is represented by poets such as Yu Jian, Han Dong and Lü De'an, and expresses the realities of current Chinese life. Intellectual Writing is represented by poets such as Xi Chuan, Wang Jiaxin and Ouyang Jianghe, who have an ardent desire to "connect" with the West - one recalls Yu Jian's displeasure at this phenomenon. Again, like Yu Jian before him, Xie misquotes Cheng Guangwei's vision of the poet as an Intellectual. Xie fails, however, to name the author of the mutilated statement, and instead ascribes it to Xi Chuan, Wang and Ouyang, thus saddling them with Cheng's sins. He adds that if poetry is to regain vitality it must be freed from the hegemony of Intellectual discourse. Xie is one of several voices in the Polemic that blend poststructuralist terminology with incrowd allusions to texts, people and events on the local poetry scene that only the initiated reader will pick up. Another feature he shares with contributors from both camps is that his article ends with a thunderous finale. The closing words of "The True Inner Face" have a nationalist ring to them:

Does poetry protect a self-respecting life or does it protect knowledge / intellect and technique? Is the goal of poetry in the Chinese language to regain the dignity of the Chinese language or is its goal to connect with the West? I believe that in their heart of hearts every sensitive person will swiftly make their choice.

Xie Youshun disapproves of undue reliance on the West, visible in things like the density of foreign names in Zhang Shuguang's poetry: not only in Cheng Guangwei's anthology, but also in journal publications, as Xie notes in his "Poetry Is Hurting" (诗歌在疼痛, \#68), in the October 1999 issue of Grand Master (p72):

[The Intellectuals] cannot hear the voice of Popular poetry, not because it isn't there but because they haven't drawn back their ears from the bodies of the Western masters.

Xie's plea for indigenous dignity is at odds with his own habitual citation of Western authors and critics rather than Chinese. In the limited space of his contributions to the Polemic, he refers to Proust, Kafka, Borges, Faulkner, Havel, Sontag, Foucault, Adorno, Akhmatova and 
Dilthey, among others. Together with his use of literary terminology, this makes the following self-portrait problematic. It is taken from “Who Is Doing Harm to True Poetry?” (谁在伤害真正的诗歌?, \#35), published in the July 1999 issue of Beïjing Literature (北京文学) (p69):

I have no high-level degree, I haven't lived in Beijing, that "center" of theory, I haven't read much of the foreigners' lofty words and great wisdom.

This statement is awkward in its differentiation between nonIntellectual and Intellectual as corroborated by an alleged difference of "high-level" and other degrees in tertiary education. As to Xie's own background, at Fujian Normal University he studied with Sun Shaozhen, a veteran champion of the avant-garde who played a major role in the early 1980s debate on Obscure Poetry. In 2006, Xie himself was to become a full professor in the Chinese Department of Zhongshan University.

Contentwise, like Xu Jiang, Xie Youshun makes no groundbreaking contributions to the debate, instead coming across as an admiring disciple who repeats the teachings of Yu Jian. His long article "Poetry Is Advancing" (诗歌在前进, \#96), published in the April 2000 issue of Mountain Flower, contains interesting reflections on colloquial diction in poetry but stands out by a lack of poetry-historical perspective and, again, by the virulence of his style.

Intellectuals such as critic Tang Xiaodu (\#32) and poets Wang Jiaxin (\#51) and Xi Du (\#28) took issue with Popular authors over what may to an outsider appear as just one more ripple in the floodwaters of text generated by the Polemic: specifically, the expression true face (真相), used in the headline of Xie's April 1999 book review. True face means 'true features,' 'true colors,' 'true situation,' and was taken as a grievous insult because it is political jargon, typically used for the exposure of matters arousing moral indignation. Yu Jian, however, would soon enthusiastically elaborate on the image of a true face, resulting in some of the most deafeningly belligerent pages in the Polemic.

\section{The Panfeng Poetry Conference, "Where Words Were Swords," and the Media}

Despite the relaxation of political control in the contemporary period, in literary life in the PRC it is still true that much more can be spoken without fear of censorship than written. Coupled with a continu- 
ing prescriptive streak in scholarship and criticism that is visible in questions of the type Whither Chinese literature? and the frequency of shoulds and oughts in the answers, this adds to the importance of institutionalized, spoken exchange. Since the late 1970s there have been many ambitious conferences on New Poetry where funding from statesanctioned institutions hasn't precluded forays far outside orthodox literary discourse and sometimes near-exclusive attention to the avantgarde. It was at one of these events, held from 16 to 18 April 1999, that the Popular-Intellectual Polemic burst out into the open.

The organizers of the Panfeng poetry conference, so named after the hotel near Beijing where it took place, were the Beijing branch of the Writers' Association, the Contemporary Chamber of the Research Institute for Literature of the Chinese Academy of Social Sciences, the literary journal Beïing Literature and the editorial board of Poetry Exploration. The conference was officially entitled "Turn of the Century: A Seminar on the State of the Art and Theory-Building in Chinese Poetry" (世纪之交: 中国诗歌创作态势与理论建设研讨会). As usual, in addition to scholars and critics, many poets were in attendance. This illustrates the generalization that demarcation lines between the literary and the scholarly, or the creative and the critical, tend to be less clear-cut in China than in many countries in the West.

The Panfeng conference is remembered as a head-on collision between the Popular and the Intellectual. Whether this confrontation was consciously planned, and by whom, is in itself irrelevant to the issues of the Polemic. Suffice it to note that various commentators have emphasized the "strategic" (策略性) behavior of certain participants in the conference and in the Polemic at large. There was much talk of conscious attempts in the run-up to the conference to help the Polemic make media headlines beyond specialist circles, and of phone calls by Popular activists trying to persuade their Intellectual fellow poets and critics to put on a show of fierce, irreconcilable conflict. ${ }^{10}$ Be that as it may, the conference generated enough publicity and collective memory to become a metonym for the entire debate, as witnessed by the fact that this is now remembered by many as “the Panfeng Polemic” (盘峰 论争).

${ }_{10}$ Personal communication on several occasions since 2000, with Tang Xiaodu, Wang Jiaxin, Zang Di and others. 
For the scholarly reader, the June 1999 issue of Poetry Exploration contained an elaborate report on the conference by Zhang Qinghua, entitled "True Dialogue and the Crossing of Swords in Poetry" (一次真 正的诗歌对话与交锋, \#26) and reprinted at the head of a two-part special feature on the Polemic in the July and August issues of Beijing Literature. Zhang's scholarly report was preceded in mid-May by a piece by Tian Yong in the China Youth (中国青年报) daily, called “No 'Wars' for Over Ten Years: The Poets Can't Hold Themselves Back Any Longer” (十几年没 “打仗”: 诗人憋不住了, \#21), later excerpted in the New China Literary Digest (新华文摘) as “A Polemic, Yet Again, on New Poetry's Course of Development” (关于新诗发展方向又起 论争). Tian's original title displays a sensationalism that is typical of much of the newspaper coverage of the Panfeng conference, especially in pieces sympathizing with the Popular cause. The author's quasiobjectivity is belied by slips of the pen and borrowings from Popular polemicists:

The [Intellectual] tendency to make the writing of poetry more and more like knowledge / intellect and abstruse learning is one of the main reasons that present-day poetry's plight is worsening by the day.

In mid-June the China Book Business Newes (中国图书商报) commissioned reviews of Yang Ke's yearbook by Intellectuals Cheng Guangwei (\#27) and Xi Du (\#28), and of Tang Xiaodu's yearbook by Popular author Yi Sha (\#29), which were printed side by side under the headline "What Are Their Quarrels About?" (他们在争什么?). Predictably, all three pieces are devastatingly critical. Cheng accuses Yang Ke of doing harm to the intellectual-cultural spirit of Poetry of the Nineties, seemingly oblivious to the widespread disapproval his use of this phrase had earlier elicited. Xi Du expresses disappointment at the sloppy, irresponsible editorial job that he claims Yang Ke has done. Yi Sha, while recognizing this deficiency, says it is made good by the vitality of Yang's yearbook, in contradistinction to the mediocrity, unoriginality and general lameness he detects in Tang's yearbook. Yi Sha's claim that Tang Xiaodu had publicly questioned the legitimacy of an anthology "edited in the provinces" provoked a fuming letter to the editor by Tang (\#41), published three weeks later and followed up by Tang in another publication late in 2000 (\#111).

Subsequently, on 1 July the fortnightly Literary Theory (文论报) devoted its full second page to the Polemic, carrying articles by Zang 
Di, Shen Qi, Xi Du and Chen Jun. In "Who Is It Has Harmed Poetry of the Nineties” (谁伤害了90年代的诗歌, \#38), critic Shen Qi foregrounds the clamor following the publication, some months earlier, of Yang Ke's yearbook and Shen's own "Square Accounts after the Autumn Harvest-1998: Memorandum on the Chinese Poetry Scene" (秋后算账一1998: 中国诗坛备忘录, \#10), first published in the February issue of Publication Panorama (出版广角). Shen's ostentatious surprise at the full-scale conflict that has emerged is unconvincing. His "Square Accounts" - the expression usually means 'wait until a political movement is over to get even with someone' - is an aggressive attack on Intellectual Writing, naming Xi Chuan, Wang Jiaxin and Zhang Shuguang as its foremost perpetrators. This is how Shen describes Intellectual Writing (p23):

The malpractice of highfalutin, lyrical poetry in a translationist language, full of perplexing images, metaphors copied from elsewhere, ossified ideas as well as a fabricated spirit and unclear character.

He says that Intellectual Writing makes him, a professional poetry reader, "giddy in the head." In "Who Is It," Shen doesn't pull his punches either, depicting the Popular poets as victims of harm done to poetry by the Intellectuals. Chen Jun's "What Poetry Does Not Relate to" (诗歌不与什么相关, \#37) is a sarcastic rejoinder to Xie Youshun's articles, alluding to Xie's "What Does Poetry Relate to?" (\#15), and berating him for his ignorance. Zang Di's contribution to Literary Theory (\#40) was soon reprinted in Beijing Literature and is included in the discussion of that journal's special feature below. Xi Du's "Is Poetry Common Knowledge?" (诗歌是常识吗?, \#39) is an excerpt from his much longer article "Thoughts on Various Issues" (对几个问题的思考, \#24) in Poetry Exploration, also reviewed below. In sum, Literary Theory canvassed the opinions of three Intellectuals and one Popular author. To explain this imbalance, editor Liu Xiangdong later said that he was forced to find a replacement for one of the four originally commissioned pieces at the eleventh hour. ${ }^{11}$

In mid-July, Jing Yi published a critical article in the widely read Beijing Daily (北京日报) entitled “The '99 Poetry Scene: The Battle of the School of 'Popular Writing' and the School of 'Intellectual Writing” (99诗坛：“民间写作” 派与 “知识分子写作” 派之争，\#42).

\footnotetext{
${ }^{11}$ Personal communication, November 2002.
} 
Like Zhang Qinghua's, Jing Yi's assessment of the debate comes across as impartial. She notes the tendency of the Popular camp to abuse the Intellectuals by calling them names like "pseudo-poets" (伪 诗人), “comprador-poets" and "domestic exile poets" (国内流亡诗 人). Like Zhang, Jing Yi wonders how much of the Polemic is really about poetry. She observes that the Panfeng clamor also gave belated expression to Popular frustrations over a March 1998 conference called "Seminar on "Post-New-Tide Poetry" (“后新诗潮” 研讨会) to which major Popular poets such as Yu Jian and Han Dong had apparently not been invited-New Tide Poetry (新诗潮, literally 'new poetry tide') being one of the many names given to the avant-garde over the years. ${ }^{12}$ The difference between these two well-written reports is that, whereas Zhang is inclined to an optimistic view of things, Jing $\mathrm{Yi}$ is disappointed that the debate hasn't yielded any theoretical insights. ${ }^{13}$ She goes on to analyze it in terms of the corporeal (肉身) and the cerebral (头脑), which she links to the Popular and the Intellectual respectively, and concludes by calling the Polemic a tragic incident.

The summer of 1999 saw a flurry of additional publicity. On 26 July the Taiyuan Daily (太原日报) dedicated a full page to the Panfeng conference and its background, featuring articles by Jing Wen, Tang Jin and Wang Wei. Jing Wen is presumably a pseudonym: "Turn-of-theCentury Poetry Polemic" (世纪之交的诗歌论争, \#43) is an abridged version of Zhang Qinghua's report in Poetry Exploration and Beijing Literature. Tang Jin's "Dangerous Trends at the 'Panfeng Conference"" (“盘峰会议”的危险倾向，\#44) is an acerbic piece with orthodox overtones. Tang points out that the conference had little time for textual analysis and criticizes the poets for their self-importance. Wang Wei's "Some Background and Other Things" (背景与其它, \#46) is a record of the words of conference moderators Wu Sijing and Lin Mang, both senior figures on the poetry scene, $\mathrm{Wu}$ as a scholar and Lin as a poet and an editor. Lin Mang observes that at a time when poetry is allegedly in danger of losing its readers, heated debate is a good thing. Wu Sijing calls the Post-New-Tide conference of the previous year a harbinger of divergent trends in criticism which have now come to the surface. According to Wu, in 1998 Xie Mian and Sun Shaozhen expressed skepticism toward current developments in poetry, while

\footnotetext{
12 Huanglin 1998, Shen Qi (\#10): 23.

13 Cf Zhang Qinghua 2002.
} 


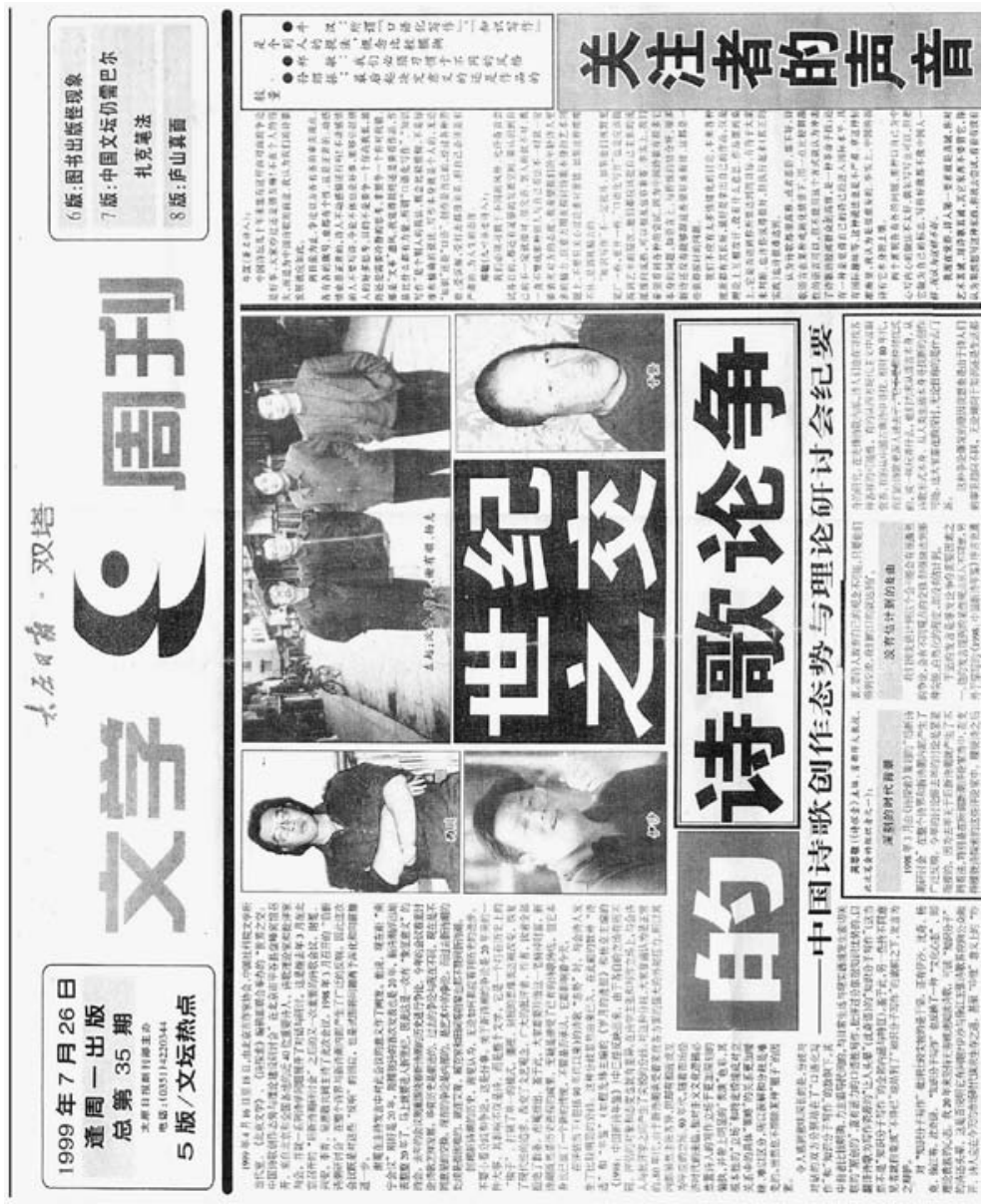

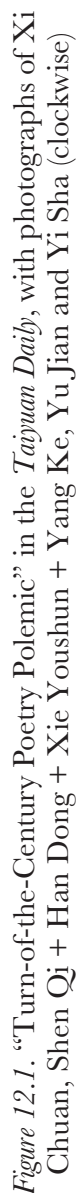


Chen Chao, Tang Xiaodu and Wu Sijing himself were optimistic. Wu says that one of the aims of the Panfeng conference was to provide the said divergence with a platform for discussion.

Wang Wei's other contribution to the Taiyuan Daily, "Voices of Concerned Onlookers" (关注者的声音, \#45), lists comments by grand old poets Niu Han and Zheng Min and by critic Sun Shaozhen. The former two choose their words carefully and avoid taking sides. Sun Shaozhen, by contrast, appears not to be "concerned" at all, opining that the roots of the debate go back to the 1980s and its culmination was hence to be expected sooner or later. He feels certain that in today's China - different from the early 1980s, when Obscure Poetry and "spiritual pollution" came under fire - avant-garde poetry will not become a problem on high-level ideological and political agendas. If the Taiyuan Daily written reports are impartial, its visuals are less so: a single portrait of Intellectual Xi Chuan, next to photographs of Popular authors Yi Sha and Yu Jian, and a group portrait of Shen Qi, Han Dong, Xie Youshun and Yang Ke.

On 31 July the Science Times (科学时报) ran a full-page feature under the headline "Quarrels after the Quarrels of 'Panfeng, Where Words Were Swords" (“盘峰论剑” 是非后的是非), giving the floor to five spokesmen of the Intellectual camp: Wang Jiaxin, Tang Xiaodu, Sun Wenbo, Jiang Hao and Chen Jun. Wang's "More on the 'True Face"" (也谈 “真相”, \#51) is a furious indictment of Yu Jian's distortion of literary history and his deception of those outside the inner circle. In "I See...." (我看到...., \#50), Tang Xiaodu concurs with Wang in accusing the Popular camp of indecent behavior, which may have been taken as a compliment by the accused in light of their self-image as hip, untamed rebels. Sun Wenbo's “The Facts Need Clarification” (事实 必须澄清, \#49) is a powerful piece, less worked up than Wang's and Tang's diatribes. Sun points to inconsistencies and lies in the words of $\mathrm{Yu}$ Jian and others, especially in their accounts of the Panfeng conference. He attributes their exaggerations and improprieties to their insecurity as poets. Sun's article also shows that moralizing and ideologizing diction is by no means limited to the Popular side. In "The Myth of Popular Poetry" (民间诗歌的神话, \#48)Jiang Hao, like Tang Xiaodu, reminds the Popular polemicists of the horror, verbal and otherwise, of the Maoist years, and joins the ranks of those shooting holes in Yu Jian's private brand of argumentative logic. In "Who Does Yu Jian Think He Is Fooling” (于坚愚谁, \#47), Chen Jun decries the 
way in which pure ambition has made the famous Kunming poet degenerate into his present state.

Four weeks later, on 28 August, the Science Times gave four Popular voices an opportunity to respond: Yi Sha, Yu Jian, Xu Jiang and Shen Haobo. The full-page feature's headline runs

Beijing Poets Sheathe Their Swords

Local Bards Now Stretch Their Bowes

If we grant po-ets two syllables, this translation retains the original line length of seven syllables, common in classical Chinese poetry (诗):

北京诗人剑入鞘

外省骚客又张弓

The parallel contrast of Beijing with the provinces (rendered as local) is followed by one of Northern poets 诗人 and Southern bards 骚 客. In this particular context the latter term can also mean something like 'rabble-rousers.' It brings to mind Qu Yuan's «On Encountering Trouble» (离骚) in Songs of the South and an opposition of this ancient "Southern" poetic tradition and a "Northern" tradition represented by the Book of Songs, even though this dichotomy is complex and by no means absolute. ${ }^{14}$ Thus, the headline's choice of words alludes to Chinese literary history to reflect the North-South and central-regional dichotomies put forward by Popular poets and critics.

As for the individual contributions to the Science Times, Yi Sha's "So Who Is It Has Gone Mad?” (究竟谁疯了?, \#60) is an example of Yi's rhetorical talent for the genres of satire and pamphlet. He attacks Xi Chuan (\#33) for having likened Popular activism to an "underworld" of poetry. The opening paragraphs of Yu Jian's "Who Is Producing Discursive Power?” (谁在制造话语权力?, \#61) are hilarious. $\mathrm{Yu}$ wonders how poets can live in a place like Beijing, which he turns into a locus of estrangement from indigenous culture, and suggests that the heated reactions to his writings are probably explained by dog-day temperatures in the capital. In 'Dare Say 'No' to the Poetry Scene” (敢对诗坛说 “不”, \#59) Xu Jiang expresses disappointment in Wang, Tang and other proponents of the Intellectual cause, and offers an account of the Panfeng conference of the type labeled tendentious and deceptive by Intellectuals like Sun Wenbo. In "Let the Polemic

\footnotetext{
14 Hawkes 1985: 15-28, Hartman 1986: 59-63.
} 
Sink In” (让论争沉下来, \#58), Shen Haobo argues against reconciling words such as those of moderators Lin Mang and Wu Sijing, and notes, not without reason, that poets and critics are dangerously inclined toward establishing mutual admiration societies.

Simultaneous with coverage of the Polemic in newspapers, the literary press, from scholarly publications to those addressing the general public, continued to publish articles by Intellectual and Popular polemicists. The special feature in the July and August issues of Beïing Literature included pieces by Chen Chao, Tang Xiaodu, Xie Youshun, Xi Chuan and Han Dong (in part one), and Yu Jian, Zang Di, Xi Du, Sun Wenbo, Wang Jiaxin, Shen Qi and Hou Ma (in part two), thus maintaining a balance between persuasions. In " $\mathrm{Q} \& \mathrm{~A}$ : Views on Some Points of Common Knowledge” (问与答: 对几个常识问题的看法, \#30), Chen Chao calls the opposition of Intellectual and Popular a fiction. He finds the charge leveled at the Intellectuals of using "Western language resources" detestable and invalid, because it forces people to take sides - Are you with the West or with China? - and because what matters is not one's raw material but what one does with it. Tang Xiaodu, in “An Open Letter to Mr Xie Youshun” (致谢有顺君的公开 信, \#32), points out the resonance of Maoist literary discourse in Xie's writing, reminding him that the avant-garde took two decades to reach its current state of pluriformity and abundance. He reprimands him for his lack of tolerance and for ideologizing the debate. Xie's "Who Is Doing Harm to True Poetry?" (\#35) in its turn accuses the Intellectuals of behavior called "obstruction" (遮蔽) in Popular discourse, meaning the manipulation of publishing opportunities and public relations of the poetry scene in the interests of one's own clique and with the aim of keeping others out; we will return to this issue in section 2. Xi Chuan's “Contemplation Is More Important Than Abuse" (思考 比谩骂要重要, \#33), its title doubtless reaffirming his Intellectual status in Popular eyes, contains rebuttals directed at Yu Jian, Yi Sha, Xu Jiang and Xie Youshun, dwells on the phenomenon of abusive criticism (骂 or 骂人) in Chinese literary circles and argues for recognition of the fact that intertextuality with foreign texts as well as Chinese is inevitable, and not a bad thing at any rate. Han Dong's "A Time That Supposedly Loves Culture” (附庸风雅的时代, \#31) is a bitter piece focusing on Han's perception of a small number of Intellectual poets, influential since the 1980s, as obstructing the careers of others. Complementary to Han's exposition of the Popular cause, discussed 
separately below, this warrants a long quote. The following passage further illustrates Han's uneasy relationship with "the West" (p74):

As for those who became famous in the 1990s . . . their reading is of the purposeful kind . . . They have in their reading gradually entered into role play. Hence, it is not at all difficult to understand their pathological love of books ... They only read books that they think they have written themselves or could have written themselves, they are only concerned with the lives (or the lifestyles) they think are their own or could have been their own ... They deeply love translated works of foreign literature and deeply love Western literary history . . . prostrating themselves in admiration before so-called masters and giants . . proving themselves familiar with their lives and anecdotes as if enumerating their own household treasures ... All of their inspiration comes from their reading, and their writing style, patterns and forms never exceed that precedence ... Like all collectors and antique lovers they identify absolutely with books, and with a bookish value-judgmental attitude toward thinking and art ... Their most extreme manifestation is if they can produce forgeries with their own hands . . . so that not even a connoisseur could see the traces of those hands. If there is a difference with top collectors and antique lovers, it has to be that our "reader-artists" ultimately fool themselves.

Part two of the Beijing Literature special feature opens with an article by $\mathrm{Yu}$ Jian, to which we will shortly return. Zang Di, in his "Poetry as a Special Kind of Knowledge / Intellect” (诗歌: 作为一种特殊的知识, \#40), emphasizes (p92)

the need to work hard to develop poetry anew toward a form of knowledge / intellect that is independent from science, history, economics, politics, philosophy.

Zang warns that popularizing trends in twentieth-century Chinese literary discourse have turned against innovative poets more than once, cautioning against a repetition of such mechanisms. Xi Du's "A Plea for the Right to Write" (为写作的权力声辩, \#56) - an abridged version of his "Thoughts on Various Issues" (\#24), discussed below-is important in that $\mathrm{Xi}$ Du questions the assumption that Intellectual poetry is divorced from things like daily life, the zeitgeist of its authors' here-and-now and so on. In "On 'Western Language Resources"” (关 于 “西方的语言资源”, \#54), Sun Wenbo berates Yu Jian for mobilizing ethnic and nationalist sentiments, citing Li Bai's Turkish descent as an example of the natural phenomenon of cross-cultural influence. 
Wang Jiaxin's “On 'Intellectual Writing” (关于 “知识分子写作”, \#55) states that

[Intellectual Writing], in a society like China's, first of all demands writing to be independent, oriented toward humanist values, to have a critical spirit; it demands a basic quality and style that have been lacking from modern Chinese poetry for too long.

Notably, the word translated as quality and style (品格) also means 'moral character.' Shen Qi's “What Is 'Intellectual Writing” (何谓 “知识 分子写作”, \#53) holds that critical discourse has generally supported Intellectual Writing and contributed to the obstruction of Popular poetry. Beijing poet Hou Ma rails at the affectations that come with Intellectual poethood in his "The Nineties: The Beginning of Professional Writing by Amateur Poets" (90年代: 业余诗人专业写作的开 始, \#52).

Part two of the Beijing Literature special feature opens with Yu Jian's “Their True Face: On 'Intellectual Writing' and New Tide Poetry Criticism” (真相: 关于 “知识分子写作” 和新潮诗歌批评, \#63). In this piece, Yu's lack of argumentative cogency appears to have been aggravated by drastic editorial cuts, but the article was soon published in full in the September issue of Poetry Exploration. In "Their True Face," which is a declaration of allegiance to Xie Youshun's controversial usage of this phrase, Yu Jian fulminates against Ouyang Jianghe's famous essay "Writing Poetry in China after '89: Indigenous Disposition, the Marks of Middle Age and Being an Intellectual." ${ }^{15} \mathrm{Yu}$ traces a monopolizing and obstructionist spirit informing publications such as Cheng Guangwei's Portrait to the early 1990s and blames poetry critics for having sold out to the Intellectuals. Earlier having charged the Intellectuals with ideologizing poetry through "hard" language and identified Intellectual discourse with orthodoxy by contrasting it with the Popular, he reaffirms this identification by claiming that attacks on the Third Generation-meaning Earthly authors from the mid-1980s onward - came first from orthodox and then from Intellectual quarters. As evidence, he cites an attack on the avant-garde by orthodox critic Zhang Hongming in the Literature $\mathcal{E}^{\circ}$ Art Review (文艺报) in 1990, entitled “New Tide Poetry”Unmasked” (对“新诗 潮” 的透视). ${ }^{16}$ Precisely because of Yu Jian's active dissociation from

\footnotetext{
15 Ouyang 1993a.

16 Zhang Hongming 1990.
} 
orthodoxy, one cannot but notice that the images of a true face and of unmasking - literally, 'seeing through' (透视) — are strikingly similar. What's more, the structure of Yu Jian's piece is near-identical to that of Zhang's: a number of central, rhetorical questions in bold type, each followed by a predictable answer, dished out in an irreconcilable tone.

Content aside, one of the reasons that the Popular camp held the upper hand in the Polemic from start to finish was the sheer productivity of authors such as Yu Jian, Yi Sha and Xu Jiang. Another was their readiness to be rude and, quite simply, shout down their Intellectual adversaries. This point is illustrated by the breathless sentence length in the concluding paragraphs of Yu's "Their True Face" (p47-48):

Poets from the provinces who insist on the Popular standpoint, on Poets' Writing, on the Chinese experience and on poetry's freedom, independence, originality and democratic spirit, who are non-ideological and position themselves in the margin [on the one hand], and hegemonic critics who use the geographical dominance of the cultural and political center that is Beijing to attempt, in line with historical practice, to make the discourse of power once more incorporate a poetry that has regained independence and dignity since the Eighties, and to establish an overweening type of order in the poetry scene [on the other] - theirs is an irreconcilable relationship of water and fire, and its true face is now there for all to see.

Superior poets making their own rut, immersed in writing in the vast lands of China's provinces, without critics to wave banners and shout battle cries for them, far from the convenience of international connections to be found in Beijing, who have relied only on creative and extraordinary poetic texts to establish within the bronze walls and iron ramparts of China's poetry scene the dignity of poetry and its individual charm [on the one hand], and the "Intellectual Writing" line of thought of make-believe, mediocre poets who are really readers of Western poetry and literary-artistic theory, who count on the discourse of power and the critics' lavish praise and who would cease to exist without this discourse and this praise [on the other] - theirs is a clear distinction of good and bad, and its true face is now there for all to see.

The Beijing part of the New Tide poetry criticism that relied on the actual achievements of excellent Third Generation works to make a name for itself in the great Eighties has now thoroughly betrayed the tolerance toward minority and alternative writing of a poetry criticism resurrected in that great time filled with the spirit of liberalism: a non-moral, non-ideological, free, independent, objective, fair professional spirit and text-oriented scholarly standpoint have pitifully turned into "Intellectual 
Writing" - spokespeople for an "inner circle" have no way any longer of upholding their make-believe "fairness and authority," their attitude toward poetry and poets is nothing but "Prosper those who are with us, perish those who are against us," they dare, utterly evil, besiege the author - a poet, and this goes to show that these "New Tide Poetry critics" have never respected poetry. Their true face is now there for all to see.

"Besieging the author" refers to Popular accounts of the Panfeng conference claiming that several Intellectual authors had physically laid siege to Yu Jian or Yang Ke. These were dismissed by their alleged besiegers.

Both specialized and general media would seem to have worked to the advantage of the Popular camp. First, if Cheng Guangwei's appropriation of the concept of Poetry of the Nineties was objectionable to many, it was not a consciously polemical maneuver. Starting with Yang Ke's yearbook and Yu Jian's "The Light," however, the Popular response was just that. As such the Popular side dealt the first blow and a few more, and it appears to have been more active in seeking publicity throughout. Second, as far as the broad reception of polemical discourse is concerned, this naturally rewards anti-elitist sentiment and the shock value of invective. Popular contributions to the debate tended to be more spectacular and suited to the sensationalism inherent in most media. In the rest of 1999 and 2000 the Popular side continued to dominate the debate.

Friends in Letters, for instance, published two more eye-catching pieces. One, in the July issue, is "Has Poetry Really Lost Its Readers?" (诗歌真的失去了读者吗, \#34) by Xiangzi, widely believed to be a pseudonym of $\mathrm{Yu}$ Jian. The article does contain argumentative, terminological and linguistic clues to that effect. Xiangzi reassures the reader that only bad-Intellectual - poetry has lost its readers. The article is rare in that it supports the Popular cause but acknowledges that good-Popular-poetry is by nature a marginal phenomenon and cannot be appreciated by many.

In addition, in November 1999 Friends in Letters featured Yi Sha's long article "End of the Century: Why the Poets Are Going to War" (世纪末: 诗人为何要打仗, \#75), which simultaneously appeared in Poetry Reference as "Two Questions against One Background: The Panfeng Poetry Conference as I Experienced It” (两个问题和一个背景: 我所经历的盘峰诗会). When reprinted in Yang Ke's next yearbook, the one covering 1999, it was still entitled "End of the Century," which 
does justice to the article's scope and ambition. It contains Yi Sha's shamelessly biased report on who said and did what at the conference, and his presentation of the event as the outcome of an overall schism in poetry and criticism dating back to the 1980s. Yi looks back on Haizi's suicide as a defining moment and a rare opportunity for the Intellectual camp to maneuver its aesthetics into a position of privilege on the poetry scene, so that (p80)

a rhetorical conspiracy made of metaphor made muddle-headed Western sinologists think they truly dared confront Chinese reality.

True enough, Haizi's posthumous mythification has been disproportionate. Still, Yu Jian's, Xu Jiang's, Yi Sha's and other Popular voices' studied irreverence toward his life, work and death strike one as strategically inspired breaches of a taboo, carried out for sheer effect. Otherwise, it is hard to see the relevance of comments like this, made by $\mathrm{Yu}$ Jian (\#36) in the July 1999 issue of Hunan Literature (湖南文学) (p75):

Apparently, Haizi couldn't even ride a bicycle but still thought of himself as a king among men who hadn't been given the position due to him, and so he went and killed himself.

Yi Sha is of the opinion that when poets hold a conference this is not to exchange views but to exhibit their temperament, and his style in "End of the Century" and elsewhere indicates that this also applies to written presentations. His promise of objectivity and fairness rings accordingly hollow, if it isn't intended as a joke to begin with. Yi's self-contradictions alternate with wickedly clever arguments. He turns Wang Jiaxin's employment of Cultural Revolution terminology against him, as if Wang were not citing such terminology to illustrate the Popular resurrection of Maoist discourse. Yi's castigations of the Intellectuals contain macho, sexist and misogynist comments, such as when he associates the phrase Middle-Aged Writing (中年写作), used by poets like Ouyang Jianghe and Xiao Kaiyu, with sexual impotence, ${ }^{17}$ and when he reports on his own speech at the conference (p79):

So-called "Intellectual Writing" makes me think of the notion of "Women's Literature." What I feel about "Women's Literature" equally applies to "Intellectual Writing": as a man, I hardly ever think about what it is grows in the crotch of my pants, and I definitely don't need to go trumpeting it around.

17 Ouyang 1993a: passim, Xiao Kaiyu 1997a: 226. 
In addition to Friends in Letters, two other publications that consistently supported the Popular side were the Social Science New Book Catalog (社 科新书目) and Poetry Reference. Especially in the spring of 2000, the weekly Catalog gave Popular voices (\#91, 93, 94, 95, 98, 99, 105) much more and, judging by the editor's notes (\#92), much more sympathetic exposure than Intellectual ones (\#97, 100). Issues 14/15 and 16 of Poetry Reference, published in November 1999 and July 2000, contained articles earlier featured elsewhere as well as contributions written especially for this long-standing unofficial journal. In 1999 its special feature called “Journal within a Journal" (刊中刊) pays lip service to impartiality by reprinting Intellectuals Wang Jiaxin and Zhang Shuguang side to side with Popular authors Yu Jian, Yi Sha, Xu Jiang, Yang Ke, Song Xiaoxian and Shen Haobo, but the loyalties of editor Zhongdao are explicitly of the Popular kind. In the 2000 edition all polemical entries in the "Journal in a Journal" are of Popular persuasion. Poet and painter Yan Li's "Preaching and Packaging" (说 教和包装, \#109) was written in 1997, long before the Polemic had begun, and Yan discusses a type of intellectual — overseas, dissidentwith political policy-making aspirations that has nothing to do with the Intellectual poets. Its mind-boggling inclusion may be explained by Yan's pejorative use of the word intellectual, grist to the editor's mill and evidence of his strategic motivation.

If publicity beyond specialist and general literary circles was by and large conducive to Popular image-building, it wasn't entirely one-sided. Ding Mang's "The True Nature of the So-Called 'Popular Standpoint” (所谓 “民间立场” 的实质, \#69), published in the China Times, manages to maintain critical distance while tearing Popular theorizing to pieces and charging it with intolerance and an attempt at monopolizing avant-garde status. As for specialized literary and literary-critical journals, Mountain Flower and Grand Master published Intellectual and Popular contributions equitably - as did Poetry Exploration, in by far the greatest number of pages and the richest variety of content.

The present chapter gives the Popular more space than the Intellectual. This reflects the sheer size of the two camps' respective output and the fact that the Popular side by and large kept the initiative in 1998 and 1999. Intellectual rejoinders, moreover, warded off or deconstructed Popular arguments but generally stopped short of attacking Popular poetry in their turn, and occasionally hinted that reacting 
to Popular invective was a waste of words. ${ }^{18}$ As such, the Intellectual role after the outbreak of the Polemic was predominantly defensive. Then again, in the Popular view - according to Yu Jian (\#63), for example - an Intellectual offensive and its sidelining of the Popular cause had been quietly operational since the late 1980s, propelled by authors such as Xi Chuan, Tang Xiaodu, Wang Jiaxin, Chen Chao, Ouyang Jianghe, Zang Di and Cheng Guangwei. We will now review some of the said Intellectual rejoinders before discussing a remarkable essay by Popular author Han Dong, and outlining how the Polemic more or less came to an end in mid-2000.

\section{Wang Fiaxin's Staunch Defense: "A Poet Is Always an Intellectual"}

Measured by hostile and partisan comments alike and by the quality and quantity of his critical output during the Polemic, the most prominent of the Intellectuals was Wang Jiaxin. Of his several contributions, the most substantial are "Intellectual Writing, or "In Dedication to a Limitless Minority” (知识分子写作, 或曰 “献给无限的少数人”, \#23) and “Start from a Misty Drizzle" (从一种蒙蒙细雨开始, \#86). "Intellectual Writing" is the written version of Wang's address at the Panfeng conference. With some modifications, the article appeared in the June issue of Poetry Exploration and the August issue of Grand Master. It was also included in Wang Jiaxin and Sun Wenbo's Chinese Poetry: Memorandum for the Nineties (中国诗歌: 九十年代备忘录, 2000) (\#85), another controversial anthology, to which we will turn in the final paragraphs of this section. "Start from a Misty Drizzle" is the introduction to this anthology, but the December 1999 issue of Poetry Exploration published the essay as a stand-alone article one month prior to the book's actual release. In dedication to a limitless minority is a phrase taken from the work of Zhai Yongming, implicitly claiming the allegiance of contemporary China's most famous woman poet, whereas Zhai herself had given no sign of taking sides. Start from a misty drizzle comes from an early poem by Xi Chuan, whose mobilization in support of the Intellectual cause entails no such problems. Both pieces are well written and forceful, and contain cogently argued passages with critical distance from the battlefield. In light of the attacks Wang had endured since 1998, this is no small feat.

18 E.g. Cheng Guangwei (\#27). 
"Intellectual Writing, or "In Dedication to a Limitless Minority" is a rebuttal to accusations from the Popular camp in which Wang primarily responds to Yu Jian and Xie Youshun. He argues convincingly that Yu Jian's creative output, particularly his «File 0», is a far cry from meeting the criteria for good poetry as laid out in Popular polemical discourse. In addition, he questions Yu's portrayal of poets of the Chinese language, cited above. Wang points out that $\mathrm{Yu}$ is guilty of the crime of "connecting" with the West as much as anyone else (p48-49):

Aren't Chinese poets writing in Chinese, and not in English? Is this something that needs to be advertised? Can it be true that the translation of works by Chinese poets into foreign languages doesn't add to the glory of Chinese poetry and becomes a poet's crime instead? How is it that Yu Jian, who himself has also hinted at and indeed flaunted the fact that foreigners place orders for his work, now poses as "refusing to connect"? In plain words, all of this is but strategic behavior. All of this is but in order to ride the rising tide of nationalism ... All of this is but to show: while the others are all busy connecting with the West, I myself am the only one working to restore the dignity of the Chinese language. Of course, to restore the dignity of the Chinese language is Chinese poets' mission throughout their lives - but how to go about that? By false, inflated, hollow words? By denouncing the languages of other nations?

Wang questions the dichotomies that underlie Popular discourse, and most of all the confluence of these dichotomies in an overall opposition of Popular and Intellectual. In a simple aphorism, he submits (p4041):

Of course an intellectual is not the same thing as a poet, but a poet is always an intellectual.

According to Wang, all those embroiled in the Polemic are intellectuals, in a country where that category of people was made to suffer through large parts of the twentieth century. He laments that they have now become antagonists, instead of allies in the face of common enemies such as official cultural policy and the rampant commercialization of Chinese life. He also rejects the parallel oppositions of North and South and of the foreign and the Chinese, drawing attention to the complexity and multi-directionality of things like literary influence, intertextuality and intercultural relations.

As noted, a little over a month after Wang Jiaxin's "Start from a Misty Drizzle" had appeared in Poetry Reference and Poetry Exploration, 
it served as the introduction to Wang and Sun's Chinese Poetry, which came out in January 2000. Wang makes no attempt to appear impartial; the essay's journal publication aside, we will shortly consider the results of his partiality - as editor - for the anthology as a whole. He acknowledges that during the early and mid-1980s Chinese poets sometimes uncritically absorbed and imitated Western literature, theory and criticism, perhaps to make up for the spiritual famine of the Cultural Revolution; but he rightly observes that since the late 1980s Chinese poetry's interaction with the West has been the subject of critical reevaluation, and that this is visible in poetry by various Intellectuals. As open-minded as Wang is when discussing such developments, as rigid is he when reiterating Cheng Guangwei's appropriation of the notion of Poetry of the Nineties to denote but one of many possible literary persuasions rather than a non-judgmental, chronological category. Another weakness is that, contradicting Wang's habitual remarks on the "bitter struggle" in which he sees poetry as forever engaged, his essay breathes a complacent sense of the end of history. With hindsight, previous trends are shown to have led inevitably to $(\mathrm{p} 10-11)^{19}$

independent intellectual individual writing.

That is: to the ultimate poetry - of the kind to which Wang Jiaxin subscribes. But Wang is not the only one who feels that the poetry of his preference is the only right poetry, not to say the necessary poetry, for contemporary China. The same holds for various authors from the Popular camp, Yu Jian (\#14) most of all.

\section{Other Intellectual Rejoinders: Xi Du and Cheng Guangwei}

$\mathrm{Xi} \mathrm{Du}$ was another impassioned and productive defender of the Intellectual cause (\#24, 28, 39, 56). His "Thoughts on Various Issues" (\#24), first published in the June 1999 issue of Poetry Exploration and excerpted as "Is Poetry Common Knowledge?" for the special feature in Literary Theory, also appeared under the more apposite title "Challenging Some of Yu Jian's Poetical Propositions” (对于坚几个诗学命题 的质疑) in the July issue of Mountain Flower. Xi Du tends to get carried away when he speaks out in support of Intellectual Writing, but he ef-

\footnotetext{
19 The page reference is to the article's publication in Chinese Poetry. Cf note 3.
} 
fectively puts his finger on the flaws in Yu Jian's allegations. He argues that a linkage of poetry and the zeitgeist is by no means the exclusive prerogative of the Popular. As regards the opposition of things foreign and Chinese, language resources and other, he diagnoses Popular xenophobia as an expression of insecurity. With frequent reference to Shao Jian's “So What Is It You Want from Poetry?” (你到底要求诗 干什么?, \#9), an article commissioned for Yang Ke's first yearbook that turned out to be highly critical of Popular discourse, Xi Du rejects Yu Jian's usage of popular. He notes that as recently as the 1980s, Popular authors who now affiliate themselves with Tang and Song poetry still claimed to reject Chinese cultural tradition in its entirety.

After the frenzied polemicizing in the summer of 1999, Cheng Guangwei responded to his various critics in the October 1999 issue of Grand Master. His "New Poetry Runs through History's Veins: In Response to A Polemic" (新诗在历史脉络之中: 对一场论争的回答, \#66) is balanced and level-headed. If the article fails to enervate the charge of Cheng's partiality, it does put Popular discourse in a useful historical perspective. Cheng says that important parts of the debate can be subsumed under recurrent issues in the history of China's New Poetry. He associates the present Popular activism with certain aspects of "leftist" zealotry from the 1920s through to the 1970s. In a nutshell (p191):

Problems that occurred earlier in history but have never been solved very well have now been refined, on the suitable occasion that was constituted by the 1990s. [The Popular camp] uses a separation of the poet and the people to derive an opposition of a so-called "Popular standpoint" and "Intellectual Writing"; it makes the development of New Poetry and foreign influence, a well-known issue in the history of New Poetry from the start, sound like the shifting of allegiances to "Western language resources"; it attempts to move poetical problems into the realm of politics and nationalism. In truth, all this leads to the pitfall of cultural fundamentalism, of turning criticism into personal vendettas and something quite out of proportion.

Cheng also dwells on matters such as the complexity of literary influence, the interaction of modernity and ethnicity in twentieth-century poetry and the perpetual debate on the "difficulty" or "incomprehensibility" of certain types of poetry. He sees Popular discourse as an instance of the cultural radicalism that has manifested itself at various times and places in modern China. 
Han Dong's Begeisterung: "Abandoning the Arena of Power"

Be they poets, novelists, critics, scholars, journalists or politicians, Chinese authors are astoundingly prolific and the speed at which they produce books is both exciting and worrisome. He Xiaozhu's Selected Chinese Poems of 1999 (1999中国诗年选, \#78) bears testimony to this side of Chinese graphomania. The editorial committee of this anthology set to work in June 1999 and must have finished in October or so, for the book appeared in December of the year it claims to cover. Then again, it is called a selection of poetry, and as such under no obligation of completeness or representativeness. The editor's postscript (\#79) emphasizes this point, but with an eye to literary persuasion not calendar chronology. He Xiaozhu frankly relates how in spite of admonitions by several poets, he hasn't undertaken to be objective or fair and is partial to the Popular point of view. The order of poets included was determined by drawing lots, with the exception of Xiao An and Sheng Xing, whose pole positions are in explicit homage to the quality of their work.

Amid the accumulation of metatext that is the present chapter, let's read another poem for a change, as a counterpart to Zhang Shuguang's "A Portrait of Years Gone By», cited in the first pages of this section. As we have seen, Zhang's «Portrait» opens an anthology shaped by a particular literary preference. So does this poem by Xiao An (p19):

«Mental Patients

what must you do to walk out of here

tilt your head

a bit more to the right

set your hands in the correct position

confused person

keen appearance in the glass

we've no way to tidy up your brain

to wash you cleaner

you may be the best-looking

and the most complete

but anywhere and everywhere

you're always in such disorder

and whether you're called xiao li or ping'er

all we can do is call you xiao li or ping'er 
you come home

through the streets

with a sign that's been on your body

ever since you were born

you love bananas

and you hate apples

We need no detailed analysis of «Portrait» or «Mental Patient» (精神 病者) to observe considerable differences between the two texts, the figureheads of Intellectual and Popular flagship books respectively - in subject matter, tone, form and overall experience. But let's return to our metatextual business and examine a final, substantial contribution to the Polemic.

Han Dong's “On the Popular” (论民间, \#77)- he often uses 民 间 as a noun phrase - is the introduction to He's Selected Chinese Poems. The tone of "On the Popular" is reminiscent of "A Time That Supposedly Loves Culture," Han's article in the Beijing Literature special feature of the previous summer: not quite as bitter but equally heavy, with a penchant for moralizing and abstractions of the sort we encountered in chapter Eleven. Whereas in "A Time" Han scolds Intellectual Writing, "On the Popular" is a much more constructive undertaking. The essay is divided into fourteen sections marked by subheadings. Some are rhetorical questions predictably answered in the negative (p1, 6, 10):

Is the Popular a Fiction?

Has the Popular Accomplished Its Mission?

Does the Popular Cancel Out the Individual?

Han includes a short history of the Popular. Here, the term cannot but be read in the institutional sense of 'published outside state control.' Like Yu Jian (\#14), Han traces Popular poetry's genealogy through a number of unofficial publications, back to Today. The importance of unofficial status as a criterion for the Popular is clear in this passage from the section entitled "The Popular in the Nineties" (p8):

Some poets who come from the Popular as it existed in the Eighties have now set foot in the mainstream poetry scene, publishing their poetry in official collections, getting public reviews, making regular appearances in all kinds of media, craving to take part in foreign sinological conferences - they have knowingly divorced themselves from the Popular way. 
One immediately thinks of the impressive track record of official publications, public reviews, media appearances and foreign conference attendance of prominent Popular poet and theorizer Yu Jian-whom Han Dong doesn't mention a single time. Are we to take this as evidence of Yu's eviction from the Popular ranks, at least in Han's book? Also, if it seems reasonable to assume that Han sees himself as a Popular poet, we should note that a first official collection of his poetry had in fact come out as early as 1992 - and that this was to be followed in 2002 by a major, official survey collection of his work as well as the first ten volumes in the Epoch Poetry Series of which Han was editor, including books by authors associated with the unofficial journals Them and Not-Not who had no previous official book publications to their name. ${ }^{20}$ Does this mean that Han Dong and the Epoch authors set foot in the mainstream poetry scene, too? If so, how tenable are Han's views on the Popular any longer?

Han Dong particularly disapproves of poets entering mainstream discourse for the wrong reasons, even if it be - in his two examplesthrough no fault of their own. With some justification, he holds that Haizi and $\mathrm{Gu}$ Cheng became martyrs or heroes of poetry in broad public view because they killed themselves, not primarily through the merits of their writing. He risks invalidating this point when he himself invokes as exemplary for the Popular cause two authors who died before their time and one whose saintly status is closely connected to his mental illness: Hu Kuan, Wang Xiaobo and Shizhi. This bespeaks the very image of poethood that has contributed so much to Haizi's thanatography - to which Popular, demystifying and more generally Earthly authors should in theory not subscribe.

As noted in chapter Eleven, according to Han Dong the Popular inherently resists the influence of the three "big beasts" of the System, the Market and the West, with big beast denoting the expansive corruption of an original, authentic category. Han finds the Popular itself inherently incapable of becoming a big beast in its turn. Its standpoint is characterized by $(\mathrm{p} 2)$

an independent spirit and free creation.

20 Han 1992a and 2002. 
Han proclaims an undisguised mission statement, making clear that the Popular has a vocation which reaches far beyond a simple literary preference (p8):

The Popular mission is to safeguard literature, and to ensure that in an age that is growing more materialistic by the day and honors the balance of power as its only standard, literature gets a chance to survive and develop; and to protect the free spirit of art and its capacity for creation.

As a whole the essay is impressive in its Begeisterung. To Han Dong, the Popular appears to be rather like a way of life, a worldview or indeed a religion, and at the very least part of the vision of poetry as a sacred cause that characterizes his explicit poetics throughout. Leading up to a brief, final section on the future of the Popular, as opposed to what he calls the pseudo-Popular (伪民间), Han concludes (p17):

The Popular in its true form means: (1) abandoning the arena of power, and operating in unknown, dark and mute places; (2) the womb of the independent spirit and the vortex of free creation, where what is upheld is talent, steadfast character and a sensitive soul; (3) the necessary, unyielding struggle that is carried out in order to protect the survival of literature and art, in order to protect their expression and the right to write (not the power to write).

The highfalutin, moralizing tone of "On the Popular" comes in sharp contrast with the Colloquial Poetry for which Han is famous, but it blends well into the register established by other central contributors to the Polemic reviewed above: Cheng Guangwei, Yu Jian, Wang Jiaxin.

\section{$A$ Sense of Closure: The End of the Polemic}

In the first half of 2000 many publications still addressed the opposition of the Popular and the Intellectual: again, mostly from the Popular point of view. In March, for instance, the Social Science New Book Catalog reserved yet another full page for blatantly partial, Popular coverage of the Polemic, under the headline "Poetry Scene Explodes into Warfare Yet Again” (诗坛再次爆发战争, \#92, 93, 94, 95), and in May it ran a special feature entitled "Reflections on the First Anniversary of the “Panfeng Polemic” (“盘峰论争”: 周年反思专版, \#97, 98, 99, 100) that gave each camp its own page. By and large, however, these publications repeated or rehashed things that had been said before. Some authors began to take a retrospective stance, Shen Qi (\#101) and Xu 
Jiang (\#108) even hinting at possibilities for reconciliation, saying that this was in the interests of Chinese poetry as a whole and invoking the beginning of a new century as an opportunity for a fresh start.

Viewed in this light, the unabashed partiality of He Xiaozhu's Selected Chinese Poems emanates a sense of closure, reflecting the stalemate in which the two camps now found themselves. The same goes for Chinese Poetry: Memorandum for the Nineties (\#85), the above-mentioned collection of essays edited by Wang Jiaxin and Sun Wenbo, with the editors disdaining to look beyond their own literary loyalties and stubbornly reenacting Cheng Guangwei's appropriation of a chronological category for a particular literary persuasion. Following "Start from a Misty Drizzle," Wang's introduction, the collection includes some forty critical articles from the 1990s. It is a strictly Intellectual, one-sided selection of material, with a few outsiders to the Polemic thrown in for good measure: mostly commentators who are neutrally critical of Popular discourse, such as Zhou Zan (\#88), Yang Xiaobin (\#73), Geng Zhanchun (\#6, 76) and Jiang Tao (\#62). The editorial policy of Chinese Poetry implies that Popular contributions need not be regarded as anything more than transient fashions of the day. This impression is maintained throughout the book's appendices. The first of these contains the "Annals of Poetry of the Nineties" (90年代诗 歌纪事) by Zi An, previously published in Mountain Flower under the author's customary name of Wang Jiaxin (\#67). This was immediately attacked for its partiality by Yi Sha in "Wang Jiaxin's Forged Records of the Historian" (王家新伪史记, \#87) in the January 2000 issue of Friends in Letters, and later by Xu Jiang in "Eyes Turned Green" (眼睛 绿了, \#108) in the 2000 issue of Poetry Reference. The second and third appendix in Chinese Poetry are a discussion of 1990s poetical terminology by Chen Jun and an index to theoretical and critical essays and essay collections from the 1990s by Liu Fuchun and Zi An / Wang Jiaxin. All this makes for a bizarre, complete absence in Chinese Poetry of those considered to be formidable enemies - Yu Jian, Yi Sha, Xie Youshun and so on-judging by the unforgiving way several of the book's contributors take them to task. For Popular poetry and its immediate forebears, this is not a memorandum but an oblitterandum instead. When asked about the exclusion of Popular contributors, Wang Jiaxin at first called the authors in question uncooperative, and then added that he hadn't bothered to contact them. ${ }^{21}$

21 Personal communication, August 2000. 
In June 2000 Yang Ke published the 1999 Yearbook of China's New Poetry (1999中国新诗年鉴, \#102), keeping a promise to make the Yearbook an annual production. While publications such as the Social Science New Book Catalog, Poetry Exploration and Poetry Reference would continue to carry provocative articles by Popular and Intellectual authors, the appearance of Yang's second yearbook can arguably be seen as the public conclusion to the Polemic. In line with Yang Ke's style of public relations throughout (e.g. \#82), the 1999 Yearbook makes some superficial concessions to impartiality in its choice of poetry and criticism, but no more than that. Here is a final quotation from Xie Youshun's aggressive introduction to the anthology, pre-published in Mountain Flower as "Poetry Is Advancing" (\#96) (p76):

Let poetry be clearly distinguished from non-poetry, truth from lies, creation from imitation, contemplation of the West from the blinkered following of Western masters, dignified writing from the worship of knowledge / intellect, lively speech from reticence vis-à-vis existence, plain words from incomprehensible prattle, the soul's presence from a would-be profound "complex art of poetry," sensitive people from rigidified intellectuals.

As the last quotation in this critical inventory of the sources, Xie's words serve to reaffirm the seriousness of the Polemic and the alarming echo of Maoist literary discourse.

\section{What Was at Stake?}

The Polemic was ignited by Cheng Guangwei's appropriation of the full breadth of the 1990s for a poetry representing but one of several important trends. Authors who united under the Popular flag felt this to be a flagrant instance of what they called the obstruction of their art. It is impossible to verify whether Intellectually inclined poets and critics had actually blocked exposure of other poetries than their own for years on end, consciously or otherwise - and it is easy to verify that no such thing ever happened to, say, Yu Jian or Yi Sha, as a glance at their publication record will show. Then again, for what it's worth, allegations of obstruction in previous years are not made any less likely by Wang Jiaxin and Sun Wenbo's Chinese Poetry as another key Intellectual publication in which Popular authors were given short shrift, even if we take into account that this book was produced when the Polemic was already running at full steam. In any case, from the Popular per- 
spective, the obstruction of one type of poetry or the occupation of the scene by another were not merely detonators or catalysts, but among the root causes of the conflict.

Throughout the Polemic the distinction between authors and texts was blurred. Thus, the indictment of Cheng Guangwei's selection of authors in Portrait seamlessly led to the tendentious dichotomies that we have reviewed, together creating an opposition of the Intellectual and the Popular. This was put forward as representing an opposition of two types of poetry. In itself, as I have argued throughout this study, the avant-garde can perfectly well be viewed as a broad spectrum contained within the outer limits of two divergent aesthetics, and textual analysis and interpretation conducted within such a framework and focused on typically Popular or Intellectual aesthetics yield equally divergent poetics. But as observed above, aside from vague and unsubstantiated mutual accusations, the Polemic had little time for poetry per se.

The genre of polemics has an inherent right to some unreasonableness. Still, this near-complete neglect of supposedly central subject matter is astonishing, all the more so because an opposition of two types of poetry cannot even be maintained on the basis of the explicit poetics found in the polemicists' writings. On the contrary, they display some notable similarities. Take, for example, Intellectual Tang Xiaodu's claim, in both the foreword and the postscript to his yearbook (\#19, 18), to occupying a Popular standpoint (民间立场). These exact words are also the shortest, best-known summary of the poetics proclaimed by Yu Jian in the introduction to Yang Ke's first yearbook, which reprints the phrase as an article of faith on one of the inside cover pages $(\# 14,12)$, henceforth giving it the status of an antiIntellectual slogan. Or take Cheng Guangwei's (\#1) invocation of one of his favorite poets, Xiao Kaiyu, as saying (p5):

Writing shouldn't merely hinge on one's social ambitions, but rather on "material" from politics, economics, love and indeed current affairs and everyday life, it should plant itself firmly in its cultural context.

For all we know, this could be Yu Jian or Xie Youshun talking. Or take discontent with the damage done to poetry by political ideology and commercialization, regularly expressed by Intellectual and $\mathrm{Popu}-$ lar voices alike, with a shared penchant for moralizing - and they were no extras, either, but key players like Wang Jiaxin and Han Dong. A fi- 
nal example of explicit-poetical consistency across the board is Cheng Guangwei's description of the Intellectual creative author as having independent views and an independent position, and Han Dong's typification of the Popular as signaling an independent spirit and free artistic creation.

At this point we may turn to author personalities to help explain what the Polemic was all about, as Leo Ou-fan Lee has done for modern Chinese literary battles in the $1920 \mathrm{~s} .{ }^{22}$ Geographical-cultural dividing lines between authors were put forth by the Popular camp: (i) the Intellectual capital versus the Popular provinces, (ii) the Intellectual North versus the Popular South and (iii) Intellectual Westernization versus Popular Chineseness. All three are each rhetorically smooth and factually problematic. (i) Zhang Shuguang, for instance, labeled a prominent member of the Intellectual camp, has always lived in Harbin, and Popular firebrand Shen Haobo only began to write after he had entered university - in Beijing, where he has remained ever since. (ii) If, in addition to their current whereabouts, we take into account poets' and critics' provenance and their formative years, the list of mismatches becomes much longer. Intellectuals Cheng Guangwei, Wang Jiaxin, Tang Xiaodu, Sun Wenbo and Ouyang Jianghe are all Southerners who moved to Beijing later in life, and Chen Dongdong is a Shanghai resident to this day. (iii) Complicated though things like literary influence and intertextuality may be, it is demonstrably untrue - as is evident from the poetry that most polemicists didn't deign to discuss - that the Popular poets reject or mistrust the West. Why should they, anyway? Conversely, it is equally untrue that the Intellectuals blindly embrace the West.

Incidentally, even if Chinese poets look to the West or anywhere beyond an indigenous frame of reference, a considerable measure of Chineseness is guaranteed as long as they write in Chinese. Language, both the abstraction and its varied manifestations throughout the world, is rather more than a simple tool for dressing up some kind of independent, unchanging content, and poetry is the art of language. Before getting into all that and recalling the discussion of Chineseness in chapter One, one might ask a question whose long history doesn't detract from its relevance today. Why should poetry written by Chi-

\footnotetext{
${ }^{22}$ Lee (Leo Ou-fan) 1973: 19-27.
} 
nese people in the Chinese language have to be Chinese beyond these two features?

Then again, if geographical-cultural dividing lines are questionable, they are probably more than just the figments of a bellicose imagination, especially the dividing line between the capital and the provinces - and this phenomenon and the arrogance of the capital are obviously not particular to China. When asked about the exact nature of the obstruction of their work, Popular poets responded in various ways. Yi Sha, for instance, didn't see himself as a victim of obstruction at all. On the other hand, Popular poets were unanimous in their observation that in Beijing there are more "opportunities" than elsewhere: conferences, foreign media and scholar-translators, and the overall climate of a cultural center. This status undisputedly belongs to Beijing, not just in automated broadcasts on trains and planes approaching the capital but also according to angry Popular poets - even if they ridicule it, as does Yu Jian. A final point regarding geographical-cultural dividing lines in the Polemic is that they can of course be taken as a continuation of earlier moments in Chinese literary history. One recent example in poetry is the late 1970s rivalry between Huang Xiang's Guizhou-based Enlightenment troupe and authors associated with the Beijing journal Today. Another is Chengdu poet Zhong Ming's assertion of Southern poetic strength vis-à-vis a perceived Northern-capital hegemony in his 1982 unofficial anthology Born-Again Forest (次生林), and later in other publications such as the unofficial journal Image Puzzle (象罔). A third is a general Southern connotation of Third Generation poetry from the mid-1980s onward, as the first challenge to the primacy of Today within the avant-garde.

Author personalities are also divided along institutional lines that go back to the 1980s. These lines run between unofficial journals of the kind known as "soulmate journals" or "peer journals" (同仁刊 物、同人刊物), the formation of which is governed by ties of literary allegiance - meaning a broadly shared poetics - and sometimes by regional identity. As noted, the concept of Intellectual Writing, in a proud not a derogatory sense, captures the ambition of Tendency (1988-1991), with Chen Dongdong, Xi Chuan, Ouyang Jianghe, Lao $\mathrm{Mu}$ and Wang Jiaxin as founding editors or close associates. In the early 1990s Intellectual Writing was associated with several other unofficial journals, most of all with the Southern Poetry Review (南方诗 志, 1992-1993); contributors to the Review included Chen Dongdong, 
Wang Jiaxin and Xi Chuan, among other authors who counted as Intellectuals during the Polemic. In his controversial anthology, Cheng Guangwei places Tendency and the Review on a pedestal, to the chagrin of Popular polemicists. The historical affinity of the Popular lies with Colloquial Poetry's milestone Them, the indecorous Macho Men and the iconoclast Not-Not, which advertised its poetics as "anti-cultural" or "pre-cultural." The picture is complete once we realize that the Tendency founders were in part motivated by the wish to counterbalance the impact of colloquializing and vulgarizing trends, in a conscious effort to have their own poetics recognized as an important part of the poetry scene.

There is no reason to doubt the significance of textual considerations in the emergence of individual journals of varying literary persuasion, meaning aesthetic - as distinct from "strategic" - preferences for this or that poetic style. But the personality factor does come into play when individual oeuvres develop and diverge or converge while personal ties of allegiance and enmity remain, whether according to the authors involved or to their audience. On that note, over and above the examples cited in the previous paragraph and their immediate connection to the Polemic, it is possible to observe an affiliation with either of the overarching categories of the Elevated and the Earthlyas well as "Northern" and especially "Southern" identities - for many of the unofficial journals that have helped shape the face of contemporary Chinese poetry from the late 1970s until today. ${ }^{23}$

Geographical-cultural and institutional dividing lines frequently coincide. Interwoven with them and discernible throughout the Polemic are biographical connections and personal ties of allegiancefriendships and so on - which can overlap with literary kinship but need not. Let's consider an example of what these various filters can do to the critical perception of literature.

Yu Jian and Yi Sha had been widely associated with one another long before they both came to occupy central positions in the Popular camp. Xi Chuan and Haizi continue to be mentioned in the same breath by poets, critics, scholars and other readers to this day. And granted, while Yu Jian and Yi Sha are colloquialists and demystifiers, Xi Chuan's and Haizi's early poetries share an aversion to these trends and are both marked by religious overtones. In their poetry, however,

${ }^{23}$ On North-South rivalries and unofficial journals, see Van Crevel 2007. 
$\mathrm{Yu}$ and $\mathrm{Yi}$ are worlds apart and so are the mature $\mathrm{Xi}$ Chuan and Haizi - even if any supposition about Haizi's development beyond the time of his death must remain conjecture. Indeed, one could argue that Yi Sha's poetry is akin to Haizi's and that Yu Jian's poetry is akin to Xi Chuan's, as follows. Essentially, the poetic voices in Yi Sha's and Haizi's oeuvres speak of who they are, and those in Yu Jian's and Xi Chuan's work speak of what they see, a distinction which provides a perfectly valid point of departure for the analysis and interpretation of literature. But both Yu Jian and Yi Sha are from the provincesnever mind the distance from Kunming to Xi'an - and both tend toward irreverence if not stylized trouble-making, especially when they write about poetry. Hence, they are lumped together. The same thing happens to Xi Chuan and Haizi, because they went to the same university and they were friends, and their friendship is documented in Xi Chuan's memorial essays after Haizi's suicide. Here, the Chinese adage that the text is like the person (文如其人) operates as an axiom rather than a general proposition that is defensible in itself but requires empirical, textual evidence before it may be applied to individuals or be used to demonstrate their literary kinship. In situations that ultimately arise out of an interest in the text itself, one is tempted to counter that the person is not like the text, or perhaps not invariably "as good as" the text (人不如其文).

Geographical-cultural, institutional and biographical angles help to expose a skeleton inside the tempestuous dynamics of the Polemic, but an answer to the question of what was at stake remains incomplete without some reflection on the sociology of Chinese poethood. As noted in the opening pages of this book, scholars such as Lloyd Haft and Michelle Yeh have shown how early modern Chinese poets grappled with the loss of the highly placed, well-defined social identity that their predecessors had self-evidently enjoyed for centuries. Even if the moderns themselves added to their loss by acts of their own initiative that aimed to change the face of Chinese poetry, prior to that their status had already suffered blows dealt out by socio-political forces that were bigger than literature. As such, the poets' identity crisis could not be stemmed by a return to the old ways. At the same time, turning themselves into a different, twentieth-century species wasn't made any easier by the bumpy road that poets traveled from the final years of the Qing dynasty to the advent of the Reform era in 1978. Those eight 
decades saw social upheaval, war, political terror and, generally, a society in which poetry was rarely left to its own devices. In this respect the publication of Today in 1978 opened up an entirely new space, beyond the pale of the official literary establishment.

In the late 1970s and the early 1980s, government suppression of the experiment would have been realistically possible, under the fickle winds of the PRC literary climate and its institutions - but after the failure of the 1983-1984 campaign to Eliminate Spiritual Pollution, as China entered into years of rapid and profound socio-cultural change, the avant-garde began to grow and ramify to where it outshone the establishment and that one-time common enemy of various new trends became largely irrelevant. In the same period, which witnessed what I have called multiple reinventions of contemporary poethood, conflicts and repositionings within the avant-garde began to occur, and the rampant commercialization of society - a new common enemy as perceived by many - didn't make the poets close ranks. Subsequently, in an admittedly crude scheme of things, the divergence and rivalry of the Elevated and the Earthly culminated in the Polemic of 1998-2000. As such, it was a showdown over the right of residence in the space opened up by Today, with older poets and critics expressing anxiety over what they perceived as the careless endangerment of the avantgarde's hard-won territory, and other bystanders registering everything from amusement to indignation at the poets' antics. The initial description of this space as beyond the pale no longer fits the central position it acquired in the 1990s: central, that is, within the "margins" of society, to where the avant-garde had repaired after its exceptional prominence in the late 1970s and the 1980s.

The Popular-Intellectual Polemic, then, was about nothing less than the legacy of Chinese poethood, meaning the right to see oneself and one's comrades-in-arms as torchbearers in a long-standing tradition, and the symbolic capital this should entail now that Chinese poetry had regained artistic independence. To zealous polemicists such as Yu Jian and Wang Jiaxin, torchbearer status called for the exclusion, loudmouthed or taciturn, of other poetic persuasions than their own. In addition, quite a few of the parties involved seemed to envisage the entitlement of poethood in not just literary but also social terms, and to yearn for a position in society closer to center stage. This reaffirms that although many avant-garde poets will declare that poetry should be autonomous from mainstream social development, they have not 
internalized this view. Albeit in a loose and abstract sense, they still subscribe to a time-honored poetics of literature to convey the Way, whether in a traditional or a modern frame of reference. This applies to not just the text but also the author. Indeed, several of the similarities in Popular and Intellectual discourse spring from what may be called their shared poetal views, especially the sheer importance both sides ascribe to poethood.

There are of course continuities with other polemics in modern Chinese poetry and modern Chinese culture at large, and with the phenomenon of abusive criticism as analysed by Michel Hockx for the Republican era, with a premodern history leading back to thirdcentury statesman-poet-theorist Cao Pi's famous declaration that "Literary men disparage one another-it's always been that way" (文 人相轻. 自古而然). ${ }^{24}$ For one thing, the present chapter has shown that the Polemic was a grim carnival of what Bourdieu calls positiontakings in the literary field. Of the substantive motivations behind such position-takings, which Yeh identifies as recurrent in debates throughout the modern era, one that obviously holds continued relevance is that of cultural identity, embodied in oppositions of Chinese and foreign, indigenous and Westernized, nativist and cosmopolitan. ${ }^{25}$ Another perennial issue is poetry's and the poet's contested social position, meaning their visibility and the degree of their involvement in and impact on socio-political development; but it is hard to say how far this discussion has extended into society beyond the poetry scene itself since the controversy over Obscure Poetry and the campaign to Eliminate Spiritual Pollution in the late 1970s and the early 1980 s. For one thing, what was left of traditional associations of poetry with national essence (国粹) at the time has thoroughly broken down during the avant-garde's subsequent development. On a general note, social change in the PRC has been so rapid and profound that it is unthinkable that an event like the Polemic would simply be a reprise of an earlier edition of more than a few years ago. More than anything else, this is visible in the unbridled rhetoric that characterized the Polemic, a crucial point being that substantial parts of the discourse displayed unmistakable irony — which, as noted at several points in this study, is

${ }^{24}$ Hockx 2003: ch 6. The translation of Cao Pi's words follows Owen 1992: $58 f f$.

25 Yeh 2001: 5ff. 
a distinguishing characteristic of contemporary Chinese poetry when compared to the recent past.

Did things look different than before, once the dust had settled? Incidentally, several Popular voices claim that the dust hasn't settled to this day. They are intent on continuing the struggle, so to speak. However, the Polemic "proper" lost its real momentum early in 2000, and when the many unresolved disputes flare up again — as they have done and will continue to do-it is unlikely that they will substantially change the issues or the stakes. They have in the meantime become the subject of scholarly analysis.

One thing the Polemic did change was the atmosphere on the poetry scene, whether viewed from a moral or a pragmatic perspective. Pre-Polemic days were of course not some sort of hunky-dory family gathering, but what basic solidarity and mutual respect existed throughout the avant-garde was seriously damaged. A development that has been more tangible and more important - again, this is according to Popular voices - is that the shake-up of reputations and hierarchies has encouraged poets who would previously have suffered from the phenomenon of obstruction, and given them concrete opportunities for publication. One example is the Epoch series, another the frantic activity displayed by unofficial poetry journals of recent years - such as Poetry Text, Poetry and People and The Lower Body - and most of all on the web. Still, these things might also have happened without the Polemic, just as slumbering conflicts might also have burst out, or strategic ambition manifested itself, without Cheng Guangwei's anthology. Leaving what-if questions aside, it is safe to say that the Polemic spurred reflection on the life and times of the avant-garde since the Cultural Revolution. It enhanced the retrospective reflex that tends to occur at the close of decades and centuries, even if there is nothing decimal to time itself.

In modern China, even more so than elsewhere, literary retrospectives are prone to end by directing our gaze from the past to the future. This illustrates a view of literature as a coherent body of self-evident significance, moving through time with a sense of direction-rather than, say, the somewhat unpredictable accumulation of artistic im- 
pulses held together by expression in a common linguistic medium, even if this is never entirely divorced from social development. This consideration provides some useful background to a question often raised by poets and critics in recent years, in formal and informal settings: was the Polemic a meaningful thing (有意义吗)?

The answers given in domestic critical discourse cover the full range from definitely yes to definitely no, which was to be expected if we consider how thoroughly divided opinions were at the time. In between, perhaps benefiting from the distance in time, there are recent, nuanced assessments in literary-historical and critical survey works such as those by Luo Zhenya in 2005 and Wei Tianwu in 2006, with Luo maintaining a neutral position and Wei cautiously siding with the Intellectuals, mostly because of the flaws in the Popular argument. Their differences aside, both authors decry the Popular distortion of key concepts such as "Intellectual," but also observe that the debate led to much-needed, increased contemplation of the state of the art. As for English-language scholarship, while Yeh holds that by scandalizing the poetry scene as a whole, the Polemic did more damage than good, Li Dian calls it a valiant collective effort by Chinese poets and critics to reconfigure the meaning of poetry in an age of commercialism and globalization. ${ }^{26}$

Perhaps an alternative to calling the Polemic meaningful or meaningless is to view it as a natural phenomenon - like a tidal wave, or a thunderstorm. The impact of such things merits contemplation, as do the forces that unleash them.

${ }^{26}$ Yeh 2007a: 34, Li Dian 2007. 


\section{Appendix: A Chronologigal Bibliography}

This bibliography includes everything from focused, partisan contributions by the foremost polemicists to writings of broader scope and greater critical distance that contain important passages on the debate. Especially for the former category, it lays claim to a reasonable degree of completeness. It stops in January 2002, when the Polemic "proper" had been over for some time and was among the topics treated in a state-of-the-field survey of Chinese literature at the end of the twentieth century (\#120).

Most entries appear in the previous two sections of this chapter. There are a few scholarly essays toward the end of the list that don't feed directly into the above discussion but may be of interest for future research. Entries are listed chronologically by year-month-(day), and alphabetically by author names in transcription. Beyond the month of publication, recorded in most Chinese books and journals, one cannot ascertain the exact time of appearance of these items as precisely as for newspapers and weeklies. Moreover, time between the completion of manuscripts and their publication varies. If the following record is therefore less than perfect, it still provides a reliable representation of the metatextual and discursive events that constituted the PopularIntellectual Polemic.

1 1998-02 | Cheng Guangwei (ed) 程光炜编, 《岁月的遗照: 九十年代文学 书系, 诗歌卷》 [A Portrait of Years Gone By: Literature of the Nineties, Poetry Volume], 北京: 社会科学文献

2 1998-02 | Cheng Guangwei 程光炜, 〈不知所终的旅行〉 [Journey with Unknown Destination], introduction to entry 1: 1-21 (earlier published in 《山花》1997-11: 69-75)

3 1998-02 | Hong Zicheng \& Li Qingxi (eds) 洪子诚、李庆西主编, 《九十 年代文学书系》 [Literature of the Nineties], 北京: 社会科学文献

4 1998-02 | Hong Zicheng 洪子诚, 〈总序〉 [Foreword to the Series], in entry 1: 1-9

5 1998-03 | Yu Jian 于坚，〈诗歌之舌的硬与软: 关于当代诗歌的两类语言 向度〉 [The Hard and Soft of the Tongue of Poetry: On Two Different Directions in the Language of Contemporary Poetry], in 《诗探索》1998-1: 1-18 (reprinted in entry 12: 451-468)

6 1998-05 | Geng Zhanchun 耿占春, 〈一场诗学与社会学的内心论争〉 [An Inner Polemic of Poeticology \{i.e. Poetics\} and Sociology], in 《山 花》1998-5: 77-81 (reprinted in entry 85: 268-277)

7 1998-09 | Hou Ma 侯马, 〈抒情导致一首诗的失败〉 [Lyricism Leads to a Poem's Failure], in 《诗探索》1998-3: 150-154

8 1998-10-10 | Shen Haobo [Choushui] 沈浩波，〈谁在拿 “九十年代” 开 涮〉 [Who's Fooling “the Nineties”], first published under pseudonym 仇 
水 in 北京师范大学中文系五四文学社主办, 《五四文学报》, 10 October 1998: 1-2 (reprinted in December 1998 issue of 《东方文化周刊》[cited by the author and Yi Sha, without page numbers], 《文友》1999-1: 20-21 and entry 102: 540-544)

9 1999-02 | Shao Jian 邵建, 〈你到底要求诗干什么?〉 [So What Is It You Want from Poetry?], in entry 12: 403-419

10 1999-02 | Shen Qi 沈奇, 〈秋后算账 - 1998: 中国诗坛备忘录〉 [Square Accounts after the Autumn Harvest-1998: Memorandum on the Chinese Poetry Scene], in 《出版广角》1999-2: 22-26 (reprinted in entry 12: 384-395 and 《诗探索》1999-1: 18-30)

11 1999-02 | Xu Jiang 徐江〈玩弄中国诗歌〉 [Playing Chinese Poetry], in《文友》1999-2: 20-21

12 1999-02 | Yang Ke (ed) 杨克编, 《1998 中国新诗年鉴》[1998 Yearbook of China's New Poetry], 广州: 花城

13 1999-02 | Yang Ke 杨克, 〈《中国新诗年鉴》98工作手记〉 ['98 Work Notes on the Yearbook of China's New Poetry], in entry 12: 517-520

14 1999-02 | Yu Jian 于坚, 〈穿越汉语的诗歌之光〉 [The Light of Poetry, Cutting through the Chinese Language], in entry 12: 1-17

15 1999-03 | Xie Youshun 谢有顺, 〈诗歌与什么相关〉 [What Does Poetry Relate to?], in 《诗探索》1999-1: 1-7 (earlier published in entry 12: 396-402)

16 1999-03 | Xu Jiang 徐江, 〈乌烟瘴气诗坛子〉 [The Noxious Poetry Scene], in 《文友》1999-3: 4-8

17 1999-04 | Tang Xiaodu (ed) 唐晓渡编, 《1998年现代汉诗年鉴》[1998 Yearbook of Modern Han Poetry], 中国文联: 379-380

18 1999-04 | Tang Xiaodu 唐晓渡, 〈后记〉 [Postscript], in entry 17: 1-2

19 1999-04 | Tang Xiaodu et al: Yearbook of Modern Han Poetry Editorial Committee 《现代汉诗年鉴》编委会, 〈序〉 [Preface], in entry 17

20 1999-04-02 | Xie Youshun 谢有顺, 〈内在的诗歌真相〉 The Inner True Face of Poetry], in 《南方周末》, 2 April 1999 (reprinted in entry 102: 526-530)

21 1999-05-14 | Tian Yong 田涌，〈十几年没 “打仗”: 诗人憋不住了〉 [No "Wars" for Over Ten Years: The Poets Can't Hold Themselves Back Any Longer], in 《中国青年报》, 14 May 1999: B4 (reprinted, citing the author's name as Tian Song 田诵, as 〈关于新诗发展方向又起论争〉 [A Polemic, Yet Again, on New Poetry's Course of Development], in 《新华文 摘》1999-8: 128)

22 1999-06 | Sun Wenbo 孙文波，〈我理解的90年代: 个人写作、叙事及其 他〉 [The Nineties as I See Them: Individual Writing, Narrativity and Other Things], in 《诗探索》1999-2: 26-37, 77 (reprinted in entry 85: 10-21)

23 1999-06 | Wang Jiaxin 王家新, 〈知识分子写作, 或曰 “献给无限的少数 人”〉 [Intellectual Writing, or "In Dedication to a Limitless Minority"], in《诗探索》1999-2: 38-52, 85 (reprinted in 《大家》1999-4: 83-89 and as the introduction to entry 85: 151-165)

24 1999-06 | Xi Du 西渡, 〈对几个问题的思考〉 [Thoughts on Various Issues], in 《诗探索》1999-2: 53-67 (reprinted as 〈对于坚几个诗学命题 的质疑〉 [Challenging Some of Yu Jian's Poetical Propositions], in 《山 花》1999-7: 79-85 and as 〈写作的权利〉 [The Right to Write] in entry 85: 22-34) 
1999-06 | Xu Jiang 徐江, 〈俗人的诗歌权利〉 [Ordinary People's Right to Poetry], in 《诗探索》1999-2: 21-25

26 1999-06 | Zhang Qinghua 张清华, 〈一次真正的诗歌对话与交锋: “世纪 之交: 中国诗歌创作态势与理论建设研讨会” 述要〉 [True Dialogue and the Crossing of Swords in Poetry: A Report on "Turn of the Century: A Seminar on the State of the Art and Theory-Building in Chinese Poetry"], in《诗探索》1999-2: 68-77 (reprinted in《北京文学》1999-7: 59-62)

27 1999-06-15 | Cheng Guangwei 程光炜, 〈令谁痛心的表演〉 [A Performance to Make Whom Suffer?], in 《中国图书商报》书评周刊, 15 June 1999: 4

28 1999-06-15 | Xi Du 西渡, 〈民间立场的真相〉 [The True Face of the Popular Standpoint], in 《中国图书商报》书评周刊, 15 June 1999: 4

29 1999-06-15 | Yi Sha 伊沙, 〈两本年鉴的背后〉 [What's Behind These Two Yearbooks], in 《中国图书商报》书评周刊, 15 June 1999: 4

30 1999-07 | Chen Chao 陈超, 〈问与答: 对几个常识问题的看法〉 [Q \& A: Views on Some Issues of Common Knowledge], interview with Li Zhiqing 李志清, in《北京文学》1999-7: 63-64 (reprinted as 〈关于当下诗歌论争 的答问〉 [Q \& A on the Current Poetry Polemic] in entry 85: 63-70)

1999-07 | Han Dong 韩东, 〈附庸风雅的时代〉 [A Time That Supposedly Loves Culture], in 《北京文学》1999-7: 73-74 (reprinted in entry 102: 555-557)

32 1999-07 | Tang Xiaodu 唐晓渡, 〈致谢有顺君的公开信〉 [An Open Letter to Mr Xie Youshun], in《北京文学》1999-7: 65-68 (reprinted in entry 85: 75-81 and entry 102: 530-537)

33 1999-07 | Xi Chuan 西川, 〈思考比谩骂要重要〉[Contemplation Is More Important Than Abuse], in 《北京文学》1999-7: 75-76 (reprinted in entry 85 and entry 102: 537-540)

34 1999-07 | Xiangzi 湘子, 〈诗歌真的失去了读者吗〉 [Has Poetry Really Lost Its Readers?], in 《文友》1999-7: 8-9 (pseudonym of Yu Jian?)

35 1999-07 | Xie Youshun 谢有顺, 〈谁在伤害真正的诗歌?〉 [Who Is Doing Harm to True Poetry?], in 《北京文学》1999-7: 69-73

36 1999-07 | Yu Jian 于坚, 〈抱着一块石头沉到底〉[Clutch a Stone and Sink to the Bottom], interview with Tao Naikan 陶乃㑆, in 《湖南文 学》1999-7: 70-80

37 1999-07-01 | Chen Jun 陈均, 〈诗歌不与什么相关〉 [What Poetry Does Not Relate to], in 《文论报》, 1 July 1999: 2

38 1999-07-01 | Shen Qi 沈奇, 〈谁伤害了90年代的诗歌〉 [Who Is It Has Harmed Poetry of the Nineties], in 《文论报》, 1 July 1999: 2

39 1999-07-01 | Xi Du 西渡, 〈诗歌是常识吗?〉 [Is Poetry Common Knowledge?], in 《文论报》, 1 July 1999: 2

40 1999-07-01 | Zang Di 藏棣, 〈诗歌: 作为一种特殊的知识〉 [Poetry as a Special Kind of Knowledge / Intellect], in 《文论报》, 1 July 1999: 2 (reprinted in 《北京文学》1999-8: 91-92 and entry 85: 42-45 and entry 102: 551-554)

41 1999-07-06 | Tang Xiaodu 唐晓渡, 〈读者来信〉 [Letter to the Editor], in 《中国图书商报》书评周刊, 6 July 1999 (reprinted as 〈请尊重批评的 底线〉 [Please Respect the Base Line of Criticism], in 周伦佑编, 《非 非·2000年特刊: 21 世纪汉语文学写作空间》: 206-208) 1999-07-12 | Jing Yi 静矣，〈99诗坛: “民间写作” 派与 “知识分子写作” 派之争〉 [The '99 Poetry Scene: The Battle of the School of "Popular Writing" and the School of "Intellectual Writing"], in 《北京日报》, 12 July 1999 
43 1999-07-26 | Jing Wen 京文，〈世纪之交的诗歌论争: 中国诗歌创作态势 与理论研讨会纪要〉 [Turn-of-the-Century Poetry Polemic: Summary of the Seminar on the State of the Art and Theory in Chinese Poetry], in《太原日报》, 26 July 1999: 5

44 1999-07-26 | Tang Jin 唐晋，“盘峰会议”的危险倾向〉 [Dangerous Trends at the "Panfeng Conference"], in 《太原日报》, 26 July 1999: 5

45 1999-07-26 | Wang Wei 王巍, 〈关注者的声音〉 [Voices of Concerned Onlookers], in 《太原日报》, 26 July 1999: 5

46 1999-07-26 | Wang Wei 王巍, 〈背景与其它〉 [Some Background and Other Things], in 《太原日报》, 26 July 1999: 5

47 1999-07-31 | Chen Jun 陈均, 〈于坚愚谁〉 [Who Does Yu Jian Think He Is Fooling], in 《科学时报》, 31 July 1999

48 1999-07-31 | Jiang Hao 蒋浩，〈民间诗歌的神话〉 [The Myth of Popular Poetry], in 《科学时报》, 31 July 1999 (reprinted in entry 102: 563-565)

49 1999-07-31 | Sun Wenbo 孙文波, 〈事实必须澄清〉 [The Facts Need Clarification], in 《科学时报》, 31 July 1999 (reprinted in entry 102: $547-548)$

50 1999-07-31 | Tang Xiaodu 唐晓渡, 〈我看到.... . [I See....], in《科学时 报》, 31 July 1999 (reprinted in entry 102: 570-572)

51 1999-07-31 | Wang Jiaxin 王家新,〈也谈 “真相”〉 [More on the “True Face"], in 《科学时报》, 31 July 1999 (reprinted in entry 102: 544-547)

52 1999-08 | Hou Ma 侯马, 〈90年代: 业余诗人专业写作的开始〉 [The Nineties: The Beginning of Professional Writing by Amateur Poets], in 《北 京文学》1999-8: 95-96 (reprinted in entry 102: 567-568)

53 1999-08 | Shen Qi 沈奇, 〈何谓 “知识分子写作”〉 [What Is “Intellectual Writing”], in 《北京文学》1999-8: 94-95 (reprinted in entry 102: 565567)

54 1999-08 | Sun Wenbo 孙文波，〈关于 “西方的语言资源”〉 [On “Western Language Resources”], in《北京文学》1999-8: 93

55 1999-08 | Wang Jiaxin 王家新，〈关于 “知识分子写作”〉 [On “Intellectual Writing”], in 《北京文学》1999-8: 94

56 1999-08 | Xi Du 西渡, 〈为写作的权力声辩〉 [A Plea for the Right to Write], in 《北京文学》1999-8: 92-93

57 1999-08 | Yu Jian 于坚, 〈诗人及其命运〉 [The Poet and His Fate], in 《大家》1999-4: 80-83

58 1999-08-28 | Shen Haobo 沈浩波, 〈让论争沉下来〉 [Let the Polemic Sink In], in 《科学时报》, 28 August 1999 (reprinted in entry 102: 604-606)

59 1999-08-28 | Xu Jiang 徐江, 〈敢对诗坛说 “不”〉 [Dare Say “No" to the Poetry Scene], in 《科学时报》, 28 August 1999 (reprinted in entry 102: 569-570)

60 1999-08-28 | Yi Sha 伊沙, 〈究竟谁疯了?〉 [So Who Is It Has Gone Mad?], in 《科学时报》, 28 August 1999 (reprinted in entry 102: 548550)

61 1999-08-28 | Yu Jian 于坚, 〈谁在制造话语权力?〉 [Who Is Producing Discursive Power?], in 《科学时报》, 28 August 1999

62 1999-09 | Jiang Tao 姜涛, 〈可疑的反思及反思话语的可能性〉 [Dubious Reflection and Possibilities of the Discourse of Reflection], in 《诗探 索》1999-3: 56-71 (reprinted in entry 85: 137-150)

63 1999-09 | Yu Jian 于坚, 〈真相: 关于 “知识分子写作” 和新潮诗歌批评〉 [Their True Face: On "Intellectual Writing" and New Tide Poetry Criti- 
cism], in 《诗探索》1999-3: 30-48 and 《诗参考》1999: 57-67 and entry 102: 587-604 (earlier published in 《北京文学》1999-8: 88-90, 81 [abridged])

64 1999-09 | Zhang Shuguang 张曙光, 〈90年代诗歌及我的诗学立场〉

[Poetry of the Nineties and My Poetical Standpoint], in 《诗探索》1999-3: 49-55 (reprinted in 《诗参考》 1999: 82-85 and entry 85: 3-9 and entry 102: 557-563)

65 1999-09 | Zou Jianjun 邹建军, 〈中国 “第三代” 诗歌纵横论: 从杨克主 编《1998中国新诗年鉴》谈起〉[Sweeping Remarks on China's “Third Generation" Poetry: On the 1998 Tearbook of China's New Poetry, edited by Yang Ke], in 《诗探索》1999-3: 79-87

66 1999-10| Cheng Guangwei 程光炜, 〈新诗在历史脉络之中: 对一场论争 的回答〉 [New Poetry Runs through History's Veins: In Response to a Polemic], in 《大家》1999-5: 190-193 (reprinted in entry 85: 120-125 and entry 102: 579-584)

67 1999-10 | Wang Jiaxin [Zi An] 王家新, 〈90年代诗歌纪事〉 [Annals of Poetry of the Nineties], in 《山花》 1999-10: 82-93 (reprinted in entry 85: 365-394, using pseudonym子岸)

68 1999-10 | Xie Youshun 谢有顺, 〈诗歌在疼痛〉 [Poetry Is Hurting], in 《大家》1999-5: 186-190 (reprinted in entry 102: 572-578)

69 1999-10-25 | Ding Mang 丁芒，〈所谓 “民间立场” 的实质：评广东版 《1998中国新诗年鉴》的理论话语〉 [The True Nature of the So-Called "Popular Standpoint": A Review of the Theoretical Discourse of the 1998 Yearbook of China's New Poetry, Guangdong Publishers], in《华夏时报》总 128期, 25 October 1999

70 1999-11 | Song Xiaoxian 宋晓贤, 〈中国诗坛的可悲现状〉 [The Sorry State of the Chinese Poetry Scene], in 《诗参考》1999: 98-99

71 1999-11 | Xu Jiang 徐江, 〈一个人的论争〉 [One Man's Polemic], in《诗 参考》1999: 96-97

72 1999-11 | Xu Jiang 徐江, 〈这就是我的立场〉 [This Is My Standpoint], in 《诗参考》1999: 86-90

73 1999-11 | Yang Xiaobin 杨小滨, 〈一边秋后算账, 一边暗送秋波〉 [Square Accounts after the Autumn Harvest While Stealthily Sending Autumn Waves], in 《诗参考》1999: 93-95 (reprinted in entry 85: 71-74)

74 1999-11 | Yi Sha 伊沙, 〈上一课〉 [Teach You a Lesson], in《诗参 考》1999: 100-101

75 1999-11 | Yi Sha 伊沙,〈世纪末: 诗人为何要打仗〉 [End of the Century: Why the Poets Are Going to War], in《文友》1999-11: 7-11 (reprinted as〈两个问题和一个背景: 我所经历的盘峰诗会〉 [Two Questions against One Background: The Panfeng Poetry Conference as I Experienced It], in 《诗参考》1999: 75-81 and with its original title in entry 102: 515-526)

76 1999-12 | Geng Zhanchun 耿占春, 〈没有终结的现实〉 [Unending Reality], in 《青年文学》1999-12 (cited by the author, without page numbers; reprinted in entry 85: 126-130)

77 1999-12 | Han Dong 韩东，〈论民间〉 [On the Popular], in entry 78: 1-18 (reprinted in entry 102: 464-478)

78 1999-12 | He Xiaozhu (ed) 何小竹编, 《1999中国诗年选》[Selected Chinese Poems of 1999], 西安: 陕西师范大学

79 1999-12 | He Xiaozhu 何小竹, 〈每年端出一些好吃的东西: 编辑工作手 记〉 [Serve Some Goodies Each Year: Editor's Note], in entry 78: 481483 
80 1999-12 | Sun Jilin 孙基林, 〈世纪末诗学论争在继续: 99中国龙脉诗会 综述〉 [The End-of-the-Century Polemic in Poetics Goes On: A Summary of the '99 Poetry Meeting in Longmai, China], in 《诗探索》1999-4: 51-61

81 1999-12 | Sun Wenbo 孙文波, 〈论争中的思考〉 [Thoughts from amid the Polemic], in 《诗探索》1999-4: 18-30

82 1999-12 | Yang Ke 杨克, 〈并非回应〉 [Not a Response], in《诗参 考》1999: 91-92 (reprinted in 《诗探索》1999-4: 31-33)

83 1999-12 | Zang Di 藏棣, 〈当代诗歌中的知识分子写作〉 [Intellectual Writing in Contemporary Poetry], in 《诗探索》1999-4: 1-5 (reprinted in entry 85: 42-45)

84 2000-01 | Chen Chao 陈超, 〈置身其中: 世纪末诗坛论争〉 [Position Oneself in the Midst of It: A Polemic on the Poetry Scene at the End of the Century], interview with Cao Jian 曹剑, in 《现代都市》2000-1: 35-38 (reprinted as 〈置身其中: 关于当下诗歌论争的答问〉 in 周伦佑编, 《非 非・2000年特刊: 21世纪汉语文学写作空间》: 229-242)

85 2000-01 | Wang Jiaxin \& Sun Wenbo (eds) 王家新、孙文波编, 《中国诗 歌: 九十年代备忘录》[Chinese Poetry: Memorandum for the Nineties], 北京: 人民文学

86 2000-01 | Wang Jiaxin 王家新, 〈从一种蒙蒙细雨开始〉 [Start from a Misty Drizzle], introduction to entry 85: 1-11 (earlier published in 《诗探 索》1999-4: 6-17 and 《诗参考》1999: 68-74)

87 2000-01 | Yi Sha 伊沙, 〈王家新伪史记〉 [Wang Jiaxin's Forged Records of the Historian], in 《文友》2000-1: 27-28 as part of〈激情点射〉 [Passionate Fixed Fire]

88 2000-01 | Zhou Zan 周瓒, “知识实践” 中的诗歌 “写作”〉 [The "Writing" of Poetry in "Knowledge / Intellectual Practice"], in entry 85: 46-62

89 2000-01-15 | Miao Yushi 苗雨时, 〈90年代诗坛的一场论争〉 [A Polemic on the Poetry Scene in the 1990s], in 《文论报》, 15 January 2000: 2

90 2000-03 | Geng Zhanchun 耿占春, 〈真理的诱惑〉 [The Temptation of Truth], in 《南方文坛》2000-5: 28-29

91 2000-03-08 | Xu Jiang \& Yi Sha 徐江、伊沙, 〈将骂人进行到底〉 [Carry Abuse Through to the End], interview with Shen Lang 沈浪, in《社科新 书目》阅读导刊, 8 March 2000: 5

92 2000-03-28 | Bianzhe an 编者按 [Editor's Note] to 《社科新书目》阅读 导刊, 28 March 2000: 13

93 2000-03-28 | Gu Changjun 谷昌君, 《“知识分子写作” 或曰 “新左派”: 《中国诗歌九十年代备忘录》导读〉 ["Intellectual Writing," or “The New Left": A Reader's Guide to Chinese Poetry: Memorandum for the Nineties], in 《社科新书目》阅读导刊, 28 March 2000: 13 (reprinted in《诗参 考》2000: 73-74)

94 2000-03-28 | Shen Haobo 沈浩波, 〈真正的民间精神的光〉 The Light of the True Popular Spirit], in 《社科新书目》阅读导刊, 28 March 2000: 13 (reprinted in 《诗参考》2000: 72-73)

95 2000-03-28 | Zhongdao 中岛，〈一场蓄意制造的阴谋〉 [A Premeditated Conspiracy], in 《社科新书目》阅读导刊, 28 March 2000: 13 (reprinted in 《诗参考》2000: 71-72)

96 2000-04 | Xie Youshun 谢有顺，〈诗歌在前进〉 [Poetry Is Advancing], in 《山花》2000-4: 76-81 (reprinted as 〈序〉 [Preface], in entry 102: $1-16)$ 
97 2000-05-28 | Sun Wenbo 孙文波, 〈“知识分子写作”发言〉 [Statement on Behalf of “Intellectual Writing"], in 《社科新书目》阅读导刊, 28 May 2000: 15

98 2000-05-28 | Yi Sha 伊沙, 〈“民间立场” 发言〉 [Statement on Behalf of the "Popular Standpoint"], in《社科新书目》阅读导刊, 28 May 2000: 16

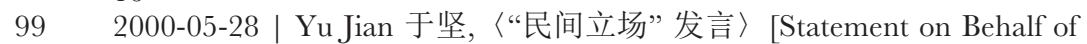
the “Popular Standpoint"], in《社科新书目》阅读导刊, 28 May 2000: 16

100 2000-05-28 | Zang Di 藏棣, “知识分子写作” 发言〉 [Statement on Behalf of “Intellectual Writing"], in 《社科新书目》阅读导刊, 28 May 2000: 15

101 2000-06 | Shen Qi 沈奇,〈中国诗歌: 世纪末论争与反思〉 [Chinese Poetry: A Polemic and Reflection at the End of the Century], in 《诗探 索》2000-1/2: 17-34 (reprinted in 周伦佑编, 《非非・2000年特刊: 21世纪 汉语文学写作空间》: 209-228, entry 102: 577-591 and《诗参考》2000: 55-65)

102 2000-06 | Yang Ke (ed) 杨克编, 《1999中国新诗年鉴》[1999 Yearbook of China's New Poetry], 广州: 广州

103 2000-06 | Yang Ke 杨克, 〈《中国新诗年鉴》99工作手记〉 ['99 Work Notes on the Yearbook of China's New Poetry], in entry 102: 652-656

104 2000-06 | Zeng Feiye 曾非也，〈看诗坛热闹〉[Check Out the Action on the Poetry Scene], in entry 102: 584-586

105 2000-06-28 | Fang Chen 方辰，〈《1999中国新诗年鉴》出来啦! 〉 Out Now! The 1999 Yearbook of China's New Poetry], in《社科新书目》阅读导 刊, 28 June 2000: 15

106 2000-07 | Ma Junhua 马俊华,〈诗坛夺嫡〉 [Infighting on the Poetry Scene], in 《诗参考》2000: 79-80

107 2000-07 | Tang Xin 唐欣，〈写作何必 “知识分子”〉 [Why Should Writing Be "Intellectual"], in 《诗参考》2000: 68-69

108 2000-07 | Xu Jiang 徐江, 〈眼睛绿了〉 [Eyes Turned Green], in《诗参 考》2000: 75-78

109 2000-07 | Yan Li 严力, 〈说教和包装〉 [Preaching and Packaging], in 《诗参考》2000: 66-67

110 2000-07 | Zhongdao 中岛，〈我对《1999中国新诗年鉴》的几点看法〉 [My Ideas about the 1999 Yearbook of China's New Poetry], in 《诗参考》2000: 69-70

111 2000-08 | Tang Xiaodu 唐晓渡,〈诗坛 “后厚黑学”, 或开塞露主义〉 ["Post-Thick-n-Blackology," or Laxativism on the Poetry Scene], in周伦佑 编, 《非非・2000年特刊: 21 世纪汉语文学写作空间》: 197-205

112 2000-10 | Zhou Zan 周瓒, 〈当代文化英雄的出演与降落: 中国诗歌与诗 坛论争研究〉 [The Rise and Fall of Contemporary Cultural Heroes: A Study of a Polemic in Chinese Poetry and the Poetry Scene], in 戴锦华 编, 《书写文化英雄: 世纪之交的文化研究》, 南京: 江苏人民: 72-129

113 2000-11 | Li Zhen 李震, 〈先锋诗歌的前因后果与我的立场〉 [The Ramifications of Avant-Garde Poetry and My Standpoint], in 《唐》1: 144-149 (reprinted in entry 116: 596-604)

114 2000-12 | Shen Haobo \& Hou Ma \& Li Hongqi 沈浩波、侯马、李红旗, 〈关于当代中国新诗一些具体话题的对话〉 [Dialogue on Some Concrete Issues in Contemporary Chinese New Poetry], in《诗探索》2000-3/4: $51-59$ 
115 2000-12-11 | Wang Gan 王干, 〈走出90年代〉[Out of the Nineties], in《太原日报》, 11 December 2000

116 2001-07 | Yang Ke (ed) 杨克编,《2000中国新诗年坚》[2000 Yearbook of China's New Poetry], 广州: 广州

117 2001-10 | Lan Dizhi 蓝棣之, 〈论当前诗歌写作的几种可能性〉 [On Various Possibilities for Writing Poetry in This Day and Age], in《文学评 论》2001-5: 80-87

118 2001-12 | Huang Tianyong 黄天勇, 〈反叛与游戏: 对中国20世纪最后15 年诗歌实验的考察〉 [Rebel and Play: An Examination of Chinese Poetic Experiment in the Final 15 Years of the Twentieth Century], in 《诗探 索》2001-3/4: 64-74

119 2001-12 | Xi Yunshu 席云舒，〈困顿中的反思: 关于世纪之交的诗坛现 状及其局限〉 [Reflections in the Midst of Fatigue: On the State of the Poetry Scene at the Turn of the Century, and Its Limitations], in 《诗探 索》2001-3/4: 55-63

120 2002-01 | Cao Wenxuan 曹文轩, 〈第十章・诗人诗话〉 [Chapter Ten: Poets on Poetry], in 《20世纪末中国文学现象研究》 [A Study of Phenomena in Chinese Literature at the End of the Twentieth Century], 北京: 北京大学: 277-308 


\section{CHAPTER THIRTEEN}

\section{MORE THAN WRITING, AS WE SPEAK: YAN JUN}

This final chapter functions as a coda in that it is short, it is different from the preceding, regular chapters and it attempts to end this study in a way that transcends simple termination - but most of all, that it is to do with music. Brevity aside, its difference from chapters One through Twelve lies in that it covers much less material than any of those and that it is no hardcore scholarship inasmuch as section 1, a report on a spectacular poetry recital in 2003, tends toward the journalistic instead. I first wrote this for the publications page of the Modern Chinese Literature and Culture Resource Center, a forum which has room for a wide range of things including quick on-site reports and translations.

I hope to do more work on interfaces of poetry and music or poetry and other art forms in future. Here, rather than expanding the original piece into something more like the preceding chapters, I choose to present section 1 in its original form as a recollection of the experience at the time, with only minor editorial changes. As such, it is a stepping stone toward section 2, which contains some brief reflections on the current state and scope of the Chinese avant-garde as a more or less coherent, Easthopian poetic discourse. In chapter One, I said that the difficulty of studying something from our own time lies in the closeness and the ongoing transformations of the object of study. This chapter presents the original on-site report - indented like a long quote, and thus set apart from the main narrative of this study, which was drafted in 2007-2008 - in the hope of conveying the excitement of studying something from our own time, which has precisely the same source. It is positively wonderful to experience firsthand not just poetry's written, static sediment but also its dynamic emergence in local settings with which it interacts, be they institutional or individual, public or private, formal or informal, domestic or foreign in whatever way.

But it is for the reader to decide what section 1 conveys: difficulty, or excitement, or both, or something else.

(C) MAGHIEL VAN CREVEL, 2008 | DOI 10.1163/9789047442738_014

This is an open access chapter distributed under the terms of the Creative Commons AttributionNoncommercial 3.0 Unported (CC-BY-NC 3.0) License. 


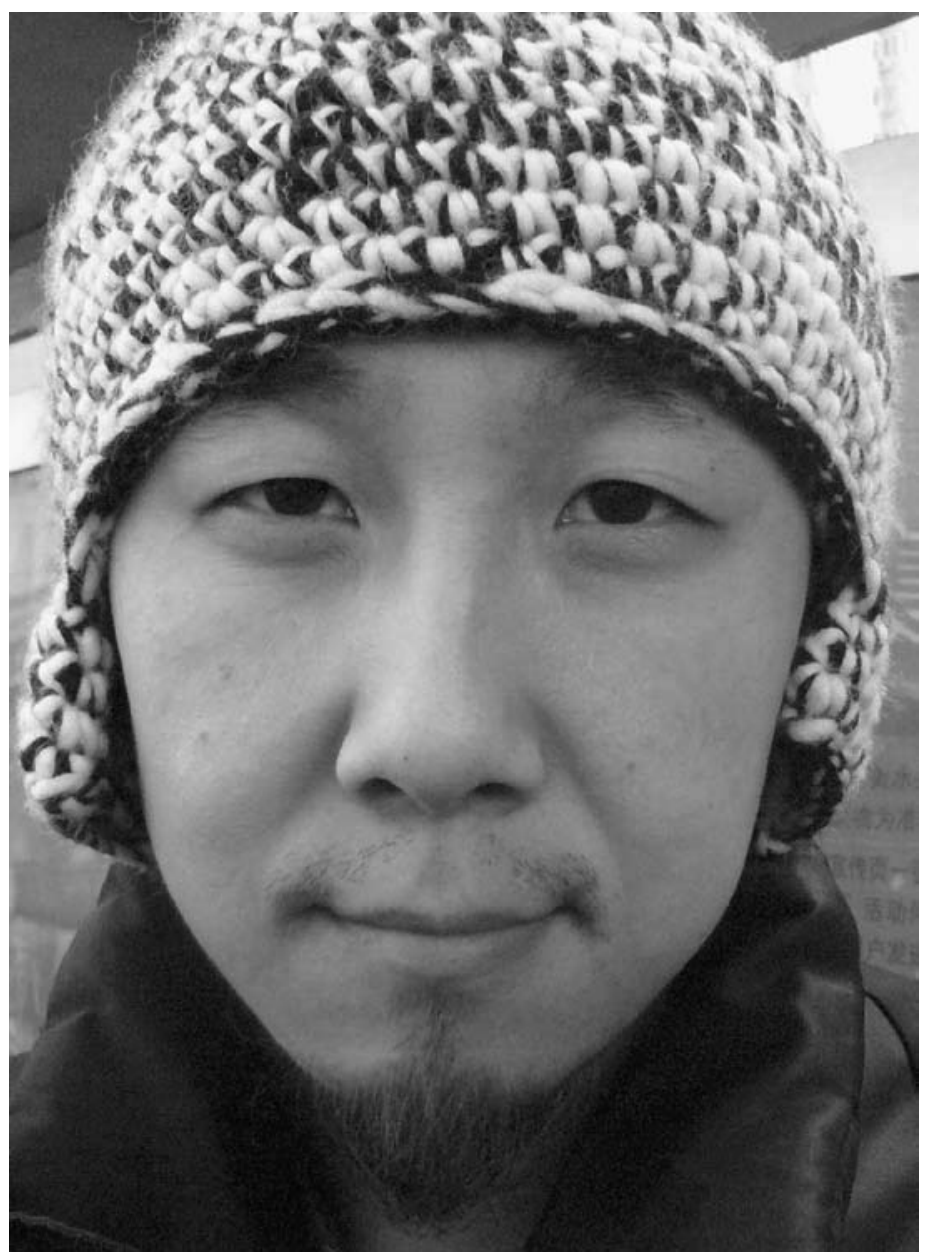

Figure 13.1. Yan Jun, 2007 (photograph by Qiaoqiao) 


\section{Three-Dimensional Performance}

Beïing, May 2003-Peking University is one of several schools that have left their mark on contemporary Chinese poetry, through the voices of poets and those of scholars and critics. In December 2002 alumnus Huang Yibing, also known as poet Mai Mang, offered lively reminiscences on poetry at PKU in the 1980s and the early 1990s during an informal seminar at the University's Department of Chinese. A few months on, on 26 March 2003, it was time for the PKU May Fourth Literary Society's annual Lake with No Name Poetry Reading (未名湖诗歌朗诵会), participants in the twenty-first edition including Liang Xiaoming, Che Qianzi, Song Lin, Sun Wenbo and others. Since the 1990s the date of the Reading has been fixed in commemoration of famed poet and PKU graduate Haizi, who ended his life on 26 March 1989.

As in the past couple of years, the Reading marked the beginning of a poetry festival made up of a series of events in March and April. This year's motto was an adaptation of Descartes' famous words, with 诗 shī'poetry' replacing the near-homophonous 思 $s \bar{\imath}$ 'think': 我诗, 故我在, meaning something like 'I do poetry, therefore I am' or, in a free rendition and counter-pun, 'I sing, therefore I am.' The program included a Women's Poetry recital in the Sculpting in Time café (雕刻时光), which used to be located outside the University's small east gate, but the remaining few blocks of traditional alleyway architecture there have long since been torn down to make room for the PKU Science Park, and Sculpting in Time has moved to the Weigongcun quarter. The recital took place in the garden of its beautiful second outlet at the foot of the Fragrant Hills, northwest of the city. Different generations were represented by Xiaoxiao, Tong Wei, Yin Lichuan, Cao Shuying and others including Zhou Zan, founding editor of Wings (翼), an influential unofficial journal for Women's Poetry. The April program included lectures by Zhou, with special attention to the work of Mu Qing, and by Yang Xiaobin, on narrativity in present-day poetry. Presentations by Zang Di and Tang Xiaodu that had been planned for the following weeks were canceled because of the SARS crisis, along with just about all other organized gatherings of more than a handful of people, in order to lower the danger of contagion. On 8 April, about a week before the 
true proportions - well, the beginnings of the approximate proportions - of SARS in Beijing were made known to the public, a third poetry recital still slipped through. It was well worth it.

Poetry in the time of SARS: let's hope the virus is contained soon enough and funding for medical facilities beyond China's privileged coastal cities is increased sufficiently to dispel the association with love in the time of cholera. By early April rumors about the spread of SARS in the capital had been persistent enough to put one on the alert and create the sort of collective consciousness that will make people try harder than usual to suppress the urge to cough or sneeze. But at the time of Yan Jun's reading the atmosphere wasn't nearly as tense as it has since become, and if the experimental duo $\mathrm{fm} 3$ and video artist-cum-VJ Wu Quan donned mouth masks for their technical-artistic accompaniment of Yan, this was theatrical behavior as much as anything else.

Yan Jun (1973) lived in Lanzhou, where he studied Chinese at the Northwest Normal University and worked as an editor until he moved to Beijing in 1999. He has since become a central figure in the unofficial music scene, as a critic, a publisher and an artist. He has also made himself heard in poetry, as contributing editor of the unofficial journal Writing (書, that's right, the full-form character), with three issues since 2001 including a special issue of Yan's own work, and as the author of an unofficial book of poetry called Infrasonic Sound (次声波, 2001), a selection of his poetry from 1991 to 2000. [Postscript: In 2006 Yan Jun brought out a second unofficial collection of his poetry, called Impossible (不可能), with one side "traditionally" threadbound. ${ }^{1}$ The reader soon discovers that the opposite side is glue-bound and the thread functions to keep the book closed exactly where it should be opened in order to be read. In April 2007, during a recital at the One Way Street bookstore on the grounds of the Old Summer Palace in northwest Beijing, Yan ostentatiously "forced" open a new copy of Impossible before he began to read.]

Yan's performance on 8 April took place in the Thinker Café. Its English name is probably the original rather than a transl(iter)ation. In Chinese, the café is called 醒客 (xingkè), meaning something like 'Aware Guest' or 'Aware Traveler,' through

\footnotetext{
1 Yan Jun 2006b.
} 


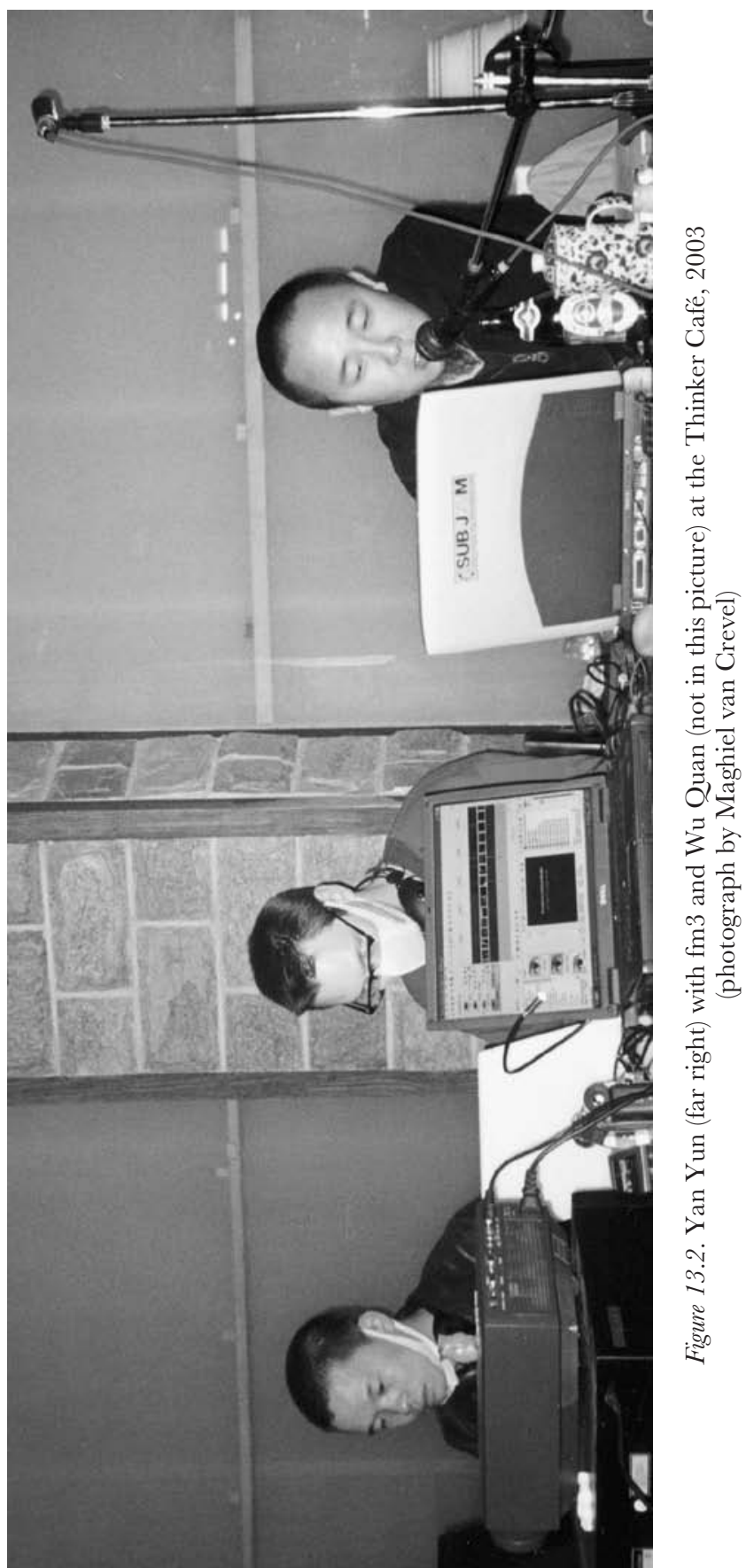




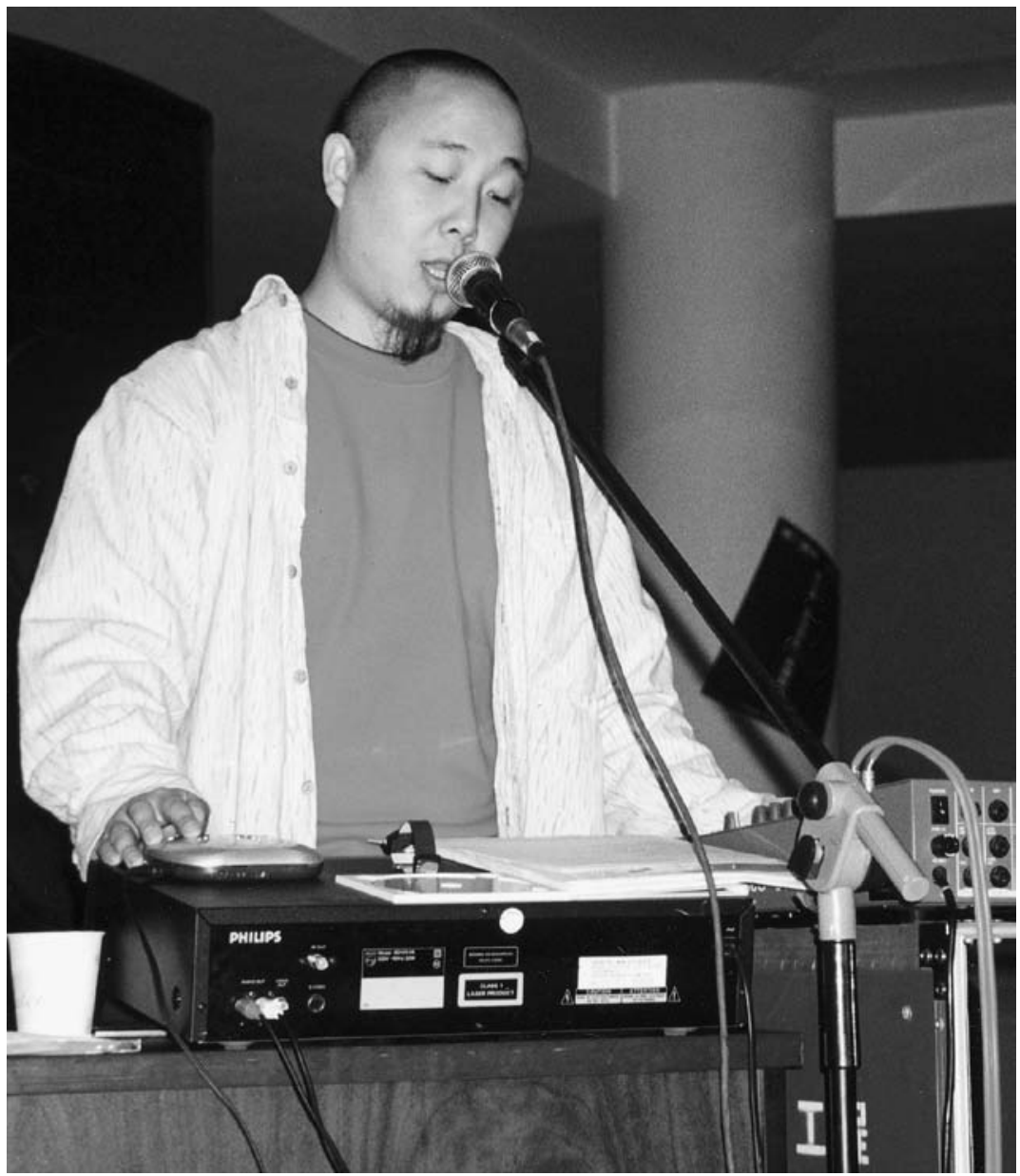

Figure 13.3. Yan Jun as support act for Hei Dachun and Vision, 2002 (photograph by Maghiel van Crevel) 
association with 侠客 (xiákè) 'knight errant': a neologism of clear phonetic inspiration. The Thinker Café is part of the wonderful All Sages bookstore (万圣书园) on Chengfu Road, between PKU and Tsinghua University. All Sages was once based in a couple of rooms along the same alley as the original Sculpting in Time, and likewise shifted its location to rise from the rubble once the demolition crew had moved in to pave the way for Science.

If Yan Jun is a young voice on the poetry scene, he is well known for the spectacular acoustics of his readings, and a good crowd had assembled by the time the lights in the café went out. Yan has a deep, powerful voice and isn't shy about using it to the full to roar and sing, such as when he participated in the Guangzhou Poet's Voice Happening (诗人发声) in November 2002, before an audience of about five hundred. What's more, he is in the habit of reading his poetry to the accompaniment of music and soundscapes. When he appeared in December 2002 as support act for one of Hei Dachun's recitals with the rock band Vision, he operated the sound equipment himself. It was a good reading but nothing like that in the Thinker Café, where fm3's and Wu Quan's acoustic and visual contributions allowed Yan to concentrate entirely on his vocal delivery.

The overall effect was that of a three-dimensional poetry performance. In the first dimension, the technician-artists projected a dynamic, sometimes poetically repetitive collage of documentary images on a large screen facing the audience. These included fuzzy, newsreel-type footage of the American-British invasion of Iraq, of operations on the ground as well as political leaders like Donald Rumsfeld and Saddam Hussein orchestrating the events. This was alternated with glimpses at other worlds such as the inside of a hospital, with a double focus on the helplessness of patient-victims and the power, both comforting and macabre, of medical personnel, the "army clad in white" hailed in the Chinese press as the vanguard in the fight against SARS. Another recurrent image was that of a child learning to read, implying a vision of education as another System held together by seemingly self-evident power relationships. The audience also got a good look at residential areas with the character 拆 'disassemble, tear down' slapped onto the walls of houses marked for demolition, an eye-catching bit of local color in contemporary Chinese cities 
and the sort of thing that is typically appropriated by the hip and disaffected for decorating T-shirts. Just in case the general political position of the collage needed any elucidation, unmistakable signals were delivered by famous footage of the decapitation of a giant Lenin statue somewhere in the former Soviet bloc.

But while many of the images had explicitly ideological themes, they also included pensive, stationary shots of a bird, of the stern of a boat traveling through the waves and of the mechanical choreography of traffic on an intersection. Moreover, the collage was visually manipulated throughout by the adjustment of color and contrast settings, and by the overlying projection of different images. If the entire show displayed obvious socio-political engagement, this didn't get in the way of its aesthetic qualities. The overall mood was one of alienation, oppression and bleakness - but also one of bitter-sweet melancholy, nostalgia and compassion, leading to association with Godfrey Reggio's Koyaanisqatsi.

One reason for such association is that in Yan Jun's collage, as in Reggio's cinematic masterpiece, the images were not accompanied by their own sound. In Koyaanisqatsi, breathtaking views of natural and human-made environments lie amid music by Philip Glass, now majestic and then maniacal. This method is essentially one of defamiliarization. It intensifies both the visual and the acoustic experience in themselves - and yet, paradoxically, it also undoes their conjunction because they can to some extent be separated by an act of will on the part of the audience. Similarly, the images in Yan Jun's collage acquired new meanings, because in a second dimension of the performance they were accompanied by semi-musical, computer-generated soundscapes and by Yan's recitation of his poetry.

A third dimension took shape in the projection of fragments of this poetry in its written form below the images described above. Crucially, these "subtitles" rarely if ever coincided with the texts that Yan Jun was reading aloud. Thus, (i) blurred images of tanks and soldiers, Rumsfeld or Saddam or Lenin, medical doctors and nurses, pupils and teachers, anonymous townsfolk and other living and lifeless matter would be (ii) accompanied by Yan Jun's voice amid an eerie soundscape, saying things like abolish mental slavery or against ourselves, against everything we are against, and (iii) simultaneously subtitled by — and, as it were, translated into - written snip- 


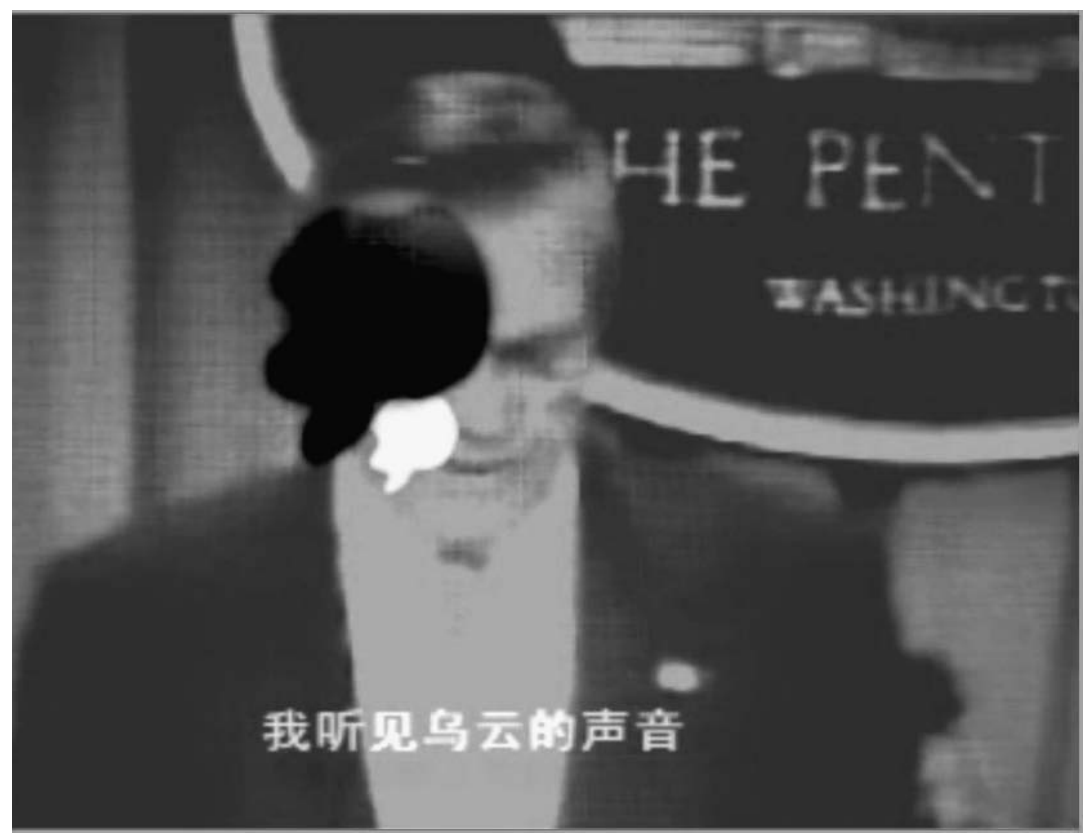

Figure 13.4. Two of the three dimensions in the remix of the event: fuzzy, newsreeltype footage of US Defense Secretary Donald Rumsfeld during a Pentagon press conference, with "subtitles" that read $i$ heard the sound of dark clouds. The inverted Apple logos flutter across the screen throughout. To hear and see all three dimensions simultaneously, play track 6 of Sub Jam 012 (Yan Jun 2005, also available online).

pets of poetry such as $i$ heard the sound of dark clouds, or imprisoned in song, catching fire, like a dream vanished in valleys of art, forever, or welcome to the underground! The effect was electrifying.

Yan Jun's poetry is perhaps best realized and experienced in settings like that of his recital at the Thinker Café, but considered in isolation on the page, it is also definitely worthwhile. His prose poem «Against All Organized Deception» (反对一切有组织的欺 骗, 2000), the source of the above quotations and of the subtitles during the performance, brings to mind an unlikely combination of intertexts: works by Allen Ginsberg and William Burroughs as well as by Xi Chuan, most of all «Salute». «Against» and «Salute» are similar in stanza structure, sentence-level devices like parallelism, and occasionally even in their specific imagery. The associative leaps in «Against» are another feature that Yan Jun shares with Xi Chuan - and, in different fashion, with the novels 
of Burroughs, especially in the negotiation of fragmented historical, fictional and dreamlike or intoxicated experience. Intertextuality with Ginsberg is clearest in Yan's dogged socio-political and ethical commitment, and in his anarchist streak. ${ }^{2}$

The literary-sociological context of Yan Jun's writing and its performance is formed by other trends in poetry of recent years, with young authors displaying social engagement in decadent, arrogant or idealist fashion, while also being down to earth, direct and irreverent. Somehow these poets are ultimately unassuming and less obsessed with the greatness of poethood than most avantgarde authors to date. Beijing-based Lower Body poets Yin Lichuan and Shen Haobo are prime examples, each in their own inimitable way. So is Wenmang, whose pen name means 'illiterate,' originally from Chongqing and now living in Guangzhou after several years in north and northeast China. Wenmang's work is riddled with expletives and profanities. Occasionally marred by the speaker's self-indulgence, it contains urgent, aggressive indictments of social problems. He has published in unofficial journals like Original Writing and put a number of his poems to music, for unofficial circulation on a CD called Our People Are Everywhere (到 处都是我们的人, 2003). The music is extremely unconstrained, which is both its charm and its curse.

Yan Jun's April performance, too, was recorded in full. He plans to issue some of the video and audio material on CD-rom through his unofficial record label called Subjam / Iron Henchman Workshop (铁托工作室). Below is a translation of «Against All Organized Deception», which played a central, overarching role in the Thinker Café recital. The poem is all over the place, but in a strangely energizing manner. There is much China in here, most of it anchored in a rough-edged present. There is selfmockery and humor, there is anger and vicious obscenity, there are allusions to divergent sources: Yu Hua, Li Bai, Maksim Gorky, the Popular-Intellectual Polemic, the May 1968 Paris riots, the Book of fin (晋书), Mao Zedong, «The Internationale», John Lennon and more. There is playful and serious contemplation, there is cosmopolitan rebellion and courage and style - and there is a relaxed self-consciousness of all that. Yan Jun makes things happen.

2 Yan Jun 2001: 149-152. 


\section{«Against All Organized Deception»}

last night, $i$ dreamed of soy sauce - last night, $i$ began to germinate-last night, the vast desert moved far away, like a sigh. $i$ heard the sound of dark clouds, while under the eaves, the last of the young ones who had to move when their houses were torn down finished his cigarette. last night, for lack of a woman's tears, shanghai turned into a city of wooden stallions - last night, for lack of thin mist crossing the bridge, guangzhou turned into pill heaven.... and in xining, the streetlights went out while a fellow hiding a knife in his clothes ran through the alley splattered with sheep oil - last night, the beijing god went out the door.

against all organized deception!

against meetings at dusk, stars twinkling. against yelling my name from a tree-top, against cries in the drizzle. against capitalist contemplation. against those who are two-faced and triple-knived. against dead souls reincarnating in another corpse. against your lowering of my IQ. against a movie interrupted halfway through - when the light rips through our overcoats, the nightmare fairy stops in mid-air, she's got no love and no future, and her loneliness is our loneliness.... against power.

to the flea market, imperishable and immortal!

yesterday you were a scholar, today you're a thug, tomorrow you'll be talking in your sleep and turn into a philosopher. could that really be what life is all about? could it really be that cell phones won't come through but airplanes can just strut about in public, scratching brittle skies? go out, together with the ox, prince of demons, go see that god - a year should be enough for you to learn to be silent, observe, go live in iron-n-clay caves and sob. winter is coming to an end, you must believe your memories.

sex is a cure-all!

against advertisements, against forgetfulness. against tearing up anyone's ID and ugly face. against coming through meteoric showers clad in a golden cape but forgetting your daughter's name. against carnivores dancing. against computers dying. against living like a sickle. against night fragrance dying at night. against faddish magazines and dotcoms. against day-dreaming, see-through garments, the heart exploding like goose feathers.... booze killing a man from ten steps away.... dumb shits ruling the world.... porn magazines for exam papers.... against fear. 
let the storm rage with greater force and fury!

against qigong masters, against rock stars. against electricity destroying the earth's beautiful atmosphere. against closing the bars where wandering spirits go. against a god gone around the bend. against breast worship. against selling flowers, against selling out nether world flowers with seven stars roaming above, against flowers for valentine's day and for mother's day, against eating flowers. against skin. against azure conspiracies.

free the grasslands from the artist's hands!

doubts come from blood pressure stimulating the brain, but could worship really come from hunger? hence, against the speech of the mantis, against the mysophobic scientist — she has hurt me! and then against intellectuals disguised as thugs. likewise, against forests disguised as wooden homes to foreign birds, finally carried off by street acrobats selling their art, imprisoned in song, catching fire, like a dream vanished in valleys of art, forever....

free the computer's body!

one hears it said that sound going around can wake up night shift workers, and that blood falling can hit black people born in the fifties. your casual drawings of air and wooden sandals will make the afternoon grow longer, until the thief comes down from the slopes and blankly stares into the sunset. and those fellows holding meetings in the sky, they'll dance and tumble down. and people are gathering, it's time to get going.

welcome to the underground!

there is no such thing as punk theory, only punk action.

if dead then bury me.

believe in the infinity of love and other articles for daily use.

the world is yours.

against entertainment journalists and their twisted grins.

sing a song on rusty nails.

leave a little happier.

noise can improve your life, but please don't perform inside a study filled with smoke - he says, with dark clouds packed overhead, science is but superstition. then he says, cigarettes give the angry a headache, snacks make hippies ponder, 
smoke will change the life of an iron henchman. as for human life, a human being's full life, a human being's full life.... his territory is clean, the neighbors howling every day, he says, no savior from on high delivers.

gay love - so what.

learn from comrade li bai-

change the world, change ourselves.

do you believe in reincarnation now?

cattle in the distance and their staring eyes: against matrimony.

abolish mental slavery.

one who has money needs a moneybag.

spring's every detail resembles a coastline.

into the trees! like a bird looking down on the struggle.

into the trees! and welcome the foxy women.

into the trees! disband america.

whoever can fly is a magician.

except mosquitoes, of course.

against. against everything.

against ourselves. against everything we are against.

against everything we are not against.

against everything about ourselves.

against everything we must not be against and cannot be against.

against.

\section{Writing, Event Gulture and Poetry Opening Up}

I have suggested that while Yan Jun's poetry can hold its own as "mere" writing, it is best realized and experienced in its live performance. Fortunately, the technology that enables him to do what he does also enables more people than his live audiences to get a sense of what happens when he does it. On the MCLC Resource Center website the above report and translation are followed by the written texts of several of Yan's poems and audio recordings of the recital. In 
addition, a CD-rom Yan later made of the event contains a remix of his recitation of "Against All Organized Deception», set against an edited version of the visual dimension which includes shadowy shots of Yan Jun, fm3 and Wu Quan during the original performance. The vocal part is a remix too, called «Against Cannot Be Against» (反对不 可能反对) and containing several simultaneous loops of Yan's voice reading strings from the original poem's penultimate stanza. The CD is called Sub Fam 012; the material is available in full from DACHS Leiden, including the video recording. A third online resource is Yan Jun's MySpace page, which contains the audio recording of a performance at PKU in 2006. ${ }^{3}$

As writing, Yan Jun's poetry sits comfortably inside the discourse of the avant-garde as this developed in the 1980s and 1990s. As part of larger cultural trends summed up as technologization and remediation, it prompts reflection on the current nature and scope of this discourse, which is no longer limited to writing on the page and reading from the page, so to speak. The acoustic and visual dimensions of Yan's readings make them eminently fit for performance of a more memorable type than that practiced in many present-day poetry recitals in China and elsewhere.

The 2007 edition of the Lake with No Name Poetry Reading at $\mathrm{PKU}$ was a case in point. Without wanting to detract from the quality of many of the contributions as writing on the page, one was struck by the sheer dreariness of most of the readings by well-known avant-garde poets as well as authors who had only recently taken up the pen. What is the added value of recitation if the reciter's ambitions don't exceed the standard, unmarked, unoriginal spoken representation of the writing on the page? This is not to say that successful recitation requires special effects. The human voice itself can captivate an audience- as long as it energizes what it has to say, recreating it at the moment of recitation rather than delivering it like a perfunctory classroom assignment with eyes glued to the page. If worse comes to worst, painful misreadings will reveal that the reciter is mechanically processing the writing rather than experiencing the text as living language.

Although this discontent stems from about twenty years of regular recital attendance, I am guilty of generalization here. Festivals in China and elsewhere also feature reciters whose individual styles punctu-

\footnotetext{
${ }^{3}$ Van Crevel 2003c and 2005, Yan Jun 2006a.
} 
ate the dreariness. And to be sure, there were favorable exceptions at PKU in 2007. One was Hu Xudong, who has been known to read in his native Sichuanese to considerable effect. His easy manner on stage and his articulate, well-timed, humorous delivery ensured that there was more in it for the audience than the ritual confirmation-bypolite-applause of the poet's authorship of texts read out in otherwise unremarkable ways. In Hu's case, the only drawback is that he is so easy on stage that the stories he tells about his poetry come dangerously close to being longer than the poetry itself. A second exception was Yan Jun, who had less technical-artistic support than during the Thinker Café reading - just one laptop computer, which he operated himself - but managed to keep the audience spellbound nonetheless. He did so through a combination of effective lighting, computergenerated soundscapes and a repetitive reading like that of «Against Cannot Be Against», using two short poems called «January $1^{\text {st }}$ (For Those Who've Never Seen Snow)» (1月1日 [给没见过雪的人], 2007) and «February 13 $3^{\text {th }}$ (For Those Who've Never Seen Rain)» (2月 13 日 [给没见过雨的人], 2007). And there are more: the PKU festival's 2003 edition famously included a reading by Che Qianzi, who is renowned for many unforgettable performances using simpler means than audio-visual equipment. Witness, for example, his "reading" at the Rotterdam Poetry International festival in the same year, beautifully documented in one of Victor Vroegindeweij and Daniëlle van Ark's Camera Poetica film clips on the Poetry International Web: this qualifies as nothing less than theater, with masterful vocal delivery. ${ }^{4}$

The bigger picture here may be that of "event" (活动) settings, which are quickly gaining in importance in socio-cultural life in China. In his work on poetry recitation John Crespi characterizes the "event" as a decentralized and highly autonomous practice that has superseded the centralized, orchestrated political movement (运动). He views its rise and current ubiquity as nothing less than a reorganization of public life that is taking place in tandem with the state's deliberate promotion of the cultural economy (文化经济). ${ }^{5}$ Poetry recitation in whatever form constitutes but a tiny fraction of what we may broadly term event culture, but it is important to recognize that the evolution of the poetic discourse doesn't take place in isolation.

\footnotetext{
4 Che 2003.

${ }^{5}$ Crespi 2001 and 2007b, Crespi \& Tsou 2007.
} 
On that note, just as Yan Jun combines poetry with soundscapes and video, thus making it part of something bigger, it is precisely because appreciation of his work doesn't hinge exclusively on a command of Chinese or the availability of translations that for him, uploading a recording of a Chinese-language poetry reading onto his predominantly English-language MySpace page is the most natural thing in the world. As such, because he crosses boundaries between media and genres and because what he does with words involves infinitely more than their referential and prosodic functions in one particular linguistic environment, he is naturally part of globalization, be it in "Chinese" or "foreign" settings. Or, it is precisely because he operates primarily in avant-garde music and sound - which are, on the whole, less incompatible with popular culture than poetry - that once what he writes becomes part of a full-fledged performance, it is less definitely high art than most other avant-garde poetry.

In chapter One, I noted that the advent of the Internet has meant vastly more than technical change and that its effects on various aspects of the poetry scene may make it a landmark for literary-historical periodization; and that online developments have an interface with multimedial poetry performance that is crying out to be further explored. More generally, one side of the poetic discourse that this final case study highlights is the breakdown or at least the increasing porousness of compartmentalization between poetry and other arts, the Chinese and the foreign, the high and the low, and so on.

This doesn't mean that the "old thing" is going to disappear. "Mere" writing isn't an old thing in any bad sense, and we should have plenty more of it. What it does mean is that the poetic discourse that has been the subject of this book will likely be opening up in new ways, as it continues to move through a rapidly changing cultural landscape-and that it is, quite literally, evolving as we speak. 


\section{WORKS GITED}

In light of the unstable nature of many websites and to ensure the continuing availability of online resources cited in China-related research, DACHS Leiden now hosts citation repositories containing downloads of websites and web pages as they were originally accessed for the project in question. A citation repository for this book, created in February 2008, is found at http://leiden.dachs-archive.org/citrep/vancrevel2008/. Its back-up function aside, this has made it unnecessary to include lengthy URLs in the list below. If search engines, website names and occasional click-through directions provided in the bibliography don't suffice to find the material in its original form, the reader may wish to turn to the repository instead.

All unofficial publications are identified as such. Information on unofficial poetry journals is available from the dedicated bibliography mentioned in the preface (Van Crevel 2007).

Interviews are identified as such unless their title makes this unnecessary, and listed under the interviewee's name, followed by that of the interviewer, just like co-authored and co-edited articles and books.

Different from the main narrative, the translations of Chinese titles in the list of works cited don't distinguish between "the Eighties" and "the Nineties" as intellectual-cultural periodizations and "the 1980s" and "the 1990s" as indications of calendar time, but literally follow the originals, for reasons of bibliographical accuracy that also inform the use of simplified and full-form characters.

Abrams, M H. 1971: The Mirror and the Lamp: Romantic Theory and the Critical Tradition, London etc: Oxford UP (first edition 1953)

Alvarez, A. 1971: The Savage God: A Study of Suicide, London: Weidenfeld \& Nicolson An et al (eds). 2004: An Qi, Yuancun \& Huang Lihai 安琪、远村、黄礼孩, 《中间代 诗全集》[Collected Poems of the Middle Generation], 共二册, 福州: 海峡文艺 Ang, Ien. 2001: On Not Speaking Chinese: Living between Asia and the West, London etc: Routledge

Ash, Adrienne. 1982: "Lyric Poetry in Exile," in Spalek \& Bell 1982: 1-18

Attridge, Derek. 1981: "The Language of Poetry: Materiality and Meaning," in Essays in Criticism 31-3: 228-245 
Aviram, Amittai. 1994: Telling Rhythm: Body and Meaning in Poetry, Ann Arbor: University of Michigan Press

Bailey, Alison. 2006: review of David Der-wei Wang, The Monster That Is History: History, Violence, and Fictional Writing in Twentieth-Century China, MCLC Resource Center $\rightarrow$ Book Reviews (online, see also p475)

Barmé, Geremie. 1999: In the Red: On Contemporary Chinese Culture, New York: Columbia UP

\& Jaivin, Linda (eds). 1992: New Ghosts, Old Dreams: Chinese Rebel Voices, New York: Times Books / Toronto: Random House

Barnstone, Tony (ed). 1993: Out of the Howling Storm: The New Chinese Poetry, various translators, Hanover etc: Wesleyan UP

Baudelaire, Charles. 1943: Le spleen de Paris: petits poèmes en prose, suivis des journaux intimes et de choix de maximes consolantes sur l'amour [Paris Spleen: Little Poems in Prose, Followed by the Intimate Journals and a Choice of Consoling Maxims on Love], Paris: Éditions de Cluny

1989: Charles Baudelaire, The Parisian Prowler: Le Spleen de Paris: Petits Poèmes en prose, translated by Edward K Kaplan, Athens GA etc: University of Georgia Press

Beach, Sophie. 2001: "Straining at the Leash: China's Journalists Battle Local Interests and Censorship to Get the News Out," in China Rights Forum, fall 2001: 12-15, 44

Bei Dao 北岛. 1978: 《陌生的海滩》 [Strange Shores], 北京 (unofficial publication, reprinted 1980)

1983: Notes from the City of the Sun, bilingual, edited and translated by Bonnie S McDougall, Ithaca: Cornell University East Asia Papers (revised edition 1984) -1987: 《北岛诗选》 [Selected Poems by Bei Dao], 广州: 新世纪 (second, expanded edition; first edition 1986)

1988: The August Sleepwalker, translated by Bonnie S McDougall, London: Anvil 1990: "Terugblik van een balling" [An Exile Looking Back], in Carly Broekhuis, Dirk Jan Broertjes, Simon Franke, Simon Gunn \& Bert Janssens (eds), Het collectieve geheugen: over literatuur en geschiedenis [The Collective Memory: On Literature and History], translated by Maghiel van Crevel, Amsterdam: De Balie / The Hague: Novib: 65-79

1991: Old Snow, bilingual, translated by Bonnie S McDougall \& Chen Maiping, New York: New Directions

1994: Forms of Distance, bilingual, translated by David Hinton, New York: New Directions

— 1995: (北島)《午夜歌手: 北島詩選1972-1994》 [Midnight Singer: Selected Poems by Bei Dao (1972-1994)], 台北: 九歌

1996: Landscape over Zero, bilingual, translated by David Hinton with Yanbing Chen, New York: New Directions

1998: (北島)《藍房子》[The Blue House], 台北: 九歌

1999: "From the Founding of Today to Today: A Reminiscence," translated by

Perry Link, Stanford Presidential Lectures in the Humanities and Arts (online, see also p475; republished as "How the 'Revolution' Occurred in Chinese Poetry," in Jefferey Paine [ed], The Poetry of Our World: An International Anthology of Contemporary Poetry, New York: HarperCollins, 2000: 433-437) 2000: Unlock, bilingual, translated by Eliot Weinberger \& Iona Man-Cheong,

New York: New Directions 2003a:《北岛诗歌集》 [Poems by Bei Dao], 海口: 南海 2003b: 《北岛的诗》 [The Poetry of Bei Dao], 长春: 时代文艺 
2004: 《失败之书: 北岛散文》 [The Book of Failure: Short Prose by Bei Dao], 汕头: 汕头大学

\& LaPiana, Siobhan. 1994: "Interview with Visiting Artist Bei Dao: Poet in Exile," in The Fournal of the International Institute 2-1 (online, see also p475)

— \& Tang Xiaodu 唐晓渡. 2003: 《“我一直在写作中寻找方向”: 北岛访谈 录》 ["I've Always Sought Direction from My Writing": An Interview with Bei Dao], in《诗探索》2003-3/4: 164-172

\& W Wedell-Wedellsborg, Anne. 1995: "Secrecy and Truth: An Interview by Anne Wedell-Wedellsborg," in Søren Clausen, Roy Starrs \& Anne WedellWedellsborg (eds), Cultural Encounters: China, Japan and the West, Aarhus: Aarhus UP: 227-240 (dated 1992)

— \& Zha Jianying 查建英. 2006: 〈北岛〉, in Zha 查, 《八十年代访谈录》 [nterviewing the Eighties], 北京: 三联: 66-81 (interview)

\& Z Zhang-Kubin, Suizi. 1989: Suizi Zhang-Kubin, "Endzeit: Ein Gespräch mit Bei Dao" [End Times: An Interview with Bei Dao], in die horen: Zeitschrift für Literatur, Kunst und Kritik 34-3: 55-58

Beiling 贝岭. 2006: 〈流亡带来了什么一答日本文学刊物《蓝》主编提问〉[What Has Exile Brought? In Response to the Editor of Blue, a Japanese Literary Journal], 獨立中文筆會 / Independent Chinese Pen Center (online, see also p475; revised as Beiling 2007)

2007: 〈流亡中的文学〉 [Literature in Exile], 自由聖火 / Fire of Liberty (online, see also p475; revised edition of Beiling 2006)

Berry. 2005: Michael Berry, "Rupture Writers," in Edward L Davis (ed), Encyclopedia of Contemporary Chinese Culture, London etc: Routledge: 517-518

Bertens. 2001: Hans Bertens, Literary Theory: The Basics, London etc: Routledge

Bevan, David (ed). 1990: Literature and Exile, Amsterdam etc: Rodopi

Birch, Cyril. 1960: "English and Chinese Metres in Hsü Chih-mo," in Asia Major 8: 258-293

Blume, Georg. 2005: "Die Internetpoetin" [The Internet Poetess], in Die Zeit, 24 February 2005

Bourdieu, Pierre. 1993: The Field of Cultural Production: Essays on Art and Literature, edited by Randal Johnson, various translators, Cambridge: Polity Press

Boym, Svetlana. 1998: "Estrangement as a Lifestyle: Shklovsky and Brodsky," in Suleiman 1998: 241-262

Brady, Anne-Marie. 1997: "Dead in Exile: The Life and Death of Gu Cheng and Xie Ye," in China Information xi-4: 126-148

Brems, Hugo. 1991: De dichter is een koe: over poëzie [The Poet Is a Cow: On Poetry], Amsterdam: Arbeiderspers

Brodsky, Joseph. 1973: Selected Poems, translated by George L Kline, Harmondsworth: Penguin

1990: "The Condition We Call 'Exile'," in Glad 1990: 100-130

Bronfen, Elisabeth. 1992: Over Her Dead Body: Death, Femininity and the Aesthetic, Manchester: Manchester UP

Brouwers, Jeroen. 1984: De laatste deur: Essays over zelfmoord in de Nederlandstalige letteren [The Last Door: Essays on Suicide in Dutch-Language Literature], Amsterdam: Synopsis / De Arbeiderspers (first edition 1983)

Brown, Edward. 1984: "The Exile Experience," in Olga Matich with Michael Heim (eds), The Third Wave: Russian Literature in Emigration, Ann Arbor: Ardis: 53-61

Bruno, Cosima. 2003: Contemporary Chinese Poetry in Translation, PhD thesis, School of Oriental and African Studies, University of London

Buruma, Ian. 2000: De neoromantiek van schrijuers in exil [The Neoromanticism of Writers 
in Exile], Amsterdam: Prometheus (translated into English, with minor revisions, as Buruma 2001)

2001: "The Romance of Exile: Real Wounds, Unreal Wounds," in The New Republic, 12 February 2001: 33-38 (translation of Buruma 2000, with minor revisions)

Cai Yi 蔡毅. 1997: 〈诗一非诗: 《0档案》评析〉 [Poetry-Non-Poetry: Review and Analysis of «File 0»], in 《滇池》1997-1: 61-63 1999: 《文艺沉思集》[Thoughts on Literature and Art], 昆明: 云南人民

Cao Wenxuan 曹文轩. 2002: 《20 世纪末中国文学现象研究》 [A Study of Phenomena in Chinese Literature at the End of the $20^{\text {th }}$ Century], 北京: 北京大学

Chang Li \& Lu Shourong 常立、卢寿荣. 2002: 《中国新诗》 [China's New Poetry], 上海: 上海人民美术

Che Qianzi. 2003: "Che Qianzi-HOSPITAL ILLUSTRATION 3," film clip by Victor Vroegindeweij \& Daniëlle van Ark, Poetry International Web $\rightarrow$ All Camera Poetica (online, see also p475)

Cheesman, Tom \& Gillespie, Marie. 2002: "Talking Diasporas," in Index on Censorship 31-3: 6-7

Chen Chao 陈超. 1989: 《中国探索诗鉴赏词典》[A Critical Anthology of Chinese Explorative Poetry], 石家庄: 河北人民 (revised and expanded as Chen Chao 1999)

— 1993: 《以梦为马: 新生代卷》 [With a Dream for a Horse: Newborn Generation Volume], 北京: 北京师范大学 (in Xie Mian \& Tang 1993)

1994: 〈王家新诗二首赏析〉 [Appreciations of Two Poems by Wang Jiaxin], in 《诗探索》1994-4: 111-118

- 1999: 《20世纪中国探索诗鉴赏词典》 [A Critical Anthology of 20 $0^{\text {th }}$-Century Chinese Explorative Poetry], 共二册, 石家庄: 河北人民 (revised and expanded edition of Chen Chao 1989)

2003 (ed). 《最新先锋诗论选》 [A Selection of Essays on the Newest AvantGarde Poetry], 石家庄: 河北教育

- 2005: 〈贫乏中的自我剥夺: 先锋 “流行诗” 的反文化、反道德问题〉

[Wretched Self-Deprivation: Questions of Anti-Culture and Anti-Morality in "Popular Poetry" of the Avant-Garde], in 《新诗评论》2005-2: 3-10

Chen Dongdong 陈东东. 1991: 〈丧失了歌唱和倾听: 悼海子、骆一禾〉 [The Loss of Song and Ear: In memoriam Haizi and Luo Yihe], in Haizi \& Luo 1991: 337-339 (dated 1989)

1995: (陳東東) 〈魚刺在魚肉中成長: 中國地下詩刊《傾向》始末〉[Fishbones Growing inside Fish-Flesh: The Chinese Underground Poetry Journal Tendency, from Beginning to End], in 《文藝報》(香港) 2: 48-50 (reprinted as 〈《傾向》詩刊創刊始終〉 [The Founding of the Poetry Journal Tendency, from Beginning to End], in 《傾向》10 [1997] : 283-288)

Chen Qufei 陳去飛. 1995: ““搞怪”就是“前衛”: 大陸詩作于堅《0檔案》深度批 評〉 ["Misbehaving" Will Make You "Avant-Garde": An In-Depth Critique of the Mainland-Chinese Poem «File 0» by Yu Jian], in 《臺灣詩學季刊》12: 44-59 and 13: 43-46

Chen Sihe 陈思和. 1997: 〈无名的时代: 九十年代中国小说〉 [The Nameless Era: Chinese Fiction in the 1990s], in Wan Zhi 1997a: 58-57

Chen Xuguang 陈旭光. 1996: 《诗学: 理论与批评》 [Poetics: Theory and Criticism], 天津: 百花文艺

Chen Zhongyi 陈仲义. 1993: 〈第三代与朦胧诗之比较〉 [A Comparison of the Third Generation and Obscure Poetry], in 《作家》1993-12: 74-77 
1994:《诗的哗变：第三代诗面面观》[A Mutiny of Poetry : Perspectives on Third Generation Poetry], 厦门: 鹭江

1996: 《中国朦胧诗人论》[On China’s Obscure Poets], 南京: 江苏文艺 2000: 《扇形的展开: 中国现代诗学谫论》 [Unfold Like a Fan: A Shallow

Treatise on Modern Chinese Poetics], 杭州: 浙江文艺 2002a: 〈大陆先锋诗歌 (1976-2001) 四种写作向度〉 [Four Directions in Mainland Avant-Garde Poetry Writing (1976-2001)], in《诗探索》2002-1/2: $115-125$

2002b: 〈肉身化诗写刍议〉 [A Modest Proposal on Corporealized Poetry Writing], in 《蓝》6: 148-157

Chen Zishan 陈子善 (ed). 1993:《诗人顾城之死》[The Death of Poet Gu Cheng], 上海: 上海人民

Cheng Guangwei 程光炜. 1993:〈王家新论〉 [On Wang Jiaxin], in《南方诗 志》1993 秋: 58-67 (unofficial publication, reprinted in Cheng 程, 《雨中听 枫: 文坛回忆与批评》[Hearing Maples in the Rain: Memoirs and Critique of the Literary Scene], 武汉: 湖北教育, 2000: 168-184, as〈跨时代的写作〉

[Trans-Epoch Writing]; and in Cheng 程, 《程光炜诗歌时评》 [Cheng Guangwei on Current Issues in Poetry], 开封: 河南大学, 2002: 165-179, as 〈王家新 论〉 [On Wang Jiaxin])

- 1997a:〈90年代诗歌: 叙事策略及其它〉 Poetry of the 90s: Narrative Strategies and Other Things], in 《大家》1997-3: 137-143

- 1997b: 〈叙事及其它〉 [Narrative and Other Things], in Sun 1997: 5-8

- (ed) 1998a: 《岁月的遗照: 九十年代文学书系, 诗歌卷》 [A Portrait of Years Gone By: Literature of the Nineties, Poetry Volume], 北京: 社会科学文献

1998b: 〈不知所终的旅行〉 Journey with Unknown Destination], in Cheng 1998a: 1-20

1999: 〈现成的诗歌与可能的诗歌〉 [Ready-Made Poetry and Possible Poetry], in Cui 1999a: 221-225 (dated 1991)

2003: 《中国当代诗歌史》[A History of Contemporary Chinese Poetry], 北 京: 中国人民大学

Cheng Weidong 程蔚东. 1987: 〈别了, 舒婷北岛〉 [Farewell, Shu Ting and Bei Dao], in 《文汇报》, 14 January 1987: 3

Chi, Pang-yuan \& Wang, David Der-wei (eds). 2000: Chinese Literature in the Second Half of a Modern Century, Bloomington etc: Indiana UP

Chow, Rey. 1991: Woman and Chinese Modernity, Minneapolis etc: University of Minnesota Press

1993: Writing Diaspora: Tactics of Intervention in Contemporary Cultural Studies, Bloomington etc: Indiana UP

- (ed) 2000: Modern Chinese Literary and Cultural Studies in the Age of Theory: Reimagining a Field, Durham etc: Duke UP

Chuang-tzù. 1981: Chuang-tzǔ: The Seven Inner Chapters and Other Writings from the Book Chuang-tzǔ, translated by A C Graham, London etc: George Allen and Unwin

Coelho, Alain. 1995: Arthur Rimbaud fin de la littérature: lecture d'Une saison en enfer [Arthur Rimbaud, the End of Literature: Reading A Season in Hell], Nantes: Joseph K

Cooper, G Burns. 1998: Mysterious Music: Rhythm and Free Verse, Stanford: Stanford UP

Crespi, John. 2001: "The Lyric and the Theatric in Mao-Era Poetry Recitation," in Modern Chinese Literature and Culture 13-2: 72-110

2005: "The Poetry of Slogans and Native Sons: Observations on the First China Poetry Festival," MCLC Resource Center $\rightarrow$ Publications (online, see also p475) 
2007a: "Poetic Memory: Recalling the Gultural Revolution in the Poems of Yu Jian and Sun Wenbo," in Lupke 2007: 165-183 and 219-232

-2007b: Jiang Keping 江克平, 《从 “运动” 到 “活动”: 诗朗诵在当代中国的

价值〉 [From "Movement" to "Event": The Value of Poetry Recitation in Contemporary China], translated by Wu Hongyi 吴弘毅, in 《新诗评论》2007-2: 3-19

\& Tsou, Zona Yi-ping. 2007: "An Interview with John Crespi on Performance Poetry in China, with a Sampling of Live Recordings," in Full Tilt 2 (online, see also p475)

Cui Weiping 崔卫平. 1992: 〈西川: 超度亡灵〉 [Xi Chuan: Releasing the Souls of the Dead], in 《现代汉诗》1992秋冬: 118-123 (reprinted in Xi Chuan 1997d: 5-9)

— (ed) 1999a: 《不死的海子》 [The Undying Haizi], 北京: 中国文联

- 1999b: 〈真理的祭奠〉 [In Memory of Truth], in Cui 1999a: 89-98 (dated 1992) 1992)

Culler, Jonathan. 1981: The Pursuit of Signs: Semiotics, Literature, Deconstruction, London etc: Routledge \& Kegan Paul 1997: Literary Theory: A Very Short Introduction, Oxford: Oxford UP

DACHS poetry chapter: Leiden University division of the Digital Archive of Chinese Studies (DACHS Leiden) $\rightarrow$ Poetry (online, see also p475)

Daruvala, Susan. 1993: "Zhou Zuoren: 'At Home' in Tokyo," in Lee (Gregory) 1993a: $35-54$

Day, Michael Martin. 2005a: China's Second World of Poetry: The Sichuan Avant-Garde, 1982-1992, Leiden: DACHS poetry chapter $\rightarrow$ China's Second World of Poetry (online, see also p475)

2005b: "China's Second World of Poetry: The Grand Poetry Exhibition of 1986," DACHS poetry chapter $\rightarrow$ China's Second World of Poetry $\rightarrow$ Related material (online, see also p475)

2007a: "Online Avant-Garde Poetry in China Today," in Lupke 2007: 201-217 and 219-232

2007b: "On Paper or Online, or Both?," paper presented at the annual RMMLA conference, Calgary

De Meyer, Jan A M. 1996: "Voorwoord" [Foreword], in Yu Jian, Poëzie als incident: gedichten van 1982 tot 1995 [Poetry as Incident: Poems from 1982 to 1995], translated by Jan A M De Meyer, Gent: Poëziecentrum: 5-9

De Roder, J H. 1999: Het schandaal van de poëzie [The Scandal of Poetry], Nijmegen: Vantilt / Wintertuin

DeFrancis, John (ed). 1996: ABC Chinese-English Dictionary, Honolulu: University of Hawai'i Press

Denton, Kirk A (ed). 1996: Modern Chinese Literary Thought: Writings on Literature, 18931945, Stanford: Stanford UP

1999: editor's note to Modern Chinese Literature and Culture 11-2

2003: "Literature and Politics: Mao Zedong's 'Talks at the Yan'an Forum on Art and Literature'," in Mostow et al 2003: 463-469

Duoyu 朵渔. 2000: 〈是干, 而不是搞〉 [It's Do, Not Make], in 《下半身》1: 114117

Duoduo 多多. 1989: Looking Out from Death: From the Cultural Revolution to Tiananmen Square, translated by Gregory Lee \& John Cayley, London: Bloomsbury 2005: 《多多诗选》 [Selected Poems by Duoduo], 广州: 花城 
Eagleton, Terry. 1996: Literary Theory: An Introduction, second, revised edition, Oxford: Blackwell

Easthope, Antony. 1983: Poetry as Discourse, London etc: Methuen

Edmond, Jacob. 2004: "Locating Global Resistance: The Landscape Poetics of Arkadii Drogomoshchenko, Lyn Hejinian and Yang Lian," in AUMLA: Fournal of the Australasian Universities Language \& Literature Association 101: 71-98

2005a: "Beyond Binaries: Rereading Yang Lian's 'Norlang' and 'Banpo'," in Fournal of Modern Literature in Chinese 6-1: 152-169

2005b: “Yang Lian and the Globalization of Poetry," paper presented at 中国 新诗: 百年国际研讨会 (北京大学、首都师范大学举办), 18-20 August 2005

2006: "Dissidence and Accommodation: The Publishing History of Yang Lian from Today to Today," in The China Quarterly 185: 111-127

_ 2008a: "A Poetics of Translocation: Yang Lian's Auckland and Lyn Hejinian's Leningrad," in Chris Prentice, Henry Johnson \& Vijay Devadas (eds), Cultural Transformations: Perspectives on Translocation in a Global Age, forthcoming

_ 2008b: "The Flâneur in Exile," unpublished manuscript

\& Chung, Hilary. 2006: "Yang Lian, Auckland and the Poetics of Exile," in Yang Lian 2006: 1-23

Edwards, Robert. 1988: "Exile, Self, and Society," in Lagos-Pope 1988: 15-31

Eliot, T S. 1990: "The Music of Poetry," in Eliot, On Poetry and Poets, London: Faber \& Faber: 28-38 (first published 1942)

Emerson, Andrew G. 2001: "The Guizhou Undercurrent," in Modern Chinese Literature and Culture 13-2: 111-133

2004: "Poet's Life - Hero's Life," in Huang Xiang, A Bilingual Edition of Poetry out of Communist China, translated by Andrew G Emerson, Lewiston etc: Edwin Mellen Press: 1-37

Eoyang, Eugene Chen. 1998: "Tianya, the Ends of the World or the Edge of Heaven: Comparative Literature at the Fin de Siècle," in Zhang Yingin 1998: 218-232, 280-282

Fang Xiang 方向. 1997: 《挽留: 方向詩集》 [Urge the Guest to Stay: Poems by Fang Xiang], edited by Xu Yi 胥七, 香港: 香港金陵書社

Ferry, Megan M. 2003: "Marketing Chinese Women Writers in the 1990s, or the Politics of Self-Fashioning," in Foumal of Contemporary China 12-37: 655-675

Findeisen, Raoul David. 1999: "Two Works-Hong (1930) and King'er (1993) as Indeterminate Joint Ventures," in Li Xia 1999: 135-178

Finkel, Donald (ed \& transl). 1991: A Splintered Mirror: Chinese Poetry from the Democracy Movement, with additional translations by Carolyn Kizer, San Francisco: North Point Press

Forrest-Thomson, Veronica. 1978: Poetic Artifice: A Theory of Twentieth-Century Poetry, Manchester: Manchester UP

Frye, Northrop. 1973: Anatomy of Criticism: Four Essays, Princeton: Princeton UP (first edition 1957) 1965: Northrop Frye, "Verse and Prose," in Preminger 1965: 885-890

Fu Mahuo 符马活 (ed). 2002:《诗江湖: 2001 网络诗歌年选: 先锋诗歌档案》 [Poetry Vagabonds: Selected Web Poetry from 2001: The Avant-Garde Poetry Files], 西宁: 青海人民

Gao Bo 高波. 2003: 《解读海子》 Interpreting Haizi], 昆明: 云南人民 2005: 《现代诗人和现代诗》 [Modern Poets and Modern Poetry], 昆明: 云 南／云南人民 
Gao Xingjian \& Yang Lian 高行健、杨炼. 1994: 〈漂泊使我们们获得了什么? 杨炼 $(\mathrm{Y})$ 和高行健 $(\mathrm{G})$ 的对话〉 [What Have We Gained from Wandering? A Dialogue of Yang Lian and Gao Xingjian], in Yang Lian \& Yo Yo 1994: 293-327 (reprinted in Yang Lian 1998b: 323-367; for German, Italian and [abridged] English translations, see Gao \& Yang 2001a, 2001b and 2002)

2001a: Was hat uns das Exil gebracht? Ein Gespräch zwischen Gao Xingïan und Yang Lian über chinesische Literatur [What Has Exile Brought Us? A Conversation on Chinese Literature between Gao Xingjian and Yang Lian], translated by Peter Hoffmann, Berlin: DAAD Berliner Künstlerprogramm

200 1b: Il pane dell'esilio: La letteratura cinese prima e dopo Tienanmen [The Bread of the Exile: Chinese Literature before and after Tiananmen], translated by Gianni Santamaria, Milan: Medusa

2002: "The Language of Exile: When Pain Turns to Gain," translated by Ben Carrdus, in Index on Censorship 31-3: 112-120

Ge Mai 戈麦. 1993:《彗星: 戈麦诗集》[Comet: Poems by Ge Mai], edited by Xi Du 西渡, 上海: 上海三连

C 1999: 《戈麦诗全编》[The Complete Poems of Ge Mai], edited by Xi Du 西 渡, 上海: 上海三连

Geng Zhanchun 耿占春. 1999: 〈没有故事的生活: 从王家新的《回答》看当代诗 学的叙事问题〉 [Life without a Story: Wang Jiaxin's «Answer» and the Question of Narrative in Contemporary Poetics], in 《当代作家评论》1999-6: 113-120 (reprinted in Geng 耿, 《中魔的镜子》[A Mirror Possessed], 上海: 学林, 2002: 232-248)

Gerbrandy, Piet. 1995: "Pindarus en free jazz, of: Hoe classificeer je poëzie?" [Pindar and Free Jazz, or: How Do You Classify Poetry?], in Hollands Maandblad 1995-4: $13-20$

1999: "De muur: over poëtica, pornografie en innerlijke noodzaak" [The Wall: On Poetics, Pornography and the Inner Urge], in Hollands Maandblad 199912: $25-31$

Glad, John (ed). 1990: Literature in Exile, Durham etc: Duke UP

Glazier, Loss Pequeño. 2002: Digital Poetics: The Making of E-Poetries, Tuscaloosa etc: University of Alabama Press

Golden, Séan \& Minford, John. 1990: "Yang Lian and the Chinese Tradition," in Howard Goldblatt (ed), Worlds Apart: Recent Chinese Writing and its Audiences, Armonk NY etc: M E Sharpe: 119-137

Gong Jingran \& Nie Zuoping 龚静染、聂作平 (eds). 2000: 《中国第4代诗人诗 选》[Selected Poems of China's $4^{\text {th }}$ Generation Poets], 成都: 四川文艺

Gu Cheng 顾城. 1995: 《顾城诗全编》 [The Complete Poems of Gu Cheng], edited by Gu Gong 顾工, 上海: 上海三连

2006: 《顾城》 [Gu Cheng], 北京: 人民文学

website: 《顾城之城》(online, see also p475)

Gu Xiang 顾乡. 1994: 《我面对的顾城最后十四天》 [Gu Cheng's Final Fourteen Days as I Faced Them], 北京: 国际文化

Gui Xinghua 桂兴华. 2002: 《青春宣言》 [Manifesto of Youth], 上海: 上海人民

Guo Xiaochuan 郭小川. 1985: 《郭小川诗选》 [Selected Poems by Guo Xiaochuan], 共二册, 北京: 人民文学

Haft, Lloyd (ed). 1989: A Selective Guide to Chinese Literature, 1900-1949: Volume III: The Poem, Leiden etc: Brill 2000: The Chinese Sonnet: Meanings of a Form, Leiden: CNWS

Haizi 海子. 1990:《土地》[The Land], 沈阳: 春风文艺 
1995: 《海子的诗》 [The Poetry of Haizi], edited by Xi Chuan 西川, 北京:

人民文学 (republished with minor changes as Haizi 2006)

1997: 《海子诗全编》 [The Complete Poems of Haizi], edited by Xi Chuan 西川, 上海: 上海三连

2005: Haizi, An English Translation of Poems of the Contemporary Chinese Poet Hai Zi, translated by Zeng Hong, Lewiston etc: Edwin Mellen Press 2006: 《海子》[Haizi], 北京: 人民文学 ( $\approx$ Haizi 1995, with minor changes) \& Luo Yihe 骆一禾. 1991: 《海子、骆一禾作品集》[Works by Haizi and

Luo Yihe], edited by Zhou Jun \& Zhang Wei 周骏、张维, 南京: 南京

— \& Xi Chuan 西川. 1986:《麦地之翁》[Lord of the Wheatfields], 北京 (unofficial publication)

- website: 《海子 1989》 (online, see also p475)

Han Dong 韩东. 1986: 〈青年诗人谈诗: 韩东〉 [Young Poets on Poetry: Han Dong], in《诗刊》1986-11: 29 51 1988: 〈奇迹和根据〉 [Miracles and Foundations], in 《诗刊》1988-3: 50-

4: $18-20$

- 1991:〈海子: 行动〉 [Haizi: The Act], in Haizi \& Luo 1991: 335-336

1992a: 《白色的石头》 [White Stones], 上海: 上海文艺

1992b: (韓東) 〈《他們》, 人和事〉 [The Life and Times of Them], in 《今

天》1992-2: 188-200 (excerpted as 〈《他们》略说〉 [A Few Words on Them ] in《诗探索》1994-1: 159-162)

1995:〈关于诗歌的十条格言或语录〉 [Ten Aphorisms or Sayings on Poetry], in 《他们》9: 85-86 $35-41$

1996: 〈从我的阅读开始〉 [Starting from My Reading], in Wan Zhi 1997a: - 1997: 〈关于诗歌的两千字〉 [Two Thousand Words on Poetry], in《广西 文学》1997-9: 54

1998a:〈韩东论诗〉 [Han Dong on Poetry], in 《诗歌报月刊》1998-2: 6

1998b:〈我的文学宣言〉 [My Literary Manifesto], in 《文友》1998-9: 15

1998c: 〈备忘: 有关 “断裂” 行为的问题〉 [Memorandum: Questions Concerning the "Rupture" Action], in 《北京文学》1998-10: 41-47

1999:〈论民间〉[On the Popular], in He Xiaozhu 何小竹 (ed), 《1999中国 诗年选》 [Selected Chinese Poems of 1999], 西安: 陕西师范大学: 1-18

2002: 《爸爸在天上看我》 [Daddy's Watching Me in Heaven], 石家庄: 河 北教育

2007: “Ten Maxims or Utterances Concerning Poetry," translated by Simon Patton, Poetry International Web $\rightarrow$ China $\rightarrow$ All Articles of China (online, see also $\mathrm{p} 475)$

＆ Chang Li 常立. 2003: 〈关于 “他们” 及其它: 韩东访谈录〉 [On “Them” and Other Things: An Interview with Han Dong], in 《他们论坛》, 26 August 2003: 斑驳文学网 (online, see also p475)

\& \& Liu Ligan \& Zhu Wen 刘立杆、朱文. 1994: 〈韩东采访录〉 [An Interview with Han Dong], in 《他们》7: 113-123 (excerpted in《诗探索》1996-3: 124129)

- \& Malingshu Xiongdi 马铃薯兄弟. 2004:〈访问韩东〉 [An Interview with Han Dong], in 《中国诗人》2004-1: 98-103

\& Yang Li 杨黎. 2004: 〈韩东访谈〉 [An Interview with Han Dong], in Yang Li 2004: 284-311

\& Z Z hu Wen 朱文. 1993: 〈古闸笔谈〉 [Brushtalk at the Old Sluice], in《作 家》1993-4: 68-73 
Hanne, Michael (ed). 2004: Creativity in Exile, Amsterdam etc: Rodopi

Hartman, Charles. 1986: "Poetry," in William H Nienhauser Jr with Charles Hartman, Y W Ma, Stephen H West (eds), The Indiana Companion to Traditional Chinese Literature, Bloomington: Indiana UP: 59-74

Hawkes, David. 1985: "General Introduction," in The Songs of the South: An Ancient Anthology of Chinese Poems by Qu Yuan and Other Poets, translated by David Hawkes, revised edition, Harmondsworth etc: Penguin

2007: "The Poetry of Liu Hongbin," MCLC Resource Center $\rightarrow$ Publications (online, see also p475)

He Jingzhi 贺敬之. 1979: 《贺敬之诗选》 [Selected Poems by He Jingzhi], 济南: 山 东人民

$\mathrm{He} \mathrm{Yi}$ 贺奕. 1994: 〈九十年代的诗歌事故: 评长诗《0档案》〉 [An Accident in Poetry of the Nineties: A Review of the Long Poem «File 0»], in《大家》1994-1: 59-65

He Yuhuai. 1992: Cycles of Repression and Relaxation: Politico-Literary Events in China 19761989, Bochum: Brockmeyer

Herman, Luc \& Vervaeck, Bart. 2001: Vertelduivels: handboek verhaalanalyse [Narradevils: A Handbook of Narratological Analysis], Nijmegen: Vantilt / VUB Press

Hirsch, Charlotte. 2007: "37०8 - Erhöhte Temperatur": Selbstdarstellung und-reflektion einer neuen Generation am Beispiel der Bloggerin Yin Lichuan [“37ㅇ- A Slight Temperature": Self-Representation and Self-Reflection of a New Generation: A Case Study of Yin Lichuan, Bloggeress], MA thesis, Universität Hamburg

Hockx, Michel (ed). 1999: The Literary Field of Twentieth-Century China, Richmond: Curzon

2000: "Liu Bannong and the Forms of New Poetry," in Fournal of Modern Literature in Chinese 3-2: 83-117

2003: Questions of Style: Literary Societies and Literary Fournals in Modern China, 1911-1937, Leiden etc: Brill

_ 2004: "Links With the Past: Mainland China's Online Literary Communities and Their Antecedents," in Fournal of Contemporary China, 13-38: 105-127

2005: "Virtual Chinese Literature: A Comparative Case Study of Online Poetry Communities," in The China Quarterly 183: 670-691

Hoffmann, Hans Peter. 1993: Gu Cheng: eine dekonstruktive Studie zur Menglong-Lyrik [Gu Cheng: A Deconstructive Study of Menglong Poetry], vols I-II, Frankfurt am Main etc: Peter Lang

Holton, Brian. 1994: "Translator's Afterword," in Yang Lian 1994b: 119-127

1999: "Translating Yang Lian," in Yang Lian 1999: 173-191

Hong. 1998: Hong Zicheng 洪子诚, 〈九十年代文学书系总序〉 [Literature of the Nineties, Foreword to the Series], in Cheng Guangwei 1998a: 1-9

2001: 《20世纪中国文学研究: 当代文学研究》 Research on $20^{\text {th }}$-Century Chinese Literature: The Contemporary Era], 北京: 北京

- (ed). 2002: 《在北大课堂读诗》[Reading Poetry in the Classroom at Peking University], 武汉: 长江文艺

— \& Liu Denghan 刘登翰. 2005: 《中国当代新诗史》 [A History of China's Contemporary New Poetry], 北京: 北京大学 (revised edition; first edition 1993) \& Meng Fanhua 孟繁华 (eds). 2002: 《当代文学关键词》[Keywords in Contemporary Literature], 桂林: 广西师范大学

Hsu Kai-yu. 1975: The Chinese Literary Scene: A Writer's Visit to the People's Republic, New York: Vintage Books

Hu Shi. 1996: "Some Modest Proposals for the Reform of Literature," translated by Kirk A Denton, in Denton 1996: 123-139

Hu Tingwu 胡廷武. 2004:〈序〉 [Preface], in Yu Jian 2004a: 1-11 
$\mathrm{Hu}$ Xudong 胡续冬. 2005: 〈脱下隐身衣之后的诗歌: 2000 年以来 “诗歌生态” 的 一个侧面〉 [A Poetry That Sheds the Garb Which Makes It Invisible: A Profile of the “Poetry Ecology" since 2000], paper presented at 中国新诗: 百年国际研讨 会 (北京大学、首都师范大学举办), 18-20 August 2005

$\mathrm{Hu}$ Yan 胡彦. 1995: 〈于坚与诗的本质〉 [Yu Jian and the Essence of Poetry], in《诗探索》1995-2: 142-147

Huang Liang 黄粱. 1999: 〈文化与自然的本质对话: 纵论于坚诗篇的朴质理想〉 [An Essential Dialogue of Culture and Nature: A Broad Discussion of Yu Jian's Ideal of Simplicity], in 《当代作家评论》1999-4: 67-70 (originally the preface to Yu Jian 1999a)

Huang Lifang 黄黎方 (ed). 1994: 《朦胧诗人顾城之死》[The Death of Obscure Poet Gu Cheng], 广州: 花城

Huang Lihai 黄礼孩 (ed). 2001: 《’70后诗人诗选》 [Selected Poems by Post-70 Poets], 福州: 海风

Huang Xiang 黄翔. 2005: 〈流亡游戏: 质疑所谓 “反对派” 并对 “异议者”持异议〉 [The Exile Game: Challenging the So-Called "Oppositionists" and Dissenting from the “Dissenters"], 博讯文坛 $\rightarrow$ 独立中文作家笔会 $\rightarrow$ 黄翔文集 (online, see also p475)

Huang Yibing. 2007a: Contemporary Chinese Literature: From the Cultural Revolution to the Future, New York: Palgrave Macmillan

2007b: "The Ghost Enters the City: Gu Cheng's Metamorphosis in the 'New World'," in Lupke 2007: 123-143 and 219-232

Huang Yunte. 2002: Transpacific Displacement: Ethnography, Translation, and Intertextual Travel in Twentieth-Century American Literature, Berkeley etc: University of California Press

Huanglin 荒林. 1998: 〈当代中国诗歌批评反思: “后新诗潮” 研讨会纪要〉 Reflections on Contemporary Chinese Poetry Criticism: A Report on the Seminar on "Post-New Tide Poetry"], in 《诗探索》1998-2: 73-82

Huot, Claire. 1999: "Here, There, Anywhere: Networking by Yong Chinese Writers Today," in Hockx 1999: 198-215

2000: China's New Cultural Scene: A Handbook of Changes, Durham etc: Duke UP

Idema, Wilt \& Grant, Beata. 2004: The Red Brush: Writing Women in Imperial China, Cambridge MA etc: Harvard UP

_ \& Haft, Lloyd. 1997: A Guide to Chinese Literature, Ann Arbor: Center for Chinese Studies, University of Michigan

Inwood, Heather. 2008: On the Scene of Contemporary Chinese Poetry, PhD thesis, School of Oriental \& African Studies, University of London

Jakobson, Roman. 1960: "Closing Statement: Poetics and Linguistics," in Thomas Sebeok (ed), Style in Language, Cambridge MA: MIT Press

Jameson, Fredric. 1991: Postmodernism, or, the Cultural Logic of Late Capitalism, London etc: Verso

Janssen, Ronald R. 2002: "What History Cannot Write: Bei Dao and Recent Chinese Poetry," in Critical Asian Studies 34-2: 259-277

Jenner, WJ F. 1990: review of Bei Dao 1988, in The Australian Fournal of Chinese Affairs 23: 193-195

Jiang Keping 江克平: see Crespi, John

Jiang Ruoshui 江弱水. 1997: 〈孤獨的舞蹈〉 [A Lonely Dance], in 《傾向》10: 2130

Jiang Xi \& Wan Xiang 江熙、万象. 1995: 《灵魂之路: 顾城的一生》 $[\operatorname{Road}$ of the Soul: The Life of Gu Cheng], 北京: 中国人事 
Jiangjiang 江江. 1990:〈詩的放逐與放逐的詩〉 [The Banishment of Poetry and the Poetry of Banishment], in 《今天》1990-2: 68-75

Jin Han 金汉 (ed). 2002: 《中国当代文学发展史》 [A History of the Development of Contemporary Chinese Literature], 上海: 上海文艺

Jingbute 京不特. 1998: 〈從主流文化下的奴隸到一個獨立的個體人: 回憶八十年 代上海的地下文化〉 [From Slave to Mainstream Culture to Independent Individual Person: A Recollection of Shanghai Underground Culture in the Eighties], in 《傾向》11: 226-247

Jones, Andrew. 1994: "Chinese Literature in the "World' Literary Economy," in Modern Chinese Literature 8-1/2: 171-190

Kaldis, Nicholas. 2000: "The Prose Poem as Aesthetic Cognition: Lu Xun's Yecao," in Fournal of Modern Literature in Chinese 3-2: 43-82

Knight, Deirdre Sabina. 2003a: "Scar Literature and the Memory of Trauma," in Mostow et al 2003: 527-532

2003b: "Shanghai Cosmopolitan: Class, Gender and Cultural Citizenship in Weihui's Shanghai Babe," in Fournal of Contemporary China 12-37: 639-653

Kong Shuyu. 2005: Consuming Literature: Best Sellers and the Commercialization of Literary Production in Contemporary China, Stanford: Stanford UP

Kramer, Oliver: see Krämer, Oliver

Krämer, Oliver. 1999: Oliver Krämer, "No Past to Long For? A Sociology of Chinese Writers in Exile," in Hockx 1999: 161-177

2002: Heinz Oliver Kramer (Oliver Krämer), Chinese Fiction Abroad: The Exilic Nature of Works Written by Chinese Writers Living Abroad after the Tiananmen Massacre, $\mathrm{PhD}$ thesis, University of Edinburgh

Krol, Gerrit. 1982: Het vrije vers [Free Verse], Amsterdam: Querido

Kubin, Wolfgang. 1993: "The End of the Prophet: Chinese Poetry between Modernity and Postmodernity," in Wendy Larson \& Anne Wedell-Wedellsborg (eds), Inside Out: Modernism and Postmodernism in Chinese Literary Culture, Aarhus: Aarhus UP: 1937

Lagos-Pope, María-Inés (ed). 1988: Exile in Literature, Lewisburg: Bucknell UP / London etc: Associated University Presses

Lan Dizhi 蓝棣之. 1994: 〈西川诗二首评点〉 [Comments on Two of Xi Chuan's Poems], in 《诗探索》1994-2: 85-91

Lao Mu 老木 (ed). 1985a:《新诗潮诗集》[A Collection of New Tide Poetry], 共二 册, 北京: 北京大学五四文学社 (内部交流) (semi-official publication)

- (ed) 1985b:《青年诗人谈诗》[Young Poets on Poetry], 北京: 北京大学五 四文学社

Larson, Wendy. 1989: "Realism, Modernism and the Anti-'Spiritual Pollution' Campaign in China," in Modern China 15-1: 37-71

1999: "Never This Wild: Sexing the Cultural Revolution," in Modern China 25-4: 423-450

Lee, Gregory B (ed). 1993a: Chinese Writing and Exile, Chicago: The Center for East Asian Studies, University of Chicago

1993b: "Contemporary Chinese Poetry, Exile and the Potential of Modernism," in Lee (Gregory) 1993a: 55-77 (revised as Lee [Gregory] 1996: ch 5)

1996: Troubadours, Trumpeters, Troubled Makers: Lyricism, Nationalism, and Hybridity in China and Its Others, London: Hurst

Lee, Leo Ou-fan. 1973: The Romantic Generation of Modern Chinese Writers, Cambridge MA etc: Harvard UP 
1991: "On the Margins of the Chinese Discourse: Some Personal Thoughts on the Cultural Meaning of the Periphery," in Dedalus 120-2: 207-226 (reprinted in Lee [Gregory] 1993a: 1-18, and in Tu 1994: 221-238)

1995: Li Ou-fan 李欧凡, 〈既亲又疏的距离感〉 [An Intimate Yet Strange Sense of Distance], in Bei Dao 1995: 9-22

Lee, Mabel. 1990: "Introduction: The Philosophy of the Self and Yang Lian," in Yang Lian, Masks and Crocodile: A Contemporary Chinese Poet and His Poetry, translated by Lee, Sydney: University of Sydney East Asian Series: 9-36

1993: "Before Tradition: The Book of Changes and Yang Lian's $\$$ and the Affirmation of the Self Through Poetry," in Lee \& A D Syrokomla-Stefanowska (eds), Modernization of the Chinese Past, Sydney: Wild Peony, 1993: 94-106

Levie, Sophie. 2004: "Biografisme: een nieuwe plaats voor de auteur in de literatuurwetenschap?" [Biographism: A New Place for the Author in Literary Studies?], in Jaarboek van de Maatschappï der Nederlandse Letterkunde te Leiden, 2002-2003 [Yearbook of the Society of Dutch Literary Studies, 2002-2003], Leiden: Maatschappij der Nederlandse Letterkunde: 43-60

Leys, Simon. 1978: "Introduction," in Chen Jo-hsi, The Execution of Mayor Yin and Other Stories from the Great Proletarian Cultural Revolution, Bloomington etc: Indiana UP

Li Chao 李超. 1999: 〈形而上死〉 [Metaphysical Death], in Cui 1999a: 54-61 (dated 1992)

Li Dian. 2006: The Chinese Poetry of Bei Dao, 1978-2000: Resistance and Exile, Lewiston etc: Edwin Mellen Press

2007: "Naming and Anti-Naming: Poetic Debates in Contemporary China," in Lupke 2007: 185-200 and 219-232

Li Fukang \& Hung, Eva. 1992: "Post-Misty Poetry," in Renditions 37: 92-148

$\mathrm{Li} \mathrm{Ji}$ 李季. 1982: 《李季文集》[Collected Works of Li Ji], 共三册, 上海：上海文艺

Li Lizhong et al (eds). 1990: Li Lizhong, Zhang Lei \& Zhang Xu 李丽中、张雷、 张旭，《朦胧诗后：中国先锋诗选》 [After Obscure Poetry: Selected Chinese Avant-Garde Poems], 天津: 南开大学

Li Ou-fan 李欧凡: see Lee, Leo Ou-fan

Li Runxia 李润霞. 2004: 〈从历史深处走来的诗兽: 论黄翔在文革时期的地下 诗歌创作〉 [Poetry Beast Come Forth from the Depths of History: On Huang Xiang's Underground Poetry Writing during the Cultural Revolution], in 《蓝》2004-1: 133-147

2008: (李潤霞)《亂世潛流: 文化大革命時期的地下詩歌研究》 Undercurrent in a World in Turmoil: A Study of Underground Poetry during the Cultural Revolution], 台北: 台灣秀威, forthcoming

Li Shaojun 李少君. 1998: 〈现时性: 九十年代诗歌写作中的一种倾向〉 [Contemporeality: A Trend in Poetry Writing of the Nineties], in 《山花》1998-5: 82-86, 9

Li Xia (ed). 1999: Essays, Interviewes, Recollections and Unpublished Material of Gu Cheng, Twentieth-Century Chinese Poet: The Poetics of Death, Lewiston etc: Edwin Mellen Press

Li Xinyu 李新宇. 2000: 《中国当代诗歌艺术演变史》[An Evolutionary History of the Art of Contemporary Chinese Poetry], 杭州: 浙江大学

Li Yawei 李亚伟. 2006: 《豪猪的诗篇》 [Porcupine Poetry Writings], 广州: 花城

Li Zhen 李震. 1994: 〈神话写作与反神话写作〉 [Mythical Writing and Anti-Mythical Writing], in 《诗探索》1994-2: 4-17

1995: 〈伊沙: 边缘或开端一神话 / 反神话写作的一个案例〉 [YiSha: Margins or Beginnings - A Case Study of Mythical / Anti-Mythical Writing], in 《诗 探索》1995-3: 90-99

_ 2001a:《母语诗学纲要》[Mother-Tongue Poetics: An Outline], 西安: 三秦 $2001 \mathrm{~b}$ : 〈先锋诗歌的前因后果与我的立场〉 [The Ramifications of Avant- 
Garde Poetry and My Standpoint], in Yang Ke 杨克 (ed), 《2000中国新诗年 鉴》 [2000 Yearbook of China's New Poetry], 广州: 广州: 596-604

Liao Yiwu 廖亦武 (ed). 1999:《沉沦的圣殿: 中国二十世纪70年代地下诗歌遗 照》 [Sunken Temple: China's Underground Poetry in the 70s of the Twentieth Century, a Portrait of Things Gone By], 乌鲁木齐: 新疆青少年

Liaoyuan 燎原. 1991: 〈孪生的麦地之子〉 [Twin Sons of the Wheatfields], in Haizi \& Luo 1991: 347-355 (dated 1989)

2001: 《扑向太阳之豹: 海子评传》 [Leopard Pouncing at the Sun: A Critical Biography of Haizi], 海口: 南海

Lin Kehuan 林克歡. 1995: 〈成熟的生命與冰冷的世界〉 [Mature Life and an IceCold World], in 《現代詩》23: 20-21

Lin Xingqian 林幸謙. 2001: 〈當代中國流亡詩人與詩的流亡: 海外流放詩體的一 種閱讀〉[Contemporary China's Exile Poets and Poetry's Exile: Reading a Style of Poetry Banished Overseas], in 《中外文學》30-1: 33-64

Lin Yiliang 林以亮. 1976: 《林以亮詩話》 [Lin Yiliang's Poetry Talk], 台北: 洪範

Link, Perry. 1993: "Ideology and Theory in the Study of Modern Chinese Literature," in Modern China 19-1: 4-12

2000: The Uses of Literature: Life in the Socialist Chinese Literary System, Princeton: Princeton UP

2002: "The Anaconda in the Chandelier," in The New York Review of Books, 11 April 2002: 67-70

Liu Binyan \& Link, Perry. 1998: “A Great Leap Backward?”, review of He Qinglian 何清漣, 《中國的陷阱》[China's Pitfall], in The New Tork Review of Books, 8 October 1998: 19-22

Liu Fuchun 刘福春. 2004: 《新诗纪事》 [A Chronicle of New Poetry], 北京: 学苑

Liu He 劉禾 (ed). 2001: 《持燈的使者》[The Lamp-Bearing Messenger], 香港 etc: Oxford UP

Liu, James J Y. 1975: Chinese Theories of Literature, Chicago etc: University of Chicago Press

Liu, Melinda. 2004: “The Avant-Garde Art Goes Too Far?", in China Daily, 2 August 2004 (online, see also p475)

Liu Na 刘纳. 1994: 〈西川诗存在的意义〉 [The Significance of the Existence of Xi Chuan's Poetry], in 《诗探索》1994-2: 75-84

Liu Shijie 刘士杰. 1999: 《走向边缘的诗神》[The God of Poetry, Moving toward the Margins], 太原: 山西教育

Liu Shuyuan 刘树元 (ed). 2005: 《中国现当代诗歌赏析》 [Appreciations of Modern and Contemporary Chinese Poetry], 杭州: 浙江大学

Liu Tao Tao. 2001: "Exile, Homesickness and Displacement in Modern Chinese Literature," in Wolfgang Kubin (ed), Symbols of Anguish: In Search of Melancholy in China, Bern: Peter Lang: 335-351

Lovell, Julia. 2002: "Misty in Roots: Chinese Poetry after Mao," in Poetry Review 92-3: 64-68

2006: The Politics of Cultural Capital: China's Quest for a Nobel Prize in Literature, Honolulu: Hawai'i UP

Lu Jie. 2004: "Rewriting Beijing: A Spectacular City in Qiu Huadong's Urban Fiction," in Fournal of Contemporary China 13-39: 323-338

Lu Xun. 1996: "On the Power of Mara Poetry," translated by Shu-ying Tsau and Donald Holoch, in Denton 1996: 96-109

Lü Zhouju 吕周聚. 2001: 《中国当代先锋诗歌研究》[A Study of Contemporary Chinese Avant-Garde Poetry], 北京: 中国广播电视

Luo Gaolin 罗高林. 1996:《邓小平》 [Deng Xiaoping], 北京: 作家 
Luo Yihe 骆一禾. 1990: 〈“我考虑真正的史诗”〉 [“I Contemplate the True Epic”], in Haizi 1990: 1-10 (dated 1989) 1997a:〈海子生涯〉[Haizi’s Career], in Haizi 1997: 1-5 (dated 1989) 1997b: 《骆一禾诗全编》[The Complete Poems of Luo Yihe], edited by Zhang $\mathrm{Fu}$ 张玞, 上海: 上海三连

Luo Zhenya 罗振亚. 2002: 《中国现代主义诗歌史论》 [On the History of Chinese Modernist Poetry], 北京: 社会科学文献

- 2005: 《朦胧诗后先锋诗歌研究》 [A Study of the Avant-Garde after Obscure Poetry], 北京: 中国社会科学

Lupke, Chris (ed). 2007: New Perspectives on Contemporary Chinese Poetry, New York: Palgrave MacMillan

Lyne, Sandra. 2002: “Consuming Madame Chrysanthème: Loti's 'Dolls' to Shanghai Baby," in Intersections: Gender, History \& Culture in the Asian Context 8 (online, see also p475)

Ma Ce 马策. 2001: 〈诗歌之死: 主要是对狂奔在 “牛B” 路上的 “下半身” 诗歌 团体的必要警惕〉 [The Death of Poetry: First of All, on the Need to Guard against the "Lower Body" Poetry Group Running Wild on a "Crash-Hot" Road], in《芙蓉》2001-2: 141-145

Maas, Michel. 1995: "Een postpostduistere dichter over de grenzen" [A Post-PostObscure Poet Crossing Borders], in De Volkskrant, 22 June 1995

MacLeish, Archibald. 1985: Collected Poems, 1917-1982, Boston: Houghton Mifflin

Mai Tong \& Xiaomin 麦童、晓敏. 1994: 《利斧下的童话》 [A Fairy Tale under the Axe], 上海: 上海三联

Mallarmé, Stéphane. 1935: Vers et prose: morceaux choisis [Verse and Prose: Selected Pieces], Paris: Librairie Académique Perrin

Malmqvist, Göran. 1983: "On the Emergence of Modernistic Poetry in China," in Museum of Far Eastern Antiquities, Bulletin 55: 57-69

Mang Ke 芒克. 1988: 《阳光中的向日葵》[Sunflower in the Sun], 桂林: 漓江 -2003: 《燋! 这些人》 [Look at Them All!], 长春: 时代文艺

MaoJian 冒键. 2005: 《最后的神话: 诗人自杀之谜》 [The Last Myth: The Riddle of the Poet's Suicide], 银川: 宁夏人民

Mao Tse-tung. 1967: Selected Works of Mao Tse-tung, vols I-V, Beijing: Foreign Languages Press

Martin, Helmut. 1973: "A Transitional Concept of Chinese Literature 1897-1917: Liang Ch'i-ch'ao on Poetry-Reform, Historical Drama and the Political Novel," in Oriens Extremus 20-2: 175-217

McDougall, Bonnie S. 1980: Mao Zedong's 'Talks at the Yan'an Conference on Literature and Art": A Translation of the 1943 Text with Commentary, Ann Arbor: University of Michigan, Center for Chinese Studies

1985: "Bei Dao's poetry: Revelation \& Communication," in Modern Chinese Literature 1-2: 225-252

1993: "Censorship \& Self-Censorship in Contemporary Chinese Literature," in Susan Whitfield (ed): After The Event: Human Rights and Their Future in China, London: Wellsweep: 73-90 2003: Fictional Authors, Imaginary Audiences: Modern Chinese Literature in the Twentieth Century, Hong Kong: The Chinese University Press

\& Louie, Kam. 1997: The Literature of China in the Twentieth Century, London: Hurst

Meng Lang 孟浪. 2005: 〈必要的丧失: 一九八九后的中国流亡文学〉 [Necessary Loss: Chinese Exile Literature since 1989], 博讯文坛 $\rightarrow$ 独立中文作家笔会 $\rightarrow$ 孟浪作品选编 (online, see also p475) 
Mi Jiayan. 2007: "Poetics of Navigation: River Lyricism, Epic Consciousness and the Post-Mao Sublime Poemscape," in Modern Chinese Literature \& Culture 19-1: 91-137

Mian Mian 棉棉. 2000: 《糖》[Candy], 北京: 中国戏剧

Michaud, Guy. 1953: Mallarmé: L'homme et l'œuvre [Mallarmé: The Man and the Works], Paris: Hatier-Bovin

Morewedge, Rosemarie T. 1988: "Exile in Heinrich Boell's Novel: Billiards at Half Past Nine," in Lagos-Pope 1988: 102-120

Morin, Edward (ed). 1990: The Red Azalea: Chinese Poetry since the Cultural Revolution, translated by Fang Dai, Dennis Ding \& Edward Morin, Honolulu: University of Hawai'i Press

Mostow et al (eds). 2003: Joshua Mostow with Kirk A Denton, Bruce Fulton \& Sharalyn Orbaugh: The Columbia Companion to Modern East Asian Literature, New York: Columbia UP

Nijhoff, Martinus. 1978: Verzamelde gedichten [Collected Poems], Amsterdam: Bert Bakker

Oosterhoff, Tonnus. 2006: "Wat er staat als er niets staat" [What It Says When It Says Nothing], review of Yra van Dijk, Leegte, leegte die ademt: Het typografisch wit in de moderne poëzie [Emptiness, Emptiness That Breathes: Typographical White in Modern Poetry], in NRC Handelsblad, 27 October 2006: 27

Ouyang Jianghe 欧阳江河. 1993a: (歐陽江河)〈89 後國內詩歌寫作: 本土氣質, 中年特徵與知識份子身份〉 [Writing Poetry inside China after '89: Indigenous Disposition, the Marks of Middle Age and Being an Intellectual], in 《今天》 1993-3: 176-198 (reprinted in domestic publications such as Wang Jiaxin \& Sun 2000: 181-200 and Chen Chao 2003: 165-185)

1993b: (歐陽江河) 〈另一種閱讀〉 [Another Kind of Reading], in《今 天》1993-4: 228-238

1996a: (歐陽江河)〈初醒時的孤獨: 序《零度以上的風景》〉[Awaken to Loneliness: Preface to Landscape over Zero], in Bei Dao 北島, 《零度以上的風景: 北島 1993-1996》 [Landscape over Zero: Bei Dao, 1993-1996], 台北: 九歌, 1996: 7-35 (reprinted as 〈北岛诗的三种读法〉 [Three Ways of Reading Bei Dao's Poetry] in Ouyang 欧阳, 《站在虚构这边》 [Side with the Fictitious], 北京: 三 联, 2001: 187-210

- 1996b: (歐陽江河)〈當代詩歌的昇華及其限制〉[Contemporary Poetry's Sublimation and Its Limitations], in 《今天》1996-3: 157-170

- 1997: 《谁去谁留》[Who Leaves and Who Stays], 长沙: 湖南文艺

Oversteegen, J J. 1983: "Analyse en oordeel" [Analysis and Assessment], in Oversteegen, De Novembristen van Merlyn: een literatuuropvatting in theorie en praktijk [The Novembrists of Merlyn: A View of Literature in Theory and Practice], Utrecht: HES: 15-71 (first published 1965)

Owen, Stephen. 1979: "Transparencies: Reading the T'ang Lyric," in The Harvard Fournal of Asiatic Studies 39-2: 231-251

1990: "What Is World Poetry? The Anxiety of Global Influence," in The New Republic, 19 November 1990: 28-32

1992: Readings in Chinese Literary Thought, Cambridge MA etc: Harvard UP 2003: "Stepping Forward and Back: Issues and Possibilities for 'World' Poetry," in Modern Philology 100-4: 532-548

Patton, Simon. 1994: A Poetics of Wubuwei: Two Texts by Gu Cheng, PhD thesis, University of Melbourne 
1995a: review of Bei Dao 1994, in Modern Chinese Literature 9-1: 139-145

1995b: review of Yang Lian 1994b, in World Literature Today 69-4: 871

1998: "Raindrops and Bottle Tops: An Introduction to Chinese Poetry in the 1990s," paper presented at the Chinese University of Hong Kong, 10 November 1998

2003a: "On Yu Jian's «Afternoon A Colleague Walking in Shadow»," in Cipher Fournal (online, see also p475)

2003b: "Yu Jian," Poetry International Web $\rightarrow$ China (online, date provided by Poetry International secretariat; see also p475)

2006: "Han Dong," Poetry International Web $\rightarrow$ China (online, date provided by Poetry International secretariat; see also p475)

Perelman, Bob. 1996: The Marginalization of Poetry: Language Writing and Literary History, Princeton: Princeton UP

Perloff, Marjorie. 1996: The Dance of the Intellect: Studies in the Poetry of the Pound Tradition, Evanston: Northwestern UP (first edition 1985)

1999: The Poetics of Indeterminacy: Rimbaud to Cage, Evanston: Northwestern UP, (first edition 1981)

Poe, Edgar Allan. 1973: The Portable Poe, edited by Philip Van Doren Stern, New York: Penguin

Pollard, D E. 1985: “The Controversy over Modernism 1979-1984," in The China Quarterly 104: 641-656

Porter, Peter. 2007: "Introduction: A Day within Days by Liu Hongbin," MCLC Resource Center $\rightarrow$ Publications (online, see also p475)

Preminger, Alex (ed). 1965: Encyclopedia of Poetry and Poetics, Princeton: Princeton UP

Qin Bazi 秦巴子. 1999:〈海子批判: 史诗神话的破灭〉 [Criticizing Haizi: Shattering the Myth of the Epic], in Yi et al 2001: 225-252.

Renminwang 人民網. 2006:〈十年間從人們嘴邊消失的49個老詞〉[Forty-Nine Old Words That Have Disappeared from People's Lips in the Last Ten Years], 人民網 $\rightarrow$ 文化 $\rightarrow$ 新聞, 15 September 2006 (online, see also p475)

Robb, Graham. 2000: Rimbaud, London etc: Picador

Safran, William. 1991: "Diasporas in Modern Societies: Myths of Homeland and Return," in Diaspora 1-1: 83-99

Said, Edward W. 1984: "The Mind of Winter: Reflections on Life in Exile," in Harper's 269: 49-55

2001: "Reflections on Exile," in Said, Reflections on Exile and Other Literary and Cultural Essays, London: Granta Books: 173-186 (revised and expanded edition of Said 1984)

Saussy, Haun. 1999: "Bei Dao and his Audiences," Stanford Presidential Lectures in the Humanities and Arts (online, see also p475)

Schneider, Laurence A. 1980: A Madman of Ch'u: The Chinese Myth of Loyalty and Dissent, Berkeley etc: The University of California Press

Shang Zhongmin 尚仲敏. 1988: 〈反对现代派〉 [Against the Modernists], in Wu Sijing 1993: 228-235

Shanghai Literature \& Art Press 上海文艺出版社 (ed). 1986:《探索诗集》 [A Collection of Explorative Poems], 上海: 上海文艺

Shen Haobo 沈浩波. 1999: 〈后口语写作在当下的可能性〉 [The Possibilities of Post-Colloquial Writing in the Here-and-Now], in 《诗探索》1999-4: 34-42

— 2001a:《一把好乳》 [A Handful of Tit], 北京 (unofficial publication) - 2001b: 《我要先锋到死! 在 “中国南岳九十年代汉语诗歌研究论坛” 上的 
发言〉 [Avant-Garde unto Death! Speech at the "Nanyue Forum for the Study of Poetry of the Nineties in Chinese"], in 《原创性写作》2: 30-34

- 2002: 〈下半身阿下半身〉 [Lower Body Oh Lower Body], in 《蓝》6: 98101

2004: 《心藏大恶》 [Great Evil Hidden in the Heart], 大连: 大连

\& Yin Lichuan 沈浩波、尹丽川. 2001:〈实话实说 “下半身”〉 [Straight Talk on the "Lower Body"], in 《诗江湖》1: 69-73

Shen Qi 沈奇 (comp). 1995: 〈对《0档案》发言〉 [Statements on «File 0»], in 《诗 探索》1995-2: 155-156

- 1996: 《詩是什麼: 20世紀中國詩人如是說 (當代大陸卷)》[What Is Poetry: Views of $20^{\mathrm{th}}$-Century Chinese Poets (Contemporary Mainland Volume)], 台北: 爾雅

Shi Jile 释极乐 (ed). 1982: 《次生林》 [Born-Again Forest], 成都 (unofficial publication; pseudonym of Zhong Ming)

Shikan she 诗刊社. 1998: 〈中国诗歌现状调查〉 [Investigation into the Current State of Chinese Poetry], in 《诗刊》1998-9: 4-8

Shizhi 食指. 2006:《食指》[Shizhi], 北京: 人民文学

Shu Ting 舒婷. 1982: 《双桅船》[Two-Master], 上海: 上海文艺

Simon, John. 1965: "Prose Poem," in Preminger 1965: 664-666

1987: The Prose Poem as a Genre in Nineteenth-Century European Literature, New York etc: Garland

Song Lin 宋琳. 2002: 〈主導的迴圈: 《空白練習曲》序〉 Dominant Cycles: Preface to Blank Études], in Zhang Zao \& Song 2002: xv-xxvi

Song Xiaoxian 宋晓贤. 1999: 〈中国诗坛的可悲现状〉 [The Sorry State of the Chinese Poetry Scene], in 《诗参考》1999: 98-99

Song Yongyi 宋永毅. 1997: 〈文革中的黄皮書和灰皮書〉 [Yellow Books and Grey Books in the Cultural Revolution], in 《二十一世紀》42: 59-64

_ 2007: "A Glance at the Underground Reading Movement during the Cultural Revolution," in Fournal of Contemporary China 16-51: 325-333

Song Zuifa 宋醉发 (ed, phot). 2008: 《中国诗歌的脸》[The Face of Chinese Poetry], 香港: 中国文化

Soong, Stephen C \& Minford, John (eds). 1984: Trees on the Mountain: An Anthology of New Chinese Writing, Hong Kong: The Chinese University Press

Sötemann, A L. 1985: "Vier poetica's" [Four Poetics], in W J van den Akker \& G J Dorleijn (eds), A L Sötemann, Over poetica en poëzie [On Poetics and Poetry], Groningen: Wolters-Noordhoff: 119-130

Spalek, John M \& Bell, Robert F (eds). 1982: Exile: The Writer's Experience, Chapel Hill: University of North Carolina Press

Su Wei \& Larson, Wendy. 1995: "The Disintegration of the Poetic 'Berlin Wall'," in Deborah S Davis, Richard Kraus, Barry Naughton \& Elizabeth J Perry, Urban Spaces in Contemporary China: The Potential for Autonomy and Community in PostMao China, Washington etc: The Woodrow Wilson Center Press / Cambridge: Cambridge UP: 279-293

Suleiman, Susan Rubin (ed). 1998: Exile and Creativity: Signposts, Travelers, Outsiders, Backward Glances, Durham etc: Duke UP (first published as Poetics Today 17-3/4 [1996])

Sun Wenbo 孙文波. 1997: 《地图上的旅行: 孙文波诗选》 Journey on the Map: Selected Poems by Sun Wenbo], 北京: 改革

1998b: 〈我的诗歌观〉 [My Poetics], in 《诗探索》1998-3: 148-156 2001a: 《孙文波的诗》 [The Poetry of Sun Wenbo], 北京: 人民文学 2001b: 〈我怎麼成为了自己〉 [How I Became Myself], unpublished manuscript 
Tabori, Paul. 1972: The Anatomy of Exile: A Semantic and Historical Study, London: Harrap

Tan Chee-Lay. 2007: Constructing a System of Irregularities: The Poetry of Bei Dao, Yang Lian and Duoduo, $\mathrm{PhD}$ thesis, University of Cambridge

Tan Wuchang 谭五昌. 1999:〈海子论〉 [On Haizi], in Cui 1999a: 187-214

Tang Chao \& Robinson, Lee (eds \& transl). 1992: New Tide: Contemporary Chinese Poetry, Toronto: Mangajin Books

Tang Xiaobing. 2000: Chinese Modern: The Heroic and the Quotidian, Durham etc: Duke UP

Tang Xiaodu (ed). 1992: 《灯芯线幸福的舞蹈: 后朦胧诗萃》 [The Happy Dance of Corduroy: Selected Post-Obscure Poems], 北京: 北京师范大学

1999: 〈90 年代先锋诗的若干问题〉 [Some Issues in Avant-Garde Poetry of the 90s], in Tang 唐 (ed), 《先锋诗歌》[Avant-Garde Poetry], 北京: 北京师 范大学: 1-19 (abridged; the full text is included in Tang 唐, 《唐晓渡诗学论 集》 [Tang Xiaodu's Essays in Poetics], 北京: 中国社会科学, 2001: 104-123) - 2006: “终于被大海摸到了内部”: 从大海意象看杨炼漂泊中的写作〉

["Finally Touched on the Inside by the Sea": The Image of the Sea as a Perspective on Yang Lian's Wandering Writing], in 《新诗评论》2006-2: 111-138 (also available from Yang Lian's website $\rightarrow$ 中文 $\rightarrow$ 评论研究)

— \& Wang Jiaxin 王家新 (eds). 1987: 《中国当代实验诗选》 [Selected Contemporary Experimental Chinese Poems], 沈阳: 春风文艺

Tang Xin 唐欣. 2000: 〈写作何必 “知识分子”〉 [Why Should Writing Be “Intellectual”], in 《诗参考》2000: 68-69

Tao Naikan. 2006: "Introduction: The Changing Self," in Tao \& Prince 2006: 3-26 \& Prince, Tony (eds \& transl). 2006: Eight Contemporary Chinese Poets, Sydney: Wild Peony

Teeuwen, Rudolphus. 2004: "Fading into Metaphor: Globalization and the Disappearance of Exile," in Hanne 2004: 283-298

Teng, Emma J. 2005: "What's 'Chinese' in Chinese Diasporic Literature?”, in Charles Laughlin (ed), Contested Modernities in Chinese Literature, New York etc: Palgrave MacMillan: 61-79

Them Literature Web. 《他们文学网》(online, see also p475)

Tian Zhiwei 田志伟. 1987: 《朦胧诗纵横谈》 [A Free and Easy Discussion of Obscure Poetry], 沈阳: 辽宁大学

Tong Ziguang \& Chen Rongbin 佟自光、陈荣斌 (eds). 2004: 《人一生要读的60首 诗歌》 [60 Poems One Must Read in This Life], 北京: 中国书籍

Tu Wei-ming. 1991: "Cultural China: The Periphery as the Center," in Dedalus 120-2: 1-32 (reprinted in Tu 1994: 1-34, 261-268)

- (ed) 1994: The Living Tree: The Changing Meaning of Being Chinese Today, Stanford: Stanford UP

Twitchell-Waas, Jeffrey. 2005: "Dazzling Songs Hanging in the Void: Yang Lian's \$," in Chicago Review 50-2/3/4: 334-345

\& Huang Fan. 1997: "Avant-Garde Poetry in China: The Nanjing Scene, 1981-1992," in World Literature Today 71-1: 29-38

Van Crevel, Maghiel. 1996: Language Shattered: Contemporary Chinese Poetry and Duoduo, Leiden: CNWS

2000: Poëzie in tïden van geest, geweeld en geld [Poetry in Times of Mind, Mayhem and Money], Leiden: CNWS

2001: “Translator's Introduction [to Yu Jian's «File 0»]," in Renditions 56: $19-23$

2003a: "Zhai Yongming," in Lily Lee (ed), Biographical Dictionary of Chinese Women: The Twentieth Century, 1912-2000, Armonk, NY: M E Sharpe: 672-678 
2003b: "The Horror of Being Ignored and the Pleasure of Being Left Alone: Notes on the Chinese Poetry Scene," MCLC Resource Center $\rightarrow$ Publications (online, see also p475)

2003c: "The Poetry of Yan Jun," MCLC Resource Center $\rightarrow$ Publications (online, see also p475)

-2004: "Who Needs Form? Wen Yiduo's Poetics and Post-Mao Poetry," in Peter Hoffmann (ed), Poet, Scholar, Patriot: In Honour of Wen Kiduo's $100^{\text {th }}$ Anniversary, Bochum etc: Projektverlag: 81-110

2005: "Yan Jun," DACHS poetry chapter $\rightarrow$ Yan Jun (online, see also $\mathrm{p} 475)$

2007: "Unofficial Poetry Journals from the People's Republic of China: A Research Note and an Annotated Bibliography," MCLC Resource Center $\rightarrow$ Publications (online, see also p475)

2008a: "Avant-Garde Poetry from the People's Republic of China: A Bibliography of Single-Author and Multiple-Author Collections," MCLC Resource Center $\rightarrow$ Publications (online, see also p475)

2008b: "Avant-Garde Poetry from the People's Republic of China: A Bibliography of Scholarly and Critical Books in Chinese," MCLC Resource Center $\rightarrow$ Publications (online, see also p475)

\& Van Toorn, Willem. 1990: "Een innerlijke culturele revolutie: een gesprek met Bei Dao en Duoduo" [An Inner Cultural Revolution: A Conversation with Bei Dao and Duoduo], in Raster 50: 124-127

Visser, Robin. 2002: "Privacy and Its Ill Effects in Post-Mao Urban Fiction," in Bonnie McDougall \& Anders Hansson (eds), Chinese Concepts of Privacy, Leiden etc: Brill: 171-194

Wan Xia \& Xiaoxiao 万夏、潚潇 (eds). 1993: 《后朦胧诗全集: 中国现代诗编年 史》 [The Complete Post-Obscure Poetry: Annals of Modern Chinese Poetry], 共二册, 成都: 四川教育

Wan Zhi 萬之 (ed). 1997a: 《溝通: 面對世界的中國文學》[Breaking the Barriers: Chinese Literature Facing the World], Stockholm: Olof Palme International Center (English translation in Wan Zhi 1997b)

(ed) 1997b: Breaking the Barriers: Chinese Literature Facing the World, translated by Chen Maiping, Anna Gustafsson \& Simon Patton, Stockholm: Olof Palme International Center (Chinese translation of Wan 1997a)

Wang Ban. 1997: The Sublime Figure of History: Aesthetics and Politics in Twentieth-Century China, Stanford: Stanford UP

Wang Bin 王涁 (ed). 1991: 《二十世纪中国新诗鉴赏辞典》[A Critical Anthology of China's New Poetry of the Twentieth Century], 北京: 中国文联

(ed). 1998:《二十世纪中国新诗选》[A Selection of China's New Poetry of the Twentieth Century], 北京: 大众文艺

Wang, David Der-wei. 1994: "Afterword: Chinese Fiction for the Nineties," in Wang with Jeanne Tai (eds), Running Wild: New Chinese Writers, New York: Columbia UP: 238-258

2000: David Der-wei Wang, "Introduction," in Chi \& Wang 2000: xiii-xliii

2004: David Der-wei Wang, The Monster That Is History: History, Violence and Fictional Writing in Twentieth-Century China, Berkeley: University of California Press

Wang Guangdong 王光东. 2002:〈民间〉 [Popular], in Hong \& Meng 2002: 213-217

Wang Guangming 王光明. 1986:〈散文诗〉 [Prose Poetry], in《中国大百科全书: 
中国文学 II》 [The Great Chinese Encyclopedia: Chinese Literature II], 北京: 中国大百科全书: 687-688

- 1993: 《艰难的指向: “新诗潮” 与二十世纪中国现代诗》 P Pointing the Way in Hardship: "New Tide Poetry" and Twentieth-Century Modern Chinese Poetry], 长春: 时代文艺

1999: 〈个体承担的诗歌〉 [Poetry Undertaken by the Individual], in《诗探

索》1999-2: 17-20, 25

2003: 《现代汉诗的百年演变》 [Modern Han Poetry: A Hundred Years of Evolution], 石家庄: 河北人民

Wang Guozhen 汪国真. 1991: 《汪国真爱情诗选》 [Selected Love Poetry by Wang Guozhen], 北京: 中国友谊

WangJiaping 王家平. 2004《文化大革命时期诗歌研究》 [A Study of Poetry during the Cultural Revolution], 开封: 河南大学

Wang Jiaxin 王家新. 1993: Selected Poems by Wang Fiaxin, translated by John Cayley, London: Wellsweep (floppy disk containing written texts and audio recordings)

1994: 《谁在我们中间》[Who Is Among Us], in《诗探索》1994-4: 99103

1997: 《游动悬崖》[Moving Cliffs], 长沙: 湖南文艺

- 1999: 〈知识分子写作, 或向 “献给无限的少数人’ [Intellectual Writing, or

“In Dedication to a Limitless Minority”], in《诗探索》1999-2: 38-52 and 85

2001: 《王家新的诗》 [The Poetry of Wang Jiaxin], 北京: 人民文学

2002: 《没有英雄的诗: 王家新诗学论文随笔集》 [Poetry without Heroes:

Wang Jiaxin's Essays and Short Prose on Poetry], 北京: 中国社会科学

\& C Chen Dongdong 陈东东 \& Huang Canran 黄灿然. 1993: 〈回答四十个 问题〉[Answers to Forty Questions], in 《南方诗志》1993 秋: 42-57 (interview, unofficial publication, reprinted [abridged] in Wang Jiaxin 1997: 187-214)

— \& Sun Wenbo 孙文波 (eds). 2000: 《中国诗歌: 九十年代备忘录》[Chinese Poetry: Memorandum for the Nineties], 北京: 人民文学

Wang Jifang 汪继芳 (ed). 2000: 《断裂: 世纪末的文学事故一自由作家访谈录》 [Rupture: An Accident in Literature at the End of the Century-Interviews with Free Writers], 南京: 江苏文艺

Wang Jing. 1996: High Culture Fever: Politics, Aesthetics, and Ideology in Deng's China, Berkeley etc: University of California Press

Wang Ping (ed). 1999: New Generation: Poems from China Today, translated by Wang and various others, New York: Hanging Loose Press

Wang Yichuan 王一川. 1998: 《中国形象诗学: 1985 至1995 年文学新潮阐释》 [Chinese Image Poetics: Interpretations of the New Tide in Literature from 1985 to 1995], 上海: 上海三联 1999a:〈在口语与杂语之间〉 [Between Colloquialism and Miscellanism], in 《当代作家评论》1999-4: 43-51

1999b:〈海子: 诗人中的歌者〉 [Haizi: Singer among Poets], in Cui 1999a: 245-259

Wang Yuechuan. 1999: "A Perspective on the Suicide of Chinese Poets in the 1990s," translated by Li Xia, in Li Xia 1999: 77-95

Wang Zheng \& Xiaohua 汪政、晓华. 1999: 〈词语物: 有关于坚写作的讨论〉 [Words and Things: A Discussion of Yu Jian's Writing], in 《当代作家评论》 1999-4: 50-57

Weber, Eugen. 1960: Paths to the Present: Aspects of European Thought from Romanticism to Existentialism, New York: Dodd, Mead and Company

Wei Tianwu 魏天无. 2006: 《新诗现代性追求的矛盾与演变: 九十年代诗论研 究》[Contradiction and Evolution in the New Poetry's Pursuit of Modernity: A Study of Poetics in the Nineties], 武汉: 湖北教育 
Wei'an 苇岸. 1994:〈怀念海子〉 [n Commemoration of Haizi], in《诗探索》19943: $98-108$

Weihui 卫慧. 1999: 《上海宝贝》[Shanghai Babe], 沈阳: 春风文艺

Wen Xin 文听. 1994: 《顾城绝命之谜: 英儿解秘》 [The Riddle of Gu Cheng on the Verge of Death: The Secret of Ying'er Divulged], 北京: 华艺

Wigman, Menno (ed \& transl). 1998: Wees altïd dronken! Franse prozagedichten uit het fin de siècle [Be Forever Drunk! French Prose Poems from the Fin de Siècle], Amsterdam: Voetnoot

Wong, Lawrence Wang-chi. 1993: "I Am a Prisoner in Exile': Wen Yiduo in the United States," in Lee (Gregory) 1993a: 19-34

Wong, Lisa Lai-ming. 2001: "Writing Allegory: Diasporic Consciousness as a Mode of Intervention in Yang Mu's Poetry of the 1970s," in Fournal of Modern Literature in Chinese 5-1: 1-28

Wu Jingrong \& Cheng Zhenqiu 吴景荣、程镇球 (eds). 2000: 《新时代汉语大词 典》 [New Age Chinese-English Dictionary], 北京: 商务

Wu Kaijin 吴开晋 (ed). 1991: 《新时期诗潮论》 [On the Rising Tide of Poetry in the New Era], 济南: 济南

Wu Sijing 吴思敬 (ed). 1993: 《磁场与魔方: 新潮诗论卷》 Magnetic Field and Magic Square: New Tide Poetry Criticism Volume], 北京: 北京师范大学 (in Xie Mian \& Tang 1993

- 1996:〈启蒙・失语 - 回归: 新时期诗歌理论发展的一道轨迹〉 [Enlightenment-Speechlessness - Homecoming: A Path of Development for Poetic Theory in the New Era], in 《诗刊》1996-7: 51-54

- 1997: 〈九十年代中国新诗走向摭谈〉 [Scattered Remarks on the Alignment of China's New Poetry in the Nineties], in 《文学评论》4: 79-85

-2002: 《走向哲学的诗》 [Poetry Moving toward Philosophy], 北京: 学苑 2005: 〈中国新诗: 世纪初的观察〉 [China's New Poetry: Observations for the New Century], in 《文学评论》2005-5: 107-112

Wu Xiaodong \& Xie Linglan, 吴晓东、谢凌岗. 1991: 〈诗人之死〉 Death of the Poet], in Haizi \& Luo 1991: 356-360

Wu Xinhua 吴新化. 2004: 〈固守人类精神的高地: 对当代诗歌边缘化的思考〉 [Guard the Heights of the Human Spirit: Thoughts on the Marginalization of Contemporary Poetry], in《湖州师范学院学报》26-4: 15-18

Xi Chuan 西川. 1988: 〈艺术自释〉 [The Author's Explanation of His Art], in Xu Jingya et al 1988: 361-362 - 1991a:〈怀念〉 [Remembrance], in Haizi \& Luo 1991: 307-312 (dated 1990, on Haizi)

- 1991b: 〈怀念〉 [Remembrance], in Haizi \& Luo 1991: 313-318 (dated 1990, on Luo Yihe)

1994a: 〈死亡后记〉 [Afterword to Death], in《诗探索》1994-3: 88-97

1994b: 〈诗歌炼金术〉[The Alchemy of Poetry], in 《诗探索》1994-2:

$72-74$

61-66

- 1997a: 《虚构的家谱》[A Fictitious Genealogy], 北京: 中国和平

1997b: 《让蒙面人说话》[Let the Masked Speak], 上海: 东方

1997c: 《大意如此》 [This Is the Idea], 长沙: 湖南文艺

1997d: 《隐秘的汇合》[Secret Convergence], 北京: 改革

1997e: 〈在路上〉 [On the Road], in《作家》1997-4: 68-69

- 1999a: 《西川的诗》 [The Poetry of Xi Chuan], 北京: 人民文学 
1999b:〈鹰的话语〉 [What the Eagle Says]，in《第三届爱文文学奖颁奖

会》 [Award Ceremony for the Third Aiwen Award for Literature], 北京: 爱文文学

院, 14 February 1999 (reprinted in Zhang Zao \& Song 2002: 181-193) 2001: 《水渍》[Water Stains], 天津: 百花文艺

Xi Du 西渡. 2000: 《守望与倾听》[Stand Guard and Listen Close], 北京: 中央编译 Xi Mi 奚密: see Yeh, Michelle

Xi Yunshu 席云舒. 2001: 〈困顿中的反思: 关于世纪之交的诗坛现状及其局限〉

[Reflections in the Midst of Fatigue: On the State of the Poetry Scene at the Turn of the Century, and Its Limitations], in 《诗探索》2001-3/4: 55-63

Xia Yuanming 夏元明. 2005: 〈回到隐喻之前: 于坚诗学与创作〉 [Return to before Metaphor: Yu Jian's Poetics and His Creative Writing], in《长江学术》7: 113119

Xiang Weiguo 向卫国. 2002: 《边缘的呐喊: 现代性汉诗诗人谱系学》 [Shouts from the Margins: A Genealogy of Poets of Modern Han Poetry], 北京: 作家

Xiao Hai 小海. 1998: 〈诗到语言为止吗〉 [Poetry Goes No Farther Than Language?], in 《诗探索》1998-1: 19-21

Xiao Kaiyu 肖开愚. 1995: 〈生活的魅力〉 [The Charm of Life], in《诗探索》19952: $157-161$

— 1997a: 〈九十年代诗歌: 抱负, 特征和资料〉 [Poetry of the Nineties: Aspirations, Characteristics, Material], in 《学术思想评论》1997-1: 215-234

1997b: 〈当代中国诗歌的困惑〉 [Confusion in Contemporary Chinese Poetry], in《读书》1997-11: 90-97

- 2000: 《学习之甜》 [Sweetness of Learning] , 北京: 中国工人 2004: 《肖开愚的诗》 [The Poetry of Xiao Kaiyu], 北京: 人民文学

Xiao Quan 肖全. 2006: 《我们这一代》 [This Our Generation], 广州: 花城

Xiao Xialin 萧夏林 (ed). 1994: 《顾城弃城》 [Gu Cheng Abandons the City \{or: Gu Cheng Abandons Cheng\}], 北京: 团结

Xiao Ying 肖鹰. 1999: 〈向死亡存在〉 [Existence Leading toward Death], in Cui 1999a: 226-231

Xiaoxiao 萧萧. 1998: 〈台湾散文诗美学〉 [The Aesthetics of Taiwan Prose Poetry], in Xiandai Hanshi bainian yanbian ketizu 现代汉诗百年演变课题组 (ed), 《现代汉诗: 反思与求索》[Modern Han Poetry: Introspection and Exploration], 北京: 作家: 315-338

Xie Mian 谢冕. 1980:〈在新的崛起面前〉 [Facing the New Rising], in《光明日 报》, 7 May 1980

\& Meng Fanhua 孟繁华 (eds). 1996: 《中国百年文学经典文库1895-1995: 诗歌卷》 [Classics from the Treasure House of One Hundred Years of Chinese Literature, 1895-1995: Poetry Volume], 深圳: 海天

— \& Tang Xiaodu 唐晓渡 (eds). 1993: 《当代诗歌潮流回顾》 [A Review of Trends in Contemporary Poetry], 共六册, 北京: 北京师范大学

Xie Youshun 谢有顺. 1999: 〈回到事物与存在的现场: 于坚的诗与诗学〉 [Back to the True Site of Objects and Being: The Poetry and Poetics of Yu Jian], in 《当代 作家评论》1999-4: 58-66

- 2001: 〈文学身体学〉 [The Bodily Art of the Literary Art], in 《花城》2001-6: 193-205

Xin Yue 辛月. 1995: 〈于坚诗二首赏析〉 [Appreciations of Two Poems by Yu Jian], in《诗探索》1995-2: 148-154

Xiping 溪萍 (ed). 1988: 《第三代诗人探索诗选》[Selected Explorative Poems by Poets of the Third Generation], 北京: 中国文联

Xu Jiang 徐江. 1999a:〈玩弄中国诗歌〉 [Playing Chinese Poetry], in 《文友》19992: 20-21 86-90 
2001: 〈从头再来-1999-2001：诗人的被缚与诗歌的内在抗争〉 [Start All Over Again - 1999-2001: The Poet's Bonds and Poetry's Internal War of Resistance], in 《芙蓉》2001-2: 130-135

Xu Jingya 徐敬亚 (ed). 1986:〈中国诗坛1986 现代诗群体大展〉 [Grand Exhibition of Modern Poetry Groups on China's Poetry Scene, 1986], in 《诗歌报》, 21 October 1986 and 《深圳青年报》, 21 and 24 October 1986

1989: 《崛起的诗群》[A Volant Tribe of Bards], 上海: 同济大学

- et al (eds). 1988: Xu Jingya, Meng Lang, Cao Changqing \& Lü Guipin 徐 敬亚、孟浪、曹长青、吕贵品, 《中国现代主义诗群大观 1986-1988》[Overview of Chinese Modernist Poetry Groups 1986-1988], 上海: 同济大学

Yan Jun 颜峻. 2001: 《次声波》 [Infrasonic Sound], 北京: 铁托出品 SUB JAM B (unofficial publication)

2005: Sub Fam 012 (CD-rom), 北京 (unofficial, also available at DACHS poetry chapter $\rightarrow$ Yan Jun, with an introduction by Maghiel van Crevel; online, see also p475)

2006a: "live at Beida poem....," Yan Jun's MySpace page (online, see also $\mathrm{p} 475)$

2006b: 《不可能》[Impossible], 北京(unofficial publication)

Yan Yuejun et al (eds). 1985: Yan Yuejun, Gao Yan, Liang Yun \& Gu Fang 阎月君、 高岩、梁云、顾芳, 《朦胧诗选》 [Selected Obscure Poems], 沈阳: 春风文艺

Yang Changzheng 杨长征. 1994: 〈西川: 仰望星空的智者〉 [Xi Chuan: Wise Man Gazing at the Starry Sky], in 《北京青年》7:47-48

Yang Jian 杨健. 1993: 《文化大革命中的地下文学》 [Underground Literature during the Cultural Revolution], 济南: 朝华

Yang Ke 杨克 (ed). 2000:《1999 中国新诗年鉴》 [1999 Yearbook of China’s New Poetry], 广州: 广州

- \& Wen Yuanhui 温远辉. 1996:〈在一千种鸣声梳理诗的羽毛〉 [Comb Out Poetry's Feathers from among a Thousand Bird Calls], in 《山花》9: 75-77

Yang Lan. 1998: Lan Yang, Chinese Fiction of the Cultural Revolution, Hong Kong: Hong Kong UP

Yang Li 杨黎. 2004: 《灿烂: 第三代的写作和生活》 [Splendor: The Writing and the Lives of the Third Generation], 西宁: 青海人民

Yang Lian 杨炼. 1980: 《太阳每天都是新的》 [There Is a New Sun Every Day], 北 京 (unofficial publication) 1989a:《黄》[Yellow], 北京: 人民文学

1989b: 《人的自觉》[The Self-Awakening of the Human Being], 成都: 四 川人民

- 1990: Yang Lian, The Dead in Exile, bilingual, translated by Mabel Lee,

Canberra: Tiananmen

- 1991: 《太阳与人》

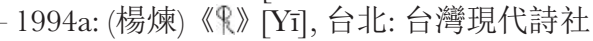

1994b: Non-Person Singular, bilingual, translated by Brian Holton, London: Wellsweep

1996: "Living in the Now and Forever: A Way Forward for Chinese Literature," translated by Yang Lian \& John Cayley, in The Times Literary Supplement, 25 October 1996: 14

1998a: 《大海停止之处: 杨炼作品 1982-1997—诗歌卷》 [Where the Sea Stands Still: Works by Yang Lian, 1982-1997-Poetry Volume], 上海: 上海文 艺

1998b: 《鬼话. 智力的空间: 杨炼作品1982-1997一散文 - 文论卷》 [Ghost- 
speak - Intellectual Space: Works by Yang Lian, 1982-1997- Short Prose and Essays Volume], 上海: 上海文艺

1998c: "The Writer and the Party: Western Misunderstandings of Contemporary Chinese Literature," translated by Brian Holton, in The Times Literary Supplement, 6 November 1998: 18-19

1999: Where the Sea Stands Still, bilingual, translated by Brian Holton, Newcastle upon Tyne: Bloodaxe

2002a: Notes of a Blissful Ghost, translated by Brian Holton, Hong Kong:

Renditions

_ 2002b: $\Upsilon_{i} \$$, bilingual, translated by Mabel Lee, Los Angeles: Green Integer 2002c: "In Search of Poetry as the Prototype of Exile," translated by Torbjörn Lodén, in 00tal 9/10: 35-41 (for a Chinese edition, see Yang Lian's website or Yang 杨, 〈追寻作为流亡原型的诗〉 [In Search of Poetry as the Prototype of Exile], in Zheng et al 2005: 235-240) - 2003: 《幸福鬼魂手记: 杨炼作品1998-2002-诗歌、散文、文论》 [Notes of a Blissful Ghost: Works by Yang Lian, 1998-2002-Poetry, Short Prose, Essays], 上海: 上海文艺

2006: Unreal City: A Chinese Poet in Auckland, edited and introduced by Jacob Edmond \& Hilary Chung, Auckland: Auckland UP

- website: Yang Lian (online, see also p475)

\& Yo Yo 友友. 1994: 《人景. 鬼话: 杨炼、友友海外漂泊手记》 [Peoplescapes - Ghostspeak: Notes by Yang Lian and Yo Yo on Wandering Overseas], 北京: 中央编译

Yang Lihua 杨立华. 2003: 〈北岛诗二首解读〉 [Two Poems by Bei Dao: An Interpretation], in《诗探索》2003-3/4: 173-183

Yang Siping 杨四平. 2004: 《20世纪中国新诗主流》[The Mainstream in China's New Poetry of the $20^{\text {th }}$ Century], 合肥: 安徽教育

Yang Xiaobin 杨小滨. 1994: 〈今天的 “今天派” 诗歌: 论北岛、多多、严力、杨 炼的海外诗作〉 [The Poetry of the "Today School" Today: On Overseas Poetry by Bei Dao, Duoduo, Yan Li and Yang Lian], in 《现代汉诗》15/16: 107-120 (reprinted as [楊小濱] 〈今天的 “今天派” 詩歌〉 [The Poetry of the “Today School" Today], in 《今天》1995-4: 244-261)

1999: 《历史与修辞》[History and Rhetoric], 兰州: 敦煌文艺

YaoJiahua 姚家华 (ed). 1989: 《朦胧诗论争集》[Essays on the Polemic over Obscure Poetry], 北京: 学苑

Yeh, Michelle. 1991 a: Modern Chinese Poetry: Theory and Practice since 1917, New Haven etc: Yale UP

1991b: Xi Mi 奚密,〈差異的憂慮: 一個回響〉 [The Anxiety of Difference: A Rejoinder], in 《今天》1991-1: 94-96

1991c: "Nature's Child and the Frustrated Urbanite: Expressions of the Self in Contemporary Chinese Poetry," in World Literature Today 65-3: 405-409

_ (ed \& transl) 1992a: Anthology of Modern Chinese Poetry, New Haven etc: Yale UP

1992b: "Light a Lamp in a Rock: Experimental Poetry in Contemporary China," in Modern China 18-4: 379-409

1993a: Xi Mi 奚密,〈海子《亞洲銅》探析〉 [A Tentative Analysis of Haizi's «Asia Bronze»], in 《今天》1993-2: 123-132

1993b: Xi Mi 奚密, “落地生根” 還是 “落葉歸根”? 海外中文詩隨想〉

["Fall to the Ground and Take Root" or "Falling Leaves Returning to the Root"? Thoughts on Overseas Poetry in Chinese], in 《中時晚報》時代副刊, 20 June 1993 (reprinted in奚密，《現當代詩文錄》[Essays on Modern and Contemporary Poetry], 台北, 1998: 聯合文學: 264-278) 
1994: Xi Mi 奚密〈死亡: 大陆与台湾地区近期诗作的共同主题〉 Death: A Common Theme in Recent Poetry from Mainland China and the Taiwan Area], in 《诗探索》1994-3: 36-54

1995: "Death of the Poet: Poetry and Society in Contemporary China and Taiwan," in Sung-sheng Yvonne Chang \& Yeh (eds), Contemporary Chinese Literature: Crossing the Boundaries, a special issue of Literature East \& West: 43-62 (reprinted with minor revisions in Chi \& Wang 2000: 216-238)

- 1996a: "The 'Cult of Poetry' in Contemporary China," in Fournal of Asian Studies 55-1: 51-80 (reprinted in Zhang Yingjin 1998: 188-217) 1996b: Xi Mi 奚密,〈北島: 我在語言中漂流〉[Bei Dao: I Drift in Language], in 《自由時報》, 10-11 October 1996

1998a: Xi Mi 奚密, 〈诗与戏剧的互动: 于坚《0档案》探微〉 [Exploring Interactions of Poem and Play: Yu Jian's «File 0»], in 《诗探索》1998-3: 102-114

1998b: "International Theory and the Transnational Critic: China in the Age of Multiculturalism," in boundary 2 25-3: 193-222 (reprinted in Chow 2000: 251-280)

2000a: "Chinese Postmodernism and the Cultural Politics of Modern Chinese Poetry," in Wen-hsin Yeh (ed), Cross-Cultural Readings of Chineseness: Narratives, Images and Interpretations of the 1990s, Berkeley: Institute of East Asian Studies, University of California at Berkeley: 100-127

2000b: "From Surrealism to Nature Poetics: A Study of Prose Poetry from Taiwan," in Fournal of Modern Literature in Chinese 3-2: 117-156

2001: "Frontier Taiwan: An Introduction," in Yeh \& N G D Malmqvist (eds), Frontier Taizwan: An Anthology of Modern Chinese Poetry, New York: Columbia UP: $1-53$

2003: "Misty Poetry," in Mostow et al 2003: 520-526

2005: "The Poet as Mad Genius: Between Stereotype and Archetype," in Fournal of Modern Literature in Chinese 6-2/7-1: 119-144

2007a: "Anxiety and Liberation: Notes on the Recent Chinese Poetry Scene," in World Literature Today 81-5: 28-35

2007b: “'There Are No Camels in the Koran': What Is Modern about Modern Chinese Poetry?", in Lupke 2007: 9-26 and 219-232

Yemen 也门. 2001: 〈一块提醒哭泣的手帕: 王家新批判〉 [A Handkerchief for Reminding Yourself to Cry: Criticizing Wang Jiaxin], in Yi et al 2001: 287-320 (pseudonym of Yi Sha)

Yi Sha 伊沙. 1994: 《饿死诗人》 [Starve the Poets], 北京: 中国华侨

1999a: 《我终于理解了你的拒绝》 [I Finally Understand Your Refusal], 西 宁: 青海人民

-1999b:〈两个问题和一个背景：我所经历的盘峰诗会〉 [Two Questions against One Background: The Panfeng Poetry Conference as I Experienced It], in《诗参考》1999: 75-81

2001a:〈现场直击: 2000 年中国新诗关键词〉 [On-the-Spot Direct Attack:

Keywords for the Year 2000 in China's New Poetry], in《芙蓉》2001-2: 123-129

- 2001b: 〈我所理解的下半身和我〉 [The Lower Body as I Understand It and ], in 《下半身》1: 113-114

2003:《伊沙诗选》 [Selected Poems by Yi Sha], 西宁: 青海人民

et al. 2000: Yi Sha, Xu Jiang \& Qin Bazi 伊沙、徐江、秦巴子, 《时尚杀

手: 三剑客挑战时尚》 [Assassins of Fashion: Three Musketeers Challenging Fashion], 广州: 花城 et al. 2001: Yi Sha, Zhang Hong, Xu Jiang, Qin Bazi \& Shen Haobo 伊沙、 
张闪、徐江、秦巴子、沈浩波, 《十诗人批判书》[Criticizing Ten Poets], 长 春: 时代文艺 - see also Yemen

Yin Lichuan 尹丽川. 2001: 《再舒服一些》[Make It Feel Even Better], 北京: 中国 青年

2006:《因果》[Cause and Effect], 福州: 海风

\& Bradbury, Steve. 2005: "Have Net, Will Travel: Is This the New Face of Chinese Poetry? PRC Poet and Head-Turner Yin Lichuan Talks about Her Image, Her Verse, and Publishing on the Web," in POTS, 21 October 2005: 17-18 (interview)

\& That's Beijing. 2004: "Beijing Writers Face a Dilemma," in China Daily, 2 April 2004 (interview, online, see also p475)

Yip Wai-lim. 1985: "Crisis Poetry: An Introduction to Yang Lian, Jiang He and Misty Poetry," in Renditions 23: 120-130

Yiping 一平. 2003: 〈孤立之境: 读北岛的诗〉 [The Predicament of Standing Alone: Reading Bei Dao's Poetry], in 《诗探索》2003-3/4: 144-163

Yu Hong 余虹. 1999:〈神・语・诗〉 [The Divine-Language-Poetry], in Cui 1999a: 111-121 (dated 1992)

Yu Jian 于坚. 1986:〈青年诗人谈诗: 于坚〉 [Young Poets on Poetry: Yu Jian], in《诗刊》1986-11:31 1989a: 《于坚诗六十首》 [Sixty Poems by Yu Jian], 昆明: 云南人民

1989b: 《阳光下的棕㭣树》 [Palm Trees in the Sun], 昆明 (unofficial publication) cation)

1989c:《作品，1988-1989》[Works，1988-1989]，昆明 (unofficial publi1989d: 〈重建诗歌精神〉 [Rebuild the Spirit of Poetry], in《滇池》1989-6:

62-64

- 1990:《诗集, 1989-1990》 [Poems, 1989-1990], 昆明 (unofficial publication)

1991: 〈拒绝隐喻〉 Reject Metaphor], in Wu Sijing 1993: 308-312

1993: 《对一只乌鸦的命名》 [The Naming of a Crow], 昆明: 国际文化

1994: 〈0档案〉 File 0], in 《大家》1: 48-58

1995a: (于堅)〈0檔案〉 [File 0], in《現代詩》23: 1-11

1995b: (于堅)《戲劇車間〈零檔案〉》[Theater Workshop: «File Zero»], 北京, 戲劇車間 (unofficial publication, original in full-form characters)

1995c:〈传统, 隐喻及其他〉 [Tradition, Metaphor and Other Things], in 《诗探索》1995-2: 137-141

69-75

1996: "Four Poems by Yu Jian," translated by Simon Patton, in Renditions 46:

1997a: 〈从隐喻后退: 作为方法的诗歌〉 [Retreat from Metaphor: Poetry as Method], in 《作家》1997-3: 68-73

- 1997b: 《棕皮手记》 [Brown Notebook], 上海: 东方

1998a: 〈诗歌之舌的硬与软：关于当代诗歌的两类语言向度〉 [The Hard

and Soft of the Tongue of Poetry: On Two Different Directions in the Language

of Contemporary Poetry], in 《诗探索》1998-1: 1-18

1998b: 《王中文化奖: 首届获奖者诗人于坚》 Poet Yu Jian, Laureate of the

First Wang Zhong Culture Award], 昆明 (unofficial publication)

1999a: (于堅) 《一枚穿過天空的釘子》[A Nail through the Sky], 台北: 唐山 1999b:〈穿越汉语的诗歌之光〉 [The Light of Poetry, Cutting through the

Chinese Language], in Yang Ke 杨克 (ed), 《1998 中国新诗年鉴》[1998 Year-

book of China's New Poetry], 广州: 花城: 1-17

1999c: 〈诗人及其命运〉 [The Poet and His Fate], in 《大家》1999-4: 80-83

2000: 《于坚的诗》[The Poetry of Yu Jian], 北京: 人民文学 
2001a: 《诗歌 •便条集1996-1999: 1-216》 Poetry: Collected Notes，19961999: 1-216], 昆明: 云南人民

2001b: 〈诗言体〉 [Poetry Articulates the Body], in《芙蓉》2001-3: 69-75 (reprinted in 《诗江湖》1: 52-59)

2003: 《诗集与图像2000-2002》[Poems and Images, 2000-2002], 西宁: 青 海人民

2004: 《于坚集》 [Collected Works of Yu Jian], 共五册, 昆明: 云南人民 (see Yu Jian 2004a, 2004b, 2004c, 2004d, 2004e)

-2004a: 《一枚穿过天空的钉子: 诗集, 1975-2000》 [A Nail through the Sky:

Poems, 1975-2000], in Yu Jian 2004

2004b: 《0档案: 长诗七部与便条集》[File 0: Seven Long Poems and Collected Notes], in Yu Jian 2004

2004c: 《人间笔记: 散文》 [Notes from the Human World: Short Prose], in $\mathrm{Yu}$ Jian 2004

2004d:《正在眼前的事物: 散文》[Objects Right in Front of Your Eyes:

Short Prose], in Yu Jian 2004

- 2004e: 《拒绝隐喻: 棕皮手记 - 评论 • 访谈》 Reject Metaphor: Brown Notebook-Criticism-Interviews], in Yu Jian 2004 征

- 2006a: 《只有大海苍茫如幕》 [Only the Sea, Vast Like a Canopy], 北京: 长 - 2006b: 《八十八张便条: 便条集1996-2005选》 [Eighty-Eight Notes: Selected

Notes 1996-2005], New York: 诗歌报 / 惠特曼出版社-Walt Whitman Literature Fund

\& De Meyer, Jan A M. 1995: "Yu Jian: ik heb China nodig" [Yu Jian: I Need China], in Poëziekrant 1995-6: 28-30 (interview)

\& \& Han Dong 韩东. 1988: 〈在太原的谈话〉 [A Conversation in Taiyuan], in《作家》1988-4: 75-77

\& Jin Xiaofeng 金小风. 2002:〈于坚访谈〉 [nterview with Yu Jian], in《诗 参考》19/20: 211-219

\& T Tao Naikan 陶乃㑆. 1999: 〈抱着一块石头沉到底〉 [Clutch a Stone and

Sink to the Bottom], in 《湖南文学》1999-7: 70-80 (interview)

＆Xie Youshun 谢有顺. 2001: 〈真正的写作都是后退的〉 [What All True

Writing Does Is to Retreat], in 《南方文坛》2001-3: 28-33

＆ Z hu Wen 朱文1993: 〈回答诗人朱文的二十五个问题〉[Answers to

Twenty-Five Questions by Poet Zhu Wen], 昆明 / 南京 (interview, unofficially circulated manuscript)

－\& Zhu Wen 朱文 1994: 〈回答二十五个问题〉 [Answers to Twenty-Five Questions], in 《他们》7: 124-134 (interview: published version of Yu Jian \& Zhu 1993, with interviewer Zhu Wen unidentified)

Yu Liwen 余麗文. 2006: 〈邊緣與中心的對話: 解構于堅與華鳴〉 [A Dialogue of the Margins and the Center: Deconstructing Yu Jian and Hua Ming], in 《創世 紀詩雜誌》147: 162-182

Yu, Pauline et al (eds). 2000: Pauline Yu, Peter Bol, Stephen Owen \& Willard Peterson, Ways with Words: Writing about Reading Texts from Early China, Berkeley etc: University of California Press

Yu Xugang 余徐刚. 2004: 《海子传: 诗歌英雄》 [A Biography of Haizi: Hero of Poetry], 南京: 江苏文艺

Yuan Youming 袁幼鸣. 1992: 《“汪国真现象” 备忘录》[Memorandum on “the Wang Guozhen Phenomenon”], 北京: 学林

Zang Di 蔵棣. 1994:〈王家新: 承受中的汉语〉 [Wang Jiaxin: Testing the Endurance of the Chinese Language], in 《诗探索》1994-4: 103-110 
Zhang Er \& Chen Dongdong (eds). 2007: Another Kind of Nation: An Anthology of Contemporary Chinese Poetry, bilingual, various translators, Jersey City: Talisman House

Zeng Hong. 2005: "Foreword," in Haizi 2005: xiii-xxiii

Zhang Hong 张闳. 2003: 《声音的诗学》 [The Poetics of Voice], 北京: 中国人民大 学

Zhang Hongming 章宏明. 1990: 〈对“新诗潮” 的透视〉 [“New Tide Poetry” Unmasked], in 《文艺报》, 17 November 1990

Zhang, Jeanne Hong. 2004: Jeanne Hong Zhang, The Invention of a Discourse: Women's Poetry from Contemporary China, Leiden: CNWS

Zhang Longxi. 1992: The Tao and the Logos: Literary Hermeneutics, East and West, Durham etc: Duke UP

1993: "Out of the Cultural Ghetto: Theory, Politics and the Study of Chinese Literature," in Modern China 19-1: 71-101

Zhang Ning 张柠. 1999: 〈《0档案》词语集中营〉 [《File 0», a Concentration Camp of Words], in 《作家》1999-9: 41-50

Zhang Qinghua 张清华. 1997: 《中国当代先锋文学思潮论》[On Trends of Thought in Contemporary Chinese Avant-Garde Literature], 南京: 江苏文艺 1999: 〈“在幻像和流放中创造了伟大的诗歌”〉 [“In Phantasms and Exile Create Poetry of Greatness"], in Cui 1999a: 172-186

2002: 〈序〉 [Preface], in 《2001年中国最佳诗歌》[China's Best Poetry of 2001], 沈阳: 春风文艺: 9-24

Zhang Shuguang 张曙光. 1998: 《小丑的花格外衣》 [The Clown's Checkered Facade], 北京: 文化艺术

1999: 〈关于诗的谈话: 对江涛书面提问的回答〉 [A Conversation about Poetry: In Reply to Jiang Tao's Written Questions], in Sun Wenbo, Zang Di \& Xiao Kaiyu 孙文波、藏棣、肖开愚 (eds), 《语言: 形式的命名》, 北京: 人民 文学: 235-250

Zhang Xudong. 1997: Chinese Modernism in the Era of Reforms: Cultural Fever, Avant-Garde Fiction and the New Chinese Cinema, Durham etc: Duke UP

Zhang Yingjin. 1993: "Re-envisioning the Institution of Modern Chinese Literature Studies: Strategies of Positionality and Self-Reflexivity," in positions 1-3: 816-832

1998: China in a Polycentric World: Essays in Chinese Comparative Literature, Stanford: Stanford UP

Zhang Zao 張柬. 1999: 〈當天上掉下來一個鎖匠.... 〉 [When from Heaven Fell a Locksmith....], in北島, 《開鎖》, 台北: 九歌, 1999: 7-29

2004: Zhang Zao, Auf der Suche nach poetischer Modernität: Die Neue Lyrik Chinas nach 1919 [In Search of Poetic Modernity: China's New Poetry after 1919], PhD thesis, Eberhard-Karls-Universität Tübingen

— \& Song Lin 宋琳 (eds). 2002: 《空白練習曲: 〈今天〉十年詩選》 Blank Études: Selected Poems from Ten Years of Today], 香港 etc: Oxford UP

Zhang Zhen. 1999a: "The World Map of Haunting Dreams: Post-1989 Chinese Women's Diaspora Writings," in Mayfair Mei-hui Yang (ed), Spaces of Their Own: Women's Public Sphere in Transnational China, Minneapolis etc: University of Minnesota Press: $308-335$

1999b: "The Jet Lag of a Migratory Bird: Border Crossings toward / from 'The Land That Is Not',' in Sharon K Hom (ed), Chinese Women Traversing Diaspora: Memoirs, Essays, and Poetry, New York etc: Garland: 51-75

Zhao, Henry Y H. 1997a: Zhao Yiheng 赵毅衡, 〈“流外丧志”, 而后有文学: 关于 海外大陆小说的几点观察〉 [“Those Who Live in Exile Lose Belief," But Create Literature: Some Remarks on Fictional Works by Chinese Writers Living Overseas], in Wan Zhi 1997a: 115-128 
1997b: Zhao Yiheng, “'Those Who Live in Exile Lose Belief,' But Create Literature: Some Remarks on Fictional Works by Chinese Writers Living Overseas," in Wan Zhi 1997b: 130-149

-1999: "The Poetics of Death," in Li Xia 1999: 9-20

2003: "The River Fans Out: Chinese Fiction since the Late 1970s," in the European Review 11-2: 193-208

- \& Cayley, John (eds). 1994: Under-Sky UnderGround: Chinese Writing Today: I, London: Wellsweep

_ \& Cayley, John (eds). 1996: Abandoned Wine: Chinese Writing Today: II, London: Wellsweep

Cet al (eds). 2000: Henry Zhao, Yanbing Chen \& John Rosenwald, Fissures: Chinese Writing Today, Brookline: Zephyr Press

Zhao Qiguang. 2005: "Preface: In Memory of Hai Zi," in Haizi 2005: i-xi

Zhao Xun 赵㻏. 2002: 《还需要多久, 一场大雪才能从写作中升起: 王家新的《伦 敦随笔》解读〉 [How Long until A Heavy Snow Will Rise from Writing? Wang Jiaxin's «London Jottings»: An Interpretation], in Hong 2002: 27-52

Zhao Yiheng 赵毅衡: see Zhao, Henry Y H

Zheng Yi et al (eds). 2005: Zheng Yi, Su Wei, Wan Zhi \& Huang Heqing 鄭義、蘇 煒、萬之、黃河清, 《不死的流亡者》[The Undying Exile], 台北: INK

Zhong Ming 钟鸣. 1991: 〈中间地带〉 [Intermediary Zone], in Haizi \& Luo 1991: 343-346 (dated 1989)

1998:《旁观者》[Spectator], 共三册, 海口: 海南 - see also Shi Jile

Zhongdao 中岛 (ed). 1998: 《伊沙这个鬼: 伊沙的诗及相关评论集》 [That Devil of an Yi Sha: The Poetry of Yi Sha and Collected Reviews], 北京: 《诗参考》编辑 部 (unofficial publication)

Zhongguo Shehui Kexueyuan Yuyan Yanjiusuo Cidianshi 中国社会科学院语言研 究所词典室 (ed). 1996:《现代汉语词典》[Dictionary of Modern Chinese], 北 京: 商务 (revised edition)

Zhou Lunyou 周倫佑. 1999: 《在刀鋒上完成的句法旋轉換》[Syntactic Transformation Completed on the Edge of a Knife], 台北: 唐山

Zhou Yubing 周玉冰. 2005: 《面朝大海 春暖花开: 海子的诗情人生》 [Face to the Sea Spring Warmth Flower Glee: Haizi’s Poetic Life], 合肥: 安徽文艺

Zhu Dake 朱大可. 1999: 〈先知之门〉 [Door of the Prophets], in Cui 1999a: 122142 (dated 1991)

- 2006:《流讯的盛宴: 当代中国的流讯叙事》 [The Hooligan Banquet: Contemporary China's Hooligan Narrative], 北京: 新星

Zhu Wen 朱文. 1998: 〈断裂: 一份问卷和五十六份答卷〉 [Rupture: One Set of Questions, and Fifty-Six Sets of Answers], in 《北京文学》 1998-10: 19-40, 47

Zhuang Rouyu 莊柔玉. 1993: 《中國當代朦朧詩研究: 從困境到求索》[A Study of Contemporary Chinese Obscure Poetry: From Predicament to Exploration], 台北: 大安

Zou Jianjun 邹建军. 1999: 〈试论海子的诗歌创作〉 [Tentative Remarks on Haizi's Poetry], in Cui 1999a: 232-244

Zou Jingzhi 邹静之. 1991: 〈正午的黑暗〉 [Darkness at Noon], in Haizi \& Luo 1991: 332-334 (dated 1989) 


\section{INDEX AND GLOSSARY}

Chinese names in transcription are followed by Chinese characters, unless they occur with reference to publications in alphabetic languages only (e.g. Dai Sijie, Kong Shuyu). Life years are included for all wellknown avant-garde poets mentioned in this study (see p xiv).

Terms and expressions are listed in Chinese as well as English if they are originally Chinese (e.g. wen yi zai dao 文以载道 'literature to convey the Way') or have a specifically Chinese usage (e.g. xianfeng 先 锋 'avant-garde').

Texts listed include unofficial poetry journals (e.g. Today / Fintian《今 天》, Poetry Reference / Shi cankao 《诗参考》) and several serial book publications (e.g. Epoch Poetry Series / Niandai shicong《年代诗从》), in recognition of their importance for the avant-garde; and a few canonical texts from antiquity, whose significance is undiminished today (e.g. Songs of the South / Chuci《楚辞》).

A Cheng 阿城: 379

A Fei 阿斐 (1980): 335

A Jian 阿坚 (1955): 406

Abraham, Nicolas: 298

Abrams, Meyer Howard: 347, 360

abusive criticism (骂、骂人): 425, 448

Academicized Writing (泛学院化写 作): 334

Adorno, Theodor: 416

Ah Q阿Q: 404

Ai Qing 艾青: 4, 102, 106

Akhmatova, Anna: 6, 416

Alternative Poetry (另类诗歌): 20

Alvarez, Alfred: 91, 94, 113

Analects (论语): 261

anti-intellectualism: 193, 318, 321, 353, 382, 391, 411, 442

Apollinaire, Guillaume: 403

Arbus, Diane: 315

Ash, Adrienne: 146

Ashbery, John: 220, 404-405

Attridge, Derek: 33, 284
Auden, Wystan Hugh: 403

author, historical person of: 50-51, 93-95, 123-124, 149, 161, 164, 192, $196,321,443-446$

authorial intent: 51, 93, 190, 196, 345-346, 376

avant-garde (先锋): chapter One (esp 5-12) et passim

Aviram, Amittai: 59, 285, 288, 298-304

Ba ling hou shixuan 《八○后诗选》 $\rightarrow$ Selected Post-80 Poetry

Ba ling hou yi dai 八O后一代 $\rightarrow$ Post-80 Generation

bad behavior: 305, 334, 339-341

Bai Hua 柏桦 (1956): 83, 103, 402

Bai Ye 白夜 (= Duoduo): 7n8

Bailey, Alison: 113

Barmé, Geremie: 8, 148, 319

Barnstone, Tony: 287

Baudelaire, Charles: 6, 132, 226, 229-230, 243, 375 
Beauty Writers (美女作家) $\rightarrow$ Glamlit Writers

Bei Dao 北岛 (1949): xiv-xv, 7, 15-16, $18,26,31,34,39,42,52,55,66$, 68n7-69, 71, 83n26, 89, 91, 93n1, 95, 106, 239, 247, 254-255, 341, 378-379, 406, 408; chapter Four; $\rightarrow$ Zhao Zhenkai

Beiling 贝岭 (1959): xiv, 139, 141; $\rightarrow$ Huang Beiling

Bell, Robert: 146, 179

benbanshu 本版书 $\rightarrow$ original editions

Bertens, Hans: 191

Bevan, David: 143, 160

Bian Zhilin 市之琳: 4

Bing Xin 冰心: 4

Birch, Cyril: 287

Blue Star Poetry Treasure House (蓝星诗 库): 247, 249, 281

book agents (书商) $\rightarrow$ book brokers

book brokers (书商): 12

Book of Songs (诗经): 1, 185, 424

Borges, Jorge Luis: 189, 403, 416

Bourdieu, Pierre: 11, 22, 34, 36, 47, 49, 57, 144, 191, 346, 392, 448

Boym, Svetlana: 160, 178

Bradbury, Steve: 60

Brems, Hugo: 51

Breton, André: 403

Brodsky, Joseph: 160, 178, 214, 385, 403, 406

Bronfen, Elisabeth: 93

Brouwers, Jeroen: 91

Brown, Edward: 161

Bruno, Cosima: 251

Burroughs, William: 467-468

Buruma, Ian: 160, 178

Bush, George Herbert Walker: 149

Bush, George Walker: 148

Byron, George Gordon: xiii, 107, 109, 121,412

Cai Kelin 蔡克霖: 68-69

Cai Yi 蔡毅: 33, 250-251

Campus Poetry (校园诗歌): 65-66

Can Xue 残雪: 247

Cardinal, Roger: 220

Cayley, John: 154

Cao Pi 曹丕: 448

Cao Shuying 曹疏影 (1979): 461

Celan, Paul: 108 censorship: 5, 8, 14, 22, 143, 147-150, 153-159, 162, 168, 175-176, 287, 307, 330, 336, 417

Chang Li 常立: 101, 113, 379

Chang Yao 昌耀: 113

changduanju 长短句 $\rightarrow$ long-short line

Che Qianzi 车前子 (1963): iv, 20, 48, 461, 473

Cheesman, Tom: 143

Chen Chao 陈超: xiv, 33, 120-121, 129-130, 168, 399, 423, 425, 432

Chen Dongdong 陈东东 (1961): 17, 83, 100-103, 135, 169, 178, 189-190, 230, 402-403, 406, 443-444

Chen Duxiu 陈独秀: 3

Chen Jingrong 陈敬容: 4

Chen Jun 陈均: 420, 423, 440

Chen Qufei 陈去非: 250-251

Chen Ran 陈染: 247

Chen Zhongyi 陈仲义: 77, 251-252, 333

Cheng Guangwei 程光炜: 102, 105, $124,161,168,281$; passim in chapter Twelve (esp 400-405, 434-435)

Cheng Weidong 程蔚东: 71

Chi Li 池莉: 247

Chinese Writers' Association (中国作家 协会): 4, 11, 260, 272-273, 390, 418

Chineseness: 54-59, 136, 143, 386-389; passim in chapter Twelve (esp 443-444)

Choushui 仇水 (= Shen Haobo): 405

Chow, Rey: 54-55, 59

Chuci 《楚辞》 $\rightarrow$ Songs of the South

Chung, Hilary: 161, 178

chunshi 纯诗 $\rightarrow$ pure poetry

ci 词 $\rightarrow$ lyric

citation repository: $\mathrm{xv}, 475$

close reading (definition): 59

Coleman, Steve: 244

Coleridge, Samuel: 228

Colloquial Poetry (口语诗) and colloquialization: $16,18,52,78,80$, 88, 135, 189, 252, 278, 310, 362, $365,373,439,445$

commercialization: 14-15, 32-33, 36, 46-47, 49, 111, 119, 161-162, 187, 191-196, 203, 209, 214, 221, 321-322, 337, 352, 362, 382-384, 415, 433, 438-439, 442, 447, 450

Confucius 孔子: 359 
“connecting” (接轨) with the West: 57 , 386-387, 416, 428, 433, 444

content: 288 (definition); $\rightarrow$ form and content....

content bias: 284-287, 302-303

Contemporary Chinese Experimental Poetry (中国当代实验诗歌): 95

context $\rightarrow$ text, context and metatext

Cooper, Burns: 296

Coquetry Poetry Fournal (撒娇诗刊): 38

Coquetry School (撒娇派): 17, 42

Crespi, John: 12, 36, 251, 283, 473

crisis discourse: 32-33, 119, 305, 335

Cui Jian 崔建: 107n21

Cui Weiping 崔卫平: 102, 118, 194, 197, 214

Culler, Jonathan: 33, 107, 293

cult of poetry: 18, 37, 46, 52, 103-104, 108, 112-113, 115, 190, 197, 204, 349, 365-366, 370, 372, 382, 394

cultural economy (文化经济): 32, 36, $48-49,473$

Curtis, Ian: 94

DACHS: xv, 472, 475

Dai Sijie: 162n46

Dai Wangshu 戴望舒: 4, 403

Dark Skin Poetry Series (黑皮诗丛): 247

Dawei 大卫 (= Yu Jian): 262

Daxu 〈大序〉 $\rightarrow$ "Great Preface"

Day, Michael: 21-22n29, 53, 60, 103, 113, 338, 341

De Haan, Martin: 306

De Meyer, Jan: 251, 385

De Roder, Jan: 299, 347

DeFrancis, John: 193

demystification: $37,46,71,80,168$, 214, 305, 338-339, 341, 365, 438, 445

Deng Xiaoping 邓小平: 14, 149, 230

Denton, Kirk: 59, 107

Descartes, René: 461

di er qudao 第二渠道 (= er qudao二渠道) $\rightarrow$ second channel

Di san dai 第三代 $\rightarrow$ Third Generation

Di shige yundong 低诗歌运动 $\rightarrow$ Low Poetry Movement

Di si dai 第四代 $\rightarrow$ Fourth Generation

dialect: 267, 373-374, 376, 387-388, 407-408, 410

Digital Archive for Chinese Studies $\rightarrow$ DACHS
Dilthey, Wilhelm: 417

Ding Dang 丁当 (1962): 72, 261

Ding Mang 丁芒: 431

dixia 地下 $\rightarrow$ underground

Don Quixote: 404

$\mathrm{Du} F \mathrm{Fu}$ 杜甫: 1

Duanlie 断裂 $\rightarrow$ Rupture

Duchamp, Marcel: 240, 323

Duoduo 多多 (1951): xiv, 7, 18, 119, 137-139, 146, 150, 157, 170-171, 406; $\rightarrow$ Bai Ye

Duoyu 朵渔 (1973): 305, 335, 393

Eagleton, Terry: 229

Earthly aesthetic: 10, 18, 20, 23-27

(definition), 29-30, 37-38, 45,

52-53, 73, 125, 168, 187, 190, 193, 221, 223, 251-252, 267, 281, 305, 314, 318, 331, 333-334, 338-339, 341-342, 346, 363, 365, 372, 382, 392, 394, 396-397, 399, 427, 438, 445,447

Easthope, Anthony: 50, 53, 223, 459

Edmond, Jacob: 153, 161, 178

Edwards, Robert: 141

Elevated aesthetic: 10, 18, 20, 23-27 (definition), 30, 37, 45, 47, 52-53, 73, 79, 125, 135, 187, 189-190, 193, 197, 218, 221, 223, 251, 281, 305, 334, 338-339, 341-342, 346, 363, 365, 370, 372, 394, 396-397, 399, 445,447

Eliot, Thomas Stearns: 286, 299, 403-405

Enlightenment (启蒙): 15, 444

Eoyang, Eugene: 160

Epoch Poetry Series (年代诗丛): 63, 247, 438, 449

er qudao 二渠道 (= di er qudao 第二渠 道) $\rightarrow$ second channel

establishment: 6 ; $\rightarrow$ orthodox poetics

exile and exile literature: $18,52,54,57$, 59, 287, 385-386, 406, 410, 414, 421; chapter Four (definitions: 141-143, 146-147, 158-161, 177-179)

experimental (实验): 10

explicit poetics: 10, 13, 37-38, 51-52, 65, 71-73, 95, 108, 122, 124n47, $152,164,180,213,250-251,263-$ 265, 267, 283, 303, 315, 315-318, 331, 338, 409, 416, 439, 442-443; 
passim in chapters Ten (esp 345-347, definition: 345) and Eleven

explorative (探索): 10

Fan xueyuanhua xiezuo 泛学院化写作 $\rightarrow$ Academicized Writing

Fang Lizhi 方励之: 149

Fang Xiang 方向: 104

fangyan 方言 $\rightarrow$ dialect

Faulkner, William: 416

fei guanfang 非官方 $\rightarrow$ unofficial

Fei Jia 费嘉: 260, 262

Fei Sha 飞沙 (= Yang Lian): 7n8, $147 \mathrm{n} 15$

Feifei 《非非》 $\rightarrow$ Not-Not....

feminist critical discourse $\rightarrow$ Women's Poetry....

Feng Zhi 冯至: 4

Ferry, Megan: 321-322

Findeisen, Raoul: 101

Finkel, Donald: 287

First Line (一行): 141

fm3: 23, 462-463, 465, 472

foreign literatures, modern Chinese poetry's relation to: $3,6,15,55-59$, 123, 136, 152-153, 155-156, 162, 266, 362, 375, 379, 385-390; passim in chapter Twelve

form: 299 (definition); $\rightarrow$ form and content....

form and content, synergy of: 52, 59, 125, 200-201, 215-221, 274-280, $325,465-467$; passim in chapters Six and Eight

Forrest-Thomson, Veronica: 284, 286287, 299

Foucault, Michel: 416

Fourth Generation (第四代): 17

Freud, Sigmund: 298

Frost, Robert: 387

Frye, Northrop: 225, 293

$f u$ 赋 $\rightarrow$ poetic exposition

Fu Mahuo 符马活 (1970): 330-331

Futurism: 342

Gao Bo 高波: 102-103, 105, 122, 123， 251

Gao Xingjian 高行健: 148, 161-162

Gaoyuan shïi 《高原诗辑》 $\rightarrow$ Highland Poetry Compilation

Garbage School (垃圾派) $\rightarrow$ Trash School
Ge Mai 戈麦 (1967-1991): 98, 100-101, 103n14, 111, 196, 247,381

Geng Zhanchun 耿占春 (1957): 412， 440

Gerbrandy, Piet: 125

Geren xiezuo 个人写作 $\rightarrow$ Individual Writing

Gerenhua xiezuo 个人化写作 $\rightarrow$ Individualized Writing

Gillespie, Marie: 143

Ginsberg, Allen: 467-468

Glad, John: 59, 143, 146-159, 183

Glamlit Writers (美女作家): 320-322

Glass, Philip: 466

Glazier, Loss Pequeño: 22n29, 244

Goethe, Johann Wolfgang von: 98, 245

Gorky, Maksim: 468

Graham, Angus: 382n37

“Great Preface" (大序): 185

Gu Cheng 顾城 (1956-1993): 7, 26, 31, 34, 91, 93n1, 98, 100-101, 103, 112-113, 139, 147, 163, 247, 249, 287, 381, 391, 414, 438

guanfang 官方 $\rightarrow$ official

guanxi 关系 $\rightarrow$ ties of allegiance

Gui Xinghua 贵兴华: 24, 48

Guo Lusheng 郭路生 (= Shizhi, 1948): xiv, 15, 101; $\rightarrow$ Shizhi

Guo Moruo 郭沫若: 4, 106, 110, 125

Guo Xiaochuan 郭小川: 102, 130, 136, 275,408

Ha Jin: 162n46

Haft, Lloyd: 3, 287, 446

Haizi 海子 (1964-1989): xiii-xiv, 17, 31, 37, 39, 43, 52, 189-190, 196, 206-208, 210, 214, 218, 247, 249, 303, 333, 339, 365, 375, 381, 408, 414, 430, 438, 445-446, 461; chapter Three; $\rightarrow$ Zha Haisheng

Hamlet: 404-405

Han Dong 韩东 (1961): xiii, xv, 17, 45, 51-52, 102, 116-117, 120, 168, 252, 257, 259, 261, 278, 309-310, 315, 318, 338-339, 346-347, 361, 363; chapters Two and Eleven; passim in Twelve (esp 436-439)

Han Poetry (汉诗): 17

Hanne, Michael: 160

Hanshi 《汉诗》 $\rightarrow$ Han Poetry 
Havel, Václav: 416

He Jingzhi 贺敬之: 102, 130, 136, 230, 275, 408

He Qifang 何其芳: 4

He Qinglian 何清涟: 14

He Xiaozhu 何小竹 (1963): 399, 436-437, 440

He Yi 贺奕: 223, 250-251

Hei Dachun 黑大春 (1960): 22, 37, 464-465

Hei pi shicong 《黑皮诗从》 $\rightarrow$ Dark Skin Poetry Series

Heine, Heinrich: 207

Heraclitus: 219

Hettinga, Tsjêbbe: 358

high culture fever (文化热): 13, 35, 162， 187

Highland Poetry Compilation (高原诗辑): 262

Hinton, David: 145

Hockx, Michel: 21, 123, 448

Hoffmann, Peter: 287

Hölderlin, Friedrich: 108

Holton, Brian: 60

Homer: 152, 358

Hong Kong poetry: 53

Hong Zicheng 洪子诚: 32, 83, 101-102, 281, 400, 406

Hooligan Literature (流讯文学、㾙子 文学): 321, 334, 339

Hou kouyu 后口语 $\rightarrow$ Post-Colloquial

Hou Ma 侯马 (1967): 318, 406, 414, 425, 427

Hou menglongshi 后朦胧诗 $\rightarrow$ PostObscure Poetry

Hou xin shichao 后新诗潮 $\rightarrow$ Post-NewTide Poetry

Houssaye, Arsène: 226, 243

Hu Dong 胡冬 (1962): 139

Hu Kuan 胡宽 (1952-1995): 438

Hu Shi 胡适: 3, 63, 107

Hu Tingwu 胡廷武: 251

Hu Xudong 胡续冬 (1974): 83, 334, 473

Hu Yan 胡彦: 251

Hu Yaobang 胡耀邦: 156

Huang Beiling 黄贝岭 (= Beiling): xiv

Huang Canran 黄灿然 (1963): 178

Huang Fan: 65, 71

Huang Heqing 黄河清: 163

Huang Liang 黄粱: 249, 251
Huang Lihai 黄礼孩 (1971): 331

Huang Nubo 黄怒波 (= Luo Ying): 32

Huang Rui 黄锐: 16

Huang Xiang 黄翔 (1943): xiv, 15, 139, 444

Huang Yibing 黄亦兵 (= Mai Mang): 461

Huang Yunte: 55

Huang Zunxian 黄遵宪: 107, 403

Hung, Eva: 190

Huot, Claire: 251

Hussein, Saddam $\rightarrow$ Saddam Hussein

Image Puzzle (象国): 444

indeterminacy: 52, 59, 239, 283, 359; chapter Five (definition: 197)

Individual Writing (个人写作): 19, 102, 187, 362, 434

Individualized Writing (个人化写作): 19

Intellectual Writing (知识分子写作): 17-18, 20, 190, 331-332, 338, 349, 365, 371, 375, 391-393; chapter Twelve

Intellectual Youths (知识青年): 5-6, 15

Internet: 21-23, 47, 54, 330, 332-333, $362,400,474$

Inwood, Heather: 12, 21-22, 338

Jakobson, Roman: 240, 298

Jameson, Fredric: 77

Janssen, Ronald: 23, 172, 180

Jenner, William: 55, 155

Jiang Hao 蒋浩 (1972): 334, 423

Jiang He 江河 (1949): 34, 135, 139, 341

Jiang Tao 姜涛 (1970): 334, 440

Jiangjiang 江江: 172

jiegui 接轨 $\rightarrow$ “connecting”....

Jin Xiaofeng 金小风: 393

Jing Wen 京文 (= Zhang Qinghua): 421

Jing Yi 静矣: 420-421

Jingbute 京不特 (1965): 17, 139

jingshen wuran 精神污染 $\rightarrow$ spiritual pollution

fintian 《今天》 $\rightarrow$ Today

Fiushi niandai 《九十年代》 $\rightarrow$ Nineties

Fiushi niandai shige 九十年代诗歌 $\rightarrow$

Poetry of the Nineties

Fireuxing de xiezuo 及物性的写作 $\rightarrow$

Transitive Writing

Jones, Andrew: 55 
June Fourth (六 ・四): 8, 14, 18-19, 52, 72, 98, 103-104, 113, 187, 196, 198, 385-386, 411; passim in chapter Four

Kafka, Franz: 6, 403, 406, 416

Kaiyu 开愚 $\rightarrow$ Xiao Kaiyu

Kao, Anne $\rightarrow$ Liu Li'an

Kerouac, Jack: 6

Knight, Deirdre Sabina: 321-322

Kong Shuyu: 9n9, 321-322

Kongzi 孔子 $\rightarrow$ Confucius

Kouyu shi 口语诗 $\rightarrow$ Colloquial Poetry....

Krämer, Oliver: 147-148

Kristeva, Julia: 298

Krol, Gerrit: 229, 241-244, 294

Kubin, Wolfgang: 110, 161, 172

Kui $《$ 葵》 $\rightarrow$ Sunflower

Lacan, Jacques: 298

Lacoue-Labarthe, Philippe: 298

Lajipai 垃圾派 $\rightarrow$ Trash School

Lan Dizhi 蓝棣之: 193, 197, 314, 353

Lan xing shiku 《蓝星诗库》 $\rightarrow$ Blue Star Poetry Treasure House

Lao Mu 老木: 96, 368, 444

Lao She 老舍: 5

Larson, Wendy: 63-65, 71, 77, 321-322

Lee, Gregory: 23, 55, 57

Lee, Leo Ou-fan: 25, 161, 172-173, 443

Lee, Mabel: 148, 162, 164n49, 166

Lei Feng 雷锋: 130, 230

Leng Shuang 冷霜 (1973): 83

Lenin, Vladimir Ilyich: 466

Lennon, John: 468

Lermontov, Mikhail: 68, 412

Li Bai 李白: 1, 286, 299, 354, 413, 426, 468,471

Li Bo 李勃: 260, 262

Li Chao 李超: 101-102, 110

Li Dian: 158-159n40, 161, 172-173, 379,450

Li Duoduo 栗多多: xiv

Li Fukang: 190

Li Hongqi 李红旗 (1976): 40, 335

LiJi 李季: 230, 239

LiJinfa 李金发: 4, 403

$\mathrm{Li} \mathrm{Li}$ 李笠: 156n36, 162n46

$\mathrm{Li} \mathrm{Ou}-\mathrm{fan}$ 李欧凡 $\rightarrow$ Lee, Leo Ou-fan

Li Qingzhao 李清照: 1

Li Shangyin 李商隐: 1, 403
Li Shaojun 李少君: 281

Li Shijiang 李师江 (1974): 335

Li Xia: 112

Li Yawei 李亚伟 (1963): 17, 259, 339-340

Li Yu 李显: 2, 403

Li Zhen 李震: 251

Liang Qichao 梁启超: 342

Liang Xiaobin 梁小斌 (1955): 34

Liang Xiaoming 梁晓明 (1963): 461

Liao Yiwu 廖亦武 (1958): 38, 230

Liaoyuan 燎原: 97n7, 102, 105, 114-115, 118, 120, 124

Lin Mang 林莽 (1949): 421, 425

Lin Xingqian 林幸谦: 161, 164, 172, 175

Lin Yiliang 林以亮: 226, 246

Ling dian ditie shicong 《零点地铁诗 从ᄊ》 $\rightarrow$ Midnight Subway Poetry Series

Lingenfelter, Andrea: 60, 219

Linglei shige 另类诗歌 $\rightarrow$ Alternative Poetry

Link, Perry: 55, 151

literary men disparage one another... (文人相轻....): 448

Literary Revolution (文学革命): 3, 63

literature to convey the Way (文以载 道): 2, 30, 49, 253, 352, 448

Liu Bannong 刘半农: 229

Liu Binyan 刘宾雁: 162-163

Liu Fuchun 刘福春: 440

Liu, James: 360

Liu Jun 刘军 (= Xi Chuan): 210

Liu Kexiang 刘克襄: 229

Liu Li'an 刘丽安: 413

Liu Ligan 刘立杆 (1967): 368, 373, 379, 383

Liu Na 刘纳: 192, 194, 203

Liu Shijie 刘士杰: 251

Liu Shuyuan 刘树元: 68n7, 70

Liu si 六・四 $\rightarrow$ June Fourth

Liu Xiangdong 刘向东: 420

Liumang wenxue 流讯文学 $\rightarrow$ Hooligan Literature

long-short line (长短句): chapter Seven (esp 274-280)

Longfellow, Henry Wadsworth: 387

Lovell, Julia: 46, 55, 65

Low Poetry Movement (低诗歌运动): 20,338, 341 
Lowell, Robert: 403-405

Lower Body, Lower Body (下半身): 20, 27, 29, 31, 38, 47, 52, 267, 405, 449, 468; chapter Nine

Lü De’an 吕德安 (1960): 72, 83-84, 408, 416

Lu Jie: 321

Lu Shourong 卢寿荣: 101, 113

Lu Xun 鲁迅: 11, 107, 229, 390

Lu Yang 鲁羊 (1963): 385

Lu Yimin 陆忆敏 (1962): 72, 408

Lü Zhouju 吕周聚: 9

Lunyu 《论语》 $\rightarrow$ Analects

Luo Gaolin 罗高林: 230, 245

Luo Hanchao 骆寒超: 67n4

Luo Jiasheng 罗家生: 274

Luo Qing 罗青: 225

Luo Yihe 骆一禾 (1961-1989): 39, 43, 95-124, 189, 196, 206-207, 214, 247

Luo Ying 骆英: $32 ; \rightarrow$ Huang Nubo

Luo Zhenya 罗振亚: 9, 102, 124, 281, 303, 319n 14, 334, 450

Lyne, Sandra: 321-322

lyric (词): 274

$m a$ 骂, ma ren 骂人: $\rightarrow$ abusive criticism

$\mathrm{Ma}$ Ce 马策: 332-333, 336

Ma Fei 马非 (1971): 335

Macho Men, Macho Men (芙汉): 17, 52, 193, 259, 267, 339, 445

MacLeish, Archibald: 303

Mai Mang 麦芒 (1967): 461; $\rightarrow$ Huang Yibing

male dominance of metatext: 46, 347, 366, 399

Malingshu Xiongdi 马铃薯兄弟 (1960): 391, 395

Mallarmé, Stéphane: 71, 240, 362

Mandelstam, Osip: 403

Mang Ke 芒克 (1950): 7, 16, 34, 38-39， 42, 254

Manghan 《䒭汉》 $\rightarrow$ Macho Men

Mao Dun 茅盾: 101

Mao Jian 冒键: 91, 105

Mao Style (毛文体): 5

Mao wenti 毛文体 $\rightarrow$ Mao Style

Mao Zedong 毛泽东: 2, 4, 5, 230, 369, 468

Maoist poetics $\rightarrow$ orthodox poetics

Maospeak (毛文体) $\rightarrow$ Mao Style

marginality: ix, 3, 32, 35, 46-49,
119, 159, 161, 177, 209, 213, 332,

388-390, 408, 428-429, 447

Marinetti, Filippo Tommaso: 342

May Fourth (五四): 9, 369

McDougall, Bonnie: 55, 58-59, 89n32, 154, 175, 180-181n80, 379

Meinü zuojia 美女作家 $\rightarrow$ Glamlit Writers

metatext $\rightarrow$ text, context and metatext

methodology $\rightarrow$ theory and methodology

Meng Lang 孟浪 (1961): 139

Menglongshi 朦胧诗 $\rightarrow$ Obscure Poetry

Mi Jiayan: 113

Mian Mian 棉棉: 321-322

Middle Generation (中间代): 17

Middle-Aged Writing (中年写作): 430

Midnight Subway Poetry Series (零点地铁 诗丛): 247

Mill, John Stuart: 293

Miłosz, Czeslaw: 403

Min, Anchee: 321

mind, mayhem and money: 13-14

Minjian xiezuo 民间写作 $\rightarrow$ Popular Writing

Mishima Yukio: 93

Mo Fei 莫非 (1960): 169, 406

Mo Yan 莫言: 247

Modern Han Poetry (现代汉诗): 19

Modern Poetry Materials for Internal Exchange (现代诗内部交流资料): 95

Modern Standard Chinese (普通话) $\rightarrow$ Standard Language

Momo 默默 (1964): 17, 38-39

Morewedge, Rosemarie: 178

Mou Sen 牟森: 224

Mozart, Wolfgang Amadeus: 350

Mu Qing 穆青 (1973): 461

Muguang 目光 $\rightarrow$ Vision

Nanfang shizhi 《南方诗志》 $\rightarrow$ Southern Poetry Review

Nanren 南人 (1970): 335

Narrative Poetry (叙事诗) and narrativity: 20, 52; chapter Eight (definition: 283)

nationalism: 33, 387-389, 405, 410, 412, 416, 426, 433, 435

Neruda, Pablo: 403

New Culture Movement (新文化运 动): 31 
New Literature (新文学): 9

New Period (新时代): 65

New Poetry (新诗): 3-4, 418-419, 435

New Tide Poetry (新诗潮): 421, 427429

New Youth (新青年): 3

Newborn Generation (新生代): 17, 113

Niandai shicong 《年代诗从》 $\rightarrow$ Epoch Poetry Series

Nietzsche, Friedrich: 298

Nijhoff, Martinus: 237

Nineties (九十年代): 198

Niu Han 牛汉: 71, 423

North and South, opposition of: 373 , $376,407,410,424,433,444-445$

Not-Not, Not-Not (非非): 17, 20, 26, 75, 193, 259, 338-339, 409, 438, 445

Nüxing shige 女性诗歌 $\rightarrow$ Women's Poetry....

Oates, Joyce Carol: 72

objectification: 28, 52; chapter Seven (esp 252-274)

objectivism: 77-79

Obscure Poetry (朦胧诗): 16-18, 26, 31-32, 34-35, 45, 51-52, 57, 65-76, 78-79, 88, 91, 95, 130, 135, 147, 151, 168, 189-190, 252, 254, 256, 259, $262,303,320,334,338,341,365$, $368,370,379,408,417,423,448$

obstruction (遮蔽): 425-427, 441-442, 444, 449

official (官方): 5-12; $\rightarrow$ orthodox poetics

Oosterhoff, Tonnus: 61, 287

original editions (本版书): 48

Original Writing (原创性写作): 331, 340, 468

orthodox poetics: 4-12, 16, 24, 31, 48$49,51,63,65,68,71,89,102,110$, $113,125,130,132-133,136,139$, 141, 143-144, 149, 159, 161, 177, 192, 197, 230, 245, 275, 320, 339, 341-342, 352, 361-362, 369-370, 382, 389, 402, 408-411, 413, 415, 418, 421, 425, 427-428, 430, 441

Ouyang Jianghe 欧阳江河 (1956): 83, 139, 157, 168-169, 172, 189-190, 230, 251, 298, 309, 402, 406, 408, $416,427,430,432,443-444$
Oversteegen, Jaap: 288

Ovid: 178

Owen, Stephen: 2, 55, 123, 155, 179, 185n84, 354, 359

Panfeng Poetry Conference (盘峰诗会): 309, 417-432, 439

Panfeng shihui 盘峰诗会 $\rightarrow$ Panfeng Poetry Conference

Parker, Charlie: 244

Pasternak, Boris: 153, 341, 403, 406, 414

Patton, Simon: 60, 65, 93n2, 163, 243, 251, 253, 368n7, $37 \ln 14$

peer journals (同仁刊物、同人刊物) $\rightarrow$ soulmate journals

Perelman, Bob: 35

Perloff, Marjorie: 27, 59, 189, 197, 220, 246

Pizi wenxue 㾂子文学 $\rightarrow$ Hooligan Literature

Plath, Sylvia: 108, 403

poethood: 10, 16, 18, 28, 30-50, 145146, 177-179, 187-197, 203, 214215, 305, 338-339, 343, 468; passim in chapters Three (esp 91-123), Ten (esp 348-350), Eleven (esp 366-392) and Twelve (esp 446-448)

poetic discourse (definition): 50

poetic exposition (赋): 264

poetic prose: 225

poetic rhythm: 52, 59, 199, 227;

chapter Eight (esp 285, 298-300)

poetic sentiment (诗意): 83, 87, 317318, 336, 351

poetic voice (definition): 50

poetry (definitions): 2, 61, 71-72, 82-83, 191, 253, 318, 330, 335-337, 349; passim in chapters Six (esp 225-229), Eight (esp 284-285, 298-299), Ten (esp 353-359) and Eleven (esp 366378)

Poetry and People (诗歌与人): 331, 449 poetry articulates what is on the mind intently (诗言志): 2, 228, 253, 354, 383, 396

poetry as religion: $18,37,107,109-111$, 190, 195, 303, 348-349, 354, 356359, 367-372, 394, 439, 445; $\rightarrow$ cult of poetry 
Poetry of the Nineties (九十年代诗歌): 13, 83-84, 281, 334, 401-406, 413, 419-420, 429, 434, 440

Poetry Reference (诗参考): 331, 340, 429, 431, 433, 440-441

poetry scene (诗坛, definition): 6

Poetry Text (诗文本): 38-39, 331, 449

Poetry Vagabonds (诗江湖): 331-332

poetry verbalizes emotion (诗言志) $\rightarrow$ poetry articulates....

Poets' Writing (诗人写作): 371-372, 428

Polemic, Popular-Intellectual: 11, 20, 27, 29, 37-38, 46, 52-53, 83, 107, 153, 190, 251, 281, 307, 309, 314, $318,320,331,338,345,349,353$, 365, 370-371, 382, 388, 392-393, 397, 468; chapter Twelve

Political Lyricism (政治抒情诗): 4, 24, 125, 130, 136, 145, 408

politics and literature: 2, 4, 13-15, 76, 103, 135, 287, 352, 361-362, 379-380, 385, 388, 417, 442, 447; passim in chapter Four

Popular Writing (民间写作): 20, 25， 47, 338, 365, 382, 388, 392; chapter Twelve

Post-70 Generation (七○后一代): 17, 38, 331, 334

Post-80 Generation (八○后一代): 17-18, 18n25

Post-Colloquial (后口语): 318-320, 334

Post-New-Tide Poetry (后新诗潮): 421

Post-Obscure Poetry (后朦胧诗): 17-18, 65, 408

Pound, Ezra: 189, 403

print culture: 22

prose poetry: 30, 189, 197-199, 277, 467; chapter Six (definition: 230)

Proust, Marcel: 416

publication (definition): 7-8

Pumin 普珢 (1962): 72

pure poetry (纯诗): 196, 362

Pushkin, Aleksandr: 412

Putonghua 普通话 $\rightarrow$ Standard Language

Qi Guo 祁国 (1968): 39

Qi ling hou yi dai 七O后一代 $\rightarrow$ Post-70

Generation
Qiaoqiao 乔乔: 460

Qimeng 《启蒙》 $\rightarrow$ Enlightenment

Qin Bazi 秦巴子 (1960): 105-107, 124

Qingxiang 《倾向》 $\rightarrow$ Tendency

Qu Yuan 屈原: 1, 16, 108, 136-137, 178, 225, 386, 424

quotidianism (日常主义): 252

reading the poet: $2,120-123,173,359$,

$377-378$; $\rightarrow$ text is like the person

recitation: 1, 29, 104 199-200, 233-235, 278-280, 294-301, 315, 329, 394;

chapter Thirteen

Reggio, Godfrey: 466

regional language (方言) $\rightarrow$ dialect

rhythm $\rightarrow$ poetic rhythm

richangzhuyi 日常主义 $\rightarrow$ quotidianism

Rilke, Rainer Maria: 403

Rimbaud, Arthur: 105, 108-109, 204, 220, 362

romanticism: xiii, 37, 195, 203, 208, 212-214, 235, 264, 360-361, 372, $375,380,392,394,411$; passim in chapter Three; $\rightarrow$ Romanticism

Romanticism: xiii, 4, 16, 25n33, 106107, 110, 360; $\rightarrow$ romanticism

Root-Seeking (寻根): 17, 190, 245, 256, 303

Rubbish School (垃圾派) $\rightarrow$ Trash School

Rumsfeld, Donald: 465-467

Rupture (断裂): 389-390

Saddam Hussein: 465-466

Safran, William: 143

Said, Edward: 141, 160

Sajiao shikan《撒娇诗刊》 $\rightarrow$ Coquetry Poetry fournal

Sajiaopai 撒娇派 $\rightarrow$ Coquetry School

Salinger, Jerome David: 6

Same Generation (同代): 68

sanwenshi 散文诗: 225 ; $\rightarrow$ prose poetry

Saussy, Haun: 57, 139

Sax, Broia: 110

Scar Literature (伤痕文学): 320

second channel (第二渠道、二渠道):

9n9

Selected Post-80 Poetry (八○后诗选): $18 \mathrm{n} 25$

Shang Qin 商禽: 229 
Shang Zhongmin 尚仲敏 (1964): 71

Shanghen wenxue 伤痕文学 $\rightarrow$ Scar Literature

Shao Fei 绍飞: 150

Shao Jian 邵建: 435

Shelley, Percy Bysshe: xiii, 107, 169, 228,412

Shen Haobo 沈浩波 (1976): 20, 52, 59, 152-153, 468; chapter Nine; passim in Twelve (esp 405-406); $\rightarrow$ Choushui; $\rightarrow$ Shen Lang

Shen Lang 沈浪 (= Shen Haobo): 415

Shen Qi 沈奇: 72n12, 420, 422-423, 425, 427, 439

Sheng Xing 盛兴 (1978): 335, 436

Shi cankao 《诗参考》 $\rightarrow$ Poetry Reference

Shi Guanghua 石光华 (1958): 17

Shi jianghu 《诗江湖》 $\rightarrow$ Poetry Vagabonds

Shi Jile 释极乐 (= Zhong Ming): 133n62

Shi Mingzheng 施明正: 113

shi sanwen 诗散文: 225 ; $\rightarrow$ poetic prose

Shi wenben 《诗文本》 $\rightarrow$ Poetry Text

shi yan zhi 诗言志 $\rightarrow$ poetry articulates....

Shige yu ren 《诗歌与人》 $\rightarrow$ Poetry and People

Shïing 《诗经》 $\rightarrow$ Book of Songs

Shiren xiezuo 诗人写作 $\rightarrow$ Poets' Writing

shitan 诗坛 $\rightarrow$ poetry scene

shiyan 实验 $\rightarrow$ experimental

shiyi 诗意 $\rightarrow$ poetic sentiment

Shizhi 食指 (= Guo Lusheng, 1948):

15, 101, 151, 249, 438; $\rightarrow$ Guo

Lusheng

Shu 《書》 $\rightarrow$ Writing

Shu 坚 (1972): 335

Shu Ting 舒婷 (1952): 7, 31, 34, 70-71, 91, 93n1, 101, 106, 159n40, 249, 341

shushang 书商 $\rightarrow$ book brokers

Simon, John: 225, 227, 229, 240, 246

sinologists: 54-59, 319, 382, 388-390, $403,430,437,444$

social concern: 20, 305, 326, 340-342

Solzhenitsyn, Aleksandr: 6

Song Lin 宋琳 (1959): 139, 461

Song Qu 宋渠 (1963): 17

Song Wei 宋炜 (1964): 17

Song Xiaoxian 宋晓贤 (1966): 152, 431

Song Zuifa 宋醉发: 38-39, 138

Songs of the South (楚辞): 1, 424
Sontag, Susan: 416

Sötemann, August Lammert: 347, 360-361

soulmate journals (同仁刊物、同人刊 物): 444

South $\rightarrow$ North and South....

Southern Poetry Review (南方诗志): 154, 444-445

Spalek, John: 146, 179

spiritual pollution (精神污染): 16, 35, $147,149,162,423,447-448$

Standard Language (普通话): 266-267, 373-374, 376, 387-388, 407-408, 410

Stein, Gertrude: 220

Su Shaolian 苏绍连: 229

Su Shi 苏轼: 1, 413

Su Wei 苏炜: 63, 71, 77, 163

subjectification: chapter Seven (esp 252-274)

sublime: $25 \mathrm{n} 33$

suicide and literature: chapter Three

Suleiman, Susan: 160

Sun Shaozhen 孙绍振: 417, 421, 423

Sun Wenbo 孙文波 (1956): xiii, 20, 52, 59, 83, 169, 249, 309, 461; chapter Eight; passim in Twelve

Sun Wukong 孙悟空: 404

Sunflower (葵): 331

Survivors, Survivors (幸存者): 95, 119

Tabori, Paul: 143, 159-160

Tagore, Rabindranath: 412

Taiwan poetry: 53

Tamen 《他们》 $\rightarrow$ Them

Tan Chee-Lay: 162, 172

Tan Wuchang 谭五昌: 102, 124

Tang Jin 唐晋: 421

Tang Xiaobing: 25

Tang Xiaodu 唐晓渡: xiv, 130, 152, $161,184,281,393,461$; passim in chapter Twelve

Tang Xin 唐欣: 152

tansuo 探索 $\rightarrow$ explorative

Tao Naikan 陶乃㑆: 386-389

Teeuwen, Rudolphus: 178

Tendency (倾向): 141 (edited by Beiling); 17, 100, 135, 189-190, 402, 444-445 (edited by Chen Dongdong et al) text $\rightarrow$ text, context and metatext text, context and metatext (definition): $1,13,50$ 
text is like the person (文如其人): 192， 446 ; $\rightarrow$ reading the poet

thanatography: 438; chapter Three (definition: 93 )

Them (他们): 16, 63, 72-76, 78, 193, 250, 252, 261, 338, 341, 365, 380, $396,409,438,445$

theory and methodology: 59-60

Third Generation (第三代): 17-18, 65, 77, 334, 408, 427-428, 444

Thug Literature (流讯文学、㾂子文 学) $\rightarrow$ Hooligan Literature

Tian Jian 田间: 4, 102

Tian Yong 田涌: 419

Tiantian 田田: 150

ties of allegiance (关系): 57, 399, 441-450

Today (今天): 7, 15-16, 20, 26n 35,42 , 65-76, 101, 113, 141, 147, 149, 151, 153, 160, 168n53, 185, 254, 370, 380, 409, 437, 444, 447

Tong Wei 童蔚 (1956): 461

Tongdai 《同代》 $\rightarrow$ Same Generation tongren kanzeu 同仁刊物、同人刊物 $\rightarrow$ soulmate journals

traditional Chinese poetics: 2, 15, 30, $33,48,54,107,114-116,121,123$, 146, 173, 185, 192, 228, 253, 261, 287, 302-303, 314, 321, 341-342, $352,354,357,361-362,377-378$, 382-383, 396, 403, 447-448

Transitive Writing (及物性的写作): 303

Trash School (垃圾派): 20, 338

Tsvetayeva, Marina: 6, 108

Twitchell-Waas, Jeffrey: 65, 71

underground (地下): 6-7, 12, 15, 30, 32， 38-39, 141, 145, 151

unofficial (非官方): chapter One (esp 5-12) et passim

Van Ark, Daniëlle: 473

Van Gogh, Vincent: 105, 108, 260

Vandermeer, Pieter: 64, 140, 142, 248

verse-external poetics: 263, 267, 278, 303, 331, esp 345-346 (definition: 345), 348, 399

Vision (目光): 22, 464-465

Visser, Robin: 321

visualization: $38-39,45-47,335$

voice $\rightarrow$ poetic voice
Vroegindeweij, Victor: 473

vulgarization: 18, 52, 135, 189, 214 , 362,445

Wah, Fred: 357

Wan Xia 万夏 (1962): 17, 39, 43, 97n7, 116,259

Wan Zhi 万之: 163

Wang Ai 王艾 (1971): 334

Wang Ban: 25, 125

Wang Bin 王涁: 150

Wang, David Der-wei: 53, 113

Wang Guangming 王光明: 225-226

Wang Guozhen 汪国真: 24, 106, 408

Wang Jiaxin 王家新 (1957): 19, 52, 83, 103, 106-108, 119, 249, 281, 309, 315, 341, 387, 393; chapter Four; passim in Twelve (esp 432-434); $\rightarrow$ $\mathrm{Zi} \mathrm{An}$

Wang Jing: 13, 321

Wang Shuo 王朔: 247, 321

Wang Wei 王巍: 421, 423

Wang Xiaobo 王晓波: 438

Wang Xiaoni 王小妮 (1955): 406

Wang Yichuan 王一川: 70, 125, 251

Wang Yin 王寅 (1962): 72

Wang Yuechuan: 111-112

Wang Zheng 汪政: 251

Wang Zhong 王中

Wangluo wenxue 网络文学 $\rightarrow$ Web

Literature

Web Literature (网络文学): 330

Wedell-Wedellsborg, Anne: 178

Wei Tianwu 魏天无: 281, 303, 450

Wei'an 苇岸: 119

Weihui 卫慧: 321-322

Wen Jie 闻捷: 113

wen ru qi ren 文如其人 $\rightarrow$ text is like the person

Wen Tingyun 温庭云: 403

wen yi zai dao 文以载道 $\rightarrow$ literature to convey the Way

Wen Yiduo 闻一多: 4, 147, 286, 299

Wen Yuanhui 温远辉: 191

wenhua jüngi 文化经济 $\rightarrow$ cultural economy

wenhua re 文化热 $\rightarrow$ high culture fever

Wenmang 文盲 (1977): 341, 468

wenren xiang qing 文人相轻.... $\rightarrow$ literary

men disparage one another....

Wenxue geming 文学革命 $\rightarrow$ Literary

Revolution 
"West," modern Chinese poetry's relation to and image of: 15,25 , 54-59, 107, 145, 266-267, 317, 339, 378-379, 382-390; chapter Twelve

Whitman, Walt: 125, 249, 387, 412

Wholism (整体主义): 17

Wiedenhof, Jeroen: colophon

Wigman, Menno: 226

Wilde, Oscar: 38

Wings (翼): 461

Women's Poetry (女性诗歌), women's writing and feminist critical discourse: 17, 46, 53, 102, 309, 321, 335, 340, 347, 355, 389, 399, 414, 430, 432, 461

women's writing $\rightarrow$ Women's Poetry....

Wong, Lawrence Wang-chi: 147

Wordsworth, William: 228

Writers' Association $\rightarrow$ Chinese Writers' Association

Writing (書): 462

Wu Ang 巫昂 (1974): 335

Wu Kaijin 吴开晋: 66, 72n12

Wu Quan 武权: 23, 462-463, 465, 472

Wu Shaoqiu 吴少秋: 133n62

Wu si 五四 $\rightarrow$ May Fourth

Wu Sijing 吴思敬: 33, 192, 203, 335, 421, 423, 425

Wu Wenguang 吴文光: 259-263, 330

Wu Xiaodong 吴晓东: 102, 110

Wu Xinhua 吴新化: 33

Xi Chuan 西川 (1963): xiv, 11, 13, 17, 26-30, 37, 47-48, 52-53, 59, 83 , 95-123, 125, 127n51, 135, 168, 249, 274, 298, 309, 315, 342, 365-366, 392, 397, 467; chapters Five, Six and Ten; passim in Twelve; $\rightarrow$ Liu Jun

Xi Du 西渡 (1967): 399, 406, 417 , 419-420, 425-426, 434-435

Xi Mi 奚密 $\rightarrow$ Yeh, Michelle

Xi Yunshu 席云舒: 332, 334

Xia Yuanming 夏元明: 251

Xiabanshen 《下半身》 $\rightarrow$ Lower Body

Xiandai Hanshi 《现代汉诗》 $\rightarrow$ Modern Han Poetry

Xiandaishi neibu jäaliu ziliao 《现代诗 内部交流资料》 $\rightarrow$ Modern Poetry Materials for Internal Exchange xianfeng 先锋 $\rightarrow$ avant-garde

Xiang Weiguo 向卫国: 332
Xiangwang 《象罔》 $\rightarrow$ Image Puzzle

Xiangzi 湘子 (= Yu Jian?): 429

Xiao An 小安 (1964): 436-437

Xiao Hai 小海 (1965): 72, 72n12

Xiao Jun 小君 (1962): 72

Xiao Kaiyu 肖开愚 (1960): 20, 83, 139, $169,249,281,283,303,341,402-$ 403, 406, 430, 442

Xiao Quan 肖全: 39

Xiao Ying 肖鹰: 101, 111

Xiaohua 晓华: 251

Xiaoxiao (China, ㅇ) 潇潇 (1962): 461

Xiaoxiao (Taiwan, ठ) 萧萧: 225-227

Xiaoyuan shige 校园诗歌 $\rightarrow$ Campus Poetry

Xie Linglan 谢凌岗: 102, 110

Xie Mian 谢冕: 32-33, 102, 130, 250, 421

Xie Ye 谢烨: 31, 91, 391, 414

Xie Youshun 谢有顺: 251, 261, 333, 388, 393, 396; passim in chapter Twelve (esp 415-417)

Xin qingnian 《新青年》 $\rightarrow$ New Youth

Xin shichao 新诗潮 $\rightarrow$ New Tide Poetry

$X i n$ shidai 新时代 $\rightarrow$ New Period

Xin wenhua yundong 新文化运动 $\rightarrow \mathrm{New}$ Culture Movement

Xin wenxue 新文学 $\rightarrow$ New Literature

Xinsh $i$ 新诗 $\rightarrow$ New Poetry

Xin Yue 辛月: 251

Xingcunzhe 幸存者 $\rightarrow$ Survivors

Xinshengdai 新生代 $\rightarrow$ Newborn Generation

Xu Jiang 徐江 (1967): 105-107, 152, 314, 318, 331, 333; passim in chapter Twelve (esp 412-415)

Xu Jingya 徐敬亚 (1949): 18, 20, 73, 190, 347

Xu Yi 胥式: 104

Xu Zhimo 徐志摩: 4, 106, 287

Xuanyuanshike 轩辕轼轲 (1971): 335

Xue Di 雪迪 (1957): 139, 230

Xungen 寻根 $\rightarrow$ Root-Seeking

Xushish $i$ 叙事诗 $\rightarrow$ Narrative Poetry...

Yan Jun 颜峻 (1973): xiii, 22, 27, 29-30, 47, 53, 341-343; chapter Thirteen

Yan Li 严力 (1954): 139, 141, 431

Yang Changzheng 杨长征: 192, 194, 197, 203 
Yang Ke 杨克 (1957): 39, 191, 332; passim in chapter Twelve

Yang Lan: $5 \mathrm{n} 4$

Yang Li 杨黎 (1962): 17, 38, 259, 339340, 391, 408

Yang Lian 杨炼 (1955): xv, 7, 18, 34, 52, 68-69, 93n2, 135, 230, 247, 365, 408; chapter Four; $\rightarrow$ Fei Sha

Yang Lihua 杨立华: 172

Yang Siping 杨四平: 172

Yang Xiaobin 杨小斌: 161, 164, 172, 176, 440, 461

Yeats, William Butler: 403-405

Yeh, Michelle: 3, 18, 25, 33, 49, 53, 55, 63, 91, 102-103, 107-108, 112-113, $117,130,172,190,251,349,362$, 366, 372, 446, 448, 450

Yemen 也门 (= Yi Sha): 153n30

Yi 《翼》 $\rightarrow$ Wings

Yi hang 《—行》 $\rightarrow$ First Line

Yi Sha 伊沙 (1966): 20, 24, 38-39, 41, 44, 48, 105-107, 152-153, 309, 314, 318, 319n14, 333, 338-340; passim in chapter Twelve; $\rightarrow$ Yemen

Yin Lichuan 尹丽川 (1973): 20, 27, 29-30, 47, 52, 461, 468; chapter Nine

Yiping 一平: 161, 172, 180

Yo Yo 友友: 147, 153

Yu Guangzhong 余光中: 106

Yu Hong 余虹: 102, 110

Yu Hua 余华: 247, 468

Yu Jian 于坚 (1954), 11, 26-30, 37-38, 47, 52, 71-72, 78, 83-84, 86, 107, 132-133, 187, 283, 309-310, 315, 318, 325, 338-339, 346-347, 361, 363; chapters Six, Seven and Eleven; passim in Twelve (esp 407-412); $\rightarrow$ Dawei; $\rightarrow$ Xiangzi

Yu Liwen 余丽文: 251

Yu Luoke 遇罗克: 69

Yu Xiaowei 于小韦 (1961): 72

Yu Xugang 余徐刚: 102, 115-116

Yuanchuangxing xiezuo 《原创性写作》 $\rightarrow$ Original Writing

Yufeng 宇峰: 153

Zang Di 㶓棣 (1964): 83-84, 167, 402, 406, 418n10, 419-420, 425-426, 432, 461

Zang Kejia 縅克家: 4

Zang Li 藏力 $\rightarrow$ Zang Di

Zeng Hong: 112
Zha Haisheng 查海生 (= Haizi): xiv, 96-97

Zhai Yongming 翟永明 (1955): 17, 46, 53, 83, 139, 402-403, 408, 432

Zhang Chengzhi 张承志: 113

Zhang Hong 张闳: 33, 172, 176, 180

Zhang Hongming 章宏明: 427-428

Zhang, Jeanne Hong: 53

Zhang Longxi: 2, 55, 354, 357

Zhang Ning 张柠: 251

Zhang Qinghua 张清华: 102, 333, 419, $421 ; \rightarrow$ Jing Wen

Zhang Shuguang 张曙光 (1956): 20, 83, 169, 281, 303, 402-404, 406, 416, 420, 431, 436, 443

Zhang Wei 张维: 100

Zhang Xiafang 张夏放: 83, 85, 87

Zhang Xudong: 57, 139

Zhang Yingjin: 55

Zhang Zao 张來 (1962): 70n9, 83, 139, 161,172

Zhang Zhen 张真 (1962): 139, 144, 185

Zhang-Kubin, Suizi: 151

Zhao, Henry: 34-36, 45, 112n33, 143n5

Zhao Qiguang: 112

Zhao Xun 赵㻏: 168

Zhao Yiheng 赵毅衡 $\rightarrow$ Zhao, Henry

Zhao Zhenkai 赵振开 (= Bei Dao): xiv zhebi 遮蔽 $\rightarrow$ obstruction

Zheng Min 郑敏: 4, 423

Zheng Yi 郑义: 163

Zhengtizhuyi 整体主义 $\rightarrow$ Wholism

Zhengzhi shuqingshi 政治抒情诗 $\rightarrow$

Political Lyricism

Zhishi qingnian 知识青年 $\rightarrow$ Intellectual Youths

Zhishifenzi xiezuo 知识分子写作 $\rightarrow$

Intellectual Writing

Zhong Ming 钟鸣 (1953): 38, 102, 118n40, 133n62, 444; $\rightarrow$ Shi Jile

Zhongdao 中岛 (1963): xiv, 399, 431

Zhongguo dangdai shiyan shige 《中国当代 实验诗歌》 $\rightarrow$ Contemporary Chinese Experimental Poetry

Zhongguo zuojia xiehui 中国作家协会 $\rightarrow$

Chinese Writers' Association

Zhongjiandai 中间代 $\rightarrow$ Middle

Generation

Zhongnian xiezuo 中年写作 $\rightarrow$ Middle-

Aged Writing

Zhou Jun 周俊: 100 
Zhou Lunyou 周伦佑 (1952): 17, 26

Zhou Weihui 周卫慧 $\rightarrow$ Weihui

Zhou Yubing 周玉冰: 102, 115-116

Zhou Zan 周瓒 (1968): 334, 440, 461

Zhu Dake 朱大可: 101-102, 110,334, 339

Zhu Jian 朱剑 (1976): 335

Zhu Wen 朱文 (1967): 368, 370, 373, 375, 379, 382-384, 389, 391, 396, 408
Zhu Xiaoyang 朱小羊: 260, 262

Zhuang Rouyu 庄柔玉: 180

Zhuangzi 庄子: 219, 382

Zi An 子岸 (= Wang Jiaxin): 168n53, 440

Zou Jianjun 邹建军: 132

Zou Jingzhi 邹静之 (1952): 102

Zuozhuan 《左传》: 359 
Chinese Poetry in Times of Mind, Mayhem and Money is a groundbreaking contribution to scholarship, well-suited to classroom use in that it combines rigorous analysis with a lively style. Covering the period from the 1980 s to the present, it is organized around the notions of text, context and metatext, meaning poetry, its socio-political and cultural surroundings, and critical discourse in the broadest sense. Authors and issues studied include Han Dong, Haizi, Xi Chuan, Yu Jian, Sun Wenbo, Yang Lian, Wang Jiaxin, Bei Dao, Yin Lichuan, Shen Haobo and Yan Jun, and everything from the subtleties of poetic rhythm to exile-bashing in domestic media. This book has room for all that poetry is: cultural heritage, symbolic capital, intellectual endeavor, social commentary, emotional expression, music and the materiality of language art, in a word.

Maghiel van Crevel ( $\mathrm{PhD}$ in Chinese Literature: Leiden, 1996) lectured at the University of Sydney (1996-1999) and is currently Professor of Chinese Language \& Literature at Leiden University. His publications include Language Shattered: Contemporary Chinese Poetry and Duoduo (CNWS, 1996).

'This monograph fully confirms Maghiel van Crevel's status as the world's leading expert on contemporary Chinese poetry. His extremely meticulous documentation, his unbiased approach to a wide range of poets and poems, his terminological consistency and theoretical originality all combine to make this book outclass anything uritten previously on this topic, whether by western scholars or by Chinese scholars.'

Michel Hockx, Professor of Chinese, SOAS, University of London

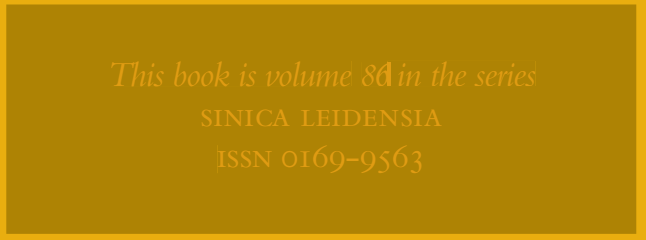

